Facultad de Educación y Trabajo Social. Departamento de Pedagogía Facoltà di Scienze della Formazione. Dipartimento di Pedagogia

Tesis doctoral

\title{
LA VALIDACIÓN DE COMPETENCIAS PROFESIONALES EN ESPAÑA E ITALIA
}

Presentada por Estefanía García González para optar al grado de doctora por la Universidad de Valladolid en cotutela con la Università degli Studi Roma Tre

Dirigida por

Dr. Luis Carro Sancristobal (Universidad de Valladolid) Dr. Paolo Di Rienzo (Università degli Studi Roma Tre)

Valladolid, junio de 2016 

Dedicatoria

Alla mia famiglia, sostan₹a dei giorni miei 


\section{Agradecimientos}

Quiero empezar dando las gracias a la Universidad de Valladolid y a la Università degli Studi di Roma Tre, así como al Departamento de Pedagogía de la Facultad de Educación y Trabajo Social de la UVa y al Dipartimento di pedagogia della Facoltà di Scienze della Formazione di Roma Tre, por la oportunidad que me han brindado de realizar este trabajo de investigación.

Gracias a mi director Luis Carro, quién me inició en el mundo de la investigación y me ofreció su ayuda y apoyo moral en todo momento.

Voglio ringraziare Paolo di Rienzo, il mio co-direttore in Italia, grazie di cuore per l'accoglienza e per il sostegno nei momenti difficili.

Grazie Professor Paolino Serreri per l'aiuto, la collaborazione e per tutti i tuoi consigli.

Ringrazio il Profesor Pierpaolo Triani nel cui trovai una persona disposta ad aiutare senza chiedere niente in cambio e un amico che mi aprí le porte di casa sua.

Expreso mi agradecimiento a la Junta de Castilla y León y a la Regione Emilia-Romagna, por ayudarme a hacer realidad la parte empírica de este trabajo. Gracias a todas las personas y organismos que tanto en España como en Italia han colaborado activamente y desinteresadamente para hacer posible esta tesis.

Quiero dar las gracias a Natalia, Laura y Javi, quienes a través de vuestra experiencia me habeís dado vuestro apoyo y comprensión en diferentes momentos de este recorrido. Gracias a todos los amigos que habéis sabido entender y disculpar los momentos de ausencias y sobre todo por haber soportado mi conversación monotemática.

Por supuesto, quiero dar las gracias a mi familia, a mis abuelos, a los que no están por dejar su huella en mí. A los que están, por escucharme, animarme y apoyarme en este proceso. Quiero agradecer a mis padres Luis y Azu y a mi hermana Irene su apoyo y paciencia, por haber vivido estos años conmigo, haber sufrido y disfrutado a mi lado cada momento de esta aventura y por no soltar mi mano en ningún momento. 
Gracias a ti, Javier, compañero, amigo, marido, director, guía, principal propulsor de mi energía para enfrentarme a una complicada tesis y a toda dificultad en la vida.

Questo percorso senza di te non sarebbe mai esistito. Senza il tuo incoraggiamento, le tue forze, il tuo entusiasmo, il tuo umorismo, il tuo impegno, la tua pazienza, il tuo sapere, il tuo saper fare, e soprattutto il tuo saper essere nel mondo e nella vita accanto a me. Grazie in tutte le nostre lingue. Gracias, grazie, merci, thank you, danke. 


\section{Resumen}

El argumento de la validación de competencias ha adquirido un interés creciente en Europa En los últimos 15 años. Italia y España son dos países que han iniciado su andadura en el terreno de la validación de competencias con cierto retraso respecto a otros países de la Unión Europea, como Dinamarca, Finlandia, Países Bajos o Francia, esta última situada a la cabeza de Europa en este ámbito. Esta investigación presenta un estudio comparado entre España e Italia, centrado en el desarrollo y la aplicación del dispositivo de validación y certificación de competencias profesionales adquiridas a través de la experiencia. Con nuestro estudio establecemos similitudes y diferencias entre los sistemas de validación de estos dos países, profundizando en la comunidad autónoma de Castilla y León (España) y en la región de Emilia-Romagna (Italia). Para realizar este estudio hemos tomando como referencia las pautas indicadas por la Unión Europea y nos hemos servido de fuentes tanto documentales como vivas. La comparación se realiza a través del paradigma epistemológico de la metodología holística, manteniendo una actitud integradora durante todo el proceso. Nuestro trabajo puede contribuir a la mejora de la praxis de los sistemas de validación, ofreciendo un análisis exhaustivo de dos perspectivas europeas.

\section{Abstract}

The validation and certification of non-formal and informal learning is becoming increasingly important over the last fifteen years. Italy and Spain have both started to work in the field of formalizing and certifying experiential competences with some lag with respect to other countries in the European Union, such as Denmark, Finland, the Netherlands or France, this latter leading the EU countries in this area. This research presents a comparative analysis of Spain and Italy, focused on the development and operation of the procedure for formalizing and certifying experiential competences. Our study identifies similarities and differences between both countries, performing a fine-grained comparison of the region of Castilla y León (Spain) and the region of Emilia Romagna (Italy). To do so, we base on existing European guidelines as a reference framework, and analyze documentary and living sources. We use an holistic methodology, maintaining an integrating attitude throughout the process. Our work can contribute to the practice of validation systems by offering a deep analysis of two European perspectives. 


\section{Índice General}

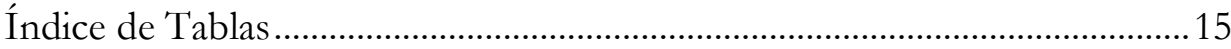

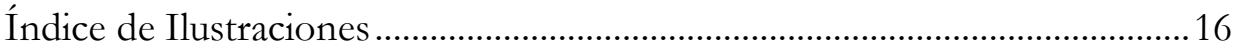

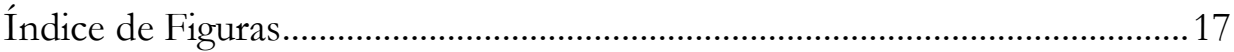

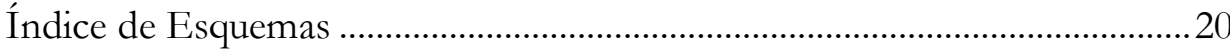

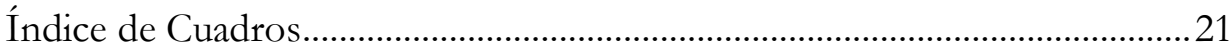

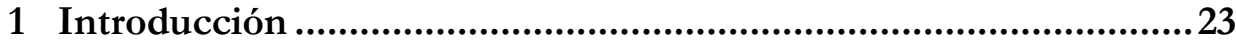

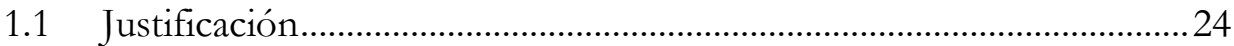

1.2 Planteamiento del problema de investigación. ...........................................30

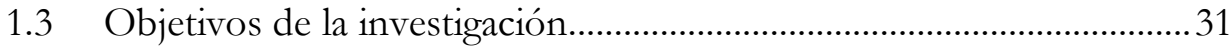

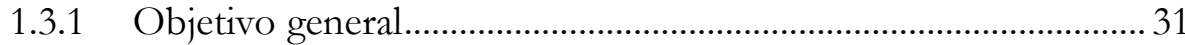

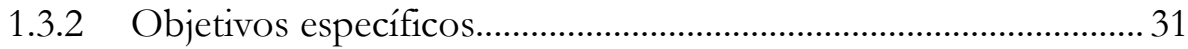

1.4 Estructura del trabajo de investigación........................................................32

2 El concepto de competencia y aprendizaje permanente ...............37

$2.1 \quad$ El concepto de competencia ................................................................. 38

2.1.1 Los orígenes del concepto de competencia ........................................38

2.1.2 Introducción al concepto de competencia: enfoque en ámbito

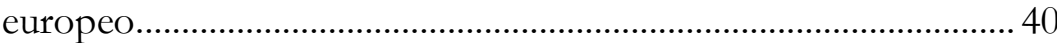

2.1.3 Enfoques sobre el concepto de competencia en España.............. 42

2.1.4 Enfoques sobre el concepto de competencia en Italia.................. 45

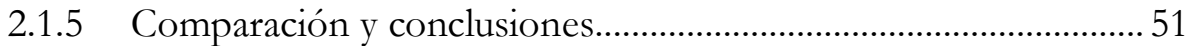

$2.2 \mathrm{El}$ aprendizaje permanente (lifelong \& lifewide learning)..............................53

2.2.1 Términos relacionados con el aprendizaje permanente ................ 53

2.2.1.1 El aprendizaje formal, no formal e informal.............................54

2.2.1.2 La formación continua....................................................................... 58

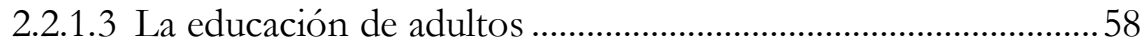

2.2.2 La evolución del aprendizaje permanente....................................... 61 
2.2.2.1 El aprendizaje permanente en España ………………………....... 65

2.2.2.2 El aprendizaje permanente en Italia …………………………..... 68

2.2.3 Comparación y conclusiones................................................................ 70

3 Los sistemas educativos y de formación profesional en España y en Italia.............................................................................................73

3.1 Los sistemas educativo y de formación profesional en España............75

3.1.1 El sistema educativo en España ………………………………...... 75

3.1.2 El sistema de formación profesional en España .............................. 85

3.1.2.1 La formación profesional inicial..................................................... 86

3.1.2.2 La formación para el empleo .......................................................... 93

3.1.2.3 La formación profesional dual....................................................101

3.1.3 La formación profesional en Castilla y León................................... 103

3.1.3.1 Formación profesional inicial en Castilla y León......................103

3.1.3.2 Formación profesional para el empleo en Castilla y León ...104

3.2 El sistema educativo y de formación profesional italiano.....................105

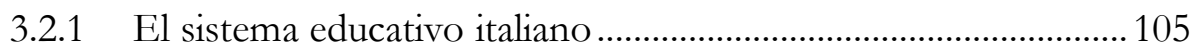

3.2.2 El sistema de formación profesional italiano.................................. 112

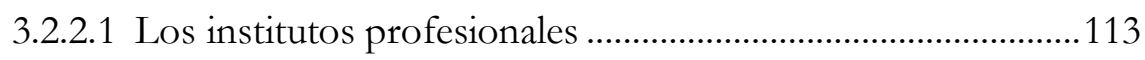

3.2.2.2 La educación y formación profesional (IeFP)..........................114

3.2.2.3 La Educación y Formación Técnica Superior...........................114

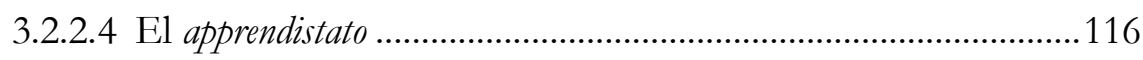

3.2.2.5 La formación continua ………………………..............................117

3.2.3 La formación profesional en Emilia-Romagna .............................. 118

3.2.3.1 El Sistema Regional de Educación y Formación ProfesionalIstruzione e Formazione Professionale (IeFP)..........................................................120

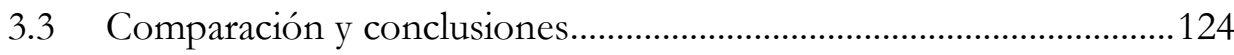

3.3.1 diferencias y similitudes entre los sistemas educativos de España e Italia 
3.3.2 Diferencias y similitudes entre los sistemas de formación profesional de España e Italia 128

3.3.3 Diferencias y similitudes entre los sistemas de formación profesional de Castilla y León y Emilia-Romagna .......................... 130

4 La validación de competencias profesionales.............................. 135

4.1 La validación de competencias desde la Unión Europea.....................138

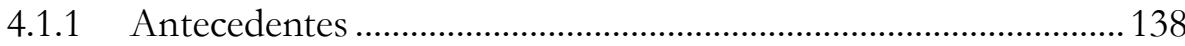

4.1.2 Inicios de la Unión Europea en el reconocimiento de competencias ................................................................................... 141

4.1.3 El sistema general de reconocimiento de títulos ...........................142

4.1.4 El Marco Europeo de cualificaciones ............................................... 146

4.1.4.1 Los instrumentos del EQF .....................................................148

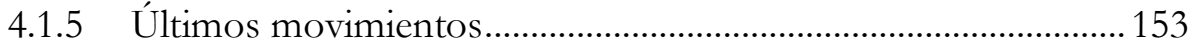

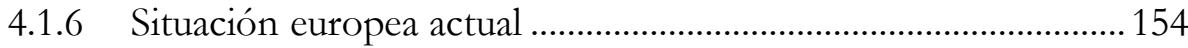

4.2 La evaluación y acreditación de competencias profesionales en

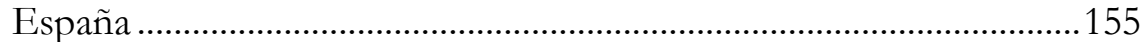

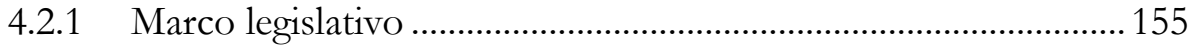

4.2.2 El Sistema Nacional de Cualificaciones y Formación Profesional

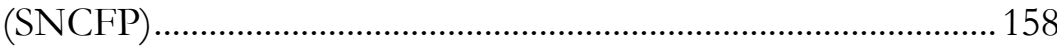

4.2.2.1 El Catálogo Nacional de Cualificaciones Profesionales (CNCP) 159

4.2.3 Primeras experiencias de validación en España ..............................162

4.2.4 Experiencias de validación en el sector privado.............................. 163

4.2.5 Experiencias de validación en el tercer sector ............................... 164

4.2.6 El procedimiento de evaluación y acreditación de competencias profesionales en Castilla y León ....................................................... 164

4.2.6.1 Profesionales del procedimiento ...................................................166

4.2.6.2 Fases del procedimiento ................................................................ 166

4.3 La validación de competencias profesionales en Italia.........................179 


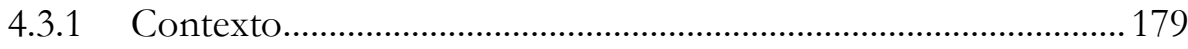

4.3.2 Impulso de la validación de aprendizajes no formales e

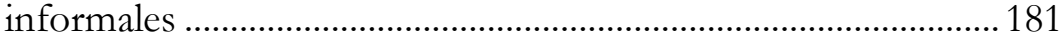

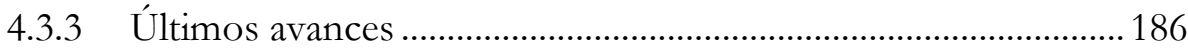

4.3.4 Experiencias de validación en el sector privado.............................191

4.3.5 Experiencias de validación en el tercer sector ................................193

4.3.6 Instrumentos nacionales para la validación y certificación de competencias profesionales............................................................... 194

4.3.6.1 El Libretto Formativo del cittadino ....................................................194

4.3.6.2 El Balance de competencias........................................................197

4.3.7 Experiencias regionales de validación..............................................198

4.3.8 La formalización y certificación de competencias profesionales

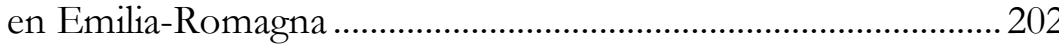

4.3.8.1 Recorrido legislativo....................................................................203

4.3.8.2 El Sistema Regional de Cualificaciones (SRQ) .......................206

4.3.8.3 El Sistema Regional de Formalización y Certificación de

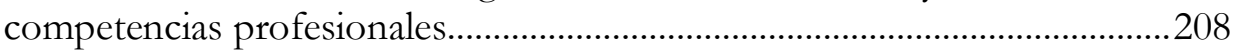

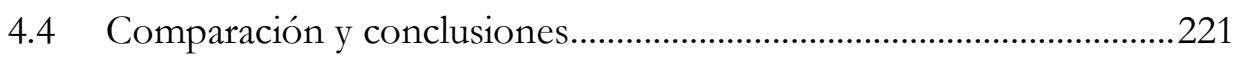

4.4.1 Diferencias y similitudes entre España e Italia en cuanto a la implantación del dispositivo de validación de competencias profesionales

4.4.2 Diferencias y similitudes entre castilla y león y emilia-romagna en cuanto a la implantación del dispositivo de validación de competencias profesionales............................................................224

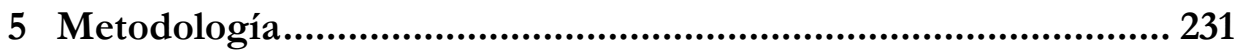

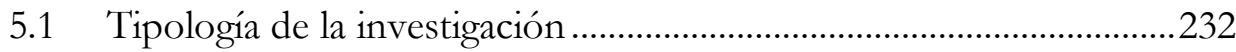

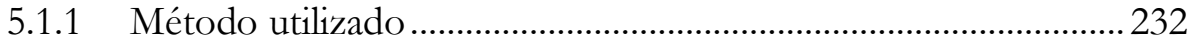

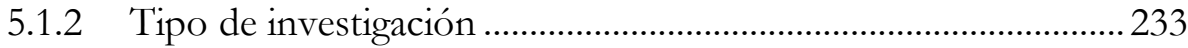

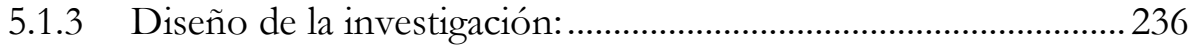


5.2 Definición del evento de estudio o de las variables de estudio..........237

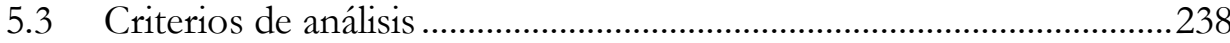

5.4 Descripción y selección de las unidades de estudio (población y

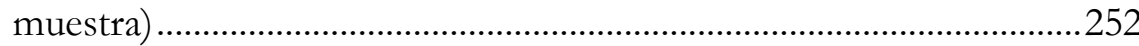

5.5 Descripción del procedimiento (actividades)..........................................256

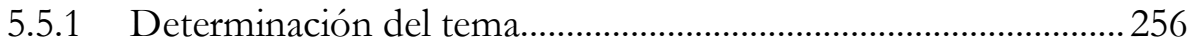

5.5.2 Recogida de información y elaboración del marco teórico ........257

5.5.3 Construcción y uso de instrumentos para la recogida de datos y su posterior análisis..........................................................................2 260

5.5.3.1 La matriz de análisis ..................................................................260

5.5.3.2 La entrevista semiestructurada ................................................22

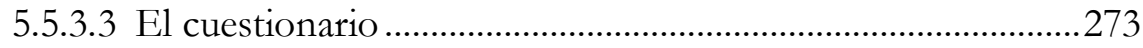

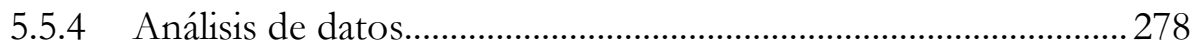

5.5.4.1 Análisis cualitativo documental y de entrevistas .....................2.278

5.5.4.2 Análisis cualitativo y cuantitativo de los cuestionarios .........284

5.5.4.3 Integración de la información analizada y realización de conclusiones 284

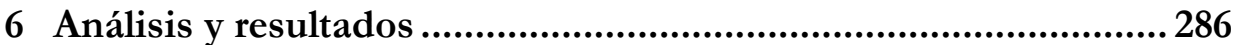

6.1 Análisis cualitativo detallado de legislación y entrevistas....................287

6.2 Análisis comparativo por indicadores......................................................396

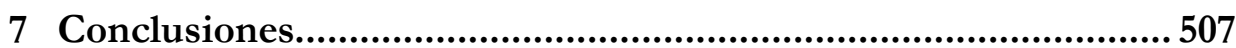

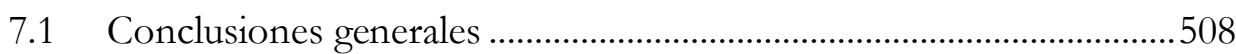

7.2 Aportaciones y prospectiva ……………………...................................540

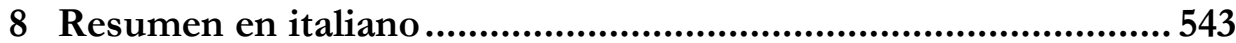

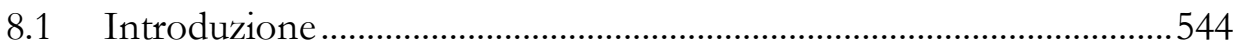

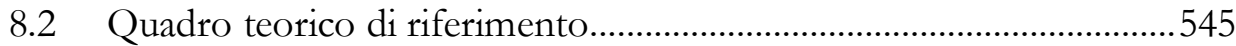

8.2.1 Bibliografía collegata allo studio ...................................................... 545 


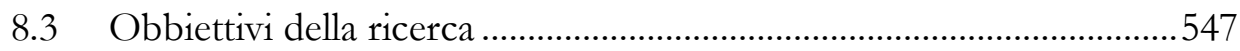

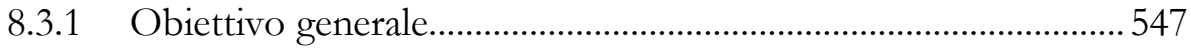

8.3.2 Objettivi specifici ………….......................................................... 547

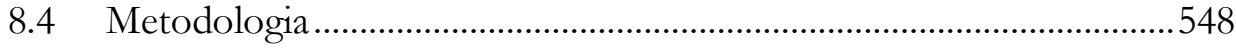

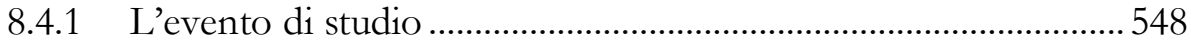

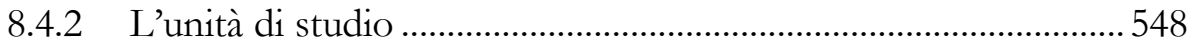

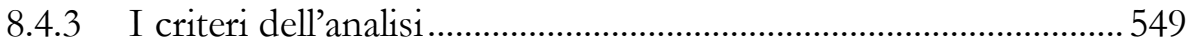

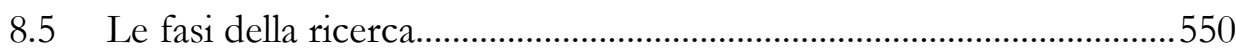

8.5.1 Raccolta d'informazione ed elaborazione del quadro teorico ... 550

8.5.2 Costruzione e utilizzo di strumenti per la raccolta dei dati e loro

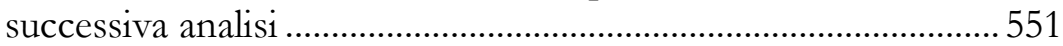

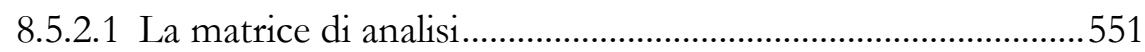

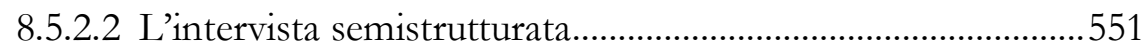

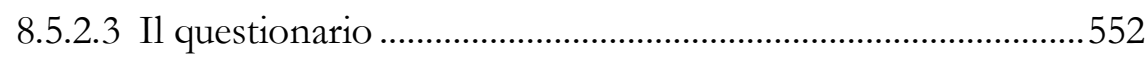

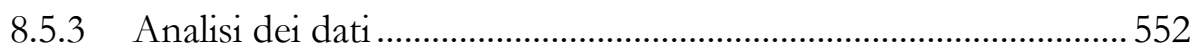

8.5.3.1 Analisi qualitativo documentale e delle interviste.....................552

8.5.3.2 Analisi quantitativa dei questionari ............................................. 553

8.5.3.3 Integrazione dell'informazione analizata e realizzazione delle conclusioni 554

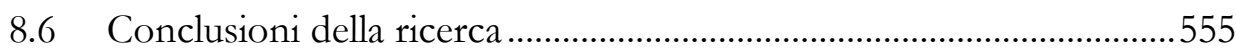

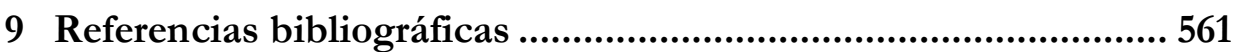

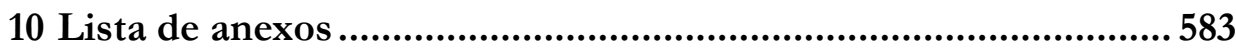




\section{Índice de Tablas}

Tabla 1: Fuentes documentales (legislación) ………………………………………....252

Tabla 2: Profesionales del procedimiento de Castilla y León entrevistados...........254

Tabla 3: Profesionales del procedimiento de Emilia-Romagna entrevistados ........254

Tabla 4: Profesionales de ambos procedimientos encuestados..................................255

Tabla 5: Matriz de análisis con principios relacionados, tipo de análisis y fuentes 262

Tabla 6: Profesionales que han validado los cuestionarios ........................................277 
La validación de competencias profesionales en España e Italia

\section{Índice de Ilustraciones}

Ilustración 1: Ejemplo descripción de situación profesional de evaluación, perteneciente a una de las guías de evidencias de la cualificación de educación infantil

Ilustración 2: Ejemplo criterios de evaluación asociados a una situación profesional, perteneciente a una de las guías de evidencias de la cualificación de educación infantil

Ilustración 3: Ejemplo de una escala de desempeño, perteneciente a una de las guías de evidencias de la cualificación de educación infantil.........................174

Ilustración 4: Entrevistas y documentos analizados sobre ambos procedimientos de validación

Ilustración 5: Estructura de análisis para la legislación y las entrevistas de ambos

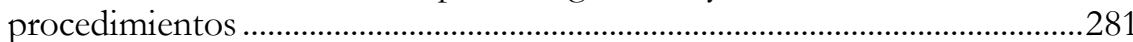

Ilustración 6: Muestra de categorías de la subsección de Legislación de España/Castilla y León

Ilustración 7: Muestra de subcategorías e indicadores de la categoría de "acceso al procedimiento” de la subsección de Legislación de España/Castilla y León

Ilustración 8: Muestra de documento legislativo abierto dentro del programa

NVivo

Ilustración 9: Muestra de fragmento de texto situado en uno de los indicadores. 283 


\section{Índice de Figuras}

Figura 1: Confrontación del porcentaje de población ocupada de 25 a 64 años según los niveles de educación en Europa y en España ......................................66

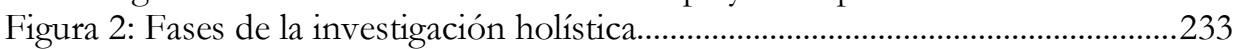

Figura 3: Espiral holística del estadio comparativo....................................................235

Figura 4: Principios esenciales que debe contener cada fase del procedimiento de

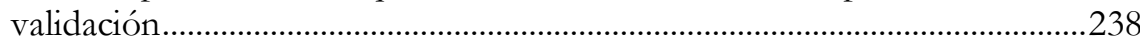

Figura 5: Esquema seguido en el análisis cualitativo detallado de legislación y

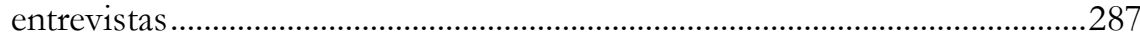

Figura 6: Esquema seguido en el análisis compararado por indicadores.................396

Figura 7: Información de asesores sobre el carácter voluntario del procedimiento

Figura 8: Información de evaluadores sobre el carácter voluntario del

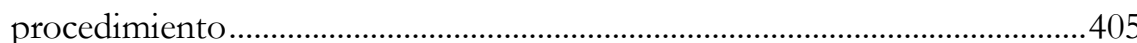

Figura 9: Información de asesores al finalizar el procedimiento...............................408

Figura 10: Porcentaje de EAPQ que ha proporcionado información al candidato al finalizar el procedimiento ................................................................................409

Figura 11: Información final por parte de los evaluadores sobre el procedimiento

Figura 12: Información por parte asesores al candidato sobre el procedimiento 413

Figura 13: Vías de información utilizadas por los asesores........................................416

Figura 14: Utilidad de instrumentos de asesoramiento en el procedimiento de Castilla y León

Figura 15: Porcentaje de asesores del procedimiento de Castilla y León que han echado en falta algún instrumento

Figura 16: Porcentaje de asesores del procedimiento de Emilia-Romagna que han participado en el asesoramiento.......................................................................424

Figura 17: Utilidad de instrumentos de asesoramiento en el procedimiento de

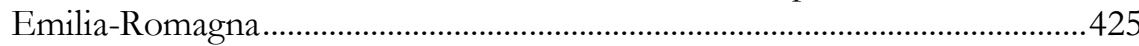

Figura 18: Utilidad de la guía según asesores del procedimiento de Castilla y León

Figura 19: Instrumento utilizado por los evaluadores en el procedimiento de Emilia-Romagna

Figura 20: Satisfacción de los evaluadores del procedimiento de Emilia-Romagna con la DGR 530/2006

Figura 21: Satisfacción de los evaluadores del procedimiento de Emilia-Romagna con la DGR 739/2013.

Figura 22: Conocimiento de los asesores sobre aspectos generales de los sistemas, en Castilla y León y en Emilia-Romagna. 
La validación de competencias profesionales en España e Italia

Figura 23: Conocimiento de los asesores sobre aspectos específicos de los sistemas en Castilla y León y en Emilia-Romagna.

Figura 24: Conocimiento por parte de los asesores de otros sistemas de validación

Figura 25: Vías de comunicación de resultados utilizadas por los asesores de ambos procedimientos

Figura 26: Conocimiento de los asesores de ambos procedimientos sobre el candidato

Figura 27: Flexibilidad por parte de los asesores de ambos procedimientos hacia el candidato

Figura 28: Lenguaje utilizado con el candidato por los asesores de ambos procedimientos

Figura 29: Porcentaje de evaluadores de ambos procedimientos que han proporcionado información al candidato

Figura 30: Cantidad de información proporcionada por evaluadores al candidato sobre el procedimiento.

Figura 31: Vías de información utilizadas por los evaluadores de ambos procedimientos

Figura 32: Opinión de los profesionales de la evaluación, de ambos procedimientos, sobre la calidad de esta

Figura 33: Fiabilidad de la evaluación en ambos procedimientos.

Figura 34: Utilidad de los instrumentos de evaluación según los evaluadores del procedimiento de Castilla y León

Figura 35: Utilidad de los instrumentos de evaluación según los evaluadores del procedimiento de Emilia-Romagna .....

Figura 36: Porcentaje de evaluadores de ambos procedimientos que han echado en falta algún instrumento.

Figura 37: Utilidad de instrumentos de apoyo para evaluadores en el procedimiento de Castilla y León ...................................................................................................476

Figura 38: Instrumento de apoyo utilizado por los profesionales de la evaluación en el procedimiento de Emilia-Romagna

Figura 39: Utilidad de las DGR 530/2006 y 739/2013 según los evaluadores del procedimiento de Emilia-Romagna ....

Figura 40: Conocimiento de los evaluadores sobre aspectos generales de los sistemas en Castilla y León y en Emilia-Romagna.....

Figura 41: Conocimiento de los evaluadores sobre aspectos específicos de los sistemas, en Castilla y León y en Emilia-Romagna.

Figura 42: Porcentaje de evaluadores de ambos procedimientos que conoce otros sistemas de validación.

Figura 43: Vías utilizadas por los evaluadores para comunicar los resultados de evaluación. 
Figura 44: Conocimiento de los evaluadores de ambos procedimientos sobre el candidato

Figura 45: Flexibilidad por parte de los evaluadores de ambos procedimientos hacia el candidato

Figura 46: Lenguaje utilizado con el candidato por los evaluadores de ambos procedimientos

Figura 47: Información de los profesionales de ambos procedimientos, a los candidatos, sobre la posibilidad de recurrir el resultado de la evaluación...494

Figura 48: Porcentaje de profesionales de la evaluación de ambos procedimientos que han hecho reuniones para mejorar el procedimiento

Figura 49: Porcentaje de profesionales de la evaluación de ambos procedimientos que consideran útiles las reuniones para mejorar el procedimiento..............504

Figura 50: Presencia de principios en cada fase del procedimiento (legislación)...509

Figura 51: Presencia de principios en cada fase del procedimiento (opiniones profesionales).

Figura 52: Presencia de principios en los procedimientos (legislación)

Figura 53: Presencia de principios en los procedimientos (opinión profesionales)

Figura 54: Presencia de principios en procedimiento de Castilla y León, comparación entre legislación y opiniones

Figura 55: Presencia de principios en procedimiento de Emilia-Romagna, comparación entre legislación y opiniones

Figura 56: Presenza dei principi in ogni fase della procedura (legislazione)............555

Figura 57: Presenza dei principi in ogni fase della procedura (opinioni professionisti)

Figura 58: Presenza dei principi nelle procedure (legislazione)

Figura 59: Presenza dei principi nelle procedure (opinioni professionisti) .............558

Figura 60: Presenza dei principi nella procedura di Castilla y León, comparazione fra legislazione e opinioni

Figura 61: Presenza dei principi nelle procedure di Emilia-Romagna, comparazione fra legislazione e opinioni 
La validación de competencias profesionales en España e Italia

\section{Índice de Esquemas}

Esquema 1: La estructura del sistema educativo español..............................................79

Esquema 2: La formación profesional en España.......................................................103

Esquema 3: La estructura del sistema educativo italiano ............................................107

Esquema 4: Trienio unitario de IeFP en Emilia-Romagna.......................................122 


\section{Índice de Cuadros}

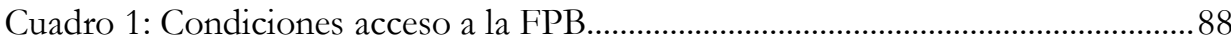

Cuadro 2: Acceso a ciclos de grado medio.....................................................................91

Cuadro 3: Acceso a ciclos de grado superior .............................................................. 91

Cuadro 4: Estructura y articulación de los posibles itinerarios de los institutos profesionales ...............................................................................................113

Cuadro 5: Cuadro comparativo de los sistemas educativos español e italiano ......126

Cuadro 6: Cuadro comparativo de los sistemas de formación profesional español e

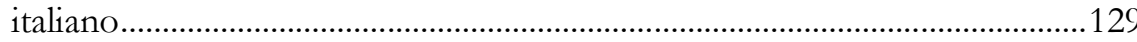

Cuadro 7: Cuadro comparativo de los sistemas de formación profesional de Castilla y León y de Emilia-Romagna ..................................................................132

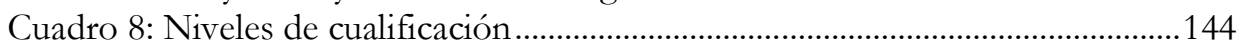

Cuadro 9: Documentos que conforman el Europass ...................................................149

Cuadro 10: Familias profesionales y niveles y cualificaciones profesionales en

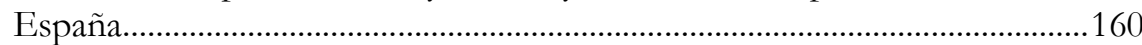

Cuadro 11: Niveles del MECES..................................................................................161

Cuadro 12: Fases del procedimiento de evaluación y acreditación de competencias en Castilla y León.................................................................................................176

Cuadro 13: Niveles de desarrollo y ámbito de aplicación de los procedimientos de validación de competencias no formales e informales en las regiones

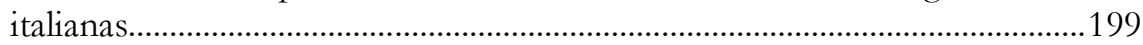

Cuadro 14: Indicaciones para la validación de las unidades de competencia del

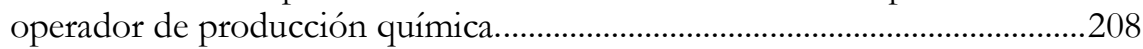

Cuadro 15: Fases del procedimiento de formalización y certificación de competencias de la experiencia en Emilia-Romagna.......................................219

Cuadro 16: Principales leyes, normas y acuerdos en España e Italia, relativos a la validación y certificación de competencias profesionales................................222

Cuadro 17: Normativa de soporte para la validación y certificación de competencias profesionales en Castilla y León y en Emilia-Romagna.........225

Cuadro 18: Cuadro comparativo sobre el procedimiento de validación y certificación de competencias en Castilla y León y en Emilia-Romagna ....227

Cuadro 19: Holotipos de la investigación holística .........................................................234 

1 Introducción 
La validación de competencias profesionales en España e Italia

\subsection{Justificación}

Hoy en día vivimos una situación de globalización en la que el constante cambio impera en nuestras vidas, prueba de ello son las transformaciones en los medios tecnológicos, en los procesos productivos y el continuo avance de la sociedad de la información.

Como consecuencia de todo esto, la Unión Europea (en adelante, UE) ha empezado a orientar su labor a la obtención de una población activa cualificada. Es por ello que, en la cumbre celebrada en Lisboa en el año 2000, la UE reconoció la importancia de la educación en las políticas económicas y sociales para aumentar la competitividad de su mercado laboral. Por eso propuso, a los Estados miembro, el reto de basar la economía europea en el conocimiento y convertirla en la más dinámica del mundo. Una de las estrategias para lograr este objetivo es la del lifelong y lifewide learning, es decir el aprendizaje a lo largo y a lo ancho de la vida. Este aprendizaje trae consigo una dimensión longitudinal y otra transversal, reconoce y otorga valor al hecho de que los seres humanos no solo aprendemos a una determinada edad, sino que lo hacemos durante todo el arco de nuestras vidas (dimensión longitudinal-lifelong) y al mismo tiempo en todos los contextos en los que nos movemos (dimensión transversal-lifewride).

Este nuevo paradigma nos introduce en los aprendizajes, y por tanto en la adquisición de competencias, no formales e informales, alcanzados en ámbitos más allá de la formación reglada, entre los que se encuentra el profesional.

Son muchas las personas que desarrollan habilidades y competencias excepcionales en sus puestos de trabajo, sin llegar a ser conscientes de ello y sin un reconocimiento socio-laboral, del que el propio sector productivo podría beneficiarse. Consciente de ello y con la intención de dar soluciones, la UE propone la validación y certificación de competencias adquiridas a través de la experiencia laboral o de vías de formación no formales e informales. Esta herramienta favorece el acceso al empleo para los ciudadanos, el aprendizaje a lo largo de la vida, la movilidad y la cohesión social.

Consideramos la cumbre de Lisboa del año 2000 como el momento clave, en el que la UE empezó a reconocer este tipo de aprendizajes y a publicar recomendaciones (ver apartado 4.1) que impulsaban la puesta en marcha de prácticas de validación no formal e informal. La última recomendación de esta índole se publicó en el año 2012, exigiendo a los Estados 
miembro poner en marcha, como muy tarde en 2018, los recursos necesarios para realizar prácticas de validación.

Por tanto, a partir del año 2000 y ante la creciente importancia que Europa empezó a conceder a la validación de competencias, los países pertenecientes a la UE comenzaron a poner en marcha dispositivos de validación y certificación de competencias profesionales, al mismo tiempo que se hacía necesaria la difusión y el intercambio de estas prácticas, para tener diferentes perspectivas sobre ellas (Cedefop, 2009).

A pesar de que todavía hoy no existen suficientes estudios que muestren o comparen diferentes realidades sobre validación profesional, en los últimos años se ha ido desarrollado un número creciente de estudios acerca de este tema. A continuación enunciamos algunas de estas publicaciones:

- Making learning visible: identification, assessment and recognition of non-formal learning in Europe, publicado por Björnavåld en el año 2000: esta publicación trata sobre cómo hacer más visible el aprendizaje que tiene lugar fuera de la educación y formación formales (Jens Bjørnavold, 2000);

- Inventario Europeo sobre la validación no formal e informal del aprendizaje $^{1}$. Este inventario se realiza cada cierto tiempo (actualmente se han presentado 5 informes, en 2004, 2005, 2008, 2010 y 2014). Tiene la intención de acercar, a los profesionales de este ámbito, una visión actualizada de estas prácticas europeas de validación. Su aportación es de gran utilidad, ya que en muchas ocasiones la información sobre prácticas europeas a la hora de identificar, evidenciar, evaluar y certificar las competencias derivadas de los aprendizajes no formales e informales, no resulta de fácil acceso (European Commission, Cedefop, \& ICF International, 2014, pp. 3-4).

- Validation of Formal, Non-Formal and Informal Learning: policy and practices in EU Membres States, publicado en 2004 por Colardyn y Bjørnavold: este documento presenta la situación de varios países europeos en cuanto a sus políticas sobre validación del aprendizaje

${ }^{1}$ Realizado con la cooperación de la Comisión Europea. 
La validación de competencias profesionales en España e Italia

adquirido a través de cualquier vía, formal, no formal e informal (Colardyn \& Bjørnavold, 2004);

- The unfinished story of VPL. Valuation \& Validation of Prior Learning in Europes learning cultures, vio la luz en 2005: este libro pretende mostrar la existencia de una base sólida para ofrecer un enfoque más orientado a la persona, en el aprendizaje y en el trabajo. Es decir, generar una estrategia personal para el aprendizaje permanente (Duvekot, Schuur, \& Paulusse, 2005).

- Validation of non formal and informal learning in Europe: key developments and the chellenges: publicado por Bjørnavold en 2009. Este artículo es el resultado de una investigación coordinada por el Centro Europeo para el Desarrollo de la Formación Profesioal (Cedefop). El documento aborda los avances en el campo de la validación de aprendizajes no formales e informales en Europa, para ofrecer una evolución real en Europa sobre este aspecto (Jean Bjørnavold, 2009).

- Recognising Non-Formal and Informal Learning: Outcomes, Policies and Practices: realizado por Werquin en 2010: este libro resultante del estudio de la OCDE, sobre el reconocimiento de aprendizajes no formales e informales, pretende mostrar una perspectiva interna de los 22 países que estudia. Describe las circunstancias nacionales, según los informes de los propios países, y al mismo tiempo informa sobre sus prácticas (Werquin, 2010).

- Quality in validation in the nordic countries. Final report for "Quality in the Nordic Countries-A Mapping Project': se trata de un estudio comparado que posee grandes similitudes con el nuestro. Este proyecto fue llevado a cabo en 2012 por los países nórdicos: Islandia, Noruega; Suecia; Finlandia y Dinamarca. Este estudio pretendía mejorar la transparencia y la garantía de calidad en los procesos de validación de competencias no formales e informales en las prácticas locales y nacionales. Para ello documentó las prácticas específicas de validación y de qué manera conducían hacia la calidad en la validación (Dahler \& Grunnet, 2012).

- Directrices Europeas de 2009 para la validación de aprendizajes no formales e informales, publicadas por Cedefop: este documento, además de proporcionar pautas para garantizar la calidad de la validación, señalaba la necesidad de conocer experiencias de evaluación de otros países, para obtener diferentes perspectivas y referencias 
del proceso (Cedefop, 2009). Cabe mencionar que recientemente, el Cedefop ha realizado una revisión del documento sobre las Directrices Europeas para la validación del aprendizaje no formal e informal, para introducir algunas mejoras en el mismo. El nuevo documento se ha publicado a principios de 2016 (Cedefop, 2016).

Nosotros, con el objetivo de contribuir a esa necesidad de dar a conocer diferentes experiencias de validación en distintos países, presentamos un estudio comparado entre España e Italia sobre la implantación del dispositivo de validación de las competencias profesionales adquiridas a través de la experiencia. Más concretamente, nos centramos en la comparación entre los dispositivos de validación puestos en marcha en la comunidad autónoma de Castilla y León (España) y en la región de Emilia-Romagna (Italia).

Italia y España se iniciaron en la andadura de la validación con cierto retraso respecto a otros países de la UE como Dinamarca, Finlandia, Países Bajos o Francia, esta última situada a la cabeza de Europa en este ámbito.

El último inventario europeo de validación, sitúa a España como uno de los pocos países que ha logrado establecer y poner en práctica estrategias nacionales de validación, junto con Francia y Finlandia (European Commission et al., 2014).

España ha desarrollado, en los últimos años, un marco legislativo relacionado con la evaluación y acreditación de competencias. Como documento clave en este proceso cabe destacar el Real Decreto 1224/2009, que siguiendo las Directrices Europeas de 2009, definió un procedimiento nacional de evaluación y acreditación de competencias profesionales único, tanto para el ámbito educativo como para el laboral. De este modo, se permitió, a partir de ese momento, la evaluación y acreditación profesional, de forma oficial en todo el territorio español.

Por su parte, Italia queda clasificada, por el último inventario europeo, en el grupo de los países que también han logrado desarrollar e implementar este tipo de prácticas de validación, pero que carecen de algún elemento importante para llevarlo a cabo correctamente a nivel nacional (European Commission et al., 2014).

Italia ha mantenido durante años un amplio debate sobre el tema relacionado con validación y certificación de competencias profesionales (Elisabetta Perulli, 2014). Sin embargo, este país no ha conseguido definir 
un sistema nacional consolidado de validación y certificación. Como veremos durante esta investigación, el talón de Aquiles de Italia, a la hora de desarrollar un sistema nacional de validación, es principalmente la falta de un sistema de formación profesional único para todo el país, aunque en los últimos años está trabajando para logar la homogeneización de los diferentes sistemas regionales.

A pesar de esta situación desfavorable existen algunas regiones que han sido capaces de poner en funcionamiento procedimientos de calidad de validación y certificación. Una de las pioneras en el mencionado campo es la región de Emilia-Romagna, ya que ha sido una de las pocas y primeras regiones, en Italia, en lograr definir y poner en marcha su propio sistema regional de formalización y certificación de competencias, en el que se incluye el dispositivo de validación de competencias experienciales.

La elección del tema de investigación surgió del creciente auge que suscita el argumento de la validación de competencias profesionales. Concretamente, nuestra investigación nace en el contexto del proyecto Observal $^{2}$, dirigo por el profesor Luis Carro, director de esta tesis.

El hecho de hacer una comparación entre un contexto español y otro italiano vino motivado por las similitudes que presentan los dos países en cuanto a la organización educativa y de formación profesional, base imprescindible para entender el procedimiento de validación de competencias. Asimismo, ha influido el hecho de que España e Italia iniciasen su andadura en el mundo de la validación de competencias casi al mismo tiempo. También han sido factores decisivos la cercanía, el conocimiento del idioma y la estrecha relación con profesionales italianos relacionados con este tema (como el co-director de la tesis Paolo di Rienzo), así como la posibilidad de acceso a documentación valiosa para la investigación.

Consideramos innegable la utilidad de esta investigación para poder conocer la posición de estos dos territorios, respecto a las indicaciones del marco europeo, en cuanto a la implantación del dispositivo de validación y certificación de competencias profesionales. Además, este tema de investigación conlleva una relevancia social. La validación de competencias no formales e informales se considera un instrumento para disminuir las dife-

2 Observal en un observatorio de validación de competencis profesionales, tiene sus iniciones en el marco del Proyecto europeo Leonardo da Vinci 133980-LLP-1-2007-1-BELEONARDO-LNW. 
rencias sociales y una valiosa herramienta para promover la educación y la formación continua (Cedefop, 2002). Existen muchas personas con una gran experiencia profesional que no poseen una certificación oficial que acredite sus conocimientos, circunstancia que limita su situación laboral. A través del reconocimiento de competencias informales y no formales las personas podrán situarse en una buena posición para poder obtener un mayor rendimiento de su trabajo. Conocer la posición de estos dos territorios (español e italiano), comparar sus enfoques y puesta en práctica del dispositivo de validación, puede conllevar la optimización de la práxis de ambos procedimientos, y de ese modo influir positivamente en el componente social que supone la validación de competencias profesionales. 
La validación de competencias profesionales en España e Italia

\subsection{Planteamiento del problema de investigación.}

El problema de investigación expresa aquello que deseamos conocer a través del estudio, indicado de forma condensada pero precisa, clara, breve y concreta. Según una metodología holística, que nos hace mantener una actitud integradora a lo largo de todo el proceso, podemos denominar al problema de investigación como enunciado holopráxico. En este enunciado se integran cinco interrogantes sobre aquello a lo que queremos dar respuesta: qué queremos saber, cómo, durante cuánto tiempo, dónde y en quiénes. Con él expresamos la totalidad de la investigación. Supone el punto de partida de la misma y focaliza la atención en un punto específico, asimismo proporciona las pautas del nivel de investigación holística que realizamos (ver capítulo 5 sobre metodología).

En este caso, considerando la existencia de antecedentes previos descriptivos sobre el argumento y teniendo en cuenta la necesidad de una comparación y no de descripciones aisladas, nuestro enunciado holopráxico es comparativo (Hurtado de Barrera, 2000) y lo expresamos del siguiente modo:

"Identificar las semejanzas y diferencias existentes entre Castilla y León y Emilia-Romagna, en cuanto a la implantación del dispositivo de validación y certificación de competencias profesionales (2010-2015).” 
Introducción

\subsection{Objetivos de la investigación}

Los objetivos de nuestra investigación están relacionados con la finalidad, las metas o los propósitos finales del trabajo. Presentamos un objetivo general y varios objetivos específicos derivados de este (Hurtado de Barrera, 2002).

\subsubsection{OBJETIVO GENERAL}

- Comparar la implantación del dispositivo de validación y certificación de competencias profesionales en la comunidad autónoma de Castilla y León (España) y en la región de Emilia-Romagna (Italia), para identificar semejanzas y diferencias entre ellos respecto a las pautas dadas por las directrices europeas sobre la validación de aprendizajes no formales e informales.

\subsubsection{OBJETIVOS ESPECÍ́FICOS}

- Identificar la estructura de los sistemas educativos y de formación profesional en España, en Castilla y León, en Italia y en EmiliaRomagna, para conocer su organización y funcionamiento y así entender mejor el sistema de evaluación y validación de competencias profesionales de ambos territorios.

- Comparar la terminología relacionada con la validación de competencias profesionales, según se entiende en España y en Italia, para comprender la importancia y el enfoque que ambos países conceden al procedimiento de validación.

- Caracterizar la implantación de los sistemas de España, de Castilla y León, de Italia y de Emilia-Romagna de validación y certificación de competencias profesionales, para tener una visión sobre las medidas legislativas y las experiencias realizadas al respecto.

- Valorar la implantación de los dispositivos de validación y certificación de competencias profesionales de Castilla y León y EmiliaRomagna, desde una perspectiva europea, a través de una matriz comparativa, resultante del estudio de las Directrices Europeas de 2009, sobre validación de aprendizajes no formales e informales, para establecer semejanzas y diferencias entre ambos dispositivos. 
La validación de competencias profesionales en España e Italia

\subsection{Estructura del trabajo de investigación}

Este trabajo comienza con una introducción en la que se justifica la investigación, se plantea el problema que se pretende afrontar y el objetivo que se quiere alcanzar. A partir de ahí el estudio se estructura en dos grandes bloques, el primero se corresponde con el marco teórico de la investigación y el segundo con la parte empírica. El primer bloque contiene la fundamentación teórica, que aborda la descripción y breve comparación de los principales términos relacionados con el ámbito de investigación que nos ocupa, en España y en Italia (ver capítulo 2); de los sistemas educativos y de formación profesional en España, en la comunidad autónoma de Castilla y León, en Italia y en la región de Emilia-Romagna (ver capítulo 3); de la validación y certificación de competencias profesionales, en España, en Castilla y León, en Italia y en Emilia-Romagna (ver capítulo 0.), todo ello desde una perspectiva europea.

Asimismo, el segundo bloque está formado por la metodología, donde se explica el tipo de investigación y el diseño llevado a cabo, se define el evento de estudio, los criterios de análisis y las unidades de estudio, así como los instrumentos para la recogida y análisis de datos y los pasos del procedimiento a seguir para la elaboración de la investigación (ver capítulo 5). También en este bloque se incluyen el análisis de datos y los resultados de la investigación (capítulo 6), las conclusiones y los alcances del estudio (capítulo 7).

Cabe también mencionar, que cada capítulo de la parte teórica de la tesis empieza con una breve introducción sobre el mismo y finaliza con un apartado de comparación y conclusiones del tema tratado en él. En la introducción de cada capítulo se explica cómo está estructurado y los temas que van a tratarse, en algunos casos, las introducciones contienen también aclaraciones o consideraciones necesarias para comprender mejor el capítulo al que se refieren. Excepcionalmente el capítulo 2 cuenta con dos subapartados de comparación y conclusiones, uno por cada apartado que compone el capítulo. En cuanto a la parte empírica, cada capítulo se presenta con una pequeña introducción, pero se omite la parte de comaparación y conclusiones en cada uno de ellos, ya que estas se exponen al final en el último capítulo.

En último lugar se presenta la bibliografía a la que se ha hecho referencia durante la construcción del informe del trabajo de investigación. 
Introducción

Antes de la bibliografía hemos incluido, tal y como establece el acuerdo de co-tutela con la Università degli studi Roma Tre, un resumen en italiano de la tesis. 



\section{PARTE I}

\section{ESTUDIO TEÓRICO}





\section{El concepto de competencia y aprendizaje permanente}

En este capítulo del marco teórico pretendemos conceptualizar dos términos fundamentales, desde una perspectiva europea, española e italiana, para comprender y contextualizar nuestro estudio. Se trata del concepto de competencia y de aprendizaje permanente, los cuales traen consigo otros términos relacionados con la presente investigación.

El capítulo se divide en dos apartados, el primero dedicado al concepto de competencia y el segundo al de aprendizaje permanente. 


\subsection{El concepto de competencia}

El tema central de nuestra investigación versa sobre la validación y certificación de competencias profesionales, por eso, creemos fundamental dedicar este apartado a explicar el término de competencia, en el ámbito pedagógico y laboral. Con este fin, describimos la aparición del término y su evolución a nivel europeo, para centrarnos después en el discurso teórico que ha tenido lugar sobre este tema, tanto en España como en Italia, indicando los enfoques más difundidos en ambos países. Como parte final, realizamos un breve análisis comparado del estado del arte en ambos países, aportando también nuestra propia definición y forma de entender el término de competencia, orientado a la validación y certificación de competencias no formales e informales.

\subsubsection{LOS ORÍGENES DEL CONCEPTO DE COMPETENCIA}

Más o menos desde los años 80, la noción de competencia comenzó a asumir una gran importancia a nivel internacional, en la gestión de los recursos humanos, en el campo educativo y en el ámbito de la formación continua ${ }^{3} \mathrm{y}$ de la orientación profesional.

La aparición y el desarrollo de este término se originaron con la mundialización de la economía y la aceleración de los cambios tecnológicos. Todo ello produjo una transformación en la producción (que hasta ese momento se había centrado, sobretodo, en una actividad manual y mental mecánica y repetitiva), hacia operaciones dinámicas y transversales, más indicadas para los nuevos empleos que requerían un renovado mundo laboral (Joras, 1995; Michel, 1993).

Por tanto, el desarrollo del término coincide con el abandono progresivo de la organización del trabajo Taylorista ${ }^{4}$. En este periodo se generó un cambio en los mercados, que trajo a su vez continuas modificaciones en las empresas y en el modo de producir.

${ }^{3}$ Véase primer apartado de este capítulo para profundizar sobre este término.

${ }_{4}$ Método de organización industrial, caracterizado por la organización del trabajo en la máxima división de tareas del proceso de producción para lograr un aumento de la misma. 
Las estructuras organizativas del trabajo tuvieron que responder con flexibilidad y dando valor a los recursos humanos. La adquisición, el mantenimiento y el desarrollo de competencias y habilidades estratégicas empezaron a adquirir mayor relevancia, provocando que la organización se centrase más en las personas y en sus competencias (Carretta, Dalziel, \& Mitrani, 1992). Por primera vez en la historia de la organización del trabajo, se sitúa a la persona en el centro de la organización, y es considerada como el factor estratégico más importante de la misma (Varchetta, 1993).

Gracias al llamado movimiento de las competencias, poco a poco, el concepto de cualificación fue puesto en duda y se fue sustituyendo por el de competencia. El primer término dominó hasta los años 70, estaba asociado a una visión estática del mundo del trabajo, considerando que los trabajadores operaban únicamente con un "saber hacer" estereotipado y siempre idéntico (Jolis, 1997).

Este movimiento se vio impulsado por MacClelland, quien puso en entredicho la capacidad de los test tradicionales de cultura y actitud, y de los títulos y certificados escolares para predecir la actitud para el trabajo y el éxito en la vida profesional. El autor defendía que era más fácil prever el comportamiento o el éxito de una persona, descubriendo lo que haría o pensaría espontáneamente y en una situación no estructurada (McClelland, 1995).

Mientras la psicología organizativa realizaba análisis separados de la profesión y de la persona y después intentaba combinarlos, el método de las competencias realiza el análisis de la persona en el puesto de trabajo y define la profesión en términos de características y comportamientos personales que pueden asociarse a la misma.

Paralelamente a este cambio en el mundo laboral se producían cambios en el ámbito educativo-formativo. Dichos cambios estaban motivados por la Formación Basada en Competencias (en adelante, FBC).

Este enfoque, que llegó a Europa en los años 70, estaba centrado en la adquisición de competencias, lo que introdujo una novedad respecto a los programas orientados en un enfoque tradicional, diseñados a través de con-

${ }^{5}$ Entendido como el conocimiento práctico o experiencia en el ejercicio de una actividad (Cedefop, 2014, p. 63). 
La validación de competencias profesionales en España e Italia

tenidos formativos que normalmente estaban bastante relacionados con teorías y conceptos para la adquisición de conocimientos.

Según el enfoque de la FBC, al contrario de lo que ocurre en la situación tradicional, en la que toda la responsabilidad recae sobre el docente, el programa formativo, y en particular la parte relativa a la definición de las competencias relacionadas con el trabajo, es fruto de un trabajo integral. Este trabajo también prevé la participación de expertos (no necesariamente docentes) como exponentes del mundo profesional.

El enfoque de la FBC incluye competencias teóricas, como el modelo tradicional, de hechos y contenidos (leyes o principios), llamados "saberes"; competencias en relación con el "saber hacer", de carácter procedimental (realizaciones, capacidades, estrategias...) y competencias relacionadas con el "saber ser/estar", de carácter actitudinal (actitudes, valores y normas como cooperación, esfuerzo o disposición por el trabajo en equipo). Normalmente este enfoque adopta una lógica individualizada también en los procesos de evaluación, que tienen como objeto los resultados de aprendizaje en términos de competencias adquiridas (Blas Aritio, 2007).

\subsubsection{INTRODUCCIÓN AL CONCEPTO DE COMPETENCIA: ENFOQUE EN ÁMBITO EUROPEO.}

Partiendo de una idea general de competencia, podemos entenderla como una característica del individuo que le permite realizar una profesión o actividad determinada, de forma eficaz, exitosa y competitiva (Spencer \& Spencer, 1995). Es decir, se asocia la competencia al éxito en la realización de una actividad.

Sin embargo, este concepto de competencia es muy amplio y nos lleva a preguntarnos sobre cuáles son los factores que permiten a la persona reaccionar de forma eficaz, competente y con éxito, en una profesión o situación de vida.

En el ámbito europeo existen numerosos enfoques y modelos que intentan dar respuesta a este interrogante. Por su repercusión, tanto en España como en Italia, hemos decidido, describir los 6 grandes enfoques que propone uno de los autores más relevantes en este campo (Michel, 1993): 
- El enfoque basado en las aptitudes

Entiende la competencia como una habilidad. La competencia consiste en poner en marcha las disposiciones personales que desarrollan la habilidad, es decir, la aptitud. Se entiende como la propensión a hacer algo, como una capacidad potencial (Levati, 1993). Sin aptitudes no puede haber competencia.

- Enfoque basado en los "saberes"

Aquello que conduce y explica el éxito es la posesión de conocimientos. La competencia son saberes puestos en práctica. El individuo es más competente cuantos más "saberes" tiene.

- Enfoque basado en el "saber-hacer"

La competencia se asocia a la acción realizada con éxito, definida como un saber-hacer operacional valido. La competencia está estrechamente unida al hecho de que el "saber-hacer" tiene que ser practicado, visible y medible.

- Enfoque basado en los comportamientos "saber-ser"

Este enfoque atribuye al comportamiento de la persona, el motivo por el cual una acción se realiza con éxito. Esto está muy relacionado con la personalidad del sujeto ("saber-ser"). Para hablar de competencia es necesaria la presencia de rasgos personales y motivaciones, que hacen al individuo capaz de utilizar de forma competente todos los recursos de los que dispone. Es decir, es necesario "saber-ser".

- Enfoque basado en los "saberes", "saber-hacer" y "saber-ser"

Este enfoque recoge las ideas de los tres anteriores, entendiendo la competencia como un conjunto estructurado de conocimientos, habilidades y comportamientos necesarios para un eficaz desarrollo de una tarea en una profesión (Pellerey, 1983).

- Enfoque basado en las competencias cognitivas

Define la competencia como la combinación de diferentes factores, entre ellos los procesos intelectuales, que juegan un papel fundamental para realizar la acción. Este enfoque introdujo la idea de que la competencia no 
La validación de competencias profesionales en España e Italia

existe en sí misma, debe estar relacionada con un problema particular y en un contexto específico.

Para cerrar este subapartado hacemos referencia a la definición dada por el Parlamento Europeo y el Consejo de la Unión Europea, en relación al concepto de competencia en ámbito educativo-formativo:

"capacidad de una persona para poner en práctica adecuadamente los resultados de aprendizaje en un contexto concreto (educación, trabajo o desarrollo personal o profesional). O capacidad para utilizar conocimientos, destrezas y habilidades personales, sociales y metodologicas en situaciones de trabajo o estudio y en el desarrollo profesional y personal" (Cedefop, 2014, p. 48).

Este concepto tiene en cuenta conocimientos teóricos, aspectos funcionales y personales. En ámbito europeo se toma en cuenta en cuestiones de validación y certificación de competencias.

\subsubsection{ENFOQUES SOBRE EL CONCEPTO DE COMPETENCIA EN ESPAÑA}

En España, el estado del arte sobre el concepto de competencia revela algunos enfoques del contexto europeo que se han tomado como referencia, y las aportaciones de varios autores españoles.

Todavía hoy (en consonancia con la situación internacional), podemos decir que no existe consenso sobre el concepto de competencia. Este ha sufrido numerosos cambios, sobre todo en los últimos 30 años, lo que explica el gran número de definiciones que se han dado y los diferentes enfoques que se han discutido en este país (Martínez \& Carmona, 2009). Sin embargo, en comparación con Italia, la reflexión teórica sobre el tema ha sido tardía y no demasiado extensa.

Martínez y Carmona parten de la idea de que este término está relacionado con la idoneidad para intervenir en un hecho determinado (Martínez \& Carmona, 2009). Para especificar un poco más e intentar perfilar el término con más detalle, veamos algunos enfoques que consideramos más relevantes, respecto a su influencia en España y a su cercanía en cuanto a nuestra idea de competencia.

En un primer estudio podemos distinguir los enfoques: conductista, genérico y cognitivo (Mulder, Weigel, \& Collings, 2008): 
- Enfoque conductista

Entiende la competencia como las características de una persona, que están en relación con el desarrollo efectivo de un trabajo (Delamare Le Deist \& Winterton, 2005; Gonczi, 1994; Spencer \& Spencer, 1993). Es decir, el comportamiento determina la competencia de la persona.

- Enfoque genérico

Este enfoque, está dirigido a identificar las habilidades comunes que explican las variaciones en las diversas tareas y actividades de trabajo que realizan las personas y que dan lugar a conductas profesionales (Norris, 1991). Según Hager, en línea con esta idea, la competencia está más relacionada con un proceso global adaptado a un contexto específico (Hager, 1998, p. 533).

- El enfoque cognitivo

En este enfoque, el concepto de competencia incluye todos los recursos mentales que las personas necesitan para desarrollar tareas importantes, para adquirir conocimientos y para conseguir una buena realización de las mismas (Weinert, 2001).

Posteriores estudios, realizados por Rodriguez Moreno, Serreri y Del Cimmuto, también han contribuido al debate español sobre el concepto de competencia, distinguiendo los siguientes enfoques, surgidos anteriormente en el ámbito europeo:

- El enfoque racionalista

Esta teoría se remonta a los estudios de Taylor. Se caracteriza por el análisis de las capacidades, los conocimientos y el modo en el que estos se utilizan para desarrollar una actividad laboral de forma eficaz.

Este enfoque tiene una orientación funcionalista. El trabajo se considera una realidad objetiva, conocible y separada del sujeto, que constituye una entidad diversa. La realidad existe como fenómeno en sí, objetivo e independiente de la mente humana (Sandberg, 1994; Veres, Locklear, \& Sims, 1990). 
La validación de competencias profesionales en España e Italia

- El enfoque holístico

Este enfoque comparte con el racionalista la idea de la naturaleza funcional de la competencia, pero también se concentra en la naturaleza global y compleja del concepto de competencia, que no se refiere únicamente al trabajo, sino también a situaciones típicas de la vida. Esta corriente sostiene que la estructura interna de la competencia encierra diversos aspectos, como los conocimientos de base, la capacidad cognitiva, la capacidad de pensamiento analítico o crítico, la capacidad de tomar decisiones o la capacidad de resolver problemas y los componentes comportamentales, como la motivación, la estructura emocional y el marco de valores.

Uno de los autores que entiende la competencia en esta línea es Weinter, considerándola la posesión de un conjunto de capacidades y estrategias que se ponen en funcionamiento gracias al contexto, las motivaciones y la voluntad del sujeto (Weinert, 2001).

Como en el enfoque genérico, en el holístico, el contexto en el cual tiene lugar la actividad, es fundamental para definir la competencia.

- El enfoque interpretativo

Max Weber es considerado el iniciador de este enfoque, aunque diferentes autores como Antony Giddens o Jörgen Sandberg lo han seguido desarrollando posteriormente.

Esta corriente entiende la competencia como el conjunto de trabajador y trabajo dentro de un contexto en el que la experiencia del trabajador es fundamental. En otras palabras, es la conciencia práctica la que hace competente al individuo, este tipo de conciencia incluye todo aquello que el sujeto conoce de forma tácita sobre los modos de proceder en el ámbito profesional y personal, aunque no lo pueda explicar (Rodríguez Moreno, Serreri, \& Del Cimmuto, 2010, p. 27).

De esta forma entra en juego la reflexión, gracias a la cual los sujetos cambian el modo de adquisición y desarrollo de las experiencias (Schön, 1983). Esto implica la capacidad de auto-aprender y de aprender de la experiencia.

Otros autores españoles como Valverde, Barreda o Echevarría, aportan su punto de vista, sobre el concepto de competencia, participando también en la idea de la relevancia del contexto. Valverde señala que la 
competencia es la "interacción dinámica [...] de conocimientos, habilidades, destrezas, actitudes, aptitudes, movilizados según las características del contexto y desempeño en el que se encuentre el individuo" (Echeverría, 2002, p. 16).

Barreda y Benito Echeverría se centran en el contexto profesional, indicando que para realizar eficientemente una actividad es necesario tener los conocimientos requeridos para ello ("saber"). También hay que saber poner en práctica dichos conocimientos ("saber hacer"). Y además, para ser funcionales en un mundo de continuos cambios es fundamental contar con el "saber estar" y "saber ser" (Echeverría, 2002, p. 17), referidos a la dimensión participativa y personal de la persona respectivamente.

Como hemos visto, en España el concepto de competencia presenta múltiples términos y significados. Algunos enfoques se centran en campos concretos del "saber" o del "saber hacer" y otros más holísticos, más abiertos e integradores, dan también relevancia a las actitudes ("saber ser/estar") y al contexto. Esto demuestra que a día de hoy todavía no existe unanimidad ni uniformidad en la definición, aunque si existe consenso en entender el término de competencia como algo dinámico y en permanente construcción (Martínez \& Carmona, 2009, p. 83).

Sin embargo, concretamente en el ámbito de la validación y certificación de competencias y desde una perspectiva profesional se ha adoptado la siguiente definición de competencia: "conjunto de conocimientos y capacidades que permitan el ejercicio de la actividad profesional conforme a las exigencias de la producción y el empleo" (R.D. 1224, 2009, n. art. 4). El término está orientado hacia aspectos teóricos y de aptitud. Asimismo, está definido de forma abierta, dando cabida a diferentes formas de adquisición de aprendizaje.

\subsubsection{ENFOQUES SOBRE EL CONCEPTO DE COMPETENCIA EN ITALIA}

En Italia, el debate sobre la definición del concepto de competencia ha sido notablemente más rico que en España. Varios han sido los autores italianos que han hecho aportaciones al respecto. Buena parte del discurso sobre este concepto se ha apoyado en algunos autores franceses como Levy-Levoyer o, sobre todo, Guy Le Boterf. 
La validación de competencias profesionales en España e Italia

Italia ha dado numerosas definiciones de competencia desde diferentes puntos de vista, ámbitos y disciplinas. Por ejemplo, la primera disciplina en recoger el concepto fue la histórico-científica, a través de Chomsky, quien lo entendió como la capacidad de producir una lengua (Chomsky, 1965). En cuanto al ámbito pedagógico, comenzó a crearse debate sobre el concepto de competencia, en los años 80-90 (coincidiendo con el abandono de la idea Taylorista), poniendo poco a poco en duda la validez de una concepción estática que hasta ese momento se tenía sobre la definición de competencia (Castelli \& Ancona, 1998).

El concepto ha sido y sigue siendo objeto de numerosas modificaciones desde hace aproximadamente tres décadas. Algunos de los primeros autores que contribuyeron a la definición de competencia, en el ámbito pedagógico, fueron Foulquié o Mialaret. Entendieron el término como una capacidad jurídica o profesional para asumir funciones y hacerse cargo de una actividad determinada (Foulquié, 1997; Mialaret, 1979).

Otro autor, Malglaive, dio al concepto de competencia movilidad y operatividad, entendiéndolo como un saber práctico fruto de la experiencia (Malglaive, 1992). De forma progresiva se dejó paso a la idea de que la competencia no era una simple acumulación de saberes y técnicas, no sólo expresaba un "saber" o un "saber hacer" referido a una actividad mecánica, también había que tener en cuenta las características personales (Bresciani, 1997).

Según esta idea, Jolis recogió la intervención de varios factores para lograr una adecuada realización de la acción (Jolis, 1997):

- los conocimientos declarativos referidos a los saberes teóricos sobre el trabajo, las actividades que se deben realizar, el puesto que ocupa el sujeto, el contexto, la empresa, etc. Este factor está relacionado con el "saber";

- los conocimientos procedimentales, tienen que ver con los métodos, los procedimientos, los razonamientos sobre el cómo hacer, y se conforman a través de las acciones y las experiencias. En este caso, se habla de "saber-hacer";

- las disposiciones individuales, se trata de actitudes (mentales, físicas y sensoriales), motivaciones, valores, representaciones y comportamientos de cara al trabajo y factores estrechamente ligados a la identidad personal, y a la estima e imagen que el sujeto tiene de sí mismo. Este factor está ligado al "saber ser/estar". 
Algunos autores como Meghnagi, se centran en las habilidades cognitivas del individuo. Este autor critica el enfoque que decide el nivel de competencia de un individuo a través de una evaluación final de actividades (un determinado comportamiento profesional). Afirma que de este modo pueden medirse los resultados a través de habilidades observables, pero se ignoran los contenidos de los conocimientos (Meghnagi, 1992).

Otros autores se muestran más integristas, indicando que ni las habilidades ni los conocimientos, por sí solos, pueden construir una competencia. Para ser competente hay que "saber" y "querer" utilizar la compleja estructura de conocimientos y habilidades y no limitarse a la ejecución de una única actividad de forma repetitiva, es necesario desarrollar la capacidad de aprender y modificarse (Battistelli, 1996).

Serreri, basándose en diferentes aportes italianos y franceses de psicología y sociología, sigue la línea de Battistelli, hablando de "saber y querer actuar". El autor entiende la competencia como una combinación de "saber", "saber hacer", "saber ser", "saber actuar" y "querer actuar" (Alberici \& Serreri, 2005). Según esta definición, se pone el acento en la persona y en las diferentes dimensiones del "saber actuar". El "saber" y "querer actuar" son términos que implican la capacidad de activar las competencias y la voluntad de movilizarlas por parte de los sujetos.

Según lo expuesto hasta ahora, en ámbito italiano, se puede entender la competencia como un conjunto de características (actitudes y rasgos de personalidad), más subjetivas y profundas que los modelos clásicos de los "saberes" y del "saber hacer". Sin embargo, incluimos también el contexto (el poder hacer), un punto importante relacionado con la flexibilización ante los frecuentes cambios del mundo laboral (Le Boterf, 2000). Para abordar este tema la literatura italiana se basa en estudios realizados por varios autores, entre los que destacan dos franceses, Levy-Leboyer y Guy Le Boterf.

El primero de ellos, Levy-Leboyer, subraya la importancia de la correcta articulación e integración de "saberes", "saber hacer" y actitudes, siempre ligados a una actividad determinada. Es decir, a un contexto (LevyLeboyer, 1996).

Guy Le Boterf también ha defendido con gran ahínco la interacción y la actuación de la competencia en contextos de trabajo. Este experto en gestión por competencias ha influido enormemente en la literatura italiana sobre el concepto de competencia. Por ello creemos oportuno exponer, 
aunque de forma breve, algunas de sus teorías relacionadas con nuestro objeto de estudio en este apartado.

Le Boterf considera que una persona actúa con competencia cuando lo hace a través de tres dimensiones, que además ayudan al sujeto en la autoevaluación de sus competencias (Le Boterf, 2000):

- de la práctica o de la acción: se corresponde con las prácticas profesionales utilizadas en una situación profesional, en relación a las exigencias de la misma;

- de los recursos disponibles: se refiere a los recursos personales (conocimientos, capacidad, saberes prácticos, recursos emotivos, actitudes, etc...) y del ambiente (bancos de datos, soportes de documentación, guías, redes, compañeros, etc...), que un sujeto puede utilizar, combinar y movilizar para actuar con competencia. Cabe señalar que la competencia comprende también la capacidad de gestionar todos los recursos disponibles;

- de la reflexión: pertenece al campo de la meta-cognición (reflexión sobre los procesos mentales de uno mismo), se basa sobre todo en el distanciamiento del sujeto respecto a sus recursos y a la actividad que realiza. El sujeto se sitúa fuera de la acción y la contextualiza a través de su sentimiento de autoeficacia6, que le ayudará a juzgar su propia capacidad para realizar dicha acción. La autoeficacia es importante para que el sujeto actúe con competencia y pueda transferir el aprendizaje a otras situaciones (Daniele, 2010). Si el sujeto comprende cómo actúa en un determinado contexto, quiere decir que analiza sus actos y puede explicarlos. De este modo, las competencias y conocimientos se hacen explícitos, lo que significa que el sujeto puede reconocer sus recursos y ponerlos en marcha ante diferentes situaciones. En otras palabras, puede transferir sus actividades profesionales a diversos contextos de trabajo.

La transferencia de competencias y conocimientos de una situación a otra puede ser de dos tipos: asimilativa o adaptativa. En el tipo asimilativo, se produce una traslación de competencias y conocimientos de una situación profesional a otra que sea parte de la misma familia de prácticas

${ }^{6}$ Entendemos autoeficacia como el juicio que tiene el sujeto sobre su propia capacidad de realización de una actividad finalizada a obtener unos resultados determinados (Bandura, 1997). 
profesionales. En cuanto al tipo adaptativo, el sujeto debe modificar su esquema operativo al enfrentarse a una nueva situación o problema. Es decir, debe realizar una adaptación en la combinación de recursos de los que dispone, buscar otros nuevos y abandonar los que no sean pertinentes (Le Boterf, 2000).

Le Boterf resalta que la capacidad de transferir competencias y habilidades debe pasar por una abstracción de estas al contexto específico en el que se aplican, aunque no a través de una operación de generalización. Esto quiere decir que la capacidad de transferir las propias competencias se adquiere más a partir de la reflexión sobre el propio modo de actuar en determinados contextos, que a partir de un aprendizaje de método general y abstracto. En este sentido, la transferencia, no es una aplicación directa, sino una desviación, a través de la reflexión sobre los objetivos, las teorías de acción, las representaciones del trabajo, para reutilizar de forma adecuada las propias competencias (Le Boterf, 2000).

Según esta idea puede afirmarse que poseer conocimientos, capacidades y aptitudes particulares no es suficiente para que exista competencia. Es necesario, también, el uso adecuado de todos los recursos disponibles en una situación de trabajo. La competencia no puede separarse de las condiciones que la rodean durante su puesta en práctica, ya que se realiza siempre en un contexto específico y con una determinada finalidad (Castelli \& Ancona, 1998).

Varios autores italianos como Basttistelli y Bertolini se han mostrado afines a las teorías de Le Boterf, poniendo en evidencia la importancia del contexto. Bastistelli entiende la competencia como una capacidad adquirida para gestionar el contexto, defiende que los saberes, las capacidades y comportamientos se pueden organizar para numerosos objetivos y en diferentes situaciones (Battistelli, 1996). Bertolini define la competencia sin perder de vista el ámbito determinado en el que el individuo desarrolla su habilidad (Bertolini, 1996).

Domenico Lipari es otro autor italiano que ha hecho una importante aportación en cuanto a la definición del término de competencia en el ámbito laboral y en sintonía con la importancia del contexto. El autor reconoce las competencias como algo más que simples conocimientos cognitivos adquiridos a lo largo de una formación de tipo formal. Lipari otorga un gran valor a la experiencia en el trabajo, entendiendo que facilita la adaptación de 
La validación de competencias profesionales en España e Italia

los conocimientos a contextos operativos. Considera que dicha experiencia pasa por una reelaboración intelectual, enriqueciendo el conjunto de conocimientos teóricos y operativos, ya que la gran complejidad de contextos y de prácticas laborales estimulan una constante búsqueda de soluciones a los nuevos problemas que surgen en contextos de trabajo (Lipari, 2009).

También en consonancia con las teorías de Le Boterf, Aureliana Alberici afirma que los conceptos de conocimiento, competencia y metacompetencia ${ }^{7}$ expresan la capacidad personal de cada individuo para adaptarse y re-adaptarse a las dinámicas evolutivas de sus contextos, construyendo y transformando continuamente sus propios modelos de conocimiento y de actuación. Esta interpretación apoya el concepto de competencia estratégica que Aureliana Alberici define en términos de saber aprender. La competencia se fundamenta en el "aprender a aprender" y en las implicaciones formativas (Alberici, 1999).

Varchetta, siguiendo y reflexionando sobre la teoría de Alberici, entiende el desarrollo de las competencias y el aprendizaje como un apoyo y una práctica continua en el ambiente laboral, en las organizaciones y en la existencia individual y social (Varchetta, 2003).

Aprender a aprender se ha convertido en la directriz fundamental propuesta para la reflexión y para las prácticas de cuantos se ocupan de formación en todos los campos y en todas las dimensiones. La metacompetencia "aprender a aprender" permite la gestión consciente del aprendizaje en todo momento y lugar en el que pueda ocurrir. De este modo la competencia se entiende como una capacidad estratégica de actuar sobre procesos de aprendizaje y de organizar un modelo de acción (Alberici, 2008).

Por último, como hemos hecho en los dos subapartados anteriores, queremos reflejar la definición de competencia que se admite en Italia para las prácticas de validación y certificación de competencias: "la capacidad comprobada de utilizar, en situaciones laborales, de estudio o en el desarrollo profesional y personal, un conjunto estructurado de conocimientos y de habilidades adquiridas en los contextos de aprendizaje formal, no formal e informal" (Decreto Legislativo 13, 2013, n. art. 2.1. e).

${ }^{7}$ Capacidad para aprender a aprender (Alberici, 1999). 
En este caso Italia tiene en cuenta en la definición de competencia los contextos no formales e informales además del formal.

\subsubsection{COMPARACIÓN Y CONCLUSIONES}

El discurso sobre el concepto de competencia ha sido más amplio en Italia que en España, a pesar de que en los últimos años, este último país se ha ocupado de mejorar este aspecto.

Observamos que, aunque con trayectorias diferentes, ambos países han ido abandonando la idea estática que se tenía en un principio sobre el concepto de competencia, para entender el término de forma dinámica. Este cambio de paradigma ha permitido allanar el camino para llegar a la validación y certificación de competencias.

De ese modo, tanto España como Italia han dado importancia a las dimensiones, surgidas en el contexto europeo, del "saber", "saber hacer", "saber ser/estar" y "poder hacer" (contexto). En Europa y en Italia se habla también de las dimensiones del "saber y querer actuar", entendidas como la capacidad de activar las competencias necesarias para realizar una actividad con éxito y el aspecto motivacional para querer hacerlo. Sin embargo, creemos que "saber y querer actuar" pueden quedar recogidas en el "saber ser/estar". Ya que, en línea con el autor Benito Echeverría, lo entendemos como la dimensión personal, relacionada con la imagen de uno mismo y la convicción para actuar (saber ser) y la dimensión participativa, relacionada con la actuación interpersonal, la comunicación y la cooperación con el grupo de trabajo (saber estar) (Echeverría, 2002, p. 18).

Tras el análisis del estado del arte en España e Italia, y sin perder de vista el argumento central de este estudio, la validación y certificación de competencias no formales e informales, hemos dado forma a la siguiente definición de competencia:

"conjunto de varios recursos, formados por conocimientos teóricos y técnicos ("saberes"), habilidades prácticas ("saber hacer") y capacidades personales relacionadas con las actitudes comportamentales de interacción, de imagen de uno mismo y motivacionales ("saber ser/estar"). Estos recursos, no suponen la suma o yuxtaposición de partes, sino que interaccionan entre ellos de forma positiva (Rodríguez Moreno et al., 2010, p. 28) sobre la base de un contexto determinado (Le Boterf, 2001) y según el modo en el 
La validación de competencias profesionales en España e Italia

cual cada individuo concibe e interpreta su propia experiencia (Sandberg, 2000)".

Parafraseando a Benito Echevarría y utilizando su juego de palabras, podemos decir que la competencia profesional es la suma del saber (conocimientos teórico-prácticos) y del sabor (competencias transversales) (Echeverría, 2002, p. 17).

Mientras que las dimensiones que hacen referencia al "saber" y al "saber hacer" son fácilmente observables como la punta de un iceberg, existe también la parte sumergida de este, que serían las dimensiones transversales del "saber ser/estar", más difíciles de apreciar en una evaluación de competencias.

Asimismo, recurrimos a la idea de Alberici y de Rodríguez sobre aprender a aprender, basada en la reflexión de la práctica para poder autoaprender y así mejorar y hacer transferibles las competencias a otros contextos.

Durante estas páginas hemos intentado definir el concepto de competencia, desde una perspectiva pedagógico-profesional, enmarcado en el ámbito de la validación y certificación de competencias profesionales. Queremos cerrar este apartado señalando que entendemos el concepto desde el paradigma holístico. Por eso, consideramos que cualquier tipo de competencia, del ámbito que sea y sin importar su vía de adquisición, podría ser una competencia susceptible de ser utilizada y desarrollada en ámbito profesional, así como susceptible de validación y certificación. De este modo relacionamos la adquisición de competencia con el aprendizaje a lo largo y a lo ancho de la vida. 
El concepto de competencia y aprendizaje permanente

\subsection{El aprendizaje permanente (lifelong \& lifewide learning)}

Para poder hablar de validación de competencias debemos situarnos en un contexto teórico más amplio que nos ayude a entender la necesidad de validar los aprendizajes no formales e informales y por tanto, la importancia de la implantación de dispositivos de validación y certificación de competencias profesionales. El contexto al que nos estamos refiriendo es el del aprendizaje permanente o aprendizaje a lo largo de toda la vida (también conocido por su nombre en inglés lifelong learning).

El aprendizaje permanente ha adquirido, sobre todo en los últimos años, una relevante importancia en las políticas educativas y económicas. Como ya señalaron organismos internacionales, el aprendizaje de adultos supone un instrumento clave para el siglo XXI, ya que puede convertirse en condición del desarrollo humano, de la riqueza, de la competitividad económica y de la cohesión social (Delors, 1996).

Por su importancia y pertinencia respecto al objeto de estudio que nos ocupa le dedicamos este espacio en la investigación. En primer lugar, comenzamos realizando algunas aclaraciones terminológicas, para después centrarnos en el aprendizaje permanente propiamente dicho, Por último, finalizamos con un breve subapartado de comparación y conclusiones sobre todo lo expuesto y detallamos nuestra forma de entender el aprendizaje a lo largo de la vida y su relación con la validación y certificación de competencias. Todo ello desde la perspectiva de la UE, España e Italia.

\subsubsection{TÉRMINOS RELACIONADOS CON EL APRENDIZAJE PERMANENTE}

Han sido muchas las confusiones creadas con la terminología relacionada con el aprendizaje permanente, por eso creemos importante diferenciar algunos términos que por su cercanía con el lifelong learning se han utilizado erróneamente como sinónimos de éste o simplemente no se han definido correctamente. También creemos oportuno distinguir tres términos clave en el aprendizaje permanente: el aprendizaje formal, no formal e informal. 
La validación de competencias profesionales en España e Italia

Asimismo nos acercaremos al modo de entender los términos relacionados con el aprendizaje permanente en España y en Italia de acuerdo a las pautas que la UE ha ido dando en los últimos años.

\subsubsection{El aprendizaje formal, no formal e informal}

Los aprendizajes formales, no formales e informales son los componentes del aprendizaje permanente, por eso es imprescindible delimitarlos y explicar lo que entendemos por cada uno de ellos. Para ello, tomamos las últimas definiciones dadas por el Consejo Europeo en su última recomendación sobre validación de aprendizaje no formal e informal.

El aprendizaje formal se define como: "el que tiene lugar en entornos organizados y estructurados, dedicado especificamente al aprendizaje, y por lo general da lugar a la concesión de una cualificación, por lo general en forma de certificado o de titulo, y abarca los sistemas de enseñanza general, de formación profesional inicial y de enseñanza superior" (Recomendación del Consejo, 2012, n. Anexo, a).

Mientras que el aprendizaje no formal se entiende como: "el derivado de actividades planificadas (en cuanto a objetivos didácticos y duración) en el que existe alguna forma de apoyo al aprendizaje (como, por ejemplo, una relación entre estudiante y profesor). Puede abarcar programas para impartir capacidades laborales, alfabetización de adultos y la educación básica para personas que han abandonado la escuela prematuramente" (Recomendación del Consejo, 2012, n. Anexo, b).

En España y en Italia el primer tipo de aprendizaje se adquiere a través de los sistemas oficiales educativos y de formación profesional, mientras que el segundo se obtiene fuera de estos sistemas, aunque también está planificado. Un ejemplo de aprendizaje no formal sería la formación organizada dentro de las empresas.

El aprendizaje informal es, seguramente, el más reciente de los tres y desde nuestro punto de vista el más controvertido en el ámbito del aprendizaje permanente, por eso le dedicaremos mayor atención en este apartado. Se trata de un término que desde hace unos años está cobrando fuerza en Italia y en España, gracias a la resonancia que tiene a nivel internacional y concretamente a nivel Europeo.

A pesar de haber existido siempre, el aprendizaje informal no ha empezado a gozar de una cierta importancia hasta el año 2000 con el Consejo Europeo de Lisboa, cuando empezó a considerarse como una herramienta 
para poder llegar a hacer de Europa la economía más competitiva del mundo a través de la sociedad del conocimiento o del aprendizaje.

Ya en el año 1916, Dewey, en su libro de Democracia y Educación, habló del enseñar y del aprender como una necesidad de la sociedad para poder seguir existiendo, y de la sociedad que a su vez es capaz de educar (Dewey, 1916, p. 6). Esta idea nos saca del contexto formal e incluso del no formal, abriendo un campo del aprendizaje más amplio e integrador de los aspectos cotidianos de la vida.

El término de aprendizaje informal ha ido adquiriendo mayor importancia con el paso del tiempo, y su relevancia ha hecho que en el ámbito internacional y europeo se trabajase para llegar a un consenso en las definiciones de aprendizaje formal, no formal e informal. Uno de los investigadores que ha trabajado sobre este aspecto, a nivel europeo, ha sido Werquin. En el año 2007 publicó el documento Terms, concepts and models for analysing the value of recognition programmes, en él expuso la evolución de los términos otorgados, a nivel internacional y europeo, desde los años 70, al aprendizaje formal, no formal e informal (OECD, 2007).

En este documento habló de la intencionalidad y no intencionalidad a la hora de aprender para diferenciar el aprendizaje no formal del informal y señaló que en el informal no existe una guía, sino que el encargado de dirigir el proceso de aprendizaje es el propio sujeto.

Actualmente en Europa se entiende el aprendizaje informal como: "el resultante de actividades cotidianas relacionadas con el trabajo, la familia o el ocio y que no está organizado o estructurado en cuanto a objetivos, tiempo o apoyo para el aprendizaje. El aprendizaje informal puede ser no intencionado desde el punto de vista de quien aprende [...]”" (Recomendación del Consejo, 2012, n. Anexo, c).

Por tanto, podemos considerar aprendizaje informal, la adquisición de capacidades a través de experiencias de vida y de trabajo. Por ejemplo, serán aprendizajes informales aquellos que proporcionan competencias a través de la gestión de proyectos o del manejo de las Tecnologías de la Información y Comunicación (TIC); del uso de idiomas; de experiencias interculturales en estancias en países extranjeros; de actividades de voluntariado, culturales, deportivas, o incluso, desarrolladas en nuestra propia casa.

En esta nueva definición, respecto a la de Werquin, se puede observar que la intencionalidad se considera un aspecto no discriminante para distin- 
La validación de competencias profesionales en España e Italia

guir este tipo de aprendizaje. Es decir, que en el aprendizaje informal, se aprende, teniendo intención de hacerlo o no.

\section{- Aprendizaje informal en España}

En España, el debate sobre el aprendizaje informal, sobre todo comparado con el ámbito italiano, no se ha extendido demasiado. Hemos observado que, normalmente, en la legislación sobre políticas educativas se habla de aprendizaje experiencial pero no de aprendizaje informal.

Diversos autores españoles como Esther Rubio Herrárez mencionan en su discurso sobre el aprendizaje informal la definición que le otorgó Coombs (1980):

"El proceso a lo largo de la vida por el que cada persona adquiere y acumula conocimientos, habilidades, actitudes y criterios a través de las experiencias cotidianas y de su relación con el medio; en casa, en el trabajo, en el juego; a través del ejemplo y de las actitudes de familiares y de las amistades; de los viajes, de la lectura de periódicos y libros; escuchando la radio o viendo cine o televisión" (Coombs, 1980, p. 47).

Se entiende como un proceso continuo y espontáneo de aprendizaje, que tiene lugar fuera de lo que entendemos como marco de la educación formal y no formal.

\section{- Aprendizaje informal en Italia}

En el contexto italiano el debate sobre el aprendizaje informal ha tenido un mayor desarrollo respecto a España.

Varios autores han proporcionado su contribución en este ámbito. Por ejemplo, Aureliana Alberici entiende el aprendizaje informal como un "proceso que el individuo realiza, a partir de una situación dada, en la cual se ponen en funcionamiento determinados procedimientos y se actúa para lograr el resultado" (Alberici, 2001, p. 102).

Autores como Fabbri o Jarvis (cuyas teorías sobre aprendizaje informal se encuentran muy presentes en Italia), comparten la idea de que desde este punto de vista, no interesa tanto una respuesta bien dada o una actividad bien realizada como el camino que se ha recorrido para llegar a esa respuesta o a la realización de la actividad. Por tanto este modo de entender 
el aprendizaje otorga gran importancia al aprendizaje en situaciones naturales de la vida cotidiana (Fabri, 1990; Jarvis, 1992).

En la última ley italiana sobre la reforma laboral se define el aprendizaje informal como: "Aquello que, sin tener en cuenta la elección o no intencional, se realiza en el desarrollo, por parte de cada persona, de actividades en situaciones de vita cotidiana y en las interacciones que tienen lugar en ésta, en el ámbito del trabajo, familiar y en el tiempo libre” (Ley 92, 2012, n. art. 4, párrafo 54).

Dicho de otro modo, la definición que se atribuye en Italia hoy en día al término de aprendizaje informal se refiere a todo aprendizaje que tiene lugar fuera de los contextos específicamente pensados para tal fin. Esta descripción encierra una amplia gama de situaciones en las que puede tener lugar el aprendizaje, desde la imitación espontánea de la primera infancia a los ámbitos profesionales y el tiempo libre (Ugolini, 2013, p. 11).

Esta definición está ligada a lo que se entiende por aprendizaje a lo largo de la vida (lifelong learning). No se fundamenta únicamente en la alternancia de trabajo y formación en edad adulta, como se promovía, en los años 70 desde la $\mathrm{OCDE}^{8}$, sino que ahora se tiene en cuenta el aprendizaje, no sólo a lo largo de la vida, sino también a lo ancho de la vida. Es decir, que se caracteriza por una continuidad, ya sea a nivel temporal (lifelog), durante toda la vida, como a nivel espacial (lifewide), en todos los contextos de la vida.

Como hemos reflejado, el debate sobre la importancia del aprendizaje informal como herramienta para mejorar en ámbito profesional y sobre todo personal, está más extendido en Italia que en España. La definición de Coombs, que se toma en el contexto español, no hace referencia, como la italiana o la europea, a la intencionalidad del aprendizaje informal. Aunque nosotros entendemos la omisión de este punto como que el aprendizaje informal puede ser intencional o no, ya que podemos ser conscientes o no de lo que aprendemos a través de las actividades cotidianas y de trabajo.

8 Organización para la Cooperación y el Desarrollo Económico: fue fundada en 1961, actualmente agrupa a 34 países miembros, con el objetivo de promover políticas de mejora del bienestar económico y social de las personas (OCDE, 2015). 
La validación de competencias profesionales en España e Italia

\subsubsection{La formación continua.}

La formación continua (también conocida por su nombre en inglés, continuing education and training) tiene por lo general un carácter funcional. No se puede confundir con el aprendizaje permanente, ya que forma parte del mismo. Este último tiene el objetivo final de garantizar el desarrollo de la persona en todos sus aspectos: como individuo miembro de una sociedad productiva, como sujeto que participa en la política de su país en la cultura y en el tiempo libre (Sabán Vera, 2009). Mientras que la formación continua se encuentra más dirigida a la mejora profesional de la persona.

Siguiendo la definición que da el Cedefop ${ }^{9}$, la formación continua tiene lugar de forma permanente y después de la educación o formación iniciales (o tras acceder a la vida activa) y tiene como finalidad ayudar a las personas a adquirir, perfeccionar o actualizar conocimientos y/o destrezas para un puesto de trabajo y/o fomentar el desarrollo personal o profesional.

También resalta su importancia para mejorar en la persona las perspectivas de encontrar trabajo, de mantenerlo y de progresar en el ámbito profesional, es decir, de mejorar su empleabilidad (Cedefop, 2008, p. 19).

\subsubsection{La educación de adultos}

Otro de los términos importantes que se encuentran bajo el paraguas del aprendizaje permanente es el de educación de adultos, confundido en numerosas ocasiones con la formación continua que acabamos de explicar y con el aprendizaje permanente.

Así como la formación continua está más orientada hacia la actualización de conocimientos, capacidades o competencias en un ámbito profesional específico, la educación de adultos se dirige, sobre todo, a la formación formal de adultos que ya tengan una formación inicial y que pretendan retomar su educación por motivos personales o profesionales (Cedefop, 2008, p. 5).

A pesar de que la formación de adultos esté enfocada (en mayor medida) a la educación y formación formales, esta puede utilizarse como herramienta para mejorar o actualizar las competencias en el campo laboral.

9 Cedefop: Centro Europeo para el desarrollo de la formación profesional. Su misión en proporcionar asistencia a la Comisión Europea para contribuir, a nivel europeo, a promocionar y desarrollar la formación profesional y continua (EUR-Lex, 2015). 
Es decir, a nuestro modo de entender, la formación formal no es un sinónimo de la formación de adultos, sino un integrante de ésta.

A continuación exponemos, de forma resumida, cómo interpretan la terminología de formación continua y de educación de adultos España e Italia a la hora de adaptar sus políticas educativas y de formación a las recomendaciones de la UE.

\section{- La formación continua y la educación de adultos en España:}

En España, la formación continua está enfocada a la población activa ocupada, aunque en el año 2007 se unió a la formación ocupacional (dirigida a la población activa desempleada), produciéndose como resultado la formación para el empleo. La fusión se produjo a través del RD 395/2007, con objeto de adaptar la formación dirigida a trabajadores y personas demandantes de empleo y unirla en una formación para la población activa, como respuesta a la actual realidad socioeconómica en el nuevo contexto de aprendizaje permanente. El objeto de este tipo de formación es impulsar y extender entre empresas y trabajadores ocupados y en situación de desempleo, una formación que dé respuesta a sus necesidades y ayude al desarrollo de una economía basada en el conocimiento (Real Decreto 395, 2007, n. art. 2).

En cuanto a la educación de adultos, es competencia del Ministerio de Educación, pretende ofrecer a todos los mayores de 18 años la posibilidad de adquirir, actualizar, completar o ampliar sus conocimientos y aptitudes para su desarrollo personal y profesional, y que la persona pueda adquirir sus aprendizajes por medio de actividades de enseñanza reglada o no reglada, así como servirse de la experiencia laboral o social (L.O. 2, 2006, n. art. 66).

Podemos decir, por tanto, que la formación continua (formación para el empleo, ahora) en España está más dirigida al aspecto profesional y la educación de adultos al académico. 
La validación de competencias profesionales en España e Italia

\section{- La formación continua y la educación de adultos en Italia:}

El Isfol (Istituto per lo sviluppo della formazione professionale dei lavoratori) ${ }^{10}$ entiende la formación continua desde un punto de vista orientado al trabajo. Es decir, a la re-cualificación profesional y a la actividad de actualización del trabajador. En este contexto se encuentran las personas con empleo interesadas en la actualización y el perfeccionamiento de competencias profesioprofesionales, con objeto de mejorar su desempeño laboral (Isfol, 2015a).

Respecto a la educación de adultos en Italia, conocida como EdA (Educazione degli Adulti), cabe decir que ha pasado por múltiples definiciones. En un principio estaba formada por acciones formativas dirigidas a la adquisición de competencias básicas generales (por ejemplo, se utilizaba para lograr el título de la escuela primaria o media ${ }^{11}$ ). Sin embargo, en los últimos tiempos la importancia de la EdA ha trascendido del ámbito laboral al personal (Alberici, 2000) y sus acciones formativas se han visto encuadradas cada vez más en el contexto de aprendizaje permanente (Ministero del Lavoro e delle Politiche Sociali, 2015).

Todo esto ha desembocado en la redefinición de un concepto de educación de adultos enriquecida por el aprendizaje a lo largo de la vida. De este modo, hoy se entiende en Italia como aprendizaje de adultos, los procesos, las actividades y las experiencias dirigidos y no dirigidos de forma intencional al aprendizaje, ya que aunque no se tenga intención de aprender se aprende a través de la experiencia de vida (Alberici, 2000, p. 111). De esta forma entran en juego no sólo los aprendizajes formales y no formales sino también los informales.

Siempre desde esta perspectiva de aprendizaje permanente la EdA engloba varios tipos de actividades formativas (Alberici, 2002, p. 29):

- de carácter compensativo, para aquellas personas que en su momento no pudieron estudiar lo suficiente y no llegaron a obtener un título académico;

- de carácter empresarial, dirigido a trabajadores y/o nuevos contratados;

10 Istituto per lo Sviluppo della Formazione Professionale dei Lavoratori (Instituto para el Desarrollo de la Formación de los Trabajadores). (Explicado en el subapartado 4.3.1).

11 Actualmente denominada escuela secundaria de primer grado. 
- de formación continua, enfocada al desarrollo de las competencias profesionales.

Según esta clasificación, actualmente, en Italia, la formación continua estaría incluida en la formación de adultos.

En resumen, puede decirse que, tanto en España como en Italia, los actuales cambios sociales y económicos están readaptando los términos de formación continua y educación de adultos, bajo la influencia europea del lifelong learning.

\subsubsection{LA EVOLUCIÓN DEL APRENDIZAJE PERMANENTE}

Tras esta definición y contextualización de los términos relacionados con el lifelong learning, podemos decir que hemos perfilado el propio aprendizaje permanente, sin embargo, en este apartado nos centraremos todavía más en este y en su evolución en la UE, en España y en Italia.

La UNESCO ${ }^{12}$ y la UE son dos asociaciones que han supuesto, siempre, una gran influencia en las políticas educativas de los Estados miembros. Tal vez por ello España e Italia ${ }^{13}$ consideran el aprendizaje permanente un concepto clave en su apuesta por la mejora de sus culturas a través de la educación.

Como señaló Paul Lengrand (personaje clave en la concepción del pensamiento de la UNESCO sobre la educación), el aprendizaje permanente ha tenido un desarrollo lento en cuanto a su inserción en programas políticos (Sabán Vera, 2009). Quizá por eso, todavía hoy en España y en Italia, el concepto de aprendizaje a lo largo de toda la vida sigue en proceso de definición en el ámbito social y político.

12 La UNESCO (Organización de las Naciones Unidas para la Educación, la Ciencia y la Cultura) se fundó en el año 1945. Esta organización pretende impulsar la consolidación de la paz, la erradicación de la pobreza, el desarrollo sostenible y el diálogo intercultural a través de la educación, las ciencias, la cultura, la comunicación y la información. Entre las prioridades de la UNESCO está lograr una educación de calidad para todos y el aprendizaje a lo largo de la vida (UNESCO, 2015).

13 Estos dos países forman parte de ambas organizaciones desde hace años. Italia ingresó en la UNESCO en el año 1948 y España lo hizo en el 1953. En cuanto a la Unión Europea, Italia fue uno de los miembros fundadores, mientras que España se incorporó en el año 1986. 
La validación de competencias profesionales en España e Italia

La UNESCO ha dirigido, especialmente en los últimos años, la educación permanente hacia el desarrollo personal en todas sus vertientes, como sujeto autónomo, como ciudadano, como miembro activo de la sociedad, para la participación política, cultural, para la producción y el tiempo libre (Sabán Vera, 2009). Todo este recorrido que ha traído consigo la evolución del concepto y el paso de educación a aprendizaje, se ha visto plasmado en un gran número de conferencias e informes para la $\mathrm{UNESCO}^{14}$.

A principios de los años 70 la UNESCO habla de educación permanente, entendiéndola como un proceso que acompaña el desarrollo personal, profesional y social de los individuos durante el curso de su existencia, para mejorar su calidad de vida y la de sus colectivos. Consideraba la educación como algo más que la simple adquisición de conocimientos, teniendo en cuenta también el desarrollo del individuo a través de las experiencias de vida (Alberici, 2002, p. 16).

Esta idea de educación permanente superó la idea de formación únicamente en el sistema educativo (formación formal), para abrirse a todos los campos formativos (formales, no formales e informales).

También en el ámbito de la Comunidad Europea se ha otorgado una gran relevancia al aprendizaje permanente. Han sido numerosos los esfuerzos por parte de la UE dirigidos a definir y a mejorar la educación a lo largo de la vida, instando a los Estados miembros a la creación de pasarelas entre las diferentes modalidades de formación y a facilitar el reconocimiento y la certificación de las competencias adquiridas por cualquier vía.

Por ejemplo, el Libro Blanco sobre la educación y la formación "Enseñar y aprender", publicado en el año 1995, demuestra el compromiso y el apoyo que ha brindado la UE al aprendizaje permanente. (Comisión de las Comunidades Europeas, 1995).

La primera definición consensuada por los países pertenecientes a la UE, sobre el aprendizaje a lo largo de la vida, se dio tras el Consejo Europeo de Lisboa del año 2000, en el que se entendió este aprendizaje como

14 Aquí se hace referencia a las conferencias de la UNESCO: Elsinor en el 1949; Montreal en el 1960; Tokio en el 1972; París en el 1985; Hamburgo en el 1997 y Belén en el 2009. 
una pieza fundamental del modelo social europeo y de la estrategia europea de empleo.

A partir del Consejo y con la intención de crear un debate en cada país sobre el aprendizaje permanente, la UE publicó un documento de trabajo titulado "Memorándum sobre el aprendizaje permanente". Con este documento la unión manifestó su preocupación por no limitar el significado del aprendizaje a lo largo de la vida a un enfoque económico-laboral o restringido al aprendizaje de adultos. De igual modo, mostró su intención de entender el aprendizaje en la vida de las personas como un proceso permanente desde el nacimiento hasta después de la jubilación (de la cuna a la tumba), abarcando los aprendizajes formales, no formales e informales, que busque una ciudadanía activa, la realización personal y la integración social, además de los aspectos relacionados con el empleo (Commissione delle Comunità Europee, 2000).

Años más tarde la UE, manteniendo el enfoque de siempre, propuso un aprendizaje permanente con una nueva perspectiva añadida, la del aprendizaje a lo ancho de la vida, o lo que es lo mismo, del aprendizaje en todos los contextos de la vida.

Definió el aprendizaje a lo largo de la vida como: "Toda actividad formativa emprendida en cualquier momento del ciclo vital de una persona con el fin de mejorar sus conocimientos teóricos o prácticos, sus destrezas, competencias y/o cualificaciones por motivos personales, sociales y/o profesionales" (Cedefop, 2008, p. 57).

Y se refirió al aprendizaje a lo ancho de la vida como: "Formación o aprendizaje formal, no formal o informal que puede tener lugar a través de todo el amplio rango de actividades de la vida (personales, sociales o profesionales), y llevarse a cabo en todo momento" (Cedefop, 2008, p. 58).

De estas definiciones deducimos que el aprendizaje a lo ancho de la vida es una dimensión que siempre ha estado presente en el aprendizaje a lo largo de la vida. Ya que desde nuestro punto de vista, en la primera definición queda implícita la idea de los aprendizajes formales, no formales e informales ${ }^{15}$, o lo que sería la mismo, la idea del aprendizaje en cualquier contexto.

15 Más adelante, veremos cómo estas definiciones han sido aceptadas e incluidas en las políticas educativas y formativas de España e Italia, como países pertenecientes a la UE. 
La validación de competencias profesionales en España e Italia

Los términos de aprendizaje a lo largo y a lo ancho de la vida se han hecho necesarios en la medida en la que se ha empezado a entender la sociedad como un proceso de enseñanza-aprendizaje (Rubio Herráez, 2007, p. 15) que hace posible el aprendizaje en todas las etapas y en todos los contextos de la vida, para poder mejorar a nivel profesional y personal.

Poco a poco se ha pasado de concebir la formación y el aprendizaje centrado en edades tempranas al aprendizaje a lo largo y ancho de la vida, que comprende desde la infancia hasta la vejez y el aprendizaje formal, no formal e informal. Las primeras etapas de la vida de la persona suelen estar marcadas por la educación formal, sin embargo, a medida que la persona crece y se desarrolla empieza a formarse fuera de las instituciones educativas, para dar respuesta a sus necesidades profesionales y sobre todo personales (autorrealización).

Como señala Rubio Herráez (2007, p. 15), la idea de usar el término de aprendizaje y no el de educación o formación supone un gran cambio, al dar valor no sólo a la formación formal sino a los aprendizajes que tienen lugar fuera de las instituciones educativas, es decir, a los aprendizajes no formales e informales.

Creemos que esta perspectiva del aprendizaje es importante para que las personas optimicen su trabajo y prosperen profesionalmente mejorando la productividad del mercado laboral, pero sin olvidar (como se ha esforzado siempre en señalar la UE y en especial la UNESCO) que la finalidad del aprendizaje a lo largo y a lo ancho de la vida radica, sobre todo, en la autorrealización del ser humano (Commissione delle Comunità Europee, 2000; Delors, 1996), que desarrollará su propio proceso formativo según el contexto en el que se encuentre (Alberici, 2000).

L'Éducation. Un trésor est caché dedans (La educación encierra un tesoro) es el informe que Jacques Delors realizó en 1996 por encargo de la UNESCO. Consideró el aprendizaje a lo largo de la vida como una de las claves del siglo XXI para responder al reto de un mundo en constante cambio, además, definió los pilares que ayudaron a entender la educación como un procedimiento permanente durante toda la vida ${ }^{16}$ (Delors, 1996).

16 Aprender a vivir juntos, valorando y respetando la pluralidad; Aprender a conocer, aprender a aprender, para un aprendizaje a lo largo de la vida; Aprender a hacer para enfrentarse a diversas situaciones y para aprender a trabajar en equipo; Aprender a ser para conocerse uno mismo y actuar con autonomía de juicio y de responsabilidad personal. 
Para resumir, podemos decir que hoy en día el aprendizaje a lo largo y a lo ancho de la vida abarca los aprendizajes derivados de los sistemas de educación formal, los aprendizajes no formales y los aprendizajes informales, adquiridos en cualquier etapa de la vida.

El empeño de la UE por crear una sociedad del conocimiento capaz de convertir a Europa en la economía más dinámica del mundo ha hecho que España e Italia, como países pertenecientes a la unión, desarrollen políticas de aprendizaje a lo largo de la vida en sus políticas educativas.

\subsubsection{El aprendizaje permanente en España}

En España se ha vivido una evolución en el término de aprendizaje permanente según han ido cambiando las exigencias socioeconómicas europeas y españolas.

En un principio se utilizaba el término de educación permanente, sin embargo, la palabra educación se asocia al sistema educativo, es decir a la formación reglada (formal), y por lo tanto no era la más adecuada.

Más tarde empezó a hablarse de formación continua, que permitió la ampliación de los aprendizajes no formales, y con el tiempo se comenzó a hablar de competencias y de aprendizajes, lo cual nos condujo al término de aprendizaje permanente (Rubio Herráez, 2007) o aprendizaje a lo largo de la vida, dando valor a los aprendizajes que tienen lugar más allá de las instituciones educativas, haciendo especial hincapié en los aprendizajes informales que se adquieren en la cotidianidad del día a día (Rubio Herráez, 2007, p. 17).

En España, para hablar del primer impulso para la definición de políticas de formación de adultos nos remontamos a la Ley General de Educación del año 1970, aunque no fue hasta la última década del siglo XX cuando se dedicó a estas políticas una dotación presupuestaria relevante, en ámbito educativo y en ámbito laboral. Actualmente existe una clara preocupación por parte de las Administraciones educativas por la formación de las personas adultas (Ministerio de Educación, 2011).

Según la "Encuesta de Población Activa $2010\left(2^{\circ} \mathrm{T}\right)$ ", en España existen 12.881 .100 personas mayores de 16 años (el 33.5\%), que no poseen un título de educación básica obligatoria, y 13.459.400 trabajadores (el 58,2\%), 
que no tiene una preparación específica para desarrollar actividades en un puesto de trabajo.

Estos datos ponen de manifiesto la necesidad de establecer mecanismos para facilitar la participación de los adultos en actividades pertenecientes a sistemas formativos formales o no formales, de tal forma que cada uno pueda escoger las vías que se adapten mejor a su nivel y necesidades para participar en el aprendizaje permanente.

Como hemos comentado, nuestra sociedad vive inmersa en continuos cambios derivados de las necesidades creadas por los nuevos mercados, lo cual hace inevitables los cambios en el ámbito formativo para poder respuesta a las nuevas exigencias de producción.

La situación futura y actual requiere de nuevas necesidades. Según estudios del CEDEFOP, Europa tendrá en el año 2020, 235 millones de puestos de trabajo, de los cuales un $50 \%$ corresponderán a niveles medios de cualificación, un $35 \%$ a niveles altos y un $15 \%$ a niveles bajos (Ministerio de Educación, 2011, p. 7).

Como podemos ver en la Figura 1, la realidad Española no es la más idónea para responder adecuadamente a la demanda de empleo prevista.

Figura 1: Confrontación del porcentaje de población ocupada de 25 a 64 años según los niveles de educación en Europa y en España

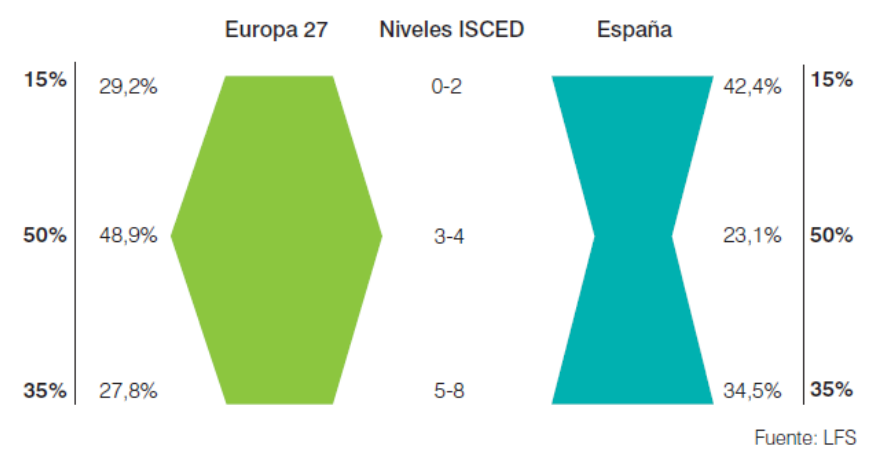

Fuente: (Ministerio de Educación, 2011, p. 20).

Como puede observarse, en general la media de los 27 países pertenecientes a la UE todavía debe mejorar aumentando las cualificaciones superiores y reduciendo las más bajas. Sin embargo, particularmente España no se encuentra en una situación ventajosa para poder dar respuesta a los 
cambios que está experimentando el mercado a nivel nacional e internacional. A pesar de situarse en niveles superiores del ISCED $^{17}$ a la media europea en cuanto a la participación de personas adultas en educación y formación ${ }^{18}$, es alarmante el bajo porcentaje que muestra en cuanto a las cualificaciones del tercer y cuarto nivel educativo respecto a la media europea. Asimismo, corre el riesgo de poseer un gran número de personas con un alto nivel de cualificación pero sin salida laboral y debe prestar especial atención a las personas que tienen un bajo nivel de cualificación, y reforzando sus políticas de aprendizaje permanente. ${ }^{19}$

Asimismo, es importante recordar que no basta con el simple hecho de aumentar la participación de la población sin títulos en educación y formación, también es necesario lograr resultados positivos en cuanto a personas cualificadas, para que mejoren y adquieran nuevas competencias profesionales.

Como ya hemos visto, en Europa predominan las cualificaciones de nivel medio, mientras que en España predominan las de nivel bajo, por lo que es necesario regular la situación reduciendo el número de cualificaciones bajas y aumentar las medias y altas. Creemos que para reducir el porcentaje de personas con una baja cualificación y aumentar el de cualificaciones medias sería importante, no sólo facilitar el acceso de las personas al aprendizaje permanente, sino también proporcionar orientación, y sobre todo acelerar el proceso de reconocimiento y validación de las competencias adquiridas por cualquier vía. Ya que de este modo se da la oportunidad de

17 Niveles de clasificación internacional normalizada de la educación.

18 En el ámbito de la Estrategia de Educación y Formación 2010 la UE fijó el objetivo de alcanzar el porcentaje del $12,5 \%$ en la participación de adultos en educación formal o no formal. En el año 2010, el 10,8\% de la población española entre 25 y 64 años participaba en la educación formal y no formal, mientras que la cifra europea se situaba en el 9,1\% (Ministerio de Educación, 2011, p. 11).

${ }^{19}$ Relativo a las personas que tienen un nivel bajo de cualificación, merecen especial atención: la población adulta que no posee las competencias básicas de la educación obligatoria; la población activa que no está en posesión de la acreditación de su cualificación profesional; jóvenes que no han adquirido el título de graduado en educación secundaria obligatoria; jóvenes que abandonan de forma prematura sus estudios (Ministerio de Educación, 2011, p. 12). 
La validación de competencias profesionales en España e Italia

valorizar y acreditar las competencias de muchos profesionales que en su día no pudieron obtener un certificado oficial de un trabajo que de todos modos saben realizar gracias a su experiencia profesional.

\subsubsection{El aprendizaje permanente en Italia}

El discurso sobre aprendizaje permanente en Italia, ha llevado a considerarlo como un proceso intencionalmente predispuesto y finalizado a desarrollar y realizar aprendizaje: conocimientos, saberes, habilidades, competencias, comportamientos (Alberici, 2000, p. 104).

En Italia existe un déficit en términos de capital humano y cultural y en competencias base, esto se debe a la falta de actualización del pueblo italiano en los conocimientos profesionales y de desarrollo de su nivel cultural (Bulgarelli, Zucchermaglio, \& Provenzano, 2011, p. 153).

Un $48 \%$ de los italianos de entre 24 y 65 años tiene un nivel bajo de cualificación y sólo el $30 \%$ de los adultos tiene un nivel adecuado de competencias.

Sólo el 17\% de la población activa (15-75 años) presenta un grado de educación elevado. Se encuentra distante de la media de la UE que tiene un 26\% (Bulgarelli, 2011, p. 158).

Italia no sólo acumula retrasos derivados del ámbito educativo, también existe un empobrecimiento en las competencias base y sociales, adquiridas a través del aprendizaje no formal e informal.

Apenas cinco millones de italianos participan de forma autónoma en diversas actividades, no sólo formativas, que contribuyen al desarrollo cultural de la persona. Entre los objetivos más importantes de la estrategia de Lisboa (2000) se encontraba el de potenciar la participación de los adultos en el aprendizaje permanente, que en Italia se reduce al 6,2\% mientras, como ya se ha señalado anteriormente, la media europea está en $9,6 \%$.

El bajo nivel de escolarización de la población adulta y la escasa propensión al aprendizaje permanente que deriva de la primera, influyen negativamente en la educación de las nuevas generaciones (Bulgarelli et al., 2011, p. 153). Además, hay que señalar que la situación italiana en este aspecto es todavía más crítica cuando se habla del sur del país.

Italia es uno de los países con menor nivel de aprendizaje permanente respecto a los países de la UE, con el $6 \%$ de la población adulta, sin embar- 
go este dato mejora en la formación continua de las personas con trabajo (35\%). El aprendizaje continuo de los trabajadores constituye un componente de los instrumentos de formación de las competencias (unido a los aprendizajes más consolidados: pre-escolar, escolar en todos los niveles, universidad) (Bulgarelli, 2011, p. 159).

Diversas investigaciones explican que la escasa iniciativa de las empresas italianas en la formación de sus trabajadores, podría deberse a una falta de impacto en el valor de la producción y en sus aprovechamientos sucesivos, lo cual nos haría comprender la falta de calidad y la carencia de coherencia entre las necesidades y la formación.

Recientes estudios a nivel internacional y nacional sobre las empresas y sobre las competencias de los trabajadores coinciden en que es necesario desarrollar una combinación de competencias específicas y competencias clave. Los jóvenes que hoy acceden al mercado laboral tienen muchas probabilidades de cambiar de empleo y tipo de ocupación muchas veces durante su vida profesional. Es decir, los trabajadores están expuestos a transiciones en el mercado de trabajo y deberán actualizar y cambiar sus propias competencias para el mismo empleo.

En este escenario es importante que las personas sean capaces de gestionar el cambio, de poseer fuertes competencias cognitivas de base (lingǘsticas, matemáticas, problem solving) que les permita seguir aprendiendo y desarrollar competencias específicas y generales (Bulgarelli, 2011, p. 161).

A pesar de esta situación, y de afirmaciones que dudan de los esfuerzos realizados por el Estado y por las regiones para fomentar el aprendizaje permanente en Italia (Florenzano, 2011, p. 172), en febrero del año 2010 se publicaron las "Linee Guida per la Formazione, dal Governo, dalle Regioni e dalle Parti Sociali" ("Las Líneas Guía para la Formación, del Gobierno, de las Regiones y de las Partes Sociales"). Estas líneas guía pretenden constituir un estímulo estratégico y operativo para potenciar instrumentos que ayuden al reconocimiento de necesidades, la definición de dispositivos para el reconocimiento y la validación de competencias adquiridas en el trabajo (Bulgarelli, 2011, p. 162).

Italia se enfrenta al reto de elevar los bajos niveles de educación de los ciudadanos, mejorar y proyectar hacia competencias de innovación en el campo laboral, recualificar y mejorar el sistema socio-económico italiano. 
La validación de competencias profesionales en España e Italia

\subsubsection{COMPARACIÓN Y CONCLUSIONES}

Lo que tradicionalmente ha sido el campo de la educación de adultos y de la formación profesional y continua se está transformando, con la intención de dar respuesta a los cambios teóricos y sociales a los que nos vemos sometidos en la actualidad.

Hoy en día está claro que el aprendizaje se puede realizar en multitud de contextos o situaciones (más allá de los formales o no formales, como en el trabajo, en casa, en grupo o por nuestra cuenta).

Es evidente que con esta transformación el modo tradicional de entender la práctica educativa y formativa ha cambiado, obligando a modificar la terminología en este ámbito y empezando a hablar de aprendizaje permanente a lo largo y a lo ancho de la vida.

Creemos que el aprendizaje, más que un tipo de formación, debe ser una dimensión permanente, o una filosofía, durante toda la vida. Debe abarcar, por tanto, todos los ámbitos posibles en los que se mueve el ser humano, incluyendo cualquier tipo de contexto formal, no formal e informal. La formación durante el curso de la vida debe permitir a las personas responder a sus necesidades y aspiraciones, desarrollando sus propios recursos humanos y gestionando sus vidas en el campo profesional y personal.

En Europa, el auge y la evolución del aprendizaje se deben a la estrategia de la Comunidad Europea, dirigida a incrementar y ampliar las competencias de las personas durante todo su recorrido de vida profesional y social. Tiene el objetivo de lograr unos profesionales más cualificados, capaces de adaptarse a los continuos cambios tecnológicos, a los procesos y a la organización del trabajo y a los servicios prestados, y a su vez ser capaces de anticipar situaciones para actuar mejor a través de la innovación.

En el marco de esta estrategia, la Comisión Europea, a través del documento "Europa 2020", pide a los países miembros un porcentaje del 50\% en cualificaciones intermedias y otro del $35 \%$ en superiores (universitarias y terciarias no académicas)

España e Italia no se encuentran en condiciones de cumplir con las expectativas. Ambos países cuentan con un porcentaje muy alto de cualificaciones bajas. En cuanto a las cualificaciones intermedias, España posee un número muy reducido de población con cualificaciones intermedias (forma- 
ción profesional) mientras que Italia no es capaz de acercarse al 35\% que demanda la UE en educación superior.

Consideremos el aprendizaje permanente como una de las herramientas que pueden ayudar a mejorar esta situación. La formación y recualificación de las personas, con empleo o sin él, es imprescindible para dotar a los sujetos de las competencias que den respuesta a las necesidades de la actual demanda de innovación y del reto de la competitividad global.

Así pues, se trata, no sólo, de desarrollar conocimientos en el aula, sino también de proporcionar cursos integrados de aprendizaje que incluyan contextos profesionales que expliciten las competencias adquiridas en el trabajo y darles valor y reconocimiento. Las competencias adquiridas en contextos no formales, en el trabajo, deben hacerse transparentes, reconocibles y certificables.

Todo esto implica disponer de una oferta formativa en el mundo de la educación/formación y en el mundo del trabajo, reactiva y flexible al dinamismo de las profesiones, y poner en marcha dispositivos de validación y certificación de las competencias adquiridas a través de cualquier vía. 
La validación de competencias profesionales en España e Italia 


\section{Los sistemas educativos y de formación profesional en España y en Italia}

Este capítulo tiene el objetivo de exponer los sistemas educativos y de formación profesional en España y en Italia. Así como los sistemas de formación profesional de la comunidad autónoma española de Castilla y León y de la región italiana de Emilia-Romagna, territorios objeto de estudio, en cuanto a sus dispositivos de validación de competencias no formales e informales, en este trabajo de investigación. Asimismo, se pretenden mostrar las similitudes y diferencias más relevantes existentes entre estos sistemas.

El capítulo está compuesto por dos grandes apartados, el primero explica el sistema educativo y el sistema de formación profesional en España, 
en este último se incluye el sistema de formación profesional en Castilla y León. El segundo gran apartado se refiere al sistema de educación y al de formación profesional en Italia, este último también incluye el sistema de formación profesional en Emilia-Romagna.

Pretendemos explicar las estructuras de estos sistemas tomando como referencia la legislación existente al respecto y teniendo en cuenta las últimas modificaciones a las que han sido sometidos estos sistemas. Nos detendremos con más detalle en los sistemas de formación profesional, con el objetivo de sentar las bases para la posterior explicación de la validación de competencias no formales e informales en ambos países y en concreto en Castilla y León y en Emilia-Romagna.

Dado que hacemos más hincapié en la formación profesional, hemos presentado por separado los sistemas de educación y de formación profesional. Considerando que el sistema educativo está más enfocado al ámbito académico y el formativo profesional al ámbito laboral.

Para hablar de las enseñanzas de sistemas profesionales hemos tenido en cuenta, para los dos países, un concepto de formación profesional dirigido a acciones formativas orientadas a lograr un desempeño cualificado en las diferentes profesiones, y orientado a facilitar el acceso al empleo y la participación activa en la vida social, cultural y económica (Ley Orgánica 5, 2002).

Por último, el capítulo finaliza con un apartado dedicado a la comparación de estos sistemas, acompañada de unas breves conclusiones. 


\subsection{Los sistemas educativo y de formación profe- sional en España}

Presentaremos por un lado el sistema educativo español tal y como lo entiende la Ley Orgánica de Educación 2/2006 (en adelante, LOE). Y por otro lado describiremos el sistema de formación profesional en España, siguiendo la estructura establecida por Ley Orgánica 5/2002, de 19 de junio, de las Cualificaciones y de la Formación Profesional (en adelante LO $5 / 2002)$.

\subsubsection{El SISTEMA EDUCATIVO EN ESPAÑA}

En España se considera la educación como instrumento fundamental para alcanzar el bienestar individual y colectivo, para el desarrollo de la personalidad y sus capacidades y para lograr una cohesión social. Por ello, se retiene que su regulación general debe estar en manos del Estado.

El sistema educativo, a excepción del nivel universitario, está regulado desde el año 2006 por la Ley Orgánica 2/2006 de 3 de mayo.

Para situarnos y comprender mejor la situación actual del sistema haremos un breve recorrido histórico sobre las últimas leyes que se han encargado de organizarlo.

El sistema educativo empezó a modernizarse en el año 1970 con la Ley General de Educación y Financiamiento de la Reforma Educativa. Esta ley intentó renovar el modelo de formación profesional, recogiendo las nuevas corrientes europeas que proponían una formación profesional que actuase de pasarela, para permitir a los jóvenes pasar del sistema educativo al mercado de trabajo con una formación especializada y adaptada a las necesidades de la empresa (Homs, 2008; L.O. 2, 2006).

Aunque esta ley no llegó a alcanzar los objetivos de mejora previstos introdujo algunos cambios importantes como la integración de la formación profesional en el sistema educativo; la transmisión de la importancia de alargar los estudios (Homs, 2008); el establecimiento de la obligatoriedad y gratuidad de la enseñanza básica hasta los 14 años, a través de la $\mathrm{EGB}^{20}$ que,

${ }^{20}$ Educación General Básica. 
al igual que la ley orgánica $8 / 1985^{21}$, declaró la educación como un derecho público (L.O. 2, 2006).

Fue 20 años más tarde, con la Ley General del Sistema Educativo ${ }^{22}$ (en adelante LOGSE), cuando se produjo un cambio sustancioso que hizo el sistema más abierto y flexible a través de:

- el establecimiento de un sistema descentralizado de enseñanza, permitiendo a las comunidades autónomas gestionar los centros educativos y participar en los contenidos curriculares;

- la instauración de la formación permanente del profesorado;

- la prolongación de la enseñanza obligatoria hasta los 16 años y de este modo se retrasó la incorporación al mundo del trabajo;

- la creación de pasarelas entre la educación general y el mercado de trabajo;

- el establecimiento del requisito de haber obtenido el título en Educación Secundaria Obligatoria para poder acceder a la formación profesional.

La LOGSE dio un gran impulso y prestigio a la formación profesional. Uno de los objetivos principales era dar respuesta a las demandas del sistema productivo, dando así un enfoque más moderno a la formación profesional, que buscaba con este cambio una mayor especialización y cualificación para poder acceder al mercado laboral (Ley Orgánica 1, 1990).

Otra de las grandes novedades de la LOGSE fue que, con la creación de los Institutos de Enseñanza Superior, se dio la posibilidad de que en un mismo centro educativo se ofreciesen los estudios de ESO y Bachiller y de los ciclos de formación profesional (Homs, 2008, p. 26).

A pesar de los avances logrados con esta ley no se consiguió dar respuesta al sector de alumnos que no conseguían superar la enseñanza obligatoria.

En el año 1995 se publicó la Ley Orgánica 9/1995, de 20 de noviembre, de la participación, la evaluación y el gobierno de los centros

${ }^{21}$ Ley Orgánica 8/1985, reguladora del Derecho a la Educación, que no afecta a la estructura del sistema educativo.

${ }^{22}$ Ley actualmente derogada, que a su vez derogó la anterior Ley General de Educación de 1970. 
docentes, ${ }^{23}$ que pretendía desarrollar algunas disposiciones de la LOGSE para aumentar la calidad educativa y con el mismo objetivo, en el año 2002, se publicó la Ley de Calidad de la Educación. ${ }^{24}$

En el año 2004 el Ministerio de Educación y Ciencia propuso un debate educativo a comunidades autónomas, organizaciones representadas en los consejos escolares del Estado y autonómicos, a través de una serie de propuestas recogidas en un documento llamado "Una Educación de Calidad para todos y entre todos", el objetivo era recoger ideas y opiniones para elaborar un proyecto de ley y llevarla al parlamento con la intención de mejorar la calidad de la educación.

En el año 2006 se publicó la Ley Orgánica 2/2006 de Educación (en adelante, LOE), que en la actualidad regula fundamentalmente el sistema educativo. Recientemente se publicó la Ley Orgánica 8/2013, para la mejora de la calidad educativa. Esta ley modificó la LOE y se está aplicando paulatinamente desde el curso académico 2014-15.

La LOE se encarga de organizar las siguientes enseñanzas del sistema educativo en etapas, ciclos, grados, cursos y niveles de enseñanza, asegurando la transición entre los mismos y dentro de cada uno de ellos (ver Esquema 1):

Educación infantil.

$>$ Educación primaria.

$>$ Educación secundaria obligatoria, (en adelante, ESO).

$>$ Bachillerato.

$>$ Formación profesional.

$>$ Enseñanzas de idiomas.

$>$ Enseñanzas artísticas.

$>$ Enseñanzas deportivas.

$>$ Educación de personas adultas.

$>$ Enseñanza universitaria.

Estas enseñanzas se agrupan en varios niveles:

23 Actualmente derogada.

24 Actualmente derogada. 
La validación de competencias profesionales en España e Italia

La educación básica está formada por la educación primaria y la educación secundaria obligatoria (en adelante ESO), va desde los 6 hasta los 16 años de edad, es obligatoria y gratuita.

La educación secundaria está también integrada por la ESO y la educación secundaria postobligatoria, que a su vez está compuesta por el bachillerato, la formación profesional de grado medio, las enseñanzas profesionales de artes plásticas y diseño de grado medio y las enseñanzas deportivas de grado medio.

La educación superior está formada por la enseñanza universitaria (regulada por sus propias normas específicas), las enseñanzas artísticas superiores, la formación profesional de grado superior, las enseñanzas profesionales de artes plásticas y diseño de grado superior y las enseñanzas deportivas de grado superior.

Existen también enseñanzas no integradas en el régimen general, son conocidas como enseñanzas en régimen especial y están constituidas por las enseñanzas artísticas, deportivas y de idiomas. Tienen validez académica nacional y pueden cursarse simultáneamente a las enseñanzas generales (L.O. 2, 2006). 


\section{Esquema 1: La estructura del sistema educativo español}

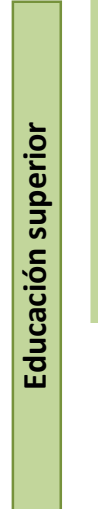

\begin{tabular}{|c|c|}
\hline \multirow{6}{*}{ 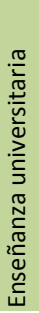 } & Título de doctor \\
\hline & $\begin{array}{l}\text { Estudios de } \\
\text { doctorado }\end{array}$ \\
\hline & Título de master \\
\hline & $\begin{array}{c}\text { Estudios de } \\
\text { posgrado }\end{array}$ \\
\hline & Título de grado \\
\hline & Estudios de grado \\
\hline
\end{tabular}

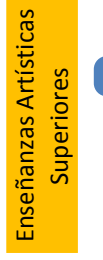

Título Superior

Enseñanzas

artísticas

superiores

Estudios de grado
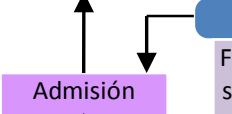

Título de técnico superior

\begin{tabular}{|l|l|l|}
\hline PP grado & Técnico & Grado \\
\hline
\end{tabular}

superior deportivo de superior de grado superior artes plásticas
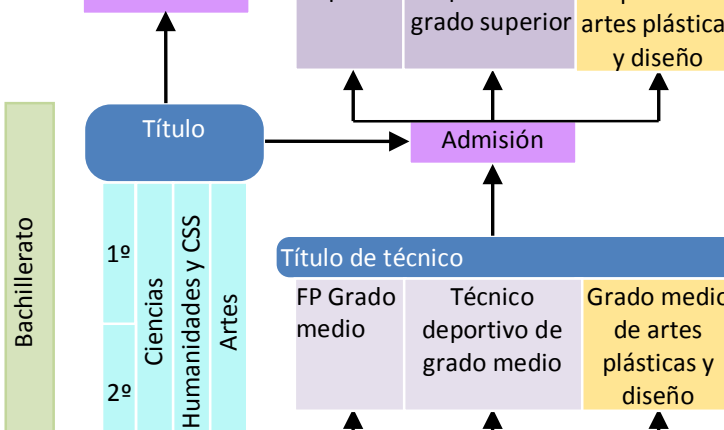

Admisión

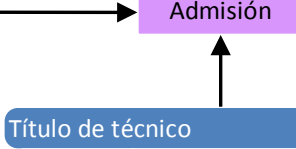

FP Grado Técnico Grado medio

medio

deportivo de

de artes

plásticas y
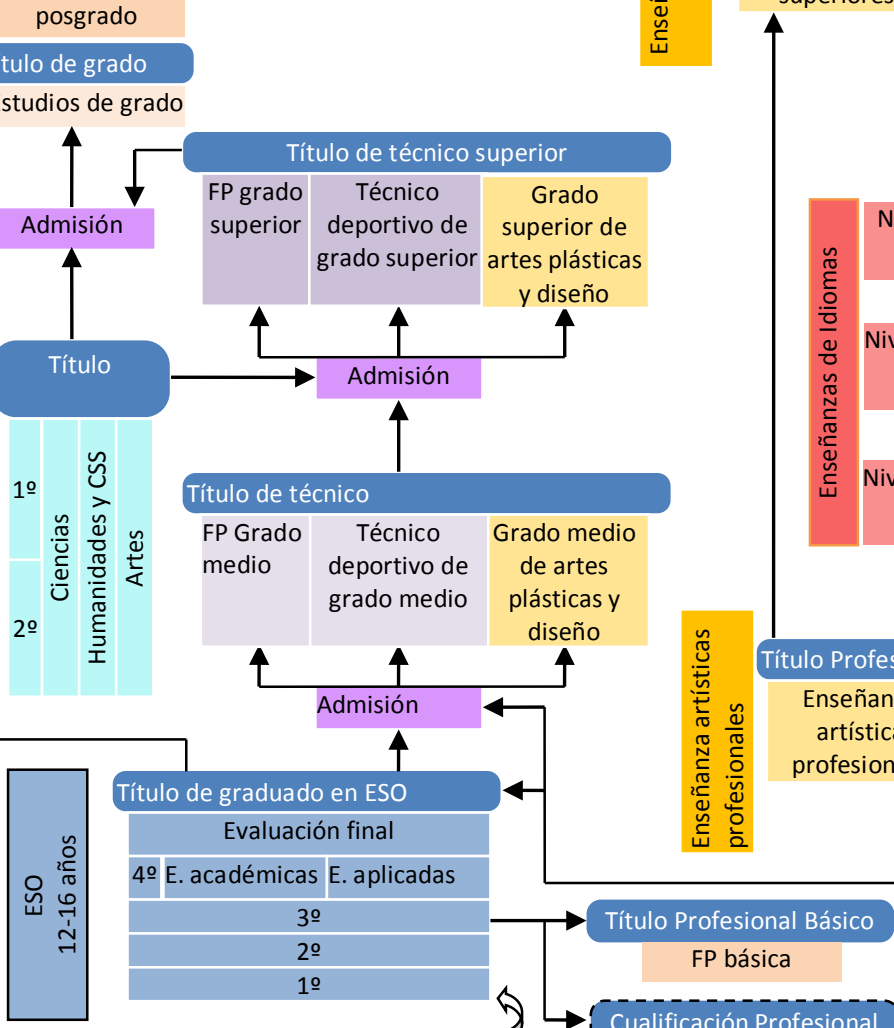

diseño

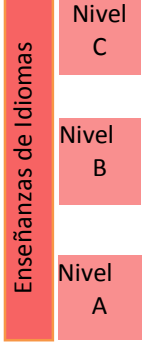

4 E. académicas E. aplicadas
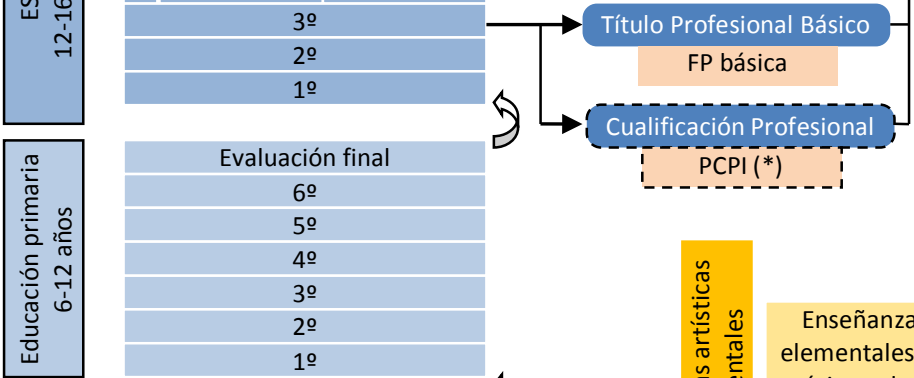

Evaluación final
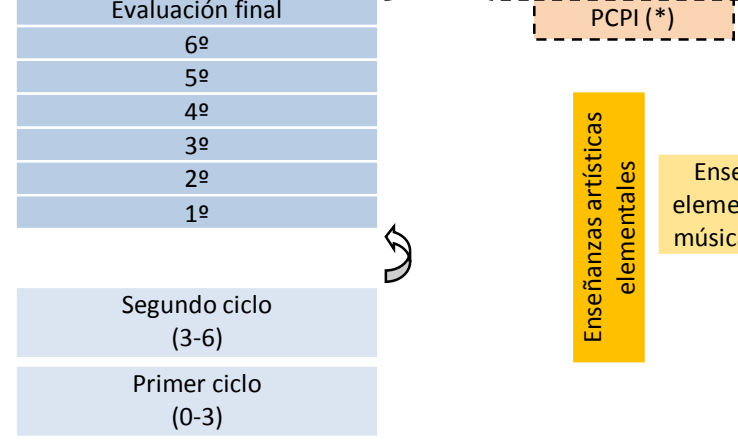

Enseñanzas

elementales de

música y danza

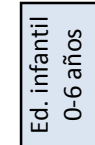

mer ciclo

$(0-3)$ 
La validación de competencias profesionales en España e Italia

A continuación, apoyándonos en las citadas LOE y LOMCE, desarrollaremos brevemente las diferentes enseñanzas vigentes que acabamos de mencionar:

\section{Educación infantil}

La educación infantil es una etapa con identidad propia y de carácter voluntario, que abarca desde los 0 a los 6 años de edad. Está dividida en dos ciclos de 0 a 3 y de 3 a 6 años, siendo este último gratuito.

\section{Educación primaria}

Se trata de una etapa educativa que comprende 6 cursos académicos, a cursar normalmente entre los 6 y 12 años de edad. Los cursos están organizados en áreas de carácter global e integrador.

Como novedad cabe destacar la introducción, a través de la LOMCE, de una prueba final de evaluación al terminar la etapa.

\section{Educación secundaria obligatoria (ESO)}

Esta etapa está formada por cuatro cursos que se realizan normalmente entre los 12 y los 16 años de edad. Se organiza de acuerdo a los principios de educación común y de atención a la diversidad del alumnado.

La finalidad de la educación secundaria es lograr que los alumnos adquieran los elementos básicos de la cultura, en especial en los ámbitos humanístico, artístico, científico y tecnológico; el desarrollo y consolidación de hábitos de estudio y de trabajo; la preparación necesaria para su incorporación a estudios posteriores y para su inserción en el mundo del trabajo y la formación para el ejercicio de sus derechos y obligaciones como ciudadanos.

Como novedad, la LOMCE modifica el cuarto y último curso de la $\mathrm{ESO}$, dando a elegir al alumno, según su intención de proseguir con sus estudios en el Bachillerato o de introducirse en la Formación Profesional, entre la opción de enseñanzas académicas y enseñanzas aplicadas respectivamente.

La LOMCE también incluye, a partir del segundo curso, programas de mejora del aprendizaje y del rendimiento y una prueba final de evaluación de la ESO al terminar el cuarto curso. 
La LOE dispuso la activación de programas de cualificación profesional inicial ${ }^{25}$ (en adelante, PCPI) dirigidos a mayores de 16 años que no hubiesen logrado obtener el título de ESO, aunque actualmente estos programas están en vías de extinción por disposición de la LOMCE.

\section{Bachillerato}

El Bachillerato comprende dos cursos, se desarrolla en modalidades diferentes, tiene una organización flexible con el objetivo de ofrecer una preparación especializada a los alumnos, según sus perspectivas e intereses de formación o para facilitar la incorporación al mercado laboral, para ello ofrece distintas modalidades:

- Ciencias

- Humanidades y Ciencias Sociales

- Arte

Los alumnos pueden cursar bachillerato en régimen ordinario durante cuatro años, aunque este está dividido en dos cursos, primero y segundo de bachiller.

Pueden acceder a los estudios de bachillerato los alumnos que estén en posesión del título de Graduado en Educación Secundaria Obligatoria y hayan superado la evaluación final de la ESO por la opción de enseñanzas aplicadas.

La finalidad del bachillerato es dotar a los alumnos de una formación, madurez intelectual y humana, conocimientos y habilidades que les concedan la posibilidad de desarrollar funciones sociales y la incorporación a la vida activa de manera responsable y competente. También capacita a los alumnos para el acceso a la educación superior.

Como novedad a destacar en este tipo de enseñanzas cabe señalar la realización de una prueba de evaluación final de bachillerato (añadida por la LOMCE, al igual que en la Educación Primaria y en la ESO).

25 Se hablará con mayor detenimiento de estos programas en el subpartado 3.1.2.1. 
La validación de competencias profesionales en España e Italia

\section{Formación profesional ${ }^{26}$}

Según el artículo 39 de la LOE, se entiende por formación profesional "el conjunto de acciones formativas que capacitan para el desempeño cualificado de las diversas profesiones, el acceso al empleo y la participación activa en la vida social y económica".

La Formación Profesional está constituida por las enseñanzas propias de la formación profesional inicial, las acciones de inserción e reinserción laboral de los trabajadores, también las orientadas a la formación continua en las empresas, que permitan la adquisición y actualización permanente de las competencias profesionales.

La LOE regula de forma general la formación profesional inicial dentro del sistema de formación profesional español, que veremos más adelante con mayor detalle (ver subapartado 3.1.2.1).

La formación profesional inicial es aquella que se encuentra dentro del sistema educativo. Está formada por la formación profesional básica, la formación profesional de grado medio y la formación profesional de grado superior.

Cabe señalar la introducción, por parte de la LOMCE, en el sistema educativo español de la formación profesional dual (ver subapartado 3.1.2.3). Dicha ley la define como un conjunto de acciones e iniciativas formativas, en corresponsabilidad con las empresas, y con el objetivo de dotar a las personas de una cualificación profesional, intercalando procesos de enseñanza y aprendizaje en centros educativos y de trabajo (Ley Orgánica 8, 2013, n. Modificación 36, art. 42).

\section{$>$ Enseñanzas artísticas}

Estas enseñanzas tienen como finalidad proporcionar al alumno una formación artística de calidad y garantizarle una buena cualificación, facilitando también la posibilidad de cursar de forma simultánea la educación secundaria. Las enseñanzas artísticas se subdividen a su vez en tres tipos de enseñanzas:

- las enseñanzas elementales de música y de danza;

26 Profundizaremos en el aspecto de la formación profesional del sistema educativo en el apartado 3.1.2. 
- las enseñanzas artísticas profesionales, compuestas por las enseñanzas profesionales de música y danza, así como los grados medio y superior de artes plásticas y diseño;

- las enseñanzas artísticas superiores, hacen referencia a los estudios superiores de música y de danza, las enseñanzas de arte dramático, las enseñanzas de conservación y restauración de bienes culturales, los estudios superiores de diseño y los estudios superiores de artes plásticas, entre los que se incluyen los estudios superiores de cerámica y los estudios superiores del vidrio.

\section{Enseñanzas de idiomas}

La finalidad de este tipo de enseñanzas es capacitar al alumno para el correcto uso de los diferentes idiomas fuera de las etapas ordinarias del sistema educativo.

Están estructuradas en los niveles básico, intermedio y avanzado, correspondiéndose con los niveles A, B y C del Maco Común Europeo de Referencia para las Lenguas. Para el acceso a este tipo de enseñanzas es requisito indispensable tener 16 años, aunque también podrán acceder los mayores de 14 años que sigan enseñanzas de un idioma distinto del cursado en la educación obligatoria.

\section{Enseñanzas deportivas}

Las enseñanzas deportivas pretenden preparar a los alumnos para desarrollar una actividad profesional relacionada con una modalidad deportiva y contribuir a su adaptación a la evolución del mundo laboral y deportivo y a la ciudadanía activa.

\section{$>$ Educación de personas adultas}

Este tipo de educación tiene como objetivo permitir la adquisición de una formación básica, ampliar y renovar conocimientos y destrezas de forma permanente y facilitar el acceso al sistema educativo. Asimismo pretende mejorar las cualificaciones profesionales, desarrollar las capacidades personales de expresión, de comunicación, de relación y de construcción del conocimiento; desarrollar también la participación en la vida social; desarrollar programas de prevención de exclusión social; dar la oportunidad de aumentar y actualizar las competencias a personas de mayor edad y fomentar la igualdad de derechos y oportunidades entre mujeres y hombres. 
La validación de competencias profesionales en España e Italia

La finalidad de la educación de las personas adultas es poder ofrecer a todos aquellos mayores de edad la posibilidad de obtener, actualizar, completar o ampliar sus conocimientos y aptitudes para alcanzar un desarrollo personal y profesional.

La LOE establece que las personas adultas pueden realizar sus aprendizajes a través de actividades de enseñanza reglada o no reglada, por medio de experiencia laboral o en actividades sociales y para ello se establecerán medidas para la validación de estos aprendizajes.

\section{$>$ Enseñanza universitaria}

La enseñanza universitaria se regula por sus propias normas específicas. Ofrece estudios de Grado, Máster y Doctorado ${ }^{27}$.

Hasta el ahora, los alumnos en posesión del título de Bachiller o equivalente que pretendían acceder a los estudios universitarios debían realizar la Prueba de Acceso a la Universidad ${ }^{28}$ (la PAU). Sin embardo, ahora la LOMCE establece que las Universidades pueden permitir la entrada a los estudios de grado, a los alumnos que estén en posesión del título de Bachiller o equivalente, según la calificación lograda en el Bachillerato. Asimismo, determina que las universidades pueden fijar sus propios procedimientos de admisión $^{29}$ a las enseñanzas universitarias oficiales de grado para los alumnos que estén en posesión del título de Bachiller o equivalente, siguiendo la normativa básica que establezca el Gobierno.

${ }^{27}$ Estudios regulados por el Real Decreto 1393/2007, de 29 de octubre, por el que se establece la ordenación de las enseñanzas universitarias oficiales (Boletín Oficial del Estado, núm. 260, de 30 de octubre de 2007).

${ }^{28}$ Este tipo de admisión, se llevará a cabo hasta el año académico 2016/17 y está regulado por el Real Decreto 558/2010, de 7 de mayo, por el que se modifica el Real Decreto 1892/2008, de 14 de noviembre (Boletín Oficial del Estado, núm. 113, de 8 de mayo de 2010).

${ }^{29}$ Procedimientos de admisión regulados por el Real Decreto 412/2014, de 6 de junio, por el que se establece la normativa básica de los procedimientos de admisión a las enseñanzas universitarias oficiales de Grado (Boletín Oficial del Estado, núm. 138, de 7 de junio de 2014). 


\subsubsection{EL SISTEMA DE FORMACIÓN PROFESIONAL EN ESPAÑA}

El sistema de formación profesional está regulado básicamente por la Ley Orgánica 5/2002, de 19 de junio, de las Cualificaciones y de la Formación Profesional (en adelante LO 5/2002). Esta ley entiende la formación profesional como el conjunto de acciones de formación para lograr un desempeño cualificado en las diferentes profesiones, el acceso al empleo y la participación activa en la vida social, cultural y económica. Integra las enseñanzas correspondientes a la formación profesional inicial, las acciones de inserción y reinserción laboral de los trabajadores, así como las dirigidas a la formación continua en las empresas.

La LO 5/2002 supone una de las primeras bases para el posterior desarrollo del procedimiento de evaluación y acreditación de competencias profesionales, tema principal que ocupa nuestra investigación. Esta normativa pretende establecer un sistema integral de formación profesional, cualificaciones y acreditación que fomente la transparencia y pueda responder de forma eficaz a las exigencias del mercado de trabajo. Por ello se desarrollaron posteriormente los dos subsistemas que actualmente conforman la formación profesional (Ley Orgánica 5, 2002):

- La formación inicial.

- La formación para el empleo.

El Real Decreto 1147/2011 (en adelante RD 1147/2011) establece la ordenación general de la formación profesional del sistema educativo español (formación inicial). Esta normativa regula la formación inicial en el marco del sistema educativo, la cual depende del Ministerio de Educación, Cultura y Deporte.

Por el contrario, la formación para el empleo depende del Ministerio de Empleo y Seguridad Social. Este tipo de formación se ocupa de la integración de la antigua formación ocupacional y la formación continua, su existencia se debe a la aprobación del Real Decreto 395/2007, por el que se regula el subsistema de formación profesional para el empleo (en adelante RD 395/2007). A continuación desarrollamos ambos subsistemas de forma más detallada. 
La validación de competencias profesionales en España e Italia

\subsubsection{La formación profesional inicial}

La formación profesional entró a formar parte del sistema educativo en el año 70 con la Ley General de Educación. Hoy se la conoce como formación profesional inicial, al estar integrada en el sistema educativo está reguregulada por la Ley Orgánica de Educación.

Este tipo de formación ha ido cambiando y evolucionando con el paso del tiempo. En el año 2006, con el antiguo real decreto de regulación de la formación profesional inicial, ${ }^{30}$ se permitió una mayor flexibilidad en el acceso a este tipo de enseñanza y en las relaciones entre los dos tipos de subsistemas. Se pretendió también impulsar el aprendizaje a lo largo de la vida. Este real decreto ha estado vigente hasta finales de julio de 2011 que fue derogado por el mencionado RD 1147/2011 de regulación de la formación profesional inicial.

El artículo 1 del RD 1147/2011 define la formación profesional del sistema educativo como el conjunto de ciclos formativos compuestos por acciones formativas que permiten adquirir una cualificación para poder desempeñar las diferentes profesiones, para la empleabilidad ${ }^{31}$ y para una buena participación social, cultural y económica.

Los certificados y títulos que se obtienen a través de este subsistema de formación están asociados al Catálogo Nacional de Cualificación de Competencias Profesionales ${ }^{32}$ (en adelante, CNCP).

Las enseñanzas de la formación profesional del sistema educativo se estructuran en:

- los programas de cualificación profesional inicial (en adelante $\left.\mathrm{PCPI}^{33}\right)$;

${ }^{30}$ Real Decreto 1538/2006, de 15 de diciembre, por el que se establece la ordenación general de la formación profesional del sistema educativo, (Boletín Oficial del Estado, núm. 3 , de 3 de enero de 2007).

${ }^{31}$ Entendemos el concepto de empleabilidad como la combinación de factores que permiten a una persona prepararse, incorporarse y permanecer en el mercado de trabajo y progresar en su carrera profesional (Cedefop, 2014, p. 34).

32 El Catálogo Nacional de Cualificaciones español recoge las cualificaciones profesionales susceptibles de reconocimiento y acreditación, pertenecientes al sistema productivo (ver 4.2.2.1). 
- la formación profesional básica (en adelante, FPB);

- la formación profesional de grado medio (en adelante, FP de grado medio);

- la formación profesional de grado superior (en adelante, FP de grado superior);

- cursos de especialización.

\section{- Los Programas de Cualificación Profesional Inicial (PCPI)}

Los PCPI tienen una duración de dos años (aunque de forma excepcional para los alumnos de 16 años pueden tener una duración de un año). Pretenden proporcionar una integración social y educativa, a través de una formación y una titulación, a jóvenes mayores de quince años que no hayan podido obtener el título de graduado en ESO (L.O. 2, 2006, n. art. 30; R.D. 1147, 2011, n. art. primero).

Los alumnos que participen en estos programas tienen la posibilidad de adquirir competencias profesionales correspondientes a cualificaciones profesionales de nivel 1 del Catálogo Nacional de Cualificaciones Profesionales (CNCP), que permitan obtener al menos un certificado de profesionalidad $^{34}$ de nivel $1 \mathrm{y}$ al mismo tiempo favorecer la inserción en el mundo del trabajo (R.D. 1147, 2011, n. art. 11).

Los PCPI incluyen módulos obligatorios y voluntarios. Los módulos obligatorios tienen el objetivo de preparar al alumno para realizar una actividad profesional determinada y para que pueda conseguir el acceso a los ciclos formativos de grado medio. Estos módulos son de dos tipos:

- específico-profesionales, dirigidos a la adquisición de competencias profesionales, por parte del alumno, relacionadas con unidades de

33 Los Programas de Cualificación Profesional Inicial fueron creados por la LOE en el año 2006, actualmente, están siendo sustituidos progresivamente por los ciclos de formación profesional básica, según establece la disposición final quinta 4 de la LOMCE.

${ }^{34}$ Los certificados de profesionalidad acreditan de forma oficial las competencias profesionales que capacitan para el desarrollo de una actividad laboral con significación en el empleo. Dichas competencias estarán referidas a las UC de las cualificaciones profesionales del Catálogo Nacional de Cualificaciones Profesionales (CNCP) (Real Decreto 395, 2007, n. art. 10). 
La validación de competencias profesionales en España e Italia

competencia $^{35}$ (en adelante, UC) pertenecientes a cualificaciones profesionales del nivel 1 del CNCP;

- de carácter general, pensados para desarrollar competencias básicas que permitan realizar con éxito un ciclo formativo de grado medio.

Todos aquellos alumnos que superen los módulos profesionales específicos incluidos en un PCPI tendrán derecho a obtener los certificados de profesionalidad de nivel 1 de las cualificaciones profesionales correspondientes.

Aquellos que no hayan superado todos los módulos profesionales específicos del PCPI podrán solicitar un certificado académico, en este aparecerán los módulos profesionales superados y las unidades de competencia acreditadas del CNCP.

\section{- La formación profesional básica (FPB)}

La FPB ha sido instituida recientemente a través de la LOMCE. Está empezado a ponerse en práctica desde el curso académico 2014/15 y está sustituyendo progresivamente a los PCPI (Ley Orgánica 8, 2013, n. Modificación 33, art. 40).

El acceso a los ciclos de FPB requiere el cumplimiento simultáneo de algunas condiciones (ver Cuadro 1).

\section{Cuadro 1: Condiciones acceso a la FPB}

a) Tener más de 15 y menos de 17 años.

b) Haber cursado el primer ciclo de Educación Secundaria Obligatoria 0, excepcionalmente, haber cursado el segundo curso de la Educación Secundaria Obligatoria.

c) Haber propuesto el equipo docente a los padres, madres o tutores legales la incorporación del alumno o alumna a un ciclo de Formación Profesional Básica, de conformidad con lo indicado en el artículo 30.

Fuente: Modificación 33, art. 41. LOMCE.

Este tipo de formación está compuesto por ciclos de dos años de duración. Tiene el objetivo de garantizar la adquisición de las competencias del aprendizaje permanente a través de la impartición de enseñanzas organizadas en los siguientes bloques comunes:

a) bloque de Comunicación y Ciencias Sociales;

35 La unidad de competencia es el agregado mínimo de competencias profesionales, susceptible de reconocimiento y acreditación parcial (INCUAL, 2014). 
b) bloque de Ciencias Aplicadas.

Las enseñanzas de la FPB están pensadas para garantizar al estudiante, al menos, la obtención de una cualificación de nivel 1 del Catálogo Nacional de las Cualificaciones Profesionales. Los alumnos que superen un ciclo de FPB recibirán el título Profesional Básico correspondiente (Ley Orgánica 8, 2013, n. modificación 38, art. 44).

\section{- La formación profesional de grado medio y superior}

La formación profesional de grado medio y superior es la vía para la obtención de los títulos de formación profesional, establecidos en la LOE, de técnico y técnico superior respectivamente. Cada título de formación profesional está compuesto por una serie de cualificaciones profesionales ${ }^{36} \mathrm{y}$ estas, a su vez, por un conjunto de unidades de competencia. Los títulos de Técnico y Técnico Superior están agrupados en 26 familias profesionales. ${ }^{37}$

Los ciclos formativos de grado medio son parte de la enseñanza secundaria postobligatoria (R.D. 1147, 2011, n. art. 14), proporcionan una especialización profesional y una cualificación que permiten acceder al mercado laboral de la producción directa en los sectores de la industria o de los servicios (Real Decreto 1538, 2006). También amplían y adaptan las competencias de la enseñanza básica al mundo profesional, permitiendo el aprendizaje a lo largo de la vida (Ley Orgánica 8, 2013, n. Modificación 33: art. 40.2).

Los ciclos formativos de grado superior forman parte de la educación superior del sistema educativo (R.D. 1147, 2011, n. art. 14), proporcionan una formación para futuros técnicos altamente especializados o para los mandos intermedios de las empresas de cualquier sector económico (Real Decreto 1538, 2006).

Los ciclos formativos tienen una estructura modular de duración variable, aunque normalmente duran dos cursos académicos. Sus contenidos

${ }^{36}$ La cualificación profesional es el conjunto de competencias profesionales con significación para el empleo, que pueden adquirirse mediante formación modular u otros tipos de formación y a través de la experiencia laboral (Ley Orgánica 5, 2002, n. art. 7).

37 Las 26 familias profesionales fueron establecidas en el Anexo I del Real Decreto 1128/2003, de 5 de septiembre, por el que se regula el Catálogo Nacional de Cualificaciones Profesionales (CNCP). 
La validación de competencias profesionales en España e Italia

curriculares están organizados como mínimo en los siguientes tipos de módulos:

- los módulos asociados a unidades de competencia del Catálogo $\mathrm{Na}$ cional de Cualificaciones Profesionales (CNCP);

- el módulo de formación y orientación laboral, dirigido a ayudar al alumno a conocer las oportunidades de aprendizaje y de empleo para facilitar su entrada o reinserción en el mundo laboral;

- el módulo de empresa e iniciativa emprendedora proporciona al alumno conocimientos sobre los mecanismos de creación y gestión básica de empresa, el autoempleo, el desarrollo de responsabilidad social de las empresas, la innovación y la creatividad en la actividad laboral;

- el módulo de formación en centros de trabajo no tiene carácter laboral y pretende ayudar al alumno a completar la adquisición de competencias profesionales, lograr madurez y motivación para el aprendizaje a lo largo de la vida, alcanzar nuevos conocimientos sobre gestión, producción, comercialización y relaciones sociolaborales y proporcionar al alumno una situación real de trabajo;

- el módulo de proyecto se realiza al finalizar el ciclo formativo, aunque únicamente en ciclos formativos de grado superior. Se hace teniendo en cuenta las características de la actividad laboral del ámbito del ciclo formativo y aspectos relativos al ejercicio profesional y a la gestión empresarial. Pretende integrar todas las capacidades y conocimientos del currículo de todos los módulos del ciclo formativo;

- también podrán incluirse otros módulos profesionales no asociados a las unidades de competencia.

Los citados ciclos fueron instituidos en el año 1990, con la Ley Orgánica 1/1990 sobre la ordenación general del sistema educativo (LOGSE).

Según señala la LOMCE, se dan varios tipos de acceso a los ciclos formativos de grado medio (ver Cuadro 2) y superior (ver Cuadro 3). 
Cuadro 2: Acceso a ciclos de grado medio

\begin{tabular}{|c|c|}
\hline Tipo de acceso & \\
\hline \multirow[t]{2}{*}{ Directo } & $\begin{array}{l}\text { Estar en posesión de: el título de graduado en ESO, habiendo } \\
\text { superado la evaluación final de ESO por la opción de enseñan- } \\
\text { zas aplicadas; título Profesional Básico; el título de Bachiller; un } \\
\text { título universitario; un título de Técnico o de Técnico Superior de } \\
\text { Formación Profesional; un certificado acreditativo de haber supe- } \\
\text { rado todas las materias de Bachillerato. }\end{array}$ \\
\hline & $\begin{array}{l}\text { Superación de los módulos obligatorios de un programa de cuali- } \\
\text { ficación profesional inicial. }{ }^{38}\end{array}$ \\
\hline Curso de formación & $\begin{array}{l}\text { Superación de un curso de formación diseñado para el acceso a } \\
\text { ciclos de grado medio en centros públicos o privados autorizados } \\
\text { por la administración educativa (mínimo } 17 \text { años). }\end{array}$ \\
\hline \multirow{3}{*}{ Prueba de acceso } & $\begin{array}{l}\text { Superación de la prueba de acceso para ciclos formativos de } \\
\text { grado medio }{ }^{39} \text { (mínimo } 17 \text { años). }\end{array}$ \\
\hline & $\begin{array}{l}\text { Superación de la prueba de acceso para ciclos formativos de } \\
\text { grado superior para la universidad para mayores de } 25 \text { años. }\end{array}$ \\
\hline & $\begin{array}{l}\text { Superación de la prueba de acceso a la universidad para mayo- } \\
\text { res de } 25 \text { años. }\end{array}$ \\
\hline
\end{tabular}

Fuente: Art. 15, RD 1147/2011 \& Modificación 34: art. 41.2, LOMCE.

Cuadro 3: Acceso a ciclos de grado superior

\begin{tabular}{|l|l|}
\hline Tipo de acceso & \\
\hline Directo & $\begin{array}{l}\text { Estar en posesión del título de Bachiller; de un título univer- } \\
\text { sitario, o de un título de Técnico o de Técnico Superior de } \\
\text { Formación Profesional, o de un certificado acreditativo de } \\
\text { haber superado todas las materias de Bachillerato. }\end{array}$ \\
\hline
\end{tabular}

38 Vía de acceso establecida por el RD 1147/201. Con la extinción de los PCPI, el acceso a través de esta opción también se está extinguiendo.

39 En el año 2006 la LOE modificó, entre otras cosas, la edad permitida para acceder a la formación profesional a través de una prueba de acceso regulada por las administraciones educativas y contempló varias exenciones. 
La validación de competencias profesionales en España e Italia

\begin{tabular}{|c|c|}
\hline Tipo de acceso & \\
\hline Curso de formación & $\begin{array}{l}\text { Posesión de un título de técnico de grado medio y la su- } \\
\text { peración de un curso de formación específico para el } \\
\text { acceso a ciclos de grado superior en centros públicos } 0 \\
\text { privados autorizados por la administración educativa. }\end{array}$ \\
\hline \multirow{2}{*}{ Prueba de acceso } & $\begin{array}{l}\text { Superación de la prueba de acceso a ciclos formativos de } \\
\text { grado superior (mínimo } 19 \text { años). }\end{array}$ \\
\hline & $\begin{array}{l}\text { Superación de la prueba de acceso a la universidad para } \\
\text { mayores de } 25 \text { años. }\end{array}$ \\
\hline
\end{tabular}

Fuente: Art. 18, RD 1147/2011 \& Modificación 34: art. 41.3, LOMCE.

Asimismo, en caso de que la demanda de plazas de ciclos formativos de grado medio y superior supere la oferta, las Administraciones educativas pueden establecer procedimientos de admisión siguiendo las condiciones que el Gobierno determine reglamentariamente (Ley Orgánica 8, 2013, n. Modificación 34, art. 41).

Los alumnos que no logren superar las enseñanzas de los ciclos de FPB o de los ciclos de la FP de grado medio o superior obtienen un certificado académico de los módulos profesionales, bloques o materias superados. Este certificado tiene validez académica y posibilidad de acreditación parcial acumulable de las competencias profesionales adquiridas relacionadas con el Sistema Nacional de Cualificaciones y Formación Profesional $^{40}$ (Ley Orgánica 8, 2013, p. modificación 38, art. 44).

\section{- Los cursos de especialización}

Los cursos de especialización tienen como objetivo completar las competencias de aquellos que ya estén en posesión de un título de formación profesional y favorecer el aprendizaje a lo largo de la vida (R.D. 1147, 2011, n. art. 27).

${ }^{40}$ Este sistema es un conjunto de instrumentos y acciones para facilitar la integración de las ofertas de la formación profesional a través del CNCP (INCUAL, 2015b). (Ver subapartado 4.2.2). 


\section{- Otros programas formativos}

Las administraciones educativas pueden organizar programas formativos dirigidos a formar personas mayores de 17 años, que abandonaron el sistema educativo sin una cualificación profesional, con la idea de facilitarles la entrada al mundo laboral, la empleabilidad y la adquisición de un título de formación profesional.

Los programas pueden realizarse en un centro docente público o privado o en alternancia con la actividad en la empresa. ${ }^{41}$

\subsubsection{La formación para el empleo}

La oferta de formación profesional para el empleo, al igual que la relativa a la formación profesional inicial, está vinculada al CNCP y está constituida por la formación dirigida a la obtención de los certificados de profesionalidad (Real Decreto 395, 2007, n. art. 10.1).

La formación profesional relativa al mundo laboral en España, ha pasado por diversas transformaciones sobre todo desde las últimas décadas. A continuación haremos un breve recorrido para explicar estos importantes cambios que poco a poco han conformado lo que hoy en día se entiende por formación profesional para el empleo en España.

La entrada de España en la Unión Europea en el año 1986 jugó un papel importante para el desarrollo de este tipo de formación. Con el objetivo de formar a la población activa desocupada se aprobó, con el Real Decreto 1618/1990, el plan de Formación e Inserción Profesional (en adelante, Plan PIF), cofinanciado por el Fondo Social Europeo ${ }^{42}$. De este modo se inauguró la llamada formación ocupacional (Homs, 2008). Sin embargo, con el traspaso de la gestión de la formación ocupacional a las comunidades autónomas, el alto grado de responsabilidad en la impartición

41 Para aquellas personas que tengan un contrato de trabajo, un contrato para la formación, una beca de formación en empresas o entidades públicas o la condición de voluntario, será necesaria la realización de un convenio entre la empresa y la administración pública. Además el alumno deberá tener un tutor en el centro educativo y otro en la empresa (R.D. 1147, 2011, n. art. 31).

42 El Fondo Social Europeo es el principal instrumento del que se sirve Europa para apoyar la creación de empleo y garantizar oportunidades laborales más justas (Comisión Europea, 2013). 
de formación continua a trabajadores asalariados y la necesidad de hacer complementarias la formación reglada y la ocupacional, se hizo necesario un cambio en el Plan FIP. Dicho cambio se materializó con el Real Decreto $631 / 1993^{43}$. Esta nueva regulación pretendió reorganizar las acciones de formación ocupacional, intentando vincular estrechamente la formación ocupacional con la inserción laboral de personas en situación de paro. Quiso también garantizar la transparencia del mercado de trabajo a través de la expedición de certificados de profesionalidad. Asimismo posibilitó la convalidación o la correspondencia entre los conocimientos adquiridos en la formación profesional ocupacional y las enseñanzas impartidas en la formación profesional perteneciente al sistema educativo.

Por lo tanto, se puede afirmar que a inicios de los años 90 España contaba con una formación inicial y ocupacional, aunque todavía no tenía formación continua. Esta llegó en el año 1992 con el Primer Acuerdo Nacional sobre formación continua, tras las negociaciones con agentes sociales y representantes de la administración estatal y gracias al impulso que la UE concedió a la formación a lo largo de la vida. De forma paralela se creó la Fundación para la Formación Continua (en adelante, FORCEM), de ámbito estatal, encargada de organizar, gestionar y dar apoyo técnico a la formación (Pineda \& Sarramona i López, 2006, pp. 709-710). En el año 2001 la Fundación FORCEM fue sustituida por la Fundación Estatal para la formación en el empleo ${ }^{44}$. En este momento la administración pública se empezó a implicar más en la gestión y en los fondos del subsistema, lo que produjo alguna que otra discrepancia con los agentes sociales y ante lo cual el Estado decidió publicar el Real Decreto 1046/2003 de 1 de agosto por el que se regulaba el subsistema de formación profesional continua. Este real decreto cambió el sistema de financiación y abrió el subsistema a las comunidades autónomas con su presencia en la Fundación Tripartita (Homs, 2008, p. 35; Pineda \& Sarramona i López, 2006, pp. 710-714).

43 Este real decreto estuvo vigente hasta la fusión de la formación profesional ocupacional con la formación profesional continua en el año 2007.

${ }^{44}$ La Fundación Estatal para la formación en el empleo pertenece al Sector Público Estatal, se trata de uno de los componentes de la estructura organizativa y de participación institucional del subsistema de formación profesional para el empleo. Es de carácter tripartito, está formada por la Administración Pública y por las organizaciones empresariales y sindicales más representativas. Sus funciones están definidas en el Real Decreto 395/2007 de 23 de marzo que regula el subsistema de formación profesional para el empleo (Fundación Tripartita, 2011). 
Los sistemas educativos y de formación profesional en España y en Italia

Así nacieron los dos subsistemas de formación profesional: ocupacional y continua, dirigida a trabajadores desocupados y ocupados respectivamente.

Estos dos tipos de formación estuvieron vigentes en España durante trece años, hasta que en el año 2007 se integraron en un solo tipo de formación, la profesional para el empleo, creada y regulada por el Real Decreto 395/2007 (en adelante, RD 395/2013). Esté cambio fue motivado por la urgencia de adaptar la formación dirigida a los trabajadores ocupados y desempleados a la nueva realidad económica, social y a las exigencias del mercado de trabajo. De este modo se dio respuesta a la necesidad de integración de la formación y de fomento del aprendizaje permanente, considerado por la Unión Europea un pilar fundamental para la estrategia de empleo en una economía basada en el conocimiento, que pretende alcanzar los objetivos en educación y formación propuestos para el 2010 desde la Cumbre de Lisboa (Real Decreto 395, 2007). Todavía en la actualidad existen los dos antiguos subsistemas.

A todos estos cambios realizados en el ámbito de la formación para el empleo tenemos que añadir el más reciente de ellos, se trata del Real Decreto-ley 4/2015 (en adelante, RD-L 4/2015) sobre la reforma urgente del Sistema de Formación Profesional para el Empleo en el ámbito laboral. Este último cambio, viene también motivado por las recientes políticas europeas sobre la mejora de la empleabilidad y por la intención de hacer frente a la crisis económica.

El nuevo real decreto-ley tiene prevista su aplicación de forma inmediata en aquellos casos en los que sea posible. Este real decreto-ley no transforma por completo el modelo de formación profesional, está previsto que en su desarrollo se aprueben un real decreto y una orden ministerial que deroguen todo lo dispuesto por el RD 395/2007. Sin embargo, hasta que esto ocurra ambos decretos convivirán en el sistema de formación profesional para el empleo. Por este motivo presentaremos las características y las modalidades formativas establecidas por ambas normativas, (las contempladas en el RD 395/2007 y las establecidas por el RD-L 4/2015).

Según el Real Decreto-ley 4/2015 se entiende por formación profesional para el empleo "el conjunto de iniciativas, programas e instrumentos que tienen como finalidad impulsar y extender entre las empresas y los trabajadores ocupados y desempleados una formación que responda a las 
La validación de competencias profesionales en España e Italia

necesidades del mercado laboral y esté orientada a la mejora de la empleabilidad de los trabajadores y la competitividad empresarial, conforme a sus fines y principios" (Real Decreto-ley 4, 2015, n. art. 26.1).

Respecto a la definición dada en el RD 395/2007, el nuevo decretoley, hace mayor hincapié en las necesidades del mercado laboral y en la mejora de la empleabilidad de los trabajadores.

El RD 395/2007 estableció que la formación para el empleo estaba dirigida a favorecer la formación a lo largo de la vida de los trabajadores, dotarles de conocimientos y prácticas adecuados al mercado laboral, mejorar su empleabilidad y promover la acreditación de competencias profesionales formales, no formales e informales (Real Decreto 395, 2007, n. art. 2). A todos estos fines, el nuevo decreto-ley añade la mejora en la productividad y competitividad de las empresas (Real Decreto-ley 4, 2015, n. art. 2).

En cuanto a las modalidades formativas de la formación profesional para el empleo, El artículo 4 del Real Decreto 395/2007, establece la formación para el empleo, la formación de la demanda; la formación de la oferta; la formación en alternancia y las acciones de apoyo y acompañamiento. Por su parte, el Real Decreto-ley 4/2015 modifica estos tipos de formación instituyendo la formación programada por las empresas (que equivaldría a la formación de la demanda), la oferta formativa para trabajadores ocupados y la oferta formativa para trabajadores desocupados (estas dos modalidades de formación serían el resultado de la división de la formación de la oferta).

Hemos decidido presentar las modalidades del RD 395/2007 que siguen vigentes, $y$ de forma paralela presentamos en un cuadro las nuevas modalidades que se pondrán en funcionamiento tan pronto como sea posible:

\section{- La formación de demanda}

Comprende las acciones formativas de las empresas y los permisos individuales de formación financiados de forma parcial o total por fondos públicos, para dar respuesta a las necesidades concretas de formación de empresas y trabajadores. Dichos permisos los autoriza la empresa al trabajador para que la realización formativa que este realice tenga una acreditación oficial (Real Decreto 395, 2007, n. art. 12.3). 
La formación de la demanda recibe este nombre porque son los beneficiarios directos, empresas y trabajadores, los que tienen que solicitar su financiación (Homs, 2008, p. 62).

La planificación y gestión de esta formación recae en las empresas según sus necesidades formativas, con la participación de los representantes de los trabajadores. Su financiación se organiza mediante un sistema de bonificación de las cuotas a la Seguridad Social que ingresan las empresas y que pagan trabajadores y empresas.

Este tipo de formación puede ser de dos tipos: general o específica. La general proporciona cualificaciones que pueden ser transferibles a otras empresas y ámbitos y no sólo aplicable al puesto de trabajo actual o fututo del trabajador. Por el contrario, la específica proporciona una formación aplicable al futuro o actual puesto de trabajo del trabajador (Real Decreto 395,2007 , n. art. 12.2).

En la Formación de Demanda pueden participar los trabajadores asalariados de empresas o entidades públicas no incluidas en el ámbito de aplicación de los acuerdos de formación en las Administraciones Públicas. También pueden participar trabajadores fijos discontinuos en los períodos de no ocupación, aquellos que accedan a situación de desempleo cuando se encuentren en período formativo, y los trabajadores acogidos a regulación de empleo en sus períodos de suspensión de empleo por expediente autorizado (Real Decreto 395, 2007, n. art. 5).

Real Decreto-Ley 4/2015:

Formación programada por las empresas.

La formación programada por las empresas se correspondería con la formación de demanda establecida por el RD 395/2007. Está dirigida a trabajadores asalariados de empresas o de algunas entidades públicas.

Las acciones formativas programadas por las empresas responderán a necesidades formativas reales, específicas e inmediatas de estas y de sus trabajadores.

Las empresas podrán organizar la formación por sí mismas o encomendársela a una entidad externa. Asimismo, podrán impartirla a través de medios propios o de la contratación de los mismos.

Para la financiación de este tipo de formación las empresas dispon- 
drán de un crédito de formación, que podrán hacer efectivo a través de bonificaciones en las correspondientes cotizaciones empresariales a la Seguridad Social, al comunicar la finalización de la formación (Real Decretoley 4, 2015, n. art. 10).

\section{- La formación de oferta}

La formación de oferta abarca los planes de formación orientados sobre todo a trabajadores ocupados y las acciones formativas dirigidas principalmente a trabajadores desempleados, con el objetivo de proporcionarles una formación útil para el buen desempeño de una profesión y para acceder al mundo laboral (Real Decreto 395, 2007, n. art. 4).

Este tipo de formación se llama de oferta porque su iniciativa organizativa no procede del demandante de formación, como en la formación de demanda, sino que se da por parte de intermediarios que pueden ser agentes sociales, las administraciones públicas o las entidades sociales y privadas colaboradoras que organizan una oferta formativa (Homs, 2008, p. 69).

Real Decreto-Ley 4/2015:

La nueva normativa divide más específicamente la formación de la oferta en oferta formativa para trabajadores ocupados y desempleados:

Oferta formativa para trabajadores ocupados

La oferta formativa para trabajadores ocupados pretende ofrecerles una formación que responda a las necesidades de producción y competitividad de las empresas y a las necesidades de adaptación de los trabajadores al cambio del sistema productivo. Asimismo tiene el objetivo de ayudarles en su promoción profesional y desarrollo personal para mejorar su empleabilidad.

Esta oferta formativa se ocupará de dar respuesta a las necesidades no cubiertas por la formación programada por las empresas y se desarrollará de manera complementaria a esta. Garantizará, además de los programas de formación sectorial, una formación en competencias transversales.

También las Administraciones competentes pondrán en marcha programas de cualificación y reconocimiento profesional, proporcionando una oferta formativa que favorezca la acreditación parcial acumulable, así como los procedimientos de reconocimiento de competencias adquiridas en el ámbito laboral. 
Podrán participar en esta oferta formativa, los trabajadores ocupados y algunos desempleados en determinadas situaciones (Real Decreto-ley 4, 2015, n. art. 11).

Oferta formativa para trabajadores desempleados.

La oferta formativa para trabajadores desempleados se llevará a cabo a través de programas de las administraciones competentes. Estos pretenden ofrecer a los trabajadores una formación ajustada a sus necesidades formativas individuales y a la del sistema productivo, con objeto de mejorar su empleabilidad.

Este tipo de formación dará prioridad a aquellas personas que se encuentren en situación de desempleo y tengan un bajo nivel de cualificación. Asimismo, tratará de ofrecer preferentemente acciones formativas con vistas a la obtención de certificados de profesionalidad (Real Decreto-ley 4, 2015, n. art. 12).

\section{- La formación en alternancia}

Este tipo de formación comprende las acciones formativas de los contratos para la formación y los programas públicos de empleo-formación, permitiendo al trabajador compatibilizar la formación con la práctica profesional en su puesto de trabajo.

Se incluyen en esta formación: los Talleres de Empleo, los programas de las escuelas-taller, y casas de oficios (Homs, 2008, p. 73).

Los Talleres de Empleo están regulados por el Real Decreto 282/1999 sobre el programa de talleres de empleo. Según este real decreto se trata de un programa de empleo y formación dirigido a desempleados de 25 o más años. Los participantes obtienen una formación profesional y experiencia laboral para facilitar su posterior inserción laboral por cuenta ajena o mediante la creación de proyectos empresariales o de economía social. La duración es de seis meses como mínimo y un año como máximo. Los trabajadores participantes, además de suscribir un contrato con la entidad promotora, reciben una formación profesional acorde con la ocupación a desempeñar, en alternancia con el trabajo y la práctica profesional.

También se prepara para la obtención del título en ESO a aquellos que carecen de la formación general básica, asimismo reciben orientación y 
La validación de competencias profesionales en España e Italia

apoyo en la búsqueda de empleo y una formación para la creación y puesta en marcha de empresas o la constitución de un empresario autónomo. Por esta vía también se puede adquirir destrezas profesionales y experiencia en ocupaciones nuevas. Al final se concede una certificación donde se indican las horas dedicadas a la formación y el itinerario modular seguido (Eurydice, 2009, p. 76).

Podrán acceder a este tipo de programa los desempleados de 25 o más años que tengan especiales dificultades para insertarse en el mercado de trabajo, (parados de larga duración, mayores de 45 años, mujeres, personas con discapacidad) o que se consideren como colectivos preferentes de actuación de los Planes de Acción para el empleo (Real Decreto 282, 1999, n. art. 2).

Las Escuelas Taller y Casas de Oficio están reguladas por la Orden de 14 de noviembre de 2001, sobre la regulación del programa de Escuelas Taller y Casas de Oficio y de las Unidades de Promoción y Desarrollo. La orden define estos estudios como un programa mixto de empleo y formación con el objetivo de facilitar la inserción laboral de jóvenes desempleados menores de 25 años.

A parte de los requisitos ya mencionados, se requiere tener más de 16 años y ser demandante de empleo inscrito en los servicios públicos de empleo para poder acceder a estos programas. En general no se necesita una titulación para entrar en las Escuelas Taller o Casas de Oficio.

Las Escuelas Taller tienen una duración de entre uno y dos años e incluyen dos etapas: en la primera se imparte formación profesional teóricopráctica y conocimientos sobre riesgos laborales. En la segunda etapa los alumnos trabajadores suscriben un "contrato de trabajo para la formación" con la entidad promotora, realizan un trabajo de utilidad pública y social y continúan con el proceso formativo iniciado en la primera parte. Las Casas de Oficio tienen una duración de un año y también constan de dos etapas, con los mismos contenidos que las etapas de Escuelas Taller (Eurydice, 2009, p. 80).

- Las acciones de apoyo, acompañamiento y acciones complementarias a la formación.

Estas acciones tienen como finalidad mejorar la eficiencia de la formación. La formación está orientada a la adquisición y a la mejora de las 
competencias y cualificaciones profesionales y se puede estructurar en varios módulos formativos. Su impartición puede ser presencial, a distancia o mixta (Eurydice, 2009, pp. 76-77).

Por último, cabe señalar que el último real decreto de 2015 hace referencia también a otras iniciativas de formación profesional para el empleo, relativas a los permisos individuales de formación, la formación en alternancia con el empleo, la formación de los empleados públicos y la formación no financiada con fondos públicos desarrollada por centros y entidades de iniciativa privada, destinada a la obtención de certificados de profesionalidad.

\subsubsection{La formación profesional dual}

Como aspecto novedoso debemos hablar de la formación profesional dual. En España se entiende por formación profesional dual el conjunto de acciones e iniciativas formativas, mixtas de empleo y formación, con la finalidad de cualificar a los trabajadores, a través de la alternancia de actividad laboral con la formación perteneciente al sistema de formación profesional para el empleo o del sistema educativo (Real Decreto 1529, 2012, n. art. 2).

Esto quiere decir que la formación profesional dual se desarrolla en el ámbito del sistema educativo y en el laboral. El Real Decreto 1529/2012 desarrolla y establece las bases para este tipo de formación en estos dos ámbitos. Asimismo, distingue las siguientes modalidades de formación profesional dual:

a) formación exclusiva en centro formativo;

b) formación con participación de la empresa;

c) formación en empresa autorizada o acreditada y en centro de formación;

d) formación compartida entre el centro de formación y la empresa;

e) formación exclusiva en la empresa. 
La validación de competencias profesionales en España e Italia

\section{- La formación profesional dual en el sistema educativo}

La formación profesional dual en el sistema educativo se lleva a cabo con un sistema de becas, a través de un convenio de colaboración entre los centros de formación participantes y las empresas del sector correspondiente.

La formación dual en el sistema educativo puede durar hasta 3 años y pretende facilitar la obtención de un título de enseñanza secundaria postobligatoria, a través de las enseñanzas de la formación profesional; facilitar la inserción laboral; reducir el abandono escolar y estrechar los vínculos entre el mundo formativo-profesional y laboral (Real Decreto 1529, 2012).

\section{- El contrato para la formación y el aprendizaje}

La formación profesional dual en el ámbito laboral se desarrolla a través del contrato para la formación y el aprendizaje.

Este tipo de contrato está dirigido a mayores de 16 años y menores de 30 sin cualificación profesional reconocida.

Suele tener una duración de entre 1 y 3 años y la actividad formativa ${ }^{45}$ que se realiza es la necesaria para obtener un título de formación profesional, certificado de profesionalidad, certificación académica o acreditación parcial acumulable, y debe estar relacionada con la actividad laboral desarrollada en el puesto de trabajo.

Podrán llevar a cabo esta formación los Centros de Referencia Nacional (CRN), los Centros Públicos del Sistema Nacional de Empleo (SNE) y los Centros Privados acreditados del SNE que ofertan formación para el empleo) (Real Decreto 1529, 2012).

Cerrando este apartado, mostramos, con el Esquema 2, la estructura de la formación profesional en España.

${ }^{45}$ La Orden ESS/2518/2013, de 26 de diciembre, regula los aspectos formativos del contrato para la formación y el aprendizaje, en desarrollo del Real Decreto 1529/2012, de 8 de noviembre, por el que se desarrolla el contrato para la formación y el aprendizaje y se establecen las bases de la formación profesional dual. 
Los sistemas educativos y de formación profesional en España y en Italia

Esquema 2: La formación profesional en España

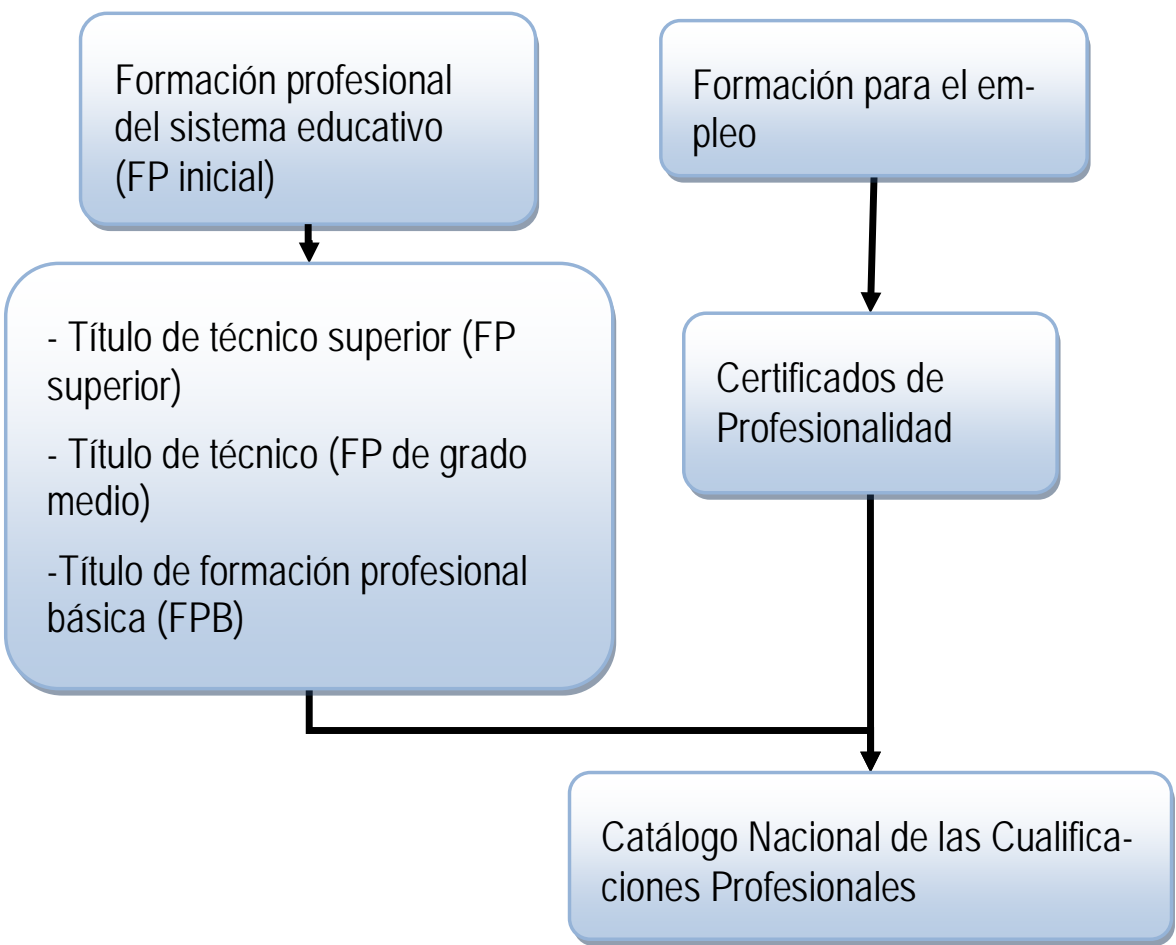

(*) En extinción

\subsubsection{LA FORMACIÓN PROFESIONAL EN CASTILLA Y LEÓN}

En España, la formación profesional está en manos del Estado, por ello las comunidades autónomas ofrecen una formación profesional regulada por la normativa nacional que hemos visto en los apartados anteriores sobre los sistemas de educación y formación profesional en España.

El modelo de gestión de la formación profesional en Castilla y León, es un modelo compartido por las Administraciones públicas (Administración General del Estado y comunidades autónomas) y los interlocutores sociales.

\subsubsection{Formación profesional inicial en Castilla y León}

Respecto a la formación profesional inicial en Castilla y León, el Gobierno es quien fija los objetivos, las competencias, el 65\% de los contenidos del 
La validación de competencias profesionales en España e Italia

currículo, los resultados de aprendizaje y los criterios de evaluación. La comunidad autónoma de Castilla y León se encarga de decidir el 35\% restante del contenido curricular.

En Castilla y León existe una oferta de formación profesional básica, de grado medio y de grado superior (estas dos últimas pueden hacerse también a distancia). Asimismo, en el curso 2014/15 se ha iniciado el proyecto de formación dual "Aula-Empresa" (Junta de Castilla y León, 2015b). Los proyectos de formación dual podrán comprender la totalidad o parte de un curso académico, pudiéndose extender durante cursos posteriores (Orden EDU/915, 2014).

\subsubsection{Formación profesional para el empleo en Castilla y León}

En cuanto a la formación para el empleo se ofrecen planes de formación para ocupados, cursos de formación para desempleados y un programa mixto de formación en alternancia con el empleo.

Los cursos de formación para desempleados se subdividen en los cursos de FOD (formación para desempleados) y en los cursos incluidos en itinerarios OFI (Orientación, formación e inserción profesional). Los primeros tienen la finalidad de preparar para la reinserción en el mundo laboral a través de formación reconocida oficialmente. Los segundos tienen la finalidad de proporcionar un acompañamiento integral y continuo a los trabajadores desempleados.

Los programas mixtos de formación en alternancia con el empleo también están dirigidos a desempleados, pretenden favorecer la adquisición de competencias profesionales y la inserción laboral, a través de formación teórica alternada con la prestación de un trabajo remunerado.

Existen dos modalidades de acciones de formación y empleo de esta índole, las destinadas a personas desempleadas menores de 25 años y las dirigidas a personas desempleadas en general (Junta de Castilla y León, 2015a).

Respecto a la formación dual, Castilla y León está llevando a cabo un programa llamado "Formación y Empleo", con una duración de 6 a 12 meses, con jornadas de trabajo real del $50 \%$ y el resto de formación teóricopráctica (Orden EYE/952, 2012). 


\subsection{El sistema educativo y de formación profesional italiano}

Siguiendo la estructura utilizada en el anterior apartado con el sistema educativo y de formación profesional español y con la intención de facilitar la comprensión del sistema educativo y de formación profesional italiano, presentaremos por un lado el sistema educativo y por otro el sistema de formación profesional.

\subsubsection{EL SISTEMA EDUCATIVO ITALIANO}

El sistema educativo italiano está regulado por un gran número de leyes. Esto se debe en parte al gran número de reformas que ha sufrido y sigue sufriendo el sistema desde el año 2003. A continuación exponemos todas las enseñanzas que ofrece y la situación actual del mismo.

En Italia, la ley 3/2001 otorgó al Estado la competencia exclusiva para definir las normas generales en materia educativa. La responsabilidad general del sistema educativo está en manos del Ministerio de Educación, Universidad e Investigación (en adelante, en sus siglas en italiano MIURMinistero dell'struzione, dell'Università e della Ricerca), que regulan todas las enseñanzas menos las de la educación y formación profesional (en adelante, en sus siglas en italiano IeFP-istruzione e formazione professionale) y de formación continua. Las regiones y provincias autónomas tienen competencias en materia de programación de la oferta educativo-formativa (IeFP) y de programación de la red escolar, asimismo pueden definir el calendario escolar.

El sistema de educación italiano se compone de (ver Esquema 3):

$>$ Escuela de la infancia.

$>$ Escuela primaria.

$>$ Escuela secundaria de primer grado.

$>$ Escuela secundaria superior.

$>$ Educación y formación profesional (IeFP).

$>$ Educación y formación técnica superior

$>$ Alta formación artística y musical (en adelante, AFAM).

$>$ Institutos con fines especiales.

$>$ Educación superior universitaria. 
La validación de competencias profesionales en España e Italia

Educación de personas adultas.

Estas enseñanzas se agrupan en los siguientes niveles o ciclos educativos.

El primer ciclo educativo es de carácter obligatorio, tiene una duración de ocho años y se articula en dos segmentos, la escuela primaria y la escuela secundaria de primer grado, comprende desde los 6 a los 11 años de edad. Se articula en tres periodos didácticos: un primer año y dos periodos didácticos de dos años cada uno.

El segundo ciclo educativo ${ }^{46}$ está constituido por la educación secundaria superior y por el sistema de educación y formación profesional (en adelante, en sus siglas en italiano IeFP-Istruzione e Formazione Professionale).

La educación y formación superior está conformada por los estudios superiores que pueden seguirse en Italia:

- el sistema de educación y formación técnica superior, que a su vez está compuesto por la educación y formación técnica superior (en adelante, en sus siglas en italiano, IFTS-Istruqione e Formazione Tecnica Superiore) y los institutos técnicos superiores (en adelante, en sus siglas en italiano, ITS-Istituti e Tecnici Superiori).

- La educación superior universitaria y no universitaria. Esta última abarca la Alta Formación Artística y Musical (AFAM) y los institutos con fines especiales.

La educación es obligatoria y gratuita durante 10 años, comprende el primer ciclo de educación y los dos primeros años del segundo ciclo (de los 6 a los 16 años).

Una vez concluida la educación obligatoria no se puede abandonar el sistema antes de los 18 años sin haber obtenido un diploma o una cualificación. A esto se le llama derecho-deber a la educación y formación, que prevé la formación de un joven durante al menos 12 años. Este derechodeber se puede realizar dentro del sistema de educación secundaria superior, en el sistema de educación y formación profesional regional o en el apprendistato (Ley 53, 2003).

${ }^{46} \mathrm{El}$ segundo ciclo educativo (secondo ciclo di istruzione) no se rige por la ley 53/2003, ya que fue restituido posteriormente por la reforma Fioroni y se mantuvo la estructura del antiguo sistema. 
Los sistemas educativos y de formación profesional en España y en Italia

Esquema 3: La estructura del sistema educativo italiano

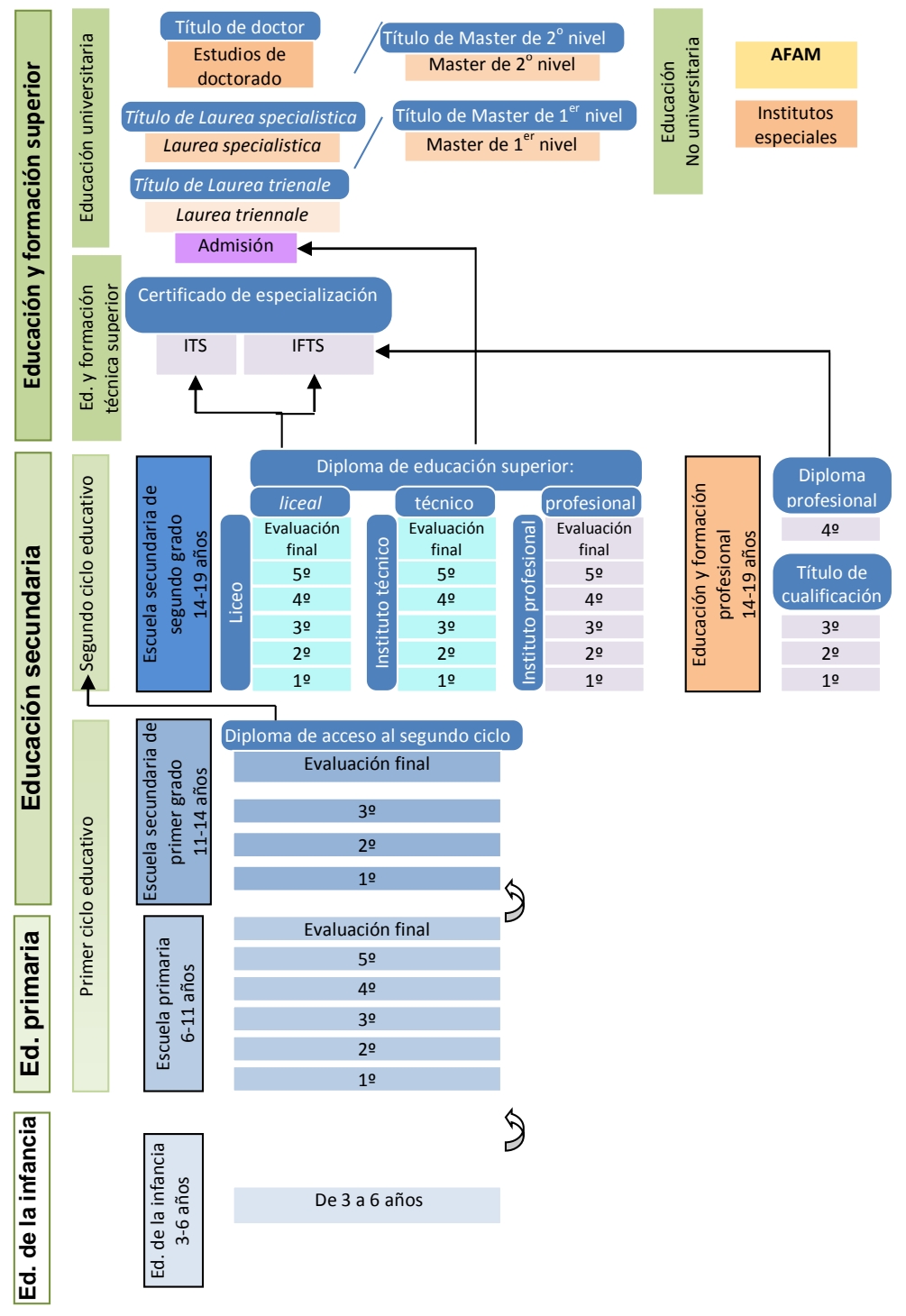

A continuación, apoyándonos en la legislación italiana sobre el sistema educativo y en el documento nacional: "Primo rapporto italiano di referenciazione delle qualificazioni al quadro europeo EQF", mostramos la estructura del sistema educativo con mayor detalle.

\section{La escuela de la infancia}


La validación de competencias profesionales en España e Italia

Es de carácter no obligatorio. Está dirigida a los niños de 3 a 6 años de edad, tiene como finalidad el desarrollo afectivo, psicomotriz, cognitivo, moral, religioso y social de los niños y niñas, promoviendo las capacidades de relación, autonomía, creatividad y aprendizaje. Antes de la escuela de la infancia, existe la posibilidad de que los niños de 0 a 3 años asistan al asilo nido, el cual no pertenece al MIUR.

\section{$>$ La escuela primaria}

Tiene cinco años de duración, comprende desde los 6 a los 11 años de edad. Se articula en tres periodos didácticos: un primer año y dos periodos didácticos de dos años cada uno.

\section{La escuela secundaria de primer grado}

Tiene una duración de tres años, comprendiendo en este caso, de los 11 a los 14 años de edad. Se articula en un bienio y en un tercer año de orientación y unión con el segundo ciclo educativo. Al finalizar esta escuela, coincidiendo con el fin del primer ciclo educativo, los alumnos deben realizar un examen de Estado para poder obtener el diploma de acceso al segundo ciclo educativo y decidir la vía en la que terminarán los últimos dos años de la educación obligatoria. ${ }^{47}$ Es decir, si entrarán en la educación secundaria superior o en el sistema de formación profesional (IeFP).

\section{La educación secundaria superior}

Este tipo de educación sufrió varios cambios en el año 2010. El 15 de junio de ese año se publicaron tres decretos presidenciales ${ }^{48}$ sobre la reforma en la escuela secundaria superior, reduciendo los cursos y las posibles ramas de estudio.

${ }^{47}$ Siguiendo con la Recomendación Europea de 18 de diciembre de 2006, sobre las competencias clave para el aprendizaje permanente, Italia ha definido -con el reglamento de la educación obligatoria (Decreto del MIUR núm. 139 de 2007) y con el documento técnico sobre "las competencias clave del ciudadano-, las competencias de base que deben adquirir todos los alumnos antes de terminar la educación obligatoria. Dichas competencias son las siguientes: aprender a aprender; planificar; comunicar; colaborar y participar; actuar de forma autónoma y responsable; resolver problemas; identificar conexiones y relaciones; adquirir e interpretar informaciones.

${ }^{48}$ El 15 de junio de 2010 se publicaron en el número 137, en el suplemento ordinario núm. 128/L de la Gazzetta Ufficiale, los decretos presidenciales 89/2010; 88/2010 y 87/2010. 
Tiene una duración de cinco años y está dirigida a alumnos de 14 a 19 años. A esta vía pertenecen los liceos, los institutos técnicos y los institutos profesionales.

Los liceos y los institutos técnicos se articulan en dos bienios más un quinto año tras el que los alumnos realizan otro examen estatal. Por su parte, los institutos profesionales (ver subapartado 3.2.2.1) se organizan en cursos de cinco años estructurados en dos bienios (el segundo 1+1) y un quinto año. La articulación de las dos anualidades en el segundo bienio pretende facilitar los traspasos con los cursos de tres años de educación y formación. También está previsto un examen estatal al finalizar los cinco años de estudios, tras el cual se otorga un diploma de educación secundaria superior (diploma de educación liceale, técnica o profesional, según corresponda).

Este tipo de educación tiene como objetivo principal ofrecer preparación de figuras profesionales para el campo educativo (liceos), la preparación para la práctica de funciones técnicas y administrativas en algunos sectores (educación técnica) y la preparación específica teórico-práctica para el desarrollo de tareas cualificadas (educación profesional), en varios sectores y con particular atención a las exigencias del mercado de trabajo local.

La educación en los liceos puede ser de seis tipos: clásico, lingüístico, científico, de ciencias humanas, musical y de danza y artístico.

Los institutos técnicos pueden pertenecer a dos sectores diferentes, el económico y el tecnológico.

Asimismo, los institutos profesionales también se componen de dos sectores, el de servicios y el de industria y artesanía.

\section{La educación y formación profesional (IeFP)}

El artículo 117 de la constitución italiana otorga a las regiones la competencia legislativa exclusiva en el sistema de educación y formación profesional. Sin embargo, deben respetarse unos estándares formativos mínimos establecidos por el Estado (duración de los cursos, validez nacional de las certificaciones, respeto de criterios nacionales de acreditación para los sujetos que proporcionen la formación). 
La validación de competencias profesionales en España e Italia

La educación y formación profesional (IeFP) (ver subapartado 3.2.2.2) se articula del siguiente modo:

- estudios de tres años, para obtener el título de una cualificación;

- estudios de cuatro años, para obtener el diploma profesional.

\section{La educación y formación técnica superior}

La educación y formación técnica superior (ver subapartado 3.2.2.3) ha sido objeto de una reforma realizada a través de diferentes intervenciones legislativas, en especial a través del DPCM de 25 de enero de 2008. Este decreto se encargó de reorganizar las enseñanzas de la Educación y Formación Técnica Superior (IFTS-Istruzione e Formazione Tecnica Superiore) y de instaurar los Institutos Técnicos Superiores (ITS-Istituti Tecnici Superiori).

\section{$>$ La educación superior no universitaria y universitaria}

Las disposiciones legislativas, en vigor, en materia de educación superior en Italia, se refieren al artículo 33 de la Constitución italiana, que otorga a universidades y academias el derecho de actuar de forma autónoma, dentro de los límites previstos por la ley. Esta educación puede ser ofrecida tanto por instituciones públicas como privadas.

Con el objetivo de acercar el sistema italiano de educación superior al modelo europeo, la educación superior en Italia se vio modificada. El cambio se inició en el año 1998 con la Declaración de la Sorbona (Conferencia Europea de Ministros de Educación Superior, 1998).

El nuevo sistema está dividido en educación superior universitaria y no universitaria y la Alta Formación Artística y Musical (AFAM), que también está englobada en la educación no universitaria.

- El sistema de educación superior no universitario

La educación superior no universitaria es impartida por institutos que tienen su propia estructura, normativa y organización. En general están conformados por la AFAM y los institutos con fines especiales (Isfol, Dipartimento per le politiche europee, Ministero del Lavoro e delle Politiche Sociali, \& MIUR, 2012).

La Alta formación artística y musical (AFAM) está regulada por la ley número 508, de 21 de diciembre de 1999, puesta en marcha con el DPR número 212 de julio de 2005. 
Las academias y los institutos de la AFAM son sedes de alta formación, de especialización y de investigación en el sector artístico y musical. Están dotadas de personalidad jurídica y disfrutan de autonomía estatutaria, didáctica, científica, administrativa, financiera y contable. Los institutos de la AFAM pueden ofrecer cursos organizados en tres ciclos (Isfol et al., 2012):

1. el primero de tres años de duración, dirigido a la obtención de un diploma académico de primer nivel;

2. el segundo estructurado en cursos bienales, orientado a la obtención de un diploma académico de segundo nivel, a cursos de especialización y a cursos de perfeccionamiento o máster;

3. el tercero está dirigido a la formación para la investigación, a la especialización y al perfeccionamiento o máster de segundo nivel.

En cuanto a los institutos con fines especiales de educación superior no universitaria, estos ofrecen especialidades profesionales en campos muy diversos como la restauración, la cinematografía, la archivística, la formación de mediadores lingüísticos, la formación de oficiales de las fuerzas armadas y de las fuerzas públicas de seguridad. Los cursos se estructuran en clases teóricas y en prácticas. Se accede a estos institutos con el Diploma de educación secundaria superior y tras haber pasado el examen de admisión.

- El sistema de educación superior universitario

El Decreto número 270, de 22 de octubre de 2004, ha redefinido el sistema universitario con la reforma conocida como la del " $3+2$ ". Siguiendo con lo acordado en el "Plan Bologna", las universidades pueden instituir estudios organizados en tres ciclos:

1. el primero referido a estudios de tres años de duración (laurea trienna$(e)^{49}$;

2. el segundo concerniente a estudios de dos años de duración (laurea magistrale $)^{50}$ y a másteres de primer nivel;

3. el tercero dedicado a cursos de especialización; a másteres de segundo nivel y al doctorado de investigación.

${ }^{49}$ Equivalente a los estudios de grado en España, según la nueva normativa y a una diplomatura según la antigua.

${ }^{50}$ Equivalente a los estudios de máster en España, según la nueva normativa y a una licenciatura según la antigua. 
La validación de competencias profesionales en España e Italia

El acceso a los cursos de educación superior universitaria y no universitaria se consigue tras finalizar la educación superior secundaria y superar el examen del Estado (Isfol et al., 2012).

\section{El sistema de educación de adultos}

Actualmente, la educación de adultos en Italia propone (hasta el curso escolar 2014/2015) dos posibilidades de formación:

- cursos en Centros Territoriales Permanente (CTP): dirigidos a la adquisición de competencias de base y a completar la educación obligatoria. En estos centros también se enseña la lengua italiana;

- cursos nocturnos: enfocados a la adquisición de títulos de estudio de nivel superior.

La formación para adultos está dirigida a alumnos en edad laboral, incluyendo inmigrantes, que no hayan completado la educación obligatoria o que no se estén en posesión de títulos de estudio de la escuela secundaria superior.

Actualmente en la Formación de Adultos se está llevando a cabo un proceso de reorganización que comenzó con el Decreto Ministerial de 25 de octubre de 2007 y siguió con el Decreto del Presidente de la República 263/2012. Se prevé la puesta en marcha de Centros Territoriales Permanentes y de cursos nocturnos a través de la institución de los llamados Centros Provinciales de Educación para Adultos. El objetivo de estos nuevos centros es aumentar el nivel educativo de la población adulta y recuperar a los aquellos que abandonaron los estudios de forma prematura (fracaso escolar).

La oferta formativa de los Centros de Educación para Adultos engloba (Isfol et al., 2012):

- cursos educativos de primer nivel;

- cursos educativos de segundo nivel;

- cursos de alfabetización y de lengua italiana.

\subsubsection{EL SISTEMA DE FORMACIÓN PROFESIONAL ITALIANO}

En Italia, como en España, la formación profesional pretende otorgar una cualificación que posibilite el acceso al empleo y a la vida social. También puede distinguirse una formación orientada al ingreso en el mundo laboral 
(equiparable a la formación inicial en España y denominada así a partir de ahora) y una formación continua pensada para mejorar las competencias profesionales de trabajadores ocupados o desempleados.

Según esto, la formación profesional en Italia comprende los institutos profesionales; la educación y formación profesional (IeFP); la educación y formación técnica superior y la formación continua (las tres primeras enseñanzas pertenecen a la formación profesional inicial y la última a la continua). Asimismo, hemos incluido en este aparto la formación inicial postqualifica, post-diploma, post-laurea y el apprendistato, ya que consideramos que se encuadran en el marco de la formación profesional.

Recordamos que en Italia la IeFP recae sobre la competencia de las regiones, las cuales también delegan y traspasan funciones y tareas a las provincias. El Ministerio de Trabajo y Políticas Sociales define y garantiza los niveles esenciales de los servicios relacionados con el sistema de la formación profesional (IeFP) (Ley 845, 1978).

\subsubsection{Los institutos profesionales}

Los institutos profesionales pertenecen a la educación secundaria superior, están repartidos en dos sectores, el de servicios y el de industria y artesanía. A su vez por cada sector están previstas más direcciones que se corresponden con las áreas profesionales más significativas (ver Cuadro 4).

La articulación de las dos anualidades en el segundo bienio pretende facilitar los traspasos con los cursos de tres años de educación y formación (D.P.R. 87, 2010).

Cuadro 4: Estructura y articulación de los posibles itinerarios de los institutos profesionales

\begin{tabular}{|l|l|}
\hline $\begin{array}{l}\text { Sectores de institutos profesionales } \\
1 \text { bienio }+1 \text { bienio } \\
\text { (articulado en } 1+1)+V \text { año }\end{array}$ & Direcciones \\
\hline Sector servicios & $\begin{array}{l}\text { 1. Servicios para la agricultura y el desarrollo rural. } \\
\text { 2. Servicios socio-sanitarios. } \\
\text { 3. Servicios para la enogastronomía y los hoteles. } \\
\text { 4. Servicios comerciales. }\end{array}$ \\
\hline Sector industria y artesanía & $\begin{array}{l}\text { 1. Producciones artesanas e industriales. } \\
\text { 2. Manutención y asistencia técnica. }\end{array}$ \\
\hline
\end{tabular}

Fuente: Regolamento degli Istituti Professionali del DPR 87/2010. 
La validación de competencias profesionales en España e Italia

\subsubsection{La educación y formación profesional (IeFP)}

Como ya hemos comentado, la IeFP es competencia de las regiones. Estas pueden poner en marcha este tipo de formación a través de agencias formativas acreditadas y de escuelas involucradas en cursos de tres años de IeFP.

Para poder acceder a los cursos de IeFP el alumno debe haber superado la escuela secundaria de primer grado y tener (para la inscripción al primer año) una edad inferior a 15 años. Para aquellos que se incorporen a través de las pasarelas en años sucesivos la edad máxima consentida es de 17 años.

Los cursos de IeFP tienen que tener al menos una duración de tres años, deben contener disciplinas y actividades relacionadas con la formación cultural general y con las áreas profesionales específicas del campo que se imparte. Asimismo tienen que conducir a la adquisición de una cualificación profesional reconocida a nivel nacional y corresponder al menos al nivel II del Marco Europeo de Cualificaciones (EQF) (ver subapartado 4.1.4).

El sistema italiano educativo de instrucción y formación profesional (IeFP) se organiza en:

- estudios de tres años tras los que el alumno obtiene un título de una cualificación.

- estudios de cuatro años tras los que el alumno obtiene un diploma profesional.

Para facilitar la validez nacional de las cualificaciones se aprobó el Stato Regioni de 29 de abril de 2010. Este acuerdo, además de regular los cursos que permiten obtener los títulos de cualificación y los diplomas profesionales de tres y cuatro años de duración respectivamente, también define 21 figuras profesionales para ambas opciones a nivel nacional.

Este segundo ciclo educativo-formativo está destinado al crecimiento educativo, cultural y profesional de los jóvenes a través de los tres saberes promulgados por la UE, el "saber", el "saber hacer" y el "saber actuar" y la reflexión crítica de sí mismos para poder desarrollar su capacidad autónoma de juicio y el ejercicio de la responsabilidad personal y social (Ley 53, 2003).

\subsubsection{La Educación y Formación Técnica Superior}

La educación y formación técnica superior ha sido objeto de una reforma realizada a través de diferentes intervenciones legislativas, en especial a tra- 
vés del Decreto Presidencial del Consejo de Ministros de 25 de enero de 2008. Este decreto se encargó de reorganizar las enseñanzas de la educación y formación técnica superior (IFTS-Istružione e Formazione Tecnica Superiore) y de instaurar los Institutos Técnicos Superiores (ITS-Istituti Tecnici Superiori).

\section{- Educación y formación técnica superior (IFTS)}

Estos cursos nacieron en 1999 con el objetivo de preparar para profesiones intermedias, entre el segundo ciclo educativo y la universidad.

Normalmente tienen una duración de dos semestres, con un total de $800 / 1000$ horas. Su objetivo es ofrecer a jóvenes y adultos la oportunidad de especializarse como técnicos en la innovación de procesos y productos, a través de un conocimiento y formación técnica más concreta y específica. Pretenden acelerar el ingreso de los jóvenes en el mundo del trabajo y recualificar a quien ya tiene una experiencia laboral (D.P.C.M, 2008).

Los cursos de IFTS están relacionados con 49 figuras profesionales, con su correspondiente definición de estándares mínimos. ${ }^{51}$ Estas figuras están encuadradas en los sectores económicos de agricultura; ambiente; construcción; ICT (Information and communication technology); industria y artesanía; transportes y turismo (MIUR, 2008).

Los IFTS son programados por las regiones y diseñados y gestionados por al menos cuatro sistemas de formación, la escuela, la formación profesional, la universidad y la empresa.

Al terminar este tipo de formación se otorga a los alumnos una certificación de especialización técnico superior, válida a nivel nacional (Isfol et al., 2012).

\section{- Institutos Técnicos Superiores (ITS)}

Los ITS son escuelas de alta especialización tecnológica, tienen el objetivo de dar respuesta a la demanda de las empresas con nuevas y elevadas competencias técnicas y tecnológicas.

51 Estas figuras profesionales fueron definidas por varios acuerdos entre el Estado y las regiones italianas: Acuerdo de 29 de abril de 2004; Acuerdo de 16 de marzo de 2006 y Acuerdo de 28 de febrero de 2008. 
La validación de competencias profesionales en España e Italia

Estos institutos forman técnicos superiores en las áreas tecnológicas estratégicas para el desarrollo económico y la competitividad. Se constituyen en una fundación de participación que comprende escuelas, entes de formación, empresas, universidades y centros de investigación y entes locales (MIUR, 2009).

Este tipo de formación tiene una duración de 1.800/2.000 horas de cuales el 30\% está dedicado a prácticas.

El Decreto Interministerial de 7 de septiembre de 2011 identificó y describió 29 figuras nacionales de referencia para los cursos ITS (estas figuras fueron modificadas posteriormente por el Decreto Interministerial de 5 de febrero de 2013).

Las áreas tecnológicas de los ITS establecidas por el decreto de 2011son las siguientes:

- eficiencia energética;

- movilidad sostenible;

- nuevas tecnologías de la vida;

- nuevas tecnologías "made in Italy";

- tecnologías innovadoras para los bienes y las actividades culturales;

- tecnologías de la información y de la comunicación.

Se permite al acceso a los cursos de los ITS y a las vías de IFTS a jóvenes y adultos en posesión del diploma de educación secundaria superior. Además, a las vías IFTS pueden acceder aquellos que hayan completado estudios de cuatro años, logrando un diploma profesional o estando en posesión de la admisión al quinto año de un liceo; aquellos que hayan obtenido el diploma de educación secundaria superior, previa acreditación de las competencias adquiridas en precedentes vías de educación, formación y trabajo, sucesivas al cumplimiento de la educación obligatoria. (Isfol et al., 2012).

\subsubsection{El apprendistato}

El apprendistato es un contrato de trabajo que tiene el objetivo de formar y ayudar a los jóvenes a encontrar trabajo. Fue modificado por el Decreto Legislativo 167/2011. Este tipo de formación puede ser de tres tipos (Decreto Legislativo 167, 2011): 
Los sistemas educativos y de formación profesional en España y en Italia

a) apprendistato para la cualificación y el diploma profesional: está dirigido a jóvenes de edades comprendidas entre los 15 y los 25 años. Estos jóvenes pueden ser contratados en cualquier sector profesional. Este aprendistato tiene una duración máxima de tres años para el logro de la cualificación y de cuatro años para la adquisición del diploma profesional. Este tipo de apprendistato puede ser utilizado por el alumno para completar el periodo de educación obligatoria;

b) apprendistato professionalizante o contrato de trabajo: está dirigido a jóvenes de edades comprendidas entre los 18 y los 29 años. Este contrato también se puede hacer en todos los sectores profesionales. Tiene el objetivo de transmitir competencias profesionales. Un contrato de este tipo tiene una duración máxima de tres años;

c) apprendistato de alta formación y de investigación: está dirigido a jóvenes de entre 18 y 29 años, estos pueden ser contratados en todos los sectores profesionales, públicos o privados. Este tipo de apprendistato está dirigido a la obtención de títulos de estudio de educación superior (una certificación IFTS/ITS y títulos universitarios, incluido el doctorado), así como a la obtención de experiencias profesionales de investigación. La duración de este tipo de contrato depende de los acuerdos entre las universidades y las regiones.

\subsubsection{La formación continua}

En Italia la formación profesional continua está a cargo de las regiones y provincias, estas se encargan de realizar convocatorias públicas para la financiación de cursos a todos los niveles (post-escuela obligatoria, postdiploma, post-título universitario, actualización, inserción e reinserción en el mercado laboral). Dichos cursos, en su mayoría gratuitos para los participantes, permiten adquirir competencias y cualificaciones requeridas por el mercado de trabajo, favoreciendo el paso de la escuela a la formación y posteriormente al mundo laboral, o garantizando a los que ya trabajan mayor competitividad.

Las disposiciones legislativas relacionadas con la formación profesional continua a nivel nacional son el artículo 9 de la L. 236/1993 y el artículo 6 de la L.53/2000. Estas leyes prevén el reparto anual de recursos a favor de las regiones, que a su vez convocan a empresas y a trabajadores para la financiación de planes formativos en empresa y fuera de ella. 
La validación de competencias profesionales en España e Italia

Además, las empresas pueden recurrir a la adhesión de uno de los fondos interprofesionales para la formación continua, para la formación de sus trabajadores.

Las actividades de formación continua financiadas públicamente son puestas en práctica por empresas y organizaciones públicas y privadas; entes y organismos formativos y organismos de tipo institucional.

En general, no existen principios sobre la organización de las actividades formativas respecto a la duración, modalidad y lugar de la formación (Isfol et al., 2012).

\subsubsection{LA FORMACIÓN PROFESIONAL EN EMILIA-ROMAGNA}

Para hablar de la formación profesional en Emilia-Romagna tenemos que hablar de su principal instrumento, el Sistema Regional de Cualificaciones (en adelante, en sus siglas en italiano SRQ- Sistema Regionale delle Qualifiche). Se trata de un repertorio que contiene, entre otros aspectos, las cualificaciones (entendidas como títulos) relacionadas con las figuras profesionales ${ }^{52} \mathrm{y}$ las competencias profesionales ${ }^{53}$ más extendidas en el sistema productivo de Emilia Romagna. Las cualificaciones están clasificadas según el área profesional al que pertenecen, y están definidas en coherencia con las indicaciones europeas y nacionales vigentes. En el Anexo 1 puede verse el repertorio de las cualificaciones regionales de Emilia-Romagna clasificadas por áreas profesionales.

El SRQ representa una parte relevante del sistema profesional emiliano-romagnolo y tiene sus propios códigos de identificación (áreas profesionales, cualificaciones y competencias). Por ello, el SRQ se utiliza en diferentes ámbitos y con diversos objetivos, como veremos en el subapartado 4.3.8.2.

52 Figura profesional entendida como un conjunto de actividades laborales realizadas en procesos de trabajo similares y relacionados con competencias profesionales homogéneas (Emilia-Romagna, 2007, p. 66).

53 Competencias profesionales entendidas como el conjunto integrado de capacidades y conocimientos necesarios para actuar y realizar eficazmente actividades profesionales (Emilia-Romagna, 2007, p. 66). 
En Emilia-Romagna las leyes regionales 12/2003 y 5/2011 establecen los objetivos a los que deben tender las siguientes intervenciones formativas de la región:

- itinerarios de educación y formación profesional (Istruqione e Formazione Professionale) (en adelante, en sus siglas en italiano IeFP) dirigidos a jóvenes de entre 14 y 18 años que busquen alcanzar un elevado nivel cultural y unas competencias generales y específicas necesarias para una adecuada inserción en el mudo laboral;

- una formación inicial compuesta por cursos de formación planificados para la obtención de cualificaciones (recogidas en el SRQ) orientadas a la inserción en el mundo laboral;

- una formación superior referida a cursos de formación dirigidos a la obtención de cualificaciones (recogidas en el SRQ) enfocadas a proporcionar un conocimiento técnico-especializado.

- una formación continua dirigida a trabajadores ocupados, con la intención de facilitar la actualización de las competencias que requieren los nuevos procesos productivos y organizativos, y así facilitar la adaptación del trabajador a las nuevas condiciones de trabajo (Emilia-Romagna, 2007).

Por ello, Emilia-Romagna ha estructurado su oferta formativa para la obtención de una cualificación regional, distinguiendo tres niveles generales de cursos. A cada nivel le corresponde unas cualificaciones determinadas del SRQ, dichas cualificaciones han sido clasificadas según el grado de complejidad de las competencias que las componen. De este modo la formación profesional de Emilia-Romagna se organiza en:

- cursos dirigidos al desarrollo de competencias pertenecientes a títulos de cualificación que dan acceso al mundo laboral;

- cursos dirigidos al desarrollo de competencias pertenecientes a títulos de cualificación que dan acceso al mundo profesional y proporcionan una profundización técnico-especializada;

- cursos dirigidos al desarrollo de competencias pertenecientes a títulos de cualificación que proporcionan una profundización técnicoespecializada.

Además se han definido tres títulos de cualificación, estetista, operador socio-sanitario y peluquero, regulados por la legislación nacional. 
La validación de competencias profesionales en España e Italia

Cabe también señalar que Emilia-Romagna ofrece otro tipo de fornación no asociada al SRQ, como cursos de formación profesional continua. Esta formación es programada por la Regione ${ }^{54}$ en forma de actividades gratuitas para personas ocupadas y en situación de desempleo. Los cursos formativos están relacionados con las características del mercado laboral regional, tienen el objetivo de dotar a los trabajadores de los conocimientos y las competencias requeridas por el sistema económico-productivo y de aumentar su empleabilidad. Estas actividades formativas están financiadas fundamentalmente por el Fondo Social Europeo, pero también por fondos nacionales y regionales.

Asimismo, la Regione de Emilia-Romagna cuenta con una oferta formativa de enseñanzas reguladas a nivel estatal, como el apprendistato, la IFTS, los ITS o la alta formación relacionada con doctorados e investigación (Balboni, 2011).

\subsubsection{El Sistema Regional de Educación y Formación Profesional-Istruzione e Formazione Professionale (IeFP)}

El nacimiento del nuevo Sistema Regional de Educación y Formación Profesional (IeFP) se debe a un complejo recorrido constituido por numerosas normativas. Concretamente se sitúa en el marco del cumplimiento de la Ley Constitucional 3/2001, que redefinió el ya mencionado capítulo V de la Constitución (Balboni, 2011, p. 22).

En el año 2011 la Ley Regional 5/2011 instituyó en la Región de Emilia-Romagna, el sistema regional de educación y formación profesional (IeFP).

La región tiene la función de programar y organizar este sistema. Como hemos comentado, el artículo 117 de la constitución italiana otorga a las regiones la competencia legislativa exclusiva en este tipo de educaciónformación.

En general, y como hemos explicado en el subapartado 3.2.2.2, estos sistemas de IeFP ofrecen cursos de tres años para la obtención de un título

${ }^{54}$ Hablamos de Regione (en mayúscula y cursiva) cuando nos referimos al organismo dotado de capacidad de autogobierno y articulado en varios servicios y oficinas, con sedes y direcciones diversas. 
de cualificación y estudios de cuatro años para adquirir el diploma profesional. Sin embargo, en Emilia-Romagna solamente se han desarrollado cursos del primer tipo, es decir de tres años de duración.

En esta región existe el llamado "trienio unitario", consistente en la programación conjunta de cursos de tres años de duración del Sistema Regional de IeFP, por parte de institutos profesionales ${ }^{55}$ y entes de formación profesional ${ }^{56}$ acreditados por la Regione. ${ }^{57}$ Es decir, que los institutos y los entes de formación colaboran estrechamente en la realización de los cursos y otorgan el mismo título de cualificación profesional regional, aunque adoptan modalidades didácticas diversas.

Una vez que los alumnos interesados en obtener una cualificación profesional terminan la escuela secundaria de primer grado deben inscribirse, durante el primer año, a un instituto profesional. Este primer año tiene un fuerte componente orientativo para ayudar a los estudiantes a decidir la vía por la que continuar su formación, deben elegir entre completar los tres años en el instituto profesional o en un ente formativo acreditado por la Regione Emilia-Romagna.

Estos cursos de tres años de duración (realizados en el ente formativo regional o en el instituto profesional) pretenden dotar a los estudiantes de conocimientos y competencias indispensables para poder cumplir con la enseñanza obligatoria. Asimismo, tienen el objetivo de preparar a jóvenes en la planificación de su futuro en el mundo laboral como trabajadores cualificados y en la sociedad como ciudadanos bien formados.

El título de cualificación que se otorga a los alumnos tras superar estos tres años permite el acceso directo al mundo laboral. Sin embargo, el hecho de elegir esta vía formativa no excluye la posibilidad al alumno de seguir formándose. Este tiene dos posibilidades:

- seguir los estudios formativos en el instituto profesional hasta el quinto año (los alumnos que hayan logrado el título de la cualifica-

55 De regulación estatal.

56 De regulación regional.

57 Todos los centros de formación deben estar acreditados por la Regione. Esta debe comprobar que los centros cumplen con los estándares mínimos que establece el Estado para poder acreditarles como centros de formación. 
La validación de competencias profesionales en España e Italia

ción a través de un ente formativo acreditado por la región, y quieran pasar al instituto profesional, deberán realizar un examen);

- especializarse y mejorar su profesionalidad a través de las oportunidades formativas que ofrece el sistema regional (Balboni, 2011).

\section{Esquema 4: Trienio unitario de leFP en Emilia-Romagna}

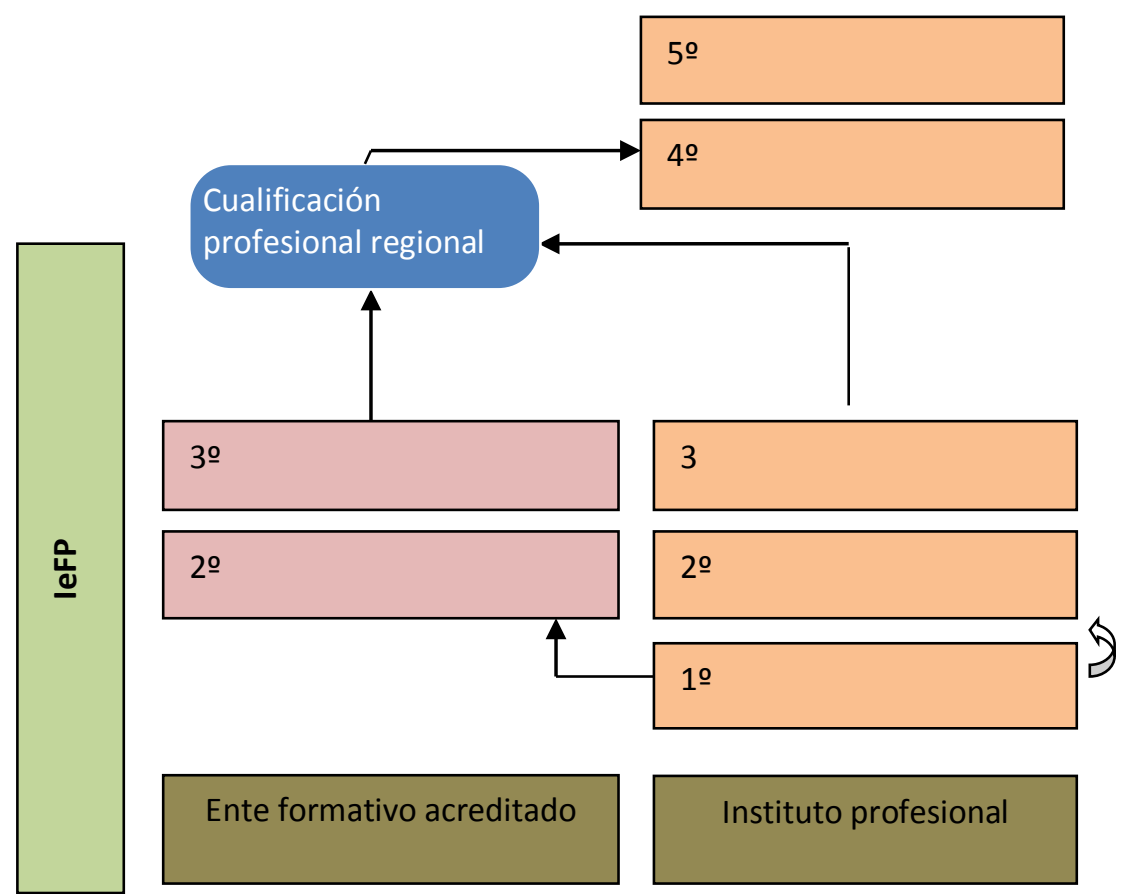

- Correlaciones entre los títulos de cualificación de la IeFP y las figuras profesionales nacionales

Para poder delinear el Sistema Regional de IeFP, la Regione de EmiliaRomagna ha establecido equivalencias entre las 21 figuras profesionales de referencia nacional para los sistemas regionales de IeFP (establecidas, como hemos visto, por el Acuerdo Stato-Regioni del 29 de abril de 2010) y los títulos de cualificación que pueden lograrse con la IeFP en EmiliaRomagna.

Así pues, con la Deliberación 1776/2010 y modificaciones e integraciones posteriores se aprobó la correlación entre las cualificaciones 
regionales, presentes en el repertorio del SRQ, y las figuras nacionales. Podemos ver esta correlación en el Anexo 2:

- estableciendo que dichas cualificaciones deben ser la única referencia para escuelas y entes de formación que trabajan en el ámbito del sistema regional de IeFP;

- aprobando los estándares obligatorios para aquellos que planifiquen y realicen itinerarios formativos (descripciones de las cualificaciones profesionales regionales, compuestas por los elementos necesarios para garantizar el pleno reconocimiento nacional);

- estableciendo que sobre los certificados de cualificación aparezca la denominación del título de cualificación profesional regional de tercer nivel europeo EQF y la figura nacional en correlación. 
La validación de competencias profesionales en España e Italia

\subsection{Comparación y conclusiones}

Con este apartado pretendemos hacer una breve comparación entre los sistemas nacionales educativos y de formación profesional de España e Italia. Asimismo, comparamos la formación profesional en Castilla y León y en Emilia-Romagna.

\subsubsection{DIFERENCIAS Y SIMILITUDES ENTRE LOS SISTEMAS EDUCATIVOS DE ESPAÑA E ITALIA}

A través de la observación de las estructuras de los sistemas educativos español e italiano hemos decido tomar como punto de referencia, para la comparación de estos, los siguientes niveles educativos: un nivel no obligatorio; un primer nivel educativo; un segundo nivel educativo y un nivel superior educativo.

Como se puede observar (ver Cuadro 5), en general las estructuras de los dos sistemas son bastante similares. Hasta el final de la educación primaria de ambos la estructura es prácticamente la misma, exceptuando que en Italia la educación de la infancia en el marco del MIUR inicia a los 3 años edad, pudiendo antes cursarse (de 0 a 3 años) el asilo-nido (ajeno a la responsabilidad del MIUR).

En cuanto a la educación primaria encontramos otra diferencia, ya que este tipo de formación dura un año menos en Italia que en España.

Tras este tipo de enseñanza da comienzo en estos países la primera parte de la educación secundaria, que en Italia tiene tres años de duración (de los 11 a los 14 años) y en España cuatro (de los 12 a los 16).

Al terminar estos estudios, los alumnos de Italia y España comienzan la segunda parte de la educación secundaria. En Italia deben decidir si quieren continuar sus estudios por la vía académica (institutos técnicos, institutos profesionales y liceos), de regulación estatal y de cinco años de duración, o por una vía más profesional (IeFP), de regulación regional y normalmente de tres o cuatro años de duración. Por otro lado, en España deberán escoger en $3^{\circ}$ de ESO y a la edad de 14 años, como en Italia, si pretenden seguir sus estudios en bachillerato (opción más académica) de dos años de duración o en la FP de grado medio (opción más profesional). 
También en algunos casos existirá la posibilidad de cursar la formación profesional básica.

Como podemos comprobar en ambos países los alumnos deberán decidir a los 14 años de edad siguen su formación por la vía académica o por la profesional.

En cuanto a la educación superior, tanto España como Italia acogen enseñanzas de alta formación profesional en la opción no universitaria. Respecto a la educación universitaria, ambas naciones se rigen por el Plan Bologna, aunque con distintas formas. España, adopta la modalidad de grado (cuatro años), máster y doctorado, e Italia la de 3+2 (estudios de tres años, más dos de especialización) y doctorado. 
Cuadro 5: Cuadro comparativo de los sistemas educativos español e italiano

\begin{tabular}{|c|c|c|c|c|c|c|}
\hline $\begin{array}{l}\text { NIVEL } \\
\text { EDUCATIVO }\end{array}$ & \multicolumn{3}{|l|}{ ESPAÑA } & \multicolumn{3}{|l|}{ ITALIA } \\
\hline \multirow{3}{*}{$\begin{array}{l}\text { Nivel superior } \\
\text { educativo }\end{array}$} & Universitaria & $\begin{array}{l}\text {-Doctorado } \\
\text {-Máster } \\
\text {-Grado }\end{array}$ & \multirow{3}{*}{$\begin{array}{l}\text { Estatal } \\
\text { (Ministerio } \\
\text { de Educa- } \\
\text { ción, } \\
\text { Cultura y } \\
\text { Deporte }\end{array}$} & Universitaria & $\begin{array}{l}\text {-Doctorado } \\
\text {-Laurea magistrale(+2 } \\
\text { años) } \\
\text {-Laurea triennale(3 años) }\end{array}$ & $\begin{array}{l}\text { Estatal } \\
\text { (MIUR) }\end{array}$ \\
\hline & \multirow{2}{*}{$\begin{array}{l}\text { NO } \\
\text { universitaria }\end{array}$} & \multirow{2}{*}{$\begin{array}{l}\text {-FP grado superior } \\
\text {-Técnico deportivo de grado } \\
\text { superior y grado superior de } \\
\text { artes plásticas y diseño } \\
\text {-Enseñanzas artísticas supe- } \\
\text { riores }\end{array}$} & & \multirow{2}{*}{$\begin{array}{l}\text { NO universi- } \\
\text { taria }\end{array}$} & IFTS & $\begin{array}{l}\text { Sistema } \\
\text { integrado } \\
\text { Regional } \\
\text { Estatal } \\
\text { (MIUR) }\end{array}$ \\
\hline & & & & & $\begin{array}{l}\text { ITS } \\
\text { AFAM } \\
\text { Institutos con fines especí- } \\
\text { ficos }\end{array}$ & $\begin{array}{l}\text { Estatal } \\
\text { (MIUR) }\end{array}$ \\
\hline
\end{tabular}


Los sistemas educativos y de formación profesional en España y en Italia

\begin{tabular}{|l|l|l|l|l|}
\hline & $\begin{array}{l}\text {-Técnico deportivo de grado medio y grado } \\
\text { medio de artes plásticas y diseño } \\
\text {-Enseñanzas artísticas profesionales }\end{array}$ & -leFP (de 3 o 4 años de duración) & Regional \\
\hline $\begin{array}{l}1^{\text {er }} \text { nivel } \\
\text { educativo }\end{array}$ & $\begin{array}{l}\text {-ESO (12-16 años)(en 3o rama para FP o } \\
\text { Bachillerato). } \\
\text {-Formación Profesional Básica } \\
\text {-Educación primaria (6-12 años) }\end{array}$ & $\begin{array}{l}\text {-Escuela secundaria de 1 } \\
14 \text { años) } \\
\text {-Escuela primaria (6-11 años) }\end{array}$ & $\begin{array}{l}\text { Estatal } \\
\text { (MIUR) }\end{array}$ \\
\hline $\begin{array}{l}\text { Nivel no obliga- } \\
\text { torio }\end{array}$ & -Educación infantil (0-6 años) & -Escuela de la infancia (3-6 años) \\
\hline
\end{tabular}




\subsubsection{DIFERENCIAS Y SIMILITUDES ENTRE LOS SISTEMAS DE FORMACIÓN PROFESIONAL DE ESPAÑA E ITALIA}

Para la comparación de los sistemas de formación profesional hemos tomado como punto de referencia dos tipos de formación que por sus características coinciden en ambos países, la denominada, en España, formación inicial (enfocada a la primera entrada en el mundo laboral), que a su vez hemos subdividido en 3 niveles, y la dirigida a trabajadores ocupados y desocupados, que hemos llamado formación continua.

$\mathrm{Al}$ igual que ocurre con los sistemas educativos, los sistemas de formación profesional de estos países también presentan una estructura similar (ver Cuadro 6), aunque con algunas diferencias destacables.

En España se ha instaurado recientemente la formación profesional básica (FPB), los alumnos pueden acceder a ella con 14 años, la misma edad a la que en Italia acceden a la IeFP o a los institutos profesionales. Sin embargo, este tipo de formación italiana es más variado y de más duración que la FPB española, ya que la FP inicial, que hemos considerado de primer nivel en Italia, tiene una duración de tres años y presenta dos modalidades (institutos profesionales o IeFP), frente a los dos años de la FPB española.

España también ofrece otro tipo de formación profesional inicial de más nivel, la FP de grado medio y superior, esta última equiparable a la educación y formación técnica superior italiana. En cuanto a la FP de grado medio española, se accede a ella como mínimo con 16 años. Si la comparamos con la FP italiana del mismo nivel (institutos profesionales e IeFP de cinco y cuatro años de duración respectivamente), al igual que ocurre en el primer nivel de FP inicial, esta última ofrece más opciones y es de más duración.

En cuanto a la FP continua, podemos señalar que ambos países dirigen esta formación tanto a ocupados como a desocupados.

Asimismo, observamos que ambos sistemas cuentan con contratos de formación, llamado formación dual en España (de reciente incorporación) y apprendistato en Italia, abarcando este último un mayor número de enseñanzas respecto a España, comprendiendo incluso los estudios de doctorado (Decreto Legislativo 167, 2011). Sin embargo, en España la FP dual se con- 
templa también en la FP continua, mientras que en Italia pertenece solo a la inicial.

Cuadro 6: Cuadro comparativo de los sistemas de formación profesional español e italiano

\begin{tabular}{|c|c|c|c|c|c|}
\hline $\begin{array}{l}\text { Tipo de } \\
\text { formación }\end{array}$ & $\begin{array}{l}\text { Nivel } \\
\text { formativo }\end{array}$ & ESPAÑA & & ITALIA & \\
\hline & & Formación & $\begin{array}{l}\text { Organismo } \\
\text { competente }\end{array}$ & Formación & $\begin{array}{l}\text { Organismo } \\
\text { competente }\end{array}$ \\
\hline $\begin{array}{l}\text { FP conti- } \\
\text { nua }\end{array}$ & $\begin{array}{l}\text { Ocupados, } \\
\text { desocupados, } \\
\text { 1er empleo }\end{array}$ & $\begin{array}{l}\text { Formación } \\
\text { profesional } \\
\text { para el } \\
\text { empleo } \\
\text {-(FP dual) } \\
\text { (1 a } 3 \\
\text { años) }\end{array}$ & $\begin{array}{l}\text { Estatal (Mi- } \\
\text { nisterio de } \\
\text { Empleo y } \\
\text { Seguridad } \\
\text { Social) }\end{array}$ & FP continua & $\begin{array}{l}\text { Sistema } \\
\text { integrado } \\
\text { Regional y } \\
\text { Estatal } \\
\text { (MIUR) }\end{array}$ \\
\hline \multirow{6}{*}{ FP inicial } & FP de nivel & $\begin{array}{l}\text {-FP supe- } \\
\text { rior } \\
\text { ( } 2 \text { años de } \\
\text { duración) }\end{array}$ & \multirow{6}{*}{$\begin{array}{l}\text { Estatal (Mi- } \\
\text { nisterio de } \\
\text { Educación, } \\
\text { Cultura y } \\
\text { Deporte) }\end{array}$} & IFTS & $\begin{array}{l}\text { Sistema } \\
\text { integrado } \\
\text { Regional y } \\
\text { Estatal } \\
\text { (MIUR) }\end{array}$ \\
\hline & superior & $\begin{array}{l}\text {-(FP dual) } \\
(3 \text { años } \\
\text { máx.) }\end{array}$ & & $\begin{array}{l}\text { ITS } \\
\text { (Apprendistato } \\
\text { superior) }\left(^{* *}\right) \\
\text { (duración variable) }\end{array}$ & \multirow{2}{*}{$\begin{array}{l}\text { Estatal } \\
\text { (MIUR) }\end{array}$} \\
\hline & \multirow{3}{*}{$2^{\circ}$ Nivel } & \multirow{3}{*}{$\begin{array}{l}\text {-FP media } \\
\text { ( } 2 \text { años) } \\
\text {-(FP dual) } \\
(3 \text { años } \\
\text { máx.) }\end{array}$} & & $\begin{array}{l}\text {-Institutos profesio- } \\
\text { nales } \\
\text { (5 años) }\end{array}$ & \\
\hline & & & & -leFP (4 años) & Regional \\
\hline & & & & $\begin{array}{l}\text {-(Apprendistato } \\
\text { professionalizante) } \\
\text { (3 años máx.) }\end{array}$ & \multirow{2}{*}{$\begin{array}{l}\text { Estatal } \\
\text { (MIUR) }\end{array}$} \\
\hline & 1er Nivel & $-\mathrm{PCPI}\left({ }^{*}\right)$ & & $\begin{array}{l}\text {-Institutos profesio- } \\
\text { nales }\end{array}$ & \\
\hline
\end{tabular}


La validación de competencias profesionales en España e Italia

\begin{tabular}{|l|l|l|l|l|}
\hline $\begin{array}{l}\text { Tipo de } \\
\text { formación }\end{array}$ & $\begin{array}{l}\text { Nivel } \\
\text { formativo }\end{array}$ & ESPAÑA & \multicolumn{2}{l|}{ ITALIA } \\
\hline & $\begin{array}{l}\text {-FP básica } \\
\text { (ambas, 2 } \\
\text { años) }\end{array}$ & & (3 años) & Regional \\
\cline { 3 - 5 } & & $\begin{array}{l}\text {-leFP (3 años) } \\
\text {-(Apprendistato de } \\
\text { educación obligato- } \\
\text { ria) } \\
\text { (3 años máx. })\end{array}$ & $\begin{array}{l}\text { Estatal } \\
\text { (MIUR) }\end{array}$ \\
\hline
\end{tabular}

() Contrato formativo. - $\left(^{*}\right)$ En vías de extinción - $\left(^{* *}\right)$ Incluye todo el nivel universitario

Como gran diferencia entre estos sistemas nos parece importante destacar que todo el sistema educativo-formativo profesional español es de competencia estatal, mientras que en Italia la formación profesional (IeFP) está en manos de las regiones.

\subsubsection{DIFERENCIAS Y SIMILITUDES ENTRE LOS SISTEMAS DE FORMACIÓN PROFESIONAL DE CASTILLA Y LEÓN Y EMILIA-ROMAGNA}

En esta ocasión hemos mantenido casi intacto el esquema anterior, ya que la situación cambia muy poco respecto a la estructura de los sistemas de formación profesional nacional (ver Cuadro 7).

Tanto Castilla y León como Emilia-Romagna procuran la formación profesional que se establece en los sistemas nacionales, en el ámbito de sus competencias y según su capacidad de decisión respecto a las enseñanzas que ofrecen. En Italia el poder de decisión de las regiones es mucho mayor que en España el de las comunidades autónomas, debido a que, como hemos comentado, las regiones italianas tienen competencia exclusiva en materia de formación profesional.

Los alumnos de ambos territorios acceden al primer nivel de la FP inicial con 14 años, siendo este tipo de formación, más variado y de más duración en Emilia-Romagna que en Castilla y León.

En cuanto a la FP inicial considerada de segundo nivel, en Castilla y León hablamos de FP de grado medio de dos años de duración y en EmiliaRomagna hacemos referencia a los institutos profesionales y a la IeFP, ambos de tres años de duración, ya que la IeFP de cuatro años que veíamos en 
los sistemas educativos y de formación profesional en España y en Italia

el cuadro anterior (ver Cuadro 6) no se lleva a cabo en Emilia-Romagna. A pesar de esta reducción en la IeFP de Emilia-Romagna, también en esta ocasión podemos afirmar que la FP en este nivel ofrece más vías y es de más duración en Emilia-Romagna que en Castilla y León.

En cuanto al nivel de FP superior y de FP continua en estos territorios, se mantiene sin cambios respecto al anterior cuadro (ver Cuadro 6).

Respecto a los contratos de formación, al igual que en el plano nacional, podemos decir que en Castilla y León son de menor duración respecto a los de Emilia-Romagna, en cualquiera de sus modalidades, y que los primeros abarcan menos nivel de estudios que los segundos. Sin embargo, también hay que señalar que en Castilla y León se ofrece una FP dual en la FP Continua que en Emilia-Romagna no se contempla. 
La validación de competencias profesionales en España e Italia

Cuadro 7: Cuadro comparativo de los sistemas de formación profesional de Castilla y León y de Emilia-Romagna

\begin{tabular}{|c|c|c|c|c|c|}
\hline $\begin{array}{l}\text { Tipo de } \\
\text { formación }\end{array}$ & $\begin{array}{l}\text { Nivel formati- } \\
\text { vo }\end{array}$ & CASTILLA Y & EÓN & EMILIA-ROMAGNA & \\
\hline & & Formación & Organismo & Formación & Organismo \\
\hline $\begin{array}{l}\text { FP conti- } \\
\text { nua }\end{array}$ & $\begin{array}{l}\text { Ocupados, } \\
\text { desocupados, } \\
\text { 1'er empleo }\end{array}$ & 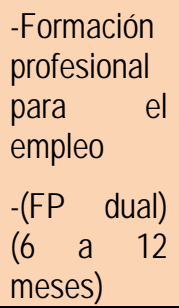 & $\begin{array}{l}\text { Estatal } \\
\text { (Ministerio } \\
\text { de Empleo y } \\
\text { Seguridad } \\
\text { Social) }\end{array}$ & FP continua & $\begin{array}{l}\text { Sistema } \\
\text { integrado } \\
\text { Regional } \\
\text { (Regione E- } \\
\text { R) y Estatal } \\
\text { (MIUR) }\end{array}$ \\
\hline \multirow{6}{*}{ FP inicial } & \multirow{2}{*}{$\begin{array}{l}\text { FP de nivel } \\
\text { superior }\end{array}$} & \multirow{2}{*}{$\begin{array}{l}\text {-FP superior } \\
\text { ( } 2 \text { años) } \\
\text {-(FP dual) } \\
\text { (1 año) }\end{array}$} & \multirow{6}{*}{$\begin{array}{l}\text { Estatal } \\
\text { (Ministerio } \\
\text { de Educa- } \\
\text { ción, Cultura } \\
\text { y Deporte }\end{array}$} & IFTS & $\begin{array}{l}\text { Sistema } \\
\text { integrado } \\
\text { Regional y } \\
\text { Estatal } \\
\text { (MIUR) } \\
\end{array}$ \\
\hline & & & & $\begin{array}{l}\text { ITS } \\
\text { (Apprendistato } \\
\text { superior) }\left(^{* *}\right) \\
\text { (duración variable) }\end{array}$ & \multirow{2}{*}{$\begin{array}{l}\text { Estatal } \\
\text { (MIUR) }\end{array}$} \\
\hline & \multirow{3}{*}{$2^{0}$ Nivel } & \multirow{3}{*}{$\begin{array}{l}\text {-FP media } \\
\text { (2 años) } \\
\text {-(FP dual) } \\
\text { (1 año) }\end{array}$} & & $\begin{array}{l}\text {-Institutos profe- } \\
\text { sionales } \\
\text { ( } 5 \text { años de dura- } \\
\text { ción) }\end{array}$ & \\
\hline & & & & -le FP (4 años) & $\begin{array}{l}\text { Regional } \\
\text { (Regione E- } \\
\text { R) }\end{array}$ \\
\hline & & & & $\begin{array}{l}\text {-(Apprendistato } \\
\text { professionalizante) } \\
\text { (3 años máx.) }\end{array}$ & \multirow{2}{*}{$\begin{array}{l}\text { Estatal } \\
\text { (MIUR) }\end{array}$} \\
\hline & 1er Nivel & $-\mathrm{PCPI}\left({ }^{\star}\right)$ & & $\begin{array}{l}\text {-Institutos profe- } \\
\text { sionales }\end{array}$ & \\
\hline
\end{tabular}


los sistemas educativos y de formación profesional en España y en Italia

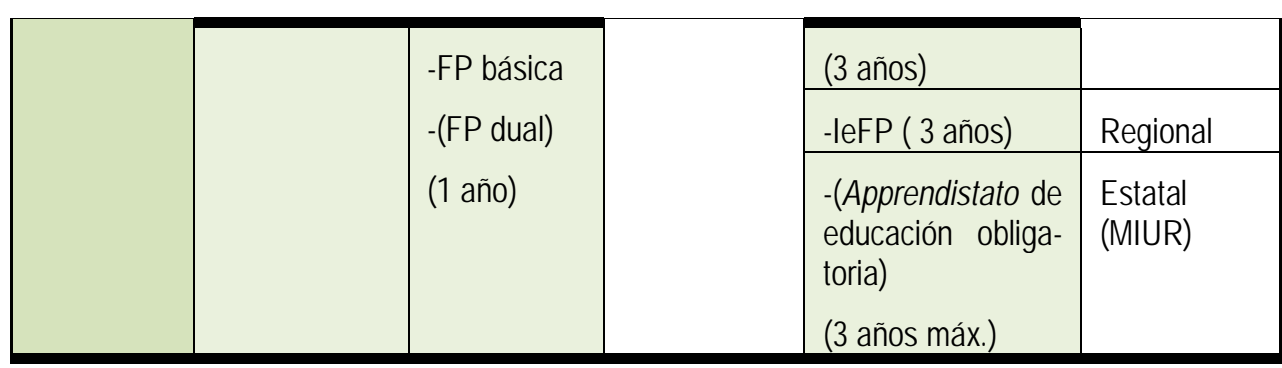

No se ofrece este tipo de enseñanza.

() Contrato formativo. $\left(^{*}\right)$ En vías de extinción. $\left(^{* *}\right.$ Incluye todo el nivel universitario. 
La validación de competencias profesionales en España e Italia 


\section{La validación de competencias profesionales}

Antes de comenzar este capítulo nos gustaría aclarar qué entendemos por validación de competencias profesionales.

Apoyándonos en la definición sobre validación que proporciona el actualmente el Cedefop, entendemos la validación de competencias profesionales como el proceso por el que un organismo autorizado confirma que una persona ha adquirido determinados resultados de aprendizaje (conocimientos, destrezas y/o competencias), obtenidos en un contexto no formal o informal, medidos respecto a un nivel pertinente. En este proceso se incluyen las fases de identificación, documentación, evaluación y certificación completa o parcial de los resultados (Cedefop, 2014). 
La validación de competencias profesionales en España e Italia

Asimismo, definimos certificación como el proceso de expedición de un certificado, diploma o título a través del cual el organismo competente acredita formalmente, según unas normas prefijadas, el conjunto de resultados de aprendizaje alcanzados por una persona (Cedefop, 2014).

Cuando hablamos de competencias profesionales tomamos como referencia el Real Decreto español 1224/2009, refiriéndonos a aprendizajes fruto de la experiencia laboral y de vías no formales de formación. Entendemos también que las competencias adquiridas en ámbito profesional son competencias informales. Por ese motivo, en el presente trabajo nos referimos a aprendizajes/competencias profesionales y a aprendizajes/ competencias no formales e informales de forma indistinta.

Asimismo, en nuestra investigación utilizamos de forma genérica el término de validación y certificación de competencias profesionales, o simplemente de validación de competencias profesionales (entendiendo que se incluye la certificación), con el fin de acortar y simplificar.

Sin embargo, cuando hablamos de forma específica de validación y certificación en España y en Castilla y León, utilizamos el término evaluación y acreditación de competencias, ya que es como se denomina en estos territorios. En cuanto a Italia, al no existir un procedimiento único nacional no tiene un nombre específico, por lo que hemos utilizado el término genérico de validación y certificación. Por otro lado, para hablar del procedimiento en Emilia-Romagna utilizamos su propia terminología: formalización y certificación.

Otro de los términos que consideramos de gran importancia aclarar es el de cualificación profesional, la entendemos, en su acepción europea, como los requisitos necesarios para el empleo, es decir, competencias, aptitudes y conocimientos adecuados para llevar a cabo determinadas tareas asociadas a un trabajo específico (Cedefop, 2014, p. 94). Cabe señalar que en Italia se utiliza el término de cualificación también para referirse a un título profesional.

Tras estas aclaraciones terminológicas pasamos a esbozar la estructura de este capítulo en el que podemos distinguir tres grandes apartados y uno más breve al final.

El primero de ellos está dedicado al recorrido, en ámbito europeo, sobre la evolución de la validación y certificación de competencias como 
herramienta del aprendizaje permanente para lograr una mejora socioeconómica.

El segundo se centra en la aparición y desarrollo de la validación de competencias profesionales en España, haciendo también hincapié en la puesta en marcha del procedimiento en Castilla y León.

El tercero está dirigido a los movimientos realizados en Italia con intención de crear un sistema nacional de validación de competencias profesionales. En el caso italiano, nos centramos en la región de EmiliaRomagna para presentar su procedimiento de formalización y certificación de competencias profesionales.

Por último, como hemos hecho en los capítulos anteriores, incluimos un apartado sobre comparación y conclusiones del capítulo. 
La validación de competencias profesionales en España e Italia

\subsection{La validación de competencias desde la Unión Europea}

En este apartado pretendemos mostrar las recomendaciones, estrategias y políticas emanadas desde Europa con la intención de impulsar la validación de competencias en los Estados miembro.

Los documentos europeos que hemos estudiado y exponemos en las siguientes páginas abarcan desde la última década del siglo XX hasta nuestros días, haciendo hincapié en la Cumbre de Lisboa y en los principales instrumentos del EQF (en adelante en sus siglas en inglés EQF-European Qualification Framework). Asimismo, al final del apartado hablamos de los últimos movimientos realizados para impulsar la validación de competencias profesionales y mencionamos la situación, en cuanto a la puesta en marcha de procedimientos de este tipo, de algunos países pertenecientes a la UE.

\subsubsection{ANTECEDENTES}

La validación de competencias profesionales aparece en la sociedad europea de forma paulatina y bajo una serie de circunstancias de continuo cambio y globalización, en la que los sistemas económicos, sociales y culturales se hacen cada vez más complejos. Como es de esperar, todo esto repercute en el mundo laboral exigiendo a los trabajadores otro tipo de cualificaciones y de preparación, impulsando el cambio en los conocimientos y en las competencias derivadas de estos.

Todos estos aspectos nos introducen en la idea del aprendizaje permanente (lifelong learning), que se empezó a considerar prioritaria, en los años 70, por la OSCE (Organización para la Seguridad y Cooperación Europea) y por la UNESCO ${ }^{58}$. Sin embargo, este término no cobró una fuerza relevante hasta el año 1995, con la publicación del Libro Blanco sobre "Educación y Formación" (Comisión de las Comunidades Europeas, 1995). Más tarde, esta idea se reafirmó con la proclamación, en 1996, del año europeo del

58 La UNESCO (Organización de las Naciones Unidas para la Educación, la Ciencia y la Cultura) se fundó en el año 1945. Esta organización pretende impulsar la consolidación de la paz, la erradicación de la pobreza, el desarrollo sostenible y el diálogo intercultural a través de la educación, las ciencias, la cultura, la comunicación y la información. Entre las prioridades de la UNESCO está lograr una educación de calidad para todos y el aprendizaje a lo largo de la vida (UNESCO, 2015). 
lifelong learning. Esto trajo consigo una serie de transformaciones en el ámbito de la formación y educación de adultos, dando más importancia a las competencias y a las habilidades que al simple estudio teórico, para después acceder a la aplicación práctica de la profesión correspondiente (Daniele, 2010, p. 36).

A raíz de todas estas variaciones y avances, la Unión Europea (UE), pretendiendo estar a la altura de las nuevas circunstancias, acordó en el Consejo de Lisboa de 23 y 24 de marzo del año 2000 que la unión debería alcanzar un nuevo objetivo estratégico para reforzar el empleo, la economía y la cohesión social. De este modo se propuso crear la economía más fuerte del mundo a través de la sociedad del conocimiento. Asimismo, en el consejo se hizo hincapié en la trasparencia de las cualificaciones, dando gran relevancia al acceso de conocimientos por parte de todos los ciudadanos, para poder vivir y trabajar en la sociedad de la información.

Se hizo así explícita la referencia al aprendizaje a lo largo de toda la vida, no sólo en el ámbito educativo y de formación, sino también en el laboral. Se invitó a la Comisión a priorizar el aprendizaje a lo largo de la vida, complementando aprendizaje y flexibilidad de las empresas para facilitar tal fin. (Parlamento Europeo, 2000)

Está decisión repercutió enormemente en el aspecto educativo y formativo, ya que para poder dar respuesta a una sociedad basada en el conocimiento los países de la UE debían estar abiertos a una mejora permanente y por tanto a un aprendizaje continuo a lo largo de la vida.

Siguiendo esta línea de cambios, en octubre de ese mismo año, salió a la luz el "Memorándum sobre la instrucción y la formación permanente". Este Memorándum supuso un hito importante en el marco del lifelong learning, pretendía crear una estrategia europea global de actuación de la instrucción y de la formación permanente, en el plano individual e institucional y en todos los aspectos de la vida. Se habló de un aprendizaje a lo largo (lifelong) y a lo ancho (lifewide) de la vida. Es decir, aprender no sólo durante toda la vida sino en todos los contextos de esta, aprender dentro y fuera de los contextos preparados para ello. También definió el aprendizaje formal, no formal e informal (Commissione delle Comunità Europee, 2000, p. 9): 
La validación de competencias profesionales en España e Italia

- el aprendizaje formal, es aquél que se desarrolla en centros educativo-formativos y conduce a la obtención de diplomas y cualificaciones reconocidos;

- el aprendizaje no formal se realiza paralelamente a los principales sistemas de educación y formación y no suele proporcionar certificados formales. Este aprendizaje puede adquirirse en el lugar de trabajo o a través de actividades de organizaciones y grupos de la sociedad civil (organizaciones juveniles, sindicatos o partidos políticos). También puede lograrse gracias a organizaciones o servicios establecidos para completar los sistemas formales (como cursos de arte, música o deportes o clases particulares para preparar exámenes);

- el aprendizaje informal es entendido como un complemento natural de la vida cotidiana, y a diferencia del aprendizaje formal y no formal, no es necesariamente intencionado.

Tras la confirmación del objetivo de Lisboa por el Consejo Europeo de Estocolmo, en marzo de 2001, se publicó la Comunicación "Hacer realidad un espacio europeo del aprendizaje permanente", abordando el tema del aprendizaje a lo largo de la vida como un tema central, de gran importancia, que abarca dimensiones individuales y sociales. Lo definió como: "toda actividad de aprendizaje realizada a lo largo de la vida con el objetivo de mejorar los conocimientos, las competencias y las aptitudes con una perspectiva personal, cívica, social o relacionada con el empleo" (Comunicación de la Comisión, 2001, p. 10).

De este modo la comunicación confería valor a cualquier tipo de aprendizaje adquirido en cualquier momento de la vida y en cualquier lugar. Es en este contexto de aprendizaje permanente donde situamos la validación de las competencias profesionales no formales e informales. Entendemos así la validación como un instrumento que facilita el intercambio y la libre circulación de profesionales en todo el territorio de la UE, con objeto de contribuir a lograr el objetivo formulado en la Cumbre de Lisboa el año 2000. 
La validación de competencias profesionales

\subsubsection{INICIOS DE LA UNIÓN EUROPEA EN EL RECONOCIMIENTO DE COMPETENCIAS}

A partir de la mencionada Cumbre de Lisboa, los países pertenecientes a la UE comenzaron un proceso de reforma en sus sistemas de educación y formación, con la idea de optimizarlos y homogeneizarlos para contribuir al objetivo de convertir la economía europea en la más competitiva del mundo a través de una sociedad del conocimiento.

Siguiendo las Conclusiones de la Cumbre de Lisboa, y de forma paralela a las reformas nacionales en curso, la UE comenzó un proceso de mejora en el campo de las cualificaciones profesionales. Por ello, en febrero de 2001 la Comisión hizo referencia al reconocimiento de las cualificaciones en su "Comunicación al Consejo sobre nuevos mercados de trabajo europeos abiertos a todos y accesibles para todos", en ella hizo pública su intención de modificar el sistema general para hacerlo más transparente, uniforme y flexible (Propuesta de Directiva del Parlamento y del Consejo, 2002). Esta Comunicación se presentó al Consejo Europeo de Estocolmo, celebrado los días 23 y 24 de marzo de 2001, pretendiendo que dicho consejo definiese una serie de propuestas específicas para un régimen de reconocimiento de cualificaciones más flexible y transparente (ICE, 2001, p. 41). La Comunicación también propuso la creación de un grupo operativo de alto nivel sobre las cualificaciones y la movilidad, que se formó ese mismo año y transmitió la importancia de facilitar y acelerar el reconocimiento profesional a través de un informe en diciembre de 2001 (Propuesta de Directiva del Parlamento y del Consejo, 2002).

Asimismo, siguiendo la petición que se hizo en el Consejo de Lisboa sobre la reflexión en relación a los sistemas de educación y formación, se presentó en el Consejo de Estocolmo, en marzo de 2001, el Informe sobre el programa de trabajo relativo a "los futuros objetivos precisos de los sistemas de educación y formación”. Este informe estableció tres objetivos estratégicos que debían alcanzarse antes de finalizar el año 2010 (Informe Consejo Educación, 2001; Programa de trabajo, 2002):

- mejorar la calidad y la eficacia de los sistemas de educación y formación;

- mejorar la accesibilidad a los sistemas de educación y formación;

- dotar de una mayor apertura a todos los sistemas de educación y formación de la UE. 
La validación de competencias profesionales en España e Italia

A raíz de la presentación de estos objetivos estratégicos, y para lograr su consecución, el Consejo aprobó el Programa de Trabajo "Educación y Formación 2010", que se empezó a aplicar el año 2001 con la intención de convertir a Europa en un referente de calidad mundial en el ámbito de los sistemas educativos y de formación.

En el año 2004, para el seguimiento del programa de trabajo, el Consejo y la Comisión Europea empezaron a elaborar un informe conjunto (que actualmente se elabora cada dos años) a partir de los informes nacionales. Ese mismo año el informe hizo referencia al tema de la validación de competencias profesionales al señalar la importancia de crear un marco europeo de cualificaciones (EQF) que estuviese basado, a su vez, en marcos nacionales, para establecer una referencia común en cuanto al reconocimiento de las cualificaciones y competencias. La idea era poder desarrollar un mercado de trabajo europeo, por lo que era imprescindible lograr el reconocimiento de títulos y certificados en toda Europa, por ello se instó a los Estados miembros a tomar medidas para mejorar la movilidad de trabajadores en sus países (Educación y Formación 2010, 2004).

\subsubsection{EL SISTEMA GENERAL DE RECONOCIMIENTO DE TÍTULOS}

Para llevar a la práctica la validación y certificación de competencias profesionales en Europa era necesario establecer un sistema general de reconocimiento de títulos profesionales que regulase el proceso.

La conformación de este sistema general ha sido un proceso lento pero continuado. Inició su andadura en el año 74 con la resolución del Consejo de 6 de junio, relativa al reconocimiento recíproco de diplomas, certificados y otros títulos. A pesar de la existencia de diferencias en los programas de formación de los Estados miembro, se observaba una cierta correspondencia en la práctica en cuanto a las cualificaciones que daban acceso al ejercicio de una determinada profesión. Por ello, esta resolución consideró necesario establecer unas listas de diplomas, certificados y otros títulos que fuesen reconocidos como equivalentes (Resolución del Consejo, 1974).

El 16 de julio de 1985 se publicó una directiva relacionada con la correspondencia de las cualificaciones de formación profesional entre los Estados miembro de las Comunidades Europeas. El objetivo de esta direc- 
tiva era posibilitar a los trabajadores el acceso a un empleo adecuado en un Estado miembro diferente al suyo, a través del establecimiento de correspondencias entre las cualificaciones de formación profesional de los distintos países de la UE. Para ello contarían con una estructura educativa de cinco niveles que permitiese identificar las categorías de las cualificaciones profesionales en los distintos países, para profesiones o grupos de profesiones específicas (Decisión del Consejo, 1985). Sin embargo, la aplicación de esta Decisión no fue eficaz debido a que el método y el planteamiento utilizado para describir y comparar las cualificaciones diferían de los aplicados en los sistemas de educación y formación de los países miembro (Decisión del Parlamento y del Consejo, 2008).

En el año 1989 se publicó una directiva del Consejo sobre un sistema general de reconocimiento de títulos de enseñanza superior que sancionan formaciones profesionales de una duración mínima de tres años. Se aplicó a todos los profesionales pertenecientes a un Estado miembro que se propusieron ejercer una profesión regulada en un estado miembro de acogida (Directiva del Consejo, 1989). Durante ese mismo año, en el ámbito universitario, se estableció el Sistema europeo de transferencia y acumulación de créditos (ECTS) que aumentó la calidad y la movilidad de estudiantes en Europa con el reconocimiento de períodos de estudio en el extranjero. Diez años más tarde tuvieron lugar los acuerdos de Bologna (referidos al campo universitario) (Comisión Europea, 2004) y la Directiva 1999/42/CE que estableció un mecanismo de reconocimiento de títulos referido a actividades profesionales. Esta Directiva se ocupaba del reconocimiento de títulos y de cualificaciones profesionales, en función de la experiencia profesional, adquiridos en otro Estado miembro.

Desde el año 1977 se elaboraron numerosas directivas relacionadas con el reconocimiento de competencias profesionales en campos específicos como el arquitectónico, ${ }^{59}$ el de aviación, ${ }^{60}$ el de transportes ${ }^{61}$ o el

${ }^{59}$ Recomendación 85/386/CEE del Consejo, de 10 de junio de 1985, relativa a los titulares de un diploma en el ámbito de la arquitectura expedido en un país tercero. (DOUE, L 223, de 21 de agosto de 1985).

${ }^{60}$ Directiva 91/670/CEE del Consejo, de 16 de diciembre de 1991, sobre aceptación recíproca de licencias del personal que ejerce funciones en la aviación civil. (DOUE, L 373, de 31 de diciembre de 1991).

${ }^{61}$ Directiva 96/26/CE del Consejo, de 29 de abril de 1996, relativa al acceso a la profesión de transportista de mercancías y de transportista de viajeros por carretera, así como al reconocimiento recíproco de los diplomas, certificados y otros títulos destinados a 
La validación de competencias profesionales en España e Italia

marítimo $^{62}$. Sin embargo, los continuos cambios y la elaboración de variantes paralelas dificultaban cada vez más el funcionamiento y la aplicación del sistema. Por este motivo, en marzo de 2002 se desarrolló la Propuesta de Directiva relativa al reconocimiento de cualificaciones profesionales, que trató de simplificar la legislación y facilitar la libre prestación de servicios en el marco de las Conclusiones de la Cumbre de Lisboa. Esta directiva consideró necesario un sistema claro, seguro y rápido de reconocimiento de cualificaciones de las profesiones reguladas para garantizar la libre circulación de personas realmente preparadas, ya que contribuiría a la sociedad del conocimiento y podría paliar la falta de personal cualificado en determinados momentos en los diferentes Estados miembro (Propuesta de Directiva del Parlamento y del Consejo, 2002).

La Propuesta estableció la norma de que un Estado miembro que subordina el acceso a una profesión regulada o su ejercicio, aceptaría la posesión de determinadas cualificaciones profesionales como condición suficiente para el acceso a dicha profesión y su ejercicio (Propuesta de Directiva del Parlamento y del Consejo, 2002, p. 1).

Tres años después se publicó la directiva referente a esta Propuesta, la Directiva 2005/36/CE, derogando la Directiva 1999/42/CE del Parlamento Europeo y del Consejo relativa al sistema general de reconocimiento de cualificaciones y otras que hasta el momento se habían publicado creando cierta confusión en el sistema.

Hoy en día el sistema general de reconocimiento se articula sobre la base de esta Directiva (2005/36/CE), la cual refunde toda la legislación comunitaria sobre el reconocimiento de cualificaciones profesionales en un único texto e incorpora elementos nuevos. Entre otras cosas, este documento estableció cinco niveles de cualificación (ver Cuadro 8):

Cuadro 8: Niveles de cualificación

\section{Niveles de cualificación}

favorecer el ejercicio de la libertad de establecimiento de estos transportistas en el sector de los transportes nacionales e internacionales. (DOUE, L 124, de 23 de mayo de 1996).

62 Directiva 2005/45/CE del Parlamento Europeo y del Consejo de 7 de septiembre de 2005 sobre el reconocimiento mutuo de los títulos expedidos por los Estados miembros a la gente de mar y por la que se modifica la Directiva 2001/25/CE. (DOUE, L 255/160, de 30 de septiembre de 2005). 


\begin{tabular}{|c|c|}
\hline \multirow[t]{2}{*}{$\begin{array}{l}\text { a. Certificado } \\
\text { de competen- } \\
\text { cia expedido } \\
\text { por Estado } \\
\text { miembro: }\end{array}$} & $\begin{array}{l}\text { 1. de una formación que no forme parte de un certificado o } \\
\text { título en el sentido de las letras b), c), d) o e), de un examen } \\
\text { específico sin formación previa, del ejercicio a tiempo comple- } \\
\text { to de la profesión en un Estado miembro durante tres años } \\
\text { consecutivos o durante un período equivalente a tiempo par- } \\
\text { cial en el transcurso de los diez últimos años, }\end{array}$ \\
\hline & $\begin{array}{l}\text { 2. de una formación general de nivel de enseñanza primaria o } \\
\text { secundaria que acredite que la persona pose conocimientos } \\
\text { generales; }\end{array}$ \\
\hline \multirow[t]{2}{*}{$\begin{array}{l}\text { b. Certificado } \\
\text { que sanciona } \\
\text { un ciclo de } \\
\text { estudios se- } \\
\text { cundarios: }\end{array}$} & $\begin{array}{l}\text { 1. de carácter general complementado con un ciclo de estu- } \\
\text { dios o de formación profesional distintos de los mencionados } \\
\text { en la letra c) y/o con el período de prácticas o la práctica pro- } \\
\text { fesional exigidos además de dicho ciclo de estudios, }\end{array}$ \\
\hline & $\begin{array}{l}\text { mo se menciona en el inciso i), y/o con el períc } \\
\text { as o la práctica profesional exiqidos además de }\end{array}$ \\
\hline \multirow[t]{2}{*}{$\begin{array}{l}\text { c. Título que } \\
\text { sanciona }\end{array}$} & $\begin{array}{l}\text { 1. formación de la enseñanza postsecundaria distinta de la } \\
\text { mencionada en las letras d) y e) de duración mínima de un } \\
\text { año o equivalente a tiempo parcial, o una formación escolar } \\
\text { equivalente de segundo nivel secundario, así como la forma- } \\
\text { ción profesional exigida en su caso además del ciclo de } \\
\text { estudios postsecundarios, }\end{array}$ \\
\hline & $\begin{array}{l}\text { 2. en el caso de una profesión regulada, una formación de } \\
\text { estructura particular, equivalente al nivel de formación indica- } \\
\text { do en el punto c.1, que confiera un nivel profesional } \\
\text { comparable y prepare a un nivel comparable de responsabili- } \\
\text { dades y funciones. }\end{array}$ \\
\hline \multicolumn{2}{|c|}{$\begin{array}{l}\text { d. Título que sanciona una formación de enseñanza postsecundaria de una } \\
\text { duración mínima de tres años y no superior a cuatro, o de una duración equiva- } \\
\text { lente a tiempo parcial, dispensada en una universidad o un centro de enseñanza } \\
\text { superior o en otro centro del mismo nivel de formación, así como la formación } \\
\text { profesional exigida en su caso además del ciclo de estudios postsecundarios. }\end{array}$} \\
\hline
\end{tabular}


e. Título que acredita que el titular ha cursado con éxito un ciclo de estudios postsecundarios de una duración mínima de cuatro años, o de una duración equivalente a tiempo parcial, en una universidad o centro de enseñanza superior 0 en otra institución de nivel equivalente $y$, en su caso, que ha cursado con éxito la formación profesional que pueda exigirse además de dicho ciclo de estudios postsecundarios.

Fuente: (Directiva del Parlamento y del Consejo, 2005).

Con la intención de apoyar y mejorar la mencionada directiva, la Comisión publicó en marzo de 2007 una decisión con la que se creó un grupo de coordinadores para el reconocimiento de las cualificaciones profesionales. Sus funciones principales eran las de crear lazos de colaboración entre las autoridades de los Estados miembro y la Comisión, respecto al reconocimiento de las cualificaciones profesionales; realizar un seguimiento de las políticas que afectasen a las profesiones reguladas por cualificaciones; facilitar la aplicación de la Directiva 2005/36/CE y favorecer el intercambio de experiencias y buenas prácticas relacionadas con el reconocimiento de cualificaciones (Decisión de la Comisión, 2007).

\subsubsection{El Marco Europeo de CUALIFICACIONES}

A la luz de todos estos cambios, la necesidad de crear un marco de referencia europeo se hizo latente muy pronto. Sin embargo, el verdadero impulso para la creación del mismo empezó con el Consejo Europeo de Lisboa, seguido por el Proceso de Copenhague ${ }^{63}$ y el Consejo Europeo de Barcelona de 2002. Los informes de 2004 y 2006 del programa de trabajo "Educación y formación 2010" y los Consejos Europeos de Bruselas en marzo de 2005 y en marzo de 2006, hicieron hincapié en la importancia de reducir los obstáculos normativos y administrativos para el reconocimiento de las cualificaciones profesionales (Consejo Europeo de Barcelona, 2002, p. 12).

63 El Proceso de Copenhague se inició en el año 2002, tenía el objetivo de mejorar el rendimiento y la calidad de la Formación Profesional en Europa. El proceso fue revisado cada dos años a través de una serie de comunicados: Comunicado de Maastricht en 2004; el Comunicado de Helsinki en 2006; Comunicado de Burdeos en 2008 y el Comunicado de Brujas en 2010. 
Finalmente, el Marco Europeo de las Cualificaciones (EQF) empezó a fraguarse en el año 2004, con la idea de aumentar la transparencia de las cualificaciones y la promoción del aprendizaje permanente.

Entre el año 2004 y 2005 la Comisión Europea, ayudada por un grupo de expertos sobre el EQF, diseñó un modelo de marco fundamentado en ocho niveles y basado en resultados de aprendizaje derivados del aprendizaje formal, no formal e informal. La finalidad del marco era mejorar la transparencia, la transferibilidad de las cualificaciones y fomentar el aprendizaje a lo largo de la vida. Durante la segunda mitad del año 2005 este modelo fue consultado a los 32 países que participaban en el programa de trabajo "Educación y formación 2010", a los interlocutores sociales europeos, a las organizaciones y suborganizaciones sectoriales, a las instituciones y asociaciones educativas y a las ONG. Las respuestas obtenidas respaldaron la propuesta, aunque pidieron algunas aclaraciones y simplificaciones. Por ello, la Comisión modificó la propuesta según las peticiones de los países participantes, presentando una versión mejorada en 2006. Asimismo, instó a los Estados miembro a utilizar el EQF como instrumento referencial para la comparación de niveles de cualificación de diferentes sistemas de cualificaciones (Propuesta del Parlamento y del Consejo, 2006).

El Parlamento Europeo y el Consejo negociaron durante el año 2007 la Propuesta de EQF que finalmente vio la luz con la Recomendación del Parlamento Europeo y del Consejo de 23 de abril de 2008. Con ella se adoptó oficialmente el $\mathrm{EQF}^{64}$ y se fijó el año 2010 como fecha límite para que los Estados miembro alineasen sus sistemas nacionales de cualificaciones, creando correspondencias entre los niveles de cualificación de sus marcos nacionales con el EQF.

Asimismo, esta recomendación daba énfasis al aprendizaje permanente, a la igualdad de oportunidades en la sociedad del conocimiento y a una mayor integración del mercado laboral europeo, respetando la diversidad de los sistemas educativos nacionales. Por ello, se recomendó que se definiesen las cualificaciones basándose en resultados de aprendizaje, promoviendo la validación de aprendizajes no formales e informales y siguiendo los principios europeos (ver subapartado 4.1.4.1); acordados en las conclusiones del Consejo de 28 de mayo de 2004; que se promoviese la calidad en educación

${ }^{64}$ Los niveles de cualificación del EQF abarcan desde la formación más básica (como la educación básica) hasta la más avanzada (como el doctorado) (Comunidades Europeas, 2009, p. 3). 
La validación de competencias profesionales en España e Italia

y formación y que se estableciesen puntos de coordinación nacionales con la idea de garantizar la transparencia en las relaciones entre los marcos nacionales y el EQF (Comunidades Europeas, 2009; Recomendación del Parlamento y el Consejo, 2008).

\subsubsection{Los instrumentos del EQF}

Es necesario tener en cuenta en un contexto más amplio de marco europeo de referencia en el que debemos integrar una serie de instrumentos y principios. Nos estamos refiriendo a los principios europeos comunes para la validación de competencias, el Europass, el Sistema Europeo de Créditos para la educación y Formación Profesionales (en adelante, en sus siglas en inglés, ECVET) o las Directrices Europeas. A continuación vemos estos instrumentos con más detalle.

- Principios europeos para la validación y certificación de competencias y Europass

El Informe del Consejo y de la Comisión del año 2004 no sólo hizo hincapié en la constitución de un marco europeo de cualificaciones, también habló del establecimiento de unos principios europeos comunes que ayudasen a los países pertenecientes a la UE en la práctica de validación de competencias. Estos principios se vieron materializados meses más tarde con el "Proyecto de Conclusiones del Consejo y de los Representantes de los Gobiernos de los Estados miembros reunidos en el seno del Consejo sobre los Principios europeos comunes para la determinación y convalidación de la educación no formal e informal".

Estos principios tenían el objetivo de promover y guiar el desarrollo de sistemas de convalidación de educación no formal e informal. Asimismo, se consideraban necesarios para asegurar la comparabilidad y la aceptación de distintos enfoques y sistemas en los Estados miembro, así como la transferencia y aceptación de todos los resultados educativos en diferentes entornos.

El Proyecto propuso cuatro principios de carácter voluntario para respetar derechos, responsabilidades y competencias de los Estados miembro y de las partes interesadas (Principios europeos, 2004):

1. derechos individuales;

2. obligaciones de los responsables. 
3. fiabilidad y confianza.

4. credibilidad y legitimidad

La necesidad de crear estos principios fue mencionada durante la Declaración de Copenhague en 2002, en la que también se hizo referencia a la creación del Europass, un importante instrumento para la transparencia de competencias y cualificaciones y la movilidad de los trabajadores en Europa con fines de aprendizaje permanente, que también salió a la luz en el año 2004.

A través de la Decisión 2241 del Parlamento Europeo y del Consejo de 15 de diciembre de 2004, el Europass sustituyó a su antecesor Europass Formación, que fue establecido en 1999 con la intención de registrar todos los periodos de movilidad transnacional llevados a cabo en Europa con fines de aprendizaje a cualquier nivel y con cualquier objetivo (Decisión del Parlamento y del Consejo, 2004).

Esta decisión definió el marco comunitario único para la transparencia de las cualificaciones y competencias, es decir, la estructura y formato de los documentos del Europass, que hoy en día se siguen usando.

Se trata de una herramienta de carácter voluntario que favorece la transparencia de las cualificaciones y de las competencias. El Europass ayuda a comunicar y a presentar competencias en Europa a través de un expediente personal y coordinado de documentos. Los documentos que conforman el Europass son (ver Cuadro 9): el Curriculum Vitae Europass, documento de movilidad Europass, suplemento del diploma Europass, portafolio de lenguas Europass y el suplemento de certificado Europass (Decisión del Parlamento y del Consejo, 2004, p. 2).

Cuadro 9: Documentos que conforman el Europass

\begin{tabular}{|c|c|c|}
\hline \multirow{2}{*}{ 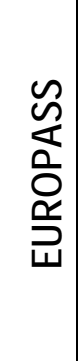 } & CV Europass & $\begin{array}{l}\text { Proporciona a los ciudadanos la posibilidad de } \\
\text { presentar en una forma clara y completa la } \\
\text { información relativa a todas sus cualificaciones } \\
\text { y competencias. }\end{array}$ \\
\hline & $\begin{array}{l}\text { Documento de } \\
\text { movilidad Euro- } \\
\text { pass }\end{array}$ & $\begin{array}{l}\text { Registra los periodos de aprendizaje realizados } \\
\text { por los titulares en países distintos al suyo. }\end{array}$ \\
\hline
\end{tabular}


La validación de competencias profesionales en España e Italia

\begin{tabular}{|l|l|l|}
\hline $\begin{array}{l}\text { Suplemento de } \\
\text { diploma Europass }\end{array}$ & $\begin{array}{l}\text { Proporciona información sobre los niveles de } \\
\text { estudio en la enseñanza superior alcanzados } \\
\text { por el titular. }\end{array}$ \\
\hline $\begin{array}{l}\text { Portafolio de len- } \\
\text { guas Europass }\end{array}$ & $\begin{array}{l}\text { Proporciona a los ciudadanos la oportunidad de } \\
\text { presentar sus conocimientos lingüísticos. }\end{array}$ \\
\hline $\begin{array}{l}\text { Suplemento de } \\
\text { certificado Euro- } \\
\text { pass }\end{array}$ & $\begin{array}{l}\text { Describe las aptitudes y cualificaciones corres- } \\
\text { pondientes a un certificado de formación } \\
\text { profesional. }\end{array}$ \\
\hline
\end{tabular}

Fuente: (Decisión del Parlamento y del Consejo, 2004)

- El Sistema Europeo de Transferencia de Créditos para la Educación y la Formación Profesionales (ECVET)

Este sistema de créditos se empezó a gestar en el curso del año 2006. Fue impulsado por la Declaración de Copenhague en 2002 y el Comunicado de Maastricht en 2004 (Documento de trabajo ECVET, 2006). La recomendación relativa a su constitución fue publicada en 2009 por la Comisión Europea.

El ECVET es el sistema de créditos equivalente, en el ámbito educativo y de formación profesional, al mencionado ECTS, en el ámbito de la educación superior. Este sistema fue creado con el objeto de facilitar la transferencia, el reconocimiento y la acumulación de los resultados evaluados de aprendizaje, en la educación y formación profesionales, de todas aquellas personas que deseasen adquirir una cualificación. De esta forma se mejoraba la comprensión general de los resultados de aprendizaje de los ciudadanos, la transparencia, la movilidad dentro del país y entre los Estados miembros, contribuyendo al mismo tiempo a mejorar la movilidad y transferibilidad de las cualificaciones a nivel nacional en los distintos sectores económicos y en el mercado de trabajo (Recomendación del Parlamento Europeo y el Consejo, 2009). 


\section{- Las Directrices Europeas para la validación y certificación del aprendizaje no formal e informal}

En el año 2009 el Cedefop publicó las "Directrices Europeas para la validación del aprendizaje no formal e informal". ${ }^{65}$ Este documento nació con el objetivo de favorecer el desarrollo de la validación de aprendizajes adquiridos por vía no formal e informal a niveles europeos, nacionales y locales.

Las directrices suponen hoy en día la guía y el punto de referencia para los Estados miembro en cuanto a validación de competencias no formales e informales. Se apoyan en los principios europeos comunes publicados en 2004, a los que hemos hecho referencia con anterioridad. La aplicación de estas directrices es de carácter voluntario. Pretenden ser una herramienta práctica, proponiendo una serie de recomendaciones realizadas por expertos y están dirigidas a aquellos que intervienen en la elaboración y puesta en práctica de los dispositivos de validación a diferentes niveles.

Esta guía establece que los procedimientos de validación no formal e informal deben contener 3 elementos estructurales (Cedefop, 2009, p. 59):

- orientación como preparación a la evaluación: con la orientación se produce y difunde la información, se motiva al candidato y se le proporcionan consejos. También incluye la identificación de los aprendizajes hasta la certificación;

- evaluación de las competencias profesionales: los candidatos deben comprender las exigencias y los estándares prefijados desde el principio de esta etapa. Las evidencias tienen que estar bien recogidas, bien documentadas y preparadas para ser evaluadas. Los candidatos deben conocer los procedimientos de evaluación y de validación de los resultados que pueden obtener;

- control externo: se trata de un proceso consecutivo al de la evaluación, consiste en someter la orientación y la evaluación a un examen externo e independiente sobre la eficacia de estas (capacidad de lograr lo que se espera).

Otro de los aspectos que consideramos de gran importancia, y que ha emergido en el análisis del documento de las directrices, es una serie de

65 Recordamos que a principios de 2016 el Cedefop publicó un nuevo documento con mejoras sobre las Directrices Europeas para la validación del aprendizaje no formal e informal, para introducir mejoras en el mismo (Cedefop, 2016). 
La validación de competencias profesionales en España e Italia

principios que debe tener el procedimiento de validación para asegurar su eficacia:

- visibilidad/transparencia: no debe haber sorpresas para el candidato ni para las partes implicadas, todo el procedimiento debe ser claro;

- igualdad: debe darse un trato igualitario a todos los candidatos, sin propiciar favoritismos ni perjudicar a otros;

- accesibilidad: debe poder acceder al procedimiento el mayor número posible de personas.

- voluntariedad: someterse al procedimiento debe ser voluntario para el candidato.

- personalización: cada sujeto es único y se sitúa en el centro del procedimiento, por ello los procesos deben ser lo menos rígidos posible.

- validez: los métodos de evaluación y los instrumentos que se utilicen en la evaluación deben medir adecuadamente la competencia que pretenden medir;

- fiabilidad: basado en los métodos y en los instrumentos, que deben ser capaces de asegurar resultados iguales o parecidos si se realiza el procedimiento bajo las mismas condiciones;

- seguridad y confidencialidad: debe respetarse la privacidad del sujeto.

- coordinación: debe existir coherencia en las prácticas de validación.

- trazabilidad: todo el procedimiento debe estar documentado.

Por tanto, la guía establece unos principios a seguir y define detalladamente las fases que deben tenerse en cuenta para el buen funcionamiento de este tipo de procedimientos. Incluye también una lista de instrumentos que pueden utilizarse para la validación, entre los que se encuentran el dossier, la entrevista o la observación. Asimismo, la guía establece los profesionales que deben encargarse del procedimiento: los que proporcionan información, asesoramiento y orientación; los que conducen la evaluación; los observadores externos del procedimiento (evaluadores del funcionamiento del procedimiento); los responsables de los centros/procedimientos de evaluación y otras partes interesadas que juegan un papel más o menos importante en el procedimiento de validación (como por ejemplo las empresas). 
Por su función de documento de referencia, entendemos estas directrices como la guía de los procedimientos de validación y certificación de aprendizajes adquiridos por vías no formales e informales.

\subsection{5 Últimos MOVIMIENTOS}

En los últimos cinco años Europa ha seguido instando a los países pertenecientes a la UE a poner en marcha dispositivos de validación y certificación de aprendizajes no formales e informales. Prueba de ello son los documentos que mencionamos a continuación.

En el año 2010 la Comisión Europea publicó la "Estrategia Europa 2020 " para un crecimiento inteligente, sostenible e integrador, pretendiendo impulsar los conocimientos, capacidades y competencias para lograr un crecimiento económico y generar empleo.

Entre los objetivos principales de la estrategia europea se encuentran (Comisión Europea, 2010, p. 5):

- reducir el porcentaje de abandono escolar y lograr que la generación más joven tengan estudios superiores completos;

- reducir el riesgo de pobreza, que debería amenazar a 20 millones menos de personas.

En este documento la UE consideró la validación del aprendizaje no formal e informal como un arma para luchar por sus objetivos, haciendo asimismo hincapié en la necesidad de crear itinerarios de aprendizaje más flexibles que facilitasen el acceso al mercado laboral.

Cabe también destacar la Recomendación del Consejo de 2012 sobre validación del aprendizaje no formal e informal, la cual establece el año 2018 como fecha límite para que los Estados miembro pongan en marcha dispositivos para la validación del aprendizaje no formal e informal. Asimismo anima a aplicar varios principios para mejorar los dispositivos de validación del aprendizaje no formal e informal. Entre otros, habla de proporcionar información y orientación sobre las posibilidades que ofrece la validación; dar prioridad de acceso a personas desempleadas; aplicar medidas transparentes a los procedimientos o mejorar la competencia profesional de las personas implicadas en la puesta en marcha del estos dispositivos de validación (Recomendación del Consejo, 2012).

Para finalizar esta contextualización legislativa europea hacemos referencia al último documento emanado sobre este campo en ámbito europeo, 
La validación de competencias profesionales en España e Italia

el Dictamen del Comité de las Regiones sobre reconocimiento de capacidades y competencias adquiridas a través del aprendizaje no formal e informal.

Este dictamen hace hincapié en las capacidades mejores y más útiles teniendo en cuenta los marcos no formales e informales. Insta a los Estados miembro a reforzar los vínculos entre el mundo educativo-formativo y el laboral, y a adoptar un enfoque de aprendizaje a lo largo de toda la vida en las políticas educativo-formativas. Asimismo, cree necesario garantizar una calidad adecuada en cuanto al reconocimiento de las capacidades y cualificaciones y mejorar la política de información sobre este tipo de procedimiento, adaptándola a las personas a las que vaya dirigida.

\subsubsection{SITUACIÓN EUROPEA ACTUAL}

Según el último Inventario Europeo sobre la validación no formal e informal del aprendizaje (2014), algunos países como Austria, Portugal o BélgicaFlandes están trabajando intensamente para mejorar sus sistemas de validación, en especial aquellos dirigidos a colectivos desfavorecidos. Otros, como los países nórdicos, junto con Suiza, se encuentran entre los países que han trabajado para mejorar los vínculos entre la validación y el sector productivo. Algunos países como Malta, que cuenta con un sistema de validación menos arraigado, también han logrado avances en los últimos años.

Asimismo, los sistemas francés o alemán, considerados sistemas "maduros", no han experimentado muchos más avances en los últimos cuatro años. Chipre, Alemania, Grecia, Lituania, Eslovaquia y Turquía son algunos de los países donde se ha detectado un bajo rendimiento en este tipo de prácticas.

En algunas zonas europeas se han logrado avances significativos, en particular respecto a estrategias; marcos jurídicos; la incorporación de la validación en sistemas de cualificación; la vinculación con los Marcos Nacionales de Cualificaciones y el establecimiento de sinergias con los sistemas de créditos en aquellos países en los que están en práctica y la involucración de las partes interesadas en estos sistemas de validación.

Aunque en general se han experimentado grandes adelantos en términos de políticas de validación, en la práctica los avances han sido más lentos. Esto es debido a que en la mayoría de países existen barreras socio/económicas que impiden un gran crecimiento en este campo (European Commission et al., 2014). 


\subsection{La evaluación y acreditación de competencias profesionales en España}

En este apartado queremos mostrar la situación general en España en cuanto a la puesta en marcha de procedimientos de validación de competencias profesionales. Con este objetivo presentamos el breve pero efectivo marco legislativo sobre relativo a este aspecto y los elementos que suponen la base de estos procedimientos, el Sistema Nacional de Cualificaciones y formación profesional (en adelante, SNCP) y la cualificación profesional.

Asimismo, proporcionamos una panorámica, sobre las primeras experiencias de este tipo que se realizaron en este país y sobre los 'diferentes sectores en los que se están llevando a cabo actualmente.

Para finalizar el capítulo exponemos el procedimiento de evaluación y acreditación de competencias profesionales en Castilla y León.

\subsubsection{MARCO LEGISLATIVO}

En España, el procedimiento de validación y certificación de competencias no formales e informales recibe el nombre de procedimiento de evaluación y acreditación de las competencias profesionales adquiridas a través de experiencia o de vías no formales de formación.

La institución de la validación y certificación de competencias es relativamente reciente en este país y se debe, en gran parte, al impulso provocado por la UNESCO y por las recomendaciones de la UE que, sobre todo a partir de la Cumbre de Lisboa del año 2000, animaban a los países pertenecientes a la Unión a poner en marcha dispositivos de validación y certificación de competencias.

España ha ido desarrollando, sobre todo en la última década, un marco legislativo referente al tema de la validación de competencias no formales $\mathrm{e}$ informales.

En el año 2002 la Ley Orgánica 5/2002 (en adelante, LO 5/2002) habla por vez primera de reconocimiento de aprendizaje no formal como un elemento complementario del sistema de formación profesional. Dedica su artículo 8 al reconocimiento, evaluación, acreditación y registro de las cualificaciones profesionales, estableciendo que: 
La validación de competencias profesionales en España e Italia

- los títulos de formación profesional y los certificados de profesionalidad tienen carácter oficial y validez en todo el territorio español;

- la evaluación y la acreditación de las competencias profesionales contarán con un referente que garantice la fiabilidad, objetividad y rigor técnico de la evaluación;

- la acreditación podrá ser parcial y acumulable.

Uno de los objetivos de esta ley fue la creación del Sistema Nacional de Cualificaciones y de Formación Profesional (SNCFP) (ver subapartado 4.2.2), como sistema integrado en el que se articulan las cualificaciones profesionales ${ }^{66}$, su formación y acreditación. Estas cualificaciones se acreditan en títulos de formación profesional y certificados de profesionalidad, como explicamos en el subapartado 3.1.2, y están organizadas en unidades de competencia.

Entre los objetivos del SNCFP está permitir la evaluación y acreditación oficial de las cualificaciones profesionales adquiridas a través de cualquier vía (Ley Orgánica 5, 2002, n. art. 3.5). Para tal fin, la LO 5/2002 establece un importante instrumento, el procedimiento de reconocimiento, evaluación, acreditación y registro de las cualificaciones profesionales (Ley Orgánica 5, 2002, n. art. 4.1. b).

Otra ley que también impulsó la validación de aprendizajes adquiridos por cualquier vía fue la Ley de empleo 56/2003. Esta normativa abordó la mejora de la empleabilidad a través de políticas activas de empleo para ocupados y desempleados. Propuso acciones preventivas frente al desempleo y formación para mejorar la cualificación y adaptación de competencias al nuevo mercado laboral. Asimismo, a través de las políticas activas de empleo, contribuyó a la libre circulación de trabajadores y a la movilidad geográfica en España y Europa (Ley 56, 2003, n. art. 2).

También los Reales Decretos 1538/2006 ${ }^{67}$ y 395/2007, encargados de regular la formación profesional del sistema educativo y para el empleo respectivamente, supusieron un empuje para la validación de competencias no formales e informales. El primero estableció que la acreditación de compe-

${ }^{66}$ Las cualificaciones profesionales son competencias profesionales con significación para el empleo que pueden adquirirse por formación modular u otros tipos de formación y mediante experiencia laboral (Ley Orgánica 5, 2002, n. 3.7).

${ }^{67}$ Disposición derogada en el año 2011 por el RD 1147/2011, donde también se contempla la evaluación y acreditación de competencias. 
tencias permitiría la convalidación de los módulos profesionales asociados a las unidades de competencia relativas al título que se desease obtener (Real Decreto 1538, 2006, n. art. 35). El segundo real decreto contempló el reconocimiento de las competencias adquiridas a través de la experiencia laboral, mediante las acreditaciones totales o parciales de los certificados de profesionalidad (Real Decreto 395, 2007, n. art. 12).

Otro real decreto significativo fue el 34/2008 sobre la regulación de los certificados de profesionalidad. Este documento dio vía libre para que el certificado de profesionalidad también pudiese obtenerse a través de los procedimientos de evaluación y acreditación de competencias profesionales, adquiridas a través de experiencia laboral o de vías no formales de formación.

Todas estas normativas han contribuido a la implantación del dispositivo de validación y certificación de competencias en España, que finalmente llegó de la mano del Real Decreto 1224/2009 (en adelante, RD 1224/2009). Tomando como referencia el artículo 8.2 de la LO 5/2002, este real decreto define y establece en todo el territorio español un procedimiento de evaluación y acreditación de competencias profesionales adquiridas a través de vías no formales de formación o de experiencia en el trabajo. El procedimiento es único, tanto para el ámbito del sistema educativo como para el laboral. El RD 1224/2009 fue definido siguiendo las Directrices Europeas, que se publicaron ese mismo año con la intención de dar respuesta a las recomendaciones emanadas por la UE.

El real decreto define la validación de competencias como: "el conjunto de actuaciones dirigidas a evaluar y reconocer estas competencias adquiridas a través de la experiencia laboral o de vías no formales de formación” (R.D. 1224, 2009, n. art. 2). Asimismo, dispone los requisitos de acceso, las fases que debe comprender, su estructura y organización, señalando también la unidad de competencia como el referente de evaluación y certificación (R.D. 1224, 2009).

Esta normativa otorga la gestión a las comunidades autónomas, indicando que sus administraciones educativa y laboral competentes establecerán de forma conjunta la gestión y las convocatorias de los procesos de evaluación y acreditación de competencias. También establece que la propia Administración General del Estado podrá realizar convocatorias de evaluación y acreditación, y que las organizaciones sindicales y empresariales más importantes podrán solicitarlas al Estado o a la comunidad autónoma 
La validación de competencias profesionales en España e Italia

correspondiente. Dichas convocatorias deberán publicarse en los boletines o diarios oficiales de las Administraciones convocantes.

El procedimiento está dirigido a personas sin titulación pero en posesión de conocimientos profesionales adquiridos a través de la actividad laboral, del desempeño de tareas en el tercer sector y/o de la realización de actividades no remuneradas (R.D. 1224, 2009).

\subsubsection{El Sistema NACIONAL DE CUALIFICACIONES Y Formación Profesional (SNCFP)}

Para hablar del Sistema Nacional de Cualificaciones y Formación Profesional (SNCFP), debemos referirnos al órgano técnico que está detrás de su funcionamiento. Estamos hablando del punto nacional español de referencia en cuanto a certificaciones, el Instituto Nacional de las Cualificaciones (en adelante, INCUAL). Este instituto depende orgánicamente del Ministerio de Educación, Cultura y Deporte y debe su existencia al Real Decreto 375/1999. Años después de su nacimiento, la LO 5/2002 encomendó al INCUAL la labor de apoyar al Consejo General de Formación Profesional ${ }^{68}$ para alcanzar los objetivos del SNCFP. El INCUAL tiene entre sus objetivos principales acreditar las cualificaciones profesionales y elaborar los instrumentos de apoyo necesarios para validar y acreditar competencias profesionales no formales.

El SNCFP debe su definición a la LO 5/2002. Está compuesto por un conjunto de instrumentos y acciones necesarios para promover y desarrollar la integración de las ofertas de la formación profesional. Su objetivo es promover y desarrollar la evaluación y acreditación de competencias.

Este sistema cuenta con los siguientes instrumentos de actuación (INCUAL, 2015b):

- el Catálogo Nacional de Cualificaciones Profesionales (en adelante $\mathrm{CNCP}$;

- un procedimiento de reconocimiento, evaluación, acreditación y registro de las cualificaciones profesionales;

${ }^{68}$ El Consejo General de Formación Profesional es un órgano consultivo de carácter tripartito, cuenta con la participación de las Administraciones Públicas, de sindicatos y organizaciones empresariales. 
- la información y orientación en materia de formación profesional y empleo;

- la evaluación y mejora de la calidad del SNCFP.

\subsubsection{El Catálogo Nacional de Cualificaciones Profesio- nales (CNCP)}

El CNCP es un instrumento del Sistema Nacional de las Cualificaciones y Formación Profesional, que ordena las cualificaciones profesionales susceptibles de reconocimiento y acreditación. Hoy en día recoge 664 cualificaciones profesionales reconocidas en España y se estructura en dos partes (ver Cuadro 10): una sectorial, formada por las 26 familias profesionales existentes, y otra por cinco niveles de cualificación. ${ }^{69}$

69 Tanto las familias profesionales como los niveles de cualificación fueron instituidos por el RD 1128/2003 que regula el Catálogo Nacional de las Cualificaciones Profesionales. 
La validación de competencias profesionales en España e Italia

Cuadro 10: Familias profesionales y niveles y cualificaciones profesionales en España.

\begin{tabular}{|c|c|}
\hline Familias Profesionales & Niveles de Cualificación \\
\hline $\begin{array}{l}\text { - Agraria } \\
\text { - Marítimo-Pesquera } \\
\text { - Industrias Alimentarias } \\
\text { - Química } \\
\text { - Imagen Personal } \\
\text { - Sanidad } \\
\text { - Seguridad y Medio Ambiente } \\
\text { - Fabricación Mecánica } \\
\text { - Electricidad y Electrónica } \\
\text { - Energía y Agua } \\
\text { - Instalación y Mantenimiento } \\
\text { - Industrias Extractivas } \\
\text { - Transporte y Mantenimiento de } \\
\text { Vehículos } \\
\text { - Edificación y Obra Civil } \\
\text { - Vidrio y Cerámica } \\
\text { - Madera, Mueble y Corcho } \\
\text { - Textil, Confección y Piel } \\
\text { - Artes Gráficas } \\
\text { - Imagen y Sonido } \\
\text { - Informática y Comunicaciones } \\
\text { - Administración y Gestión } \\
\text { - Comercio y Marketing } \\
\text { - Servicios Socioculturales y a la } \\
\text { Comunidad } \\
\text { - Hostelería y Turismo } \\
\text { - Actividades Físicas y Deportivas } \\
\text { - Artes y Artesanías }\end{array}$ & 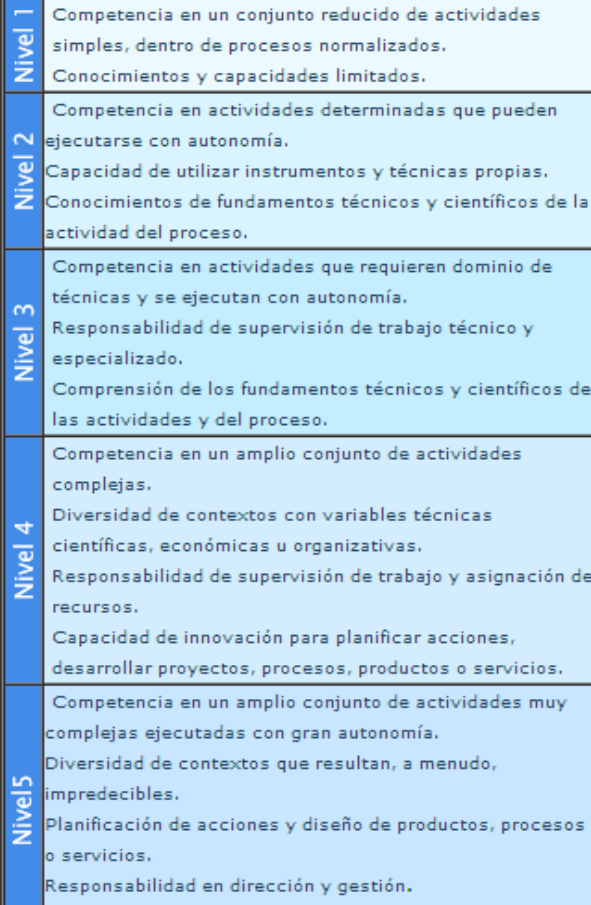 \\
\hline
\end{tabular}

Fuente: (INCUAL, 2015a).

Nos parece interesante, en este punto del trabajo, hacer un pequeño inciso en referencia a los cinco niveles que acabamos de ver. Estos deben equipararse a los 8 niveles que estipula el Marco Europeo de Cualificaciones para el aprendizaje a lo largo de la vida (EQF). Para logar dicha equiparación España está trabajando en el Marco Español de Cualificaciones para el aprendizaje a lo largo de la vida (en adelante, MECU). El objetivo del marco es facilitar la transparencia, movilidad y comparabilidad entre unos sistemas y otros.

Como hemos visto, el catálogo define 5 niveles de cualificación, abarcando desde la formación básica (nivel 1) hasta el doctorado (nivel 8). Sin embargo, el catálogo especifica únicamente las cualificaciones de los niveles 1, 2 y 3 que encontrarían correspondencia con los niveles 1, 2, 3, 4 y 5 del 
$\mathrm{EQF}$, referidos al ámbito de formación profesional inicial (formación profesional básica, media y superior) y de formación profesional para el empleo.

Los niveles 4 y 5 del marco español encontrarían correspondencia con los niveles 6, 7 y 8 del EQF, referidos al ámbito universitario e incluyendo el doctorado. Para describir las cualificaciones correspondientes a estos niveles, España ha desarrollado un marco referido a las cualificaciones superiores, el MECES. Según el Real Decreto 1027/2011 se estructura en cuatro niveles que se corresponden con las siguientes cualificaciones (ver Cuadro 11):

\section{Cuadro 11: Niveles del MECES}

\begin{tabular}{|l|l|}
\hline Niveles & Cualificaciones \\
\hline $\begin{array}{l}\text { Nivel 1. Técnico supe- } \\
\text { rior }\end{array}$ & $\begin{array}{l}\text { Técnico superior de FP } \\
\text { Técnico superior de artes plásticas y diseño } \\
\text { Técnico deportivo superior }\end{array}$ \\
\hline Nivel 2. Grado & $\begin{array}{l}\text { Título de graduado } \\
\text { Título de graduado de las enseñanzas artísticas superiores }\end{array}$ \\
\hline Nivel 3. Máster & $\begin{array}{l}\text { Máster universitario } \\
\text { Máster en enseñanzas artísticas }\end{array}$ \\
\hline Nivel 4. Doctor & Título de doctor \\
\hline
\end{tabular}

Fuente: (Real Decreto 1027, 2011).

Como podemos observar, las cualificaciones correspondientes a la formación profesional superior se encuentran descritas en ambos marcos (INCUAL y MECES). Este es solamente uno de los puntos que deben integrarse y coordinarse dentro del MECU para poder ofrecer una buena metodología y calidad y poder equipararse, por fin, al EQF.

\section{- La cualificación profesional}

En España se entiende por cualificación profesional el conjunto de competencias profesionales (entendidas como conocimientos y capacidades) con significación para el empleo que pueden adquirirse a través de formación modular u otros tipos de formación y mediante la experiencia laboral (LO, 2002, n. art. 7.4).

Los títulos de formación profesional y los certificados de profesionalidad constituyen las ofertas de formación profesional referidas al Catálogo de Cualificaciones Profesionales. Tienen carácter oficial y validez en todo el territorio nacional (Ley Orgánica 5, 2002). Es decir, las cualificaciones del 
La validación de competencias profesionales en España e Italia

catálogo se acreditan en títulos de formación profesional y certificados de profesionalidad

\section{La estructura de la cualificación profesional}

Cada cualificación tiene asignada una competencia general que define los cometidos y funciones principales de esta. La cualificación describe el entorno profesional en el que puede desarrollarse, los sectores productivos correspondientes y los puestos de trabajo relevantes a los que permite acceder. Además para cada cualificación se indica el nivel (de los cinco) al que pertenece (INCUAL, 2015a), aunque de momento el catálogo solo haya definido las cualificaciones hasta el tercer nivel.

Las cualificaciones profesionales del CNCP están compuestas por unidades de competencia (en adelante, UC).

\section{La unidad de competencia.}

La unidad de competencia está compuesta por las realizaciones profesionales que describen los comportamientos objetivos esperados en una persona para considerarla competente en esa unidad; el nivel aceptable de realización (a través de criterios de realización) y el contexto profesional referido a medios, productos, resultados de trabajo, información utilizada, etc., para enmarcar la realización profesional. Además, cada unidad de competencia tiene un módulo formativo asociado en el que se describe la formación necesaria para obtener la UC (INCUAL, 2015a).

Dado que las competencias profesionales se incluyen en las unidades de competencia de las cualificaciones (R.D. 1224, 2009, n. art. 4), la unidad de competencia supone el agregado mínimo de competencias profesionales susceptible de reconocimiento y acreditación parcial (INCUAL, 2015a).

\subsubsection{PRIMERAS EXPERIENCIAS DE VALIDACIÓN EN ESPAÑA}

La definición nacional del procedimiento de evaluación y acreditación de competencias profesionales no formales e informales llegó con el RD 1224/2009. Sin embargo, 7 años antes la LO 5/2002 supuso la base para la realización de varias iniciativas de evaluación y acreditación de competencias profesionales. Gracias a esta ley empezaron a ponerse en marcha algunas experiencias. Cabe destacar entre ellas el proyecto ERA (Evaluación 
Reconocimiento Acreditación) desarrollado en el año 2003. ${ }^{70}$ Este proyecto experimentó por primera vez en España la evaluación, el reconocimiento y la acreditación de las competencias profesionales sin importar el modo ni lugar de adquisición y usando el Catálogo Nacional de las Cualificaciones Profesionales (CNCP) (Ministerio de Educación Cultura y Deporte, 2004).

Más tarde se pusieron en marcha procedimientos de evaluación y acreditación de competencias profesionales a nivel de comunidades autónomas, siendo País Vasco, Cataluña y Canarias algunas de las pioneras en este tipo de procedimientos.

Podemos decir que en España estos procedimientos despegaron de forma lenta y un tanto desigual en cuanto al número de convocatorias realizadas entre unas comunidades autónomas y otras. ${ }^{71}$ Hoy en día todas las comunidades autónomas españolas tienen en marcha procedimientos de evaluación y acreditación que toman como referencia el RD 1224/2009, aunque sigue existiendo desigualdad en el número de convocatorias ente comunidades autónomas.

En España, la validación de aprendizajes está contemplada incluso en el acceso a la universidad para adultos mayores de 40 años. Estos pueden solicitar la validación de la experiencia laboral o profesional para cursar estudios universitarios sin necesidad de estar en posesión de los requisitos de acceso $^{72}$.

\subsubsection{EXPERIENCIAS DE VALIDACIÓN EN EL SECTOR PRIVADO}

En España el sector privado (incluidos sindicatos y organizaciones empresariales) ha participado en el desarrollo de la legislación de estos procedimientos a través de su representación en el Consejo General de la FP, que actúa como asesor en el desarrollo e implementación del procedimiento de validación y certificación de competencias.

${ }^{70}$ Para consultar la memoria del Proyecto ERA véase: http://www.educacion.gob.es/ educa/incual/pdf/rec/09 memoria\%20final\%20ERA-03.pdf

71 Para la consulta de convocatorias realizadas en España, puede consultarse la página: http://www.todofp.es/todofp/acreditacion-de-competencias.html

${ }^{72}$ El Real Decreto 412/2014, de 6 de junio, por el que se establece la normativa básica de los procedimientos de admisión a las enseñanzas universitarias oficiales de Grado. https://www.boe.es/boe/dias/2014/06/07/pdfs/BOE-A-2014-6008.pdf 
La validación de competencias profesionales en España e Italia

Aunque en España la validación es competencia de la administración pública, los sindicatos y las organizaciones empresariales pueden solicitar convocatorias de evaluación y acreditación para necesidades sectoriales. Por ejemplo, se han dado algunos casos en Valencia, Islas Baleares y Aragón (Álvarez Bermúdez, 2014).

\subsubsection{EXPERIENCIAS DE VALIDACIÓN EN EL TERCER SECTOR}

En el tercer sector, las principales medidas puestas en marcha han sido el reconocimiento de perfiles de carrera profesional en el ámbito de los jóvenes, a través del sistema de Occupational Standards. ${ }^{73}$

La acreditación de las competencias profesionales adquirida a través del aprendizaje informal o no formal está en marcha en el ámbito de tres Títulos de FP: Técnico Superior en Socio-Cultural y estimulación turística, Técnico Superior en Animación Sociocultural y Turística formación y estimulación o Técnico en Medio Ambiente Natural y Guía de Ocio.

Asimismo creemos oportuno mencionar el Instituto de la Juventud (INJUVE). Se trata de la agencia nacional española para el Programa de Juventud en Acción, es el responsable de su promoción y aplicación. Todos los que participan en este programa, reciben el certificado Youthpass ${ }^{74}$, que describe lo que han hecho y aprendido reconociendo su aprendizaje no formal.

\subsubsection{EL PROCEDIMIENTO DE EVALUACIÓN Y ACREDITACIÓN DE COMPETENCIAS PROFESIONALES EN CASTILLA Y LEÓN}

Como hemos comentado, la evaluación y acreditación de competencias profesionales está regulada en toda España por el Real Decreto 1224/2009 sobre el reconocimiento de las competencias profesionales adquiridas por

73 Para más información sobre este sistema, véase: http://www.nya.org.uk/resource/ national-occupational-standards/

${ }^{74}$ Youthpass es una iniciativa de la Comisión Europea orientada al reconocimiento y validación de aprendizajes no formales. La iniciativa está dirigida a jóvenes, en general con una baja empleabilidad, para que reflexionen sobre su proceso de aprendizaje y sobre sus resultados personales (Youthpass.eu, 2015). 
experiencia laboral. Por su parte, la gestión del procedimiento de validación está descentralizada en las Comunidades Autónomas.

Cumpliendo con la normativa nacional, la comunidad autónoma de Castilla y León publicó la Orden HAC/1605/2011 para desarrollar la gestión del procedimiento de evaluación y acreditación de competencias profesionales en el ámbito de la Comunidad de Castilla y León. Asimismo, estableció la estructura organizativa responsable (Orden HAC/1605, 2011).

Esta orden instituyó la Comisión Directora y la Comisión Asesora del procedimiento:

- la Comisión Directora: está adscrita a la Conserjería con competencias en materia de empleo. Se creó como una estructura administrativa responsable del procedimiento, con el objetivo de impulsar y garantizar el correcto desarrollo del mismo. Entre sus funciones se encuentran dirigir y coordinar la gestión del procedimiento;

- la Comisión Asesora: se encarga de garantizar la participación de los agentes económicos y sociales en el procedimiento. Prioritariamente trata temas sobre la identificación de los perfiles objeto de convocatoria y las garantías de calidad y homogeneidad de los procedimientos en el ámbito de la Comunidad Autónoma.

Actualmente en Castilla y León se han realizado dos convocatorias del procedimiento de evaluación y acreditación de competencias profesionales. Una en 2011 y otra en 2015. La primera convocatoria ha tenido tres partes, la primera en el año 2011, la segunda en el 2013 y la tercera en 2014.

En este trabajo hemos analizado las dos partes de la primera convocatoria, ya que la tercera parte de la segunda convocatoria se ha desarrollado durante la fase final de la tesis y la última convocatoria se está llevando a cabo actualmente. Ambas partes se han realizado de conformidad con el RD 1224/2009. La primera se materializó con la Orden HAC/1536/ 2011, que se encargó de convocar el procedimiento para unidades de competencia de cualificaciones profesionales de las familias profesionales de Servicios Socioculturales y a la Comunidad, y de Transporte y Mantenimiento de Vehículos. La segunda parte de la convocatoria llegó con la Resolución de 18 de septiembre de 2013, la cual preveía la ampliación de plazas para las personas en situación de reserva en la primera parte de la convocatoria, aunque solo se llevó a cabo para las unidades de competencia de cualifica- 
La validación de competencias profesionales en España e Italia

ciones profesionales de la familia profesional de Servicios Socioculturales y a la Comunidad.

Según los informes de la Junta de Castilla y León, en la primera parte de la convocatoria fueron evaluadas 2.673 personas y en la segunda 600 , obteniéndose un $95 \%$ de personas certificadas.

La evaluación de competencias se apoya, en Castilla y León y en toda España, en el Catálogo Nacional de Competencias Profesionales (CNCP) (explicado en el subapartad 4.2.2.1). Esto implica que se toman como referencia las cualificaciones definidas en dicho catálogo (hasta el tercer nivel) y sus unidades de competencia correspondientes.

\subsubsection{Profesionales del procedimiento}

El procedimiento de evaluación y acreditación de competencias en Castilla y León está guiado por dos figuras profesionales clave, el asesor y el evaluador.

El asesor es el encargado de proporcionar información al candidato sobre el procedimiento y de prestarle ayuda para preparar el proceso de evaluación. Esto implica que será su "acompañante" en la indagación para la recogida y presentación de evidencias que el candidato debe presentar con objeto de justificar sus competencias. El asesor también se encargará de realizar un informe, no vinculante, indicando la idoneidad sobre si el sujeto debe pasar o no a la fase de evaluación (INCUAL, 2010a).

El evaluador es el profesional que se ocupa de concretar las actividades de evaluación de la competencia profesional siguiendo los métodos e instrumentos dispuestos para tal fin. Asimismo, realiza la evaluación de las competencias y registra todas las actividades de evaluación y las decisiones que toma durante el proceso (INCUAL, 2010b).

\subsubsection{Fases del procedimiento}

En las próximas páginas presentamos las fases del procedimiento, para la reconstrucción de este nos hemos servido del RD 1224/2009 y de los instrumentos de apoyo (las guías del asesor y del evaluador y las guías de evidencias) creados posteriormente para facilitar la evaluación y acreditación de competencias profesionales. 
- Fase de admisión

En esta fase el candidato presenta la solicitud (ver Anexo 3), acompañada del historial profesional y/o formativo de acuerdo con el modelo de currículum vitae europeo (ver Anexo 4). Tras lo cual, las comisiones de admisión, se encargan de seleccionar a los candidatos según los criterios: Se comprueba el cumplimiento de los requisitos de participación, aplicando los criterios de admisión.

Las personas que deseen participar en el procedimiento deberán cumplir con los siguientes aspectos (R.D. 1224, 2009, n. art. 11):

a) poseer la nacionalidad española o tener el certificado de registro de ciudadanía comunitaria o la tarjeta de familiar de ciudadano de la Unión, o ser residente en España;

b) tener 18 años para UC correspondientes a cualificaciones de nivel I y 20 años para los niveles II y III;

c) tener experiencia laboral y/o formación relacionada con las competencias profesionales que se quieren acreditar

\section{- Fase de asesoramiento}

La fase de asesoramiento es de carácter obligatorio. Según las necesidades de los candidatos, puede realizarse de forma individualizada o colectiva, presencial o telemáticamente (R.D. 1224, 2009, n. art. 15).

Con objeto de facilitar el proceso de asesoramiento, el INCUAL, junto con el Ministerio de Educación, ha puesto a disposición de los asesores la guía del asesor. Como podemos ver en el Anexo 5, se trata de un instrumento que siguiendo el RD 1224/2009 proporciona pautas, instrumentos y métodos de asesoramiento.

Teniendo en cuenta el RD 1224/2009 y la guía del asesor podemos decir que esta fase se estructura en los siguientes pasos: 
La validación de competencias profesionales en España e Italia

\section{Recogida de evidencias en el dossier de competencias}

El asesor cita al candidato para la indagación y búsqueda de evidencias indirectas ${ }^{75}$ capaces de justificar las competencias profesionales que el candidato dice poseer. Posteriormente se realiza el dossier de competencias, formado por todo el conjunto de información documental y demás pruebas aportadas por la persona candidata durante el asesoramiento (INCUAL, 2010a, p. 20). Para esta indagación el asesor cuenta con una serie de instrumentos (INCUAL, 2010a; R.D. 1224, 2009):

- el cuestionario de autoevaluación, como podemos ver en el Anexo 6 , este refleja el dominio del candidato sobre las actividades profesionales principales y las secundarias ${ }^{76}$ (derivadas de las primeras). Este instrumento permite al asesor comprobar si el candidato tiene posibilidades de ver reconocidas las unidades de competencia que pretende acreditar;

- el historial profesional y/o formativo. Este documento está basado en el currículum vitae europeo. Como vemos en el Anexo 7, se encarga de recoger las actividades profesionales y formativas, llevadas a cabo por el candidato, en relación al referente de evaluación ${ }^{77}$;

- la ficha de recogida de información sobre funciones desempeñadas por el trabajador en la empresa. Esta ficha ayuda al asesor a documentar el currículum que presenta el candidato y contribuye a enriquecer el historial profesional y formativo. Podemos verla en el Anexo 8;

- la entrevista profesional con fines de asesoramiento. Este instrumento es útil para percibir indicios que ayuden a justificar la competencia profesional del candidato. Para ello, como se muestra en el Anexo 9, se hacen preguntas que den respuesta a qué sabe hacer, cómo, dónde lo ha hecho y que ha aprendido. La entrevista debe estructurarse a partir de la información dada por el candidato

75 En la fase de asesoramiento, las evidencias de competencias que se recogen son indirectas, es decir, inferidas de actividades realizadas en el pasado, pueden ser títulos, certificados o autodeclaraciones.

${ }^{76}$ Las actividades profesionales principales y secundarias son el soporte de las realizaciones profesionales y criterios de realización de la UC de referencia (INCUAL, 2010a, p. 19).

${ }_{77} \mathrm{El}$ referente de evaluación son las unidades de competencia que pretende demostrar el candidato. 
en el historial profesional y formativo y en el cuestionario de autoevaluación (INCUAL, 2010a, p. 65).

\section{Valoración de evidencias}

El asesor valora si la información profesional y/o pruebas aportadas por el candidato son capaces de justificar su competencia profesional respecto al referente de evaluación, teniendo en cuenta el cumplimiento de los siguientes requisitos (INCUAL, 2010a, pp. 21-22):

- suficiencia, es decir la evidencia aportada debe cubrir todo el referente de evaluación;

- autenticidad, en el sentido de que la información o pruebas presentadas deben ser el resultado de una actividad realizada por el propio candidato;

- actualidad, el candidato debe justificar que la competencia profesional es válida en el momento de la evaluación;

- pertinencia, la información y pruebas aportadas deben estar relacionadas con el referente de evaluación objeto de la convocatoria.

Una vez que el asesor valora si la información profesional y/o pruebas justifican la competencia profesional en relación con el referente de evaluación, este sistematiza toda la información en la ficha de sistematización de evidencias de competencia que mostramos en el Anexo 10. Este instrumento sirve de apoyo en la elaboración del informe del asesor para la comisión de evaluación (ver Anexo 11).

\section{Elaboración del informe del asesor para la comisión de evaluación}

Tras recoger toda la documentación, a modo de evidencias indirectas, el asesor realiza el informe de asesoramiento. Este documento indica las competencias que se consideran justificadas a partir del material aportado por el candidato y señala si conviene o no que el aspirante acceda a la fase de evaluación del procedimiento.

$\mathrm{El}$ informe debe contener los siguientes aspectos (INCUAL, 2010a):

- datos personales del candidato;

- asesoramiento sobre la UC;

- modalidad de asesoramiento (presencial o telemático); 
La validación de competencias profesionales en España e Italia

- fundamentos del informe (competencias profesionales suficientemente justificadas y argumentación del diagnóstico del asesoramiento);

- diagnóstico del asesoramiento (negativo o positivo), junto con la decisión del candidato de continuar o no en el procedimiento;

- propuesta de formación, en caso necesario, para que el candidato complete la UC que pretendía acreditar.

Si el informe resulta positivo se traslada a la correspondiente comisión de evaluación junto con la documentación aportada por el candidato para iniciar la fase de evaluación. Si por el contrario el informe resulta negativo se indica al candidato la formación complementaria que puede realizar y los centros que la imparten. No obstante, dado que el informe es orientativo y no vinculante, el candidato podría pasar a la fase de evaluación si lo desea, a pesar de que el informe no sea favorable. En este caso también se traslada el informe y la documentación a la comisión de evaluación.

\section{- Fase de evaluación}

Esta fase tiene por objeto comprobar si el candidato tiene las competencias profesionales requeridas para las realizaciones profesionales de la UC a evaluar, siguiendo los niveles establecidos, los criterios de realización y una situación de trabajo real o simulada (R.D. 1224, 2009, n. art. 16).

La fase se compone de los siguientes pasos:

\section{Composición de la comisión}

Las administraciones responsables del procedimiento son las encargadas de nombrar las comisiones de evaluación (R.D. 1224, 2009, n. art. 26). Están compuestas como mínimo por 5 evaluadores: un presidente, un secretario y al menos 3 vocales. Se prevé que haya evaluadores tanto del sector formativo como del productivo. Asimismo, en caso necesario, la comisión podría contar con la presencia y el apoyo de profesionales cualificados, con voz pero sin voto (R.D. 1224, 2009, n. art. 27).

\section{Análisis y evaluación de evidencias}

$\mathrm{Al}$ inicio de la fase de evaluación se analiza el informe del asesor y la documentación aportada por el candidato. La comisión de evaluación estudia estos documentos y emite un dictamen de valoración de evidencias de 
competencia indirectas, utilizando un documento como el que mostramos en el Anexo 12. En el dictamen se indica la conveniencia o no de la recogida de nuevas evidencias que demuestren la competencia profesional requerida en las unidades de competencia en las que el candidato se haya inscrito. En el supuesto de necesitar nuevas evidencias, la evaluación se desarrollará según una planificación previa en la que se señalen las actividades, los métodos de evaluación, los lugares y las fechas previstos (R.D. 1224, 2009, n. art. 28).

El candidato que no haya tenido una evaluación positiva en el dictamen recibe un informe con recomendaciones sobre un itinerario formativo para lograr la acreditación de la unidad o unidades de competencia. Para este candidato el procedimiento termina aquí.

\section{Elaboración del plan individualizado de evaluación}

En el caso de considerar que el candidato debe aportar nuevas evidencias el evaluador debe elaborar el plan individualizado de evaluación. Este plan debe ser aprobado por la comisión y debe acordarse con el candidato en la medida de lo posible en cuanto a instrumentos, fechas y lugares. En el Anexo 13 mostramos un modelo del plan de evaluación.

Durante este proceso, el evaluador va rellenando una ficha de seguimiento, como la que vemos en el Anexo 14, sobre las actividades que ha ido realizando con el candidato, indicando si las evidencias son suficientes o no, si ha realizado un plan individualizado de evaluación y si el candidato debe seguir o no en el procedimiento.

Para la selección de los métodos y su concreción en actividades de evaluación, el evaluador cuenta con la ayuda de dos importantes instrumentos: la guía del evaluador (ver Anexo 15) y las guías de evidencia (ver anexo 16) de la unidad de competencia (en adelante, guía de evidencia) que pretenda evaluarse. De este modo la evaluación se realizará de acuerdo con la naturaleza de la unidad de competencia correspondiente (referente de evaluación), las características de la persona aspirante a participar en el procedimiento y los criterios para la evaluación recogidos en la guías de evidencia. $^{78}$

78 Para cada cualificación profesional del CNCP existen unas guías de evidencias de su competencia profesional, es decir, una guía de evidencias de cada UC que compone la cualificación. 
La validación de competencias profesionales en España e Italia

El objetivo de la guía del evaluador es ayudar a este en la tarea de evaluar al candidato. En ella se exponen los principios del procedimiento y se describe el proceso de evaluación. Asimismo, se dedica un apartado a la utilización de la guía de evidencia y propone algunos métodos para la evaluación.

En lo relativo a las guías de evidencias debemos señalar que se trata de un instrumento fundamental para garantizar la validez, fiabilidad y homogeneidad, tanto en el desarrollo de los procesos como en los resultados de la evaluación. Para ello, la elaboración de estas guías parte del referente de evaluación, que está constituido por la UC a evaluar.

Cada guía desglosa las competencias profesionales de la UC correspondiente en competencias técnicas y sociales. Las competencias técnicas aparecen desglosadas en el "saber hacer" y "saber" y las sociales en el "saber estar". Estos "saberes" conforman las tres dimensiones de la competencia profesional a evaluar y para cada una de ellas la guía indica los aspectos que debe demostrar el candidato en las actividades profesionales principales y secundarias de la UC que se quiere demostrar (INCUAL, 2010c):

- la dimensión del "saber hacer" se explicita en forma de actividades profesionales subyacentes en las realizaciones profesionales y de criterios de realización. El candidato debe demostrar el dominio práctico en relación con las actividades profesionales principales y secundarias;

- en cuanto a la dimensión de la competencia en relación al "saber", esta comprende el conjunto de conocimientos técnicos, sobre conceptos y procedimientos, pertenecientes al módulo formativo de la UC correspondiente. Por tanto, el candidato debe probar la posesión de dichos conocimientos;

- respecto a la dimensión de la competencia relacionada con el "saber estar", en caso de existir, el candidato tiene que demostrar las actitudes de comportamiento relativas a la UC que se evalúa.

La guía también facilita situaciones profesionales de evaluación que definen el contexto profesional en el que se lleva a cabo la misma (ver Ilustración 1), así como unos criterios de evaluación asociados a la situación profesional de evaluación. Cada criterio de evaluación está formado por un criterio de mérito significativo, que a su vez tiene asociados unos indicado- 
res (ver Ilustración 2) y escalas de desempeño (ver Ilustración 3) para facilitar la evaluación.

Ilustración 1: Ejemplo descripción de situación profesional de evaluación, perteneciente a una de las guías de evidencias de la cualificación de educación infantil

\section{a) Descripción de la situación profesional de evaluación.}

Partiendo de la programación realizada por el candidato o la candidata, se someterá a éste a una situación de implementación de la misma, para recoger evidencias de competencia relacionadas con el "saber hacer" y "saber estar" en las que se utilizaran técnicas de dinámica de grupo, que impliquen el empleo de actividades del tipo "Role Playing". Se propone una dramatización aplicada a situaciones cotidianas de los niños y las niñas en Educación Infantil, tales como asamblea matinal, dinámicas grupales, actividades de educación no formal, entre otras, con niños y niñas de cero a tres años; y con los padres y madres mediante la realización de entrevista de tutoría, reunión colectiva, resolución de conflictos, entre otros.

Fuente: (INCUAL, 2010c, p. 18).

Ilustración 2: Ejemplo criterios de evaluación asociados a una situación profesional, perteneciente a una de las guías de evidencias de la cualificación de educación infantil

\begin{tabular}{|c|c|}
\hline Criterios de mérito & $\begin{array}{l}\text { Indicadores, escalas y umbrales de desempeño } \\
\text { competente }\end{array}$ \\
\hline $\begin{array}{l}\text { Eficacia de la intervención con la } \\
\text { comunidad educativa, realizada } \\
\text { mediante aplicación de técnicas de } \\
\text { dinámica grupal del tipo "Role } \\
\text { Playing". }\end{array}$ & $\begin{array}{l}\text { - Coherencia con la programación realizada por el } \\
\text { candidato o la candidata. } \\
\text { - Adecuación de las dinámicas de grupo a los } \\
\text { requerimientos del colectivo involucrado. } \\
\text { - Fomento de la participación de los interlocutores. } \\
\text { - Generación de ideas de aceptación colectiva. } \\
\text { El umbral de desempeño competente está explicitado en la } \\
\text { Escala C. }\end{array}$ \\
\hline $\begin{array}{l}\text { Desarrollo globalizado de las } \\
\text { actividades educativas en la } \\
\text { intervención. }\end{array}$ & $\begin{array}{l}\text { El umbral de desempeño competente requiere el } \\
\text { cumplimiento total de este criterio de mérito. }\end{array}$ \\
\hline $\begin{array}{l}\text { Uso de un lenguaje comprensible y } \\
\text { respetuoso, con una actitud empática } \\
\text { y asertiva. }\end{array}$ & $\begin{array}{l}\text { El umbral de desempeño competente requiere el } \\
\text { cumplimiento total de este criterio de mérito. }\end{array}$ \\
\hline
\end{tabular}


La validación de competencias profesionales en España e Italia

Fuente: (INCUAL, 2010c, p. 19).

Ilustración 3: Ejemplo de una escala de desempeño, perteneciente a una de las guías de evidencias de la cualificación de educación infantil

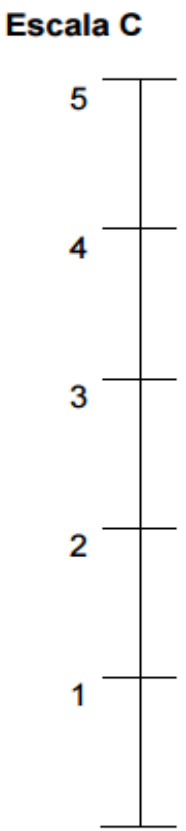

La intervención con la comunidad educativa, realizada es coherente con la programación de partida las dinámicas de grupo utilizadas se adaptan en su aplicación a los requerimientos de los colectivos involucrados, generando en cada caso ideas de aceptación colectiva y fomentando la participación de las y los interlocutores.

La intervención con la comunidad educativa, realizada es coherente con la programación de partida, las dinámicas de grupo utilizadas se adaptan en su aplicación a los requerimientos de los colectivos involucrados, generando en cada caso ideas de aceptación colectiva, pero se logra solamente una participación parcial de las y los interlocutores.

La intervención con la comunidad educativa, realizada es coherente con la programación de partida, las dinámicas de grupo utilizadas se adaptan en su aplicación a los requerimientos de los colectivos involucrados, las ideas generadas en cada caso no son aceptadas en su totalidad, lográndose solamente una participación parcial de las y los interlocutores.

La intervención con la comunidad educativa, realizada es coherente con la programación de partida, las dinámicas de grupo utilizadas presentan deficiencias en su aplicación a los requerimientos de los colectivos involucrados, las ideas generadas en cada caso no son aceptadas en su totalidad, lográndose una participación parcial de las y los interlocutores.

La intervención con la comunidad educativa, realizada no es coherente con la programación de partida, las dinámicas de grupo utilizadas presentan importantes deficiencias en su aplicación a los requerimientos de los colectivos involucrados, las ideas generadas en cada caso no son aceptadas en su totalidad.

Nota: el umbral de desempeño competente corresponde a la descripción establecida en el número 3 de la escala.

Fuente: (INCUAL, 2010c, p. 19).

Las guías de evidencia también proponen los métodos de evaluación y orientaciones para la evaluación de la UC en cuestión. Dichos métodos de evaluación son los siguientes:

- observación en el puesto de trabajo: se trata de la observación del candidato en su lugar de trabajo. El objetivo es recoger información sobre el candidato en su ambiente natural de manifestación de las competencias profesionales. Las guías proponen tomar como referente las realizaciones profesionales, los criterios de realización y el contexto profesional de la unidad de competencia. Si el evaluador lo considera oportuno puede complementar la observación con una entrevista específica sobre lo observado;

- simulaciones de actividades profesionales: la simulación práctica se puede llevar a cabo en un taller, laboratorio o empresa, en los que se 
recrean las variables principales de una actuación profesional, para que el candidato pueda demostrar sus competencias. Una variante de este método es la simulación telemática, que presenta una serie de casos prácticos, a los que el candidato debe responder, "online";

- pruebas profesionales de competencia. Consisten en pruebas teórico-prácticas para evaluar las tres dimensiones de la competencia profesional: "saber", "saber hacer" y "saber estar";

Para las simulaciones y las pruebas profesionales de competencia, las guías recomiendan recurrir a las situaciones profesionales y los criterios de evaluación correspondientes;

- entrevista profesional estructurada con fines de evaluación. Este método posibilita al evaluador la obtención de información sobre aspectos profesionales del candidato. Favorece la recogida de evidencias de competencia directas (actividades profesionales observables). La persona candidata argumenta, oralmente y con soportes visuales y otros métodos, lo que va haciendo o ha hecho. En este caso las guías recomiendan tomar como referente la UC, el contexto que incluye la situación profesional de evaluación y las especificaciones de los "saberes" correspondientes a las dimensiones de la competencia.

El evaluador realiza un informe de evaluación, siguiendo el modelo que vemos en el Anexo 17, en el que se recoge el resultado del candidato, dicho informe se presenta a la comisión de evaluación que deberá aprobarlo.

Al finalizar la actividad de evaluación se hace un registro firmado por el aspirante y el evaluador, lo cual resulta bastante útil de cara a una posible reclamación por parte del candidato.

\section{Información al candidato del resultado de evaluación}

Tras la evaluación la comisión de evaluación rellena un acta final conjunta con los resultados del proceso (ver Anexo 18). Este documento sirve de base para informar al candidato de los resultados, que se expresarán, por unidades de competencia, a través de un acta de valoración individual de la competencia profesional, en términos de "demostrada" o "no demostrada" (ver Anexo 19). Tras esto, la persona candidata tendrá derecho a realizar 
La validación de competencias profesionales en España e Italia

una reclamación ante la comisión de evaluación, mediante el modelo de solicitud de revisión individualizada que mostramos en el Anexo 20.

\section{- Fase de Acreditación y registro}

Según el procedimiento previsto en el RD 1224/2009, al finalizar el proceso de evaluación se entrega a los candidatos una acreditación, a través de un documento como el que se expone en el Anexo 21, de cada una de las unidades de competencia en las que hayan demostrado su competencia profesional (R.D. 1224, 2009, n. art. 17). Los resultados quedarán recogidos en un registro estatal, bajo la custodia del Servicio Público de Empleo Estatal y al que tendrán acceso el Ministerio de Educación y las administraciones educativas y laborales de las comunidades autónomas (R.D. 1224, 2009, n. art. 18).

En cuanto a la entrega de títulos o certificados de profesionalidad tiene lugar "fuera" de este procedimiento. La persona que reúna los requisitos para poder obtener un certificado de profesionalidad o un título de formación profesional ${ }^{79}$ será informada de los trámites para lograr su obtención.

Para cerrar la explicación del procedimiento de evaluación y acreditación de competencias profesionales en Castilla y León, reflejamos de forma sintética las fases que acabamos de ver, con los aspectos más significativos de cada una de ellas (ver Cuadro 12):

Cuadro 12: Fases del procedimiento de evaluación y acreditación de competencias en Castilla y León

\begin{tabular}{|c|c|}
\hline$\frac{.00}{\frac{0}{\frac{0}{0}}}$ & $\begin{array}{l}\text { Actividades principales } \\
\text { Comprobación del cumplimiento de los requisitos de participación } \\
\text { Aplicación de criterios de admisión }\end{array}$ \\
\hline $\begin{array}{l}\mathscr{\Xi} \\
\dddot{\Psi} \\
\dddot{\Psi}\end{array}$ & $\begin{array}{l}\text { Profesionales de esta fase } \\
\text { Comisiones de Admisión }\end{array}$ \\
\hline
\end{tabular}

${ }^{79}$ Para obtener los títulos de técnico o técnico superior, se requerirá cumplir, además, con los requisitos de acceso a las enseñanzas de formación profesional de grado medio y de grado superior respectivamente (R.D. 1224, 2009, n. art. 17). 


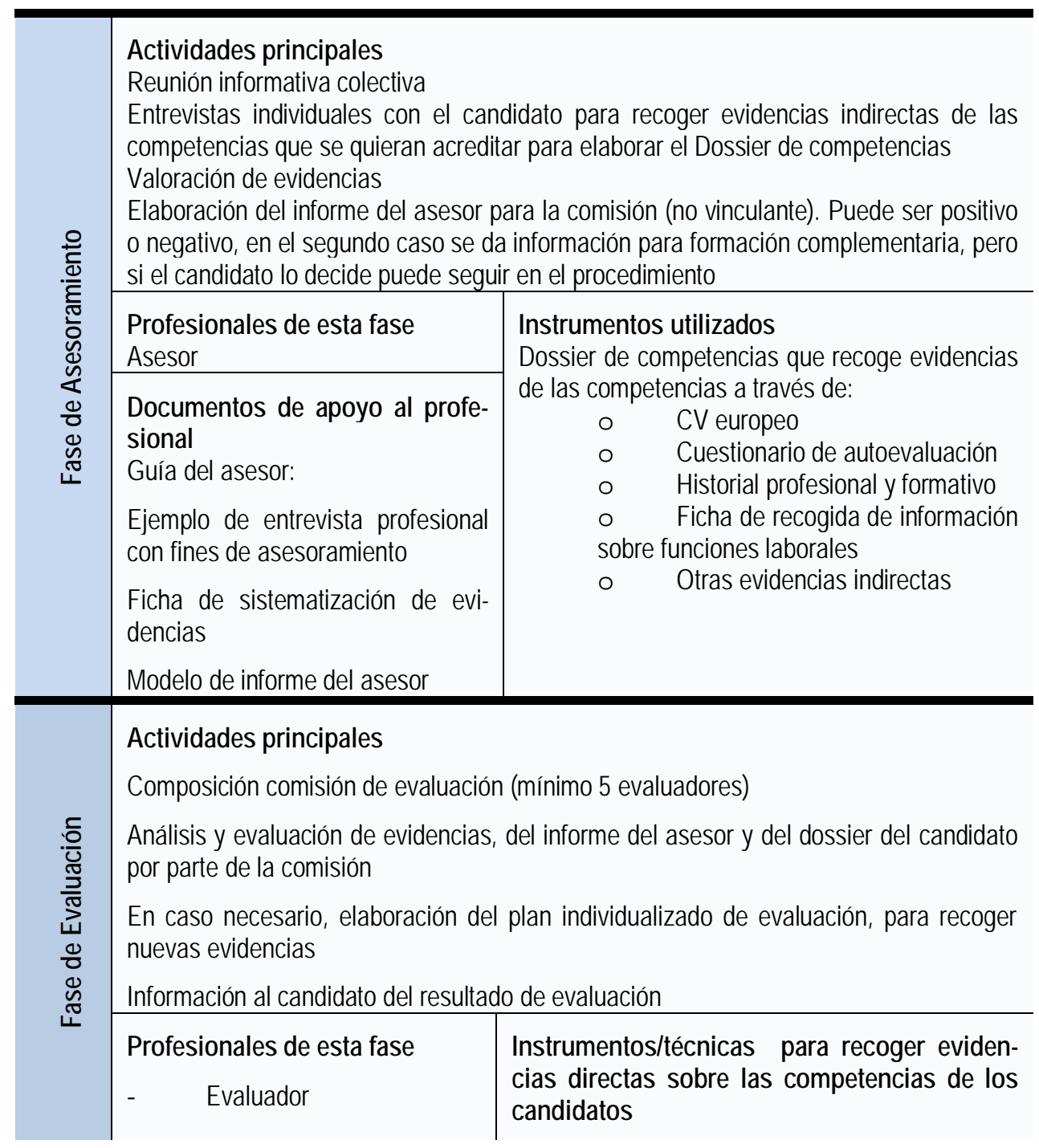


La validación de competencias profesionales en España e Italia

\begin{tabular}{|c|c|c|}
\hline & $\begin{array}{l}\text { Documentos de apoyo al profe- } \\
\text { sional } \\
\text { Guías de evidencias de la unidad } \\
\text { de competencia } \\
\text { Guía del evaluador: } \\
\text {-Modelo de plan individualizado } \\
\text {-Ficha de seguimiento } \\
\text {-Modelo de informe de evaluación } \\
\text {-Modelo acta de valoración indivi- } \\
\text { dual de la competencia profesional } \\
\text {-Modelo de acta final }\end{array}$ & $\begin{array}{l}\text { Observación del candidato en puesto de trabajo } \\
\text { Simulaciones } \\
\text { Pruebas estandarizadas de competencia profe- } \\
\text { sional } \\
\text { Entrevistas profesionales } \\
\text { Informe de asesoramiento }\end{array}$ \\
\hline 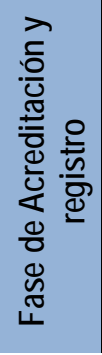 & \multicolumn{2}{|c|}{$\begin{array}{l}\text { Actividades principales } \\
\text { Expedición de una acreditación por cada una de las unidades de competencia que } \\
\text { haya demostrado el candidato } \\
\text { Indicación de trámites para obtención de certificado de profesionalidad o título de for- } \\
\text { mación profesional, si se diese el caso } \\
\text { La administración competente transferirá los resultados a un registro, de carácter esta- } \\
\text { tal, nominal y por unidades de competencia acreditadas }\end{array}$} \\
\hline
\end{tabular}


La validación de competencias profesionales

\subsection{La validación de competencias profesionales en Italia}

En este apartado presentamos la extensa producción legislativa y de políticas que se ha desarrollado en Italia a lo largo de los últimos 15 años con el propósito de crear un sistema nacional de validación de competencias profesionales que, como veremos, todavía hoy no ha logrado conformarse.

Asimismo, ante la ausencia de un procedimiento nacional, exponemos una visión general sobre la situación de cada región en cuanto a la creación y puesta en marcha de procedimientos de validación de competencias profesionales.

Por último, mostramos el procedimiento de formalización y acreditación de competencias en la región de Emilia-Romagna, la cual cuenta con su propio sistema regional de cualificaciones.

\subsubsection{CONTEXTO}

Para hablar de validación y certificación de competencias en Italia tenemos que situarnos en el escenario de la formación continua, que en este país empezó a desarrollarse en el año 1993 con la aprobación de la Ley 236/1993. Esta ley está dirigida, sobre todo, a la formación de los trabajadores (ocupados) (Ley 236, 1993).

En julio de ese mismo año tuvo lugar el "Protocollo sulle politiche dei redditi", un acuerdo entre el Gobierno y los sindicatos que acordó la modernización y recualificación de la educación y de los sistemas formativos. El acuerdo estaba dirigido a enriquecer las competencias de base y profesionales para mejorar la competitividad del sistema productivo y la calidad de los servicios. Tal proceso comportó, entre otras cosas, la necesidad de realizar mejoras en la oferta formativa para favorecer la integración, la recualificación profesional y la formación continua, a través del de un sistema flexible de formación profesional y continua, definiendo estándares formativos ${ }^{80}$ únicos nacionales (Accordo Governo-Sindacati, 1993).

${ }^{80}$ El estándar de formación hace referencia a los objetivos de aprendizaje, los contenidos curriculares, los requisitos de admisión y los recursos requeridos para alcanzar los objetivos fijados (Cedefop, 2014, p. 114). 
La validación de competencias profesionales en España e Italia

Posteriormente, y ante la urgencia de activar un plan para incrementar la tasa de actividad, tuvo lugar el "Accordo per il Lavoro", acuerdo alcanzado entre el Gobierno y las Partes sociales en 1996. Este acuerdo concretó una serie de medidas para la reforma del sistema formativo, y habló de los sistemas de certificación como un instrumento idóneo para conferir unidad y visibilidad a la formación de cada persona a lo largo de toda la vida, para promover el reconocimiento de los créditos formativos ${ }^{81}$ y documentar las competencias adquiridas.

El acuerdo también subrayó la necesidad de otorgar plena dignidad a todos los aprendizajes adquiridos en el trabajo o en contextos no formales, y prefiguró un sistema global de oportunidad de aprendizaje que tiene como punto principal el individuo (Accordo per il Lavoro, 1996).

Un año más tarde se publicó la Ley 196 sobre la promoción del empleo. Propuso la reorganización de la formación profesional para asegurar a los trabajadores oportunidades adecuadas de formación y de promoción profesional. Entre las líneas de actuación propuestas para la consecución de tal objetivo hizo especial hincapié en la creación de un sistema nacional de certificación de competencias adquiridas a través de la formación profesional (Ley 196, 1997, p. 17).

De este modo, se empezó a considerar en Italia la validación y certificación de competencias, que tiene como punto nacional de referencia el Istituto per lo Sviluppo della Formazione Professionale dei Lavoratori (Instituto para el Desarrollo de la Formación de los Trabajadores) (en adelante, Isfol).

El Isfol es un ente público de investigación nacido en el año 1972 con el Decreto del Presidente de la Republica número 10. Comenzó siendo una infraestructura de investigación, experimentación y asistencia técnica en el campo de la formación profesional. Poco a poco fue ampliando sus competencias, el estatuto del Isfol de 2003 otorgó al ente competencias formativas, laborales y sociales. Actualmente se encarga, entre otras cosas y bajo la supervisión del Ministerio de Trabajo y Políticas sociales, de promover actividades de estudio, investigación, experimentación documentación e información. El objetivo es proporcionar un apoyo técnico-científico a los ministerios, al Parlamento, a las regiones, a entes locales y a otras institucio-

${ }^{81}$ El crédito formativo se refiere al conjunto de competencias que pueden ser reconocidas en el ámbito de diferentes vías de formación o de trabajo y las modalidades de su reconocimiento. 
nes sobre políticas y sistemas de formación y aprendizaje a lo largo y ancho de toda la vida y sobre aspectos relativos al mercado laboral y a la inclusión social. Asimismo, forma parte del Sistema Estadístico Nacional y colabora con instituciones europeas (Isfol, 2015b). En el campo específico de la validación de competencias, el Isfol es el soporte del Ministerio de Trabajo en la creación de una base de datos nacional de descripción de las funciones laborales y estándares desarrollados en Italia en los últimos años, los cuales se agrupan en 24 áreas económicas y profesionales (Di Francesco \& Perulli, 2011).

\subsubsection{IMPULSO DE LA VALIDACIÓN DE APRENDIZAJES NO FORMALES E INFORMALES}

Desde que tuvo lugar la celebración de la Cumbre de Lisboa, en el año 2000 , Italia ha tratado de impulsar la validación y certificación de aprendizajes no formales e informales a través de una serie de intervenciones legislativas que se exponen a continuación.

El 18 de febrero del año 2000 tuvo lugar un importante Accordo StatoRegioni $^{82}$. Este acuerdo entre el antiguo Ministerio del Trabajo y de la Seguridad Social ${ }^{83}$ y las regiones italianas, pretendía garantizar la coordinación eficaz regional referida a las diferentes competencias en el campo de la formación profesional.

$\mathrm{El}$ anexo B del acuerdo "Procedure per la costituzione del sistema nazionale di certificazione delle competenze profesionali", planteó el procedimiento para la constitución de un sistema nacional de certificación de competencias profesionales. El objetivo era asegurar la homogeneidad de las certificaciones en el territorio nacional y su reconocimiento en el ámbito europeo.

Este anexo supuso un punto clave para la conformación del proceso de certificación por varios motivos (Accordo Stato-Regioni, 2000, n. anexo B.c):

82 Este tipo de acuerdos son emanados por la Conferenza Stato Regioni. Esta conferencia es la sede del Gobierno en la cual se realizan acuerdos entre las administraciones centrales y regionales. Los aspectos tratados son de interés nacional, regional y provincial (Governo Italiano, 2015).

83 Actualmente llamado Ministerio del Trabajo y de las Políticas Sociales. 
La validación de competencias profesionales en España e Italia

1. instó al antiguo Ministerio de Trabajo y Seguridad Social a la constitución de una comisión cuatripartita formada por representantes de este ministerio, del Ministerio de Instrucción Pública, del Ministerio de la Universidad e Investigación Científica y representantes de las regiones, para la supervisión del proceso de certificación y con la asistencia técnica del Isfol;

2. estableció que la certificación sería efectuada por las regiones, según sus leyes y respetando el mencionado artículo 17 de la ley 196/1997;

3. definió las competencias profesionales certificables como aquellas que constituyen un patrimonio de conocimiento operativo de los individuos y su conjunto constituye una cualificación o figura profesional;

4. y por último recomendó a las regiones la adopción del Libretto Formativo del Cittadino (que explicaremos en el subapartdo 4.3.6.1) como instrumento para documentar el curriculum formativo y las competencias adquiridas, con el objetivo de obtener un título de estudio o la inserción en el sistema educativo.

La Comisión cuatripartita mencionada en este anexo se constituyó en el curso del año 2000. Asimismo, un año más tarde se formuló el Decreto Ministerial 174/2001 sobre Certificazione delle competenze nel sistema della formazione professionale, una de las primeras piezas clave en los inicios de la constitución de este procedimiento en Italia.

En respuesta a la propuesta realizada en el Accordo Stato-Regioni del año 2000, este decreto definió el procedimiento para poner en marcha un sistema nacional de competencias en la formación profesional con el fin de garantizar la transparencia de los cursos formativos y de permitir la realización de pasarelas entre los diferentes sistemas (D.M. 174, 2001).

El artículo 2 del documento redefinió el concepto de competencia certificable, considerándolo como la adquisición de capacidades a través de diferentes vías de formación profesional y/o de experiencias de trabajo, y/o autoformación, evaluables también como créditos formativos. Mientras que el artículo 3 consideró la definición de estándares mínimos, relativos a las figuras profesionales y a las competencias, como un prerrequisito clave en el nuevo sistema de certificación.

Según lo estipulado en el Accordo-Regioni 2000, el decreto delegó en las regiones (a través de su artículo 4) la responsabilidad de la certificación y el artículo 5 estableció tres tipos de certificación posibles: 
a) al finalizar un proceso de formación profesional dirigido a la adquisición de un título;

b) como resultado de los procesos de formación parcial o en caso de abandono precoz del proceso de formación o en cursos formativos que no conducen a la adquisición de un título;

c) como resultado de experiencias de trabajo y de autoformación por petición de los interesados, para el ingreso a diferentes niveles del sistema de educación y formación profesional o para la adquisición de un título de estudio.

El segundo punto del artículo 5 instituyó que las certificaciones se recogerían en el Libretto Formativo del Citadino, ya nombrado y definido en el Accordo Stato-Regioni del año 2000 y entendido como un instrumento de recogida de documentación de las certificaciones adquiridas poco a poco por el individuo (D.M. 174, 2001).

El Decreto Ministerial 174 contenía las reglas para articular un sistema de certificación que, efectivamente, ha impulsado una serie de acuerdos Stato-Regioni llevados a cabo entre las regiones y las Partes Sociales. De esta forma se contribuyó a la definición de estándares mínimos de competencia ${ }^{84}$ y al impulso de la validación de competencias adquiridas en cualquier campo (formal, no formal o informal).

En 2003 se publicó la ley 30/2003 (también conocida como la Ley Biagi). Tenía el objetivo de realizar un sistema eficaz y coherente de instrumentos dirigidos a garantizar la transparencia y la eficiencia en el mercado de trabajo y mejorar la inserción profesional de las personas en situación de desempleo. Así se perseguían los objetivos propuestos por la Unión Europea en materia de ocupación y suministro de mano de obra (Ley 30, 2003).

En ese mismo año se promulgó también la Ley 53/2003, reconociendo la importancia de alternar la formación y el trabajo en la escuela, desde una perspectiva de aprendizaje permanente. Asimismo previó la creación de dispositivos institucionales para dar validez a las prácticas y a las experiencias individuales de aprendizaje, cualesquiera fuesen los contexto en los que se hubiesen adquirido (Ley 53, 2003).

${ }^{84}$ El estándar mínimo de competencia define los conocimientos, capacidades y competencias mínimos que deben poseerse para realizar un oficio específico. 
La validación de competencias profesionales en España e Italia

Otro de los pasos dados en esta dirección llegó de la mano de tres acuerdos Stato-Regioni:

El 19 de junio de 2003 tuvo lugar el Accordo Stato-Regioni 2003 que exigió activar una colaboración por parte de las instituciones, a nivel nacional y de acuerdo con las regiones, para la definición de estándares formativos mínimos con el objetivo de lograr el reconocimiento nacional de los créditos, las certificaciones y los títulos, incluidos los créditos adquiridos en el apprendistato (explicado en el subapartado 3.2.2.4) (Accordo Stato-Regioni, 2003).

El Accordo Stato-Regioni del 15 de enero de 2004 definió los estándares formativos mínimos relativos a las competencias de base en vías experimentales de educación y formación profesional (Accordo Stato-Regioni, 2004).

Por su parte, el Accordo Stato-Regioni del 5 de octubre de 2006 aprobó la definición de los estándares mínimos formativos relativos a 14 perfiles profesionales, en cursos experimentales de educación y formación profesional (IeFP) de duración trienal (Accordo Stato-Regioni, 2006).

En este periodo, concretamente en octubre de 2005, se aprobó el $\mathrm{Li}$ bretto del Cittadino, esta vez con un formato nacional que le convertía en el único instrumento de índole nacional para la validación y certificación de competencias (Decreto Interministerial, 2005).

Durante el mes de septiembre de 2006, el Ministerio de trabajo promovió un Comité Nacional dirigido a la definición y aplicación de un marco y de un sistema nacional de cualificaciones compuesto por el Ministerio de Educación, Universidad e Investigación, Regiones y Partes Sociales (Di Francesco \& Perulli, 2011). Esto se propuso como un paso importante en cuanto al desarrollo de un sistema italiano capaz de dotar de transparencia a las competencias adquiridas en cualquier contexto (formal, no formal o informal), en coherencia con las políticas europeas para el aprendizaje permanente (Perulli, 2011, p. 85).

Sin embargo, todavía en el año 2007 Italia seguía sin contar con un sistema fuerte para la implantación del dispositivo de evaluación y acreditación de competencias profesionales (Kytola \& Hawley, 2007). Pensando en poner remedio a esta situación Italia preparó, durante los años 2007 y 2008, una metodología común y un enfoque a nivel nacional de resultados de 
aprendizaje, que pueden ser considerados como base para la construcción de un sistema de cualificación integrado ${ }^{85}$.

Además durante 2009 y 2010 se firmaron otros importantes acuerdos en ámbito nacional, tales como:

El Accordo Stato-Regione del 5 de febrero de $2009^{86}$, que con respecto al sistema de educación y formación profesional ( $I e F P)$, constituyó el primer repertorio nacional de perfiles profesionales, estableciendo los estándares mínimos de las competencias técnicas. El repertorio incluye 19 figuras profesionales contenidas en cursos experimentales de duración trienal. 14 de estas figuras se introdujeron con el previo acuerdo del 5 de octubre de 2006 citado anteriormente. Añadió por tanto cinco áreas nuevas y su uso está garantizado a nivel nacional.

O el Accordo Stato-Regioni del 29 de abril de 2010, que entró en vigor en Italia en el curso 2011/2012 e incluye una reforma en los licei y los institutos. Este acuerdo define las figuras profesionales a nivel nacional (vigentes hasta el día de hoy) en los sistemas de IeFP. Fueron 21 figuras para cursos de formación profesional de duración trienal y otras 21 para los cursos de cuatro años de duración (Accordo Stato-Regioni,2010).

Estas figuras profesionales fueron incluidas, en el año 2011, en las siete áreas profesionales que mostramos en el Anexo 22. La definición de las áreas se logró gracias a la elaboración integrada de clasificaciones estadísticas internacionales referidas a actividades económicas $\left(\mathrm{NACE}^{87}-\mathrm{ATECO}^{88}\right)$

85 En 2008 se elaboró un inventario de estándares regionales de competencias y cualificaciones y fue probado con éxito en el sector del turismo y de la mecánica. En el transcurso del año 2010 otros sectores como el químico o el de alimentación y agricultura, siguieron la misma metodología, estas prácticas han inspirado la creación de estándares en algunas regiones y la revisión de aquellos nacionales previstos para las cualificaciones y los diplomas profesionales (Perulli, 2011, p. 85).

${ }^{86} \mathrm{El}$ acuerdo fue reconocido por el Decreto de 29 de mayo de 2009, publicado en el Diario Oficial núm. 140 de 19 de junio de 2009.

87 Nomenclature statistique des activités économiques dans la Communauté européenne-Clasificación estadística de las actividades económicas en la Comunidad Europea, creada por el Eurostat, el órgano estadístico de la Comisión Europea.

88 Versión nacional italiana de la clasificación europea NACE. 
La validación de competencias profesionales en España e Italia

y de la clasificación de profesiones (ISCO ${ }^{89} / \mathrm{NUP}^{90}$ ). El objetivo que se perseguía era disponer de un referente homogéneo nacional para el mundo económico y de las profesiones. En concreto, se quería crear dicho referente para las figuras profesionales nacionales de referencia de las cualificaciones y diplomas profesionales de la educación y formación profesional (IeFP).

\subsection{3 ÚlLTimos AVANCES}

En los últimos años Italia ha dado relevancia al reconocimiento de los aprendizajes adquiridos fuera del contexto institucional. Parece que este aspecto está relacionado con la crisis económica en la que se encuentra sumido el país. Ya que esta nación está intentando apostar por una mejora en las competencias de los ciudadanos, para afrontar mejor la difícil situación en la que se encuentra el mercado laboral. Prueba de esa intención son las siguientes publicaciones:

En mayo de 2009 se publicó el Libro Bianco del Ministro del Lavoro sul futuro del modelo sociale. Este documento abordó el tema del sistema social italiano, reconociendo que los jóvenes entraban tarde al mundo del trabajo y con competencias bajas en comparación con los jóvenes de otros países europeos. Además puso de manifiesto la baja tasa de actividad en Italia.

Precisamente por este motivo, Italia pretendía mejorar el futuro laboral de los jóvenes trabajando sobre la calidad del sistema educativo. Se consideró volver a partir de la educación, la formación y el trabajo para salir de la crisis en la que todavía hoy nos encontramos inmersos y que ha servido para dar valor al ser humano y al desarrollo de su capacidad personal: "El trabajo vuelve a ser el ámbito en el que se mide el logro de la integración social. Es en el trabajo donde el hombre descubre su dignidad, desarrolla relaciones sociales y ejercita su propio deseo de construir"(Ministero del Lavoro, della Salute e delle Politiche Sociali, 2009, p. 26).

89 International Standard Classification of Occupations (Clasificación Internacional Uniforme de Ocupaciones). Es la clasificación de ocupaciones de la Organización Internacional del Trabajo (OIT).

${ }^{00}$ Nomenclatura e Classificazione delle Unità Professionali (Clasificación de las Unidades Profesionales). 
El libro se centró en la persona, quien en momentos de transición debería poder disponer de un sistema capaz de dar respuesta a una pluralidad de exigencias. En este documento, el aprendizaje continuo se consideró uno de los derechos fundamentales del trabajo y se dio relevancia a los conocimientos y habilidades que se poseen, no sólo a aquellos adquiridos por vía formal. Es decir, se dio valor a las habilidades que la persona tiene y puede demostrar, no dando tanta importancia a la parte formal y burocrática.

De este modo se dio trascendencia al desarrollo de sistemas integrados de cualificaciones, dirigidos a la elaboración de un sistema nacional de validación de competencias en el que también se reconozcan los aprendizajes no formales e informales.

En el año 2010 salió a la luz el plan de acción "Italia 2020", dirigido a mejorar la ocupación de los jóvenes a través de la integración entre aprendizaje y trabajo (Italia 2020, 2009, p. 26). Este plan admitió que los jóvenes estaban bloqueados en una sociedad incapaz de valorar el propio capital humano (las competencias y conocimientos que se adquieren fuera de un ámbito formal de aprendizaje). Se reconoció que el valor legal de los títulos de estudio no había podido garantizar la calidad de los conocimientos, habilidades y competencias realmente adquiridas en la realización de los cursos que conllevan a su conseguimiento.

El documento reafirmó el valor del aprendizaje informal. Poco a poco el valor legal del título se debería sustituir por la lógica de la acreditación de los cursos, valorados según su capacidad de ofrecer una preparación de alto nivel cualitativo en coherencia con las necesidades de la persona, de la economía y de la sociedad (Italia 2020, 2009).

Por todo lo anteriormente expuesto, este plan de acción propuso facilitar la transición de la escuela al trabajo, mejorar el apprendistato y promover experiencias de trabajo durante los estudios. También animó a replantear el papel formador de la universidad, invitando a abandonar la vieja concepción de la obtención del título de estudio universitario como única meta para los estudiantes. Por el contrario, dispuso que la Universidad previese una oferta formativa coherente con la idea del aprendizaje a lo largo de la vida, para permitir la adquisición de competencias capaces de resolver los problemas que se planteen en el puesto de trabajo.

En el mes de febrero de 2010 tuvo lugar un importante acuerdo, entre el Ministerio del Trabajo, las regiones y las Partes Sociales, que se materializó en un documento guía para la formación durante el año 2010: "Linee 
guida per la formazione nel 2010". Este acuerdo recalcó la idea de favorecer y fomentar la formación continua. El Gobierno, las regiones y las Partes Sociales se mostraron de acuerdo en favorecer la inversión en el campo formativo. Sobre todo para evitar la exclusión laboral, para dar respuesta a la demanda de trabajadores cualificados y re-cualificados exigidos en el nuevo mercado laboral y para optimizar un encuentro dinámico y flexible entre demanda y oferta de trabajo. Así se propuso estudiar las necesidades de competencias y figuras profesionales, relevantes en los diferentes territorios y en los diversos sectores productivos, y difundir el uso del método de aprendizaje por competencias. Esto comportó la convergencia hacia la definición de un sistema nacional de competencias capaz de garantizar a los ciudadanos el uso de aprendizajes adquiridos por cualquier vía. Para lograrlo, las partes implicadas entendieron que era importante extender la experimentación del Libretto Formativo como instrumento de registro de competencias y relanzar el contrato de apprendistato con el objetivo de garantizar una vía de formación a todos los aprendices.

Otra de las intervenciones propuestas por las partes implicadas fue la definición (a partir de las experiencias ya presentes en el plano regional en vía experimental para el 2010), de un sistema de acreditación sobre la base regional y según estándares homogéneos compartidos a nivel nacional de "evaluadores y certificadores". Estos debían reconocer, evaluar y certificar, en situaciones de trabajo auténticas, competencias efectivas adquiridas por cualquier vía por personas en búsqueda de empleo. De esta manera se reforzaría la transparencia y se aumentaría la capacidad de oferta sobre el mercado de trabajo y se mejoraría el encuentro entre demanda y oferta. El instrumento idóneo para registrar las competencias adquiridas sería el Libretto Formativo (Linee guida, 2010).

En el año 2012 se publicó otra importante normativa relacionada con la certificación de competencias no formales e informales, en el ámbito del apprendistato. Se trata del Decreto Ministerial 96/2012, supone el acuerdo entre el Estado y las regiones sobre la definición de un sistema nacional de certificación de competencias adquiridas por cualquier vía durante el apprendistato.

Este decreto sitúa a la persona en el centro del proceso de certificación desde la perspectiva del aprendizaje permanente. Pretende facilitar el acceso y la permanencia del individuo en el mundo laboral; flexibilizar el 
trabajo y el crecimiento de las capacidades y conocimientos para darles un uso efectivo.

Asimismo, el decreto ministerial considera como objeto de certificación las competencias profesionales adquiridas en cualquier ámbito y siguiendo los estándares profesionales de los repertorios nacionales. Además establece tres fases para el proceso de certificación:

- fase de identificación de competencias del sujeto;

- fase de evaluación de competencias del candidato según criterios predefinidos;

- fase de certificación, en la que se le entregan, al sujeto, documentos estandarizados que certifican las competencias que el candidato haya conseguido demostrar.

Un importante paso que se ha dado en Italia en los últimos años, referente a la implantación de un dispositivo de acreditación de competencias profesionales, ha sido la creación de un marco nacional de cualificaciones. En junio de 2012 el Isfol publicó el "Primer informe italiano de relación de las cualificaciones con el Marco Europeo de Cualificaciones”.

Este informe relacionó las cualificaciones italianas con los niveles del Marco Europeo de Cualificaciones (Isfol et al., 2012). De esta manera Italia intenta seguir las recomendaciones de la UE, que desde el año 2006 insta a los países de la unión a la constitución un marco nacional de cualificaciones.

En cuanto al ámbito legislativo, en el año 2012 Italia, afrontó el tema del aprendizaje permanente desde una perspectiva del mundo del trabajo, a través de la reforma laboral descrita en la Ley 92/2012. Esta ley, conocida como Riforma Fornero, dicta unas normas generales dirigidas a la construcción de un sistema nacional para el aprendizaje permanente. Define el aprendizaje formal, no formal e informal en la línea de las indicaciones de la Unión Europea y hace referencia a otros aspectos relacionados con la validación y certificación de competencias (Ley 92, 2012):

- considera actividades de realización prioritaria el reconocimiento de aprendizajes adquiridos a través de cualquier vía (párrafo 55 ; art. 4);

- habla de la inclusión del aprendizaje permanente dentro de la Universidad y de la puesta en marcha de servicios que promuevan la formación, el aprendizaje y la valorización de la experiencia profesional adquirida por las personas (párrafo 56; art. 4); 
La validación de competencias profesionales en España e Italia

- insta al Gobierno a poner en marcha procesos de identificación y validación de aprendizajes no formales e informales, a través de un sistema de nacional de certificación de competencias (párrafo 58; art. 4);

- delega en las regiones el establecimiento de los costes del procedimiento que corren a cargo de la persona que quiera someterse a la validación y certificación de competencias no formales e informales (párrafo 61; art. 4);

- establece el respeto de unos principios mínimos y homogéneos, en ámbito nacional, de accesibilidad, privacidad, transparencia, objetividad y trazabilidad, por parte del sistema público nacional de certificación de competencias (párrafo 64; art.4);

- instituye la certificación de competencias adquiridas en contextos no formales e informales como un acto público dirigido a garantizar la transparencia y el reconocimiento de los aprendizajes. Asimismo, establece que la certificación conduce a un certificado, diploma o título que documente formalmente la validación efectuada por un ente público, acreditado o autorizado para la validación. (párrafo 65; art.4);

- define competencia certificable como un conjunto estructurado de conocimientos y de habilidades adquiridas en contextos formales, no formales e informales, previo procedimiento de validación en los casos de aprendizajes no formales e informales (párrafo 66; art.4).

Del año 2013 cabe destacar el decreto legislativo número 13 de 16 de enero. Este decreto define la organización y estructura generales que deben seguir los procedimientos de identificación, validación y certificación de aprendizajes no formales e informales, siguiendo las directrices europeas, y según el artículo 4 de la Ley 92/2012 que acabamos de exponer (Decreto Legislativo 13, 2013).

$\mathrm{El}$ artículo $2 \mathrm{f}$ ) establece los siguientes entes públicos titulares que deben ocuparse de la regulación del proceso de identificación, validación y certificación de competencias:

1. el Ministerio de Educación, de la Universidad y de Investigación, en materia de identificación y validación y certificación de competencias referidas a títulos de estudio del sistema escolar y universitario;

2. las regiones y las provincias autónomas de Trento y Bolzano, en materia de identificación y validación y certificación de competencias referidas a cualificaciones competencia de las regiones y comunidades autónomas; 
La validación de competencias profesionales

3. el Ministerio de Trabajo y Políticas Sociales, en materia de identificación y validación y certificación de competencias referidas a cualificaciones profesionales no organizadas en órdenes o colegios;

4. el Ministerio de Desarrollo Económico y otras autoridades competentes según el artículo 5 del Decreto Legislativo 9 de noviembre de 2007, n. 206.

En el apartado g) del mismo artículo se establecen los entes públicos o privados que pueden proporcionar en su totalidad o en parte servicios de identificación, validación y certificación de competencias. ${ }^{91}$

Por último, señalamos los artículos 3.4, 5 y 9 del decreto legislativo. El primero, garantiza los principios de simplicidad, accesibilidad, transparencia, objetividad, trazabilidad, privacidad, metodología adecuada y equidad y no discriminación, en el sistema nacional de certificación de competencias. Por su parte, el artículo 5 determina las fases que debe tener el procedimiento de validación y certificación:

1. Identificación de las competencias susceptibles de certificación.

2. Evaluación de competencias.

3. Acreditación, a través de la validación o certificación de competencias.

Para finalizar, el artículo 9 establece la realización de un seguimiento y evaluación del procedimiento, por parte de los entes públicos titulares, con el objetivo de lograr una mejora constante del sistema nacional de certificación (Decreto Legislativo 13, 2013).

\subsubsection{EXPERIENCIAS DE VALIDACIÓN EN EL SECTOR PRIVADO}

Sobre las experiencias de validación en empresas, sobre todo de los aprendizajes no formales e informales, cabe decir que en los dos últimos años se han multiplicado las prácticas de análisis de competencias profesionales de los trabajadores. Tienen el objetivo de aumentar el nivel de empleabilidad y dotar a los trabajadores de instrumentos para luchar contra la exclusión laboral o para mejorar su movilidad geográfica o empresarial.

${ }^{91}$ Estos entes públicos o privados son: sujetos públicos o privados, incluidas las cámaras de comercio, industria, artesanía y agricultura, autorizados o acreditados por un ente público titular, o habilitado por norma de ley estatal o regional, incluidas las instituciones escolares, las universidades y las instituciones de alta formación artística, musical y de danza. 
La validación de competencias profesionales en España e Italia

Sin embargo, estas prácticas no siempre tienen la finalidad ni las características de un proceso de validación como se entiende en ámbito europeo, es decir, no siempre están compuestas por:

- una fase de análisis/reconstrucción de la experiencia individual;

- la utilización de un repertorio de estándares o referentes profesionales;

- una fase de evaluación de competencias;

- la entrega final de un certificado o diploma.

La mayor parte de las prácticas empresariales de este tipo no tienen todas las características que acabamos de nombrar, sobre todo la última de ellas, ya que el objetivo suele estar centrado en la misma empresa y no en el individuo.

En este campo podemos nombrar el proyecto en el que participó la región de Marche, "Investing in people" que se cerró en el año 2007 y ha servido de ejemplo como buena práctica de validación de competencias en Italia.

A pesar de que existen ciertas resistencias a este tipo de procedimientos, hay empresas que han conseguido hacer buenas aplicaciones de estos dispositivos, en cuanto a la integración de objetivos y beneficios entre empresa y trabajador. En estos casos las empresas pretenden mejorar la gestión de los recursos internos, impulsar el crecimiento personal y profesional y el empoderamiento, así como mejorar la eficacia en la organización y el grado de motivación de los trabajadores (Perulli, 2013).

Algunas de las experiencias de validación con mayor repercusión en ámbito empresarial han sido (Perulli, 2013):

- el sistema FORMEDIL: procedimiento para la validación y certificación de competencias en la construcción;

- "Rear Window": validación de competencias en el sector de la mecánica, en el marco del Programa Leonardo Da Vinci;

- "Highlight the Competences". Experiencia sobre la transferencia de competencias y profesionalidad en empresas del sector servicios, en el marco del Programa Leonardo Da Vinci;

- "Il Nostro Valore", experiencia del Libretto en la empresa. 
La validación de competencias profesionales

\subsubsection{EXPERIENCIAS DE VALIDACIÓN EN EL TERCER SECTOR}

En los últimos años muchas asociaciones sin ánimo de lucro han resaltado su contribución formativa y su contexto de empoderamiento.

El voluntariado incrementa explícitamente las competencias transversales, sobre todo las de relación y organización. También favorece la capacidad de trabajo en grupo y de asumir responsabilidades y compartirlas. Esto fomenta la ciudadanía activa y el crecimiento personal.

En Italia, el tercer sector es consciente de la importancia de disponer de un dispositivo de validación de competencias experienciales. Por eso desde el año 2004, gracias a fondos nacionales y europeos, ${ }^{92}$ han tenido lugar prácticas de validación en vía experimental. Muchas de estas experiencias cuentan con un implante metodológico que respeta los requisitos de base indicados por el Cedefop en las Líneas Directrices de 2009. Es decir, siguen las pautas indicadas sobre la reconstrucción de la experiencia individual, el uso de un repertorio de estándares o referencias profesionales de referencia, una fase de evaluación y una certificación o acreditación (Perulli, 2013).

La finalidad de este tipo de procedimientos es dar respuesta a las necesidades concretas en términos de empleabilidad y movilidad profesional, reconocer créditos formativos y ayudar al sujeto en el desarrollo de su carrera profesional. Se dirigen a diferentes categorías de beneficiarios, entre ellos a trabajadores del sector de la construcción, de la asistencia a ancianos y a niños, de la limpieza; a trabajadores y voluntarios de organizaciones sin ánimo de lucro; a personas en situación de paro por encima de los 40 años; a mediadores interculturales; a discapacitados y a responsables de la inserción laboral de discapacitados e inmigrantes y a estudiantes en situación de cambio.

Algunas de las experiencias más interesantes en este ámbito han sido (Perulli, 2013):

- el Proyecto "RAP-VPL - Raising Awareness of Potential Benefit Provided by VPL Model in Design Lifelong Learning Strategies", promovido por el Departamento de Recursos Humanos de Roma Capital, en el ámbi-

92 Leonardo da Vinci 2000-2006, Equal, Gioventù in azione, LLP/Grundtvig, Leonardo da Vinci, Trasversale y el Fondo Social Europeo. Sobre el programa Leonardo da Vinci 2000-2006, 
La validación de competencias profesionales en España e Italia

to del Programa sobre el Aprendizaje Permanente (sub-programa transversal).

- El Proyecto "Talenti di Cura", promovido por la Società cooperativa Anziani e Non solo (Sociedad de cooperativa: Más que Ancianos), en el ámbito del Programa sobre el Aprendizaje Permanente (subprograma Leonardo da Vinci).

- El Proyecto "Fair-For a new recognition of skills informally and non formally developed in the fair trade sector", promovido por Aster Soc, Cons de Bologna y por CTM Altro Mercato de Verona, en el ámbito del Programa Leonardo Da Vinci.

\subsubsection{INSTRUMENTOS NACIONALES PARA LA VALIDACIÓN Y CERTIFICACIÓN DE COMPETENCIAS PROFESIONALES.}

En Italia únicamente se reconoce un instrumento dispuesto en ámbito nacional para el sistema de validación y certificación de competencias no formales e informales. Se trata del ya mencionado Libretto formativo del cittadino.

Sin embargo, durante nuestro estudio hemos podido constatar la presencia de un segundo instrumento que, a pesar no contar con una ley italiana que le de valor y facilite su regulación, está muy difundido en Italia y mantiene una estrecha relación con el procedimiento de validación y certificación de competencias no formales e informales. Por ello, creemos importante dedicarle un espacio en esta investigación. Nos estamos refiriendo al Balance de competencias, que a nuestro parecer bien podría integrarse como instrumento en los sistemas de validación y certificación de aprendizajes no formales e informales.

\subsubsection{El Libretto Formativo del cittadino}

Como se ha comentado, los inicios del Libretto Formativo del Cittadino tienen su origen en el año 2000 con un Accordo Stato-Regioni. Fue definido como un instrumento dirigido a documentar el curriculum formativo y las competencias adquiridas por las personas. El Libretto reapareció más tarde en 2001 con el Decreto Ministerial 174. Se estableció que este instrumento recogería las certificaciones de las competencias adquiridas siguiendo las pautas europeas del momento, convirtiéndose así en un instrumento estratégico para el desarrollo de un sistema de validación nacional. A partir de la referencia de la nueva situación generada por el DM. 174/2001, el Decreto Legislativo 
276/2003 redefinió el Libretto del cittadino integrando todo lo previsto por la Conferenza Stato-Regioni del año 2000, por el D.M. 174/2001 y aplicando lo establecido en la Ley 30/2003. Concluyó que la definición del Libretto se debería decidir entre el Ministerio de Trabajo y Políticas Sociales, el Ministerio de la Instrucción, la Universidad y la Investigación, previo acuerdo con la Conferenza Unificata Stato-Regioni y tras consultar a las partes sociales. En el mismo deberían recogerse (Decreto Legislativo 276, 2003):

- las competencias adquiridas durante la formación en apprendistato,

- las competencias adquiridas en contrato de inserción ${ }^{93}$,

- la formación especializada,

- la formación continua desarrollada durante toda la vida, incluyendo las competencias adquiridas en modo no formal e informal y según las indicaciones de la Unión Europea en materia de aprendizaje permanente.

Partiendo de la base de esta definición, el Libretto fue aprobado oficialmente en formato nacional tras el acuerdo regional y de las Partes Sociales, con el artículo 2 del Decreto Interministerial de 10 de octubre de 2005 (Decreto Interministerial, 2005).

Actualmente el Libretto se entiende como un instrumento pensado para recoger, sintetizar y documentar las diversas experiencias de aprendizaje de los trabajadores o las competencias adquiridas de cualquier modo: en la escuela, en la formación, en el trabajo y/o en la vida cotidiana. Este instrumento tiene como fin mejorar la transparencia y la legibilidad y el uso de las competencias y la ocupación de las personas. El Libretto está gestionado y proporcionado por las Regiones y Provincias Autónomas en el ámbito de sus competencias exclusivas en materia de formación profesional y certificación de las competencias. Entre los años 2006 y 2009 fue evaluado en trece de las regiones italianas (Perulli, 2011, p. 85).

El Libretto se puede considerar el correspondiente italiano del Europass. Es decir, si el Europass permite el traspaso de cualificaciones y competencias en Europa, favoreciendo de este modo la movilidad de los trabajadores, el Libretto realiza la misma función dentro del territorio nacional italiano (Ministero del Lavoro e delle Politiche Sociali, 2011).

${ }^{93}$ Contrato de trabajo dirigido a lograr, mediante un proyecto individual de adaptación de las competencias profesionales del trabajador a un determinado contexto de trabajo, la inserción o la reinserción de un grupo determinado de personas. 
La validación de competencias profesionales en España e Italia

El Libretto Formativo del Cittadino se presenta de forma íntegra en el anexo A del decreto Interministerial del 10 de octubre de 2005.

Dicho Libretto está dividido en dos secciones:

- La primera sección está compuesta a su vez,por cuatro partes:

La primera recoge información personal del usuario del Libretto, nombre, nacionalidad, domicilio, etc.

La segunda hace referencia a las experiencias de trabajo, en ella debe especificarse el tipo de contrato, el periodo de trabajo, el rol realizado, el sector económico al que pertenece y las actividades principales realizadas.

La tercera se trata de una ficha en la que se recogen los títulos obtenidos en el sistema ordinario de educación y formación que posee el usuario. En ella debe indicarse a qué nivel de enseñanza pertenece el título, el año y el centro en que se obtuvo.

Por último, la cuarta parte recopila las experiencias de formación de la persona, especificando el título de dicha actividad, el modo de adquisición, duración, certificado otorgado por el ente público y otros certificados de otro tipo en el que caso de que los hubiera.

- La segunda sección del Libretto es una tabla que hace explícitas las competencias adquiridas durante el aprendizaje. En la tabla debe aparecer el tipo de competencias, la descripción de la misma, el contexto en el que se ha adquirido, la duración de la adquisición y por último el tipo de evidencias documentales que se presentan para justificar que realmente se han adquirido las competencias descritas anteriormente.

Para finalizar, cabe señalar que este instrumento recoge las competencias adquiridas en contextos no formales e informales, aunque todavía no es un dispositivo real de reconocimiento de créditos. Por el momento se encarga de facilitar el traspaso de créditos de las competencias. A pesar de ser un instrumento bien definido y reconocido a nivel nacional no se está dando un gran uso del mismo para fines de validación y certificación no formal e informal, a excepción del ámbito del apprendistato donde es más utilizado. 
La validación de competencias profesionales

\subsubsection{E1 Balance de competencias}

El Balance de competencias tiene su origen en Canadá, aunque se ha desarrollado sobre todo en Francia. Alcanzó importancia en Italia a mediados de los años 90, con objeto de facilitar la inserción y reinserción en un mundo laboral cambiante. En los últimos años el uso de esta metodología se ha difundido mucho en Europa, viéndose como un instrumento eficaz para las políticas activas de empleo (Grimaldi, 2010, pp. 20-21).

El Balance es un método de orientación que facilita al sujeto el recorrido por su historia de vida, reconstruyendo las etapas más relevantes de su formación, de su recorrido profesional y del modo en el que han tenido lugar (Alberici \& Serreri, 2005). Es un proceso voluntario que pretende promover la reflexión y el auto-conocimiento en relación a las competencias adquiridas en cualquier contexto de vida, para posibilitar la redefinición de un plan formativo-laboral personal (Aree Politiche per l'Orientamento, 2007). El Balance de competencias se desarrolla dentro de un tiempo establecido y se articula en tres fases fundamentales (Grimaldi, 2010, p. 25):

- fase preliminar: tras la presentación se analiza la naturaleza del problema y las necesidades del sujeto, posteriormente se estipula un "pacto" en el que se señalan los objetivos, modalidades y tiempos de la intervención;

- fase central: esta fase está dirigida al análisis, valorización y reelaboración de competencias adquiridas en experiencias de vida personales y profesionales. El objetivo es construir un proyecto laboral y personal acorde con los intereses, competencias, valores y elecciones de vida del sujeto;

- fase conclusiva: la última fase se dedica a la definición del proyecto laboral y personal y a su factibilidad.

Un aspecto característico del Balance es la "reconsideración". Esta consiste en el paso repetido (una y otra vez), a través de metodologías biográficas y narrativas, por los mismos contenidos, de forma circular y multidimensional, volviendo al mismo lugar varias veces y en diferentes circunstancias. A través del Balance la persona puede pensar y volver a pensar en su experiencia y en cómo cambiarla, esto se hace por medio de modalidades de narración de las experiencias vividas. La reflexividad permite transformar esas experiencias en "saberes" y hace al sujeto consciente de su "saber hacer". 
La validación de competencias profesionales en España e Italia

El Balance logra hacer emerger competencias transversales y/o emotivas, aunque no sean siempre fácilmente visibles pueden resultar importantes recursos para planificar un futuro profesional y personal en cualquier ámbito de la vida. Este instrumento ayuda al individuo a ser consciente de sus puntos débiles y fuertes (Di Rienzo, 2015, p. 149). Algunos de los instrumentos de los que se sirve el Balance, para alcanzar los fines descritos, son los encuentros individuales entre asesor y sujeto; encuentros grupales dirigidos; fichas estructuradas o cuestionarios e instrumentos de análisis validados y estandarizados (Grimaldi, 2010, p. 26).

El Balance de competencias es un instrumento que proporciona un gran valor personal y social, poniendo las competencias en evidencia y ayudando a la persona a reconocerlas. Por todo lo expuesto en estas líneas, creemos que el Balance podría ser un buen instrumento preparatorio para el procedimiento de validación y certificación de competencias no formales e informales. De este modo la persona podría enfrentarse al procedimiento conociendo sus capacidades y sus carencias de cara a la evaluación de sus competencias.

\subsubsection{EXPERIENCIAS REGIONALES DE VALIDACIÓN}

Hemos comentado en varias ocasiones que la formación profesional y los procedimientos de validación y certificación de competencias en Italia están en manos de las regiones. Por este motivo, hemos creído necesario añadir este apartado, en el que explicamos brevemente el nivel de desarrollo de las regiones italianas en este ámbito.

En general, en los últimos años se ha dado una gran relevancia nacional a la definición, experimentación e implementación de estrategias y sistemas de validación y certificación de competencias adquiridas a través de vías no formales e informales de aprendizaje. El reflejo de esta afirmación es que todas las regiones italianas se han preocupado de garantizar a sus ciudadanos un aprendizaje a lo largo de la vida, así como de asegurar la posibilidad de otorgar valor a sus competencias adquiridas a través de cualquier vía (Perulli, 2013, p. 92). Sin embargo, existe cierta heterogeneidad entre las regiones en cuanto al nivel de desarrollo de este tipo de procedimientos de validación y certificación. Pueden distinguirse tres niveles (Perulli, 2013): 
- nivel 1: la estrategia de validación todavía no se ha formalizado y no existe una normativa. La validación se afronta poco a poco, con pequeños pasos, aplicándose en proyectos, programas o ámbitos formativos muy específicos;

- nivel 2: existe una normativa para la estrategia dentro de un sistema regional de validación y certificación pero todavía no se ha implementado. Es decir, la validación no se ha puesto en funcionamiento;

- nivel 3: existe una normativa para la estrategia de validación dentro de un sistema regional de validación y certificación. Además se han realizado actividades referentes a este procedimiento. Asimismo, se ha medido la validez de los enfoques, estrategias y metodologías utilizados para este procedimiento.

Para proporcionar una visión sintética de la situación regional en cuanto al desarrollo en materia de validación y certificación de aprendizajes no formales e informales, recogemos en el siguiente cuadro todas las regiones italianas ${ }^{94}$, indicando el nivel de desarrollo al que pertenecen y el ámbito de aplicación de sus procedimientos (ver Cuadro 13).

Cuadro 13: Niveles de desarrollo y ámbito de aplicación de los procedimientos de validación de competencias no formales e informales en las regiones italianas

\begin{tabular}{|c|c|c|c|c|}
\hline Región & Nivel 1 & Nivel 2 & Nivel 3 & Ámbito de aplicación \\
\hline Abruzzo & $x$ & & & -Apprendistato professionalizzante. \\
\hline Basilicata & & $x$ & & $\begin{array}{l}\text {-Sistema regional de estándares profe- } \\
\text { sionales, formativos, de certificación. } \\
\text {-Experiencias en vía experimental, pro- } \\
\text { gramadas por algunas áreas económico- } \\
\text { profesionales y por el apprendistato. }\end{array}$ \\
\hline Calabria & $X$ & & & -Políticas activas de empleo. \\
\hline Campania & $x$ & & & $\begin{array}{l}\text {-Apprendistato professionalizzante. } \\
\text {-Educación de adultos. } \\
\text {-Políticas activas de empleo. }\end{array}$ \\
\hline Emilia-Romagna & & & $x$ & -Sistema Regional de Certificación \\
\hline
\end{tabular}

${ }^{94}$ Las regiones italianas son 20, aunque tenemos que tener en cuenta que la Región de Trentino-Alto Adige se subdivide en las Provincias Autónomas de Trento y Bolzano y por tanto en nuestro cuadro se presentan de forma separada. 
La validación de competencias profesionales en España e Italia

\begin{tabular}{|c|c|c|c|c|}
\hline Región & Nivel 1 & Nivel 2 & Nivel 3 & Ámbito de aplicación \\
\hline $\begin{array}{l}\text { Friuli Venezia } \\
\text { Giulia }\end{array}$ & $x$ & & & $\begin{array}{l}\text {-Apprendistato professionalizzante. } \\
\text {-Educación de adultos. } \\
\text {-Alternancia escuela-trabajo. }\end{array}$ \\
\hline Lazio & & $x$ & & $\begin{array}{l}\text {-Sistema regional en funcionamiento, en } \\
\text { vía experimental en el apprendistato } \\
\text { professionalizzante, en las oficinas de } \\
\text { empleo y para el Ministerio de Defensa. }\end{array}$ \\
\hline Liguria & & $X$ & & $\begin{array}{l}\text {-Sistema definitivo de } 2009 \text { y prácticas } \\
\text { en vía experimental en el apprendistato } \\
\text { professionalizzante, en la educación de } \\
\text { adultos y para ciudadanos inmigrantes. }\end{array}$ \\
\hline Lombardia & & & $X$ & -Sistema Regional de Certificación. \\
\hline Marche & & $x$ & & $\begin{array}{l}\text {-Prácticas en vía experimental en alter- } \\
\text { nancia escuela-trabajo, en la formación } \\
\text { continua y en la educación permanente } \\
\text { de adultos. Sistema reglado en } 2010 \text {. }\end{array}$ \\
\hline Molise & $x$ & & & $\begin{array}{l}\text {-Apprendistato professionalizzante. } \\
\text {-Educación de adultos. }\end{array}$ \\
\hline $\begin{array}{l}\text { Provincia Autó- } \\
\text { noma de } \\
\text { Bolzano }\end{array}$ & $X$ & & & $\begin{array}{l}\text {-Formación continua. } \\
\text {-Educación permanente de adultos. }\end{array}$ \\
\hline $\begin{array}{l}\text { Provincia Autó- } \\
\text { noma de Trento }\end{array}$ & & $X$ & & $\begin{array}{l}\text {-Sistema Provincial en funcionamiento. } \\
\text { Anteriormente, prácticas experimentales } \\
\text { en el campo de: Apprendistato professio- } \\
\text { nalizzante; Programas europeos; } \\
\text { educación permanente de adultos y } \\
\text { voluntariado. }\end{array}$ \\
\hline Piemonte & & & $x$ & -Sistema Regional de Certificación. \\
\hline Puglia & & $x$ & & $\begin{array}{l}\text {-Sistema Regional de Competencias y } \\
\text { prácticas en vías de experimentación en } \\
\text { funcionamiento en algunas áreas eco- } \\
\text { nómico-profesionales y en el } \\
\text { apprendistato. }\end{array}$ \\
\hline Sardegna & & $X$ & & $\begin{array}{l}\text {-Sistema Regional en funcionamiento. } \\
\text { Anteriormente, prácticas en vía experi- }\end{array}$ \\
\hline
\end{tabular}


La validación de competencias profesionales

\begin{tabular}{|c|l|l|l|l|}
\hline Región & Nivel 1 & Nivel 2 & Nivel 3 & \multicolumn{1}{|c|}{ Ámbito de aplicación } \\
\hline & & & & $\begin{array}{l}\text { mental en el ámbito del apprendistato } \\
\text { professionalizzante y cursos de cualifica- } \\
\text { ción para personal de asistencia a } \\
\text { ancianos. }\end{array}$ \\
\hline Sicilia & $X$ & & & $\begin{array}{l}\text {-Educación permanente de adultos } \\
\text {-Políticas activas de empleo. }\end{array}$ \\
\hline Toscana & & & $X$ & -Sistema Regional de Certificación. \\
\hline Umbria & & & $X$ & -Sistema Regional de Certificación. \\
\hline Valle de Aosta & & & $X$ & -Sistema Regional de Certificación. \\
\hline Veneto & & & $X$ & -Sistema Regional de Certificación. \\
\hline
\end{tabular}

Fuente: elaboración propia, basada en Perulli, 2013, p. 92-150

Analizando este cuadro podemos observar que el territorio italiano ${ }^{95}$ correspondiente al norte de la península cuenta con cinco regiones pertenecientes al nivel 3 de desarrollo de sistemas de validación y certificación. Estas regiones son: Emilia-Romagna, Lombardia, Piemonte, Valle de Aosta y Veneto. Por el contrario, la región de Liguria y la Provincia Autónoma de Trento se encuentran en un nivel 2 de desarrollo y la región de Friuli Venezia-Giulia junto con la Provincia Autónoma de Bolzano, se sitúa en el nivel más bajo de desarrollo respecto a este tipo de sistemas en el norte de Italia.

Respecto a la Italia central, observamos que las regiones de Toscana y Umbria son las más evolucionadas en esta zona, situadas en el nivel 3, mientras que las regiones de Lazio y Marche muestran un nivel de desarrollo de tipo 2.

Por último, la situación en el sur de Italia presenta tres regiones situadas en el segundo nivel de desarrollo, Basilicata, Puglia y Sardegna, y cinco en el más bajo (nivel 1), Abruzzo, Calabria, Campagnia, Molise y Sicilia.

Viendo esta descripción, podemos decir que el territorio más desarrollado en Italia respecto a la validación y certificación es el norte, dado que

95 La división territorial que hemos tenido en cuenta ha sido la considerada por el Istat (Istituto Nazionale di Statistica-Instituto Nacional de Estadística): Norte de Italia: EmiliaRomagna, Friuli-Venezia Giulia, Liguria, Lombardia, Piemonte, Trentino-Alto Adige (Provincias Autónomas de Trento y Bolzano), Valle de Aosta y Veneto. Centro de Italia: Lazio, Marche, Toscana y Umbria. Sur de Italia: Abruzzo, Basilicata, Calabria, Campania, Molise, Puglia, Sardegna y Sicilia. 
La validación de competencias profesionales en España e Italia

muchas de sus regiones cuentan con sistemas de esta naturaleza completamente desarrollados. El centro de Italia también se encuentra en una buena posición, con la mitad de sus regiones en vía experimental y la otra mitad con sistemas de certificación definidos y en funcionamiento. En cuanto a la situación en el sur de Italia, apreciamos una escasa difusión del sistema de validación y certificación, ninguna de sus ocho regiones ha logrado hasta ahora definir e implantar un dispositivo para la validación y certificación.

En general puede afirmarse que todas las regiones italianas han puesto en marcha reflexiones, acciones e iniciativas en relación a la validación de aprendizajes no formales e informales. Los lugares en los que este procedimiento está más consolidado cuentan con un mejor sistema de estándares profesionales y de cualificaciones.

Se prevé que en los próximos años todas las regiones pongan en funcionamiento dispositivos de validación y certificación de competencias no formales e informales (Perulli, 2013, p. 107).

\subsubsection{LA FORMALIZACIÓN Y CERTIFICACIÓN DE COMPETENCIAS PROFESIONALES EN EMILIA-ROMAGNA}

En sintonía con las recomendaciones europeas sobre aprendizaje a lo largo y ancho de la vida, la región de Emilia-Romagna se caracteriza por una amplia participación de personas (entre ellas adultos) en el sistema formativo. Además, esta región presenta una elevada calidad en el sistema productivo, que demanda y crea nuevas y diversas competencias profesionales. Esta circunstancia pone de manifiesto la necesidad de poner en marcha dispositivos capaces de evidenciar y reconocer las competencias que poseen las personas, a través de procedimientos rigurosos y transparentes (D.G.R. 1434, 2005).

Por ello, y también siguiendo las recomendaciones europeas sobre la transparencia de las cualificaciones y competencias y sobre la valorización de la persona a través del reconocimiento de sus competencias, la región de Emilia-Romagna ha desarrollado un sistema de validación y certificación de competencias. Este sistema recibe el nombre de formalización y certificación de competencias. Por eso a partir de ahora nos referiremos a él con ese término. 
La validación de competencias profesionales

\subsubsection{Recorrido legislativo}

El inicio del sistema de validación y certificación de competencias en Emilia-Romagna está ligado a la Ley Regional 12/2003, la cual proporciona normas para la igualdad de oportunidades de acceso al saber para todos y durante toda la vida, a través del reforzamiento de la educación y formación profesional (en adelante, L.R.12/2003).

Esta ley hizo explícito el papel de la Regione Emilia-Romagna como reguladora e impulsora de intervenciones de orientación, de la educación, de la formación y del trabajo. La finalidad que persigue es aumentar el nivel educativo y formativo de todos los ciudadanos; desarrollar constantemente las competencias profesionales e impulsar el ejercicio del derecho a un trabajo cualificado. En referencia a este último principio, esta ley expone (en su quinto artículo) el derecho de cada persona a obtener el reconocimiento formal y la certificación de las competencias adquiridas, sea cual sea la vía de adquisición de las mismas.

También, el mismo artículo instó a los componentes del sistema formativo y a las partes sociales a llevar a cabo acuerdos para la definición de procedimientos de reconocimiento y certificación, aplicables a las competencias adquiridas en el mundo laboral. Asimismo, estableció que los encargados del reconocimiento y certificación fuesen los sujetos formativos del sistema (L.R. 12, 2003).

La región de Emilia-Romagna afirmó con esta ley su intención de colaborar en la definición de estándares nacionales relacionados con la formación profesional. También quiso perseguir el objetivo del reconocimiento nacional de los títulos, de las cualificaciones profesionales y de las certificaciones de competencia, a través de la identificación de equivalencias entre las diferentes vías formativas y la definición de certificaciones válidas en todo el territorio nacional (L.R. 12, 2003, n. art. 4). Todo ello, en el respeto de las recomendaciones de la Unión Europea para contribuir a la libre circulación de certificaciones en Europa.

Siguiendo en el ámbito legislativo regional, debemos tener presentes otras dos leyes que contribuyeron en gran medida al fomento y desarrollo de la certificación de competencias en Emilia-Romagna. Se trata de la Ley Regional 17/2005 sobre fomento de empleo y calidad, seguridad y regularidad en el trabajo, y de la Ley Regional 5/2011 sobre el sistema regional de 
La validación de competencias profesionales en España e Italia

educación y formación profesional que explicamos en el subapartado 3.2.3.1).

La primera ley aprobó, en su artículo 3.7, los criterios y modalidades de actuación respecto a la certificación de competencias adquiridas a través de cualquier vía. También los artículos 26 y 30.4 de esta ley se ocuparon del reconocimiento y certificación de competencias en el ámbito del apprendistato.

La segunda de estas leyes regionales estableció, en su artículo 4.3, que la certificación de las cualificaciones y de los diplomas del sistema regional de educación y formación profesional se llevaría a cabo con los instrumentos de formalización y certificación de competencias adoptados por la región.

Volviendo a la LR.12/2003, debemos mencionar que a partir de ella se desarrollaron dos relevantes deliberaciones de la Junta Regional de Emilia-Romagna ${ }^{96}$, respecto a la creación de un sistema regional de validación y certificación de competencias. Hablamos de las Deliberaciones 936/2004 y 1434/2005, (en adelante, DGR. 936/2004 y DGR. 1434/2005 respectivamente).

Ambas deliberaciones situaron a la región de Emilia-Romagna en el marco nacional y europeo de reflexión y elaboración de normativa relacionada con las cualificaciones, la validación y la certificación de competencias.

La DGR 936/2004 aprobó el documento sobe "El Sistema Regional de Cualificaciones-orientaciones, metodología, estructura". Dicho documento definió el implante regional de un sistema propio de cualificaciones e incluyó algunas pautas para un sistema regional de formalización y certificación de competencias (en adelante SRFC).

La deliberación estableció la posibilidad de obtener el certificado correspondiente a una cualificación (es decir, el título de una cualificación), con la certificación de todas las unidades de competencia asociadas a la cualificación profesional, adquiridas a través de diferentes vías de aprendizaje y en diversos momentos de la vida. Esto supuso el reconocimiento de competencias tanto en el mundo educativo-formativo como en el laboral (D.G.R. 936, 2004).

${ }^{96}$ Una Deliberación de Junta Regional (Delibera di Giunta Regionale) es un acto jurídico, de segundo nivel, emanado por la Junta Regional (órgano ejecutivo). 
En cuanto a la DGR 1434 de 2005, cabe decir que aprobó el implante metodológico del Sistema Regional de Formalización y Certificación de competencias. Es decir, los objetivos, el objeto de formalización y certificación, la metodología a seguir y los sujetos encargados de proporcionar el sistema. ${ }^{97}$ Nacía así un sistema de formalización y certificación de competencias, único e integrado, válido para las vías formales, no formales e informales de aprendizaje.

La idea de esta formalización y certificación era facilitar a las personas la definición de itinerarios profesionales, a partir del descubrimiento de sus competencias y de la comparación de estas con los estándares correspondientes del Sistema Regional de Cualificaciones.

Asimismo, esta deliberación previó la implicación de las Partes sociales y de las provincias y estableció la aplicación del sistema, en primera instancia en vía experimental, con el objetivo de llevar a cabo un seguimiento del procedimiento y realizar cambios en caso necesario (D.G.R. 1434, 2005).

Un año más tarde, la Deliberación de Junta Regional 530/2006 (en adelante, D.G.R 530/2006) definió detalladamente el SRFC siguiendo las indicaciones de la LR 12/2003.

Este documento describió las fases del sistema; los roles profesionales implicados en él; los posibles documentos que pueden entregarse al finalizar el procedimiento y los documentos de apoyo para ayudar a los profesionales del procedimiento a desarrollar correctamente sus funciones.

Desde la aprobación de esta deliberación se procedió a la puesta en marcha del SRFC, iniciándose por primera vez la práctica de este sistema en el año 2006 (D.G.R. 530, 2006).

Tras el periodo de experimentación previsto se publicaron varias modificaciones e integraciones, referentes a las modalidades de asesoramiento, de evaluación o de acceso al examen. Dichas modificaciones se produjeron con la Deliberación de Junta Regional 739/2013 (en adelante D.G.R 739/2013), con la intención de mejorar y facilitar el procedimiento de formalización y certificación. Actualmente está entrando en vigor de forma gradual.

${ }^{97}$ Entes formativos; servicios públicos de empleo acreditados o autorizados por la Regione de Emilia-Romagna y empresas autorizadas por la Regione de Emilia-Romagna. 
La validación de competencias profesionales en España e Italia

\subsubsection{E1 Sistema Regional de Cualificaciones (SRQ)}

Como hemos señalado en el subapartado 3.2.3, el Sistema Regional de Cualificaciones (SRQ) se utiliza en diferentes ámbitos y con diversos objetivos. En este caso supone una pieza clave en el procedimiento de validación de competencias en Emilia-Romagna.

Recordamos que el SRQ contiene un repertorio de estándares profesionales (cualificaciones regionales) en constante actualización, y que representa las competencias profesionales que caracterizan el sistema económico-productivo de Emilia-Romagna.

Este repertorio clasifica las cualificaciones profesionales regionales en base al área profesional ${ }^{98}$ al que pertenecen. Cada una de estas cualificaciones es un título profesional (no formativo), en el sentido de que proporciona la cualificación profesional necesaria para las actividades profesionales del mundo laboral. También supone un título formal, ya que las cualificaciones están reguladas por normativas oficiales-públicasinstitucionales, y certifica la posesión de competencias adquiridas en cualquier ámbito de la vida, ya sea en contextos formativos, profesionales, sociales o personales (Emilia-Romagna, 2007, p. 9).

Asimismo, es importante señalar que la Emilia-Romagna ha establecido correspondencias para cada cualificación regional con el Marco Europeo de las Cualificaciones (EQF). Por tanto, a cada cualificación le corresponde un único nivel (del 3 al 7) de los 8 niveles establecidos en el EQF.

\section{- La cualificación regional}

Las cualificaciones profesionales regionales hacen referencia a figuras profesionales, entendidas como un conjunto de actividades laborales compuestas por competencias que pueden llevarse a cabo en diferentes actividades.

Las unidades de competencia (en adelante, UC) conforman las cualificaciones regionales, se trata de agregados de capacidades y conocimientos (factores que componen las competencias) necesarios para desarrollar con-

98 Entendemos área profesional como un conjunto de "figuras profesionales", que actúan en diferentes niveles de profesionalidad y/o ámbitos de especialización, homogéneos en cuanto a procesos laborales de referencia y por competencias profesionales de base (Emilia-Romagna, 2007, p. 66). 
juntos de actividades que producen un resultado observable y evaluable (Emilia-Romagna, 2007, p. 66). Las unidades de competencia suponen los estándares profesionales, representan los elementos esenciales de la figura profesional a la que se asocia la cualificación, y las principales competencias mínimas necesarias para llevar a cabo las actividades correspondientes (D.G.R. 530, 2006, p. 67). Por este motivo, al igual que ocurre en todo el territorio español, la UC supone el agregado mínimo de competencias, susceptible de certificación, en el sistema de formalización y certificación de Emilia-Romagna.

\section{Estructura de la cualificación regional}

Para cada una de las cualificaciones profesionales del SRQ, la Regione ha elaborado una ficha descriptiva que podemos ver en el Anexo 23, articulada en tres secciones:

- la primera contiene una descripción sintética de la cualificación, acompañada del área profesional de referencia y de los perfiles relacionados con dicha área;

- la segunda contiene los conocimientos y capacidades relacionados con la cualificación y componentes de cada una de las cuatro UC en las que está articulada;

- la tercera contiene orientaciones para la evaluación, de cara a la validación y certificación de competencias (ver Cuadro 14). Indica el objeto a observar y medir para cada UC, a través de acciones determinadas de las capacidades y conocimientos necesarios para realizar una UC. También define los indicadores, que expresan, por cada UC, las actividades que el sujeto debe poder realizar gracias a la posesión de capacidades y conocimientos relacionados con la UC. Por último describe el resultado esperado, con el que se indica el resultado observable de las actividades ligadas a la UC (D.G.R. 530, 2006, p. 67). 
La validación de competencias profesionales en España e Italia

Cuadro 14: Indicaciones para la validación de las unidades de competencia del operador de producción química.

\begin{tabular}{|c|c|c|c|c|}
\hline UNITA DI COMPETENZA & $\begin{array}{l}\text { OGGETTO DI } \\
\text { OSSERVAZIONE }\end{array}$ & INDICATORI & $\begin{array}{l}\text { RISULTATO } \\
\text { ATIESO }\end{array}$ & MODALTA \\
\hline $\begin{array}{l}\text { 1. Approntamento } \\
\text { macchinari e } \\
\text { attrezzature della } \\
\text { produzione } \\
\text { chimica }\end{array}$ & $\begin{array}{l}\text { le operazioni di } \\
\text { approntamento dei } \\
\text { macchinari e delle } \\
\text { attrezzature della } \\
\text { produzione chimica }\end{array}$ & $\begin{array}{l}\text { esame preventivo dei } \\
\text { macchinari e delle } \\
\text { attrezzature della produzione } \\
\text { chimica } \\
\text { regolazione dei macchinari e } \\
\text { delle attrezzature in funzione } \\
\text { delle caratteristiche dei } \\
\text { materiali impiegati e delle } \\
\text { lavorazioni da effettuare } \\
\text { esecuzione manutenzioni } \\
\text { ordinarie (pulizia, controllo } \\
\text { componenti, ecc.) }\end{array}$ & $\begin{array}{l}\text { macchinari e } \\
\text { attrezzature } \\
\text { allestite in } \\
\text { condizioni di } \\
\text { efficienza e } \\
\text { sicurezza }\end{array}$ & \multirow{4}{*}{ 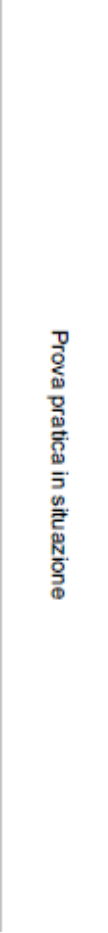 } \\
\hline $\begin{array}{l}\text { 2. Trattamento } \\
\text { materie prime/ } \\
\text { semilavorati } \\
\text { chimici }\end{array}$ & $\begin{array}{l}\text { le operazioni di } \\
\text { trattamento delle } \\
\text { materie prime/ } \\
\text { semilavorati chimici }\end{array}$ & $\begin{array}{l}\text { preparazione delle materie } \\
\text { prime/semilavorati chimici } \\
\text { rilevazione delle misure di } \\
\text { componenti/materie } \\
\text { prime/semilavorati chimici } \\
>\text { conservazione delle materie } \\
\text { prime/semilavorati chimici }\end{array}$ & $\begin{array}{l}\text { materie } \\
\text { prime/semilavorati } \\
\text { predisposti per la } \\
\text { lavorazione }\end{array}$ & \\
\hline $\begin{array}{l}\text { 3. Lavorazione } \\
\text { semilavorati/ } \\
\text { prodotti chimici }\end{array}$ & $\begin{array}{l}\text { le operazioni di } \\
\text { lavorazione dei } \\
\text { semilavorati/prodotti } \\
\text { chimici }\end{array}$ & $\begin{array}{l}\text { esecuzione delle lavorazioni } \\
\text { dei prodotti chimici trattati } \\
\text { conservazione dei prodotti } \\
\text { chimici secondo le procedure } \\
\text { previste }\end{array}$ & $\begin{array}{l}\text { prodotti chimici } \\
\text { lavorati } \mathrm{e} \\
\text { conservati }\end{array}$ & \\
\hline $\begin{array}{l}\text { 4. Controllo } \\
\text { semilavorati/ } \\
\text { prodotti chimici }\end{array}$ & $\begin{array}{l}\text { le operazioni di } \\
\text { controllo dei } \\
\text { semilavorati/prodotti } \\
\text { chimici }\end{array}$ & $\begin{array}{l}\text { verifica di eventuali anomalie } \\
\text { qualitative e difettosità dei } \\
\text { prodotti chimici } \\
\text { realizzazione delle attività di } \\
\text { controllo della qualità dei } \\
\text { prodotti chimici secondo gli } \\
\text { standard previsti }\end{array}$ & $\begin{array}{l}\text { controlli eseguiti } \\
\text { nel rispetto degli } \\
\text { standard di } \\
\text { qualità e } \\
\text { sicurezza } \\
\text { predefiniti }\end{array}$ & \\
\hline
\end{tabular}

Fuente: (Regione Emilia-Romagna, 2015).

\subsubsection{El Sistema Regional de Formalización y Certifica- ción de competencias profesionales}

El Sistema Regional de Formalización y Certificación de competencias está íntimamente relacionado con el SRQ. Es la modalidad que regula la obtención de las certificaciones (competencias y cualificaciones). Permite formalizar y certificar competencias adquiridas por vía formativa o experiencial. Formalizar se refiere a la entrega de un documento oficial, de la Regione Emilia-Romaga, que reconoce la posesión de determinados conocimientos y capacidades de una UC perteneciente a una cualificación regional. La certificación consiste en la entrega de un certificado de competencias o de cualificación de la Regione Emilia-Romagna, que certifica las UC demostradas, pertenecientes una cualificación regional. 
Como hemos explicado, este sistema nació con la DGR 530/2006 y fue modificado para su mejora por la DGR 739/2013.

Se aplica para todas las cualificaciones regionales del catálogo que otorga la Regione Emilia-Romagna. Esto quiere decir que está dirigido a personas que hayan participado de forma parcial o completa en un curso formativo con el que se obtiene una formalización y certificación; personas con experiencia en contextos de trabajo y/o informales y/o con certificados logrados a través de aprendizajes formales, que quieran obtener un documento de formalización y certificación (D.G.R. 530, 2006).

Los sujetos encargados de poner en marcha este servicio son los entres formativos, los servicios públicos de empleo y las empresas, acreditados o autorizados por la Regione Emilia-Romagna para llevar a cabo la formalización y certificación de las competencias (D.G.R. 530, 2006).

\section{- El sistema de formalización y certificación de la experiencia}

A pesar de que el SRFC es único e integrado para las vías formales, no formales e informales de adquisición de competencias, presenta pequeñas diferencias dependiendo del ámbito en el que se aplique. En esta investigación vamos a ocuparnos del estudio de la formalización y certificación de competencias en el ámbito no formal e informal. Es decir, dirigido a las personas que sobre todo tienen experiencia en el mundo del trabajo y quieren ver sus competencias reconocidas. Cuando el SRFC hace referencia a este aspecto se le conoce come SRFC de la experiencia.

Según fuentes de la Regione Emilia-Romagna, a finales de 2015 se habían realizado unas 130 convocatorias en esta región, para formalizar y certificar competencias profesionales. Estas convocatorias se realizan de forma continua, atendiendo a peticiones de centros o de personas, y se regulan y organizan según las DGR 530/2006 o 739/2013.

\section{- Profesionales del SRFC de la experiencia}

Uno de los requisitos esenciales para los sujetos que deseen poner en marcha el sistema de SRFC es disponer de tres profesionales encargados del procedimiento de formalización y certificación, estos son:

- el responsable de la formalización y certificación de competencias (en adelante, en sus siglas en italiano RFC-responsabile della fromalizzazione e certificazione). Tiene la responsabilidad de asegurar y organizar la puesta 
La validación de competencias profesionales en España e Italia

en marcha del procedimiento de formalización y certificación; nombrar y formalizar la comisión de examen; supervisar el desarrollo de las actividades, para que se respete la normativa que existe al respecto; analizar los problemas que surjan e intentar solucionarlos; garantizar el asesoramiento individual a las personas. Por lo tanto, por su función de coordinador del procedimiento, este profesional interviene en todas las fases del mismo;

- el experto de procesos de evaluación (en adelante, en sus siglas en italiano EPV-esperto del processi valutativi). Es el técnico-metodológico de las actividades de evaluación. Tiene la responsabilidad de realizar actividades de evaluación de competencias, en la comisión de examen; informar al RFC sobre el desarrollo de las actividades; proporcionar información $\mathrm{y}$ asesoramiento individual al candidato. Por las funciones que desarrolla el EPV, y para facilitar la comparación con el procedimiento español, le denominaremos asesor;

- el experto del área profesional y de la cualificación que se evalúa (en adelante, en sus siglas en italiano EAPQ-esperto di area professionale/qualifica). Es el técnico-profesional de determinadas cualificaciones agrupadas y clasificadas en áreas profesionales. Tiene la responsabilidad de realizar actividades de evaluación de competencias; actuar en la comisión de examen; desarrollar el rol de presidente de la comisión; declinar indicadores y sus correspondientes resultados esperados de los estándares del sistema regional de cualificaciones (SRQ) para evaluar las competencias profesionales. Por las funciones que desarrolla el EAPQ, y para facilitar la comparación con el procedimiento español, le denominaremos evaluador;

- Las fases del procedimiento de formalización y certificación de competencias de la experiencia

Para describir las fases del procedimiento de formalización y certificación de competencias experienciales (acceso, evaluación a través de evidencias, entrevista evaluativa y examen) hemos estudiado y analizado la DGR 530/2006 y la DGR 739/2013, ya que ambas co-existen en estos momentos. Actualmente se está produciendo el paso de una deliberación a otra, por lo que algunos procedimientos se rigen por la primera deliberación y otros por la segunda. En el momento de la recogida de datos para esta investigación, la DGR 739/2013 había sido utilizada únicamente en el ámbito del apprendistato. 
Recordamos que la DGR 739/2013 ha supuesto la modificación de la DGR 530/2006, con objeto de simplificar y facilitar la puesta en práctica del procedimiento de formalización y certificación. A continuación, durante la exposición de las fases del procedimiento intentamos plasmar las modificaciones más relevantes llevadas a cabo por la normativa.

\section{Fase 1: Acceso al procedimiento}

El procedimiento se activa a través de la petición de acceso de los posibles candidatos que desean ver reconocidas sus competencias.

Durante esta fase se explica a los candidatos el significado, la estructura, las reglas, las salidas y el valor del procedimiento, asimismo se les informa sobre las condiciones del asesoramiento individual. Dicho asesoramiento es obligatorio para aquellos candidatos que quieran validar competencias adquiridas en contextos laborales o informales en general.

El profesional encargado del asesoramiento es el experto de los procesos de evaluación (EPV). Su función consiste en preparar al candidato para la evaluación de evidencias, ayudándole a producir y presentar adecuadamente la documentación necesaria para demostrar las evidencias ${ }^{99}$ relacionadas con las competencias que pretende validar.

\section{Fase 2: Proceso de evaluación a través de evidencias}

Esta fase es obligatoria para todos los candidatos. Tiene el objetivo de determinar, a través de un análisis de evidencias, si los candidatos están en condiciones de poder acceder a las siguientes fases del procedimiento. El candidato supera esta evaluación cuando logra evidenciar las capacidades y conocimientos correspondientes a una o más unidades de competencia (UC), pertenecientes a una cualificación del Sistema Regional de Cualificaciones (SRQ), o cuando logra evidenciar una cualificación completa, es decir todas las UC que componen una cualificación.

La evaluación a través de evidencias, está constituida por los siguientes pasos:

99 Las evidencias son la prueba de los conocimientos y capacidades, relacionados con los estándares previstos por el SRC (D.G.R. 1434, 2005, n. Apartado 3). 
La validación de competencias profesionales en España e Italia

\section{Producción de evidencias:}

El EPV elabora el plan de evaluación ${ }^{100}$ (siguiendo el modelo del Anexo 24) que acuerda con el candidato. En él se especifican las evidencias que se presentarán, en relación a los estándares profesionales de la cualificación de referencia (en relación a los indicadores definidos de las UC). El plan se realiza teniendo en cuenta la experiencia de la persona, sus posibles títulos de formación formal o no formal, su $\mathrm{CV}$ u otros documentos.

Seguidamente, el candidato recoge las evidencias y las incluye en un "dossier de evidencias" (ver Anexo 25) que debe contener todas las evidencias previstas en el "plan de evaluación” (D.G.R. 530, 2006).

Las evidencias pueden agruparse en tres categorías:

Evidencias de documentación formal, hacen referencia a títulos, certificados, declaraciones y/o contratos de colaboración. Para esta categoría se aceptan certificados o títulos de carácter formativo, laboral, de voluntariado, etc. Pueden presentarse por ejemplo:

- declaraciones de superiores sobre las actividades que ha realizado el candidato en un determinado trabajo y los conocimientos y capacidades que ha adquirido;

- contratos de colaboración en proyectos o actividades de algún tipo, en ellos se indica el objeto de la colaboración;

- auto-declaraciones en el caso de que la persona considere oportuno completar las evidencias y/o no disponga de otras pruebas documentales.

Evidencias de output (rendimiento), se refieren al producto de la actividad del candidato y pueden ser:

- muestras de un producto del trabajo, como objetos, aplicaciones informáticas, etc;

- documentos realizados, como informes laborales, de investigación o documentos administrativos.

100 Con la nueva D.G.R. 739 el plan de evaluación desaparece, aunque por el momento sigue vigente para los procedimientos que siguen tomando la D.G.R. 530/2006 como referencia. 
Evidencias de acción, en relación con el comportamiento puesto en práctica por el candidato. Este tipo de evidencias pueden traducirse en:

- testimonios de personas que han observado in situ el comportamiento de la persona desarrollando una actividad determinada;

- registros de audio y/o vídeo en las que el candidato realiza una actividad;

- otra documentación explicativa de las competencias utilizadas en determinadas actividades, como por ejemplo un diario de trabajo del candidato.

\section{Análisis de las evidencias}

El EPV (asesor) examina las evidencias para verificar la adecuación de las mismas respecto al estándar de referencia. Para ello cuenta con el apoyo de un experto de área profesional y cualificación (EAPQ-evaluador) y sigue los criterios de pertinencia y exhaustividad y corrección establecidos en la DGR 530/2006, aunque la D.G.R 739/2013 prescinde del criterio de exhaustividad con el fin de simplificar la evaluación.

\section{Evaluación formalizada de las evidencias}

El EPV (asesor) acuerda la evaluación con el EAPQ (evaluador). Se evalúan todas las evidencias, presentadas por el candidato, con la ayuda de un documento del que presentamos dos versiones, la primera correspondiente a la DGR 530/2006 (ver Anexo 26a) y la segunda correspondiente a la DGR 739/2013 (ver Anexo 26b). Posteriormente, un RFC firma la evaluación tras comprobar que esta ha sido completa y correcta.

\section{Información del resultado a la persona}

El EPV (asesor) es el encargado de informar al candidato del resultado de la evaluación, este puede ser negativo o positivo:

- es negativo cuando el candidato no es capaz de evidenciar el 75\% ${ }^{101}$ de las capacidades-conocimientos correspondientes a, como mínimo, una UC. En ese caso, el candidato no puede pasar a ninguna otra fase del procedimiento. No obstante, se le entrega la ficha de

${ }^{101}$ Este porcentaje ha sido instaurado con la D.G.R. 739/2013, anteriormente, el candidato debía demostrar el 100\% de los conocimientos y capacidades de una UC. 
La validación de competencias profesionales en España e Italia

capacidades-conocimientos. Esto se conoce como formalización, se reconocen al candidato las capacidades y conocimientos evidenciados. En el caso de que el candidato estuviese interesado en adquirir una o más UC o una cualificación completa, el EPV le presenta la posibilidad de realizar algún tipo de formación para poder completar la falta de competencias y alcanzar su objetivo;

- es positivo cuando el candidato demuestra como mínimo el 75\% de las capacidades-conocimientos de una o más UC. En este caso, logra acceder a la fase de evaluación para la certificación. Según su situación y/o intereses desembocará en la entrevista evaluativa o en el examen.

\section{Fase $\left.3^{a}\right)$ Proceso de evaluación a través de la entrevista evaluativa}

Este punto intermedio se ha añadido recientemente al procedimiento. Su incorporación se debe a la D.G.R 739/2013 y pretende aligerar el procedimiento a los candidatos que, habiendo superado la fase anterior, pretendan y estén en condiciones de obtener un certificado de competencias. Es decir, para candidatos que quieran o puedan demostrar varias UC de una cualificación pero no la totalidad de UC que la componen.

La fase implica los siguientes pasos:

\section{Planificación de la entrevista}

Un EPV (asesor) y un EAPQ (evaluador) estudian los documentos de referencia (el estándar profesional de la cualificación, el dossier de evidencias y la validación de evidencias) y elaboran la entrevista, señalando el objeto de evaluación, la modalidad de desarrollo y los criterios de evaluación.

\section{Desarrollo de la entrevista}

Los dos expertos (EPV y EAPQ) realizan de forma conjunta la entrevista, formulan preguntas funcionales para poder evaluar la posesión de capacidades y conocimientos relativos a la/las UC objeto de evaluación.

\section{Evaluación}

Los dos expertos evalúan la/las UC examinada/s. Para ello, la DGR 739/2013 establece dos criterios a tener en cuenta, la adecuación de las res- 
puestas respecto a los estándares de referencia y el uso de un lenguaje técnico correcto. Además, esta deliberación indica que para la evaluación deben utilizarse fichas o cuadros y deben definirse modalidades de evaluación cerradas (por ejemplo sí/no o escalas de medida de 3 o 5 puntos). Por último, los expertos deben recoger la evaluación en el documento de validación de competencias, que presentamos en el Anexo 27 (D.G.R. 739, 2013, p. 28).

\section{Registro de actas}

El EPV (asesor) registra las actividades realizadas durante la entrevista, las decisiones que se han tomado y el por qué.

\section{Información al candidato}

El EPV (asesor) informa al candidato sobre el resultado de la entrevista. El resultado es negativo si el candidato no ha logrado demostrar al menos una UC, en ese caso se le puede entregar la formalización, es decir, una ficha de capacidades y conocimientos demostrados, como en la anterior fase.

El resultado es positivo si el candidato logra demostrar una o más UC de una determinada cualificación. En este caso la persona obtiene un certificado de competencias referido a la/las UC que haya conseguido demostrar. Si desea obtener el certificado de cualificación deberá someterse al proceso de evaluación a través de examen.

\section{Fase 3b) Proceso de evaluación a través de examen}

Esta fase verifica, a través de un examen y una entrevista, que la persona evaluada sea capaz de ejercitar las competencias correspondientes a una o más UC o a una cualificación completa.

Pueden acceder al examen aquellos candidatos que:

- tengan formalizadas el $75 \%$ de cada una de las UC de la cualificación;

- tengan un certificado de competencias de cada UC de la cualificación;

- tengan certificadas las competencias de algunas UC y formalizados el $75 \%$ de conocimientos y capacidades de las UC restantes de la cualificación. 
La validación de competencias profesionales en España e Italia

Los pasos principales que conforman esta fase son los siguientes:

\section{Constitución de la Comisión de examen}

El Responsable de la formalización y certificación de competencias (RFC) del ente en el que se realiza el procedimiento constituye la Comisión. Esta tiene que estar formada por tres componentes: dos EAPQ (evaluadores), de los cuales uno será nombrado presidente por la propia comisión, y un EPV (asesor). Los EAPQ son externos al ente que proporciona el servicio. Estos profesionales se seleccionan aleatoriamente de una lista de EAPQ, constituida por la Regine Emilia Romagna para tal fin. En cuanto al EPV, normalmente es interno al ente que lleva a cabo el procedimiento, aunque en algunas ocasiones puede ser externo a este.

\section{Definición de las pruebas}

La Comisión estudia los documentos de referencia (estándares profesionales de la cualificación a la que se refieren las competencias que quieren certificarse; el dossier de evidencias; el documento de evaluación de las evidencias y el documento de evaluación de competencias); los materiales de los que dispone para el examen y los documentos de apoyo para la programación de las pruebas. De este modo planifica una prueba práctica y una entrevista, indicando el objeto, las modalidades de desarrollo y los criterios de la evaluación.

\section{Prueba práctica}

El DGR 530/2006 establece que el objeto de la prueba está constituido por las actividades profesionales observables y evaluables, que se encuentran definidas como indicadores en la sección de indicaciones para la evaluación de competencias de la ficha descriptiva de la cualificación que se quiere certificar. La comisión podrá añadir otras actividades si lo considera útil para la evaluación.

La normativa también indica que la prueba tiene que tener en cuenta los criterios de:

- completitud: la prueba debe planificase de forma que en la realización de la misma se movilicen y se pongan en práctica todas las capacidades y los conocimientos de la cualificación de referencia; 
La validación de competencias profesionales

- media complejidad: la prueba debe requerir la realización de actividades caracterizadas por un nivel medio de complejidad.

En cuanto a la modalidad de realización de la prueba, la normativa indica que esta puede ser individual o de grupo, según las características típicas de los contextos en los que se realizan normalmente las actividades profesionales a evaluar. En el caso de una prueba de grupo debe ser posible observar individualmente a los candidatos.

Debe indicarse la duración de la prueba (que variará dependiendo de las características de los procesos laborales correspondientes), así como los instrumentos que se utilizarán.

Las instrucciones de desarrollo de la prueba se entregan por escrito y son explicadas por un componente de la comisión.

La DGR 530/2006 establece que la comisión debe definir los criterios de observación y la evaluación de la prueba. Los criterios deben ser claros, sin ambigüedades y relevantes respecto al objeto de la prueba. Durante la evaluación la comisión, debe tener en cuenta el "producto" (relacionado con el resultado esperado) y el "proceso" (relacionado con el modo de realización). Asimismo, debe establecer el nivel de la actividad considerado adecuado, por debajo del cual la evaluación sería negativa. También debe definir las modalidades de evaluación, estas deben ser cerradas (por ejemplo: sí/no o una escala de medida de 3 o 5 puntos.

\section{Entrevista} práctica.

La entrevista se efectúa para completar y/o compensar la prueba

El objeto de la entrevista está constituido por la explicitación, el comentario y las motivaciones de lo que el alumno ha realizado en el curso de la prueba práctica.

Puede estar relacionada con:

- la explicitación y la integración de algunas actividades realizadas y/o con la motivación de decisiones y soluciones tomadas (función de completar);

- el análisis y la descripción de las actividades realizadas en el curso de la prueba práctica, las dificultades encontradas, los eventuales errores cometidos y las posibles soluciones (función de compensar). 
La validación de competencias profesionales en España e Italia

La entrevista se desarrolla de forma individual. En la preparación de la misma, la comisión debe indicar la duración y los posibles materiales a disposición. Se deben definir los criterios de la evaluación relacionados con un lenguaje técnico apropiado y respuestas adecuadas a las preguntas que se le hagan al candidato.

La DGR 350/2006 incluye algunos ejemplos de pruebas prácticas y de entrevistas para algunas cualificaciones, con la intención de ayudar a la comisión a realizar la evaluación. En la prueba práctica se proporcionan ejemplos para seguir los criterios de completitud y de medio grado de complejidad (ver Anexo 28); para indicar los materiales o el tiempo a disposición (ver Anexo 29) y para evaluar el proceso y el producto (ver Anexo 30). En cuanto a la entrevista, los ejemplos están relacionados con los materiales a utilizar, y el correcto uso del lenguaje en los candidatos y la adecuación en las respuestas (ver Anexo 31).

\section{Desarrollo y evaluación de las pruebas}

La Comisión al completo sigue el desarrollo de las pruebas que pueden llevarse a cabo en diferentes espacios y lugares.

Para la evaluación, cada miembro de la comisión rellena de forma autónoma los instrumentos de observación, tras lo cual se confrontan los resultados con el objetivo de elaborar una evaluación común. Posteriormente, en base al resultado de las pruebas, la Comisión emite el juicio de "competente" o "no competente todavía".

El instrumento que se utiliza para la evaluación es el "documento de evaluación de las actividades", del que cual también mostramos sus dos versiones en los Anexos 32a y 32b, el primero referido a la DGR 530/2006 y el segundo a la DGR 739/2013.

Registro de actas

Aquí se registra el trabajo de la Comisión durante el examen, las decisiones tomadas y el por qué.

\section{Información a la persona}

Se comunica el resultado de la evaluación al candidato, de forma individual. 
Si el candidato logra demostrar una o más UC sin llegar al total de UC de una cualificación, se le entregará un Certificado de Competencias, que certifique las UC demostradas.

Si el candidato demuestra estar en posesión de todas las UC que componen una cualificación se le entregará el Certificado de Cualificación correspondiente.

A continuación, como hemos hecho en el procedimiento castellanoleonés, mostramos de forma sintética, en el Cuadro 15, las fases del procedimiento de formalización y certificación de competencias experienciales en Emilia-Romagna con los aspectos más significativos de estas.

Cuadro 15: Fases del procedimiento de formalización y certificación de competencias de la experiencia en Emilia-Romagna

\begin{tabular}{|c|c|c|}
\hline 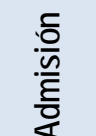 & \multicolumn{2}{|c|}{$\begin{array}{l}\text { Actividades principales } \\
\text { Explicación al candidato de aspectos fundamentales relacionados con el procedimiento } \\
\text { y con el asesoramiento individualizado. }\end{array}$} \\
\hline 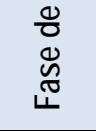 & \multicolumn{2}{|c|}{$\begin{array}{l}\text { Profesionales de esta fase } \\
\text { EPV (experto de los procesos de evaluación) } \\
\text { RFC (referentes de la formalización y certificación) }\end{array}$} \\
\hline 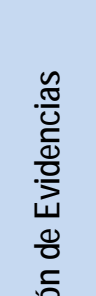 & \multicolumn{2}{|c|}{$\begin{array}{l}\text { Actividades principales } \\
\text { Producción/recogida de evidencias (formales, de rendimiento, de acción) } \\
\text { Análisis de evidencias } \\
\text { Evaluación formalizada de las evidencias } \\
\text { Información del resultado de la persona } \\
\text { En su caso, entrega de ficha de capacidades y conocimientos e información sobre } \\
\text { formación }\end{array}$} \\
\hline 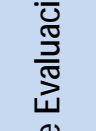 & $\begin{array}{l}\text { Profesionales de esta fase } \\
\text { EPV } \\
\text { RFC }\end{array}$ & \multirow{2}{*}{$\begin{array}{l}\text { Instrumentos utilizados } \\
\text { Plan de evaluación } \\
\text { Dossier de evidencias } \\
\text { Documento de evaluación de las evidencias }\end{array}$} \\
\hline 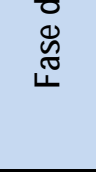 & $\begin{array}{l}\text { Documentos de apoyo al profe- } \\
\text { sional } \\
\text { Deliberación 530/2006 } \\
\text { Deliberación 739/2013 }\end{array}$ & \\
\hline 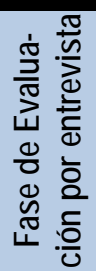 & \multicolumn{2}{|l|}{$\begin{array}{l}\text { Actividades principales } \\
\text { Planificación de la entrevista } \\
\text { Desarrollo de la entrevista y evaluación } \\
\text { Registro de actas } \\
\text { Información del resultado a la persona } \\
\text { En su caso, entrega de certificado de com }\end{array}$} \\
\hline
\end{tabular}


La validación de competencias profesionales en España e Italia

\begin{tabular}{|c|c|c|}
\hline & $\begin{array}{l}\text { Profesionales de esta fase } \\
\text { EPV } \\
\text { EAPQ (experto de área profesional } \\
\text { y cualificación) } \\
\text { RFC }\end{array}$ & \multirow[t]{2}{*}{$\begin{array}{l}\text { Instrumentos/técnicas utilizados para la realiza- } \\
\text { ción y la evaluación de la entrevista evaluativa } \\
\text { Dossier y documento de validación de } \\
\text { evidencias } \\
\text { Documento de validación de competencias }\end{array}$} \\
\hline & $\begin{array}{l}\text { Documentos de apoyo al profe- } \\
\text { sional } \\
\text { Deliberación } 739 / 2013\end{array}$ & \\
\hline \multirow{3}{*}{ 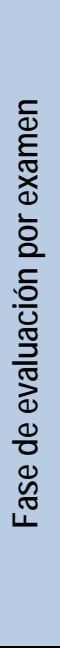 } & \multicolumn{2}{|c|}{$\begin{array}{l}\text { Actividades principales } \\
\text { Constitución de la comisión de examen } \\
\text { Definición de pruebas (práctica y entrevista) } \\
\text { Desarrollo y evaluación de las pruebas } \\
\text { Registro de actas } \\
\text { Información a la persona } \\
\text { En su caso, entrega de certificado de cualificación }\end{array}$} \\
\hline & $\begin{array}{l}\text { Profesionales de esta fase } \\
\text { EPV } \\
\text { EAPQ } \\
\text { RFC }\end{array}$ & \multirow{2}{*}{$\begin{array}{l}\text { Instrumentos/técnicas utilizados para reali- } \\
\text { zación y evaluación de pruebas de examen } \\
\text { Dossier y documento de validación de } \\
\text { evidencias } \\
\text { Documento de validación de competencias } \\
\text { Documento de evaluación de las actividades }\end{array}$} \\
\hline & $\begin{array}{l}\text { Documentos de apoyo al profe- } \\
\text { sional } \\
\text { Deliberación } 530 / 2006 \\
\text { Deliberación } 739 / 2013\end{array}$ & \\
\hline
\end{tabular}


La validación de competencias profesionales

\subsection{Comparación y conclusiones}

En este apartado queremos hacer una breve comparación entre la implantación de los dispositivos de validación y certificación de competencias en España e Italia y entre Castilla y León y Emilia-Romagna.

\subsubsection{DIFERENCIAS Y SIMILITUDES ENTRE ESPAÑA E ITALIA EN CUANTO A LA IMPLANTACIÓN DEL DISPOSITIVO DE VALIDACIÓN DE COMPETENCIAS PROFESIONALES}

Observamos una gran diferencia entre España e Italia en cuanto a la producción de legislación y políticas en lo que a validación y certificación se refiere.

Consideramos que el "pistoletazo de salida" en este ámbito llegó de la mano de la LO 5/2002 en España, y del Accordo Stato-Regioni 2000 en Italia. Lo cual explicitaba la intención de ambas naciones de ponerse manos a la obra para desarrollar sus sistemas de validación y certificación de competencias no formales e informales, tras las recomendaciones europeas emanadas a partir de la Cumbre de Lisboa del año 2000.

A partir de este momento y hasta hoy, observamos que ambas naciones han trabajado en el campo legislativo para hacer realidad las prácticas de validación de competencias (ver cuadro Cuadro 16).

Italia ha desarrollado una gran producción legislativa, bastante más extensa que la emanada por España, y marcada por importantes logros como:

- $\quad$ el DM 174/2001, que definió el procedimiento para poner en marcha un sistema nacional de competencias en la formación profesional;

- la Ley 92/2012, conocida como Riforma Fornero, que dictó unas normas generales para la construcción de un sistema nacional de aprendizaje permanente, dando importancia a la validación de aprendizajes a través de un sistema nacional de certificación de competencias;

- el DL 13/2013, que se encargó de definir la organización y estructura generales de los procedimientos de identificación, validación y certificación de aprendizajes no formales e informales. 
La validación de competencias profesionales en España e Italia

Además de estas normativas, Italia ha producido en los últimos años otros acuerdos, documentos legislativos y políticas que han intentado abrir paso en este país a los procedimientos de validación y certificación de competencias no formales e informales.

Asimismo, se ha ocupado de la creación de un Marco Nacional de Cualificaciones, relacionando las cualificaciones italianas con los niveles del Marco Europeo de Cualificaciones (EQF).

Pese a todos estos esfuerzos realizados, Italia no ha logrado instaurar un sistema nacional de validación y certificación como lo ha hecho España, que a diferencia de Italia lo ha conseguido a través de un reducido número de normativas, entre las que destacamos:

- la LO 5/2002, que dedica su artículo 8 al reconocimiento, evaluación, acreditación y registro de las cualificaciones profesionales y tuvo como principal objetivo la creación del Sistema Nacional de Cualificaciones Profesionales (SNCP), para que sirviese como referente en la validación;

- la ley de Empleo 56/2003, la cual abordó la mejora de la empleabilidad, de la cualificación y de la movilidad geográfica entre España y Europa;

- el RD 1224/2009 define y establece en España un procedimiento de evaluación y acreditación de competencias profesionales.

También cabe señalar que España está trabajando en un marco nacional de cualificaciones que se equipare al EQF.

Cuadro 16: Principales leyes, normas y acuerdos en España e Italia, relativos a la validación y certificación de competencias profesionales

\begin{tabular}{|c|c|c|c|}
\hline \multicolumn{2}{|c|}{ España } & \multicolumn{2}{|r|}{ Italia } \\
\hline Normativa & Aportación & Normativa & Aportación \\
\hline LO 5/2002 & $\begin{array}{l}\text {-Art } 8 \text { sobre } \\
\text { validación de } \\
\text { competencias } \\
\text { profesionales } \\
\text {-creación del } \\
\text { SNCP }\end{array}$ & $\begin{array}{l}\text { Accordo Stato- } \\
\text { Regioni } \\
2000\end{array}$ & $\begin{array}{l}\text {-Planteamiento de } \\
\text { procedimiento para un } \\
\text { sist. nacional de } \\
\text { certificación de compe- } \\
\text { tencias profesionales. }\end{array}$ \\
\hline & & D.M. 174/2001 & $\begin{array}{l}\text { Definición procedimien- } \\
\text { to para un sistema } \\
\text { nacional de competen- } \\
\text { cias en el campo de la }\end{array}$ \\
\hline
\end{tabular}


La validación de competencias profesionales

\begin{tabular}{|c|c|c|c|}
\hline \multicolumn{2}{|c|}{ España } & \multicolumn{2}{|r|}{ Italia } \\
\hline Normativa & Aportación & Normativa & Aportación \\
\hline & & & fp. \\
\hline $\begin{array}{l}\text { Ley de empleo } \\
53 / 2006\end{array}$ & $\begin{array}{l}\text {-Mejora em- } \\
\text { pleabilidad, } \\
\text { cualificación y } \\
\text { movilidad geo- } \\
\text { gráfica entre } \\
\text { España y Euro- } \\
\text { pa. }\end{array}$ & $\begin{array}{l}\text { Ley de empleo } \\
92 / 2012 \\
\text { (Riforma Forne- } \\
\text { ro) }\end{array}$ & $\begin{array}{l}\text {-Normas para un sist. } \\
\text { nacional } \\
\text { de aprendizaje perma- } \\
\text { nente } \\
\text {-relevancia a la valida- } \\
\text { ción de aprendizajes a } \\
\text { través de un sist. Na- } \\
\text { cional de certificación } \\
\text { de competencias. }\end{array}$ \\
\hline RD 1224/2009 & $\begin{array}{l}\text {-Definición y } \\
\text { establecimiento } \\
\text { del procedi- } \\
\text { miento nacional } \\
\text { de evaluación y } \\
\text { acreditación de } \\
\text { competencias } \\
\text { profesionales. }\end{array}$ & D.L. 13/2013 & $\begin{array}{l}\text {-Definición de organiza- } \\
\text { ción y estructura de los } \\
\text { procedimientos de } \\
\text { identificación, valida- } \\
\text { ción y certificación de } \\
\text { aprendizajes no forma- } \\
\text { les e informales. }\end{array}$ \\
\hline
\end{tabular}

En España, aunque con diferencias en el número de convocatorias, todas las comunidades autónomas han puesto en marcha este procedimiento de validación. Se trata de un procedimiento único nacional, constituido por el RD 1224/2009 que otorga validez oficial a todas las prácticas de validación de competencias profesionales realizadas bajo su marco normativo.

En Italia por el contrario, ante la falta de un sistema nacional de validación de competencias profesionales, cada región debe desarrollar su propio sistema con su propio procedimiento. Lo que está provocando grandes diferencias entre unas regiones y otras en cuanto a la implantación del dispositivo de validación.

Italia trabaja desde hace años, en el plano nacional y en el regional, para logar establecer un conjunto de estándares de referencia y para promover la puesta en marcha de dispositivos de validación de aprendizajes no formales e informales, así como su armonización en todo el territorio italiano. Para ello, esta nación ha trabajado sobre todo en la creación de perfiles profesionales, unificando algunas de las cualificaciones regionales para poder homogeneizarlas y entregar títulos válidos en todo el territorio nacional. Sin embargo, hasta ahora el funcionamiento de los sistemas de validación tiene lugar solo en el plano regional. En el ámbito nacional todavía queda un largo recorrido por hacer en cuanto a la tarea de unificación de 
La validación de competencias profesionales en España e Italia

los repertorios regionales de cualificaciones en uno nacional. Esto se perfila como uno de los retos principales para logar un sistema nacional de validación y certificación de competencias.

\subsubsection{DIFERENCIAS Y SIMILITUDES ENTRE CASTILLA Y LEÓN Y EMILIA-ROMAGNA EN CUANTO A LA IMPLANTACIÓN DEL DISPOSITIVO DE VALIDACIÓN DE COMPETENCIAS PROFESIONALES}

Centrándonos en la comparación de los procedimientos de validación profesional en Emilia-Romagna y en Castilla y León, también observamos diferencias en la producción legislativa (ver Cuadro 17). Castilla y León, como todas las comunidades autónomas españolas, se acoge al RD $1224 / 2009$ a la hora de poner en marcha el procedimiento y toma como referencia para la validación el Catálogo Nacional de Cualificaciones Profesionales (CNCP) instaurado por la LO 5/2002. Por ello, únicamente ha publicado la Orden HAC/1536/2011, que se encargó de convocar el procedimiento y la Orden HAC/1605/2011, la cual desarrolla la gestión del procedimiento de evaluación y acreditación de competencias profesionales, siguiendo el Real Decreto 1224/2009. Como aspecto novedoso incluido en el procedimiento por la normativa de la comunidad autónoma cabe destacar la creación de la Comisión Evaluadora y de la Asesora, con la intención de mejorar el funcionamiento del procedimiento.

Por otra parte, Emilia-Romagna se ha servido de su propia legislación para definir y poner en marcha la validación de competencias profesionales en su territorio. Esta región dio un paso decisivo con la publicación de la LR 12/2003, la cual reconocía el derecho de todas las personas a obtener la certificación de las competencias adquiridas a través de cualquier vía e impulsaba la definición de procedimientos de reconocimiento y certificación de competencias laborales. A partir de esta ley se desarrollaron diferentes deliberaciones que conformaron y activaron el procedimiento:

- la D.G.R. 936/2004, que se encargó de la creación del Sistema Regional de Cualificaciones (SRQ) y dio algunas pautas para un sistema regional de formalización y certificación de competencias tanto en el mundo educativo-formativo como en el laboral;

- la DGR 1434/2005, que creó el Sistema Regional de Formalización y Certificación de competencias (SRFC); 
- la DGR 530/2006, la cual definió detalladamente las fases y los instrumentos a utilizar en el SRFC;

- la DGR 739/2013, que se publicó con la intención de optimizar el SRFC, tras haber puesto en práctica el procedimiento de validación y haber detectado posibles mejoras.

Cuadro 17: Normativa de soporte para la validación y certificación de competencias profesionales en Castilla y León y en Emilia-Romagna

\begin{tabular}{|c|c|c|c|}
\hline \multicolumn{2}{|c|}{ España } & \multicolumn{2}{|r|}{ Italia } \\
\hline Normativa & Aportación & Normativa & Aportación \\
\hline & & $\begin{array}{l}\text { LR 12/2003 } \\
\text { (normativa } \\
\text { Regional) }\end{array}$ & $\begin{array}{l}\text {-Reconoce el derecho a } \\
\text { la certificación de com- } \\
\text { petencias adquiridas } \\
\text { por cualquier vía. } \\
\text {-Impulsa la definición } \\
\text { de procedimientos de } \\
\text { validación de compe- } \\
\text { tencias laborales }\end{array}$ \\
\hline $\begin{array}{l}\text { LO 5/2002 } \\
\text { (normativa nacio- } \\
\text { nal) }\end{array}$ & $\begin{array}{l}\text {-Art } 8 \text { sobre } \\
\text { validación de } \\
\text { competencias } \\
\text { profesionales. } \\
\text {-Creación del } \\
\text { SNCP }\end{array}$ & $\begin{array}{l}\text { D.G.R. } \\
\text { 936/2004 } \\
\text { (normativa } \\
\text { regional) }\end{array}$ & $\begin{array}{l}\text {-Creación del Sistema } \\
\text { Regional de Cualifica- } \\
\text { ciones (SRQ) }\end{array}$ \\
\hline $\begin{array}{l}\text { RD 1224/2009 } \\
\text { (normativa nacio- } \\
\text { nal) }\end{array}$ & $\begin{array}{l}\text {-Definición y } \\
\text { establecimiento } \\
\text { del procedimiento } \\
\text { nacional de } \\
\text { evaluación y } \\
\text { acreditación de } \\
\text { competencias } \\
\text { profesionales. }\end{array}$ & $\begin{array}{l}\text { DGR 143/2005 } \\
\text { (normativa } \\
\text { regional) }\end{array}$ & -Creación del SRFC. \\
\hline & & $\begin{array}{l}\text { DGR 530/2006 } \\
\text { (normativa } \\
\text { regional) }\end{array}$ & $\begin{array}{l}\text {-Definición de fases e } \\
\text { instrumentos del SRFC. }\end{array}$ \\
\hline $\begin{array}{l}\text { Orden } \\
\text { HAC/1536/2011 } \\
\text { (normativa auto- } \\
\text { nómica) }\end{array}$ & $\begin{array}{l}\text {-convocatoria del } \\
\text { procedimiento }\end{array}$ & & \\
\hline $\begin{array}{l}\text { Orden } \\
\text { HAC/1605/2011 } \\
\text { (normativa auto- } \\
\text { nómica) }\end{array}$ & $\begin{array}{l}\text {-Gestión del } \\
\text { procedimiento de } \\
\text { validación según } \\
\text { el RD 1224/2009. } \\
\text {-Creación de las }\end{array}$ & & \\
\hline
\end{tabular}


La validación de competencias profesionales en España e Italia

\begin{tabular}{|c|c|l|l|}
\hline \multicolumn{2}{|c|}{ España } & \multicolumn{2}{c|}{ Italia } \\
\hline Normativa & \multicolumn{1}{|c|}{ Aportación } & Normativa & \multicolumn{1}{c|}{ Aportación } \\
\hline & $\begin{array}{l}\text { comisiones direc- } \\
\text { toras y asesoras. }\end{array}$ & $\begin{array}{l}\text { DGR 739/2013 } \\
\text { (normativa } \\
\text { regional) }\end{array}$ & $\begin{array}{l}\text {-Introducción de mejo- } \\
\text { ras en el SRFC. }\end{array}$ \\
\hline & & ran
\end{tabular}

En Castilla y León, según establece el RD 1224/2009, las administraciones educativa y laboral son las encargadas de convocar el procedimiento de validación, aunque también puede hacerlo la misma Administración General del Estado y las principales organizaciones sindicales. Asimismo, cada convocatoria debe ser publicada en el boletín o diario oficial de la comunidad autónoma. Por el contrario en Emilia-Romagna, son las empresas, los centros formativos y los centros de empleo, previamente acreditados por la Regione, los que pueden poner en marcha directamente esta práctica (ver Cuadro 18), lo cual implica mayor rapidez respecto a Castilla y León.

Cabe señalar también que ambos procedimientos utilizan como referente para la validación un catálogo de competencias, el nacional en el caso de Castilla y León y el regional en el caso de Emilia-Romagna. Las cualificaciones de los dos catálogos se componen de unidades de competencia (UC), que suponen en ambos casos la unidad mínima de certificación. En Castilla y León cada UC se compone de realizaciones profesionales que describen los comportamientos objetivos y observables. Mientras que en EmiliaRomagna la UC está descrita en conocimientos y capacidades. En los dos casos se indica la competencia que el candidato debe poseer para que se le reconozca dicha UC (ver Cuadro 18).

En cuanto a las fases de los procedimientos, podemos señalar que ambos cuentan con una fase de admisión y de asesoramiento, en EmiliaRomagna esta última se denomina evaluación a través de evidencias. En la región italiana la fase de evaluación se desdobla en dos opciones, según las necesidades o posibilidades de los candidatos (entrevista evaluativa o examen), mientras que en Castilla y León todos los candidatos siguen la misma fase de evaluación. (ver Cuadro 18)

Al finalizar el procedimiento, en Castilla y León se entrega la certificación a través de la acreditación de las UC demostradas. Si con ellas puede obtenerse un certificado de profesionalidad o un título de formación profesional, el candidato podrá solicitarlo a la administración educativa/laboral correspondiente, aunque lo hará fuera del procedimiento de validación pro- 
piamente dicho. En cambio, en Emilia-Romagna la Regione entrega a los candidatos la certificación en forma de un certificado de competencias o de cualificación, según se logre demostrar una o más UC o la totalidad de las UC de una cualificación respectivamente. Además, el procedimiento de Emilia-Rommagna otorga una ficha de capacidades y conocimientos a los candidatos que no logran evidenciar la totalidad de una UC en la fase de asesoramiento. (Ver Cuadro 18).

Sobre los profesionales que participan en el procedimiento, EmiliaRomagna define en la legislación una figura más que Castilla y león, se trata del responsable de la formalización y certificación (RFC) (ver Cuadro 18). Este profesional es el responsable de que el procedimiento se desarrolle correctamente. Además, en Emilia-Romagna, a diferencia del procedimiento castellanoleonés, el EPV (asesor) participa en la fase de evaluación y el EAPQ (evaluador) interviene en el asesoramiento cuando es requerido por el asesor.

Los profesionales de ambos procedimiento cuentan con el apoyo de varios instrumentos para llevar a cabo la validación (ver Cuadro 18), resultando los de Castilla y León más precisos en cuanto a la explicación de la medición de las competencias durante la evaluación.

Cuadro 18: Cuadro comparativo sobre el procedimiento de validación y certificación de competencias en Castilla y León y en Emilia-Romagna

\begin{tabular}{|c|c|c|}
\hline $\begin{array}{l}\text { Aspectos del procedimien- } \\
\text { to a comparar }\end{array}$ & Castilla y León & Emilia-Romagna \\
\hline $\begin{array}{l}\text { Sujetos encargados de poner } \\
\text { en marcha el procedimiento }\end{array}$ & $\begin{array}{l}\text {-Administraciones educativa y } \\
\text { laboral competentes de la } \\
\text { comunidad autónoma } \\
\text {-Administración General del } \\
\text { Estado } \\
\text {-Principales organizaciones } \\
\text { sindicales y empresariales. }\end{array}$ & $\begin{array}{l}\text {-Empresas, } \\
\text {-Centros formativos, } \\
\text {-Centros de empleo }\end{array}$ \\
\hline Referencia para la validación & $\begin{array}{l}\text { Catálogo Nacional de Cualifi- } \\
\text { caciones }\end{array}$ & $\begin{array}{l}\text { Catálogo Regional de Cualifi- } \\
\text { caciones }\end{array}$ \\
\hline $\begin{array}{l}\text { Unidad mínima de certifica- } \\
\text { ción }\end{array}$ & La UC & La UC \\
\hline
\end{tabular}


La validación de competencias profesionales en España e Italia

\begin{tabular}{|l|l|l|}
\hline $\begin{array}{l}\text { Aspectos del procedimien- } \\
\text { to a comparar }\end{array}$ & \multicolumn{1}{|c|}{ Castilla y León } & \multicolumn{1}{c|}{ Emilia-Romagna } \\
\hline Fases & $\begin{array}{l}\text {-Admisión } \\
\text {-Asesoramiento } \\
\text {-Evaluación } \\
\text {-Acreditación y registro }\end{array}$ & $\begin{array}{l}\text {-Admisión } \\
\text {-Evaluación a través de evi- } \\
\text { dencias } \\
\text {-Evaluación a través de en- } \\
\text { trevista evaluativa } \\
\text {-Evaluación a través de exa- } \\
\text { men }\end{array}$ \\
\hline $\begin{array}{l}\text { Certificación otorgada } \\
\text { Organismo que otorga la } \\
\text { certificación }\end{array}$ & $\begin{array}{l}\text {-Acreditación (el títu- } \\
\text { lo/certificado de } \\
\text { profesionalidad se solicita } \\
\text { fuera del procedimiento) }\end{array}$ & $\begin{array}{l}\text {-Ficha de formalización } \\
\text {-certificación de competen- } \\
\text { cias } \\
\text {-certificación de una cualifica- } \\
\text { ción }\end{array}$ \\
\hline $\begin{array}{l}\text { Profesionales del procedi- } \\
\text { miento }\end{array}$ & $\begin{array}{l}\text { Evinistración educativa y } \\
\text { laboral }\end{array}$ & Regione Emilia-Romagna \\
\hline $\begin{array}{l}\text { Instrumentos de apoyo a los } \\
\text { profesionales }\end{array}$ & $\begin{array}{l}\text { Guía del asesor } \\
\text { Guía del evaluador } \\
\text { Guías de evidencia }\end{array}$ & $\begin{array}{l}\text {-EPV (asesor) } \\
\text {-EAPQ (evaluador) } \\
\text {-RFC (responsable del pro- } \\
\text { cedimiento). }\end{array}$ \\
\hline
\end{tabular}




\section{PARTE II}

ESTUDIO EMPÍRICO 
La validación de competencias profesionales en España e Italia 


\section{Metodología}

Entendemos por metodología el estudio de la forma en que realizamos algo. La metodología contiene métodos, técnicas, estrategias y procedimientos de los que nos serviremos como investigadores para alcanzar los objetivos que nos hemos propuesto en nuestro trabajo (Hurtado de Barrera, 2002).

Anteriormente hemos desarrollado la fundamentación teórica que sostiene esta tesis. En este capítulo pretendemos exponer y explicar los criterios metodológicos en los que se sustenta nuestro trabajo, abordando aspectos relacionados con el método utilizado y el tipo y el diseño de la investigación. Asimismo, trataremos de explicar el proceso seguido durante la elaboración de la tesis, desde la construcción de instrumentos de los que nos hemos servido para la recogida de datos, hasta el análisis de datos y la exposición de resultados. 
La validación de competencias profesionales en España e Italia

\subsection{Tipología de la investigación}

\subsubsection{MÉTOdo UTILIZADO}

Nuestro estudio sigue una metodología holística. Todo aquello que está relacionado con holismo viene de la palabra griega Holon (Yus Ramos, 2001). En castellano se utiliza como prefijo hol u holo, que significa todo, entero, completo, por lo tanto la metodología holística nos indica totalidad. Según el paradigma holístico, no podemos ver las cuestiones o argumentos de manera dividida (Löwen, 2009, p. 142), sino como un todo. Desde esta perspectiva, nos planteamos la investigación como un proceso global, en evolución continua, integrador y sinérgico. En oposición a los teóricos que defienden el uso único de los paradigmas cuantitativo o cualitativo y los consideran contradictorios, nos mostramos de acuerdo con autores como García Garrido, que niegan el monopolio metodológico, defendiendo la pluralidad de enfoques. Asimismo, la holística propone la integración de diferentes modelos epistémicos (Hurtado de Barrera, 2000).

En nuestra investigación, dado que la naturaleza de los datos determina que algunos de ellos sean tratados de forma cuantitativa y otros de forma cualitativa, hemos optado por utilizar ambos paradigmas (cualitativo y cuantitativo) de forma complementaria, en un contexto holístico integrador, facilitando así el descubrimiento de diferentes aspectos de un mismo evento.

De acuerdo con esta idea, hemos recurrido a un análisis de datos interactivo, en sintonía con las teorías metodológicas de antropólogos como Peter Woods o Clifford Geertz. Estos autores hablan de tener en cuenta todos los aspectos que afectan al evento de estudio que queremos estudiar (sinergias) y además, opinan que los investigadores podemos reformular nuestras investigaciones y forma de análisis, a la luz de nuevos hallazgos producidos en estas (Geertz, 1989; Woods, 1998). [...] debemos mantener la mente bastante abierta, sin tener prejuicios sobre el asunto a investigar, ni quedarnos necesariamente con una primera -0 incluso segunda- impresión. (Woods, 1998, p. 56). Así pues, nuestra investigación intenta estudiar los aspectos relacionados con el evento de estudio y pasa por dos momentos de análisis: el "pre" y el "post". Esto quiere decir que hemos realizado una redefinición de nuestro trabajo según hemos ido avanzando en el mismo y 
descubriendo diferentes aspectos que han motivado cambios en el desarrollo de la investigación.

La metodología holística se compone de ocho fases interrelacionadas por las que el investigador debe pasar siempre, sea cual sea el nivel al que pertenezca su investigación, como si de una espiral se tratase (Carro Sancristóbal, 2010). Estas fases, que mostramos en la Figura 2, son: descriptiva, comparativa, analítica, explicativa, proyectiva, interactiva, confirmatoria y evaluadora.

Figura 2: Fases de la investigación holística

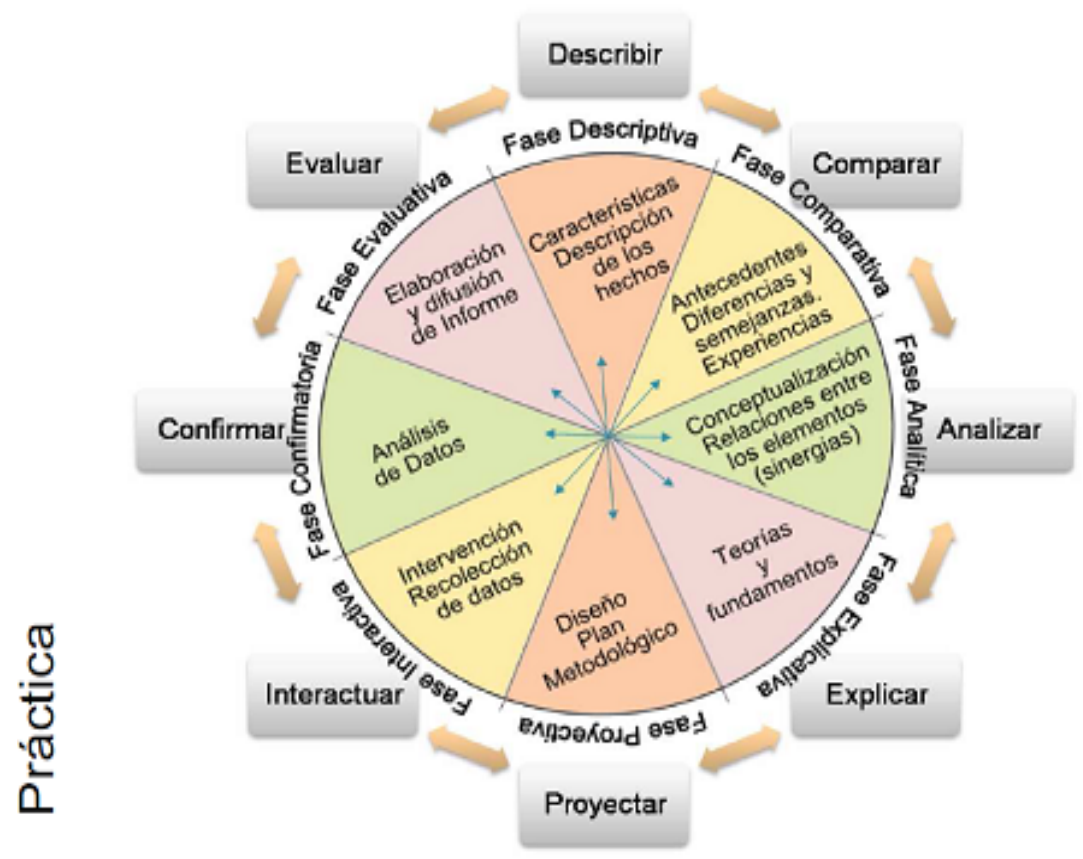

밈

Fuente: Carro (2010).

\subsubsection{TIPO DE INVESTIGACIÓN}

El tipo de investigación se define en base al objetivo a conseguir con el estudio(Hurtado de Barrera, 2002). En nuestro caso, el objetivo principal es comparar, por lo que el tipo de nuestra investigación es comparativo.

"Comparar consiste en examinar conjuntamente y contemporáneamente, es decir, al mismo tiempo, al menos dos entidades (objetos, hechos, 
personas, eventos) diferentes para buscar -y eventualmente encontrar- analogías, o para evidenciar todos los elementos diferentes y, entre ellos, los más significativos y determinantes, en relación a aquello que motiva, en esa ocasión específica, la comparación” (Todeschini \& Ziglio, 1992, p. 9).

A través de la investigación comparativa, simplemente pretendemos saber si un evento es diferente en dos o más contextos, pero no perseguimos afirmar el por qué o las causas de las diferencias halladas (Hurtado de Barrera, 2000, p. 250).

Incidiendo un poco más en el tipo de la investigación y siguiendo la metodología holística, presentamos, en el Cuadro 19, los siguientes niveles correspondientes a este paradigma, entendidos como holotipos.

Cuadro 19: Holotipos de la investigación holística

\begin{tabular}{|l|l|l|}
\hline Nivel & Objetivo & Tipo de investigación \\
\hline Perceptual & $\begin{array}{l}\text { Explorar } \\
\text { Describir }\end{array}$ & $\begin{array}{l}\text { Investigación exploratoria } \\
\text { Investigación descriptiva }\end{array}$ \\
\hline Aprehensivo & $\begin{array}{l}\text { Analizar } \\
\text { Comparar }\end{array}$ & $\begin{array}{l}\text { Investigación analítica } \\
\text { Investigación comparativa }\end{array}$ \\
\hline \multirow{3}{*}{ Comprensivo } & Explicar & Investigación explicativa \\
& $\begin{array}{l}\text { Predecir } \\
\text { Investigación predictiva } \\
\text { Investigación proyectiva }\end{array}$ \\
\hline \multirow{3}{*}{ Integrativo } & Modificar & Investigación interactiva \\
& Confirmar & Investigación confirmatoria \\
& Evaluar & Investigación evaluativa \\
\hline
\end{tabular}

Fuente: Hurtado, 2002

Nuestra investigación es comparativa, por lo tanto se corresponde con el nivel aprehensivo. El objetivo es explorar y describir un evento para lograr identificar diferencias y semejanzas respecto al mismo. Más concretamente, el objetivo es explorar y describir la implantación del dispositivo de validación y certificación de competencias no formales e informales en Castilla y León (España) y en Emilia-Romagna (Italia). Llevamos a cabo una comparación sincrónica, es decir, comparamos dos dispositivos de validación que tienen lugar en diferentes lugares pero más o menos al mismo tiempo (Todeschini \& Ziglio, 1992, pp. 19-20), para establecer analogías y diferencias entre ellos.

La Figura 3 representa el estadio comparativo en la espiral holística en la que está fundamentada nuestra investigación. 


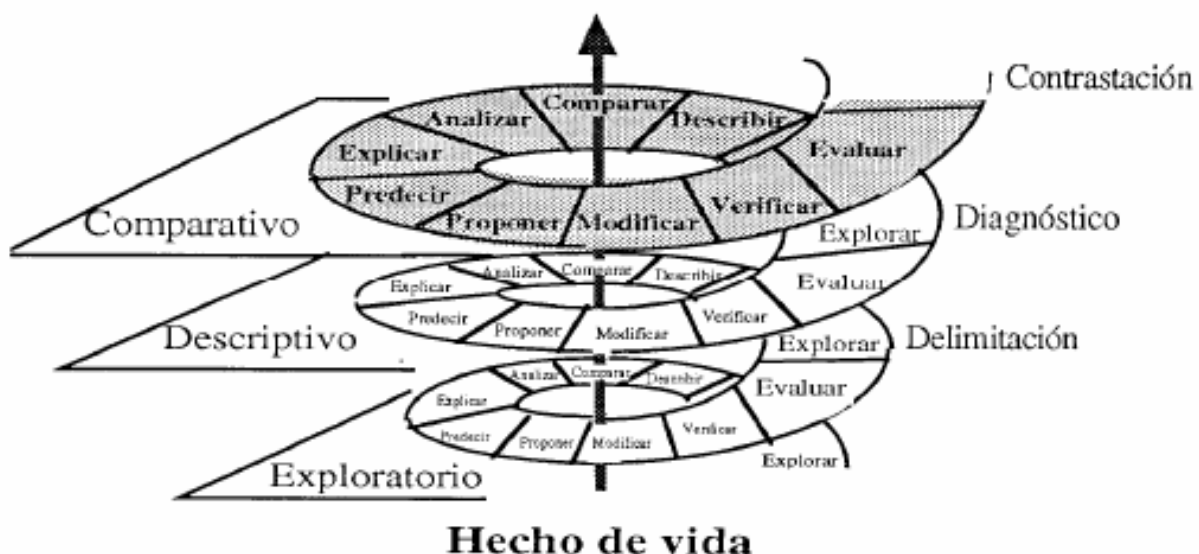

Fuente: Hurtado de Barrera, 2000

Como vemos en la Figura 3, el estadio de la comparación supone el paso previo por los estadios exploratorio y descriptivo.

Asimismo, nuestra investigación comparativa ha pasado por las 8 fases, de la holística de las que hablábamos con anterioridad:

- Fase descriptiva: en esta primera fase se ha definido el problema de investigación o evento de estudio, que hemos reflajado en el enunciado holopráxico, en el apartado 1.2. Además se ha descrito la justificación y los objetivos de la investigación, en los apartados1.1 y 1.3 respectivamente.

- Fases comparativa y analítica: en estas fases hemos desarrollado el marco teórico, llamado sintagma gnoseológico en ámbito holístico. Para ello se ha hecho una búsqueda de investigaciones y documentos relativos al tema principal de nuestra investigación. Hemos estudiado y comparado las teorías relativas al evento de estudio (capítulo 2). Asimismo, se han analizado las relaciones de los elementos ligados al objeto de estudio, llamadas, en ámbito holístico, sinergias, (capítulo 3).

- Fase explicativa: en esta fase hemos desarrollado el evento de estudio, la implantación del procedimeinto de validación de competencias no formales e informales en Castilla y León y en Emilia-Romagna. (capítulo 4). En este punto finaliza la parte teórica de la investiación. 
La validación de competencias profesionales en España e Italia

- Fase proyectiva: con esta fase comienza el desarrollo de la parte empírica del trabajo. En ella se ha decidido el método a seguir, se han construido los instrumentos de los que nos hemos servido para llevar a cabo la investigación (capítulo 5).

- Fase interactiva: este momento hace referencia a la recogida de datos, a través de los instrumentos de los que nos hemos servido y que definiremos más adelante en este capítulo (capítulo 5)

- Fase confirmatoria: durante esta fase se han analizado los datos de forma cualitativa y cuantitativa (capítulo 6).

- Fase evaluativa: Esta fase se corresponde con la elaboración del informe, incluyendo las conclusiones, alcances y prospectivas de la investigación (capítulo 7).

\subsubsection{DISEÑO DE LA INVESTIGACIÓN:}

El diseño de investigación se define en base al procedimiento, y hace referencia al dónde y cuándo se recoge la información, a su amplitud y organización de datos (Hurtado de Barrera, 2002). El dónde se refiere a las fuentes. La investigación que nos ocupa se nutre de fuentes documentales y vivas, es decir, hablamos de un diseño de fuente mixta.

El cuándo del diseño indica la perspectiva temporal, en nuestro caso sería contemporáneo y puntual. Es decir, transeccional, porque la intención de la investigación es obtener información sobre un evento actual y en un único momento del tiempo.

Aludiendo a la amplitud del foco el diseño es multivariable o multieventual y teniendo en cuenta la organización de los datos sería considerado un diseño de totalidad. Es multivariable porque realizamos una comparación a partir de dos unidades de estudio de la validación, con la intención de identificar sus diferencias y semejanzas. Por otro lado, es de totalidad porque se analiza el procedimiento entendido como un todo. El diseño es de caso, porque el énfasis está en la unidad de estudio y no tanto en las características aisladas.

Teniendo todo esto en cuenta, podemos decir que nuestro diseño es multivariable, comparativo de caso de fuente mixta (Hurtado de Barrera, 2000). 


\subsection{Definición del evento de estudio o de las varia- bles de estudio}

En este apartado determinaremos el evento comparativo del estudio, que en nuestro caso se trata del procedimiento de validación y certificación de competencias en Castilla y León y en Emilia-Romagna, según las directrices europeas. Dicho procedimiento se entiende como el proceso por el que un organismo autorizado confirma que una persona ha adquirido los resultados de aprendizaje medidos respecto a un nivel pertinente, teniendo en cuenta una fase de identificación y presentación de evidencias, otra de evaluación de esas evidencias y una última fase de certificación (Cedefop, 2014, p. 127). En esta última fase se expide un certificado, título o diploma oficial que acredita formalmente un conjunto de resultados de aprendizaje (Cedefop, 2014, p. 15).

En un estudio comparativo es insuficiente mantenernos dentro de los muros de aquello que queremos comparar, no podemos descuidar el entorno (Todeschini \& Ziglio, 1992, pp. 111-112). Por eso, nuestro evento comparativo tiene sinergias e implica otros eventos: el concepto de lifelong learning y de competencia, en ambos países y en relación a la definición de la UE; los sistemas educativos y de formación profesional de los dos países y de la comunidad autónoma española y la región italiana; el desarrollo y el procedimiento de los sistemas de validación y certificación de competencias no formales e informales en España y en Italia, así como en Castilla y León y en Emilia Romagna (sin perder de vista el referente de la UE). 


\subsection{Criterios de análisis}

El documento de las Directrices Europeas de 2009, encargado de marcar unas pautas para favorecer la homogenización de prácticas de validación en Europa, ha supuesto la clave para obtener los criterios de análisis en nuestra investigación. Tras estudiar y analizar detenidamente este el documento, hemos extraído los criterios, como mostramos en la Figura 4, en forma de principios y fases con los que debe contar un procedimiento de validación de competencias no formales e informales (Cedefop, 2009). En esta figura indicamos los principios esenciales que debe contener cada fase. Acto seguido definiremos estos criterios con mayor detalle.

Figura 4: Principios esenciales que debe contener cada fase del procedimiento de validación

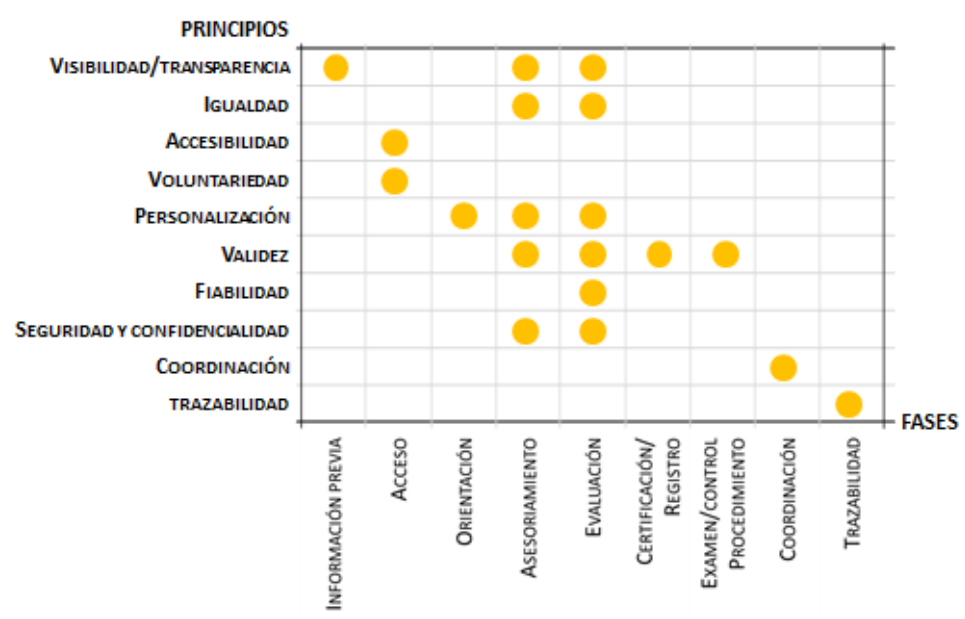

Definición de principios con los que debe contar este tipo de procedimiento:

- visibilidad/transparencia: no debe haber sorpresas para el candidato ni para las partes implicadas, todo el procedimiento debe ser claro.

- igualdad: debe darse un trato igualitario a todos los candidatos, sin propiciar favoritismos ni perjudicar a otros.

- accesibilidad: debe poder acceder al procedimiento el mayor número posible de personas. 
- voluntariedad: someterse al procedimiento debe ser voluntario para el candidato.

- personalización: cada sujeto es único y se sitúa en el centro del procedimiento, por ello, los procesos deben ser lo menos rígidos posible.

- validez: Los métodos de evaluación y los instrumentos que se utilicen en la evaluación deben medir adecuadamente la competencia que pretenden medir.

- fiabilidad: basado en los métodos y en los instrumentos, que deben ser capaces de asegurar resultados iguales o parecidos si se realiza el procedimiento bajo las mismas condiciones;

- seguridad y confidencialidad: debe respetarse la privacidad del sujeto.

- coordinación: debe existir coherencia en las prácticas de validación.

- trazabilidad: todo el procedimiento debe estar documentado.

Estos principios deben verse representados en la práctica del procedimiento de Castilla y León y de Emilia-Romagna. Para poder medirlos hemos establecido, siguiendo las Directrices Europeas de 2009, la estructura que deben presentar dichos procedimientos, a través de fases (dimensiones/eventos), desglosadas en categorías/sinergias (las cuales, en algunas ocasiones se descomponen en subcategorías) y acompañadas de su definición técnica (indicadores/indicios). Cabe señalar que las dos últimas dimensiones (coordinación y trazabilidad), que coinciden en nombre con los dos últimos principios, son transversales a todo el procedimiento de validación, aunque también puedan tener lugar al finalizar el mismo. Por su complejidad y difícil integración en las demás fases y con objeto de facilitar el análisis de datos, las hemos situado como dos fases más (dimensiones/eventos) en la parte final del procedimiento. A continuación presentamos el detalle de la categorización completa que guiará nuestro posterior análisis.

\section{Dimensión: Información previa al procedimiento}

La información previa al procedimiento es una fase que la organización/gestión del procedimiento proporciona antes del comienzo del mismo, a las partes interesadas (empresas, sindicatos, centros formativos) y a los posibles grupos objeto de validación (candidatos), con el objetivo de dar a conocer el funcionamiento y las aplicaciones de dicho procedimiento. 
La validación de competencias profesionales en España e Italia

1.1 Categoría: Información previa sobre el procedimiento de validación a las partes interesadas (empresas, sindicatos, centros formativos)

Este tipo de información, comunica a las partes interesadas, la existencia del procedimiento, su funcionamiento y ventajas.

$\underline{1.1 .0 \text { Sin subcategoría }}$

1.1.0.1 Indicador: Se informa a las partes interesadas (empresas, sindicatos, centros formativos) sobre el procedimiento de validación.

1.2 Categoría: Información previa sobre el procedimiento de validación a los candidatos

Este tipo de información está dirigida a los candidatos y su función es ofrecerles conocimiento sobre el procedimiento para que estos valoren su participación en el mismo.

\subsubsection{Sin subcategoría}

1.2.0.1 Indicador: Existe una fase de información previa, al candidato, sobre el procedimiento.

\subsection{Categoría: Accesibilidad de la información}

La información es accesible cuando las vías de transmisión son variadas y de fácil manejo para los usuarios

$\underline{1.3 .0 \text { Sin subcategoría }}$

1.3.0.1 Indicador: La información es accesible a través de internet y otras vías.

\section{Dimensión: Acceso al procedimiento}

La fase de acceso al procedimiento abarca desde la presentación de demanda por parte del candidato hasta su ingreso en el mismo, pasando por los trámites administrativos necesarios.

\subsection{Categoría: Facilidad de acceso al procedimiento}

Es fácil acceder al procedimiento cuando no existen barreras económicas y administrativas que dificulten o impidan al sujeto someterse al procedimiento.

\subsubsection{Sin subcategoría}


2.1.0.1 Indicador: Resulta fácil para los candidatos acceder al sistema en relación a la financiación

2.1.0.2 Indicador: Resulta fácil para los candidatos acceder al sistema en relación a la inscripción y admisión al procedimiento

2.1.0.3 Indicador: Resulta fácil para los candidatos acceder al sistema en relación a la documentación a presentar con la inscripción

2.1.0.4 Indicador: Resulta fácil para los candidatos acceder al sistema en relación a los requisitos de formación y experiencia profesional

\subsection{Categoría: Carácter voluntario del acceso al procedimiento}

$\mathrm{El}$ acceso al procedimiento se realiza de forma voluntaria.

\subsubsection{Sin subcategoría}

2.2.0.1 Indicador: Se hace saber al candidato la voluntariedad respecto al acceso al procedimiento.

\section{Dimensión: Orientación}

La orientación es un soporte al servicio del individuo, en todos los procesos de la validación, para ayudarle a tomar decisiones de índole educativo-profesional o personal.

\subsection{Categoría/sinergia: Orientación durante el procedimiento}

La orientación es parte integral (siempre presente) durante todo el procedimiento de validación.

\subsubsection{Sin subcategoría}

3.1.0.1 Indicador: El proceso de orientación se encuentra presente durante todo el procedimiento de validación.

\subsection{Categoría: Orientación al finalizar el procedimiento}

Tras finalizar el procedimiento se orienta al candidato sobre sus salidas formativas y/o profesionales en función de los resultados que haya obtenido en la evaluación. La evaluación tiene un efecto orientador sobre el candidato cuando esta le ayuda a conocer sus puntos fuertes y débiles, así como las amenazas y oportunidades con las que puede encontrarse para poder decidir su futuro formativo-profesional.

\subsubsection{Sin subcategoría}


La validación de competencias profesionales en España e Italia

3.2.0.1 Indicador: Se proporciona al candidato una orientación suplementaria, al finalizar el procedimiento, sobre las posibilidades de formación y/o de salidas profesionales al finalizar el procedimiento.

\section{Dimensión: Asesoramiento}

El asesoramiento cubre todo aquello que consiste en producir y difundir informaciones, motivar a los candidatos y guiarles de forma personalizada, desde la identificación de evidencias hasta la certificación.

\subsection{Categoría: Información en el proceso de asesoramiento}

$\mathrm{Al}$ iniciar el proceso de asesoramiento, el asesor informa al candidato sobre los pasos que se darán en el mismo, así como en el proceso de evaluación.

\subsubsection{Sin subcategoría}

4.1.0.1 Indicador: El asesor proporciona al candidato información acerca del procedimiento.

\section{ción) \\ 4.2 Categoría: Proceso de recogida de evidencias (documenta-}

Se trata de un proceso previo a la evaluación de competencias, consiste en documentar las competencias que la persona quiere evaluar, tratando de dibujar una imagen exhaustiva de las mismas.

\subsubsection{Subcategoría: Adecuación del proceso de recogida de evidencias}

Para que el proceso de recogida de evidencias sea adecuado, es necesario que existan unas normas para la presentación de dichas evidencias, que las competencias que quieren evaluarse estén relacionadas con estándares de validación y que el proceso está guiado por un profesional.

4.2.1.1 Indicador: Existen normas sobre lo que es relevante como documentación y cómo se debe presentar.

4.2.1.2 Indicador: Las evidencias documentadas por un individuo están directamente relacionadas con los estándares utilizados para la validación.

4.2.1.3 Indicador: El proceso de documentación está dirigido.

4.2.2 Subcategoría: Adecuación de los instrumentos para la recogida de las evidencias. 
Los instrumentos de recogida de evidencias son adecuados cuando logran demostrar la competencia profesional del candidato.

4.2.2.1 Indicador: Se emplea una amplia variedad de instrumentos para la recogida de evidencias.

4.2.2.2 Indicador: Los instrumentos para la documentación de evidencias reflejan las competencias del solicitante.

\subsection{Categoría: Preparación de los asesores}

Los profesionales del procedimiento de validación y certificación de competencias (asesores) tienen una preparación específica y conocen el sistema de validación.

\subsubsection{Sin subcategoría}

4.3.0.1 Indicador: Existen unos requisitos específicos para ser asesor.

4.3.0.2 Indicador: Existe una formación continua dirigida a asesores para el desarrollo de competencias.

4.3.0.3 Indicador: Los asesores tienen acceso a material de apoyo para llevar a cabo el proceso de asesoramiento.

4.3.0.4 Indicador: Los asesores conocen el sistema de validación y certificación de competencias y otros aspectos relacionados con el mismo

\section{miento}

4.4 Categoría: Comportamiento ético en el proceso de asesora-

El asesoramiento es ético cuando garantiza imparcialidad e igualdad de trato para los candidatos en el proceso.

4.4.0 Sin subcategoría

4.4.0.1 Indicador: El asesor proporciona un trato igualitario a todos los candidatos.

4.5 Categoría: Privacidad y confidencialidad del proceso de asesoramiento

Existe privacidad y confidencialidad en el proceso, cuando se respetan dichos principios, revelando únicamente al candidato los resultados del asesoramiento.

$\underline{4.5 .0 \text { Sin subcategoría }}$ 
La validación de competencias profesionales en España e Italia

4.5.0.1 El asesor comunica los resultados del asesoramiento únicamente al candidato.

\subsection{Categoría: Carácter personalizado del asesoramiento}

Existe carácter personalizado en el asesoramiento cuando este se centra en el individuo, teniendo en cuenta su situación y sus características personales.

\subsubsection{Subcategoría: Conocimiento del candidato por parte del asesor}

$\mathrm{El}$ asesor tiene un buen conocimiento del candidato cuando conoce la motivación y los objetivos de este para presentarse al procedimiento, así como sus condiciones personales (nivel, cultural; problemas laborales, personales, familiares, etc.) y su disponibilidad para el procedimiento (tiempo, horarios a disposición del procedimiento, colaboración con el mismo, etc.).

4.6.1.1 Indicador: El asesor conoce las motivaciones del candidato para someterse al procedimiento de validación.

4.6.1.2 Indicador: El asesor conoce los objetivos del candidato para someterse al procedimiento de validación

4.6.1.3 Indicador: El asesor conoce las condiciones personales del candidato (nivel, cultural; problemas laborales, personales, familiares, etc.).

4.6.1.4 Indicador: El asesor conoce la disponibilidad del candidato para el procedimiento (tiempo, horarios a disposición del procedimiento, colaboración con el mismo, etc.).

4.6.2 Subcategoría: Flexibilidad en el proceso de asesoramiento

Hablamos de flexibilidad en el proceso de asesoramiento cuando este tiene tan pocos procedimientos fijos como sea posible, para tener en cuenta los cambios del individuo.

4.6.2.1 Indicador: $\mathrm{El}$ asesor tiene en cuenta las condiciones personales del candidato (nivel, cultural; problemas laborales, personales, familiares, etc.), a la hora de llevar a cabo el asesoramiento.

4.6.2.2 Indicador: $\mathrm{El}$ asesor tiene en cuenta la disponibilidad del candidato (tiempo, horarios a disposición del procedimiento, colaboración con el mismo, etc.), a la hora de llevar a cabo el asesoramiento.

\subsubsection{Subcategoría: Lenguaje adaptado del asesor}

El asesor adapta su lenguaje, cuando utiliza un lenguaje sencillo de comprender para el candidato. 
4.6.3.1 Indicador: El asesor adapta su lenguaje al candidato, utilizando con él un lenguaje que le resulte comprensible.

\subsection{Categoría: Recurso o reclamación del resultado del asesora- miento}

El recurso o reclamación del resultado del asesoramiento es un procedimiento a través del cual el candidato puede expresar formalmente su desacuerdo con las decisiones tomadas respecto a él durante el asesoramiento. En este procedimiento se realiza una investigación sobre la queja interpuesta.

\subsubsection{Sin subcategoría}

4.7.0.1 Indicador: Existe un procedimiento de recurso o reclamación del resultado del proceso de asesoramiento disponible para el candidato.

\section{Dimensión: Evaluación}

La fase de evaluación se encarga de evaluar los resultados del aprendizaje del individuo, adquiridos a través del aprendizaje no formal e informal.

\subsection{Categoría: Información en el proceso de evaluación}

Al iniciar el proceso de evaluación, el evaluador explica al candidato, el funcionamiento de la evaluación y todo lo que supone esta fase.

\section{$\underline{5.1 .0 \text { Sin subcategoría }}$}

5.1.0.1 Indicador: El evaluador proporciona al candidato información sobre el procedimiento. :

5.2 Categoría: Adecuación en la investigación y análisis de evidencias con las normas estándares

Existe adecuación en la investigación y análisis de evidencias cuando los evaluadores analizan las evidencias del candidato relacionándolas con las normas o estándares de la evaluación, sirviéndose para ello de los instrumentos adecuados y de la metodología pertinente.

5.2.1 Subcategoría: Existencia de estándares/referentes de evaluación

Los estándares/referentes de evaluación definen los resultados de aprendizaje que deben lograrse, éstos deben ser claros y sin ambigüedades. 
La validación de competencias profesionales en España e Italia

5.2.1.1 Indicador: Las evaluaciones se basan en estándares/referentes.

5.2.1.2 Indicador: Los estándares están ligados/relacionados con el Marco Nacional de Cualificaciones.

5.2.1.3 Indicador: Los resultados de aprendizaje que debe demostrar el candidato están debidamente indicados.

\subsubsection{Subcategoría: Adecuación de los instrumentos de evaluación}

Los instrumentos son adecuados cuando son capaces de medir la competencia que pretenden medir y no otra. Asimismo, para que los instrumentos sean adecuados debe existir fiabilidad. Un instrumento es fiable en la medida en la cual se obtienen resultados idénticos cada vez que se evalúa a un candidato bajo las mismas condiciones.

5.2.2.1 Indicador: Los instrumentos miden las competencias que pretenden medirse y no otras.

5.2.2.2 Indicador: Los instrumentos permiten al candidato demostrar los aprendizajes que posee.

5.2.2.3 Indicador: Los instrumentos permiten medir:

- el "saber";

- el "saber hacer";

- el "saber estar".

5.2.2.4 Indicador: El individuo conoce sus competencias a través del proceso de evaluación (autoevaluación).

5.2.2.5 Indicador: $\mathrm{Al}$ realizar una evaluación a dos o más candidatos de características similares los resultados son los mismos o muy similares (fiabilidad).

\subsubsection{Subcategoría: Adecuación de la metodología}

La metodología a seguir en la evaluación es adecuada cuando existe un responsable que trace su elaboración siguiendo unas pautas claras y cuando se combinan diferentes métodos de evaluación en un medio adecuado para que el candidato demuestre sus competencias.

5.2.3.1. Indicador: Está claro quién es el responsable de la elaboración de metodologías pertinentes para la validación. 
5.2.3.2. Indicador: Se siguen unas pautas claras para la elaboración de la metodología a seguir en la evaluación.

5.2.3.3. Indicador: Existe variación en la elección del método, dependiendo de la persona y de las UC en las que esta se quiera acreditar.

5.2.3.4. Indicador: Existe una combinación de métodos usados

5.2.3.5. Indicador: Existen espacios físicos a disposición de la evaluación.

\subsection{Categoría: Preparación de los evaluadores}

Los profesionales del sistema de validación y certificación de competencias (evaluadores) tienen una preparación específica y conocen el sistema de validación.

\subsubsection{Sin subcategoría}

5.3.0.1. Indicador: Existen unos requisitos específicos para ser evaluador.

5.3.0.2. Indicador: Existe una formación continua para el desarrollo de competencias, dirigida a evaluadores

5.3.0.3. Indicador: Los evaluadores tienen acceso a material de apoyo para llevar a cabo el proceso de evaluación

5.3.0.4. Indicador: El evaluador conoce el sistema de validación y certificación de competencias y otros aspectos relacionados con el mismo.

\section{ción}

5.4 Categoría: Comportamiento ético en el proceso de evalua-

El proceso de evaluación garantiza imparcialidad e igualdad de trato para los candidatos en el proceso.

\section{$\underline{5.4 .0 \text { Sin subcategoría }}$}

5.4.0.1 El evaluador proporciona un trato igualitario a todos los candidatos.

5.5 Categoría: Privacidad y confidencialidad del proceso de evaluación

Existe privacidad y confidencialidad en el proceso cuando se respetan estos principios, comunicando únicamente al candidato, el resultado de la evaluación. 
La validación de competencias profesionales en España e Italia

\section{$\underline{\text { 5.5.0 Sin subcategoría }}$}

5.5.0.1 El evaluador comunica el resultado de la evaluación únicamente al candidato.

\subsection{Categoría: Carácter personalizado de la evaluación}

Existe carácter personalizado en la evaluación cuando esta se centra en el individuo, teniendo en cuenta su situación y sus características personales. dor

5.6.1 Subcategoría: Conocimiento del candidato por parte del evalua-

El evaluador tiene un buen conocimiento del candidato cuando conoce la motivación y los objetivos de este para presentarse al procedimiento, así como sus condiciones personales (nivel, cultural; problemas laborales, personales, familiares, etc.) y su disponibilidad para el procedimiento (tiempo, horarios a disposición del procedimiento, colaboración con el mismo, etc.).

5.6.1.1 Indicador: El evaluador conoce las motivaciones del candidato para someterse al procedimiento de validación.

5.6.1.2 Indicador: El evaluador conoce los objetivos del candidato para someterse al procedimiento de validación

5.6.1.3 Indicador: El evaluador conoce las condiciones personales del candidato (nivel, cultural; problemas laborales, personales, familiares, etc.).

5.6.1.4 Indicador: El evaluador conoce la disponibilidad del candidato para el procedimiento (tiempo, horarios a disposición del procedimiento, colaboración con el mismo, etc.).

\subsubsection{Subcategoría: Flexibilidad en el proceso de evaluación}

Hablamos de flexibilidad en el proceso de evaluación cuando este tiene tan pocos procedimientos fijos como sea posible, para tener en cuenta los cambios del individuo.

5.6.2.1 Indicador: El evaluador tiene en cuenta las condiciones personales del candidato (nivel, cultural; problemas laborales, personales, familiares, etc.). 
5.6.2.2 Indicador: El evaluador tiene en cuenta la disponibilidad del candidato para el procedimiento (tiempo, horarios a disposición del procedimiento, colaboración con el mismo, etc.).

\subsubsection{Subcategoría: Lenguaje adaptado del evaluador}

El evaluador adapta su lenguaje, cuando utiliza un lenguaje sencillo de comprender para el candidato.

5.6.3.1 El evaluador adapta su lenguaje al candidato, utilizando con él un lenguaje que le resulte comprensible.

\subsection{Categoría: Carácter formativo de la evaluación.}

La evaluación tiene un efecto formativo sobre el candidato cuando esta le facilita la inserción o reinserción en el mundo formativo.

\subsubsection{Sin subcategoría}

5.7.0.1 El procedimiento ayuda a la reinserción, de los candidatos que lo requieran, en el mundo formativo, tras el procedimiento.

\section{ción}

5.8 Categoría: Recurso o reclamación del resultado de la evalua-

El recurso o reclamación del resultado de la evaluación es un procedimiento a través del cual el candidato puede expresar formalmente su desacuerdo con las decisiones tomadas respecto a él, en el proceso de evaluación En este procedimiento se realiza una investigación sobre la queja interpuesta.

\subsubsection{Sin subcategoría}

5.8.0.1 Existe un procedimiento de recurso o reclamación del resultado de la evaluación, disponible para el candidato.

\section{Dimensión: Certificación y Registro}

La certificación tiene lugar tras la evaluación de competencias, consiste en dar un valor oficial, a nivel regional y/o nacional a las competencias evaluadas y demostradas.

\subsection{Categoría: Validez de la certificación}

La certificación es válida cuando la validación de competencias desemboca en una certificación válida en el territorio regional y/o nacional.

$\underline{\text { 6.0.1 Sin subcategoría }}$ 
La validación de competencias profesionales en España e Italia

6.1.0.1 Indicador: Existe un órgano habilitado para emitir y registrar certificaciones tras la validación.

6.1.0.2 Indicador: La certificación tiene una validez nacio$\mathrm{nal} /$ regional

6.1.0.3 Indicador: Los certificados del procedimiento de validación tienen el mismo estatus que los certificados formales o diplomas.

\section{Dimensión: Examen/Control del procedimiento}

Se trata de un proceso que sigue a la evaluación y certificación, consiste en someter el procedimiento a examen. No está relacionado con las competencias de los candidatos, se refiere a cómo se ha desarrollado la práctica del procedimiento y su eficiencia y eficacia. Está dirigido al candidato y al desarrollo de mejoras de todo el procedimiento de validación. La institución y los profesionales de la validación tienen la obligación de realizar evaluaciones y mejoras continuas para asegurar la calidad en el procedimiento.

\section{Categoría: 7.1 Control interno del procedimiento}

Proceso que somete las prácticas del procedimiento a examen interno, a través de los propios organizadores de la validación.

\subsubsection{Sin subcategoría}

7.1.0.1 Se hace un examen/control interno del procedimiento.

7.1.0.2 Existe un organismo interno (cuerpo competente), a la organización del procedimiento, encargado del examen del procedimiento.

7.1.0.3 Existe un plan de seguimiento interno (control del procedimiento)

\section{Categoría: 7.2 Control externo del procedimiento}

7.2.0.1 Se hace un examen/control externo del procedimiento.

7.2.0.2 Existe un organismo externo (cuerpo competente), a la organización del procedimiento, encargado del examen del procedimiento.

7.2.0.3 Existe un plan de seguimiento externo (control del procedimiento).

\section{Dimensión: Coordinación en el procedimiento}


La coordinación y colaboración asegura que las prácticas de validación desarrollen y utilicen una metodología, hace que las evaluaciones y decisiones se hagan en un entorno profesional. Garantiza un alto nivel de competencia, cumpliendo y respetando los derechos individuales de las personas.

\subsection{Sin categoría}

\section{$\underline{\text { 8.0.0 Sin subcategoría }}$}

8.0.0.1 Indicador: Existe una figura encargada de la coordinación del procedimiento.

8.0.0.2 Se realizan encuentros/reuniones de puesta en común entre los profesionales, dirigidos a mejorar el procedimiento.

\section{Dimensión: Trazabilidad}

La trazabilidad permite dejar constancia del procedimiento a través de la documentación de las actividades realizadas, para facilitar el control del procedimiento y un posible recurso o reclamación por parte del candidato.

\subsection{Sin categoría}

\subsubsection{Sin subcategoría}

9.0.0.0. Cada paso en el procedimiento de evaluación se documenta/registra. 


\subsection{Descripción y selección de las unidades de es- tudio (población y muestra)}

Tras definir el evento de estudio, determinamos en qué o quiénes investigamos dicho evento. Es decir, en qué ser o seres se manifiesta la situación a estudiar (Hurtado de Barrera, 2002). Por tanto, las unidades de estudio son los poseedores del evento, que en nuestra investigación son:

- El procedimiento de evaluación y acreditación de competencias no formales e informales en Castilla y León.

- El procedimiento de formalización y certificación de competencias de la experiencia de Emilia-Romagna.

En algunas situaciones, como es nuestro caso, no es posible obtener la información directamente de las unidades de estudio. Por lo que hemos recurrido a fuentes capaces de proporcionarnos la información necesaria. Nos hemos servido de fuentes documentales (documentos legislativos y de políticas de actuación) y de fuentes vivas (profesionales de ambos procedimientos). A continuación presentamos cuatro tablas para ver estas fuentes de forma más detallada. La Tabla 1 expone los documentos legislativos, nacionales españoles e italianos y autonómicos de Castilla y León y regionales de Emilia-Romagna que hemos analizado. La Tabla 2 muestra los profesionales del procedimiento en Castilla y León a los que hemos entrevistado, mientras que la

Tabla 3 se refiere a los profesionales entrevistados en EmiliaRomagna. Ambas tablas indican el rol profesional y en el procedimiento de los entrevistados. Asimismo hemos indicado las iniciales de los entrevistados, para poder reconocer sus respuestas en el apartado 6.1) sobre el análisis de datos y sus entrevistas (para consultar las entrevistas ver anexo 33). Por último, la Tabla 4 indica los profesionales de ambos procedimientos a los que hemos encuestado, señalando su función en el procedimiento correspondiente.

Tabla 1: Fuentes documentales (legislación)

\begin{tabular}{|c|l|l|l|}
\hline Territorio & Ámbito legislativo & \multicolumn{1}{|c|}{ Rango } & \multicolumn{1}{c|}{ Denominación } \\
\hline \multirow{2}{*}{ España } & Nacional & Real Decreto & $\begin{array}{l}\text { Real Decreto 1224/2009, de 17 de julio, de } \\
\text { reconocimiento de las competencias profesiona- } \\
\text { les adquiridas por experiencia laboral }\end{array}$ \\
\cline { 2 - 4 } & Autonómico de & Orden & Orden HAC/1536/2011, de 7 de diciembre, por la \\
\hline
\end{tabular}




\begin{tabular}{|c|c|c|c|}
\hline Territorio & Ámbito legislativo & Rango & $\begin{array}{l}\text { Denominación } \\
\end{array}$ \\
\hline & Castilla y León & & $\begin{array}{l}\text { que se convocan los procedimientos de evalua- } \\
\text { ción y acreditación de competencias } \\
\text { profesionales adquiridas a través de la experien- } \\
\text { cia laboral o de vías no formales de formación, } \\
\text { cofinanciados por el Fondo Social Europeo, para } \\
\text { unidades de competencia de cualificaciones } \\
\text { profesionales de las familias profesionales de } \\
\text { Servicios Socioculturales y a la Comunidad, y de } \\
\text { Transporte y Mantenimiento de Vehículos }\end{array}$ \\
\hline & & Orden & $\begin{array}{l}\text { Orden HAC/1605/2011, de } 29 \text { de diciembre, por } \\
\text { la que se desarrolla la gestión del procedimiento } \\
\text { de evaluación y acreditación de competencias } \\
\text { profesionales adquiridas por experiencia laboral } \\
\text { en Castilla y León, así como la estructura orga- } \\
\text { nizativa responsable }\end{array}$ \\
\hline \multirow{7}{*}{ Italia } & \multirow{4}{*}{ Nacional } & Ley & $\begin{array}{l}\text { Ley } 92 / 2012 \text {, de } 28 \text { de junio de } 2012 \text {, de } \\
\text { Disposizioni in materia di riforma del mercato del } \\
\text { lavoro in una prospettiva di crescita }\end{array}$ \\
\hline & & $\begin{array}{l}\text { Decreto } \\
\text { Ministerial }\end{array}$ & $\begin{array}{l}\text { Decreto Ministerial 174/2001, de } 31 \text { de mayo sul } \\
\text { sistema di certificazione delle competenze nella } \\
\text { formazione professionale }\end{array}$ \\
\hline & & $\begin{array}{l}\text { Decreto } \\
\text { Legislativo }\end{array}$ & $\begin{array}{l}\text { Decreto Legislativo 13/2013 de } 16 \text { de enero de } \\
2013 \text {, de definizione delle norme generali e dei } \\
\text { livelli essenziali delle prestazioni per } \\
\text { l'individuazione e validazione degli } \\
\text { apprendimenti non formali e informali e degli } \\
\text { standard minimi di servizio del sistema nazionale } \\
\text { di certificazione delle competenze, a norma } \\
\text { dell'articolo 4, commi } 58 \text { e 68, della legge } 28 \\
\text { giugno 2012, n. } 92\end{array}$ \\
\hline & & $\begin{array}{l}\text { Acuerdo } \\
\text { Estado- } \\
\text { Regiones }\end{array}$ & $\begin{array}{l}\text { Accordo in sede di Conferenza Stato-Regioni de } \\
18 \text { de febrero del } 2000 \text { tra il Ministro del lavoro e } \\
\text { della previdenza sociale, le Regioni e le province } \\
\text { autonome di Trento e Bolzano per } \\
\text { l'individuazione degli standards minimi delle } \\
\text { qualifiche professionali e dei criteri formativi e } \\
\text { per l'accreditamento delle strutture della } \\
\text { formazione professionale }\end{array}$ \\
\hline & \multirow{3}{*}{$\begin{array}{l}\text { Regional de Emilia- } \\
\text { Romagna }\end{array}$} & $\begin{array}{l}\text { Deliberación } \\
\text { de Junta } \\
\text { Regional }\end{array}$ & $\begin{array}{l}\text { Deliberación de Junta Regional } 739 \text { de } 10 \text { de } \\
\text { junio de } 2013 \text {, de Modifiche e integrazioni al } \\
\text { Sistema Regionale di Formalizzazione e } \\
\text { Certificazione delle competenze di cui alla DGR. } \\
\text { núm. 530/2006 }\end{array}$ \\
\hline & & $\begin{array}{l}\text { Deliberación } \\
\text { de Junta } \\
\text { Regional }\end{array}$ & $\begin{array}{l}\text { Deliberación de Junta Regional } 530 \text { de } 19 \text { de } \\
\text { abril de } 2006 \text {, de II Sistema Regionale di } \\
\text { Formalizzazione e Certificazione delle } \\
\text { competenze }\end{array}$ \\
\hline & & Deliberación & Deliberación de Junta Regional 841/2006 de \\
\hline
\end{tabular}


La validación de competencias profesionales en España e Italia

\begin{tabular}{|c|c|c|c|}
\hline Territorio & Ámbito legislativo & Rango & Denominación \\
\hline & & $\begin{array}{l}\text { de Junta } \\
\text { Regional }\end{array}$ & $\begin{array}{l}\text { Adozione di procedure di evidenza publica e } \\
\text { approvazione di modalità e requisiti per il } \\
\text { reclutamento dei ruoli prodessionali di cui al } \\
\text { allegato B della Delibera de G.R. 530/06 }\end{array}$ \\
\hline & & $\begin{array}{l}\text { Deliberación } \\
\text { de Junta } \\
\text { Regional }\end{array}$ & $\begin{array}{l}\text { Deliberación de Junta Regional } 1434 / 2005 \text { de } 12 \\
\text { de septiembre de } 2005 \text {, Orientamenti, } \\
\text { metodologia e struttura per la definizione del } \\
\text { sistema regionale di formalizzazione e } \\
\text { certificazione delle competenze }\end{array}$ \\
\hline
\end{tabular}

Tabla 2: Profesionales del procedimiento de Castilla y León entrevistados

\begin{tabular}{|c|c|c|c|c|}
\hline $\mathrm{N}^{0}$ & Nombre & Rol profesional & $\begin{array}{c}\text { Rol en el } \\
\text { procedimiento }\end{array}$ & Hora/fecha/lugar \\
\hline 1 & J.I.N & $\begin{array}{l}\text { Asesor técnico docente de la } \\
\text { Dirección General de Forma- } \\
\text { ción Profesional de Régimen } \\
\text { Especial del Servicio de las } \\
\text { Cualificaciones y Acreditación } \\
\text { de las Competencias Profesio- } \\
\text { nales }\end{array}$ & Gestor/organizador & $\begin{array}{l}\text { De } 9.30 \mathrm{~h} \text { a } 10.02 \mathrm{~h} \\
\text { 18/11/2013 } \\
\text { Valladolid }\end{array}$ \\
\hline 2 & C.T & Trabajador social. & Asesor & $\begin{array}{l}\text { De 10.00h a 11.30h } \\
\text { 22/11/2013 } \\
\text { Valladolid }\end{array}$ \\
\hline 3 & J.L & $\begin{array}{l}\text { Monitor en un centro de educa- } \\
\text { ción especial, en un taller } \\
\text { ocupacional de carpintería. }\end{array}$ & Asesor & $\begin{array}{l}\text { De } 17.30 \mathrm{~h} \text { a } 19.00 \mathrm{~h} \\
27 / 12 / 2013 \\
\text { Valladolid }\end{array}$ \\
\hline 4 & A.D & $\begin{array}{l}\text { Profesora de educación secun- } \\
\text { daria por la especialidad del } \\
\text { ciclo de servicios sociocultura- } \\
\text { les y a la comunidad. }\end{array}$ & Evaluador & $\begin{array}{l}\text { De } 18.30 \mathrm{~h} \text { a } 19.20 \mathrm{~h} \\
21 / 11 / 2013 \\
\text { Valladolid }\end{array}$ \\
\hline 5 & T.M & $\begin{array}{l}\text { Directora y trabajadora social } \\
\text { de un centro de mayores. }\end{array}$ & Evaluador & $\begin{array}{l}\text { De 14.00h a } 15.00 \mathrm{~h} \\
27 / 12 / 2013 \\
\text { Segovia }\end{array}$ \\
\hline
\end{tabular}

Tabla 3: Profesionales del procedimiento de Emilia-Romagna entrevistados

\begin{tabular}{|l|l|l|l|l|}
\hline $\mathbf{N}^{\mathbf{0}}$ & Nombre & \multicolumn{1}{|c|}{ Rol profesional } & \multicolumn{1}{c|}{ Rol en el sistema } & \multicolumn{1}{c|}{ Hora/fecha/lugar } \\
\hline 1 & P.A & $\begin{array}{l}\text { Responsables de figuras } \\
\text { profesionales. Cualificacio- } \\
\text { nes. }\end{array}$ & Gestor/organizador & $\begin{array}{l}\text { De 14.30h a 16.40h } \\
\text { 2/12/2013. } \\
\text { Bologna }\end{array}$ \\
\hline 2 & P.V & $\begin{array}{l}\text { Responsables de figuras } \\
\text { profesionales. Cualificacio- } \\
\text { nes. }\end{array}$ & Gestor/organizador & $\begin{array}{l}\text { De 14.30h a 16.40h } \\
2 / 12 / 2013 . \\
\text { Bologna }\end{array}$ \\
\hline
\end{tabular}


Metodología

\begin{tabular}{|c|c|c|c|c|}
\hline $\mathrm{N}^{0}$ & Nombre & Rol profesional & Rol en el sistema & Horalfecha/lugar \\
\hline 3 & V.F & $\begin{array}{l}\text { Referente del } \\
\text { procedimiento en la } \\
\text { Regione. } \\
\text { Servizio Formazione } \\
\text { Professionale. Direzione } \\
\text { Generale Cultura, } \\
\text { Formazione e Lavoro } \\
\end{array}$ & Gestor/organizador & $\begin{array}{l}\text { 20013. De 10.30h a } \\
\text { 12.00h } \\
6 / 12 / 2013 \\
\text { Bologna }\end{array}$ \\
\hline 4 & M.M & $\begin{array}{l}\text { Responsable del Area } \\
\text { Ricerca e } \\
\text { Proyettazione.Irecoop } \\
\text { Emilia Romagna } \\
\end{array}$ & $\begin{array}{l}\text { Responsable de la } \\
\text { Formalización y Certi- } \\
\text { ficación (RFC) }\end{array}$ & $\begin{array}{l}\text { De } 10.00 h \text { a } 12.15 h . \\
\text { 4/12/2013. } \\
\text { Bologna }\end{array}$ \\
\hline 5 & N.B & $\begin{array}{l}\text { Directora de centro de } \\
\text { formación en Emilia- } \\
\text { Romagna }\end{array}$ & $\begin{array}{l}\text { Experto de procesos } \\
\text { de evaluación (EPV) }\end{array}$ & $\begin{array}{l}\text { De } 10.00 \mathrm{~h} \text { a } 12.30 \mathrm{~h} \\
3 / 12 / 2013 . \\
\text { Bologna }\end{array}$ \\
\hline 6 & S.C & $\begin{array}{l}\text { Experto de procesos de } \\
\text { evaluación (EPV) } \\
\text { (A tiempo completo) }\end{array}$ & $\begin{array}{l}\text { Experto de procesos } \\
\text { de evaluación (EPV) }\end{array}$ & $\begin{array}{l}\text { De } 14.30 \mathrm{~h} \text { a } 15.30 \mathrm{~h} \\
6 / 12 / 2013 \\
\text { Bologna }\end{array}$ \\
\hline 7 & G.G. & $\begin{array}{l}\text { Responsable de Area } \\
\text { Estetica ECIPAR Forma- } \\
\text { zione }\end{array}$ & $\begin{array}{l}\text { Experto de procesos } \\
\text { de evaluación (EPV) }\end{array}$ & $\begin{array}{l}\text { De } 9.30 \mathrm{~h} \text { a } 12.00 \mathrm{~h} . \\
\text { 5/12/2013. } \\
\text { Modena }\end{array}$ \\
\hline 8 & C.C. & $\begin{array}{l}\text { Coordinador de un centro } \\
\text { de formación profesional. } \\
\text { Experto del área profesio- } \\
\text { nal de cualificación del } \\
\text { sector de la restauración }\end{array}$ & $\begin{array}{l}\text { Experto de área pro- } \\
\text { fesional y cualificación } \\
\text { (EAPQ) }\end{array}$ & $\begin{array}{l}\text { De 15.00ha 16.00h } \\
\text { 5/12/2013 } \\
\text { Bologna }\end{array}$ \\
\hline
\end{tabular}

Tabla 4: Profesionales de ambos procedimientos encuestados

\begin{tabular}{|c|l|l|}
\hline $\begin{array}{c}\text { Número de en- } \\
\text { cuestados }\end{array}$ & \multicolumn{1}{|c|}{ Procedimiento } & \multicolumn{1}{c|}{ Rol en el sistema } \\
\hline 27 & $\begin{array}{l}\text { Procedimiento de Emilia- } \\
\text { Romagna }\end{array}$ & $\begin{array}{l}\text { Experto de procesos de evaluación } \\
(\text { EPV) }\end{array}$ \\
\hline 49 & $\begin{array}{l}\text { Procedimiento de Emilia- } \\
\text { Romagna }\end{array}$ & $\begin{array}{l}\text { Experto de área profesional y cualifica- } \\
\text { ción (EAPQ) }\end{array}$ \\
\hline 70 & $\begin{array}{l}\text { Procedimiento de Castilla y } \\
\text { León }\end{array}$ & Asesores \\
\hline 64 & $\begin{array}{l}\text { Procedimiento de Castilla y } \\
\text { León }\end{array}$ & Evaluadores \\
\hline
\end{tabular}


La validación de competencias profesionales en España e Italia

\subsection{Descripción del procedimiento (actividades)}

En este aparatado explicamos cómo hemos construido este trabajo de investigación, pasando por la delimitación del tema, el desarrollo del marco teórico, la construcción y uso de instrumentos de recogida y análisis de datos y la redacción de las conclusiones. Cabe señalar que este procedimiento contado sobre el papel de manera lineal, ha sido más bien circular. Lo cual quiere decir que muchos de los pasos expuestos en este apartado se han dado de forma transversal durante parte o todo el proceso de construcción de la tesis.

Asimismo, es destacable el uso de métodos mixtos y eclécticos de los que nos hemos servido para lograr nuestro objetivo de conocer y comparar los dos procedimientos de validación.

\subsubsection{DETERMINACIÓN DEL TEMA}

El motivo por el que decidimos desarrollar un estudio sobre la validación de competencias profesionales está relacionado con el creciente auge, en ámbito europeo, que suscita este tema, y la necesidad de conocer otras perspectivas en cuanto a la aplicación de este tipo de procedimientos (Cedefop, 2009). En cuanto al hecho de comparar la realidad española con la italiana, tiene que ver con que España e Italia pusieran en marcha sus procedimientos de reconocimiento de competencias casi al mismo tiempo, unido a mi cercana relación con Italia (país en el que he cursado parte de mis estudios). En un principio se pretendía comparar el fenómeno en la totalidad de los territorios españoles (comunidades autónomas) e italianos (regiones). Sin embargo, tras una primera toma de contacto con el tema en Italia, a través de la lectura de artículos relacionados con la validación de competencias en este país y, sobre todo, gracias a los encuentros y entrevistas con expertos en este ámbito, nos dimos cuenta de la imposibilidad de desarrollar nuestro trabajo como lo habíamos planeado inicialmente. Esto ocurrió por el hecho de que cada región italiana tiene una realidad diferente en cuanto a validación de competencias se refiere, por lo que la magnitud del trabajo hubiese resultado imposible de abarcar.

Por ello decidimos estudiar y comparar el estado del arte en ámbito nacional en ambos países, y para profundizar en un caso concreto de validación, elegimos una región italiana y una comunidad autónoma española. En 
Italia escogimos Emilia-Romagna, ya que cuenta con un sistema de validación bastante desarrollado, representativo de la realidad italiana y comparable con el sistema de Castilla y León, comunidad autónoma que elegimos en España por la facilidad de acceso a la información necesaria para la investigación. Ambos territorios están compuestos por 9 provincias y tienen peso en la producción del sector primario, secundario y terciario

\subsubsection{RECOGIDA DE INFORMACIÓN Y ELABORACIÓN DEL MARCO TEÓRICO}

Tras delimitar el tema objeto de estudio se empezó a leer y a recoger toda la información que pudiese resultar útil para nuestra investigación. Para esta tarea contamos con la ayuda de varios encuentros y entrevistas con profesionales expertos en el tema de validación de competencias profesionales. Estos encuentros se realizaron en centros de estudios e investigación, tanto en Italia como en España. Cabe destacar que estas entrevistas no solo tuvieron lugar al comienzo de la investigación, sino que se sucedieron de forma transversal durante casi todo nuestro trabajo, para ayudarnos a resolver las dudas que surgían sobre el funcionamiento de los procedimientos de validación o sobre los sistemas educativo-formativos.

En Italia acudimos a:

- el centro de investigación Italiaforma en Piacenza (Italia): este centro fomenta la cualificación y se ocupa, en general, de recursos humanos. Recurrimos a él para obtener documentación e información sobre el proceso de evaluación y validación de competencias, a través de encuentros con los investigadores de dicho centro;

- el centro de instrucción y formación profesional Ente Nazionale Acli Istruzione Professionale de Piacenza: este centro forma parte de una red nacional de servicios para la formación y el trabajo. Acudimos a él para obtener información y resolver dudas sobre el sistema educativo y de formación profesional italiano a través de entrevistas a varios de sus profesionales;

- la Università Cattolica Sacro Cuore de Piacenza: nos dirigimos a ella para recoger información y aclarar dudas sobre el proceso de validación en Italia, por medio de entrevistas a docentesinvestigadores expertos en el tema y del acceso a material bibliográfico; 
La validación de competencias profesionales en España e Italia

- el Departamento formativo del Sindicato Cisl (Confederazione italiana sindacati lavoratori): se trata del departamento dirigido a la formación de trabajadores de la unión de sindicatos de trabajadores. Hemos acudido a este departamento para entrevistarnos con algunos de sus dirigentes con la intención de conocer mejor las prácticas de validación en el ámbito empresarial italiano;

- el centro de investigación Isfol (Instituto para el desarrollo de la formación profesional de los trabajadores). Realizamos numerosas visitas al mismo para llevar a cabo encuentros con investigadores del centro, con el fin de conocer mejor el estado del arte de la validación de competencias en Italia y las prácticas regionales. Así como para consultar bibliografía sobre el tema;

- la Università degli studi Roma Tre: Desarrollamos gran parte de nuestro trabajo en esta universidad, contando con las orientaciones y aportaciones de algunos de sus docentes-investigadores. Asimismo, dispusimos de su extensa biblioteca para consultar la bibliografía relacionada con la validación de competencias en Italia y en Europa;

- el Departamento de formación de la Regione Emilia-Romagna: se trata del departamento encargado de la formación, perteneciente al gobierno de la región de Emilia-Romagna. Acudimos a él para conocer de cerca el procedimiento de validación de competencias profesionales en Emilia-Romagna.

Por otro lado, en España también recurrimos a diferentes centros y expertos, como:

- la Consejería de Educación de Castilla y León, en Valladolid: nos dirigimos varias veces a este lugar para mantener entrevistas con los principales organizadores del procedimiento de validación en Castilla y León para conocer estas prácticas en profundidad;

- el Centro integrado de formación profesional Juan de Herrera, en Valladolid: recurrimos a este centro para acercarnos a las prácticas de validación de competencias profesionales en Castilla y León;

- la Universidad de Valladolid: realizamos entrevistas con docentes investigadores expertos en la formación profesional para conocer más afondo este sistema. Además utilizamos la biblioteca como fuente bibliográfica. 
Asimismo, nos hemos ayudado de varios instrumentos para documentarnos y poder desarrollar el marco teórico:

- WorldCat y Dialnet: plataformas de recursos y servicios documentales, cuyo objetivo es mejorar la visibilidad y el acceso a la literatura científica a través de internet, útiles para la búsqueda de libros y artículos relacionados con el tema de investigación;

- Eurydice: red europea de información sobre educación que nos ha servido como orientación y guía para la descripción de los modelos educativos y de formación profesional español e italiano;

- el Diario Oficial de la Unión Europea (en adelante, DOUE): fuente oficial del derecho comunitario europeo. La Oficina de Publicaciones Oficiales de las Comunidades Europeas, situada en Luxemburgo, se encarga de su publicación que se compone en dos series, la L para legislación y la C para comunicaciones e informaciones y un suplemento para concursos y contratos públicos. Esta es una de las principales fuentes para situarnos en el marco europeo de la validación de competencias profesionales y desarrollar el marco teórico.

- el Boletín Oficial del Estado (en adelante, BOE): órgano oficial de publicación de leyes, disposiciones y actos de inserción obligatoria del Estado español. Este boletín ha sido de utilidad para obtener información sobre el sistema educativo y de formación profesional español y el sistema de evaluación y acreditación de competencias profesionales en España.

- el Boletín Oficial de Castilla y León, (en adelante, BOCYL): periódico oficial de la Comunidad de Castilla y León, a través del cual se publican documentos oficiales, de acuerdo con el ordenamiento jurídico. Esta herramienta ha sido de interés para conocer y describir el sistema de formación profesional y de validación en Castilla y León.

- la Gazzetta Ufficiale: fuente oficial de conocimiento de las normas en vigor en Italia. Es un instrumento de difusión e información que se encarga también de oficializar actos públicos y privados que tienen que llegar a conocimiento de toda la comunidad. Esta fuente ha sido imprescindible para construir y describir el sistema educativo y de formación profesional italiano y el sistema de evaluación y acreditación de competencias en Italia. 
La validación de competencias profesionales en España e Italia

- el Bollettino Ufficiale della Regione Emilia-Romagna: órgano oficial de publicación de leyes reglamentos, disposiciones regionales en EmiliaRomagna, muy útil para el conocimiento y descripción del sistema formativo y de validación de Emilia-Romagna.

\subsubsection{CONSTRUCCIÓN Y USO DE INSTRUMENTOS PARA LA RECOGIDA DE DATOS Y SU POSTERIOR ANÁLISIS}

\subsubsection{La matriz de análisis}

Para facilitar una comparación, de los procedimientos de validación, minuciosa y analítica, parte a parte, necesitábamos seleccionar, ordenar y poner en evidencia las partes describibles y medibles (Todeschini \& Ziglio, 1992, p. 16). Por ese motivo construimos una matriz de análisis, elaborada siguiendo el documento de Directrices Europeas de 2009 sobre la validación de aprendizajes no formales e informales, y a partir del estudio de los procedimientos de validación de competencias profesionales en Castilla y León y en Emilia-Romagna. Concretamente, hemos utilizado la matriz como base para la recogida de datos, provenientes de los documentos legislativos, las entrevistas y los cuestionarios, y para su posterior análisis.

La matriz recoge el evento de estudio con sus sinergias (categorías y, en algunos casos subcategorías) y con sus indicadores. La definición de las categorías y subcategorías se corresponde con la definición teórica del evento de estudio, mientras que los indicadores hacen referencia a la definición operativa de este. (Ver apartado 5.3).

En la construcción de nuestra matriz, hemos sometido a un estudio y a una adaptación constante el diseño de la investigación, los problemas planteados para la tesis, la especificación de las categorías, las relaciones entre los datos, etc., de acuerdo a los hallazgos que se han ido produciendo en el curso del estudio (Woods, 1998, p. 55). Por ello, la construcción de la matriz empezó a elaborarse desde el momento en el que comenzamos a perfilar el marco teórico, a partir de un modelo inicial que ha seguido evolucionando casi hasta finalizar el análisis documental y de entrevistas, con la intención de permitirnos un análisis más preciso (Todeschini \& Ziglio, 1992, p. 16).

A continuación, exponemos la matriz de análisis que hemos elaborado, con las dimensiones a estudiar, categorías, subcategorías e indicadores, 
definidos en el apartado 5.3 sobre criterios de análisis de la investigación. Asimismo, en ella indicamos el tipo de análisis realizado para indagar sobre cada indicador y las fuentes utilizadas para ello. Además, en cada categoría indicamos el principio, de las directrices europeas, definidos también en el apartado 5.3, al que da respuesta. 
La validación de competencias profesionales en España e Italia

Tabla 5: Matriz de análisis con principios relacionados, tipo de análisis y fuentes

\begin{tabular}{|c|c|c|c|c|c|}
\hline Dimensión & $\begin{array}{l}\text { Categoría/*principios rela- } \\
\text { cionados }\end{array}$ & Subcategoría & Indicador & Tipo análisis & Fuente \\
\hline \multirow[t]{3}{*}{$\begin{array}{l}1 \text { Información } \\
\text { previa al procedi- } \\
\text { miento }\end{array}$} & $\begin{array}{l}\text { 1.1 Información previa sobre } \\
\text { el procedimiento de validación } \\
\text { a las partes interesadas } \\
\text { (empresas, sindicatos, centros } \\
\text { formativos) } \\
\text { *Visibilidad/Transparencia }\end{array}$ & & $\begin{array}{l}\text { 1.1.0.1 Se da una información previa, a } \\
\text { las partes interesadas (empresas, } \\
\text { sindicatos, centros formativos), sobre el } \\
\text { procedimiento de validación. }\end{array}$ & $\begin{array}{l}\text {-Análisis docu- } \\
\text { mental. } \\
\text {-Análisis de } \\
\text { entrevistas. }\end{array}$ & $\begin{array}{l}\text {-Documentos } \\
\text { legislativos } \\
\text {-Gestores/ } \\
\text { Organizadores, } \\
\text { asesores, evalua- } \\
\text { dores, y } \\
\text { referentes, del } \\
\text { procedimiento (en } \\
\text { adelante, profesio- } \\
\text { nales del } \\
\text { procedimiento). }\end{array}$ \\
\hline & $\begin{array}{l}\text { 1.2. Información previa sobre } \\
\text { el procedimiento de validación } \\
\text { a los candidatos } \\
\text { *Visibilidad/Transparencia }\end{array}$ & & $\begin{array}{l}\text { 1.2.0.1 Existe una fase de información } \\
\text { previa, al candidato, sobre el procedi- } \\
\text { miento. }\end{array}$ & $\begin{array}{l}\text {-Análisis docu- } \\
\text { mental. } \\
\text {-Análisis de } \\
\text { entrevistas. }\end{array}$ & $\begin{array}{l}\text {-Documentos } \\
\text { legislativos } \\
\text {-Profesionales del } \\
\text { procedimiento. }\end{array}$ \\
\hline & $\begin{array}{l}\text { 1.3 Accesibilidad de la infor- } \\
\text { mación } \\
\text { *Visibilidad/Transparencia }\end{array}$ & & $\begin{array}{l}\text { 1.3.0.1 La información es accesible a } \\
\text { través de internet y otras vías. }\end{array}$ & $\begin{array}{l}\text {-Análisis docu- } \\
\text { mental. } \\
\text {-Análisis de } \\
\text { entrevistas. }\end{array}$ & $\begin{array}{l}\text {-Documentos } \\
\text { legislativos } \\
\text {-Profesionales del } \\
\text { procedimiento. }\end{array}$ \\
\hline $\begin{array}{l}2 \text { Acceso al pro- } \\
\text { cedimiento }\end{array}$ & $\begin{array}{l}\text { 2.1 Facilidad de acceso al } \\
\text { procedimiento } \\
\text { *Accesibilidad }\end{array}$ & & $\begin{array}{l}\text { 2.1.0.1 Resulta fácil para los candidatos } \\
\text { acceder al sistema en relación a la } \\
\text { financiación } \\
\text { 2.1.0.2 Resulta fácil para los candidatos } \\
\text { acceder al sistema en relación a la }\end{array}$ & $\begin{array}{l}\text {-Análisis docu- } \\
\text { mental. } \\
\text {-Análisis de } \\
\text { entrevistas. }\end{array}$ & $\begin{array}{l}\text {-Documentos } \\
\text { legislativos } \\
\text {-Profesionales del } \\
\text { procedimiento. }\end{array}$ \\
\hline
\end{tabular}




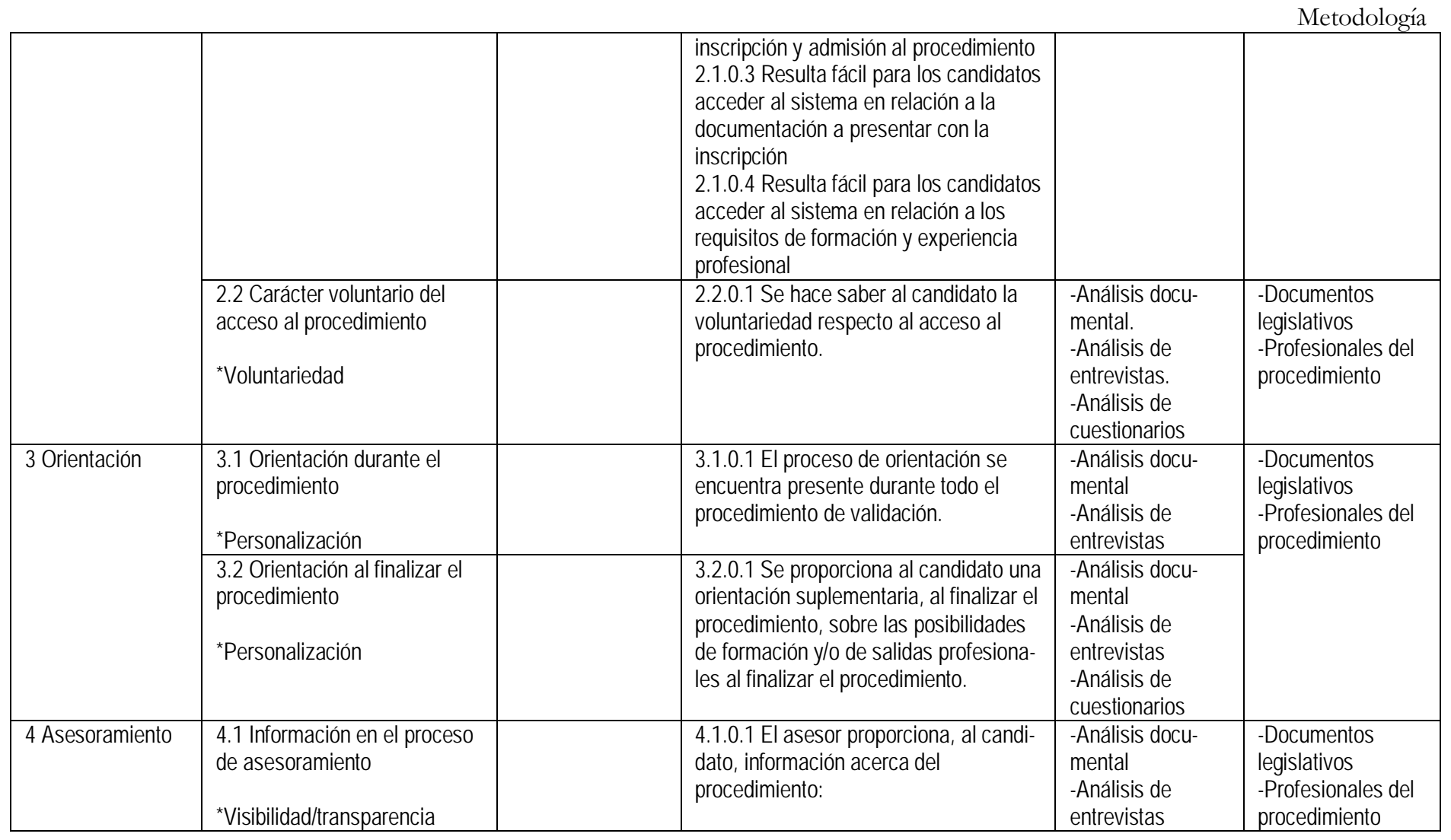


La validación de competencias profesionales en España e Italia

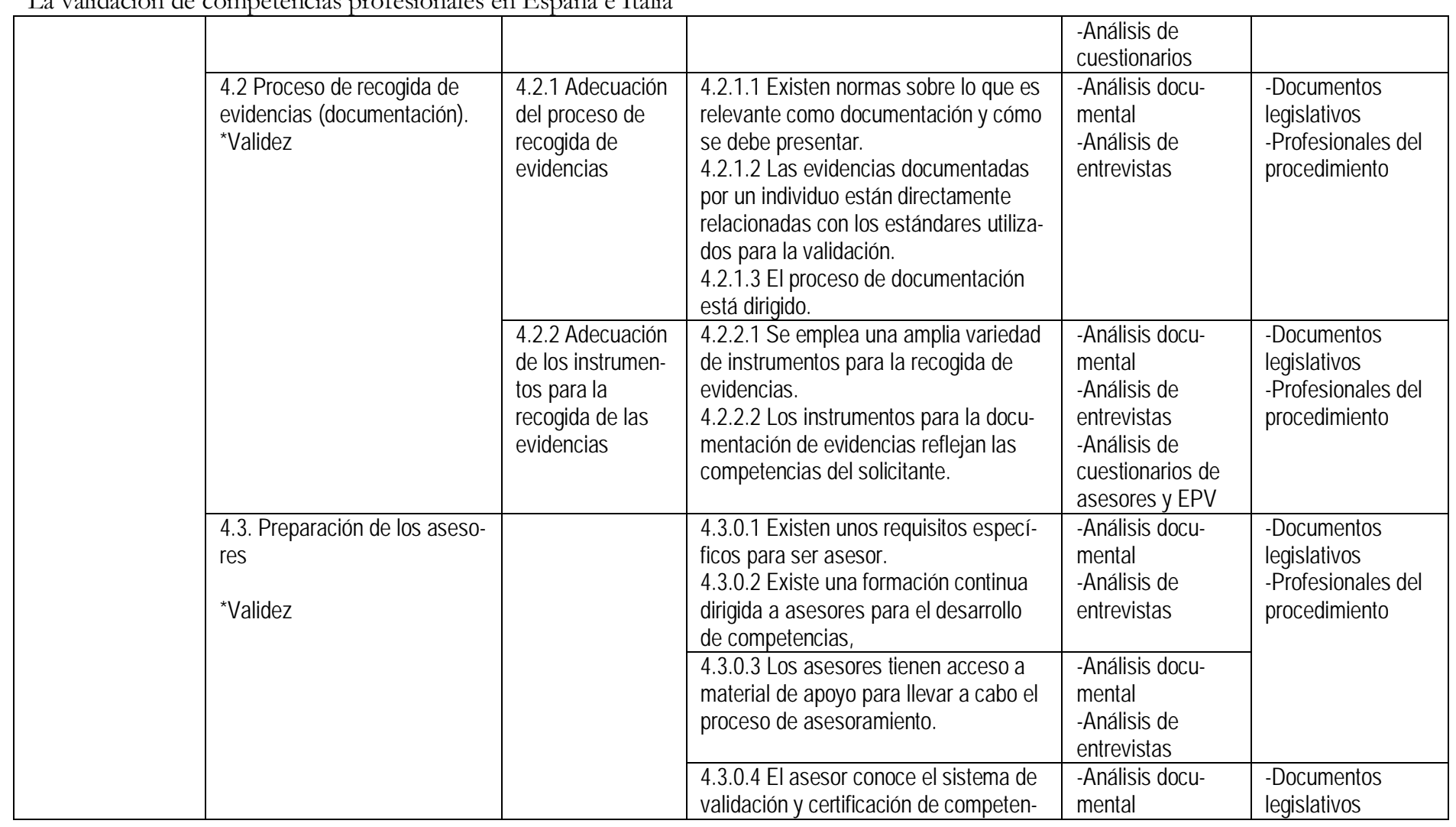


Metodología

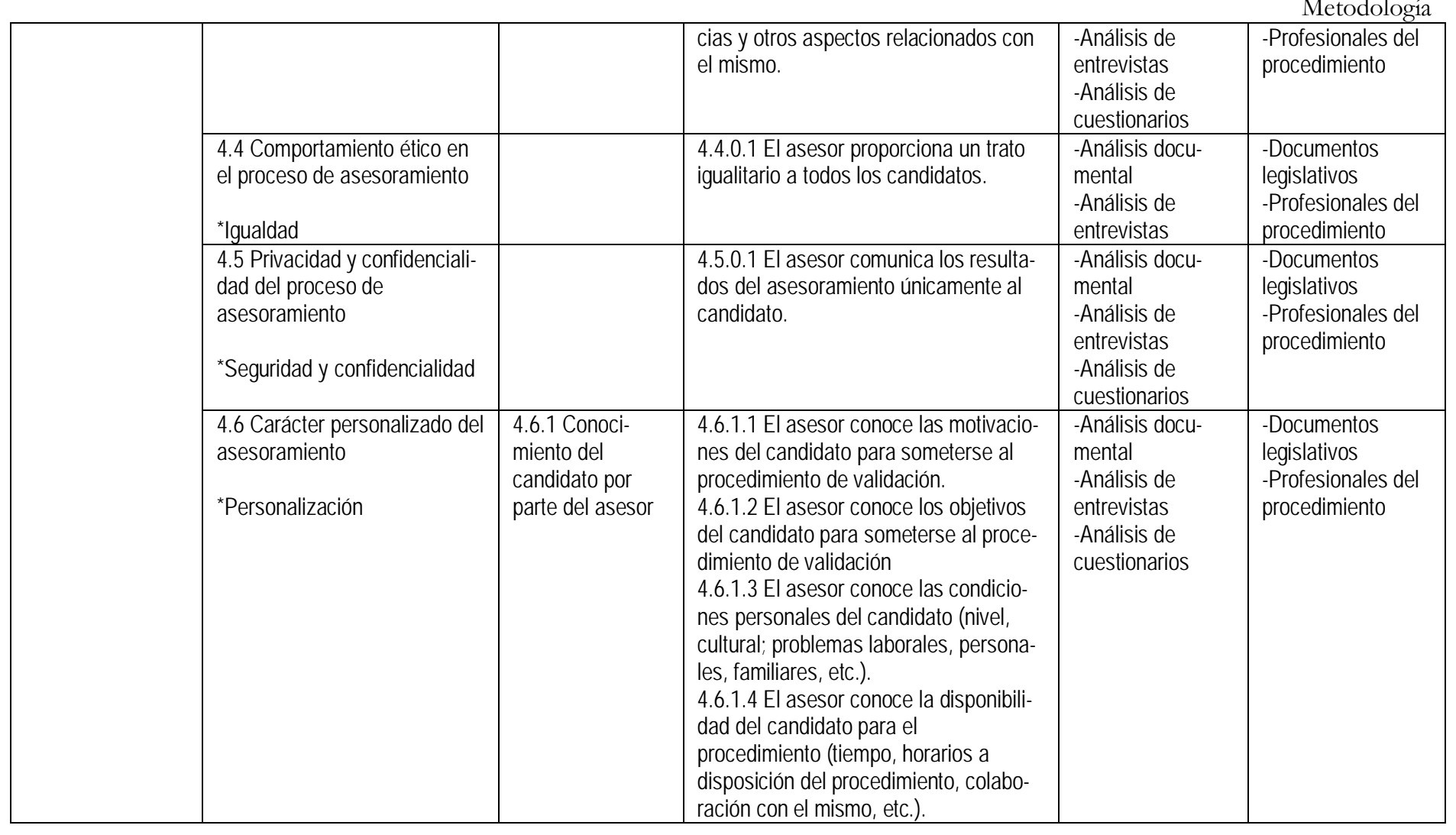


La validación de competencias profesionales en España e Italia

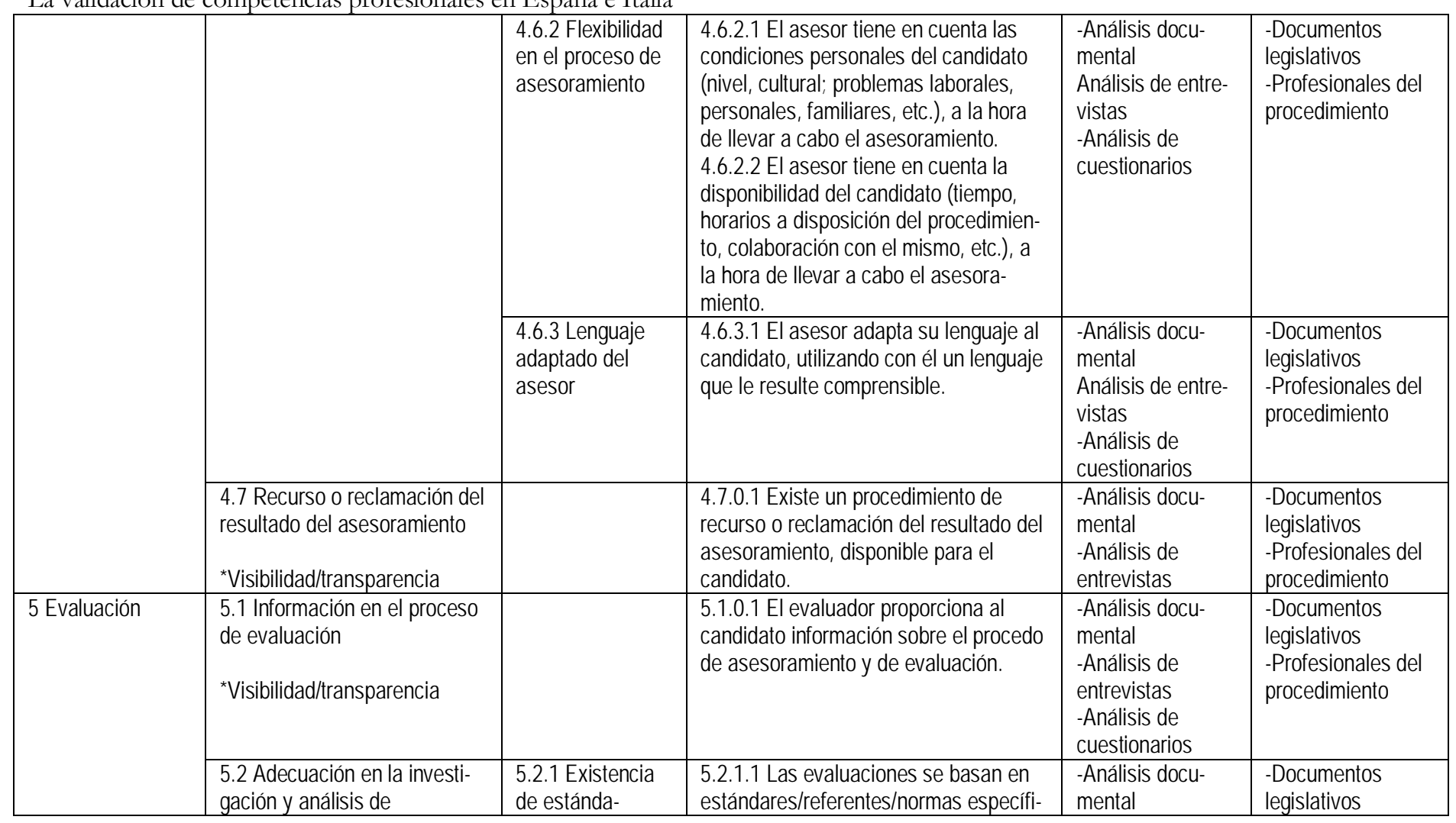


Metodología

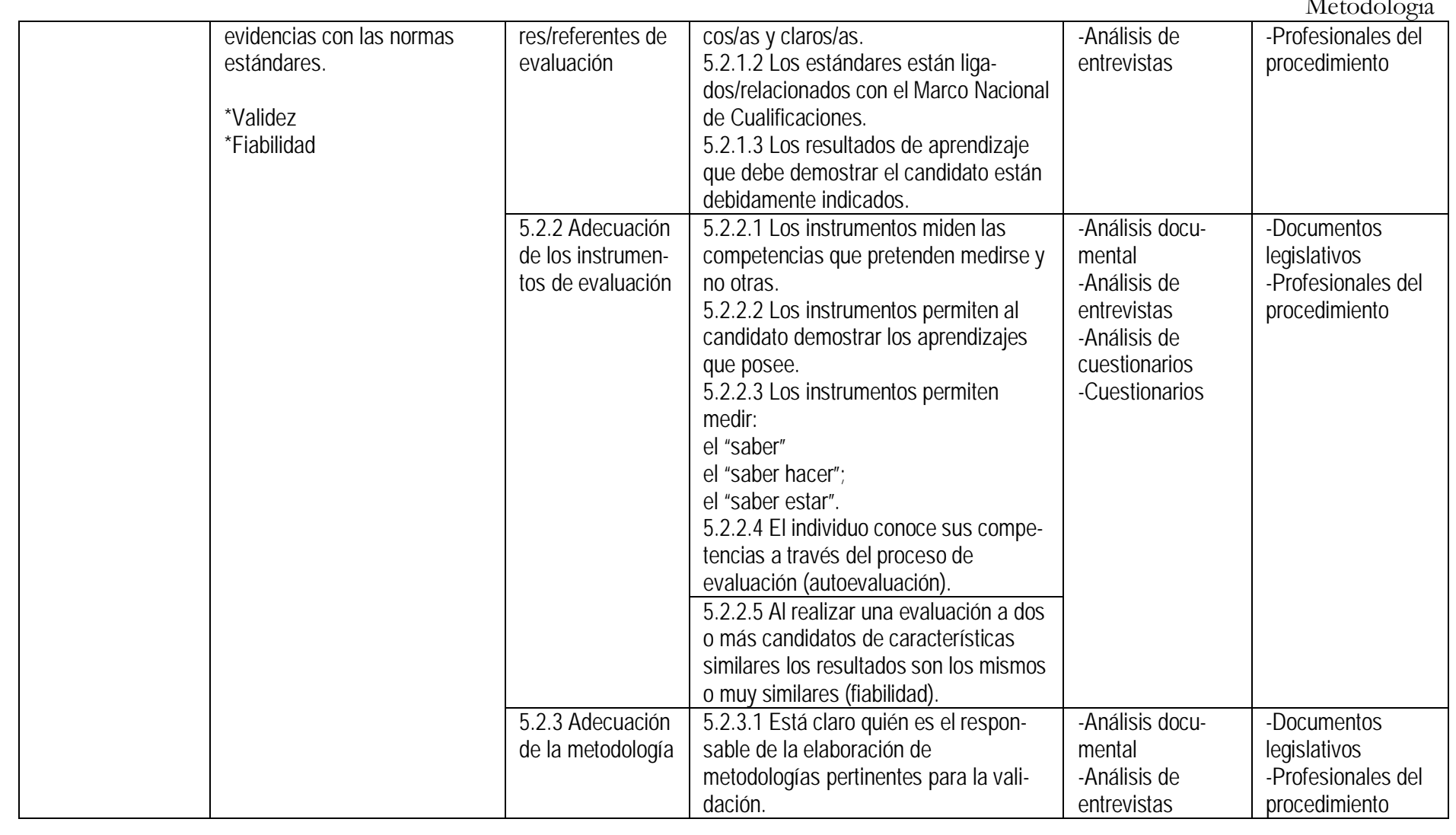


La validación de competencias profesionales en España e Italia

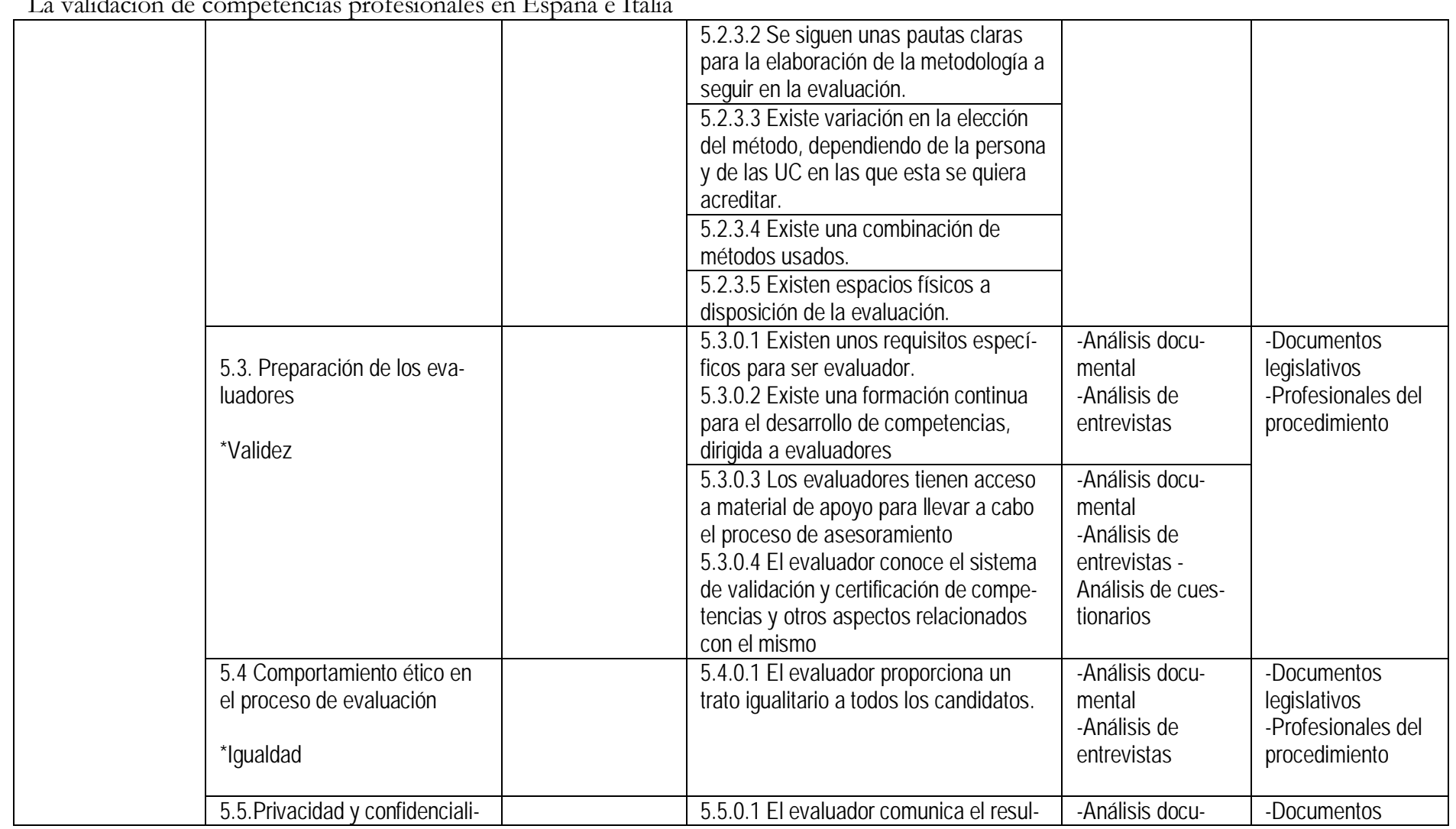




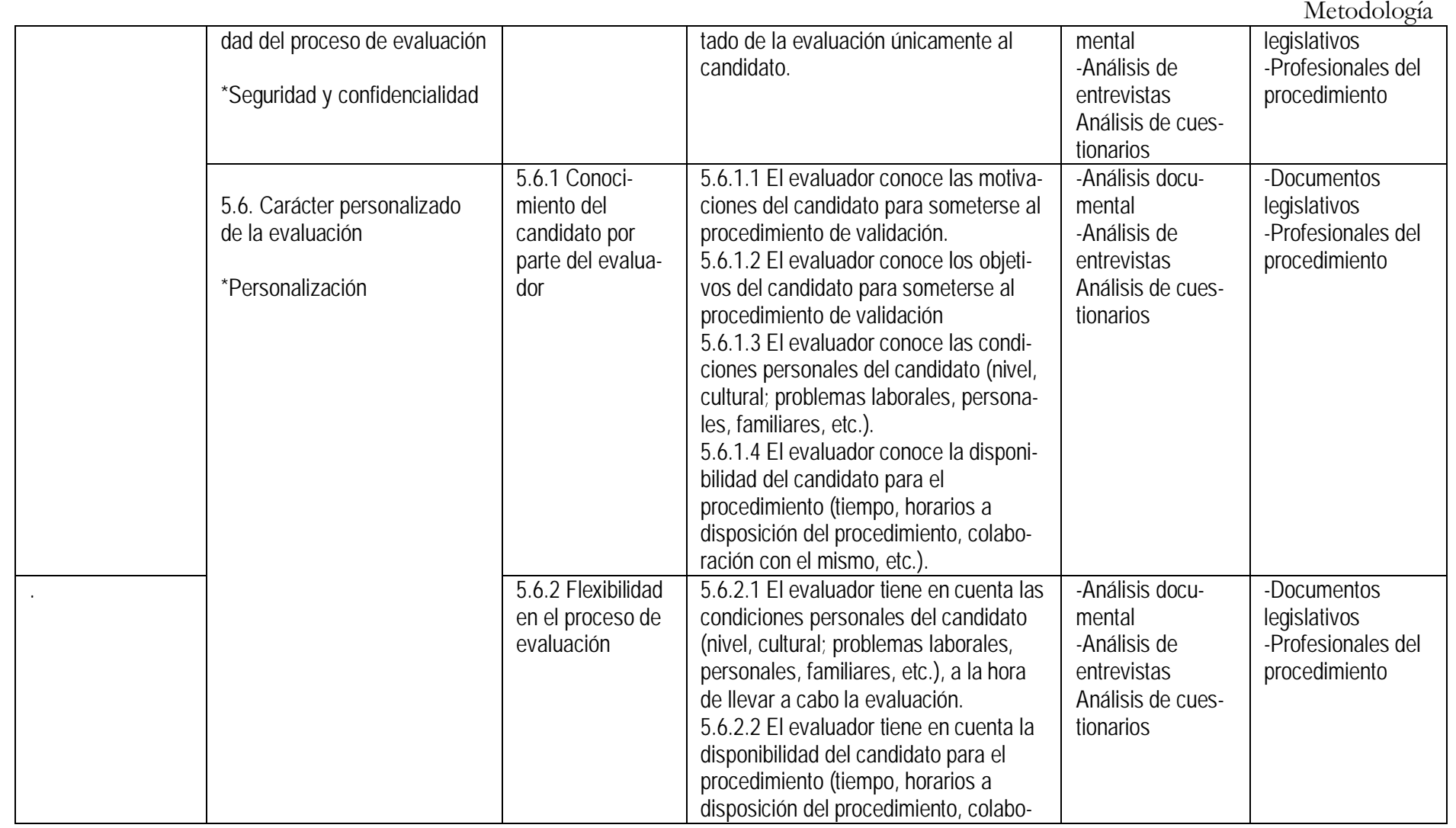


La validación de competencias profesionales en España e Italia

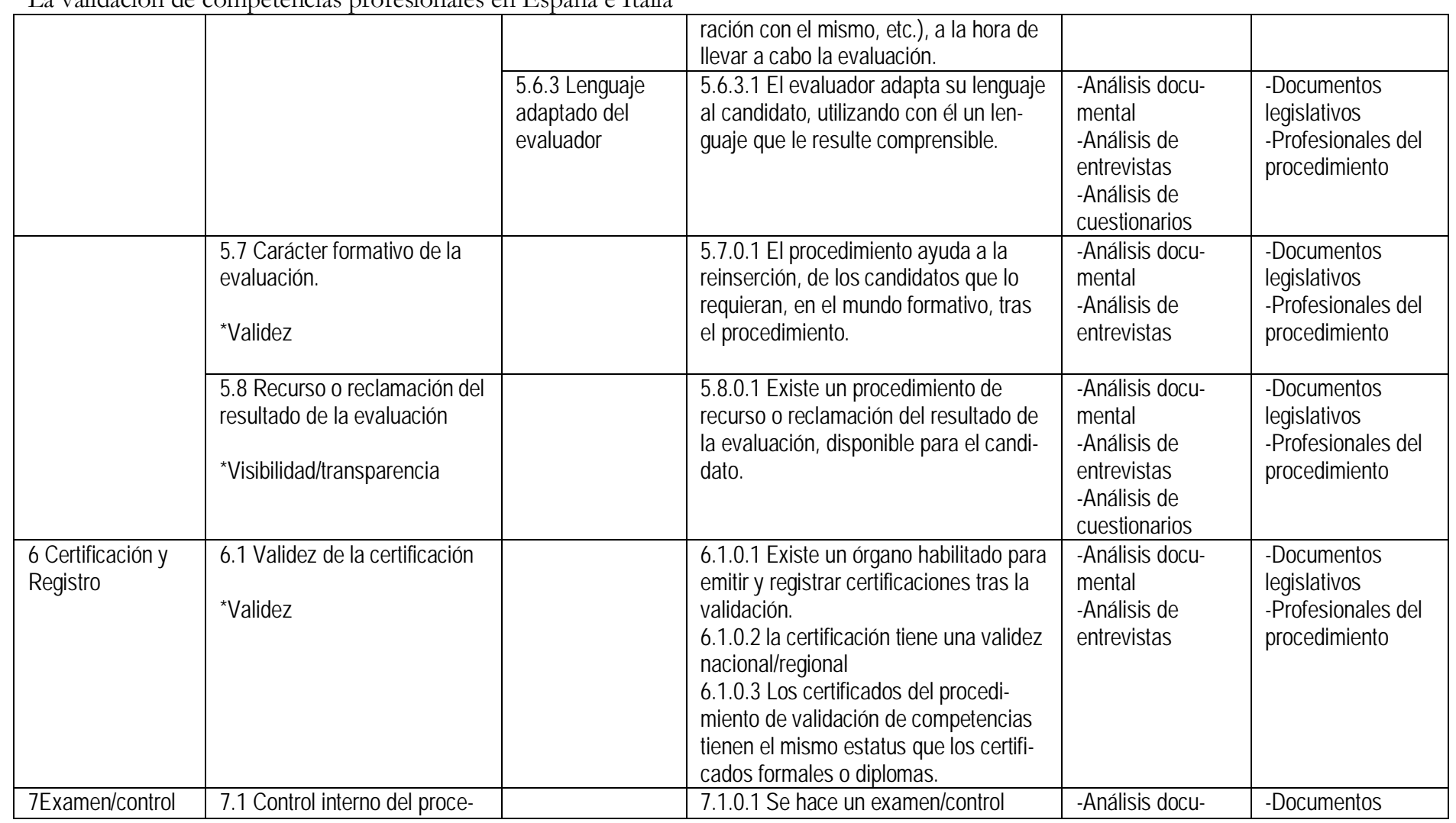




\begin{tabular}{|c|c|c|c|c|}
\hline \multirow{3}{*}{ del procedimiento } & & & & Metodologí \\
\hline & $\begin{array}{l}\text { dimiento } \\
\text { *Validez }\end{array}$ & $\begin{array}{l}\text { interno del procedimiento. } \\
\text { 7.1.0.2 Existe un organismo interno } \\
\text { (cuerpo competente), a la organización } \\
\text { del procedimiento, encargado del } \\
\text { examen/control del mismo. } \\
\text { 7.1.0.3 Existe un plan de seguimiento } \\
\text { interno (control del procedimiento). }\end{array}$ & $\begin{array}{l}\text { mental } \\
\text {-Análisis de } \\
\text { entrevistas }\end{array}$ & $\begin{array}{l}\text { legislativos } \\
\text {-Profesionales del } \\
\text { procedimiento }\end{array}$ \\
\hline & $\begin{array}{l}\text { 7.2. Control externo del pro- } \\
\text { cedimiento } \\
\text { *Validez }\end{array}$ & $\begin{array}{l}\text { 7.2.0.1 Se hace un examen/control } \\
\text { externo del procedimiento. } \\
\text { 7.2.0.2. Existe un organismo externo } \\
\text { (cuerpo competente), a la organización } \\
\text { del procedimiento, encargado del } \\
\text { examen del mismo. } \\
\text { 7.2.0.3 Existe un plan de seguimiento } \\
\text { externo (control del procedimiento). }\end{array}$ & $\begin{array}{l}\text {-Análisis docu- } \\
\text { mental } \\
\text {-Análisis de } \\
\text { entrevistas }\end{array}$ & $\begin{array}{l}\text {-Documentos } \\
\text { legislativos } \\
\text {-Profesionales del } \\
\text { procedimiento }\end{array}$ \\
\hline \multirow[t]{2}{*}{$\begin{array}{l}8 \text { Coordinación en } \\
\text { el procedimiento }\end{array}$} & \multirow[t]{2}{*}{ *Coordinación } & $\begin{array}{l}\text { 8.0.0.1 Existe una figura encargada de } \\
\text { la coordinación del procedimiento. }\end{array}$ & $\begin{array}{l}\text {-Análisis docu- } \\
\text { mental } \\
\text {-Análisis de } \\
\text { entrevistas }\end{array}$ & \multirow[t]{2}{*}{$\begin{array}{l}\text {-Documentos } \\
\text { legislativos } \\
\text {-Profesionales del } \\
\text { procedimiento }\end{array}$} \\
\hline & & $\begin{array}{l}\text { 8.0.0.2 Se realizan encuen- } \\
\text { tros/reuniones de puesta en común } \\
\text { entre los profesionales, dirigidos a } \\
\text { mejorar el procedimiento. }\end{array}$ & $\begin{array}{l}\text {-Análisis docu- } \\
\text { mental } \\
\text {-Análisis de } \\
\text { entrevistas } \\
\text {-Análisis de } \\
\text { cuestionarios }\end{array}$ & \\
\hline 9 Trazabilidad & *trazabilidad & $\begin{array}{l}\text { 9.0.0.1 Cada paso en el procedimiento } \\
\text { de evaluación se documenta/registra. }\end{array}$ & $\begin{array}{l}\text {-Análisis docu- } \\
\text { mental } \\
\text {-Análisis de } \\
\text { entrevistas }\end{array}$ & $\begin{array}{l}\text {-Documentos } \\
\text { legislativos } \\
\text {-Profesionales del } \\
\text { procedimiento }\end{array}$ \\
\hline
\end{tabular}




\subsubsection{La entrevista semiestructurada}

Hemos utilizado la entrevista semiestructurada compuesta por una serie de preguntas "obligatorias" que se sitúan en el marco de una entrevista abierta (Pellicciari, 1993, p. 197). Estas preguntas tienen el fin de indagar, sobre algunos aspectos concretos y pueden conducirnos a otros que resulten interesantes para nuestra investigación.

La intención de estas entrevistas es conocer en profundidad ambos procedimientos, para poder entresacar información relevante sobre los mismos; ayudar a dar forma a la matriz de análisis y facilitar la construcción de los cuestionarios.

Comenzamos a construir este instrumento tras un estudio previo de los aspectos sobre los que se pretendía indagar, en relación a los procedimientos de validación de competencias profesionales en Castilla y León y en Emilia-Romagna. En función de esto, decidimos realizar cuatro guiones de entrevista (para consultar los guiones ver Anexo 34), una por cada tipo de experto a entrevistar como testigo significativo (Pellicciari, 1993). De esta manera, pudimos adaptar las preguntas a cada tipo de profesional entrevistado (ver Tabla 2 y Tabla 3). Redactamos un guion para gestores/ organizadores y responsables de ambos procedimientos; otro para asesores y otro para evaluadores de los dos procedimientos y por último, realizamos otro guión para la figura del RFC (responsable de la formalización y certificación en Emilia-Romagna).

Para garantizar la validez de las entrevistas nos dirigimos a varios expertos en validación y en realización de entrevistas, de la Universidad de Valladolid y de la Università Roma Tre, y tuvimos en cuenta sus indicaciones para la construcción de estas.

Asimismo, una vez construidos los guiones para las entrevistas, contactamos con los gestores/organizadores de ambos procedimientos, quienes nos ayudaron en la selección de profesionales clave en el procedimiento, con una gran experiencia en validación de competencias profesionales, para realizarles las entrevistas.

Las entrevistas se hicieron de forma presencial, para ello tuvimos que desplazarnos a diferentes centros formativos y administrativos de Valladolid y Segovia (Castilla y León) y de Bologna y Módena (Emilia-Romagna). 
Para llevar a cabo las entrevistas recurrimos, principalmente, a la técnica de la no-dirección. El orden de los argumentos a tratar fue variando según el discurso del sujeto entrevistado. Por lo general aceptamos esta forma de desarrollar la entrevista, aunque en algunas ocasiones redirigimos el discurso, modificando el tema tratado o profundizando en algún aspecto en concreto (Pellicciari, 1993, pp. 21-23).

Antes de comenzar las entrevistas explicamos con claridad, a los entrevistados, el objetivo que perseguíamos con ellas. Para asegurar más la validez, durante la aplicación de estas procuramos ser flexibles, objetivos y empáticos, intentando realizar una buena escucha en todo momento (Flick, 2007; Patton, 1990).

Además, todas las entrevistas fueron grabadas y posteriormente transcritas (ver Anexo 30), aquellas realizadas en lengua italiana, fueron traducidas al español. Al finalizar las transcripciones, cotejamos las respuestas con los entrevistados con el fin de asegurarnos una adecuada comprensión de las mismas.

\subsubsection{El cuestionario}

Hemos recurrido también al uso de la entrevista estructurada. Esta técnica se sirve del cuestionario para su realización, a través del cual se recogen de forma sistemática informaciones, comportamientos, opiniones, etc., de las personas encuestadas, sobre la investigación (Pellicciari, 1993, pp. 201-202).

Cabe señalar que a través de los cuestionarios hemos buscado obtener información en relación a algunos indicadores, aquellos que hemos considerado más susceptibles de proporcionar datos a través de este instrumento. Es decir, cada pregunta de los cuestionarios está relacionada con uno o más indicadores. Sin embargo, no se ha indagado sobre todos los indicadores a través de la encuesta. Esto lo podemos ver reflejado en el tipo de análisis de la matriz de análisis representada en la Tabla 5 y en el Anexo 37, en el que presentamos una tabla de correspondencias de las preguntas de los cuestionarios con los indicadores de la matriz.

\section{- La fase exploratoria de Zammuner}

Previamente a la construcción del cuestionario hicimos una profundización teórica, realizando un análisis documental sobre el tema de interés (de los documentos legislativos) y de las entrevistas semiestructuradas reali- 
La validación de competencias profesionales en España e Italia

zadas (ver subapartado 5.5.4.1). Con objeto de saber qué preguntar y tener claros los objetivos precisos que perseguimos con la puesta en práctica de este instrumento (Zammuner, 1998, p. 47).

Pensando en garantizar la validez de los cuestionarios, previamente a su construcción, hemos recurrido a dos tipos de expertos con la intención de consultar aspectos sobre la elaboración de esta clase de instrumentos y sobre el argumento a indagar. El primer tipo de expertos al que recurrimos fue al de profesionales con gran experiencia en la elaboración de cuestionarios: un economista y un estadístico, de la Universidad de Valladolid y de la Università degli studi Roma Tre respectivamente.

El segundo tipo de expertos al que pedimos ayuda fue el compuesto por profesionales familiarizados con nuestro tema de investigación, tanto del ámbito español como del italiano: dos docentes-investigadores de la Università Roma Tre y un docente-investigador de la Universidad de Valladolid. El objetivo era tratar de recoger todos los argumentos y no dejar aspectos interesantes sin tratar (Bosco, 2003, p. 11).

Por tanto, a través del análisis documental y de entrevistas y de la ayuda de los expertos hemos decidido los puntos a tratar, las características y las técnicas (el número y tipo de preguntas y las modalidades de respuesta). También hemos seleccionado la muestra de referencia y en función de esta, se ha elegido el mejor procedimiento posible para la recogida de datos: el cuestionario on-line.

\section{- La construcción del cuestionario}

A partir de las experiencias de otros investigadores expertos en cuestionarios como Bosco (2003) o Zammuner (1998), y tomando en cuenta lo anteriormente expuesto, empezamos la construcción de los cuestionaros. Al percatarnos de las diferencias entre las funciones de los profesionales a los que quería pasarse el instrumento, decidimos elaborar cuatro cuestionarios diferentes, con el objetivo de ajustar en la medida de lo posible las preguntas para cada tipo de profesional y obtener datos de la forma más específica y detallada posible. Así pues, realizamos un cuestionario para los asesores del procedimiento de Castilla y León; otro dirigido a los evaluadores del procedimiento de Castilla y León; otro para los asesores del procedimiento de Emilia-Romagna (EPV) y por último, otro para los evaluadores del procedimiento de Emilia-Romagna (EAPQ) 
Hemos acompañado los cuestionarios de una explicación inicial, en la que se expone, con simplicidad y claridad, el objetivo del cuestionario (Pellicciari, 1993, p. 204). Cada cuestionario consta de cuatro grupos de preguntas, relacionados con la información proporcionada al candidato; instrumentos del proceso por el que se pregunta; desarrollo del procedimiento; conocimiento del evaluador y posibles mejoras en el procedimiento. Asimismo, hemos acompañado cada grupo de preguntas de una pequeña explicación, sobre el objetivo que pretendíamos alcanzar con cada uno de ellos. Los cuatro modelos de los cuestionarios que realizamos pueden consultarse, en versión imprimible, en el Anexo 35.

Con la intención de lograr respuestas adecuadas, en cuanto a lo que pretendía indagarse, hemos combinado diferentes tipos de preguntas:

- de respuesta cerrada de tipo dicotómico: dando la posibilidad de escoger solo una alternativa entre dos propuestas, (si/no) (Bosco, 2003 , p. 38). Se han utilizado como preguntas filtro, para acercarnos más a algunos aspectos concretos y reducir posibles efectos de distorsión (Bishop, Tuchfarber, \& Oldendick, 1986).

- de respuesta múltiple: presentando una lista de alternativas, siendo posible escoger más de una (Bosco, 2003, p. 38).

- de escalas de juicio (ratin scales): piden a la persona que rellena el cuestionario valorar la importancia de cada una de las alternativas, utilizando una escala graduada como por ejemplo: nada de acuerdo, poco de acuerdo, bastante de acuerdo, muy de acuerdo. Hemos utilizado por tanto una escala tipo Likert con 4 opciones de respuesta, eliminando la quinta (la intermedia), para que la persona se decantase por una opción u otra (Bosco, 2003, p. 38).

- de formato abierto: las hemos utilizado en preguntas más objetivas, para permitir mayor riqueza en los detalles de las contestaciones;

- de formato abierto, referida a la alternativa "otro/s": hemos incluido este tipo de preguntas abiertas al final de una lista de posibilidades, con la intención de que el encuestado pudiese añadir uno o más elementos no mencionados en la lista propuesta (Bosco, 2003, p. 21).

- Condicionantes: dependiendo de la respuesta del encuestado se presenta una u otra opción en la pregunta siguiente. El formato on-line del cuestionario nos ha facilitado en gran medida aplicar este tipo de preguntas. 
La validación de competencias profesionales en España e Italia

\section{La validación del cuestionario}

Con la intención de garantizar la fiabilidad de las respuestas, hemos intentado no crear distorsión en las preguntas al construir los cuestionarios. Por ello, a la hora de redactarlos hemos procurado prestar especial atención (Bosco, 2003, pp. 23-29):

- al efecto de las dobles negaciones, ya que desorientan a la persona que responde el cuestionario. Para evitarlo, hemos invertido las preguntas de estas características;

- a incluir varios temas en el mismo ítem, cuando se toca más de un tema contemporáneamente es difícil saber si la evaluación que la persona ha dado corresponde solo a un tema, o a los dos de forma equivalente. En estos casos hemos intentado separar los ítems;

- a la ambigüedad lingüística, por lo que hemos procurado definir bien el contexto o el concepto por el que se pregunta, con claridad y de forma lógica;

- al uso de tecnicismos, para no dificultar la comprensión de las preguntas. Por ello hemos tratado de formular las preguntas en un lenguaje sencillo y comprensible.

- a las preguntas sugestivas, es decir a aquellas que poseen una alternativa de respuesta con más posibilidades de ser elegida respecto al resto. Hemos intentado evitar las llamadas preguntas de respuesta deseable social;

- a garantizar seguridad y confidencialidad, asegurando el anonimato de los profesionales que han contestado los cuestionarios.

Asimismo, procedimos a la validación de los cuatro cuestionarios, dos de ellos en lengua española, para los asesores y evaluadores del procedimiento de Castilla y León y los otros dos en lengua italiana, dirigidos a los EPV (asesores) y EAPQ (evaluadores) del procedimiento de EmiliaRomagna. Respecto a los cuestionarios en italiano, se pidió una revisión de gramática y ortografía a un profesor de la Università Roma Tre, cuya lengua materna es el italiano, con el fin de evitar posibles errores de esa índole. Tras las mejoras pertinentes derivadas de dicha revisión, se construyeron los modelos (como el que mostramos en el Anexo 33) para la validación de los cuestionarios en formato Word. De este modo, enviamos los modelos para la validación a los expertos correspondientes, pidiéndoles leer atentamente el cuestionario para: 
- valorar a través de unas tablas el contenido del mismo, respecto a la presentación; la facilidad para contestar; el orden de las preguntas y la extensión del cuestionario;

- anotar, a través de otra tabla, los términos demasiado técnicos y/o ambiguos encontrados en el cuestionario y las preguntas que a su parecer predeterminasen la respuesta, así como las sugerencias de cambios;

- realizar cualquier observación y/o sugerencia que considerasen oportunas, debajo de cada pregunta, en los cuadros que dispusimos para tal fin.

De cuatro a seis profesionales correspondientes validaron cada uno de los cuestionarios:

Tabla 6: Profesionales que han validado los cuestionarios

\begin{tabular}{|l|l|}
\hline Tipo de cuestionario: & Validado por: \\
\hline $\begin{array}{l}\text { Cuestionario para asesores del procedimiento } \\
\text { de Castilla y León }\end{array}$ & $\begin{array}{l}\text { Seis asesores del procedimiento de Castilla y } \\
\text { León }\end{array}$ \\
\hline $\begin{array}{l}\text { Cuestionario para evaluadores del procedi- } \\
\text { miento de Castilla y León }\end{array}$ & $\begin{array}{l}\text { Seis evaluadores del procedimiento de Casti- } \\
\text { lla y León }\end{array}$ \\
\hline $\begin{array}{l}\text { Cuestionarios para EPV (asesores) del proce- } \\
\text { dimiento de Emilia-Romagna }\end{array}$ & $\begin{array}{l}\text { Dos EPV y dos dirigentes/organizadores, del } \\
\text { procedimiento de Emilia-Romagna }\end{array}$ \\
\hline $\begin{array}{l}\text { Cuestionarios para EAPQ (evaluadores) del } \\
\text { procedimiento de Emilia-Romagna }\end{array}$ & $\begin{array}{l}\text { Cuatro EAPQ del procedimiento de Emilia- } \\
\text { Romagna }\end{array}$ \\
\hline
\end{tabular}

Cuando se recibieron las evaluaciones de los cuestionarios se hicieron los cambios pertinentes y se les volvió a pasar a los mismos expertos para detectar otros posibles errores y para hacer una prueba piloto, que permitiese medir el tiempo de realización.

Posteriormente se realizaron las últimas modificaciones y se procedió a pasar los cuestionarios definitivos al formato on-line, para que su distribución y la forma de realizarlo resultase más sencilla. Para ello utilizamos el programa Lime Survey, se trata de una aplicación de código abierto, para la aplicación de encuestas en línea, escrita en PHP, cuenta con bases de datos MySQL, PostgreSQL o MSSQ.

\section{Contacto con las personas susceptibles de contestar el cuestionario}

Esta fase ha sido transversal, tuvo lugar desde que se pensó en los cuestionarios hasta que estos estuvieron preparados. Debemos mencionar que nos encontramos con bastantes dificultades para poder suministrar los 
La validación de competencias profesionales en España e Italia

cuestionarios, sobre todo en Emilia-Romagna, donde la imposibilidad de contar con profesionales que pudiesen contestar a los cuestionarios se convirtió en un verdadero obstáculo en la realización de la tesis.

Finalmente, contactamos con los profesionales susceptibles de contestar al cuestionario por vía telefónica y por medio del correo electrónico. Además, tanto en Castilla y León como en Emilia-Romagna dispusimos de la ayuda de los dirigentes/organizadores, quienes colaboraron activamente con nosotros enviando los enlaces de los cuestionarios a los expertos correspondientes.

El siguiente paso fue activar los cuestionarios on-line a través del mencionado programa Lime Survey, para que los profesionales a los que estaban dirigidos pudiesen contestarlos.

\subsubsection{ANÁLISIS DE DATOS}

En las siguientes páginas explicaremos el análisis cualitativo y cuantitativo llevado a cabo en este trabajo. Para dotar de validez este trabajo hemos divido el análisis en dos apartados. En el primero se muestra el análisis cualitativo detallado de legislación y entrevistas y en el segundo el análisis comparativo por cada indicador de la matriz de análisis (ver capítulo 6).

\subsubsection{Análisis cualitativo documental y de entrevistas}

Como hemos comentado, el análisis cualitativo que hemos realizado a partir de los documentos legislativos y de las entrevistas ha sido un análisis interactivo, ya que con él se han descubierto temas y conceptos que han ido emergiendo de entre los datos recolectados (Rubin \& Rubin, 1995).

Hemos hecho este tipo de análisis, de forma sistemática, siguiendo una secuencia y un orden a través de los siguientes pasos (Álvarez-Gayou, 2005; Miles \& Huberman, 1994; Rubin \& Rubin, 1995):

Obtuvimos la información a través de los documentos relacionados con la legislación y referentes a nuestro objeto de estudio y a través de la realización de entrevistas semiestructuradas.

Capturamos, transcribimos y ordenamos la información obtenida. En el caso de los documentos, realizamos la captura de la información a través de la recolección de material que pudimos encontrar on-line, a través del BOE, del BOCYL, de la Garzetta Uficciale; del Bollettino Ufficiale della Re- 
gione Emilia-Romagna, de las páginas web: todofp.es y E-R Ilportale della Regione Emilia-Romagna; en fotocopias y en documentos originales escaneados facilitados por expertos en el tema.

En el caso de las entrevistas la captura de la información se hizo a través de un registro electrónico (grabación) que más tarde pasamos a formato digital y posteriormente transcribimos. Dado que las entrevistas realizadas en Emilia-Romagna se hicieron en lengua italiana, en el momento de la transcripción se procedió a la traducción de las mimas.

Codificamos la información, mediante este proceso agrupamos la información obtenida en categorías que concentran las ideas, conceptos o temas similares descubiertos en la investigación (Rubin \& Rubin, 1995). Los códigos son etiquetas que permiten asignar unidades de significado a la información descriptiva o inferencial compilada durante la investigación, marcando los temas específicos en un texto.

Nosotros hemos codificado utilizando la matriz de análisis que hemos reflejado en la Tabla 5 y que comenzamos a construir una vez desarrollado el marco teórico. Tomamos como lista de códigos los indicadores definidos en la matriz, con su correspondiente numeración. Al mismo tiempo, también hemos utilizado técnicas de codificación inductivas. Es decir, hemos realizado una codificación derivada de los datos, con aquellos que quedaban fuera de la codificación inicial (de los indicadores de la matriz de análisis), con la intención de no dejarnos temas interesantes sin clasificar ni tener en cuenta. De este modo, nuestra matriz fue modificándose y tomando forma.

Para llevar a cabo la codificación pasamos todos los documentos relacionados con la legislación y las entrevistas transcritas de ambos procedimientos a formato de Word o de PDF. Posteriormente los imprimimos, dejando un margen al lado derecho e izquierdo para hacer anotaciones. Tras esto, realizamos una primera lectura en la que comenzamos a identificar las unidades de análisis, que en nuestro caso eran trozos de texto que reflejaban un tema relacionado con los indicadores de la matriz y con otros temas que emergieron del texto en sí mismo, para los que se crearon códigos nuevos, es decir nuevos indicadores y categorías o subcategorías en algunos casos.

Acto seguido importamos todos los documentos (entrevistas y documentos legislativos) del análisis, en formato Word y PDF, a los elementos internos de la herramienta de Nvivo (ver Ilustración 4). Este instrumento es un software dirigido a la investigación con métodos cualitativos, tiene el 
La validación de competencias profesionales en España e Italia

objetivo de facilitar la organización y el análisis de datos no estructurados o cualitativos.

Ilustración 4: Entrevistas y documentos analizados sobre ambos procedimientos de validación

\begin{tabular}{|c|c|c|c|}
\hline \multirow{2}{*}{ Recursos } & \multicolumn{3}{|l|}{ Elementos internos } \\
\hline & Nombre & A3 Nodos & Referencias \\
\hline Elementos externos & DS_CyL_CT & 27 & 47 \\
\hline Memos & DS_CyL_JL & 38 & 52 \\
\hline \multirow{9}{*}{ Fatrices de marcos de trabajo } & EAPQ_ER_CC & 19 & 30 \\
\hline & DPV_ER_GG & 17 & 33 \\
\hline & EPV_ER_NB & 23 & 32 \\
\hline & EPV_ER_SC & 25 & 36 \\
\hline & ESP_BOE-1224_2009 & 51 & 157 \\
\hline & ESP_CyL_BOCYL_ORDEN_HAC_1605_2011 Gestion_procedimiento & 21 & 76 \\
\hline & ESP_CYL_BOCYL_ORDEN HAC_1536_2011 Convocatoria_procedimiento & 27 & 69 \\
\hline & D EV_CyL_AD & 27 & 43 \\
\hline & EV_CyL_TM & 26 & 40 \\
\hline \multirow{2}{*}{ Recursos } & Gestor_dirigente_ER_PV_PA & 22 & 32 \\
\hline & Destor_organizador_CyL_JIN & 33 & 41 \\
\hline Nodos & Gestor_organizador_ER_VF & 30 & 55 \\
\hline \multirow{2}{*}{ (4) Clasificaciones } & IT_AccordoStato-Regioni_18_febbraio_2000 & 1 & 1 \\
\hline & (1T_Decreto_legislativo_13_2013 & 27 & 70 \\
\hline \multirow{2}{*}{ Colecciones } & IT_Decreto_Ministeriale_174_2001 & 4 & 8 \\
\hline & IT_ER_Delibera di Giunta Regionale_1434_2005 & 18 & 52 \\
\hline \multirow{2}{*}{ D. Consultas } & IT_ER_Delibera di Giunta Regionale_530_2006 & 2 & 2 \\
\hline & IT_ER_Delibera di Giunta Regionale_739_2013 & 2 & 3 \\
\hline \multirow{2}{*}{ 圈 Informes } & (3) IT_ER_Delibera di Giunta Regionale_841_2006 & 2 & 3 \\
\hline & IT_Legge_n92_riforma_mercato_lavoro_2012 & 8 & 25 \\
\hline Modelos & D RFC_ER_MM & 13 & 23 \\
\hline
\end{tabular}

Para el análisis de estos documentos recurrimos al apartado de nodos del programa (ver Ilustración 5). A través de este recurso creamos una sección denominada "LEGISLACIÓN" y otra denominada "ENTREVISTAS", con dos subsecciones para cada una. La primera está dividida en "España/Castilla y León" y en "Italia/Emilia-Romagna", en ella se ha procedido al análisis de los documentos relacionados con la legislación. La segunda se subdivide en "Castilla y León" y en "Emilia-Romagna", en esta se ha realizado el análisis de las entrevistas semiestructuradas. 
Metodología

Ilustración 5: Estructura de análisis para la legislación y las entrevistas de ambos procedimientos

\begin{tabular}{|c|c|c|c|c|c|c|}
\hline Nodos & Buscar: & $\checkmark$ & Buscar en & Nodos & Buscar ahora & Borrar \\
\hline \multirow{8}{*}{$\begin{array}{l}\text { Nodos } \\
\text { Relaciones } \\
\text { Matrices de nodo }\end{array}$} & \multicolumn{6}{|l|}{ Nodos } \\
\hline & Nombre & & 룽 & Recursos & Referencias & Creado el \\
\hline & G LEGISLACIÓN & & & 0 & 0 & $26 / 02 / 201410: 40$ \\
\hline & Ð $\bigcirc$ España_Castilla y León & & & 0 & 0 & $26 / 02 / 2014$ 10:42 \\
\hline & †. Italia_Emilia-Romagna & & & 0 & 0 & 26/02/2014 10:42 \\
\hline & $\because$ ENTREVISTAS & & & 0 & 0 & $26 / 02 / 201410: 39$ \\
\hline & † Castilla y León & & & 0 & 0 & $26 / 02 / 201416: 50$ \\
\hline & $\oplus \bigcirc$ Emilia-Romagna & & & 0 & 0 & $26 / 02 / 201416: 49$ \\
\hline
\end{tabular}

En cada subsección hemos situado nuestra matriz de análisis (ver Ilustración 6), con cada evento, categoría, subcategoría (en el caso de existir) e indicadores (ver Ilustración 7 ). Es decir, hemos situado cuatro matrices idénticas, una por subsección.

Ilustración 6: Muestra de categorías de la subsección de Legislación de España/Castilla y León

\begin{tabular}{|c|c|}
\hline Nodos & Nodos \\
\hline 9 Nodos & Nombre \\
\hline (d) Relaciones & O LEGISLACIÓN \\
\hline \multirow[t]{9}{*}{ Matrices de nodo } & España_Castilla y León \\
\hline & +O INFORMACIÓN PREVIA AL PROCEDI \\
\hline & $+\bigcirc$ ACCESO AL PROCEDIMIENTO \\
\hline & ĐO ORIENTACIÓN \\
\hline & O ASESORAMIENTO \\
\hline & + EVALUACIÓN \\
\hline & $+\bigcirc$ CERTIFICACIÓN Y REGISTRO \\
\hline & $+\mathrm{O}$ CONTROL \\
\hline & $\oplus$ COORDINACIÓN \\
\hline Recursos & O TRAZABILIDAD \\
\hline & † Italia_Emilia-Romagna \\
\hline Nodos & @ ENTREVISTAS \\
\hline 3 Clasificaciones & \\
\hline
\end{tabular}


Ilustración 7: Muestra de subcategorías e indicadores de la categoría de "acceso al procedimiento" de la subsección de Legislación de España/Castilla y León

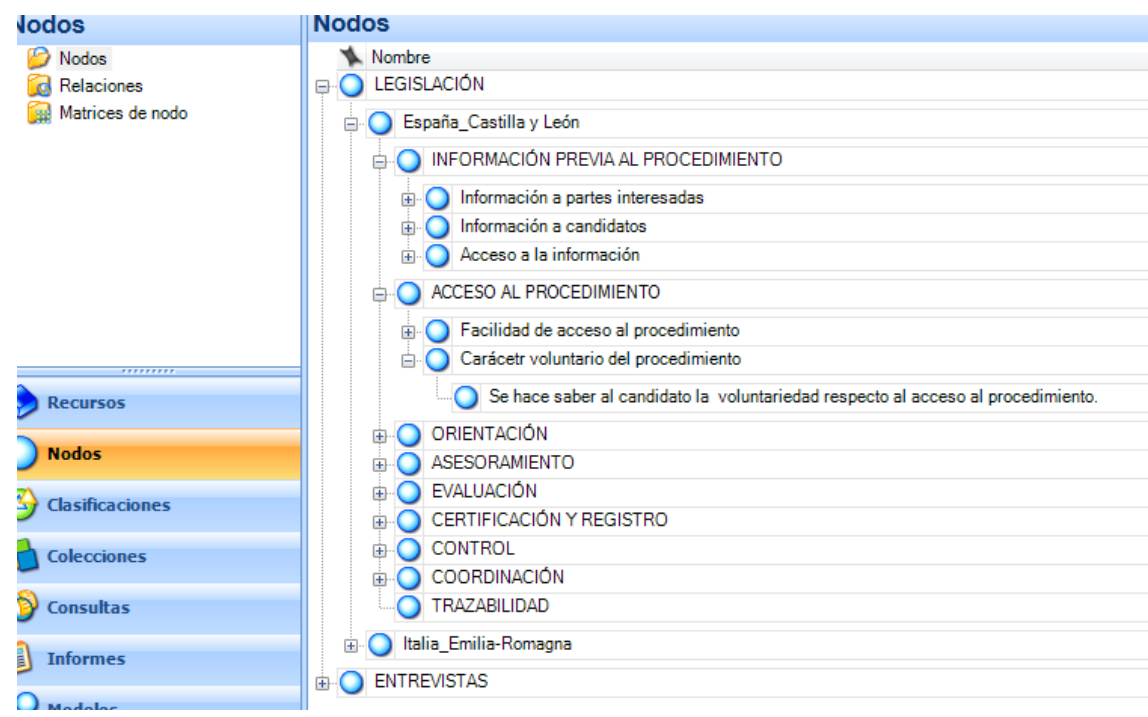

Por tanto, hemos procedido a la codificación sirviéndonos de esta matriz, utilizándola como un sistema de "cajones", en los que hemos ido ordenando la información. El sistema NVivo nos permitía abrir cualquiera de los documentos importados al programa, leerlo y trasladar una copia del fragmento de texto seleccionado al punto de la matriz al que considerábamos que hacía referencia (ver Ilustración 8 e Ilustración 9). En las primeras lecturas comenzamos situando estos fragmentos de texto en las categorías, subcategoría, o en nuevas "etiquetas" que creábamos si encontrábamos algún dato interesante que todavía no habíamos incluido en nuestra matriz. Nuestro objetivo final, era el de cuadrar todos los fragmentos en los indicadores establecidos inicialmente o creados con posterioridad.

Dado que la codificación, como hemos comentado, no es un proceso rígido, pues requiere de un desarrollo y refinamiento continuo, a medida que se avanzamos en la investigación, la matriz se vio modificada en numerosas ocasiones. Se dividieron algunos temas en sub-temas o por el contrario, se unieron algunos aspectos, incluso se incluyeron puntos nuevos, en forma de categorías, subcategorías o indicadores, con la intención de no dejar ningún aspecto importante fuera de la matriz. De este modo, hicimos dinámico y flexible el proceso de análisis (Álvarez-Gayou, 2005; Ryan \& Bernard, 2003). 
Ilustración 8: Muestra de documento legislativo abierto dentro del programa NVivo

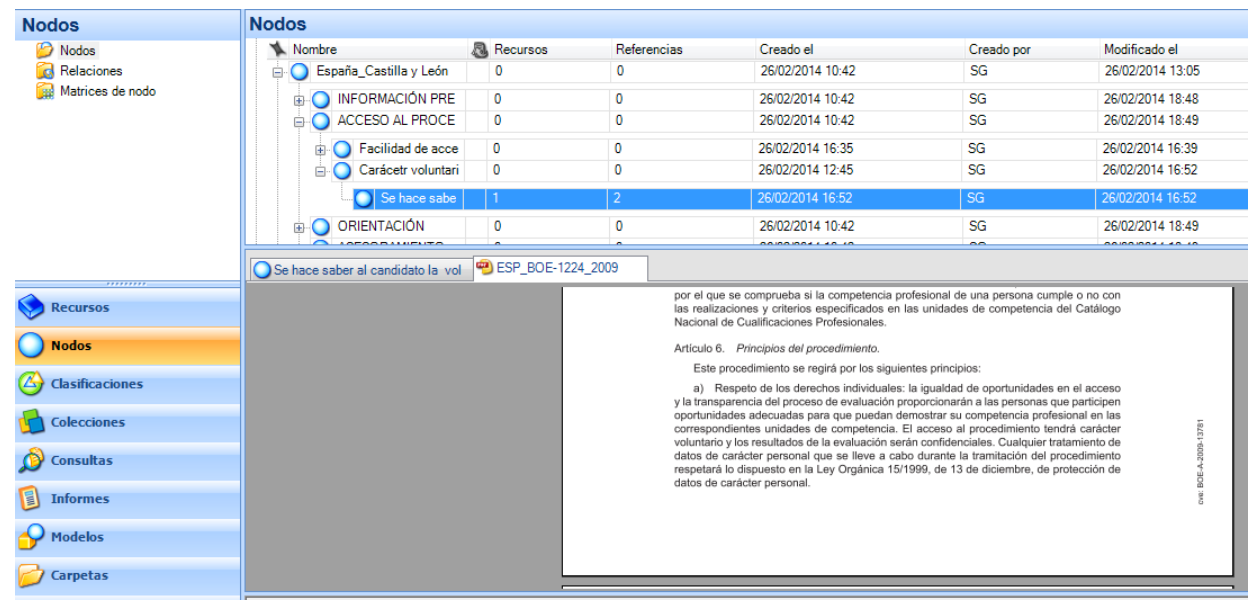

Ilustración 9: Muestra de fragmento de texto situado en uno de los indicadores.

\begin{tabular}{|c|c|}
\hline Nodos & Nodos \\
\hline \multirow{10}{*}{$\begin{array}{l}\text { Nodos } \\
\text { Relaciones } \\
\text { Matrices de nodo }\end{array}$} & Nombre \\
\hline & España_Castilla y León \\
\hline & † INFORMACIÓN PREVIA AL PROCEDIMIENTO \\
\hline & O ACCESO AL PROCEDIMIENTO \\
\hline & 由. Facilidad de acceso al procedimiento \\
\hline & Đ Carácetr voluntario del procedimiento \\
\hline & O Se hace saber al candidato la voluntariedad respecto al acceso al procedimiento. \\
\hline & TO ORIENTACIÓN \\
\hline & W ASESORAMIENTO \\
\hline & † EVALUACIÓN \\
\hline & W CERTIFICACIÓN YREGISTRO \\
\hline Recursos & Đ CONTROL \\
\hline & COORDINACIÓN \\
\hline Nodos & O TRAZABILIDAD \\
\hline (4) Clasificaciones & ఉ. Italia_Emilia-Romagna \\
\hline Colecciones & O Se hace saber al candidato la volu \\
\hline D. Consultas & $\leq$ Elementos internos $\backslash$ ESP_BOE-1224_2009> - $\$ 2$ referencias codificadas [Cobertura $0,14 \%$ ] \\
\hline Informes & Referencia 1 - Cobertura $0,20 \%$ \\
\hline & \multirow{2}{*}{$\begin{array}{l}\text { Artículo 6. Principios del procedimiento. } \\
\text { Este procedimiento se regirá por los siguientes principios: a) Respeto de los derechos individuales: I }\end{array}$} \\
\hline Modelos & \\
\hline Carpetas & Referencia 2 - Cobertura $0,08 \%$ \\
\hline
\end{tabular}

Además de estos pasos propuestos por los autores citados anteriormente (Álvarez-Gayou, 2005; Miles \& Huberman, 1994; Rubin \& Rubin, 1995), añadimos el de comparación, en el que una vez codificada toda la información, buscamos analogías y diferencias entre los dos procedimientos de validación, en cuanto a las respuestas de las entrevistas y a la documentación relativa a la legislación. (Ver apartado 6.2). 
La validación de competencias profesionales en España e Italia

\subsubsection{Análisis cualitativo y cuantitativo de los cuestiona- rios}

En cuanto al análisis de los cuestionarios, hemos realizado un análisis cuantitativo de las respuestas cerradas y un análisis cualitativo de las abiertas. El análisis cuantitativo se ha llevado a cabo a través del programa Lime Survey, el mismo del que nos hemos servido para construir y pasar los cuestionarios. A través de este programa obtuvimos los datos para la comparación, es decir, los porcentajes de respuesta otorgados, por los distintos tipos de profesionales encuestados, a las diferentes las preguntas planteadas en el cuestionario.

Posteriormente, a través del programa Excel, organizamos y creamos las gráficas necesarias para presentar los resultados de la forma que consideramos más clara y sencilla para comparar los resultados de los profesionales de ambos procedimientos y detectar las similitudes y disimilitudes en cada indicador estudiado. (Ver apartado 6.2)

Por último, cabe mencionar que el análisis cualitativo de las preguntas de respuesta abierta se ha hecho siguiendo el mismo procedimiento explicado en el análisis cualitativo de entrevistas y de documentos legislativos. (Ver subapartado 5.5.4.1).

- Obtuvimos la información a través de los cuestionarios.

- Capturamos la información obtenida con el programa Lime Survey y la pasamos a un documento de Word para poder ordenarla;

- Codificamos esa información con los indicadores de la matriz a los que hacía referencia.

- Realizamos la comparación, buscando similitudes y disimilitudes entre las respuestas de los encuestados.

\subsubsection{Integración de la información analizada y realiza- ción de conclusiones}

El último paso en el análisis de datos consiste en integrar la información (Álvarez-Gayou, 2005; Miles \& Huberman, 1994; Rubin \& Rubin, 1995).

Durante el proceso de codificación se fragmentan las transcripciones en los diferentes indicadores de la matriz, de forma separada. A través de la codificación vemos cada detalle, cada cita textual. Asimismo, con la comparación que hemos realizado de los dos procedimientos a través de cada indicador 
de la matriz hemos obtenido una visión de cada uno de ellos, pero de forma aislada.

En esta última fase hemos relacionado los resultados obtenidos, a través del análisis cualitativo y cuantitativo, con los fundamentos teóricos de la investigación. Asimismo, hemos redactado las conclusiones, relacionando unos indicadores con otros, situándolos en el marco de los principios propuestos por las directrices europeas que hemos definido en el apartado 5.3. (Ver capítulo 7) 


\section{Análisis y resultados}

En este capítulo exponemos el análisis de datos que hemos realizado y los resultados obtenidos. Dado que nos hemos servido de varias fuentes y de distintos tipos de análisis para obtener la información requerida en nuestra investigación, y con la intención de dotar de validez a nuestro estudio, hemos decidido dividir el presente capítulo en dos apartados.

En el primero de ellos presentamos el análisis cualitativo detallado de la legislación y de las entrevistas. Estos datos suponen el punto de referencia y la justificación de los resultados que mostramos en la segunda parte de este capítulo.

En el segundo apartado presentamos el resultado del análisis comparativo de los datos obtenidos a través de las tres fuentes de las que hemos obtenido información (documentos legislativos, entrevistas y cuestionarios), a través de una comparación entre los dos procedimientos, por cada indicador. 
Análisis y resultados

\subsection{Análisis cualitativo detallado de legislación y entrevistas}

En esta primera parte del capítulo presentamos de forma detallada los datos obtenidos del análisis cualitativo, derivado del análisis documental de documentos legislativos nacionales españoles/italianos y autonómicos de Castilla y León/regionales de Emilia-Romagna y del análisis de las entrevistas semiestructuradas.

Para mostrar estos datos, como vemos en la Figura 5, hemos extraído las dimensiones, categorías, subcategorías (en su caso) e indicadores de la matriz. Cada indicador contiene dos secciones: "España" (referente al procedimiento de Castilla y León) e "Italia" (referente al procedimiento de Emilia-Romagna) que a su vez se dividen en "legislación" (nacional y autonómica/regional) y "entrevistas":

Figura 5: Esquema seguido en el análisis cualitativo detallado de legislación y entrevistas

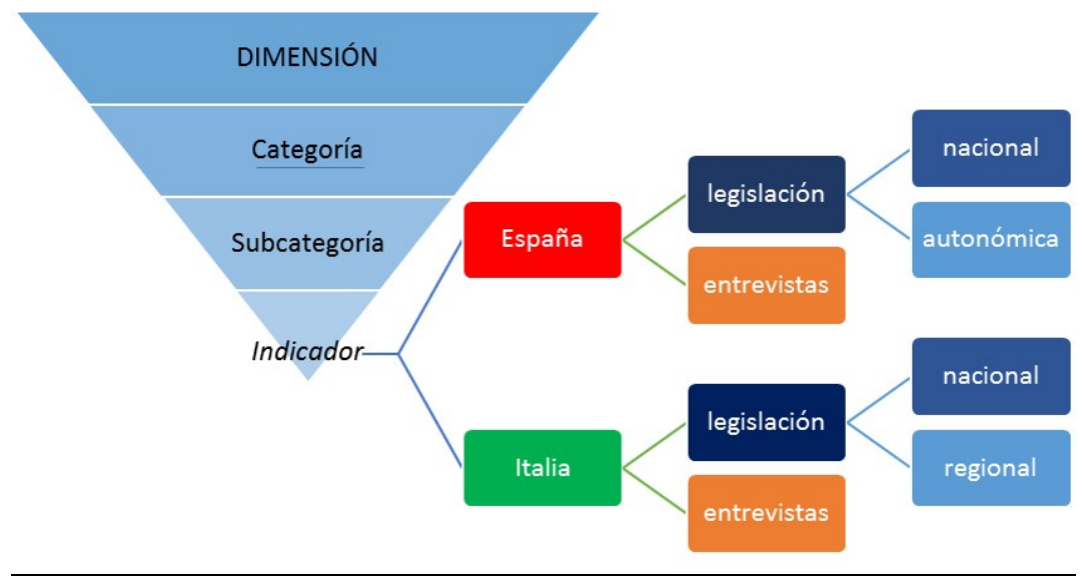

En el apartado de "legislación" se recoge toda la información obtenida a través de documentación legislativa y otros documentos derivados de esta, referidos al indicador correspondiente. Por otro lado, en el apartado de "entrevistas" se expone la información conseguida por medio de las entrevistas acerca del indicador correspondiente. Seguimos el esquema presentado en la Figura 5 para presentar los datos en este apartado. 
La validación de competencias profesionales en España e Italia

\section{Dimensión: información previa al procedimiento}

1.1. Categoría: información sobre el procedimiento de validación a las partes interesadas

\subsubsection{Sin subcategoría}

1.1.0.1. Indicador: Se informa a las partes interesadas (empresas, sindicatos, centros de formación) sobre el procedimiento de validación.

\section{- ESPAÑA}

\section{- LEGISLACIÓN}

Legislación nacional: el artículo 8.5 del RD 1224/2009 hace referencia a la creación, por parte del Ministerio de Trabajo e Inmigración y del Ministerio de Educación, de una Plataforma de Información y Orientación para informar sobre el procedimiento de evaluación y acreditación. Así mismo, el punto 7 del mismo artículo señala que la Administración General del Estado desarrollará fórmulas de cooperación y coordinación entre todos los entes implicados.

Legislación autonómica: la comunidad autónoma de Castilla y León ha publicado, en el BOCYL, la ORDEN HAC/1605/2011. En su artículo 2.3, muestra la intención de establecer un sistema para dar a conocer, a todos los interesados, las características y los requisitos del procedimiento. También instaura la publicación en la página web de la Junta de Castilla y León (www.jcyl.es), de información general sobre el procedimiento de evaluación y acreditación, y establece que la información y orientación se hagan, preferentemente, a través de oficinas y centros de formación propios del Servicio Público de Empleo de Castilla, los centros que impartan formación profesional, los centros integrados de formación profesional, los centros de referencia nacional dependientes de la Comunidad de Castilla y León, y la Fundación Autonómica para la Formación en el Empleo de Castilla y León.

\section{- ENTREVISTAS}

El responsable del procedimiento entrevistado señaló que la fase de información consistió en formar a los orientadores laborales y educativos y a otros órganos, como las organizaciones sociales de los sectores, para que pudiesen informar a la gente.

Un asesor entrevistado ha manifestado que algunas empresas tienen un desconocimiento total sobre el procedimiento. Uno de los evaluadores 
entrevistados ha señalado que a las empresas les falta información sobre el procedimiento y que por eso no ven las oportunidades que les puede ofrecer.

"La fase de información y orientación consistió en formar a los orientadores laborales y educativos y a otros órganos como podian ser las organizaciones sociales de los sectores, formarles en lo que se iba a hacer, formamos también a los del 012, tres días, para que orientasen a la gente. Pero la principal motivación y vía de orientación fueron las organizaciones de los sectores, es decir: las federaciones, las asociaciones de gente que trabajaba en el sector de dependencia” (J.I.N. Gestor/organizador).

"Algunas no, no están muy colaborativas, y algunas empresas tienen un desconocimiento total" (J.L. As).

"Yo creo que tampoco lo conocen mucho, no sé si están concienciados o no, pero yo creo que hace falta más información sobre estos procedimientos a las empresas y más de ir a las empresas y explicarles el procedimiento, las ventajas que tiene el procedimiento para ellos como empresarios... porque van a tener a gente formada y a los trabajadores quitarles el miedo que hasta abora están teniendo sobre el procedimiento y verlo más como una oportunidad, que es que en realidad es una oportunidad que tiene el empresario de tener gente formada y los trabajadores que se van a seguir formando, es que lo tienen que ver como oportunidades" (T.M.S. Ev).

\section{- ITALIA}

\section{- LEGISLACIÓN}

Legislación nacional: en Italia, el Decreto Legislativo 13/2013 habla, en el artículo 7 b), de la adopción de medidas de información sobre las oportunidades que ofrecen los servicios de identificación, validación y certificación para individuos y organizaciones.

Legislación regional: la Deliberación de Junta Regional 1434/2005 (DGR 1434/2005) establece que la Regione de Emilia-Romagna desarrollará una función esencial de promoción del sistema de validación y para ello la región contará con el mayor número posible de sujetos y/o entes interesados, de diferente modo, en el sistema.

\section{- ENTREVISTAS}

Según uno de los gestores/organizadores entrevistados, no se ha informado a la empresa, como parte interesada, sobre el procedimiento.

"ninguno de nosotros ha sabido hacer una buena publicidad para las empresas [...] en mi opinión bay que implicar más a las empresas, nos faltan estos interlocutores, 
La validación de competencias profesionales en España e Italia

totalmente, además, creo que el lugar natural de este dispositivo, da las cualificaciones está abi” (V.F. Gestor/organizador).

1.2. Categoría: Información sobre el procedimiento de validación a los candidatos

\subsubsection{Sin subcategoría}

1.2.0.1. Indicador: Existe una fase de información previa, al candidato, sobre el procedimiento

\section{- ESPAÑa}

\section{- LEGISLACIÓN}

Legislación nacional: el artículo 8.1 del RD 1224/2009 garantiza, por parte de las Administraciones competentes, un servicio abierto y permanente de información y orientación general para todos los interesados y así facilitarles la decisión de participar o no en el procedimiento. Además, el punto 2 del mismo artículo, indica que la información podrá ser facilitada, no sólo por las administraciones locales, también por los agentes sociales, Cámaras de Comercio y otras entidades y organizaciones públicas y privadas.

El punto 5 determina el desarrollo de una plataforma de información y orientación sobre el procedimiento de evaluación y acreditación, por parte del Ministerio de Trabajo e Inmigración y del Ministerio de Educación, en colaboración con las administraciones de las comunidades autónomas.

También el artículo 10, del mismo real decreto, establece que la convocatoria realizada por las administraciones competentes deberá constar como mínimo de la siguiente información: a) La identificación de las unidades de competencia objeto de evaluación y los títulos de formación profesional y/o certificados de profesionalidad en los que están incluidas; b) Los requisitos de participación; c) Los lugares o medios para formalizar las inscripciones, así como los puntos específicos en los que se facilitará la información y orientación a las que se refiere el artículo 8; d) Los lugares en los que se desarrollará el procedimiento; e) El período de inscripción y los plazos de las distintas fases del procedimiento de evaluación y acreditación; f) El procedimiento y los plazos para presentar reclamaciones al resultado de la evaluación de las unidades de competencia; g) En el caso de que se limite el número de personas que podrán ser evaluadas, ese límite deberá ser 
establecido en la convocatoria; h) Los criterios de admisión en los casos en que se convoque un número máximo de personas a evaluar.

Legislación autonómica: la ORDEN HAC 1605/20011, sobre la gestión del procedimiento de evaluación y acreditación en Castilla y León, en el artículo 2, estipula quiénes deben proporcionar preferentemente la información y orientación (oficinas y centros de formación propios del Servicio Público de Empleo de Castilla, centros que impartan formación profesional, centros integrados de formación profesional, centros de referencia nacional dependientes de la Comunidad de Castilla y León y la Fundación Autonómica para la Formación en el Empleo de Castilla y León).

La ORDEN HAC/1536/2011, sobre la convocatoria del procedimiento de evaluación y acreditación, en el artículo 9.1, garantiza un servicio abierto y permanente de información y orientación del procedimiento a todos aquellos que lo soliciten, a través de:

- el portal de educación www.educa.jcyl.es (web temática de Formación Profesional) y el portal de empleo de la Junta de Castilla y León, www.empleo.jcyl.es/web/jcyl/EconomiaEmpleo;

- el servicio de atención al ciudadano de la Junta de Castilla y León, teléfono 012;

- los servicios de orientación ubicados en las oficinas de empleo del Servicio Público de Empleo de Castilla y León, así como la Fundación Autonómica para la Formación y el Empleo de Castilla y León;

- los centros gestores del procedimiento, así como los centros públicos de educación de personas adultas de Castilla y León. En este caso, las funciones de información y orientación se realizará por quienes se encarguen de realizar este tipo de tareas en los citados centros.

\section{- ENTREVISTAS}

El responsable del procedimiento entrevistado ha indicado que la fase de información se ha realizado antes de comenzar el procedimiento como tal y que se formó sobre el procedimiento a orientadores laborales y educativos y a órganos, como organizaciones sociales de los sectores sociales. Asimismo, ha señalado que se formó a los trabajadores del 012, durante tres días, para que pudiesen orientar a las personas y que la principal vía de orientación se realizó a través de las federaciones, las asociaciones de gente 
La validación de competencias profesionales en España e Italia

que trabajaba en el sector correspondiente a la convocatoria de evaluación y acreditación.

"La fase de información y orientación consistió en formar a los orientadores laborales y educativos y a otros órganos como podian ser las organizaciones sociales de los sectores, formarles en lo que se iba a hacer, formamos también a los del 012, tres días, para que orientasen a la gente. Pero la principal motivación y via de orientación fueron las organizaciones de los sectores, es decir: las federaciones, las asociaciones de gente que trabajaba en el sector de dependencia" (J.I.N. Gestor/organizador).

Los dos asesores entrevistados sobre el procedimiento en Castilla y León, coinciden con que esta fase de información o no se ha realizado o no se ha hecho de forma correcta. Afirman que los centros en los que se ha llevado acabo el procedimiento no la han hecho y que los candidatos no estaban bien informados sobre el procedimiento, uno de ellos habla de que la empresa les había dado información, pero de forma distorsionada. Creen que la fase inicial de información ha fallado.

"En cuanto a la fase de información, el centro no la bace porque no sabe, entonces el director va alli y se planta y ya está... el centro no tiene criterio de nada, no sabe nada, no puede explicar nada, el solo da las buenas tardes y dice vais a venir aqui, y ya está. Este es el centro. Aqui en estas reuniones se explica el procedimiento, y entra el papel del asesor con las personas que toca asesorar" (C.T. As).

"[...] hemos tenido que informarles nosotros [...] Yo pienso que ni siquiera la ha habido, o si la habido, se ha basado mucho en la rumorología, hasta que poco a poco se fue diluyendo, había gente que salía de los asesoramientos que decían: "Bueno pues no era para tanto", yo creo que se vendió como algo muy... no sé porque se vendió así, no sé por qué [...] La empresa es verdad que al principio informó al candidato pero no se hizo muy bien, la información esta distorsionada, descolocada y no atendiendo a la realidad de lo que era el procedimiento" (J.L. As).

También, los dos evaluadores entrevistados de Castilla y León opinan que esta fase ha fallado y que el centro en el que se ha realizado el procedimiento no ha proporcionado la información necesaria al candidato sobre el procedimiento.

"También al inicio es un problema que los candidatos presenten el curriculum vitae con la solicitud, porque no saben hacerlo. Abi debería intervenir un orientador, antes del asesoramiento, pero esta fase falla. Depende del colectivo para el que esté destinado hay que ajustarlo y si hay que adaptarlo y facilitarlo se hace. Igual que la comunicación, abo- 
ra se ha presentado gente que no se habia enterado que estaba convocada y lo han perdido, es que lloraban, habrá que hacer diferentes mecanismos para que se enteren y si son pocos mandarles una carta a casa.

"No tengo ni idea de si en este centro la información al principio del procedimiento la ha dado el centro o no, en el centro anterior ya te digo yo que no la dio el centro. No". (A.D. Ev).

"[...] creo que la fase de información ha fallado mucho. La gente no sabe bien a lo que viene" (T.M. Ev).

\section{- ITALIA}

\section{- LEGISLACION}

Legislación nacional: el artículo 5 b) del Decreto Legislativo 13/2013 establece la adopción de medidas personalizadas de información y orientación en favor de los destinatarios del servicio de identificación y certificación de competencias, sin embargo, no especifica que esto se haga antes de comenzar el procedimiento.

Legislación regional: no se han encontrado referencias al respecto.

\section{- ENTREVISTAS}

Los tres EPV entrevistados han resaltado la importancia que tiene la fase de información previa al procedimiento para el candidato. Han señalado que la han proporcionado los centros de formación y de empleo. Uno de los EPV ha manifestado que en algunas ocasiones no estaba muy claro quién tenía que proporcionar esa información, pero que lo importante es que esta fase tenga lugar.

"...en general se hace, pero bay que tener en cuenta que bay gente que viene de fuera y para formalizar y certificar se necesita tiempo y formalizar no es lo mismo que certificar... es importante que lo entiendan... Hay gente que no es italiana y que tienen también otros problemas, es importante que entiendan el procedimiento" (G.G. EPV).

"...esta Deliberación nueva, dice que te puedes dirigir, para tener el servicio o a los centros de formación o a los centros de empleo. Aqui, El sistema lo puedes pedir o en un ente de formación acreditado o en el centro de empleo" (N.B. EPV).

“... al principio se explica cómo es el Sistema y se recogen las peticiones para acceder al sistema...es importante que entiendan cómo funciona el sistema. Y hacer una petición... para entrar y ellos tienen que saber dónde quieren entrar... no está muy claro 
La validación de competencias profesionales en España e Italia

quién la tiene que dar la información y cuándo. No lo sé..., la Regione a veces quería que lo diesen unos otras veces otros... lo importante es que exista la fase de información y la persona conozca bien el sistema" (S.C. EPV).

Uno de los gestores/referentes entrevistados, ha explicado que los encargados de realizar esta fase han sido los centros de formación profesional acreditados por la región y los servicios públicos para el empleo. La Regione ha trabajado formando a los trabajadores de centros de empleo públicos para dar este servicio que forma parte de sus actividades, aunque en la actualidad siguen trabajando para mejorar este servicio informativo. Los dos gestores/dirigentes han coincidido en la importancia de la fase y en que debe ser un paso previo al procedimiento.

"Hasta este momento han sido los centros de formación profesional acreditados por nuestra región para los servicios de formación, entre los cuales la certificación es uno de los servicios, en realidad, en el 2012 hemos trabajado mucho sobre todos los compañeros, porque en realidad son dependientes de la provincia, por lo tanto, son compañeros nuestros, de centros de empleo, por lo tanto servicios públicos para el trabajo porque también hay servicios privados para el trabajo y por el momento no tienen esta función, y los servicios públicos para el trabajo tienen entre sus actividades dar este servicio... les hemos hecho una formación en aula (por parte de la Regione), han sido seleccionados unos cien trabajadores entre todos los centros de servicios para el trabajo de nuestro territorio. En un aula cuatro o cinco días y formados abundantemente sobre todo el proceso...” (V.F. Gestor/organizador).

"Siempre está previsto, en la fase de adquisición de la petición o en general, debería ser una de esas fases que preceden al acceso al SRFC hecho por el servicio para el empleo o para quién se ocupa de la orientación.

Los que se ocupan de la orientación están fuera del procedimiento, (sería un paso previo). Actualmente, en teoría, los servicios para el empleo, (estamos todavía trabajando en esto) deberían poder dar esta información en general, por lo tanto, en el momento en el que una persona accede en el ámbito del servicio de orientación, la deberían orientar a 360 grados sobre todas las oportunidades que hay en territorio" (P.A. en P.V y P.A. Gestores/organizadores).

1.3. Categoría: Accesibilidd de la informción

\subsubsection{Sin subcategoría}

1.3.0.1. Indicador: La información es accesible a través de internet y otras vías. 
Análisis y resultados

\section{- ESPAÑA}

\section{- LEGISLACIÓN}

Legislación nacional: no se han encontrado referencias sobre este aspecto concreto.

Legislación autonómica: en la ORDEN/HAC 1605 de 20011 sobre la gestión del procedimiento contempla que la información y orientación sobre la naturaleza y fases del procedimiento de evaluación y acreditación; el acceso al mismo; las convocatorias; derechos y obligaciones; acreditaciones oficiales que pueden obtenerse y efectos de las mismas, se publique en la web de la Junta de Castilla y León (www.jcyl.es), en el portal de empleo (www.empleo.jcyl.es). Asimismo, la ORDEN/HAC 1536/2011 añade que esta información también se publicará en el portal de educación (www.educa.jcyl.es).

\section{- ENTREVISTAS}

No existen referencias al respecto.

\section{- ITALIA}

- LEGISLACIÓN

Legislación nacional y legislación autonómica: no se han encontrado alusiones sobre este aspecto, ni en ámbito nacional, ni regional.

\section{- ENTREVISTAS}

No existen comentarios al respecto en las entrevistas.

\section{Dimensión: Acceso al procedimiento}

2.1. Categoría: Facilidad de acceso al procedimiento

\subsubsection{Sin subcategoría.}

2.1.0.1. Indicador: Resulta fácil para los candidatos acceder al sistema en relación a la financiación

\section{- ESPAÑA}

\section{- LEGISLACIÓN}

Legislación nacional: el RD 122472009 menciona, en la disposición adicional segunda, el pago de tasas por parte de las personas que quieran participar en el procedimiento. Según la disposición, dichas tasas las deberán establecer las administraciones competentes. 
La validación de competencias profesionales en España e Italia

Legislación autonómica: el artículo 19 de la ORDEN/HAC 1605/2001 sobre la gestión del procedimiento en Castilla y León repite lo establecido en la legislación nacional.

\section{- ENTREVISTAS}

El gestor/dirigente del procedimiento entrevistado ha señalado que inicialmente se estableció una tasa de 24 euros para el asesoramiento y de 12 euros para cada unidad de competencia que se evaluase. Sin embargo, en la convocatoria (de dos partes) que se ha hecho, no se han aplicado tasas, por lo que el procedimiento ha resultado muy ventajoso al candidato en cuanto a relación calidad-precio y muy costoso para la administración.

"Inicialmente se estableció una tasa de 24 euros para asesoramiento y 12 euros por cada unidad de competencia evaluada, pero esas tasas van a ser modificadas porque en la siguiente orden de presupuestos se va a modificar y poner una tasa única. La tasa está creada pero ahora no se va a aplicar porque este procedimiento cuelga del anterior y por eso no se va a aplicar. Cuando se cree la nueva tasa, será tasa única” (J.I.N. gestor/organizador).

Entrevistador: "¿Cómo cree que ha sido la relación calidad precio para el candidato hasta ahora?"

Para el candidato excelente, para la administración carísimo, (J.I.N. gestor/organizador).

\section{- ITALIA}

\section{- LEGISLACIÓN}

Legislación nacional y legislación regional: no se han encontrado referencias sobre este aspecto, ni en ámbito nacional, ni regional.

\section{- ENTREVISTAS}

Uno de los gestores/organizadores y el RFC entrevistados han indicado la falta de financiación del procedimiento, por parte del Estado, como un problema, ya que resulta bastante costoso para las empresas o sujetos que quieran hacer uso del servicio de validación.

"[...] una persona que quiere hacer directamente el examen... nuestro ente vende entonces el servicio, cuando hay unas doce personas, cuando son menos no se puede sostener porque sería exageradamente caro para los candidatos. [...]El Fondo Social Europeo financia el curso, para desempleados y trabajadores, todo junto y financiado, pero si th trabajador o extrabajador no quieres hacer el curso y solo quieres la cualificación, quieres 
hacer el examen, existe la posibilidad, se puede autorizar por la Regione pero lo tenemos que hacer pagar. Si sólo tienes una persona le resulta carísimo, esto es una debilidad, porque este sistema viene aqui y me dice quiero este servicio yo tengo que decir sí, pero claro si está él solo y... sería demasiado caro, si se forma un grupo, se podría vender a unos 500 euros por persona" (M.M. RFC).

"[...] el tema de la publicidad del servicio no lo estamos llevando a cabo porque si nos dirigimos al ciudadano y a las empresas y les contamos que tipo de disponibilidad y de instrumento tenemos, nos preguntarán: "iy quién lo paga, tú?" si tuviésemos un fondo público y hacemos entender que al menos una parte estará financiada... [...]" (V.F. Gestor/organizador).

2.1.0.2. Indicador: Resulta fácil para los candidatos acceder al sistema en relación a la inscripción y admisión al procedimiento

\section{- ESPAÑA}

\section{- LEGISLACIÓN}

Legislación nacional: el artículo 13.1 del RD 1224/2009, deja en manos de las administraciones competentes la decisión de lugares y medios para la inscripción y admisión en el procedimiento.

Legislación autonómica: la ORDEN/HAC 1536/2011 sobre la convocatoria del procedimiento en Castilla y León, establece, en el apartado séptimo, el proceso a seguir para la admisión de candidatos en el procedimiento: El punto 7.1 establece la constitución de Comisiones de Admisión para la gestión del proceso de admisión de candidatos en los centros gestores, por parte de la Dirección General de Formación Profesional y Régimen Especial. El punto 7.2. indica que una vez finalizado el plazo de presentación de solicitudes, los centros gestores remitirán las solicitudes recibidas a las comisiones de admisión para que éstas comprueben el cumplimiento de los requisitos de participación y apliquen, en caso necesario, los criterios de admisión, que aparecen en el apartado 8 de la misma orden y que se exponen a continuación:

\section{Octavo. Criterios de admisión.}

8.1. Tendrán preferencia para la admisión en el procedimiento que se convoca las personas solicitantes cuya situación laboral sea de ocupado u ocupada por cuenta propia o por cuenta ajena, en el entorno profesional y funcional definido en la cualificación profesional cuyas unidades de competencia se quieran acreditar 


\subsection{Dentro de la situación anterior, tendrán preferencia:}

a) Para el reconocimiento de unidades de competencias de la cualificación profesional de «Educación Infantil», quienes estén desempeñando puestos de educadores en Guarderías Infantiles.

b) Para el reconocimiento de unidades de competencia relacionadas con la cualificación profesional de «Atención sociosanitaria a personas dependientes en instituciones sociales», quienes estén desempeñando puestos de trabajo de la categoría de «Cuidador», «Gerocultor» o similar en instituciones sociales.

c) Para el reconocimiento de unidades de competencia relacionadas con la cualificación profesional de «Atención sociosanitaria a personas en el domicilio», quienes estén desempeñando puestos de trabajo de la categoría de «Asistente personal a personas con gran dependencia» y «Auxiliar de ayuda a domicilio».

d) Para el reconocimiento de unidades de competencias de la cualificación profesional «Operaciones Auxiliares de mantenimiento de carrocería de vehículos», quienes estén ocupando o hayan ocupado puestos de trabajo de ayudante o auxiliar en el área de carrocería de empresas de Castilla y León.

8.3. Dentro del supuesto indicado en el punto 2.c) del presente apartado octavo, tendrán preferencia quienes presenten Resolución de la Gerencia de Servicios Sociales por la que se les acredita para poder trabajar como Auxiliar de Ayuda a Domicilio en esta Comunidad Autónoma al amparo de lo dispuesto en la Orden de la Consejería de Sanidad y Bienestar Social de 13 de mayo de 2000, o certificado o diploma acreditativo de haber realizado la formación mínima establecida en el artículo segundo de la Orden de 12 de septiembre de 2002, de la Consejería de Sanidad y Bienestar Social, por la que se determina la formación de los Auxiliares de Ayuda a Domicilio.

Una vez aplicada esta preferencia, si el número de personas admitidas supera el de plazas ofertadas, se reservará el $20 \%$ de las plazas inicialmente ofertadas a quienes no presenten los documentos anteriormente indicados pero estén desempeñando puestos de trabajo de la categoría de «Asistente personal a personas con gran dependencia» o de «Auxiliar de ayuda a domicilio». Si el porcentaje de reserva no se cubre, la diferencia se acumulará al 
$80 \%$ restante.

8.4. Una vez aplicados los criterios de preferencia, si el número de candidatos con preferencia supera el de plazas disponibles, se procederá a baremar y ordenar las solicitudes en función de la mayor puntuación obtenida, expresada con dos decimales, conforme a los siguientes criterios:

a) Por cada año de experiencia laboral como trabajador o trabajadora por cuenta ajena a jornada completa o como trabajador o trabajadora de carácter autónomo en los últimos 10 años: 1 punto por cada 100 días trabajados a jornada completa. Se computarán fracciones inferiores a razón de 0,1 puntos por 10 días trabajados.

Si la experiencia no hubiera sido a jornada completa, se computará: $1^{\circ}$ - Por cada 100 días trabajados a tiempo parcial: 0,5 puntos. $2^{\circ}-$ Por cada 10 días: 0,05 puntos.

b) Por cada 100 horas de formación realizadas en los últimos diez años al amparo de las Administraciones Públicas y relacionadas con las competencias profesionales que quieran ser reconocidas: 1 punto hasta un máximo de 10 puntos. Si dicha formación no hubiera sido impartida al amparo de las Administraciones Públicas, la puntuación por cada 100 horas de formación será de 0,5 puntos.

A los efectos previstos en este párrafo, no se computarán los cursos de duración inferior a 10 horas, ni la asistencia a jornadas, congresos, simposios y eventos similares.

Fuente: Apartado octavo. Criterios de admisión. ORDEN/HAC 1536/2011

El punto 7.6 establece que el listado provisional de solicitantes admitidos, excluidos y reservas se publicará en los centros gestores, en el portal de educación y en la web del Servicio Público de Empleo de Castilla y León, en un plazo máximo de tres meses.

Por último, el punto 7.9 establece que las personas en situación de reserva admitidas serán convocadas por la Dirección General de Formación Profesional y Régimen Especial.

\section{- ENTREVISTAS}

Uno de los asesores entrevistados ha declarado que se siguieron los pasos y criterios establecidos en la ORDEN/HAC 1536/2011, para la ad- 
La validación de competencias profesionales en España e Italia

misión de los candidatos. Sin embargo, ha señalado que algunas de las personas que componían Comisiones de Admisión, no estaban especialmente preparadas para baremar a los candidatos que habían presentado demanda de participación en el procedimiento, ya que en ocasiones mostraban muestras de desconocimiento sobre algunos aspectos a evaluar. Asimismo, este asesor ha comentado que hubo algunos problemas para el acceso, en la segunda convocatoria, de las personas que estaban en situación de reserva en la primera y que fueron admitidas en el procedimiento en la segunda convocatoria (que se realizó un año más tarde y que colgaba de la anterior, es decir, que se convocó para las mismas unidades de competencia y se regía también por la ORDEN/HAC 1536/2011). Dichos problemas se debieron a que, a pesar de cumplir con lo establecido en la ORDEN/HAC 1536/2011, la convocatoria para estas personas se publicó en el Boletín Oficial de Castilla y León (en adelante, BOCYL) con una diferencia de años respecto a la primera convocatoria y sin ningún otro medio de aviso, por lo que muchos no se enteraron y perdieron la oportunidad de acceder al procedimiento.

"Se abre la convocatoria para que haya personas que soliciten participar en el proceso de acreditación, eso se difunde por los centros de trabajo, por las empresas de ayuda a domicilio, por las residencias de mayores.

Entonces, la gente que está trabajando en esas empresas y que quiere trabajar en el proceso...como todas las personas que se inscriban no van a poder participar en el proceso, porque son plazas limitadas. ¿Cómo sabes quién tiene que entrar y quién no? El candidato te tiene que presentar una documentación inicial [... Tel modelo para presentarlo ha sido el europeo porque se ha aplicado todo lo del curso, la gente ha tenido que ajustar sus curriculos a este modelo, la gente ha presentado todos esos documentos en los que se pedía contratos nóminas, justificantes, certificados de cursos, todo esto venía muy regulado en la convocatoria, lo que se iba a contabilizar y lo que no, en base a eso bubo unas comisiones en los centros para hacer una pequeña puntuación de todos los papeles, baremar, para ver quien entraba y quién no, orden de prioridad. Abi se constituyeron unas comisiones, en las cuales sí participaba el centro, el director del centro, el secretario del centro, personal administrativo del centro y también personas preparadas en el procedimiento, en esas comisiones, habia gente que no sabia nada, no sé, a lo mejor se les habia informado pero no daban muestras de haberlo recibido, no tenian las competencias, si les habian formado no lo sé, no sabian en qué consistía el proceso de los objetivos que perseguiamos, ni siquiera de las características del trabajo de la ayuda a domicilio, [...] esta segunda convocatoria ha salido en el boletín de Castilla y León, entonces se ha convocado una reunión, para que las personas que babian quedado en la otra convocatoria (en reserva) se 
evaluasen, pero tú, como candidato, no sabes que van a hacer una repesca, un año después de echar la solicitud, sacan un boletín y ponen tu nombre, el candidato podría estar de vacaciones o no sé, no enterarse, (el candidato ha dado su e-mail, su teléfono, etc...) si el candidato no se entera y no va a esa reunión informativa a la que estás convocado, a través del boletín, queda fuera del procedimiento. Para mí, eso no está bien, lo raro no es que faltase alguna persona, bajo mi punto de vista, lo raro es que bubiese alguien que se bubiese enterado de que estaba convocado y estuviese alli. [...]No avisaron, de que lo podrian volver a sacar, con una distancia de años desde la primera convocatoria, no se ha hecho ninguna iniciativa de contacto, no se ha hecho nada, se ha dado paso a la siguiente $y$ a veces la siguiente tampoco se ha enterado". (C.T. As).

\section{- ITALIA}

\section{- LEGISLACIÓN}

Legislación nacional y legislación regional: no se han encontrado referencias sobre este aspecto, ni en ámbito nacional, ni regional.

\section{- ENTREVISTAS}

Dos de los gestores/organizadores han explicado que la propia Regio$n e$, junto con las partes sociales, se ha encargado de decidir quién entraba en una de las convocatorias del procedimiento, que ha sido masiva.

"En un caso como este del operador socio-sanitario, que ha sido la unica experiencia masiva de certificación de la experiencia, habia modalidades reguladas en el ámbito de la acción regional, la acción regional decidía el campo, porque eran empresas de las que la Regione tenia una lista porque estaban... o parcialmente acreditadas o debian satisfacer los requisitos de la acreditación.”(P.A. en P.V. y P.A. Gestores/organizadores).

"Ha sido un recorrido hecho con las partes sociales, con ellos se han seleccionado las personas...” (P.V. en P.V. y P.A. Gestores/organizadores).

"Esto en la acción regulada por la Regione, esta autorización, para esta cualificación ha desencadenado una demanda no solo de nuestro territorio, también de otras, de todas las regiones de Italia, no hay vínculos, funciona por petición de la persona, luego para el acceso al servicio hay que revisar que efectivamente la persona tenga las evidencias necesarias respecto a esa cualificación" (P.A. en P.V. y P.A. Gestores/organizadores). 
La validación de competencias profesionales en España e Italia

2.1.0.3. Indicador: Resulta fácil para los candidatos acceder al sistema en relación a la documentación a presentar con la inscripción

\section{- ESPAÑa}

\section{- LEGISLACIÓN}

Legislación nacional y legislación autonómica: en los artículos 12 y 13.2 del RD 1224/2009, de la legislación nacional, y en el apartado quinto de la ORDEN/HAC 1536/2011 sobre la convocatoria del procedimiento, de la legislación autonómica, se especifica la documentación que deberá presentar el candidato, dependiendo del tipo de trabajador que sea.

1. La justificación de la experiencia laboral se hará con los siguientes documentos:

a) Para trabajadores asalariados: Certificación de la Tesorería General de la Seguridad Social, del Instituto Social de la Marina o de la mutualidad a la que estuvieran afiliadas, donde conste la empresa, la categoría laboral y el período de contratación, y Contrato de Trabajo o certificación de la empresa donde hayan adquirido la experiencia laboral, en la que conste específicamente la duración de los periodos de prestación del contrato, la actividad desarrollada y el intervalo de tiempo en el que se ha realizado dicha actividad.

b) Para trabajadores autónomos o por cuenta propia: Certificación de la Tesorería General de la Seguridad Social o del Instituto Social de la Marina de los períodos de alta en la Seguridad Social en el régimen especial correspondiente y Descripción de la actividad desarrollada e intervalo de tiempo en el que se ha realizado la misma.

\section{c) Para trabajadores voluntarios o becarios:}

Certificación de la organización donde se haya prestado la asistencia en la que consten, específicamente, las actividades y funciones realizadas, el año en el que se han realizado y el número total de horas dedicadas a las mismas.

Las administraciones competentes promoverán el establecimiento de un sistema de comunicación electrónica con la Tesorería General de la Seguridad Social para la transmisión de estos datos.

2. Para las competencias profesionales adquiridas a través de vías no 
formales de formación, la justificación se realizará mediante documento que acredite que el aspirante posee formación relacionada con las unidades de competencia que se pretendan acreditar, en el que consten los contenidos y las horas de formación.

\section{Fuente: Artículo 12. Justificación del historial profesional y/o formativo.}

El artículo 13.2 del Real Decreto 1224/2009 establece que el modelo de solicitud irá acompañado del historial personal y/o formativo de acuerdo con el modelo de currículum vitae europeo. Los candidatos y candidatas, con el fin de facilitar la fase de asesoramiento, también podrán presentar cuestionarios de autoevaluación, así como la documentación que consideren necesaria para justificar la competencia profesional requerida en las unidades de competencia en las que se hayan inscrito.

Legislación autonómica: el apartado sexto de la ORDEN/HAC 1536 de la convocatoria del procedimiento en Castilla y León, añade a la documentación de carácter laboral y/o formativo la presentación de los siguientes documentos junto con la solicitud de participación en el procedimiento:

- Fotocopia del DNI, pasaporte o, en el caso de personas extranjeras, el NIE o autorización de residencia o de residencia y trabajo en vigor en España.

- Historial profesional y/o formativo, siguiendo el modelo del curríulum vitae europeo.

- En su caso, certificado acreditativo de la discapacidad, para las personas aspirantes con alguna discapacidad que soliciten algún tipo de adaptación.

\section{- ENTREVISTAS}

Uno de los asesores entrevistados ha comentado la dificultad de los candidatos a la hora de completar algunos de los documentos que se pedían para la inscripción.

"[...] con una experiencia tremenda pero que malamente sabian bacerse un curriculum vitae, malamente sabian rellenar el historial histórico formativo, sobre todo en unos formatos que nos dieron, que dificilmente se podía escribir en ellos con que una parte de esta gente que tenía dificultades para escribir... imaginate... [...]” (J.L. As).

\section{- ITALIA}

- LEGISLACIÓN 
La validación de competencias profesionales en España e Italia

Legislación nacional y legislación regional: no se han encontrado referencias sobre este aspecto, ni en el plano nacional, ni en el regional.

- ENTREVISTAS

No existen referencias sobre este aspecto.

2.1.0.4. Indicador: Resulta fácil para los candidatos acceder al sistema en relación a los requisitos de formación y experiencia profesional

\section{- ESPAÑA}

\section{- LEGISLACIÓN}

Legislación nacional y legislación autonómica: la legislación nacional hace referencia a este aspecto en el artículo 11.1 c) del RD 1224/2009. La autonómica, lo hace en el apartado cuarto de la ORDEN/HAC 1536/2011, sobre la convocatoria del procedimiento. Tanto el real decreto como la orden establecen que el candidato debe tener la siguiente experiencia y/o formación:

- En el caso de acceder por experiencia laboral, el candidato debe justificar, como mínimo 3 años con, al menos, 2.000 horas trabajadas en los últimos 10 años. Para las UC de nivel I, se requieren 2 años de experiencia laboral con un mínimo de 1.200 horas trabajadas.

- En el caso de acceder por formación, el candidato debe justificar, como mínimo, 300 horas en los últimos 10 años. Para las unidades de competencia de nivel I, se requieren al menos 200 horas. En los casos en los que los módulos formativos asociados a la UC que se pretende acreditar tengan una duración inferior, deberán acreditarse las horas establecidas en dichos módulos.

- ENTREVISTAS

No existen referencias sobre este aspecto en las entrevistas.

- ITALIA

- LEGISLACIÓN

Legislación nacional y legislación regional: no se han encontrado referencias sobre este aspecto, ni en ámbito nacional, ni regional.

\section{- ENTREVISTAS}

Uno de los gestores/organizadores entrevistados ha comentado que no hay requisitos específicos para acceder al procedimiento, simplemente se 
debe presentar documentación que demuestre que el candidato está en posesión de las competencias que quiere acreditar.

"No, no hay requisitos. Los únicos requisitos que hay están ligados al hecho de que las personas puedan demostrar con documentación de cualquier naturaleza que tienen unas competencias..." (V.F. Gestor/organizador).

\subsection{Categoría: Carácter voluntario del acceso al procedimiento}

\subsubsection{Sin subcategoría.}

2.2.0.1. Indicador: Se hace saber al candidato la voluntariedad respecto al acceso al procedimiento.

\section{- ESPAÑA}

\section{- LEGISLACIÓN}

Legislación nacional: el artículo 6 a) del RD 1224/2009, señala el carácter voluntario del acceso del procedimiento, dentro del principio de respeto a los derechos individuales.

Legislación autonómica: no se han encontrado referencias al respecto.

\section{- ENTREVISTAS}

No hay referencias al respecto.

\section{- ITALIA}

- LEGISLACIÓN

Legislación nacional y legislación regional: no se han encontrado referencias, ni en el plano nacional, ni en el regional.

\section{- ENTREVISTAS}

No existen referencias sobre este argumento.

\section{Dimensión: Orientación}

\subsection{Categaría: Orientación durante el procedimiento}

3.1.0. Sin subcategoría.

3.1.0.1. Indicador: La orientación está presente durante todo el procedimiento de validación.

\section{- ESPAÑA}

- LEGISLACIÓN 
La validación de competencias profesionales en España e Italia

Legislación nacional: el artículo 8.1-4 del Real Decreto 1224/2009 garantiza un servicio abierto y permanente de información y orientación sobre el procedimiento. Establece que dicha orientación será facilitada por las Administraciones educativas y laborales que también podrá ser facilitada por las administraciones locales, los agentes sociales, Cámaras de Comercio y otras entidades y organizaciones públicas y privadas. También garantiza la formación y actualización de los asesores.

Legislación autonómica: la convocatoria del procedimiento ORDEN/HAC 1536/2011 de Castilla y León, garantiza, en el punto noveno, el servicio abierto y permanente de información y orientación, como lo hace el artículo 8 del RD 1224/2009, estableciendo también los medios de información y orientación (el portal de educación www.educa.jcyl.es (web temática de Formación Profesional) y el portal de empleo de la Junta de Castilla y León: www.empleo.jcyl.es/web/jcyl/EconomiaEmpleo; el servicio de atención al ciudadano de la Junta de Castilla y León, teléfono 012; los servicios de orientación ubicados en las oficinas de empleo del Servicio Público de Empleo de Castilla y León, así como en la Fundación Autonómica para la Formación y el Empleo de Castilla y León, en los centros gestores del procedimiento y en los centros públicos de educación de personas adultas de Castilla y León.

También, el punto undécimo de esta convocatoria hace referencia a una intervención de orientación por parte del asesor, al finalizar la fase de asesoramiento. Así, en caso de que esta fase no haya resultado positiva para que el candidato pueda continuar el procedimiento, el asesor deberá indicarle la formación complementaria que podrá realizar y a qué centros formativos dirigirse.

\section{- ENTREVISTAS}

Los profesionales del procedimiento entrevistados no han hecho referencia a la orientación durante el procedimiento, a excepción de uno de los evaluadores, que ha indicado la carencia o deficiencia de dicha fase de orientación.

Entrevistador: "¿Cree que existe da una buena fase de información y orientación?”

"Yo pienso que ni siquiera la ha habido, o si la habido, se ha basado mucho en la rumorología, hasta que poco a poco se fue diluyendo, babia gente que salia de los asesora- 
mientos que decian: Bueno pues no era para tanto, yo creo que se vendió como algo muy... no sé porque se vendió así, no sé por qué.” (J.L. As).

\section{- ITALIA}

\section{- LEGISLACIÓN}

Legislación nacional: el artículo 5 d) del Decreto Legislativo 13/2013 asegura la adopción de medidas personalizadas de información y orientación en favor de los destinatarios de los servicios de identificación, validación y certificación de competencias. No obstante, no se especifica en que momento debe proporcionarse dicha información y orientación.

Legislación regional: la Deliberación de Junta Regional 530/2006 (DGR 530/2006), en el punto 1.1 del anexo A, hace referencia al asesoramiento, que incluye orientación por parte del EPV, pero lo hace de forma poco concreta, sin indicar qué momento ni sobre qué aspectos se proporcionará dicha orientación.

\section{- ENTREVISTA}

Uno de los gestores/dirigentes ha explicado que la orientación es un paso que se encuentra fuera del procedimiento, sería previo a este, actualmente está en manos de los servicios de empleo y todavía se está trabajando en él.

"Siempre está previsto, en la fase de adquisición de la petición o en general, debería ser una de esas fases que preceden el acceso al SRFC hecho por el servicio para el empleo o para quién se ocupa de la orientación. Los que se ocupan de la orientación están fuera del procedimiento, (sería un paso previo). Actualmente, en teoría, los servicios para el empleo, (estamos todavía trabajando en esto) deberían poder dar esta información en general, por lo tanto, en el momento en el que una persona accede en el ámbito del servicio de orientación, la deberían orientar a 360 grados sobre todas las oportunidades que hay en territorio, en términos de formación, de balance de competencias, o de acceso a un servicio de formalización y certificación de las competencias, y por lo tanto dar toda la información de forma específica sobre el servicio.” (P.A. en PV y P.A. Gestores/dirigentes).

\subsection{Categoría: Orientación al finalizar el procedimiento}

\subsubsection{Sin subcategoría.}

3.2.0.1. Indicador: Se proporciona al candidato una orientación suplementaria, al finalizar el procedimiento, sobre las posibilidades de formación y/o de salidas profesionales, al finalizar el procedimiento. 
La validación de competencias profesionales en España e Italia

\section{- ESPAÑA}

\section{- LEGISLACIÓN}

Legislación nacional: el artículo 20 del RD 1224/2009 contempla que al terminar el procedimiento de evaluación y acreditación de competencias profesionales, las administraciones competentes proporcionen, a todos los participantes en el procedimiento, un documento con las posibilidades de formación, con las orientaciones pertinentes para poder acreditar en otras convocatorias las unidades de competencias para las que habían solicitado acreditación. En el caso de que se den las condiciones, se puede proporcionar al candidato un documento con las posibilidades de formación y orientación pertinente para conseguir el título de formación profesional o certificado de profesionalidad relacionado con las unidades de competencia para las que el candidato había pedido la certificación.

Asimismo, en el artículo 28 del mismo real decreto, se señala que una de las funciones de las comisiones de evaluación es informar al candidato sobre las oportunidades existentes para seguir formándose y obtener la acreditación completa de un título de formación profesional o certificado de profesionalidad.

Legislación autonómica: la ORDEN/HAC 1605/2011 sobre la gestión del procedimiento de evaluación y acreditación de competencias, hace referencia en su artículo 2, cumpliendo así con el RD 1224/2009, a la realización de una orientación personalizada para los candidatos, para indicarles los trámites necesarios para la obtención de un certificado de profesionalidad o título de formación profesional. Así, como en el artículo 18 de la misma orden, se establece que a cada candidato se le entregará un documento con la información que acabamos de detallar en el artículo 20 del RD $1224 / 2009$.

La ORDEN/HAC 1536/2011 sobre la convocatoria del procedimiento, siguiendo el artículo 28 del RD 1224/2009, instituye en el punto 14.3 que la comisión de evaluación realizará un informe individualizado a cada candidato con una propuesta formativa adaptada a su situación.

\section{- ENTREVISTAS}

Los dos evaluadores entrevistados han comentado haber recibido instrucciones para proporcionar orientación al candidato sobre su posible formación, en caso de no haber superado alguna de las UC que quisiese acreditar. De igual modo, a las personas que sí las han superado se les dice 
como solicitar el título correspondiente. Uno de los evaluadores ha señalado, sin embargo, que la orientación para ayudar al candidato a obtener el título está en la web de la Junta y no es fácil para muchos, con escaso conocimiento informático, comprender el procedimiento. Dicho evaluador cree por tanto que este aspecto debería mejorarse y también ha añadido que a los candidatos que logren acreditar las unidades de competencia correspondientes también debería informárseles sobre sus competencias y una formación adicional.

Entrevistador: "¿Después del procedimiento, se le proporciona información sobre cómo puede continuar la formación o su carrera profesional...?”

"Si, en principio nos dicen, que solo en caso de no haber superado las unidades de competencia. Nos han colgado en la plataforma los pasos que pueden seguir, pero normalmente se lo decimos a todos, yo abi veo una carencia, tendrían que decir que es obligatorio, porque se encentran diciendo: " $\mathrm{i}$ Ahora qué? Para los que han superado las UC tendriamos que dar un documento obligatorio que diga, ahora ve al Ecyly tienes que presentar un documento con esto, esto y esto, es más si tenemos la solicitud nosotros mejor, dársela a ellos con la comunicación, creo que eso lo podríamos mejorar, porque el nivel cultural que tienen muchos... les dices, te mentes en la página de la Junta de Castilla y León... viene gente q no tiene ni idea de acceder a internet o que se pierde, entonces si tú le dices esta es la documentación que tienes que llevar y tienes que pagar esta tasa, les haces un favor enorme. En este aspecto debería mejorar.” (A.D. Ev).

Entrevistador: "¿Se ha dado información/orientación formativa y/o profesional tras terminar el procedimiento?"

"Sí, sí que se hace, hay como dos tipos: una a la persona que no tiene demostradas las unidades de competencias y entonces ha habido que darles un itinerario formativo eso es una comunicación que se les da y luego la otra comunicación que se les da es como conseguir el certificado de profesionalidad que es lo que la gente quiere saber, abi les explicas que con la comunicación que nosotros les damos, simplemente les va a servir para justificar que se han presentado al procedimiento y que tiene las unidades de competencia demostradas y que luego el certificado de profesionalidad lo tienen que pedir en el Ecyl o a través de la página web... que nos mandó José Ignacio un correo sobre los pasos que tenian que seguir." (T.M. Ev).

\section{- ITALIA}

- LEGISLACIÓN 
La validación de competencias profesionales en España e Italia

Legislación nacional: el artículo 5 d) del Decreto Legislativo 13/2013 asegura la adopción de medidas personalizadas de información y orientación en favor de los destinatarios de los servicios de identificación, validación y certificación de competencias. Aunque no especifica en que momento debe proporcionarse dicha información y orientación y no hace especial referencia a que se lleve a cabo, también, al finalizar el procedimiento.

Legislación regional: la DGR 530/2006, en el punto 1.1 del anexo A, hace referencia al asesoramiento, que incluye orientación, por parte del $\mathrm{EPV}$, pero lo hace de forma poco concreta, sin indicar qué momento ni sobre qué aspectos se proporcionará dicha orientación.

\section{- ENTREVISTAS}

EL EAPQ y un EPV entrevistado han declarado que esta fase de orientación al final del procedimiento no está prevista, y que ellos suelen animar al candidato que no ha conseguido todas las UC de una cualificación a presentarse la próxima vez. El EAPQ ha añadido que él les da indicaciones, si le preguntan, sobre qué hacer después, pero lo hace por iniciativa personal, no porque esté establecido.

"No, no se hace. Hay personas que no consiguen la cualificación y obtienen 3 unidades de competencia de cuatro, si una no se la puedes dar le das el certificado de competencia de las otras tres y generalmente le decimos, la próxima vez que se convoque el examen para esta unidad de competencia preséntate." (N.B. EPV).

"[...7 se les dice que con este sistema no se queda sin nada, tendrá una o dos unidades de competencia y la próxima vez completará la cualificación. A todos se les dice: "Tú has hecho esto, si vienes el próximo año y haces una formación, como ya tienes dos unidades de competencia tendrás que hacer un curso formativo más corto..." Yo la indicación la doy pero es una cuestión personal para dar una indicación a él o a ella me tengo que documentar yo no puedo ir a todos los centros a preguntar que tienen para ellos, yo les puedo decir, ve alli...pregunta... metete en esta página web.

Nosotros nos interesamos caso por caso, pero no a todos les damos indicaciones, si uno nos pregunta sí, pero no es una fase prevista.

Si vas al centro para el empleo no te saben informar muchas veces. Nosotros si, nos ocupamos de ellos. Nuestro trabajo es ayudarles." (C.C. EAPQ).

\section{Dimensión: Asesoramiento}

\subsection{Categoría: Información en el proceso de asesoramiento}

4.1.0. Sin subcategoría 
4.1.0.1. Indicador: El asesor proporciona al candidato información acerca del procedimiento

\section{- ESPAÑa}

\section{- LEGISLACIÓN}

Legislación nacional: no se han encontrado referencias directas sobre este aspecto. Sin embargo, el artículo 23.1. a), que se encarga de definir las funciones del asesor, indica que este debe asesorar al candidato en la preparación y puesta a punto del proceso de evaluación.

Legislación autonómica: el punto 11.2 de la ORDEN/HAC 1536/2011 sobre la convocatoria del procedimiento, expone que la página web del portal de educación, www.educa.jcyl.es, y del Servicio Público de Empleo de la Junta de Castilla y León, www.empleo.jcyl.es/web/jcyl/ EconomiaEmpleo, pondrá a disposición de los candidatos admitidos la información sobre el asesor asignado, así como la fecha, provincia y lugar de su primera reunión. Sin embargo, no especifica que el asesor tenga que dar este tipo de información al candidato.

\section{- ENTREVISTAS}

Un asesor entrevistado ha comentado que se ha proporcionado información general al candidato en una primera reunión grupal al comenzar el asesoramiento, sobre el procedimiento, las fases de las que consta, qué deben hacer, cómo se gestionará el procedimiento, el papel del asesor y del evaluador, los certificados de profesionalidad y las Unidades de Competencia. También indicó que en la primera parte de la convocatoria los candidatos llegaban más desinformados y con bastante miedo al procedimiento.

"Normalmente es grupal, con el grupo de candidatos que te asignan les explicas en lineas generales en que consiste el procedimiento, las fases de las que consta, que deben hacer, cómo se va a gestionar, el papel del asesor, el papel del evaluador, los certificados de profesionalidad, las Unidades de Competencia...el denominador común de la primera convocatoria era el miedo que tenía la gente, miedo a perder el trabajo. Yo me quedaba asustado, yo, lógicamente centraba mucha parte de mi trabajo en quitar el miedo" (J.L. As).

\section{- ITALIA}

- LEGISLACIÓN 
La validación de competencias profesionales en España e Italia

Legislación nacional: el artículo 5 del Decreto legislativo 13/2013 hace referencia a la adopción de medidas personalizadas de información, pero no especifica en qué momento y sobre qué aspectos.

Legislación regional: la DGR 530/2006, hace referencia, en el punto 1.2.1 (p. 15), del anexo A, a la información que debe darse a los candidatos sobre el procedimiento (articulación, valor, salidas, condiciones de asesoramiento).

\section{- ENTREVISTAS}

No existen referencias al respecto.

\subsection{Categoría: Proceso de recogida de evidencias}

4.2.1. Subcategoría: Adecuación del proceso de recogida de evidencias.

4.2.1.1. Indicador: Existen normas sobre lo que es relevante como documentación y cómo se debe presentar.

\section{- ESPAÑA}

\section{- LEGISLACIÓN}

Legislación nacional: el artículo 12 del RD 1224/2009 establece con precisión con qué documentos se justificará la experiencia laboral que apoyará la veracidad de las evidencias presentadas por los candidatos para el reconocimiento de sus competencias. Este artículo indica los documentos a presentar por los candidatos, con las pertinentes diferencias según sean: trabajadores asalariados; trabajadores autónomos o por cuenta propia; trabajadores voluntarios o becarios.

Además, establece que para las competencias profesionales adquiridas a través de vías no formales de formación, la justificación se realizará mediante documento que acredite la posesión, por parte del aspirante, de formación relacionada con las unidades de competencia que se pretendan acreditar, en el que consten los contenidos y las horas de formación.

Legislación autonómica: el quinto apartado de la ORDEN HAC 1536/2011, sobre la convocatoria en la comunidad autónoma de Castilla y León, reproduce el mencionado artículo 12 del RD 1224/2009.

\section{- ENTREVISTAS}

Uno de los asesores entrevistados ha declarado que los asesores se encargaban de determinar con el candidato toda la documentación que pro- 
cedía, para evidenciar la posesión de conocimientos y experiencia profesional y formativa relacionada con las unidades de competencia que querían acreditarse. Ha indicado, también, que el aspecto de documentación a presentar estaba muy bien definido en el procedimiento, y que existían normas definidas en el procedimiento sobre lo que es importante presentar como documentación de las evidencias.

"[...] determinar si cierta documentación procedia para la cualificación o no, porque te podías encontrar con gente que te presentaba un titulo o diploma o experiencia profesional que aparentemente no tenía nada que ver pero que desmenuzando los contenidos del curso, podía ver si efectivamente podía servir y encajar con la cualificación algo de eso.

Pues la candidata partía de un C. V. en el formato Europass, una vez que lo traía le ayudabas a mejorar ese C. V., por ejemplo decía: No lo he puesto pero he becho un curso de estética y peluquería, pero no tiene nada que ver con esto, ¿cómo que no tiene nada que ver con esto?, ¿cómo qué no? y tu revisabas los contenidos y veías si se podía sacar algún conocimiento relacionado con las unidad o las unidades de competencia, tratabas de que aflorasen los conocimientos que ellos tenían; en base a eso se confeccionaba el historial formativo y profesional, con toda la documentación que los candidatos aportaban en ese sobre y con ellos pues valorabas y decidías si para tal unidad de competencia, presentaba una experiencia laboral y una formación que cuadrasen y si la experiencia laboral en forma de contrato o registrada en la vida laboral que aportaba pues era válida o no lo era y si tal formación procedía o no procedía.

De lo que se trataba era de ver si yo tenía evidencias (en este aspecto el procedimiento está muy definido) de que esa persona tenía, presentaba evidencias que se correspondian con lo que reflejaba en su $C$. V., y de alguna manera esas evidencias se podian trasladar a conocimientos teóricos y conocimientos prácticos, yo era lo que buscaba, funcionábamos con evidencias que sacábamos de los papeles (contratos y cursos realizados, que tenian los contenidos por detrás) y evidencias que nosotros sacábamos de la información de los asesoramientos al rellenar el historial de las entrevistas con fines de asesoramiento" (J.L. As).

\section{- ITALIA}

\section{- LEGISLACIÓN}

Legislación nacional: no hace referencia a este aspecto.

Legislación regional: el punto 2.1 (pp. 44-47) del anexo A, perteneciente a la DGR 530/2006, establece unas pautas sobre el tipo de evidencias 
La validación de competencias profesionales en España e Italia

que deben presentarse y cómo deben ser (pertinentes respecto al Sistema Regional de Cualificaciones, exhaustivas y correctas).

\section{- ENTREVISTAS}

Uno de los gestores/organizadores y un EPV afirman que en la normativa (530) existen referencias para saber aquello que deben recoger para documentar las evidencias de los candidatos.

"[...] con dos entrevistas, máximo tres, se resuelve la fase recogida de todo lo que una persona puede demostrar que tiene en relación con la cualificación. Después el experto bace un trabajo de sintesis, nosotros en la normativa hemos dado un formato específico para hacer este trabajo de sintesis. Y después recoge en el dossier todas las evidencias de la persona. El servicio nos dice para que ámbito lo está aplicando, esto por información pero no hay distinción, da igual, nos dice que cualificación se ha tomado como referencia" (V.F. Gestor/organizador).

"[...] ya han dicho que tipo de experiencia tienen cuando hacen la entrevista con el EPV, este vuelve a controlar, que tiene las evidencias adecuadas, que lo que está escrito es verdad o se está inventando cosas. Yo nunca he tenido que decir a alguien que se retirase, si están abi es porque trabajan desde hace años, y algunos tienen una declaración de la empresa que dice que ellos tienen esas capacidades y esos conocimientos... todo esto está en la 530" (S.C. EPV).

4.2.1.2. Indicador: Las evidencias documentadas por un individuo están directamente relacionadas con los estándares utilizados para la validación.

\section{- ESPAÑA}

\section{- LEGISLACIÓN}

Legislación nacional: no se ha encontrado una referencia directa sobre este aspecto. Sin embargo, en el artículo 9 del RD 1224/2009 se habla de un manual de guía para el asesor, la Guía del Asesor. Dicha guía deja patente la relación de las evidencias con los estándares que se utilizan en la validación, al proporcionar una serie de instrumentos para el asesoramiento, que relacionan las evidencias con las UC objeto de validación (punto 3, pp.34-36).

Legislación autonómica: no se han encontrado referencias.

\section{- ENTREVISTAS}

Dos asesores entrevistados han declarado que en el asesoramiento se han utilizado instrumentos como el historial profesional formativo, los 
cuestionarios, o la ficha de sistematización de evidencias. Estos instrumentos tienen como referentes los que se utilizan para la validación (las unidades de competencia de las cualificaciones del Catálogo Nacional de Cualificaciones Profesionales).

"[...] se hace una ficha de sistematización de evidencias, se le hace una entrevista de asesoramiento para asesorarle sobre las competencias que tiene, para tener una visión de si la persona es competente o no en cuanto a lo que pretende acreditar..." (С.T. As).

"[...] revisabas el historial profesional y formativo, también les entregabas los cuestionarios de autoevaluación... el historial profesional y formativo nos daba evidencias a nosotros para después hacer una sistematización de las evidencias y emitir un informe de asesoramiento [...]” (J.L. As).

\section{- ITALIA}

\section{- LEGISLACIÓN}

Legislación nacional: no se han encontrado referencias sobre este aspecto.

Legislación regional: el punto 4.1 de la DGR 1434/200 define evidencia como la prueba de conocimientos y capacidades relacionadas con los estándares del Sistema Regional de Cualificaciones. Esto quiere decir que las evidencias que presente el candidato deben estar relacionadas con los estándares utilizados para la validación, ya que estos son los del sistema Regional de Cualificaciones.

\section{- ENTREVISTAS}

Uno de los gestores/dirigentes entrevistado ha asegurado que para la recogida de evidencias se tienen en cuenta los estándares de validación a través de una ficha descriptiva.

"En la scheda descrittiva (ficha descriptiva) de la cualificación, además de las capacidades de conocimiento, están definidos también los indicadores, ayudan mucho a comprender el significado del estándar, la ventaja del estándar es que si lo tienes como referencia puedes pensar en la certificación si no... varian las terminologías, la terminologia, los objetos y no sabes muy bien que certificar ". (V.F. Gestor/dirigente).

4.2.1.3. Indicador: El proceso de documentación está dirigido.

\section{- ESPAÑA}

- LEGISLACIÓN 
La validación de competencias profesionales en España e Italia

Legislación nacional: el artículo 15 del RD 1224/2009 establece que el asesor citará al candidato, siempre que se considere necesario, para ayudarle a autoevaluar su competencia, completar su historial personal y/o formativo o a presentar evidencias para justificarlo.

Legislación autonómica: el apartado undécimo, punto 4, de la ORDEN HAC 1536/2011, expone el orden que llevará el asesoramiento y el papel de dirigente del asesor en el proceso.

\section{- ENTREVISTAS}

Los dos asesores entrevistados han asegurado haber ayudado al sujeto a mejorar la presentación del historial personal y/o formativo, a preparar la documentación sobre las evidencias de sus competencias antes de presentarlas y a contestar el cuestionario de autoevaluación.

Entrevistador: "¿Los candidatos hacen solos el cuestionario de autoevaluación?”

"Si, lo bacen solos y luego lo revisan con nosotros. Hay gente que lo trae a lápiz... y luego tenemos que ir cambiando" (C.T. As).

"[...] la persona candidata firmaba la declaración jurada y tenías que ayudarla a hacer mejor y revisabas el historial profesional y formativo, también les entregabas los cuestionarios de autoevaluación, y yo abi dedicaba bastante tiempo en que entendiesen que aquello del cuestionario no era un examen, que el contestar un cuatro no equivalía a que les fuesen a poner un cuatro, que contestasen bien, lo que sinceramente les parecía que se ajustase más a la realidad...el historial profesional y formativo nos daba evidencias a nosotros para después hacer una sistematización de las evidencias y emitir un informe de asesoramiento, entonces, antes habia una entrevista, antes de emitir el informe, una entrevista profesional con fines de asesoramiento" (J.L. As).

\section{- ITALIA}

- LEGISLACIÓN

Legislación nacional: no se ha encontrado ninguna referencia, sobre este punto.

Legislación regional: el punto 2.2.2 del Anexo A de la DGR 530/2006, establece que el EPV guiará al candidato durante el proceso de recogida de evidencias.

\section{- ENTREVISTAS}


Dos de los EPV entrevistados declaran haber dirigido el asesoramiento con el candidato, en la explicación de sus funciones en este proceso.

"El dossier se hacia a través de una petición, hecha al EPV, se llama petición de valoración, el EPV, entonces se encuentra con la persona y le hace una especie de entrevista y después rellena un plan de valoración (se llama asi), abi le dices a la persona que recoja todos los atestados de cursos de formación que haya hecho, que traiga un papel de su jefe en el que describa las actividades que haces en el trabajo normalmente. Todo...le pides a la persona que aporte todas las evidencias posibles y pertinentes con el perfil profesional pertinente" (N.B. EPV).

"[...] cuando hacen la entrevista con el EPV, este vuelve a controlar, que tiene las evidencias adecuadas, que lo que está escrito es verdad o se está inventando cosas" (S.C. EPV).

\subsubsection{Subcategoría: Adecuación de los instrumentos para la recogida de las evidencias}

4.2.2.1. Indicador: Se emplea una amplia variedad de instrumentos para la recogida de evidencias.

\section{- ESPAÑA}

\section{- LEGISLACIÓN}

Legislación nacional: no se han encontrado referencias directas sobre este aspecto. Sin embargo, en el artículo 9 del RD 1224/2009, se menciona la Guía del Asesor. En dicha guía se exponen varios tipos de instrumentos para la recogida de evidencias (ver subapartado 4.2.6).

Legislación autonómica: el apartado decimotercero, punto 8, de la ORDEN HAC/1536/2011, establece que para la obtención de las evidencias se utilizarán los métodos que se consideren necesarios, proponiendo entre otros métodos e instrumentos: la observación del candidato en el puesto de trabajo, simulaciones, pruebas estandarizadas de competencia profesional o entrevistas profesionales.

\section{- ENTREVISTAS}

Los dos asesores entrevistados han afirmado haber utilizado diferentes instrumentos para la recogida de evidencias.

"Luego el historial profesional y formativo nos daba evidencias... a nosotros para después hacer una sistematización de las evidencias y emitir un informe de asesoramiento, entonces, antes habia una entrevista, antes de emitir el informe, una entrevista profesional 
La validación de competencias profesionales en España e Italia

con fines de asesoramiento, para tratar de ver las cosas de las autoevaluaciones, de los cuestionarios que no nos quedaban muy claras" (J.L. As).

"... se hace esa fase con todos los instrumentos que conlleva: la relaboración del historial profesional y formativo, declaración responsable de que no tiene esa formación ni el titulo, se firma un acta de la reunión, primero el tema documental, se completa, se hace una ficha de sistematización de evidencias, se le hace una entrevista de asesoramiento para asesorarle sobre las competencias que tiene, para tener una visión de si la persona es competente o no en cuanto a lo que pretende acreditar..." (C.T. As).

\section{- ITALIA}

\section{- LEGISLACIÓN}

Legislación nacional: no se han encontrado referencias al respecto.

Legislación regional: la DGR 350/2006, en el punto 2.2.1 del Anexo A (pp. 45-47), expone varios instrumentos para la recogida de evidencias.

\section{- ENTREVISTAS}

Uno de los gestores/organizadores del procedimiento ha comentado que se han tenido en cuenta diversos tipos de justificación de evidencias.

"Como lo que decía Paola antes... que el sistema de certificaciones que queríamos iniciar pudiese ser aplicado a personas que venian de recorridos formales y para aquellas que venian de experiencias profesionales o experiencia mixta con formación y experiencia profesional.

El Sistema de Formalizazione e certificazione puede ser alimentado por evidencias que no están en un recorrido formal pero que es experiencia de la persona, por ejemplo, una carta de un empresario que dice que la persona ha trabajado, que ha hecho determinadas cosas, actividades, la persona tiene documentos que puedan acreditar su experiencia, experiencias documentadas, pruebas que se pueden relacionar con el estándar profesional de la cualificación, esto constituye evidencias, el sistema esta alimentado por evidencias de naturaleza de tipo diverso, y no el resultado de un recorrido formativo de formación" (P.V. Gestor/organizador).

4.2.2.2. Indicador: Los instrumentos para la documentación de evidencias reflejan las competencias del solicitante.

\section{- ESPAÑA}

- LEgISLACIÓN 
Legislación nacional y legislación autonómica: no se han encontrado referencias al respecto, ni en el plano nacional, ni en el autonómico.

\section{ENTREVISTAS}

Los dos asesores entrevistados coinciden en que los instrumentos son útiles para determinar las competencias que posee el candidato, aunque han señalado la dificultad del lenguaje utilizado en los mismos, ya que en numerosas ocasiones han podido constatar los problemas de los candidatos para usar los instrumentos de recogida de evidencias.

"Los instrumentos están bien, pero lo negativo, no solo de los instrumentos, sino de todo el procedimiento es el lenguaje que utiliza, es un lenguaje que si tu no explicas un poco a la gente lo que están preguntando, no lo entienden”.

Este es un proceso muy cerrado aunque a mí no me parezca lógico, por ejemplo, la ficha de sistematización de evidencia, yo podía decir que ya lo he visto en el currriculum vitae del candidato, que tal persona ha trabajado diez años en el mismo centro y no tiene nada de formación, ¿qué más ficha de sistematización si lo tiene en el C. V. (C.T. As).

Entrevistador: ¿Cree que los instrumentos sirven para comprobar si la persona es o no es competente en relación a las unidades de competencia?

"Yo creo que sí, grandes sorpresas y para decir la verdad habia que, como asesor, bilar muy fino, porque algunas de las personas, a las que estaba asesorando, tenían más conocimientos que yo [...] yo me he encontrado, por ejemplo, con una señora, que babia sido la mejor puntuada, (con una experiencia tremenda), para entrar, pero babia tenido muchísimos problemas para hacer los documentos. Para el C. V. habia tenido que recurir a su bijo para el C. V. Muchas veces para trabajar yo mismo, cuando los candidatos traian el C. V. manuscrito por ellos...es que me era imposible entenderlo y yo mismo, con el mismo formato, lo pasaba a ordenador, en la siguiente sesión se lo enseñaba a ellos para comprobarlo y que me firmasen la declaración jurada de lo que ponía en el historial profesional y formativo era cierto, porque es que era la dificultad que encontraban... una vez. tuve que hacer la plantilla del bistorial profesional formativo a un tamaño más grande [...]Los cuestionarios tienen algunas preguntas un poco enrevesadas para comprender y algunas palabras muy técnicas. Por ejemplo: - ¿Colabora con el equipo interdisciplinar de su centro?", y contestaban que sí, pero luego, durante la entrevista les preguntabas y quién compone el equipo interdisciplinar y no sabian lo que era, sin embargo, al preguntarlo de 
La validación de competencias profesionales en España e Italia

otra forma, sabian perfectamente de lo que les estabas hablando, es verdad que habia muchas preguntas de dudosa interpretación (J.L. As).

\section{- ITALIA}

\section{- LEGISLACIÓN}

Legislación nacional y legislación regional: no se han encontrado referencias al respecto, ni en la legislación nacional, ni en la regional.

\section{- ENTREVISTAS}

Uno de los EAPQ entrevistados ha considerado que los instrumentos para la recogida de evidencias, como el dossier o el plan de evaluación (piano di accertamento), le han ayudado a determinar las competencias de los candidatos.

Entrevistador: “¿Los instrumentos para la recogida de evidencias le resultan útiles?"

$$
\text { "Sí...sí." }
$$

Entrevistador: “¿El plan de evaluación (piano di accertamento) es un instrumento que os ayuda en el proceso?”

"Cierto. Cada cualificación está compuesta por unidades de competencia, en el plan de valoración tú tienes que describir para cada unidad de competencia cuáles son los conocimientos que la persona tiene que producir si quiere que esa unidad de competencia se le reconozca como crédito" (N.B. EPV).

\subsection{Categoría: Preparación de los asesores}

\subsubsection{Sin subcategoría}

4.3.0.1. Indicador: Existen unos requisitos específicos para ser asesor.

\section{- ESPAÑA}

\section{- LEGISLACIÓN}

Legislación nacional: el artículo 25 del RD 1224/2009 expone los requisitos que se requieren para ser asesor o evaluador en el procedimiento de evaluación y acreditación de competencias:

Artículo 25. Requisitos para ser asesor y/o evaluador.

1. Los requisitos que deberán concurrir en todo caso para obtener de las administraciones competentes la habilitación para ejercer las funciones 
de asesoramiento y/o evaluación son:

a) Tener una experiencia de al menos cuatro años en alguno de los siguientes colectivos:

- Profesorado perteneciente a los Cuerpos de Catedráticos, Profesores de enseñanza secundaria o Técnicos de formación profesional, con atribución docente en la Familia Profesional correspondiente.

- Formadores y formadoras especializados en las unidades de competencia que se especifiquen.

- Profesionales expertos en las unidades de competencia que se especifiquen.

b) Superar un curso de formación específica organizado o supervisado por las administraciones competentes. Los contenidos del curso tomarán como referente lo establecido en los Anexos IV y V.

2. Las personas designadas por las administraciones competentes para el asesoramiento no podrán participar como evaluadores en una misma convocatoria de evaluación y acreditación.

Fuente: Art. 25; RD 1224/2009

Legislación autonómica: el artículo 12 de la ORDEN/HAC 1605/2011 sobre la gestión del procedimiento expone que la selección y formación del personal asesor y evaluador se hará siguiendo el RD 1224/2009; que la convocatoria tendrá carácter público y se publicará en el BOCYL; que cada convocatoria contemplará un perfil profesional determinado, según las unidades de competencia que vayan a evaluarse y acreditarse y establecerá un número máximo de plazas para cada proceso, el plan de formación y la duración de los cursos formativos; por último, establece que la convocatoria del proceso de selección y formación de personal asesor y evaluador establecerá los criterios de selección y los baremos de puntuación de los méritos que se determinen.

El artículo 13 de la misma orden se ocupa de los requisitos y criterios de selección del personal asesor evaluador, repitiendo el artículo 25 del RD 1224/2009. Asimismo, añade que los criterios de selección de participantes en el proceso de selección, formación y habilitación de personal asesor y evaluador los determinará la convocatoria, incluyendo, al menos, la valoración de la experiencia como docente y/o profesional. El artículo 14.2 establece que la habilitación de asesores y evaluadores tendrá carácter nacional. 
La validación de competencias profesionales en España e Italia

Asimismo, la ORDEN/HAC 1536/2011 sobre la convocatoria del procedimiento en Castilla y León establece, en el apartado décimo, que la habilitación de asesores y/o evaluadores se realizará siguiendo los criterios de experiencia y formación específica, según lo establecido en el artículo 25 del RD 1224/2009.

\section{- ENTREVISTAS}

Una de las asesoras entrevistadas ha hablado del requisito de la formación, indicando que ella realizó dicha formación a través de la Uned ${ }^{102}$. En particular, recibió una invitación personal por parte de la Junta de Castilla y León, ya que, según manifiesta, cree que la convocatoria para la participación en el procedimiento como asesor/evaluador no tuvo mucha acepción, debido a que se trataba de la primera convocatoria. Sin embargo, posteriormente Observal ${ }^{103}$ formó a más personas, aunque solo un pequeño porcentaje pasó a formar parte de los profesionales. Otro de los asesores entrevistados señala haber realizado su formación con Observal.

"Hicimos una formación que gestionaba la Uned, no teníamos ni idea de este procedimiento, ni en qué consistía, ni qué pretendía y nos seleccionaron a unas cuantas personas y nos dieron la opción para inscribirnos para ser asesores o evaluadores sin saber muy bien en qué consistía cada cosa, el procedimiento... nos dieron una información previa [...] fue en mayo de 2010, bicimos en la Uned una formación muy densa y exhaustiva de todo el proceso, toda la normativa, después nos dieron el titulo [...] Nos enteramos porque salio una convocatoria en algún boletin y el colegio profesional difundió que trabajadores sociales podian hacer esa formación, pero como no estaba muy claro ni sabiamos muy bien de que iba yo creo que no se bizo mucho caso de esa convocatoria y entonces twvo que tomar cartas en el asunto, yo creo que la Junta de Castilla y León, para proponer a gente, para invitarnos directamente, [...]. Lo bicimos con una motivación personal con una invitación directa. Los de la Uned, estudiamos, mucho, tuvimos un examen durísimo (C.T. As).

Entrevistador: “¿Cómo se formó como asesor?”

"[...] por Observal, a mi me llegó a través del sindicato, me enteré y como vi que lo que pedian era gente con una formación amplia en el sector de la dependencia o de la

102 Universidad Nacional de Educación a Distancia.

103 Observatorio de la validación de competencias profesionales (www.observal.es). Se trata de un instrumento para el seguimiento y análisis de los procedimientos, realizados en España, sobre reconocimiento de competencias profesionales y aprendizajes no formales e informales. 
atención a personas dependientes, por eso me inscribi y me admitieron. Tuve de tutor a Eulogio y muy bien, fue on-line y hubo algunas sesiones presenciales, me gustó mucho lo que aprendí y lo mejor ha sido poder hacer el asesoramiento" (J.L. As).

\section{- ITALIA}

\section{- LEGISLACIÓN}

Legislación nacional: no se han encontrado referencias al respecto.

Legislación regional: la Deliberación de Junta Regional 841/2006 (DGR 841/2006) establece los requisitos que debe poseer una persona que quiera optar al rol de EPV en el SRFC:

-Requisitos de experiencia profesional:

Haber realizado actividades laborales de tipo técnico-especialista, durante al menos 5 años en los últimos 7 y aunque no haya sido de forma continuada, consistentes en proporcionar servicios de análisis, evaluación y desarrollo de competencias profesionales (en particular la evaluación debe haber comprendido la planificación de los dispositivos de evaluación y su aplicación) en el ámbito del procedimiento de acreditación de la Regione Emilia-Romagna, relacionados con "Evaluación y seguimiento del servicio", "Programación y proporción del servicio", "Análisis contextual de las necesidades", "Planificación del servicio".

-Tener una relación de trabajo respecto al ente en el que se lleva a cabo el procedimiento (al menos de 80 días al año).

-Estar en posesión de un título de estudio correspondiente a una carrera universitaria o a un diploma de la escuela secundaria superior.

A través del punto 3.2 de la DGR 1434/05 de la legislación de la Región de Emilia-Romagna, se encomienda a la Regione la iniciativa de cualificación de las figuras clave del sistema de formalización y certificación, es decir, entre otros, la cualificación de expertos de los procesos de evaluación (EPV) y de los expertos de área profesional y cualificación (EAPQ).

Fuente: (D.G.R. 841, 2006).

\section{- ENTREVISTAS}

Uno de los EPV entrevistados ha hablado sobre el requisito de la formación, diciendo que estaba satisfecho, que la formación había sido clara y se había hecho de forma presencial, durante al menos cuatro días completos, y con la posibilidad de consultar material on-line. Sin embargo, aclara 
La validación de competencias profesionales en España e Italia

que solo fue así el primer año que se realizó este tipo de formación. Posteriormente la formación de los profesionales del procedimiento pasó a ser on-line, debido a la crisis económica. El EPV opina que este tipo de formación debería tener una parte presencial. Otro de los EPV entrevistados también ha realizado una parte de la formación presencial y otra on-line. Los gestores/organizadores entrevistados han confirmado que la Regione es el órgano encargado de proporcionar la formación para los profesionales del sistema.

"[... la formación que be becho en presencia, asistiendo a un curso, se ba becho bien, era clara, precisa. Han sido minimo cuatro días completos y con la posibilidad de consultar el material on-line, el primer año se hizo presencial, después ha cambiado.

El sistema era nuevo respecto al modo de razonar del mundo de la formación habia novedades que habia que digerir. Al final nos han hecho un test.

Ahora se hace on-line. Desde mi punto de vista, un tipo de formación asi una parte se puede hacer on-line, pero otra parte presencial es necesaria, el contacto directo es fundamental. Creo que la crisis económica que vivimos ha impactado negativamente en el procedimiento.

De la formación se ocupa la Regione.

Sobre los criterios para ser EPV, RFC (se envía la candidatura a la Regione), yo a este último experto le llamo, inapropiadamente, el notario del procedimiento, porque es el que convoca a los expertos de APQ es la persona que al final verifica que toda la documentación sea correcta, tiene un rol muy importante" (G.G. EPV).

Entrevistador: “¿Ha sido formada por la Regione?”

"Sí, pero como dependiente de un ente de formación. Porque ahora la Regione, hasta donde yo sé, todavía es asi, hace la formación a los expertos de los procesos de evaluación que vienen propuestos por el ente de formación, tú tienes que pertenecer a un ente, el ente hace la petición a la Regione, y le dice: "Quisiera que mi trabajador hiciese la formación como EPV o cono RFC". Yo lo he hecho en 2006, al principio la formación para el EPV era una parte presencial y otra on-line (S.C. EPV).

Entrevistador: “¿Cómo ha entrado a formar parte del procedimiento?"

Bien...se podía solicitar entrar como EPV teniendo una experiencia laboral en el mundo de la formación profesional o al menos cinco años si tenías un título universitario coherente o si no, al menos de diez años (S.C. EPV). 
Entrevistador: "Por lo tanto, ¿han proporcionado ustedes la formación de las figuras de expertos que intervienen en el procedimiento?"

"Si, la Regione, ahora lo hace a distancia, porque no bay dinero, no hay recursos, asistencia técnica, en el momento que ha empezado a faltar el dinero bemos tenido que optar por otras modalidades. Les formamos desde el 2006, necesitamos muchos expertos para el procedimiento" (P.V y P.A. Gestores/organizadores).

[...] los contenidos que damos serán los mismos, quizás, ponemos en evidencia por ejemplo, para el EPV y hacemos emerger de la plataforma cuando interviene él, en que momentos será él quien tendrá que intervenir.

Pero los elementos del proceso los transmitimos a todos de la misma forma (V.F. gestor/organizador).

4.3.0.2. Indicador: Existe una formación continua para el desarrollo de competencias, dirigida a asesores.

\section{- ESPAÑA}

\section{- LEGISLACIÓN}

Legislación nacional: el artículo 22 e) del RD 1224/2009 asigna a las administraciones correspondientes la función de planificar y gestionar la formación inicial y continua de los asesores y evaluadores.

Legislación autonómica: la ORDEN/HAC 1605/2011, sobre la gestión del procedimiento de Castilla y León, permite en su artículo 14.23 el acuerdo de convocatorias para cursos de formación continua para asesores y evaluadores.

\section{- ENTREVISTAS}

No hay referencias al respecto.

\section{- ITALIA}

\section{- LEGISLACIÓN}

Legislación nacional y legislación regional: no se han encontrado referencias al respecto, ni en ámbito nacional, ni regional.

\section{- ENTREVISTAS}

Uno de los EPV entrevistados ha señalado que no se hace formación continua para los profesionales del procedimiento. Sin embargo, uno de los gestores entrevistados afirma que está previsto proporcionarla, a través de una plataforma informática. 
La validación de competencias profesionales en España e Italia

Entrevistador: “¿Hacen cursos de actualización?”

“No, cero, esto es una dificultad" (S.C. EPV).

Entrevistador: "Ellos realizan una formación, pero ¿tienen también que hacer cursos para ponerse al día?”

"Ahora que ha salido la nueva normativa, saldrá en la plataforma nueva, para todos los que están en la lista de expertos, cuáles son las novedades, asi se renueva la formación" (V.F. Gestor/organizador).

4.3.0.3. Indicador: Los asesores tienen acceso a material de apoyo para llevar a cabo el proceso de asesoramiento.

\section{- ESPAÑA}

\section{- LEGISLACIÓN}

Legislación nacional: el artículo 9, sobre instrumentos de apoyo del RD 1224/2009, decreta que el Ministerio de Educación y el Ministerio de Trabajo e Inmigración, en colaboración con las comunidades autónomas, elaborará instrumentos para optimizar el procedimiento y garantizar la homogeneidad y fiabilidad, facilitando un manual de procedimiento compuesto por una guía para las personas candidatas y guías para las figuras de asesor y de evaluador.

Legislación autonómica: no se han encontrado referencias.

\section{ENTREVISTAS}

Los dos asesores entrevistados han hecho mención a la guía del asesor y a una plataforma puesta en marcha por la Junta. Ambas contienen información y documentación relativa al proceso de asesoramiento.

"[...] se ha becho una aplicación bastante estricta, de las guías, la guía del asesor, se ha usado todo lo que está marcado, [...] también hay una plataforma...en la que también están los documentos para ayudarnos en el proceso, como el informe de asesoramiento o la ficha de sistematización" (C.T. As).

Entrevistador: "¿Qué funciones lleva a cabo en el procedimiento?”

"Las que vienen especificadas en la guía [...] Hay una plataforma que gestiona José Ignacio, que cada vez que se inicia un procedimiento se abre, se nos da la clave, se cuelga toda la información y documentación. Toda la documentación que necesitamos, correos electrónicos entre nosotros, foros de debate entre nosotros para dudas, en la primera convocatoria estuvo muy activa pero en esta segunda la verdad es que no la he visto muy activa" (J.L. As). 
Análisis y resultados

\section{- ITALIA}

\section{- LEGISLACIÓN}

Legislación nacional: no se han encontrado referencias al respecto.

Legislación regional: los anexos A, B, C y D de la DGR 530/2006 y el único anexo de la Deliberación de Junta Regional 739/2013 (DGR 739/2013), contienen directrices y material de apoyo para el procedimiento de formalización y certificación.

\section{- ENTREVISTAS}

Uno de los dirigentes/organizadores del procedimiento ha afirmado la existencia de una red de apoyo para los profesionales de este sistema, indicando que actualmente la están mejorando. Dos de los EPV entrevistados también han hecho referencia a la misma red, denominada SIFER (Sistema Informativo della Formazione in Emilia-Romagna).

"Por eso estamos modificando toda la plataforma de formación de estos roles y por ello estoy trabajando con la sociedad externa para definir los contenidos de la plataforma y los contenidos que damos serán los mismos, quizás, ponemos en evidencia por ejemplo, para el EPV y hacemos emerger de la plataforma cuando interviene él, en que momentos será él quien tendrá que intervenir" (V.F. Gestor/organizador).

"[...] el sistema informativo ayuda mucho porque las comunicaciones se hacen casi todas desde el software del SIFER que funciona muy bien [...], todos los instrumentos que tú tienes están o dentro de la Deliberación/normativa como el dossier, la evaluación de las evidencias.... todo lo que es obligatorio para el recorrido"(N.B. EPV).

"[...] en el SIFER bay instrumentos para la planificación, también bay instrumentos que dan indicaciones para proyectar las pruebas, [...]” (S.C. EPV).

"La Regione te da unos instrumentos que puedes tomar como referencia para preparar la prueba de examen, en la normativa (refiriéndose a la DGR 530/2006) [...]" (G.G. EPV).

4.3.0.4. Indicador: Los asesores conocen el sistema de validación y certificación de competencias y otros aspectos relacionados con el mismo

\section{- ESPAÑA}

\section{- LEGISLACIÓN}

Legislación nacional: el artículo 25 del RD 1224/2009 señala que los asesores deberán superar un curso de formación, sin especificar los puntos. 
La validación de competencias profesionales en España e Italia

El Anexo IV, del mismo real decreto, propone como contenidos en la formación de los asesores los siguientes puntos: 1. El Sistema Nacional de Cualificaciones y Formación Profesional; 2. El Catálogo Nacional de Cualificaciones Profesionales; 3. El Sistema Integrado de Información y Orientación Profesional; 4. Acreditación de las Cualificaciones Profesionales: Títulos de Formación Profesional, Certificados de Profesionalidad y Acreditación Parcial Acumulable; 5. Recursos formativos existentes.

Legislación autonómica: no se han encontrado referencias al respecto.

\section{ENTREVISTAS}

No existen referencias al respecto.

\section{- ITALIA}

\section{- LEGISLACIÓN}

Legislación nacional y legislación regional: no se han encontrado referencias al respecto, ni en ámbito nacional, ni regional.

- ENTREVISTAS

No existen referencias al respecto.

\subsection{Categaría: Comportamiento ético}

\subsubsection{Sin subcategoría}

4.4.0.1. Indicador: El asesor proporciona un trato igualitario a todos los candidatos.

\section{- ESPAÑA}

- LEGISLACIÓN

Legislación nacional: el artículo 6 del RD 1224/2009, en su apartado a), considera que uno de los principios del procedimiento es el respeto a los derechos individuales.

Legislación autonómica: no se han encontrado referencias al respecto.

\section{- ENTREVISTAS}

No existen referencias sobre este aspecto. 
Análisis y resultados

\section{- ITALIA}

\section{- LEGISLACIÓN}

Legislación nacional: el Decreto Legislativo 13/2013 hace referencia, en su artículo 7, apartado f), al principio de objetividad en las fases del procedimiento de validación y certificación de competencias profesionales.

Legislación regional: no se han encontrado referencias.

\section{ENTREVISTAS}

No existen referencias al respecto.

\subsection{Categoría: Privacidad y confidencialidad del proceso}

\subsubsection{Sin subcategoría.}

4.5.0.1. Indicador: El asesor comunica los resultados del asesoramiento únicamente al candidato.

\section{- ESPAÑA}

\section{- LEGISLACIÓN}

Legislación nacional: el artículo 6 a) del RD 1224/2009, sobre el principio del respeto de los derechos individuales, indica que los resultados de la evaluación serán confidenciales y que se respetará la protección de datos de carácter personal.

Legislación autonómica: no se han encontrado referencias.

\section{- ENTREVISTAS}

Los dos asesores entrevistados han comentado que existe un procedimiento en el que al candidato se le entrega un documento con el resultado del asesoramiento. Sin embargo, para facilitar las cosas a la persona, ellos han preferido decírselo verbalmente y manteniendo el carácter privado de la comunicación, ya que algunos tenían que desplazarse desde lejos.

"Yo... este personalmente, no se lo he entregado en mano, se to he dicho verbalmente, [...] Si es positivo, yo creo, que no sería necesario firmarlo porque conmigo no se acaba nada. Sigue con ellos (los evaluadores), tendrá que firmar cuando acabe con ellos. No creo que esto afecte mucho al procedimiento. Si el informe fuera negativo, tú le tienes que informar y decir que lo mejor es que se siga formando y no continuar en el procedimiento, en ese caso tiene que firmar que yo le he aconsejado que no siga" (C.T. AS). 
La validación de competencias profesionales en España e Italia

"Trato de que no vengan solo para firmar un triste papel, pudiendo usar el teléfono o cualquier otra vía, ya que además les estaban poniendo problemas en la empresa... lo comenté, me dijeron que no habia problema, normalmente, [...]"(J.L. As).

\section{- ITALIA}

\section{- LEGISLACIÓN}

Legislación nacional y legislación regional: no se han encontrado referencias legislativas, ni en ámbito nacional ni regional.

\section{ENTREVISTAS}

Uno de los EPV entrevistados ha afirmado que los resultados del asesoramiento no son públicos. Asimismo, ha comentado que se llama al candidato para informarle de ellos personalmente o telefónicamente, de forma individual. blico?”

Entrevistador: “¿Los resultados, como se comunican? [...] ¿Es pú-

"No, porque no es muy bonito, se llama a las personas y se dice personalmente o por teléfono. Pero es una cosa que se hace individualmente" (S.C. EPV).

\subsection{Categoría: Carácter personalizado del asesoramiento}

*Con el fin de facilitar el análisis legislativo y de entrevistas, se ha procedido a la agrupación de los indicadores de dos de las subcategorías de esta dimensión ("conocimiento del candidato" y "flexibilidad en el proceso de asesoramiento") pertenecientes a la categoría: "carácter personalizado del asesoramiento".

Los indicadores 4.6.1.1 y 4.6.1.2, listados a continuación con su subcategoría, se agrupan para analizar si el asesor conoce las motivaciones y objetivos del candidato para someterse al procedimiento de validación.

\subsubsection{Subcategoría: Conocimiento del candidato por parte del asesor}

4.6.1.1. Indicador: El asesor conoce las motivaciones del candidato para someterse al procedimiento de validación.

4.6.1.2. Indicador: El asesor conoce los objetivos del candidato para someterse al procedimiento de validación

Los indicadores 4.6.1.3, 4.6.1.4, 4.6.2.1 y 4.6.2.2, listados a continuación con sus subcategorías, se agrupan para analizar si el asesor conoce y 
tiene en cuenta las condiciones personales del candidato (nivel cultural, problemas laborales, personales, familiares, etc) y su disponibilidad (tiempo, horarios a disposición del procedimiento, colaboración con el mismo).

\subsubsection{Subcategoría: Conocimiento del candidato por parte del asesor}

4.6.1.3. Indicador: $\mathrm{El}$ asesor conoce las condiciones personales del candidato (nivel, cultural; problemas laborales, personales, familiares, etc.).

4.6.1.4. Indicador: $\mathrm{El}$ asesor conoce la disponibilidad del candidato para el procedimiento (tiempo, horarios a disposición del procedimiento, colaboración con el mismo, etc.).

\subsubsection{Subcategoría: Flexibilidad en el proceso de asesoramiento}

4.6.2.1. Indicador: $\mathrm{El}$ asesor tiene en cuenta las condiciones personales del candidato (nivel, cultural; problemas laborales, personales, familiares, etc.), a la hora de llevar a cabo el asesoramiento.

4.6.2.2. Indicador: $\mathrm{El}$ asesor tiene en cuenta la disponibilidad del candidato (tiempo, horarios a disposición del procedimiento, colaboración con el mismo, etc.), a la hora de llevar a cabo el asesoramiento.

A continuación analizamos estas dos agrupaciones.

Indicador 4.6.1.1.+4.6.1.2: El asesor conoce las motivaciones y objetivos del candidato para someterse al procedimiento de validación.

\section{- ESPAÑA}

\section{- LEGISLACIÓN}

Legislación nacional y legislación autonómica: no se han encontrado referencias al respecto, ni en la legislación nacional, ni en la autonómica.

\section{ENTREVISTAS}

Los dos asesores entrevistados han manifestado que la experiencia del asesoramiento ha sido muy buena, han empatizado mucho con los candidatos, quienes estaban muy dispuestos a hablar sobre su trabajo y situaciones personales. Los asesores han señalado que han tenido que disipar muchos miedos de los candidatos hacia el procedimiento y que la mayor motivación de estos para someterse al mismo, ha sido el miedo a quedarse sin trabajo.

"Muy bien, he aprendido mucho con las candidatas, sabia en qué consistia su trabajo, pero luego, bablando con ellas sobre cómo lo desempeñan, preguntando detalles...me ha sorprendido muy gratamente como resuelven problemas, como se implican, el valor de lo 
La validación de competencias profesionales en España e Italia

que desempeñan, para mí ha sido la mejor experiencia de todo el proceso, [...] ellas tienen muchas ganas de hablar y exponer su trabajo porque no tienen muchas ocasiones de que alguien se siente con ellas en una habitación para intentar comprender que saben hacer, que hacen. Podemos estar, a veces, un par de horas. Aunque no las conocemos de nada, no es que establezcas una relación personal porque no las conoces de nada y las ves dos veces, pero en la entrevista, mi experiencia, es que hemos empatizado mucho y hemos estado cómodas (eran casi todo mujeres) no ha habido situaciones violentas, han tenido muchas ganas de hablar, comentar, compartir y yo a la vez. de conocer más el trabajo en profundidad [...]”.

Entrevistador: "¿Los candidatos suelen comentar por qué se someten a este procedimiento?"

"Sí, porque saben que a lo mejor en un futuro se lo van a pedir en su empresa y lo quieren tener por el trabajo, no lo entienden muy bien, en la mayoria de las ocasiones, pero entienden que a lo mejor se lo van a pedir" (C.T. As).

"Sobre todo intentaba bacerles vencer el miedo que tenian a presentarse, porque te encontrabas con gente que llevaban muchisimos años trabajando de gerocultores en una residencia de ancianos, con una experiencia tremenda pero que malamente sabian hacerse un curriculum vitae, en todo momento, una actitud muy profesional y muy alentadora y muy positiva y tratando de ser muy constructivo pero sobre todo, en la primera convocatoria, tratando de disiparles los miedos [...]...habia gente con una experiencia abrumadora, y con un miedo increíble a quedarse sin trabajo" (J.L. As).

\section{- ITALIA}

\section{- LEGISLACIÓN}

Legislación nacional y legislación regional: no se han encontrado referencias al respecto, ni en la legislación nacional, ni en la regional.

\section{- ENTREVISTAS}

En este caso, un EPV ha declarado que ha mantenido una relación muy estrecha con los candidatos y que ha sido un punto de referencia para ellos, declarando que en algunos casos la entrevista ha llegado a durar dos horas, en las que el candidato le ha contado todos sus problemas laborales. También ha señalado, que su figura es la que más contacto tiene con el candidato. Sin embargo, otro EPV entrevistado ha declarado que apenas ha tenido relación con los candidatos, se limitaba a indicar al candidato las evidencias que debía aportar. Esto es así porque el EPV, en este caso, es externo al centro en el que se ha realizado el procedimiento. 
Análisis y resultados

"Yo be tenido una relación bastante estrecha, algunas veces tienes que hacer de psicólogo. Al final eres un punto de referencia dentro del ente, luego con algunos la relación es más cercana que con otros. Unos solo te hablan del procedimiento y otros te cuentan todo, yo he tenido casos en los que la entrevista ha durado dos horas porque me han contado todos los problemas en el trabajo, el estrés... todo, se crea una relación bumana muy estrecha. Además, el EPV es la única persona que ellos conocen de la comisión porque a los EAPQ los conocen en el examen, el EPV es el que les ha acompañado durante todo el recorrido y conoce todo de ellos" (N.B. EPV).

"En los entes en los que he trabajado ha estado gestionado más por los coordinadores y la secretaria, una vez que les decia todo lo que tenian que aportar ellos lo traían, no he tenido mucha relación. [...] Las personas de experiencia laboral han venido, algunas solas, otras apoyadas por entes de formación de su región, el EPV no les ve mucho" (S.C. EPV).

Indicador 4.6.1.3. + 4.6.1.4. + 4.6.2.1. + 4.6.2.2.: El asesor conoce y tiene en cuenta las condiciones personales del candidato (nivel cultural, problemas laborales, personales, familiares, etc) y su disponibilidad (tiempo, horarios a disposición del procedimiento, colaboración con el mismo), a la hora de llevar a cabo el asesoramiento.

\section{- ESPAÑA}

\section{- LEGISLACIÓN}

Legislación nacional y legislación autonómica: no se han encontrado referencias al respecto, ni en el plano nacional, ni en el autonómico.

\section{- ENTREVISTAS}

Los dos asesores entrevistados han demostrado, por sus comentarios, conocer y tener en cuenta las condiciones personales y situación de los candidatos. Por ejemplo, uno de ellos ha adaptado uno de los instrumentos, teniendo en cuenta el nivel cultural de los candidatos, y ambos han facilitado la comunicación de resultados telefónicamente, para evitar problemas (en su trabajo) a los candidatos.

"[...] malamente sabian rellenar el historial histórico formativo, sobre todo en unos formatos que nos dieron, que difícilmente se podía escribir en ellos con que una parte de esta gente que tenía dificultades para escribir... imaginate..., lo consulté a José Ignacio, que aquella gente que twiese conocimientos de informática, o pudieran hacerme llegar tanto el C. V. como el historial por correo electrónico, que me lo biciesen llegar así, [...] 
La validación de competencias profesionales en España e Italia

Era frecuente que las empresas pusiesen problemas al candidato, ellos tenian que firmar el día de la cita (que habian estado) y el trabajo que habian becho ese día, [...] aun asi habia algunos que habia que entregarles un justificante de asistencia.[...]Trato de que no vengan solo para firmar un triste papel, pudiendo usar el teléfono o cualquier otra vía, ya que además les estaban poniendo problemas en la empresa..." (J.L. As).

"Yo... este personalmente, no se lo he entregado en mano, se lo he dicho verbalmente, $[. .$.$] quedar otra vez. con la persona para esa firma..." (C.T. As).$

\section{- ITALIA}

\section{- LEGISLACIÓN}

Legislación nacional: no se han encontrado referencias al respecto.

Legislación regional: el punto 2.2 (p. 44) del Anexo A de la DGR $530 / 2006$, señala que en la recogida de evidencias deberá tenerse en cuenta la disponibilidad de la persona.

\section{- ENTREVISTAS}

No existen referencias al respecto

\subsubsection{Subcategoría: Lenguaje adaptado}

4.6.3.1. Indicador: $\mathrm{El}$ asesor adapta su lenguaje al candidato, utilizando con él un lenguaje que le resulte comprensible.

\section{- ESPAÑA}

\section{- LEGISLACIÓN}

Legislación nacional y legislación autonómica: no se han encontrado referencias al respecto, ni en ámbito nacional, ni autonómico.

\section{- ENTREVISTAS}

Un asesor entrevistado ha comentado que los asesores han tenido que "traducir" la terminología de los instrumentos de recogida de evidencias y de los cuestionarios de autoevaluación, porque el lenguaje utilizado no estaba claro para los candidatos.

"Si, claro, tenemos que traducir las cosas, las fichas de autoevaluación bien, pero la gente las responde una vez. que se lo has explicado, $O$ a veces [...] la persona no considera que sabe hacer bien algunas cosas, a veces se ponen un dos, puntaciones bajas, se lo explicas con un ejemplo y te dicen: ;Ah síl, sí que lo sé hacer, claro, pero es que... como lo pone así... luego por el contrario, hay gente que dice: ; Ah sí., yo eso lo sé hacer, yo sé hacer todo, y le preguntas que qué entiende por esto y te dice: Ahora mismo no sé, y se ha puesto 
un cuatro, se lo explicas y dice: ¡Ab!, eso no, nunca lo be becho, no ban entendido lo que le estaban preguntando. Asi que, tenemos los dos extremos" (C.T. As).

- ITALIA

- LEGISLACIÓN

Legislación nacional y legislación regional: No se han encontrado referencias al respecto, ni en el plano nacional, ni en el regional.

- ENTREVISTAS

No existen referencias respecto a este tema.

\subsection{Categoría: Recurso o reclamación del resultado del asesoramiento}

\subsubsection{Sin subcategoría}

4.7.0.1. Indicador: Existe un procedimiento de recurso o reclamación del resultado del asesoramiento, disponible para el candidato.

\section{- ESPAÑA}

\section{- LEGISLACIÓN}

Legislación nacional y legislación autonómica: no se han encontrado referencias al respecto, ni en el plano nacional, ni en el autonómico.

\section{- ENTREVISTAS}

Según ha informado una de las asesoras entrevistadas, no existe un procedimiento de reclamación sobre el asesoramiento. Ha añadido que en España, el informe que se presenta al finalizar el asesoramiento no es vinculante, por lo que aunque este resulte negativo, el candidato puede continuar en el procedimiento si así lo desea.

Entrevistador: ¿Existe un procedimiento de reclamación, del asesoramiento, para el candidato?

No es necesario, porque al no ser vinculante, puede continuar aunque el informe no sea positivo (C.T. As).

"A mi no se me ha dado el caso, pero el informe de asesoramiento... si yo emito un informe negativo, el candidato puede pasar a la fase de evaluación pero tiene que firmar un documento en el que se dice que a pesar de... quiere pasar. De todos modos, al final del informe de asesoramiento, ya poníamos que era una decisión expresada por la persona candidata" "[...] (J.L. As). 
La validación de competencias profesionales en España e Italia

\section{- ITALIA}

\section{- LEGISLACIÓN}

Legislación nacional y legislación regional: no se han encontrado referencias al respecto, ni a nivel nacional ni regional.

\section{- ENTREVISTAS}

Uno de los expertos de los procesos de evaluación entrevistados, ha afirmado que el candidato puede presentar una reclamación durante todo el procedimiento si considera que ha sido tratado injustamente.

Entrevistador: ¿Hay un momento establecido para reclamar o se puede hacer durante todo el procedimiento?

N.B: Durante todo el procedimiento. También en el examen si cree haber sido tratado injustamente lo dice y el RFC es el que responde por todos (N.B. EPV).

\section{5. Dimensión: Evaluación}

\subsection{Categoría: Información en el proceso de evaluación}

\subsubsection{Sin subcategoría}

5.1.0.1. Indicador: El evaluador proporciona al candidato información sobre el proceso de asesoramiento y de evaluación

\section{- ESPAÑA}

- LEGISLACIÓN

Legislación nacional: no se han encontrado referencias al respecto.

Legislación autonómica: el punto 2 del apartado decimotercero de la ORDEN/HAC 1536, sobre la convocatoria del procedimiento, establece que a cada candidato le será comunicada la comisión encargada de evaluarle, la fecha, la provincia y el lugar en el que tendrá lugar la fase de evaluación. No obstante, no especifica que el evaluador tenga que dar este tipo de información al candidato.

\section{- ENTREVISTAS}

Uno de los dos evaluadores entrevistados ha declarado haber dado información para tranquilizar al candidato sobre lo que es el proceso de evaluación. El otro evaluador entrevistado ha señalado haber explicado a los candidatos, antes de empezar con la evaluación, todo el proceso de evalua- 
ción y su finalidad, sobre todo para quitarles los miedos que tenían acerca del proceso.

"[...] les tranquilizamos porque vienen muy nerviosos y abora por tal como están las cosas, están sosteniendo muchos hogares como para perder el puesto de trabajo, yo entiendo este procedimiento para facilitar no para dificultar" (A.D. Ev).

"[...] explicarles, yo por lo menos, a todos los candidatos que han pasado por mi y yo asi se lo transmitía al resto de la comisión, explicar al candidato el procedimiento porqué este procedimiento... la finalidad que tenía el procedimiento...Ellos ya venían de la fase de asesoramiento pero la palabra evaluación y comisión de evaluación les suena a examen y se esperaban que cinco personas, de alguna manera, les examinasen, tenía mucho miedo y miedo a perder el trabajo [...] Habia que tranquilizarles y decirles: esto es asi”" (T.M. Ev).

\section{- ITALIA}

\section{- LEGISLACIÓN}

Legislación nacional: en el artículo 5 del Decreto legislativo 13/2013, se establece que el ente encargado de llevar a cabo los servicios de identificación, validación y certificación de competencias deberá garantizar ciertos aspectos, entre los que se encuentra la adopción de medidas personalizadas de información y orientación en favor de los destinatarios de dicho servicio. Sin embargo, aquí no se especifica que dicha información deba realizarse también en la fase de evaluación.

Legislación regional: no se han encontrado referencias al respecto.

\section{- ENTREVISTAS}

No existen referencias al respecto.

\subsection{Categoría: Adecuación en la investigación y análisis de evidencias con las normas estándares}

\subsubsection{Subcategoría: Existencia Estándares/referentes de evaluación}

5.2.1.1. Indicador: Las evaluaciones se basan en estándares/referentes de evaluación.

\section{- ESPAÑA}

- LEGISLACIÓN 
La validación de competencias profesionales en España e Italia

La legislación nacional: menciona, en el artículo 7 del RD1224/2009, que la evaluación y acreditación tendrán como referentes las unidades de competencias del Catálogo Nacional de Cualificaciones Profesionales, incluidas en títulos de formación profesional y/o en certificados de profesionalidad. En el punto 2 del mismo artículo se establece que para la evaluación de la competencia profesional de una determinada unidad de competencia, se tomarán como referentes, las realizaciones profesionales, los criterios de realización y el contexto profesional de cada una de ellas, siguiendo también los criterios establecidos en las guías de evidencia. El punto 3 establece que la unidad de competencia será la unidad mínima de acreditación.

Legislación autonómica: el artículo 2.4 b) de la ORDEN/HAC 1605/2011, sobre la gestión del procedimiento en Castilla y León, dispone que para la evaluación del procedimiento se valorarán objetivamente las realizaciones profesionales de los candidatos, referidas a las unidades de competencia en las que están inscritos, comprobando la competencia profesional que se requiere en las realizaciones profesionales, en los niveles establecidos en los criterios de realización y en una situación de trabajo real o simulada. También el apartado decimotercero de la ORDEN/HAC 1536, sobre la convocatoria del procedimiento en Castilla y León, repite lo establecido en el artículo 7.2 del RD 1224/2009 y en el artículo 2.4 de la ORDEN/HAC 1605/2011.

\section{- ENTREVISTAS}

Uno de los evaluadores entrevistados ha comentado que han contado con el apoyo del instrumento de la guía del evaluador y las guías de evidencias, dónde aparecen pruebas y simulaciones que pueden aplicar, las actividades profesionales primarias y las secundarias, para organizar las pruebas de evaluación.

"Tenemos las guias de evaluadores, las guias de evidencias, nos habla de la cualificación profesional, aqui nos vienen las pruebas, las simulaciones que podemos aplicar, las actividades profesionales primarias, las actividades profesionales secundarias" (A.D. $\mathrm{Ev})$.

\section{- ITALIA}

- LEGISLACIÓN 
Legislación nacional: el artículo 3 del Decreto Ministerial 174/2001 hace referencia a la identificación de estándares, con el fin de asegurar unas bases mínimas homogéneas, para el sistema de certificación en todo el territorio nacional. Establece que los estándares mínimos de competencia, contienen: la referencia a la figura o grupos de figuras profesionales y a las actividades o áreas que las caracterizan; a la descripción de las competencias profesionales y los criterios para la evaluación de la posesión de tales competencias; a la identificación del umbral mínimo referido a la posesión de tales competencias, necesario para la certificación.

El punto 5 del mismo artículo añade que los estándares mínimos nacionales están sujetos a actualizaciones, en particular, para responder a peticiones específicas de las regiones.

El artículo 7.3 del mismo decreto legislativo dispone que a la espera de las definiciones a nivel nacional de los estándares mínimos de competencias, las regiones puedan realizar autónomamente, con carácter provisional, la definición de los mismos y pueden también otorgar las certificaciones pertinentes.

También en el plano nacional, el artículo 3.2 del Decreto legislativo 13/2013, dispone que el ente con la competencia de identificar, validar o certificar competencias referidas a las cualificaciones, debe hacerlo siguiendo los repertorios codificados a nivel nacional o regional, según los criterios de referencia del Marco Europeo de las Cualificaciones. El apartado f) de este mismo artículo dice que la fiabilidad del sistema nacional de certificación de competencias se basa en un sistema compartido y progresivo de indicadores, instrumentos y estándares de calidad en todo en todo el territorio nacional.

Legislación regional: el punto 2.2 de la DGR 1434/05 de EmiliaRomagna establece que la formalización y certificación de las competencias se debe realizar en referencia a estándares profesionales. Las competencias objeto de este proceso son medidas y evaluadas según las presentes en el repertorio del Sistema regional de las cualificaciones. Asimismo, añade que los estándares profesionales se actualicen de forma periódica según los criterios y las modalidades previstas en el procedimiento del Sistema regional de las cualificaciones (SRQ). 
La validación de competencias profesionales en España e Italia

\section{- ENTREVISTAS}

Un EAPQ y dos EPV han hablado de la existencia de unos estándares para la evaluación de competencias de los candidatos. En concreto, se siguen unos indicadores para cada cualificación, siendo un material proporcionado por la Regione.

Según los gestores/organizadores del Sistema de Formalización y Certificación, sí existen estándares para la evaluación de competencias. Han señalado que las figuras profesionales han sido descritas con unidades de competencia y que cada unidad de competencia está expresada en capacidad de conocimientos con los indicadores que ayudan a su evaluación. Por cómo están descritas estas figuras, pueden ser resultado de un recorrido formativo o laboral. Los indicadores están descritos en la llamada scheda descrittiva della qualifica (ficha descriptiva de la cualificación), en un lenguaje sencillo de comprender, y detallan lo que se espera que sepa hacer la persona en correspondencia a ciertas capacidades -conocimientos. De esta forma las personas que realizan la evaluación pueden comprender bien qué tienen que saber hacer los candidatos para obtener la cualificación.

"Se evalúa durante la prueba si hace todo lo que tiene que bacer y que está establecido en los indicadores" (C.C. EAPQ).

"Tenemos unos cuadros tomando lo que proporciona ya la Regione en la normativa, (es muy parecido) con los indicadores para cada cualificación, eso nos ayuda" (G.G. EPV).

"Partimos de la cualificación de la región porque en la última página de cada cualificación está la modalidad para la evaluación... prueba en situación...con los indicadores, respecto a los indicadores se prepara la prueba, por ejemplo: ver si el candidato puede levantar al paciente...y le preparas la prueba para ello para ver si tienen la capacidad. Respecto al hecho que cada prueba tiene que cubrir todas las unidades de competencia, tengo unos cuadros... construidos por nosotros con lo que nos da la Regione, a estas alturas ya hemos hecho más exámenes para la misma cualificación pero de vez. en cuando se revisa" (S.C. EPV).

"...hoy en día de las figuras profesionales o cualificaciones del catálogo regional de cualificaciones, que han sido descritas con las unidades de competencia, cada unidad de competencia expresada en capacidad y conocimientos y con los indicadores que sirven para su evaluación. [...]...la lógica del procedimiento es que tiene que haber estándares de referencia claros (P.A. en P.V y P.A. Gestores/organizadores). 
"En la ficha descriptiva (scheda descrittiva) de la cualificación, además de las capacidades de conocimiento están definidos también los indicadores, ayudan mucho a comprender el significado del estándar, la ventaja del estándar es que si lo tienes como referencia puedes pensar en la certificación si no... varian las terminologías, la terminología, los objetos y no sabes muy bien que certificar. [...] Después, pensando en el operador de ventas... si lees la cualificación, tiene dentro, la capacidad de... no sé, relacionarse con el cliente, pueden parecer... o son competencias de relación, pero aqui asumen valor de competencia profesional, no es un... además, debes tener esa competencias para obtener esa cualificación" (V.F. Gestor/organizador).

5.2.1.2. Indicador: Los estándares están ligados/relacionados al/con el Marco Nacional de Cualificaciones.

\section{- ESPAÑA}

\section{- LEGISLACIÓN}

Legislación nacional: define la evaluación del procedimiento, en el artículo 5 del RD 1224/2009, como un proceso estructurado por el que se comprueba si la competencia profesional de una persona cumple o no con las realizaciones y criterios especificados en las unidades de competencia del Catálogo Nacional de Cualificaciones Profesionales. Aclaramos, que dicho catálogo define una parte del MECU (Marco Español de Cualificaciones), todavía en construcción.

Además, en el artículo 7 del mismo real decreto, se añade que la evaluación y acreditación tendrán como referentes las unidades de competencias del Catálogo Nacional de Cualificaciones Profesionales, incluidas en títulos de formación profesional $y / o$ en certificados de profesionalidad.

Legislación autonómica: no se han encontrado referencias sobre este aspecto.

\section{- ENTREVISTAS}

El gestor del procedimiento entrevistado ha declarado que se ha aplicado el Catálogo Nacional de Cualificaciones para la evaluación y acreditación de competencias profesionales.

Entrevistador: "¿Para las normas de certificación se ha utilizado el Marco Nacional de Cualificaciones?”

"Si, aqui se aplica el catálogo Nacional de Cualificaciones" (J.I.N. Gestor/organizador). 
La validación de competencias profesionales en España e Italia

\section{- ITALIA}

\section{- LEGISLACIÓN}

Legislación nacional: el artículo 4. 67 de la Ley 92/2012, sobre la reforma del mercado laboral, expone que todos los estándares de las cualificaciones y competencias certificables, según el sistema público de certificación, se recogen en repertorios codificados a nivel nacional o regional, reconocidos oficialmente y accesibles en un repertorio de títulos de educación y formación profesional.

También, en el artículo 3.2, el Decreto Legislativo 13/2013 indica que el ente competente puede identificar y validar o certificar competencias pertenecientes a repertorios codificados a nivel nacional o regional, siguiendo los criterios de referencia del Marco Europeo de las Cualificaciones.

Legislación regional: la DGR 1434/05 de Emilia-Romagna hace referencia en el punto 2.2.a este aspecto, señalando que la formalización y certificación de competencias se hace tomando como referencia los estándares profesionales, por lo que las competencias objeto de este proceso se miden y evalúan respecto a las presentes en el repertorio del Sistema Regional de las Cualificaciones.

\section{- ENTREVISTAS}

Uno de los gestores/organizadores ha afirmado que las UC de las cualificaciones, de las que salen los indicadores para la validación, están dentro del catálogo regional de cualificaciones.

"[...] En fin, esto es un poco la panorámica hoy en día de las figuras profesionales o cualificaciones, del catálogo regional del cualificaciones, que han sido descritas con las unidades de competencia, cada unidad de competencia expresada en capacidad y conocimientos y con los indicadores que sirven para su evaluación, [...]” (P.A. en P.V y P.A. Gestores/organizadores).

5.2.1.3. Indicador: Los resultados de aprendizaje que debe demostrar el candidato están debidamente indicados.

\section{- ESPAÑA}

\section{- LEGISLACIÓN}

Legislación nacional: el artículo 7.2. del RD 1224/2009 determina que en la evaluación de la competencia profesional de una unidad de competencia determinada, los referentes de evaluación que se tomen serán: las 
realizaciones profesionales, los criterios de realización y el contexto profesional incluidos en cada una de ellas, de acuerdo con los criterios que se fijen en las correspondientes guías de evidencias. A nivel de legislación autonómica no se han encontrado referencias directas al respecto, aunque hay que tener en cuenta que el procedimiento en la comunidad autónoma de Castilla y León, toma también como referencia este real decreto.

\section{- ENTREVISTAS}

Uno de los evaluadores ha comentado que las guías de evidencias contienen la información necesaria sobre las actividades profesionales (tomadas como resultados de aprendizaje) para la evaluación.

"Tenemos las guias de evaluadores, las guias de evidencias, nos habla de la cualificación profesional, aqui nos vienen las pruebas, las simulaciones que podemos aplicar, las actividades profesionales primarias, las actividades profesionales secundarias” (A.D. Ev).

\section{- ITALIA}

\section{- LEGISLACIÓN}

Legislación nacional y legislación regional: no se han encontrado referencias al respecto, ni nivel nacional ni regional.

\section{- ENTREVISTAS}

El experto de los procesos de evaluación entrevistado, ha declarado que los resultados de aprendizaje están definidos por la Regione en los indicadores que proporciona (por cada unidad de competencia, en términos de resultados esperados) para saber si el candidato sabe hacer todo lo que tiene que saber hacer para demostrar su competencia profesional.

"Se evalúa durante la prueba si hace todo lo que tiene que bacer y que está establecido en los indicadores" (C.C. EAPQ).

\subsubsection{Subcategoría: Adecuación de los instrumentos de evaluación}

*Con el fin de facilitar el análisis legislativo y de entrevistas, se ha procedido a la agrupación de dos indicadores de esta subcategoría ("adecuación de los instrumentos de evaluación"). En concreto los indicadores 5.2.2.1 y 5.2.2.2, listados a continuación, se agrupan para analizar si los instrumentos miden las competencias que pretenden medir y no otras y muestran las competencias que posee el candidato.

5.2.2.1. Indicador: Los instrumentos miden las competencias que pretenden medirse y no otras. 
La validación de competencias profesionales en España e Italia

5.2.2.2. Indicador: Los instrumentos permiten mostrar las competencias que posee el candidato.

A continuación analizamos esta agrupación.

Indicador: 5.2.2.1 y 5.2.2.2: los instrumentos miden las competencias que pretenden medir y no otras y muestran las competencias que posee el candidato.

\section{- ESPAÑA}

\section{- LEGISLACIÓN}

Legislación nacional: el RD 1224/2009, en el artículo 6 d) sobre el principio de validez del procedimiento de evaluación y acreditación de competencias, hace referencia a este aspecto: "Los métodos de evaluación empleados, y su posible concreción en pruebas, deberán medir adecuadamente la competencia profesional de las personas que se inscriban en el procedimiento".

Legislación autonómica: no se han encontrado referencias sobre este aspecto.

\section{- ENTREVISTAS}

Uno de los evaluadores entrevistados ha declarado que los instrumentos han sido adecuados en general, pero le hubiese gustado usar más alguno más completo. En particular, menciona la observación en el puesto de trabajo, ya que no se ha hecho en ningún caso y cree que hubiese sido un buen instrumento para determinar mejor las competencias de los candidatos.

"[...]... a mi en general me parecen bien, aunque me parece... si se pudiera... que lo suyo sería hacer la observación en el puesto de trabajo, aunque nosotros no lo bemos hecho, me parece lo más completo. No bemos hecho simulaciones, nadie, hemos utilizado la guia de evidencias, la situación profesional de evaluación y hay gente que ha hecho algún cuestionario o entrevista estructurada, pero en el puesto de trabajo no lo hemos becho.” (T.M. Ev).

\section{- ITALIA}

\section{- LEGISLACIÓN}

Legislación nacional y legislación regional: no se han encontrado referencias al respecto. 


\section{- ENTREVISTAS}

El EAPQ entrevistado ha comentado que las pruebas utilizadas para medir las competencias, unas veces eran acertadas y otras no, ya que muchas veces las pruebas son inventadas o adaptadas por las comisiones de evaluación.

"[...] la vida es más complicada de lo que se prevé, hay entes que proponen, respetando los cánones de la Deliberación, una prueba y aqui son el presidente y el EPQ los que deciden si cambiarlo o no, algunas veces, que yo be sido presidente, y hemos visto una buena preparación respecto a esto, otras veces hemos tenido que hacer entender... mejorar el concepto y hemos trabajado como locos, hemos estado horas para planificar, para ayudar al EPV o al coordinador a entrar mejor en este mecanismo".

5.2.2.3. Indicador: Los instrumentos permiten medir:; el "saber"; el "saber hacer" y el "saber estar".

\section{- ESPAÑA}

\section{- LEGISLACIÓN}

Legislación nacional: no se han encontrado referencias directas al respecto. Sin embargo, en el RD 1224/2009 se mencionan las guías de evidencia, en donde la competencia profesional se desglosa en tres dimensiones: el "saber", el "saber hacer" y el "saber estar", que los instrumentos deben medir.

Legislación autonómica: no se han encontrado referencias al respecto.

\section{- ENTREVISTAS}

El gestor/organizador entrevistado ha incidido en la importancia de que la evaluación de competencias profesionales debe tener en cuenta, no solo los conocimientos teóricos, sino también los relacionados con el "saber hacer" y "saber estar".

"[...] si a este procedimiento le aplicas un criterio de evaluación basado fundamentalmente en el saber, pues esta gente falla, pero si en lugar del saber tienes en cuenta también el saber y el saber estar, la cosa mejora, porque unos profesionales que llevan muchos años, claro que desconocen muchos conocimientos teóricos, seguramente, iy quién no?, pero no se le puede evaluar con criterios de evaluación puro y duro de contenido teórico y ese fue un riesgo que intentamos atajar desde aquí, porque veíamos que la cosa derivaba en ese sentido" (J.I.N. Gestor/organizador). 
La validación de competencias profesionales en España e Italia

\section{- ITALIA}

\section{- LEGISLACIÓN}

Legislación nacional y legislación regional: no se han encontrado referencias al respecto, ni en la legislación nacional, ni en la autonómica.

\section{- ENTREVISTAS}

Los Gestores/organizadores han explicado que el sistema de EmiliaRomagna es solo profesional, no hay competencias transversales, solo profesionales. Esto se hace para intentar ser lo más objetivos posibles, porque las competencias transversales suelen ser más objetivas, aunque algunas figuras tienen dentro algunas competencias transversales.

"[...] nuestro sistema es sólo profesional. Si has visto nuestras cualificaciones no hay competencias transversales (de tipo organizativo, motivacional, de relación) como metodología se ha escogido no meterlas, y de atenerse solo y exclusivamente a las competencias profesionales, primero porque son menos discriminativas, si tú haces un estándar y debes certificar una competencia de relación es bastante discriminante, si me caes bien diré que eres capaz de socializar y si no digo que no. Es uno de los muchos problemas que existen en los sistemas de evaluación de la prestación del personal. Yo en la evaluación de la prestación profesional de un trabajador tengo en cuenta los dos componentes: las competencias profesionales y competencias organizativas relacionales y siempre surgen ahi problemas porque valoras aspectos más subjetivos y la evaluación es más difícil. Ya un proceso de evaluación tiene siempre aspectos subjetivos, si además, tengo como objeto de validación sujetos más subjetivos ciao, bye. [...] el operador de ventas... si lees la cualificación, tiene dentro, la capacidad de... no sé, relacionarse con el cliente, pueden parecer... o son competencias de relación, pero aqui asumen valor de competencia profesional, no es un... además, debes tener esa competencias para obtener esa cualificación” (V.F. Gestor/organizador).

5.2.2.4. Indicador: El individuo conoce sus competencias a través del proceso de evaluación (autoevaluación).

\section{- ESPAÑA}

\section{- LEGISLACIÓN}

Legislación nacional y legislación autonómica: no se han encontrado referencias al respecto, ni en ámbito nacional, ni autonómico.

\section{- ENTREVISTAS}

No existen referencias al respecto. 
Análisis y resultados

\section{- ITALIA}

\section{- LEGISLACIÓN}

Legislación nacional y legislación regional: no se han encontrado referencias al respecto, ni en ámbito nacional, ni autonómico.

\section{- ENTREVISTAS}

No existen referencias que aludan a este aspecto.

5.2.2.5. Indicador: Al realizar una evaluación a dos o más candidatos de características similares los resultados son los mismos o muy similares

\section{- ESPAÑA}

\section{- LEGISLACIÓN}

Legislación nacional: este aspecto está reflejado en el principio de fiabilidad que se contempla en el artículo 6 b) del RD 1224/2009: "b) Fiabilidad: Se fundamentará en criterios, métodos, e instrumentos que aseguren resultados comparables en todas las personas participantes, independientemente del lugar o momento en el que se desarrolle la evaluación de la competencia profesional".

También el artículo 9 del mismo real decreto instaura la elaboración de instrumentos que optimicen el procedimiento y garanticen su homogeneidad y fiabilidad, por parte del Ministerio de Educación y del Ministerio de Trabajo e Inmigración, en colaboración con las comunidades autónomas. Como mínimo deberán facilitarse los siguientes instrumentos: un manual de procedimiento que comprenderá una guía de las personas candidatas y guías para las figuras del asesor y del evaluador; cuestionarios de autoevaluación de las unidades de competencia; guías de evidencias de las unidades de competencia como apoyo técnico al proceso de evaluación. Además, añade que las administraciones competentes de las comunidades autónomas podrán incluir otros instrumentos de apoyo para adaptar la metodología de evaluación a sus necesidades concretas.

Los instrumentos mencionados por el RD 1224/2009 fueron creados para apoyar la fiabilidad del procedimiento. En concreto, las guías de evidencia de las unidades de competencia, contienen pautas para evaluar con precisión las competencias contenidas en las mismas. Todas las unidades de competencia evaluables cuentan con explicaciones y pautas de evaluación.

Legislación autonómica: no se han encontrado referencias. 
La validación de competencias profesionales en España e Italia

\section{- ENTREVISTAS}

Los dos evaluadores entrevistados han asegurado haber utilizado la guía del evaluador y las guías de evidencia para realizar las evaluaciones. Estas guías son instrumentos que ayudan a garantizar la fiabilidad de la evaluación.

"Esto viene en la guia del evaluador [...] nosotros hemos hecho la evaluación siguiendo esa ficha que viene en la guia [...]” (T.M. Ev).

"Tenemos las guias de evaluadores, las guias de evidencias, nos habla de la cualificación profesional, aqui nos vienen las pruebas, las simulaciones que podemos aplicar, las actividades profesionales primarias, las actividades profesionales secundarias." (A.D. Ev).

\section{- ITALIA}

\section{- LEGISLACIÓN}

Legislación nacional: no se han encontrado referencias al respecto.

Legislación regional: el punto 3.2.1 sobre elementos para identificar el objeto de la prueba, de la DGR 530/2006, presenta algunos ejemplos de evaluación para: seguir los criterios de completitud y de medio grado de complejidad. Indica los materiales y el tiempo a disposición; así como el lenguaje a utilizar con los candidatos y las respuestas adecuadas que estos deberían dar en caso de realizar la entrevista evaluativa (ver subapartado 4.3.8.3).

\section{- ENTREVISTAS}

El EAPQ y un EPV entrevistados han señalado que las pruebas se parecían en la medida de lo posible a situaciones de trabajo y que el EPV se encarga de dar homogeneidad a la evaluación, haciendo que se sigan los estándares establecidos para la misma. También afirman que se pide lo mismo a todos en un sitio o en otro de la región.

"Una vez decididos y establecidos los tiempos, las pruebas deben parecerse lo más posible a una situación real de trabajo. Porque por ejemplo, no puedes dar... nunca, dos horas a uno para hacer una tortilla, si tarda dos horas no trabajará nunca.

Entonces preparamos todo bien, normalmente les hacemos hacer dos o tres platos y les hacemos trabajar en grupo porque ningún cocinero trabaja solo. También en espacios pequeños, porque normalmente las cocinas son pequeñas y para que la prueba sea válida tiene que simular bien una situación real de trabajo [...]” (C.C. EAPQ). 
Análisis y resultados

"El EPV siendo el experto del procedimiento tiene que controlary garantizar que si el examen lo hacemos aqui o en Piacenza, lo que se pedirá al candidato será lo mismo porque el objetivo es el mismo y por eso en el cuadro de evaluación se analiza indicador por indicador que se espera de cada uno y es el EPV el que tienen que mantener un poco el estándar. Esto lo hace el EPV y no los APQ. [...] Mientras haciamos nuestros exámenes al final del curso, más o menos, la dificultad... era igual para todos, si has hecho un curso para panaderos ya has hecho muchos... tienen un peso diferente, comparado con el sistema, lo que se hacia antes."(S.C. EPV).

\subsubsection{Subcategoría: Adecuación de la metodología}

5.2.3.1. Indicador: Está claro quién es el responsable de la elaboración de metodologías pertinentes para la validación.

\section{- ESPAÑA}

\section{- LEGISLACIÓN}

Legislación nacional: el artículo 28 del RD 1224/2009 especifica que son las comisiones de evaluación las encargadas de determinar los métodos y los instrumentos de evaluación de la competencia profesional.

Legislación autonómica: el apartado decimotercero de la ORDEN/HAC 1536/2011, sobre la convocatoria del procedimiento, refleja lo establecido en el artículo 28 del RD 1224/2009, es decir, que serán las comisiones de evaluación las encargadas de elaborar un plan de evaluación, que conste al menos, de las actividades y métodos de evaluación que van a aplicar. También deberá señalarse el lugar dónde se realizarán y deberán tener en cuenta las orientaciones de las guías de evidencia.

\section{- ENTREVISTAS}

Los dos evaluadores y el gestor/organizador del procedimiento entrevistados han asegurado que la elección de la metodología y de los instrumentos de evaluación ha sido competencia de las comisiones de evaluación. Estas lo han decidido en el plan de evaluación, aunque luego cada evaluador ha podido elegir qué instrumentos (de los propuestos) pasar a sus candidatos. Las comisiones han aconsejado a los evaluadores, pero se ha respetado la decisión de estos en cuanto a la evaluación, ya que nadie mejor que ellos conocía el caso del candidato para saber qué tipo de evaluación debían realizarle.

Entrevistado: “QQuién decide los métodos y cuándo?” 
La validación de competencias profesionales en España e Italia

"Se deciden en el plan de evaluación que tenemos que elaborar al principio de la comisión, abi ponemos cuales son los que vamos a pasar...la entrevista profesional, tal... abi lo decidimos y luego cada evaluador recomienda para sus casos, y lo respetamos porque si el evaluador lo ha estudiado lo respetamos, podemos sugerirle qué puede aplicar, pero respetamos lo que el evaluador que ha estudiado ese caso haya decidido.

Por lo tanto, lo decidimos al principio, los evaluadores lo hemos decidido al principio. Hay un listado de métodos que podemos aplicar" (A.D. Ev).

"La metodología y los métodos de evaluación los decidiamos nosotros mismos, cada evaluador para su candidato, normalmente, solo nos preguntábamos para las dudas, aunque ha babido algunos que bemos estado discutiendo, que pasarle y que no, pero al final han sido cuatro casos concretos" (T.M. Ev).

"Desde aquí, como órgano gestor no bemos intervenido mucho en la metodología porque las comisiones de evaluación son autónomas para utilizar los procedimientos que consideren oportunos" (J.I.N. Gestor/organizador).

\section{- ITALIA}

- LEGISLACIÓN

Legislación nacional y legislación regional: no se han encontrado referencias al respecto.

\section{- ENTREVISTAS}

Los expertos del procedimiento entrevistados, un EAPQ, un EPV y un gestor/organizador del procedimiento, han declarado que la comisión evaluadora es la encargada de planificar las pruebas que se pasarán a los candidatos. Estas pruebas la deciden conjuntamente los componentes de la comisión (un EVP y dos EAPQ). El gestor/organizador también ha señalado que deben seguir el formato que se da en la normativa (DGR 530/2006).

"Lo decidimos los que formamos parte de la comisión. Cuando se nombra la comisión, la sesión del primer día, llamada preliminar, se dedica a decidir, planificar la prueba de examen." (C.C. EAPQ).

Entrevistador: "Las decisiones las tomáis tres personas ¿no?”

"Si, un experto de procesos de evaluación, interno del ente y dos EAPQ externos. [...]Yo cuando voy a hacer las pruebas me llevo siempre la Deliberación" (C.C. EAPQ).

Entrevistador: “¿La prueba la decidís entre vosotros, la comisión? 
"Si, exacto." (S.C. EPV).

Entrevistador: ¿Quién decide los instrumentos y la metodología?

"En la Deliberación, en la normativa se decide cómo deben operar, se transmite la modalidad y luego cada uno tiene una libertad de tipo logístico y organizativo, pero los sujetos certificantes nos tienen que garantizar el flujo, el formato que les damos nosotros [...]” (V.F. Gestor/organizador).

5.2.3.2. Indicador: Se siguen unas pautas claras para la elaboración de la metodología a seguir en la evaluación

\section{- ESPAÑA}

\section{- LEGISLACIÓN}

Legislación nacional y legislación autonómica: no se han encontrado referencias al respecto.

\section{- ENTREVISTAS}

El gestor del procedimiento entrevistado ha manifestado que los coordinadores provinciales se han encargado de unificar los criterios de evaluación. Estos no tenían competencias para modificar la evaluación de los evaluadores, pero sí para advertir de que no se podía evaluar con criterios de evaluación utilizados en los ciclos formativos de grado medio y superior. Se intentó corregir de este modo, porque se vio que las evaluaciones se estaban planteando de forma equivocada, enfocadas más al saber teórico y no a la experiencia profesional.

"Los coordinadores provinciales actuaban como vía de transmisión de las informaciones que se daban desde aquí y unificaban los criterios de evaluación entre las comisiones de evaluación, no tenemos competencias para modificar o para establecer un cortafuegos, para decirles lo que no pueden hacer, pero si que advertimos a todos sobre que no se podía evaluar en este procedimiento con criterios de evaluación que estaban utilizando los profesores en sus ciclos formativos de grado medio y superior, si a este procedimiento le aplicas un criterio de evaluación basado fundamentalmente en el saber, pues esta gente falla, pero si en lugar del saber tienes en cuenta también el saber y el saber estar, la cosa mejora, [...] ese fue un riesgo que intentamos atajar desde aqui, porque veíamos que la cosa derivaba en ese sentido." (J.I.N. Gestor/organizador).

\section{- ITALIA}

- LEgISLACIÓN 
La validación de competencias profesionales en España e Italia

Legislación nacional y legislación regional: no se han encontrado referencias al respecto.

\section{- ENTREVISTAS}

El EAPQ y un experto de los procesos de evaluación entrevistados, han manifestado que la Regione da unas pautas para evaluar, pero son un tanto rígidas para la evaluación. Así, les ha resultado difícil completar el cuadro con los indicadores que proporciona la Regione (por cada unidad de competencia, proporciona las capacidades y conocimientos que el candidato debe poseer) porque es largo y complicado.

La prueba de examen algunas veces me parece muy muy abierta, por ejemplo: "crea un plato nuevo"...

Entrevistador: ¿Sois libres para elegir metodología, instrumentos...?

Somos relativamente libres, el sistema es muy estrecho, no somos libres, [...]

Los cuadros que nos ban dado para la evaluación que nos ha dado la Regione son restrictivos. Te obligan a razonar con algunos elementos que están muy definidos.

Los cuadros forman parte de la Deliberación, cuando hablamos de complejidad media, baja complejidad, alta, bay que seleccionar e inventarse pruebas que respondan al tipo de complejidad (C.C. EAPQ).

La Regione te da unos instrumentos que puedes tomar como referencia para preparar la prueba de examen (en la normativa). Pero está vacio tú lo tienes que rellenar, están los indicadores y las variables luego tú debes decidir, tu EPV con los dos APQ los niveles de dificultad.

La dificultad es completar este cuadro. Es largo y complicado, esto nos lo da la Regione, tú tienes que rellenarlo y la comisión es la que decide el nivel de complejidad, el objeto de la prueba, como lo evaluas, al final de la prueba tienes que alegar todo: el tiempo, como lo has hecho, los materiales que has dispuesto, los cuadros...la entrevista... (G.G. EPV).

5.2.3.3. Indicador: Existe variación en la elección del método, dependiendo de la persona y de las UC en las que esta se quiera acreditar.

\section{- ESPAÑA}

\section{- LEGISLACIÓN}

Legislación nacional: el artículo 16.4 del RD 1224/2009 expone que la selección de los métodos y las actividades de evaluación se hará teniendo en 
cuenta la naturaleza de la unidad de competencia, las características del candidato y los criterios para la evaluación recogidos en las guías de evidencia.

Legislación autonómica: el decimotercero apartado de la ORDEN/HAC 1536/2011 repite lo expuesto en el artículo 16 del RD $1224 / 2009$.

\section{- ENTREVISTAS}

Uno de los evaluadores entrevistados ha comentado que existe un listado con métodos a aplicar al candidato. Asimismo, ha indicado que los evaluadores deciden cuáles aplicar según la persona que tengan que evaluar.

"Hay un listado de métodos que podemos aplicar, el evaluador es el que ha becho el estudio y decide si le va a pasar, al candidato, la entrevista o esa candidata prefiere que vayamos a su centro de trabajo y que la evaluemos. Se podría estudiar e ir allí porque está contemplado, si es necesario y hay que hacerlo vamos. Lo que pasa es que mucha gente que nos está llegando... no es necesario evaluarla porque ya nos viene con much a experiencia y con formación y en ese caso no le llamamos para evaluarla" (A.D. Ev).

\section{- ITALIA}

\section{- LEGISLACIÓN}

Legislación nacional y legislación regional: no se han encontrado referencias al respecto.

\section{- ENTREVISTAS}

Uno de los EPV entrevistados, ha explicado que se planifica la prueba para que cubra todas las unidades de competencia que se quieren evaluar.

"Veamos, somos tres el EPV y los dos APQy se planifica la prueba, hoy, gracias a la experiencia, ya se sabe que la prueba tiene que ser práctica, debe cubrir todas la unidades de competencia, y luego en el SIFER hay instrumentos para la planificación, también hay instrumentos que dan indicaciones para proyectar las pruebas, yo... después de haber estado en más de 200 exámenes, yo ya sé cómo se hacen las pruebas, el cuadro de evaluación... mucho material ya lo tenemos." (S.C. EPV).

5.2.3.4. Indicador: Existe una combinación de métodos usados. 
La validación de competencias profesionales en España e Italia

\section{- ESPAÑA}

\section{- LEGISLACIÓN}

Legislación nacional: el artículo 16.3 del RD 1224/2009 expone que se utilizarán los medios que se consideren necesarios, para comprobar lo explicitado por el candidato en la documentación aportada. Añade que los métodos pueden ser entre otros: la observación en el puesto de trabajo, simulaciones, pruebas estandarizadas de competencia profesional o entrevista profesional.

Legislación autonómica: el apartado decimotercero, punto 8, de la ORDEN/HAC 1536/2011 sobre la convocatoria del procedimiento, establece que para obtener las evidencias se utilizarán los métodos que se consideren necesarios.

\section{- ENTREVISTAS}

Uno de los evaluadores entrevistados ha señalado que el evaluador decide los métodos, del listado, que aplicará al candidato para la evaluación.

"Hay un listado de métodos que podemos aplicar, el evaluador es el que ha hecho el estudio y decide si va a pasar, al candidato, la entrevista o esa candidata prefiere que vayamos a su centro de trabajo y que la evaluemos" (A.D. Ev).

\section{- ITALIA}

- LEGISLACIÓN

Legislación nacional y legislación regional: no existen referencias al respecto.

\section{- ENTREVISTAS}

Dos EPV y un RFC han manifestado que se construyen las pruebas consideradas necesarias, tomándolas de una lista que pone la Regione a disposición, o creándolas.

"[...] todos los instrumentos que tú tienes están dentro de la Deliberación/normativa como el dossier, la evaluación de las evidencias....todo lo que es obligatorio para el recorrido, más todo lo que el EPV y el APQ creen como prueba y ahi uno es libre, se puede crear un test, un cuadro...nosotros hemos creado un cuadro una vez, ella tenía un caso simulado y ella debía ir rellenando el cuadro con los procedimientos que tenía que hacer. La persona simulaba el trabajo" (N.B. EPV). 
"Veamos, somos tres el EPV y los dos EAPQy se planifica la prueba, hoy, gracias a la experiencia, ya se sabe que la prueba tiene que ser práctica, [...]... después de haber estado en más de 200 exámenes, yo ya sé cómo se hacen las pruebas, el cuadro de evaluación... mucho material ya lo tenemos" (S.C. EPV).

"La Regione pone a disposición, una serie de pruebas ya estandarizadas porque las ba cogido de todos los cursos y pruebas que ya se han becho" (M.M. RFC).

5.2.3.5. Indicador: Existen espacios físicos a disposición de la evaluación.

\section{- ESPAÑA}

\section{- LEGISLACIÓN}

Legislación nacional y legislación autonómica: no se han encontrado referencias al respecto.

\section{ENTREVISTAS}

No existen referencias al respecto.

\section{- ITALIA}

\section{- LEGISLACIÓN}

Legislación nacional y legislación regional: No se han encontrado referencias al respecto, ni a nivel nacional ni regional.

- ENTREVISTAS

Un EPV ha manifestado que disponen de espacios físicos para la evaluación de competencias (ver Anexo 38).

Entrevistador: "¿Tienen instalaciones para hacer las pruebas?"

"Si, cierto, luego te lo enseño" (G.G. EPV).

\subsection{Categoría: Preparación de los evaluadores}

\subsubsection{Sin subcategoría}

5.3.0.1. Indicador: Existen unos requisitos específicos para ser evaluador.

\section{- ESPAÑA}

\section{- LEGISLACIÓN}

Legislación nacional: la legislación nacional que hace referencia a este indicador es la misma que la referida al indicador 4.3.0.1 sobre la existencia de requisitos para ser asesor. 
La validación de competencias profesionales en España e Italia

El artículo 25 del RD 1224/2009 expone los requisitos que se requieren para ser asesor o evaluador en el procedimiento de evaluación y acreditación de competencias:

Artículo 25. Requisitos para ser asesor y/o evaluador.

1. Los requisitos que deberán concurrir en todo caso para obtener de las administraciones competentes la habilitación para ejercer las funciones de asesoramiento y/o evaluación son:

a) Tener una experiencia de al menos cuatro años en alguno de los siguientes colectivos:

- Profesorado perteneciente a los Cuerpos de Catedráticos, Profesores de enseñanza secundaria o Técnicos de formación profesional, con atribución docente en la Familia Profesional correspondiente.

- Formadores y formadoras especializados en las unidades de competencia que se especifiquen.

- Profesionales expertos en las unidades de competencia que se especifiquen.

b) Superar un curso de formación específica organizado o supervisado por las administraciones competentes. Los contenidos del curso tomarán como referente lo establecido en los Anexos IV y V.

2. Las personas designadas por las administraciones competentes para el asesoramiento no podrán participar como evaluadores en una misma convocatoria de evaluación y acreditación.

\section{Fuente: Art. 25; RD 1224/2009}

Legislación autonómica: la legislación autonómica que hace referencia a este indicador es la misma que la referida al indicador 4.3.0.1. sobre la existencia de requisitos para ser asesor.

El artículo 12 de la ORDEN/HAC 1605/2011, sobre la gestión del procedimiento, expone que la selección y formación del personal asesor y evaluador se hará siguiendo el RD 1224/2009. Así, la convocatoria tendrá carácter público y se publicará en el BOCYL, contemplando un perfil profesional determinado según las unidades de competencia que vayan a evaluarse y acreditarse. De igual modo, establecerá un número máximo de plazas para cada proceso, el plan de formación y la duración de los cursos formativos. Por último, se estipula que la convocatoria del proceso de selec- 
ción y formación de personal asesor y evaluador establecerá los criterios de selección y los baremos de puntuación de los méritos que se determinen.

El artículo 13 de la misma orden se ocupa de los requisitos y criterios de selección del personal asesor evaluador, repitiendo el artículo 25 del RD 1224/2009. Asimismo, añade que los criterios de selección de participantes en el proceso de selección, formación y habilitación de personal asesor y evaluador los determinará la convocatoria, incluyendo, al menos, la valoración de la experiencia como docente y/o profesional. El artículo 14.2 establece que la habilitación de asesores y evaluadores tendrá carácter nacional.

También la ORDEN/HAC 1536/2011, sobre la convocatoria del procedimiento en Castilla y León, en el apartado décimo, establece que la habilitación de asesores y/o evaluadores se realizará siguiendo los criterios de experiencia y formación específica, según lo establecido en el artículo 25 del RD 1224/2009.

\section{- ENTREVISTAS}

Uno de los evaluadores entrevistados ha hablado de su formación como evaluadora en la Uned, y de su papel de formadora (tutora) en el curso de formación de Observal (para formar a otros evaluadores y/o asesores). Ha señalado que el curso de la Uned fue más completo.

"El curso lo bice a través de la Uned, a nivel nacional, y tenía compañeros de toda España, no a nivel regional. La acreditación como evaluadora la tengo a través del Ministerio y a través de la Junta, e bice el curso de formación para ser tutora, lo bice en $V$ alladolid. [...] El curso de la Uned fue más completo, teniamos trabajo en equipo, se bacía todo a través de la plataforma, utilizamos mucho los foros, se trabajaba mucho más en grupo, que al fin y al cabo, en la comisión se trabaja en grupo."(T.M. Ev).

\section{- ITALIA}

\section{- LEGISLACIÓN}

Legislación nacional: no se han encontrado referencias al respecto.

Legislación regional: A través del punto 3.2 de la DGR 1434/05, se encomienda a la Regione la iniciativa de cualificación de las figuras clave del sistema de formalización y certificación, es decir, entre otros, la cualificación de expertos de los procesos de evaluación (EPV) y de los expertos de área profesional y cualificación (EAPQ). Concretamente, la DGR 841/2006 establece unos requisitos para optar a EAPQ: 
- Requisito de edad: pueden presentar la solicitud, para ser EAPQ, aquellas personas mayores de 26 años.

- Requisito de experiencia laboral: deben haber desarrollado su experiencia en contextos de trabajo, realizando una actividad determinada, ligada a la cualificación (por la que se pide la solicitud) o llevando a cabo funciones como responsables de actividades relacionadas con la cualificación (por la que se hace la solicitud). Esta experiencia laboral debe ser de al menos 5 años, aunque no seguidos, en los últimos 6 años, respecto al momento en el que se presenta la solicitud.

- Requisito de titulación y otros aspectos: se les puede pedir, aunque como requisito no vinculante, un título de estudio; la inscripción a un colegio profesional; docencia o haber tenido funciones de tutor en actividades formativas en empresas; competencia/experiencia en materia de validación; participación en cursos; publicaciones y conocimientos informáticos y lingüísticos.

Fuente: (D.G.R. 841, 2006)

\section{- ENTREVISTAS}

El EAPQ entrevistado ha declarado haber recibido formación, por parte de la Regione, para entrar como EAPQ en el procedimiento. Los gestores/organizadores entrevistados han afirmado que la Regione es el órgano encargado de proporcionar la formación para los profesionales del sistema. EAPQ).

"Soy uno de los primeros EAPQ formados por la Emilia-Romagna." (C.C.

"Si, la Regione, ahora lo bace a distancia, porque no hay dinero, no bay recursos, asistencia técnica, en el momento que ha empezado a faltar el dinero bemos tenido que optar por otras modalidades. Les formamos desde el 2006, necesitamos muchos expertos para el procedimiento" (P.A. en P.V y P.A. Gestores/organizadores).

"[...] los contenidos que damos son los mismos, quirás, ponemos en evidencia... por ejemplo, para el EPV y hacemos emerger de la plataforma cuando interviene él, en qué momentos será él quien tendrá que intervenir [...] Pero los elementos del proceso los transmitimos a todos de la misma forma" (V.F. gestor/organizador).

5.3.0.2. Indicador: Existe una formación continua para el desarrollo de competencias, dirigida a evaluadores 
Análisis y resultados

\section{- ESPAÑA}

\section{- LEGISLACIÓN}

Legislación nacional: la legislación nacional que hace referencia a este indicador es la misma que la referida al indicador 4.3.0.2 sobre la existencia de formación continua dirigida al asesor.

El artículo 22 e) del RD 1224/2009 asigna a las administraciones correspondientes la función de planificar y gestionar la formación inicial y continua de los asesores y evaluadores.

Legislación autonómica: la legislación autonómica que hace referencia a este indicador es la misma que la referida al indicador 4.3.0.2. sobre la existencia de formación continua dirigida al asesor.

El artículo 14.23 de la ORDEN/HAC 1605/2011, sobre la gestión del procedimiento de Castilla y León, permite el acuerdo de convocatorias para cursos de formación continua para asesores y evaluadores.

\section{- ENTREVISTAS}

Uno de los evaluadores entrevistados ha hablado del curso de formación y de su participación en la formación a otros profesionales del procedimiento. Sin embargo, ni este, ni el otro evaluador entrevistado han mencionado la formación continua.

"El curso lo bice a través de la Uned, a nivel nacional, y tenía compañeros de toda España, no a nivel regional. La acreditación como evaluadora la tengo a través del Ministerio y a través de la Junta, e bice el curso de formación para ser tutora, lo bice en Valladolid." (T.M. Ev).

\section{- ITALIA}

\section{- LEGISLACIÓN}

Legislación nacional y legislación regional: no se han encontrado referencias al respecto.

\section{- ENTREVISTAS}

Uno de los EPV entrevistados ha declarado que no se hace formación continua para los profesionales del procedimiento. Uno de los dirigentes entrevistados ha comentado que se indicarán los cambios de la nueva normativa, a modo de formación, en la nueva plataforma. 
La validación de competencias profesionales en España e Italia

"Yo he hecho la formación en el 2006, estamos en el 2013 con una normativa nueva, con un SIFER (Sistema Informativo della Formazione in Emilia-Romagna) nuevo." (S.C. EPV).

Entrevistador: "¿Hacen cursos de actualización?”

"No, cero, esto es una dificultad," (S.C. EPV).

Entrevistador: "Ellos realizan una formación, pero ¿tienen también que hacer cursos para ponerse al día?’"

"Ahora que ha salido la nueva normativa, saldrá en la plataforma nueva, para todos los que están en la lista de expertos, cuales son las novedades, asi se renueva la formación" (V.F. Gestor/organizador).

5.3.0.3. Indicador: Los evaluadores tienen acceso a material de apoyo para llevar a cabo el proceso de asesoramiento

\section{- ESPAÑA}

\section{- LEGISLACIÓN}

Legislación nacional: el artículo 9, sobre instrumentos de apoyo del RD 1224/2009, decreta que el Ministerio de Educación y el Ministerio de Trabajo e Inmigración, en colaboración con las comunidades autónomas, elaborará instrumentos para optimizar el procedimiento y garantizar la homogeneidad y fiabilidad. Asimismo, facilitará un manual de procedimiento compuesto por una guía para las personas candidatas y guías para las figuras de asesor y de evaluador.

Legislación autonómica: no se han encontrado referencias al respecto.

\section{- ENTREVISTAS}

Los dos evaluadores entrevistados han hecho mención a la guía del evaluador y a las guías de evidencia, que contienen información y documentación relativa al proceso de asesoramiento.

"Tenemos las guías de evaluadores, las guias de evidencias, nos habla de la cualificación profesional, aqui nos vienen las pruebas, las simulaciones que podemos aplicar, las actividades profesionales primarias, las actividades profesionales secundarias. Depende de las pruebas, si es una simulación, venimos a la guía y vemos la simulación y ya está." (A.D. Ev). 
"[...] hemos utilizado la guia de evidencias, la situación profesional de evaluación y hay gente que ba hecho algún cuestionario o entrevista estructurada, pero en el puesto de trabajo no lo hemos hecho. [...] Esto viene en la guía del evaluador [...]” (T.M. Ev).

\section{- ITALIA}

\section{- LEGISLACIÓN}

Legislación nacional: no se han encontrado referencias al respecto.

Legislación regional: los anexos A, B, C y D de la DGR 530/2006 y el único anexo de la DGR 739/2013, contienen directrices y material de apoyo para el procedimiento de formalización y certificación.

\section{- ENTREVISTAS}

Uno de los dirigentes del procedimiento ha afirmado que existe esta red de apoyo, con información sobre el procedimiento para los profesionales de este sistema, indicando además que en la actualidad la están mejorando

"Por eso estamos modificando toda la plataforma de formación de estos roles y por ello estoy trabajando con la sociedad externa para definir los contenidos de la plataforma y los contenidos que damos serán los mismos, quizás, ponemos en evidencia por ejemplo, para el EPV y hacemos emerger de la plataforma cuando interviene él, en que momentos será él quien tendrá que intervenir." (V.F. Gestor/dirigente). examen?

Entrevistador: ¿Existen instrumentos de apoyo para la prueba de

"Si, si, los tenemos. Pero... en fin... [...] el sistema es muy rígido, no somos libres [...] Los cuadros que nos han dado para la evaluación que nos ha dado la Regione, en la Deliberación 530 y abora la nueva 739, son restrictivos. Te obligan a razonar con algunos elementos que están muy definidos. Los cuadros forman parte de la Deliberación, cuando hablamos de complejidad media, baja complejidad, alta, hay que seleccionar e inventarse pruebas que respondan al tipo de complejidad." (C.C. EAPQ)

5.3.0.4. Indicador: el evaluador conoce el sistema de validación y certificación de competencias y otros aspectos relacionados con el mismo

\section{- ESPAÑa}

\section{- LEGISLACIÓN}

Legislación nacional y legislación autonómica: no se han encontrado referencias al respecto. 
La validación de competencias profesionales en España e Italia

- ENTREVISTAS

No existen referencias al respecto.

- ITALIA

- LEGISLACIÓN

Legislación nacional y legislación regional: no se han encontrado referencias al respecto.

- ENTREVISTAS

No existen referencias al respecto.

\subsection{Categoría: Comportamiento ético en el proceso de evaluación}

\subsubsection{Sin subcategoría}

5.4.0.1. Indicador: El evaluador proporciona un trato igualitario a todos los candidatos.

\section{- ESPAÑA}

- LEGISLACIÓN

Legislación nacional: el apartado a) del artículo 6 del RD 1224/2009 considera que uno de los principios del procedimiento es el del respeto de los derechos individuales. Asimismo, el apartado d) hace referencia al principio de objetividad en la evaluación y reconocimiento de competencias profesionales, asegurando el rigor técnico y la imparcialidad de las comisiones de evaluación.

Legislación autonómica: no se han encontrado referencias al respecto.

\section{- ENTREVISTAS}

No existen referencias al respecto.

\section{- ITALIA}

\section{- LEGISLACIÓN}

Legislación nacional: el Decreto Legislativo 13/2013 hace referencia, en su artículo 7 apartado f), al principio de objetividad en las fases del procedimiento de validación y certificación de competencias profesionales.

\section{- ENTREVISTAS}

No existen referencias al respecto. 
Análisis y resultados

\subsection{Categoría:Privacidad y confidencialidad del proceso de evalua- ción}

\subsubsection{Sin subcategoría}

5.5.0.1. Indicador: El evaluador comunica el resultado de la evaluación únicamente al candidato.

\section{- ESPAÑA}

\section{- LEGISLACIÓN}

Legislación nacional: el artículo 6 a) del RD 1224/2009 refleja el principio del respeto de los derechos individuales, indicando que los resultados de la evaluación serán confidenciales y que se respetará la protección de datos de carácter personal.

Legislación autonómica: la convocatoria del procedimiento en Castilla y León establece, con la ORDEN /HAC 1536/2011, en el apartado decimocuarto, que el responsable de informar por escrito al candidato sobre los resultados de su evaluación será el presidente de la comisión de evaluación.

\section{- ENTREVISTAS}

Los dos evaluadores entrevistados han señalado que la comunicación de los resultados de evaluación es confidencial y la han hecho ellos mismos a cada uno a sus candidatos. Primero han llamado por teléfono para concertar una cita con el candidato y después le han entregado el documento con el resultado de la evaluación.

"El evaluador le llama por teléfono y concreta una cita, cuando el candidato puede venir (porque respetamos mucho cuando pueden los candidatos), y se le entrega el documento de la comunicación. [...] el resultado es confidencial, y también lo dice la guía del evaluador, se lo damos solo a él, en mano, porque si ha pasado todo: fenomenal, pero si no ha pasado alguna se podría sentir mal y es un colectivo de personas que no se lo vamos a hacer pasar mal aquí." (A.D. Ev).

"Lo hacemos nosotros de forma personal. Yo por ejemplo, no vivo en Segovia, vivo a $70 \mathrm{~km}$ de Segovia, entonces, yo lo que he hecho es... a la gente de cerca, de mi rona, la evaluación se la bacía yo y la entrega de los resultados también, primero a mi me venía bien pero a ellos también, porque nos evitábamos un viaje a Segovia.” (T.M, Ev).

- ITALIA

- LEGISLACIÓN 
La validación de competencias profesionales en España e Italia

Legislación nacional y legislación regional: no se han encontrado referencias al respecto.

\section{ENTREVISTAS}

Los dos EPV y el EAPQ entrevistados han declarado que la comunicación del resultado de la evaluación se hace respetando la privacidad. El EPV puede encargarse de hacerlo o, en caso de haberse hecho el procedimiento en un centro de formación, es el centro de formación quien lo comunica, pero siempre se comunica directamente al candidato, en persona o por teléfono. men?"

Entrevistador: "¿Quién hace la comunicación de resultados del exa-

"Lo hace internamente cada ente. En las cualificaciones viejas, las que han sido sustituidas, las que han sido hechas por la ley marco del 78, era el presidente, el que al final, anunciaba el resultado. Al candidato le puedes anticipar que ha becho una buena prueba a otros se les dice que con este sistema no se queda sin nada, tendrá una o dos unidades de competencia y la próxima vez completará la cualificación" (C.C. EAPQ).

"En general, nosotros les convocamos dos o tres días después del examen, para decirselo directamente o se lo decimos telefónicamente, luego después de un mes o cuando sea, organizamos una pequeña ceremonia para dar la cualificación. Nosotros lo hacemos asi, pero bay modalidades diversas en todos los entes." (G.G. EPV)

"Cuando estamos en un centro de formación lo hace el centro de formación."

Entrevistador: “¿Es público?”

"No, porque no es muy bonito, se llama a las personas y se dice personalmente o por teléfono. Pero es una cosa que se hace individualmente." (S.C. EPV).

\subsection{Categoría: Carácter personalizado de la evaluación}

*Con el fin de facilitar el análisis legislativo y de entrevistas, se ha procedido a la agrupación de los indicadores de dos de las subcategorías ("conocimiento del candidato por parte del evaluador" y "flexibilidad en el proceso de evaluación"), pertenecientes a la categoría: "carácter personalizado de la evaluación". 
Los indicadores 5.6.1.1 y 5.6.1.2, listados a continuación con su categoría, se agrupan para analizar si el evaluador conoce las motivaciones y objetivos del candidato para someterse al procedimiento de validación

\subsubsection{Subcategoría: Conocimiento del candidato por parte del evaluador}

5.6.1.1. Indicador: El evaluador conoce las motivaciones del candidato para someterse al procedimiento de validación.

5.6.1.2. Indicador: El evaluador conoce los objetivos del candidato para someterse al procedimiento de validación

Los indicadores 5.6.1.3, 5.6.1.4, 5.6.2.1 y 5.6.2.2 listados a continuación con sus subcategorías, se agrupan para analizar si el evaluador conoce y tiene en cuenta las condiciones personales del candidato (nivel cultural, problemas laborales, personales, familiares, etc) y su disponibilidad (tiempo, horarios a disposición del procedimiento, colaboración con el mismo), a la hora de llevar a cabo la evaluación.

\subsubsection{Subcategoría: Conocimiento del candidato por parte del evaluador}

5.6.1.3. Indicador: El evaluador conoce las condiciones personales del candidato (nivel, cultural; problemas laborales, personales, familiares, etc.).

5.6.1.4. Indicador: El evaluador conoce la disponibilidad del candidato para el procedimiento (tiempo, horarios a disposición del procedimiento, colaboración con el mismo, etc.).

5.6.2. Subcategoría: Flexibilidad en el proceso de evaluación

5.6.2.1. Indicador: $\mathrm{El}$ evaluador tiene en cuenta las condiciones personales del candidato (nivel, cultural; problemas laborales, personales, familiares, etc.), a la hora de llevar a cabo la evaluación.

5.6.2.2. Indicador: $\mathrm{El}$ evaluador tiene en cuenta la disponibilidad del candidato (tiempo, horarios a disposición del procedimiento, colaboración con el mismo, etc.), a la hora de llevar a cabo la evaluación.

A continuación analizamos estas dos agrupaciones.

Indicador 5.6.1.1 + 5.6.1.2: El evaluador conoce las motivaciones y objetivos del candidato para someterse al procedimiento de validación. 
La validación de competencias profesionales en España e Italia

\section{- ESPAÑA}

\section{- LEGISLACIÓN}

Legislación nacional y legislación autonómica: no se han encontrado referencias al respecto.

\section{- ENTREVISTAS}

Los dos evaluadores entrevistados han afirmado que los candidatos se someten al procedimiento, sobre todo, por miedo a perder el puesto de trabajo si no están cualificados. Estos creen que con un título estarán más seguros a nivel laboral. Uno de los evaluadores también ha comentado que algunas personas han utilizado el procedimiento para otros fines, por ejemplo, para lograr otro título y ganar puntos para el concurso de traslados, Sin embargo, ha señalado que la mayoría lo ha hecho por miedo a ser despedido.

"En general el candidato busca la acreditación porque se está jugando el puesto. [...] En infantil muchas personas nunca babian trabajado en centros de educación infantil, habian trabajado en otras cosas, lo querian para luego obtener el título de Técnico Superior en Educación Infantil, es más, ha habido maestros que lo querian para obtener el título de Técnico Superior en Educación Infantil y tener puntuación para los concursos de traslados. Aqui la gente se las ingenia como quiere y puede, normalmente los casos que estamos viendo lo hacen para no perder el puesto de trabajo, hay gente que viene y dice que abora les están pidiendo esto pero que no estaría de más que se sacasen el titulo y nos preguntan qué tienen que hacer, pero es por miedo, para no perder el puesto de trabajo y creen que si tienen el titulo tienen más seguridad. Igual que en infantil bubo gente que lo aprovechó para otras finalidades, otros objetivos... por lo que veo (aquí) en general, no fue por eso, [...]” (A. D. Ev).

"Lo primero ha sido quitar miedos que tenian, la gente estaba muy asustada, sobre que era esto del procedimiento. Si iban a perder su puesto de trabajo... Lo primero tranquilizarles,"

Entrevistador: “¿Lo están utilizando más bien como un medio para no quedarse sin trabajo...?”

"Si, exactamente, hombre, las cosas no están bien, yo entiendo que el nivel cultural que tienen muchas la verdad es que deja mucho que desear y esto para ellas era u obtener esto o irse a la calle." (T.M. Ev).

\section{- ITALIA}

- LEGISLACIÓN 
Legislación nacional y legislación regional: no se han encontrado referencias al respecto.

\section{- ENTREVISTAS}

El EAPQ entrevistado ha comentado que los EAPQ no tienen mucha relación con el candidato, únicamente tienen contacto con él en el momento del examen.

Entrevistador: "¿Cuándo tenéis relación con el candidato?”

"Sólo en el momento de la evaluación. Ni antes ni después." (C.C. EAPQ).

Indicador 5.6.1.3. + 5.6.1.4. + 5.6.2.1. + 5.6.2.2: El evaluador conoce y tiene en cuenta las condiciones personales del candidato (nivel cultural, problemas laborales, personales, familiares, etc) y su disponibilidad (tiempo, horarios a disposición del procedimiento, colaboración con el mismo).

\section{- ESPAÑA}

\section{- LEGISLACIÓN}

Legislación nacional y legislación autonómica: no se han encontrado referencias al respecto.

\section{- ENTREVISTAS}

Uno de los evaluadores entrevistados ha comentado que ha tenido bastante relación con los candidatos y que ha podido conocer sus experiencias personales y profesionales. Ha afirmado que los evaluadores han tenido en cuenta y respetado mucho las condiciones personales y la disponibilidad del candidato, por ejemplo a la hora de entregarle resultados o de acordar con él una fecha para la evaluación, siempre para facilitarles el procedimiento.

"[...]...es el propio candidato que tiene miedo, te dice que no quiere perder horas de trabajo y que prefiere que le evalúes tal día, mientras no podemos adaptar nos adaptamos, no hay problema." (A.D. Ev).

[...] La mayoria te vienen contando unas experiencias personales tremendas, han accedido a atención a domicilio derivadas de una situación grave, que tienen estudios primarios... y... ¿les voy a exigir yo conocimiento de graduado de secundaria? No puedo, si ella después quiere proseguir para sacar el título de atención sociosanitaria ya le harán las pruebas competentes, pero ahora mismo no es el certificado de profesionalidad y nos tenemos que adaptar eso está claro y lo tenemos muy claro todos los miembros de la comisión y 
La validación de competencias profesionales en España e Italia

las otras comisiones. De hecho, desde la Consejería se nos hizo bincapié en ese aspecto, si no se perdería el espiritu del procedimiento, por ejemplo, el año pasado que estuve en infantil, que es un nivel 3, abi yo ya exigía más, porque es un nivel 3 [...] El evaluador le llama por teléfono y concreta una cita, cuando el candidato puede venir, porque respetamos mucho cuando pueden los candidatos, y se le entrega el documento de la comunicación. [...] Al candidato se le llama por teléfono cuando se ha decidido que se le va a evaluar y le dicen las pruebas que se le van a pasar y se le pregunta si está de acuerdo. Normalmente tendría que venir aqui a firmar ese acuerdo, pero muchas veces, viven en pueblos, asi que se le comunica por teléfono y luego cuando vienen firman el documento para ratificar el acuerdo que se ha hecho por teléfono. Creemos que es mejor asi, más práctico. No voy a hacer venir a una persona solo para firmar eso."

\section{- ITALIA}

\section{- LEGISLACIÓN}

Legislación nacional y legislación regional: no se han encontrado referencias al respecto.

\section{- ENTREVISTAS}

El EAPQ entrevistado ha declarado que la información que tiene sobre las características personales del candidato se la proporciona otro profesional. Es decir, tiene un conocimiento indirecto del candidato pero, a pesar de ello, ha afirmado que de algún modo se tienen en cuenta su situación a la hora de evaluar.

Entrevistador: ¿Qué relación establecéis con el candidato? ¿Llegáis a conocerles bien?

C.C: En la sede de examen, en la preliminar, el EPV o coordinador describe la característica de cada uno, el recorrido que ba becho y la situación.

Entrevistador: ¿Se tienen en cuenta las particularidades de cada uno?

C.C: Si, en alguna parte del cerebro se tienen en cuenta, porque si nos limitásemos simplemente a ver solo lo que hace, inmediatamente podríamos decir: "no eres competente" (C.C. E $A P Q$ ).

\subsubsection{Subcategoría: Lenguaje adaptado del evaluador}

5.6.3.1. Indicador: El evaluador adapta su lenguaje al candidato, utilizando con él un lenguaje que le resulte comprensible. 
Análisis y resultados

\section{- ESPAÑA}

\section{- LEGISLACIÓN}

Legislación nacional y legislación autonómica: no se han encontrado referencias al respecto.

\section{- ENTREVISTAS}

Los dos evaluadores entrevistados han asegurado haber utilizado un lenguaje llano para hacerse entender mejor por el candidato.

"[...] Nos tenemos que adaptar al nivel cultural de las personas. El lenguaje se ha intentado adaptar al candidato, ya que muchos no tienen un nivel cultural muy alto $y$ el procedimiento no sirve de nada si el candidato no lo comprende." (A.D. Ev).

"A mi me gusta utilizar un lenguaje muy llano para que la gente se entere, pero yo creo que al final, al terminar el procedimiento siguen sin saber muy bien... lo único que tienen claro es que no se van a quedar sin trabajo" (T.M. Ev).

\section{- ITALIA}

\section{- LEGISLACIÓN}

Legislación nacional y legislación regional: no se han encontrado referencias al respecto.

\section{- ENTREVISTAS}

No existen referencias al respecto.

\subsection{Categoría: Carácter formativo de la evaluación}

\subsubsection{Sin subcategoría}

5.7.0.1. Indicador: El procedimiento ayuda a la reinserción, de los candidatos que lo requieran, en el mundo formativo, tras el procedimiento

\section{- ESPAÑA}

\section{- LEGISLACIÓN}

Legislación nacional: el artículo 3 sobre los fines del procedimiento, del RD 1224/2009, expresa la intención de facilitar la adquisición de una acreditación parcial acumulable, con objeto de que el candidato complete la formación conducente a la obtención del correspondiente título de formación profesional o certificado de profesionalidad. Asimismo, el artículo 20 de este real decreto habla del plan de formación que se realiza al finalizar todo el procedimiento de evaluación y acreditación. A través de las adminis- 
La validación de competencias profesionales en España e Italia

traciones competentes se entregará a los participantes un escrito con, según proceda: “a) Posibilidades de formación, con las orientaciones pertinentes, para que puedan acreditar en convocatorias posteriores las unidades de competencia para las que habían solicitado acreditación. b) Posibilidades de formación, con las orientaciones pertinentes, para completar la formación conducente a la obtención de un título de formación profesional o certificado de profesionalidad relacionado con las mismas" (R.D. 1224, 2009, n. art. 20).

Legislación autonómica: el apartado decimocuarto de la ORDEN/HAC 1536/2011, sobre la convocatoria del procedimiento, establece que la comisión de evaluación deberá elaborar un informe con una propuesta formativa por cada candidato.

\section{- ENTREVISTAS}

El gestor/organizador entrevistado ha manifestado que el procedimiento cumple con lo establecido por la administración central y abre una puerta a los candidatos a la formación complementaria:

"La Consejería de Educación cumple una tarea social muy importante en este sentido, cumple con lo establecido con la administración central que nos impone unas cosas y abre una puerta importante para nosotros o dos: abre una puerta para que la gente que necesite formación complementaria, nosotros los vamos a derivar a los centros de adultos, o integrados o institutos para que continúen su formación con lo cual es una vía de recuperación de gente para la formación. Eso es importante para nosotros" (J.I.N. Gestor/organizador).

Uno de los asesores y un evaluador, sin embargo, piensan que el porcentaje de personas que continua o se inserta en el mundo formativo es pequeño y que todavía no ha "calado" el espíritu formativo (en el sentido de que los candidatos se sigan formando) del procedimiento. El otro evaluador entrevistado piensa que el procedimiento es deficitario en este aspecto y podría hacerse más.

Entrevistador: ¿Cree que este procedimiento impulsa/anima al candidato a seguir formándose o a introducirse de nuevo o por primera vez en el mundo del sistema formativo formal?

"En un porcentaje muy pequeño creo que sí. Que yo me acuerde, de mi experiencia... tres casos, entre los veinticinco de la otra vezy los catorce de ésta, tres casos. Una mujer me dijo que sí, que vamos, que si la podíamos facilitar direcciones de dónde se pudiese formar, entonces yo le dije, eso los evaluadores te lo comentarán” (J.L. As). 
"[...] ese otro espiritu del procedimiento de que la gente se siga formando, yo creo que eso no ha calado todavía. Ellos ya lo tienen y yo no sé si con esto la gente se va a seguir formando." (T.M. Ev).

"Si, en principio nos dicen, que solo en caso de no haber superado las unidades de competencia, orientadles para la formación. Nos han colgado en la plataforma los pasos que pueden seguir, pero normalmente se lo decimos a todos, yo abi veo una carencia, tendrian que decir que es obligatorio, porque se encuentran que diciendo: "¿Ahora qué?", tendríamos que dar un documento obligatorio que diga, ahora ve al Ecyly tienes que presentar un documento con esto, esto y esto." (A.D. Ev).

ITALIA

\section{LEGISLACIÓN}

Legislación nacional y legislación regional: no se han encontrado referencias al respecto.

\section{ENTREVISTAS}

No existen referencias sobre este aspecto.

\subsection{Categoría: Recurso o reclamación del resultado de la evaluación}

\subsubsection{Sin subcategoría}

5.8.0.1. Indicador: Existe un procedimiento de recurso o reclamación del resultado de la evaluación, disponible para el candidato.

\section{- ESPAÑA}

\section{- LEGISLACIÓN}

Legislación nacional: el artículo 6 apartado d) del RD 1224/2009 habla del principio de objetividad, indicando que durante la evaluación y reconocimiento de competencias se asegurará el rigor técnico, la imparcialidad de las comisiones de evaluación y se permitirá la revisión del resultado de las evaluaciones. También el artículo 16.7, del mismo real decreto, especifica que el evaluado tendrá derecho a reclamar ante la Comisión de Evaluación y, en su caso, a presentar un recurso de alzada ante la administración competente.

Legislación autonómica: no se hace referencia específica al procedimiento de reclamación, pero sí se refiere a este el apartado decimocuarto de la ORDEN/HAC 1536/2011 de la convocatoria sobre el procedimiento, señalando que al finalizar la etapa de evaluación se recogerán los resultados 
La validación de competencias profesionales en España e Italia

y todos los registros producidos durante todo el procedimiento para poder hacer frente a posibles reclamaciones por parte de los candidatos.

\section{- ENTREVISTAS}

Los dos evaluadores entrevistados han comentado que este procedimiento efectivamente existe y se ha llevado a cabo. El candidato ha tenido a su disposición un documento para la reclamación, disponiendo de tres días hábiles desde el momento de recepción del resultado de la evaluación para entregarlo a la Comisión de Evaluación. Esta comisión lo estudia y en caso de no cambiar el resultado, el candidato dispone del recurso de alzada. Según ha señalado un evaluador, se dio un caso de recurso de alzada que no prosperó para el candidato ya que, según el evaluador, no estaba claro lo que reclamaba, lo cual les hizo pensar que no había entendido bien el procedimiento.

"En el caso de que una persona quiera hacer una revisión de su caso, puede presentar este documento, si te fijas en la documentación, tiene tres dias hábiles a partir del momento en el momento en el que se le entrega el resultado, porque cuando te lo entrega lo tiene que firmar y tú te quedas con una copia. Luego lo estudiamos en comisión y llegamos a una resolución, si llegamos a lo mismo y no está de acuerdo, tiene el recurso de alzada, nosotros el año pasado no nos encontramos con ningún caso." (A.D. Ev).

"Si, el año pasado bubo un caso, incluso bubo un recurso de alzada a la Consejería, con un caso de infantil, creo que se ha quedado abi y no ba ido a más. [...]"

Entrevistador: "¿Qué pasa cuando se hace una reclamación?”

"En este caso se recogió toda la documentación otra vezy se vio a ver si se habia cometido algún error. Como se vio que el método que se le había aplicado era el correcto y que realmente no tenía demostradas las evidencias, se le contestó en los mismos términos en los que se le había pasado la evaluación. Con este caso, en concreto no nos terminamos de entrar lo que realmente reclamaba, porque fue un escrito redactado de una forma tan particular... hablando de los asesores, como que no estaban preparados... realmente no conocía el procedimiento la persona que hizo la reclamación, no hablaba de los evaluadores, solo se refería a los asesores. Al final la reclamación fue una explicación de cómo se habia llevado a cabo la evaluación." (T.M. Ev).

\section{- ITALIA}

- LEGISLACIÓN

Legislación nacional y legislación regional: no se han encontrado referencias al respecto. 
Análisis y resultados

\section{- ENTREVISTAS}

El EAPQ y uno de los EPV entrevistados han afirmado la posibilidad de que el candidato reclame los resultados o el trato recibido en cualquier momento del procedimiento.

Entrevistador: “¿Existe un procedimiento de reclamación?

"Si, existe, pero a mi nunca me ha sucedido que reclamasen, si hay transparencia es difícil que reclamen, porque si tú le dices al candidato donde se ha equivocado y por qué, es difícil que reclame.” (C.C. EAPQ).

Entrevistador: "¿Hay un momento establecido para reclamar o se puede hacer durante todo el procedimiento?"

"Durante todo el procedimiento. También en el examen si cree haber sido tratado injustamente lo dice y el RFC es el que responde por todos. " (N.B. EPV).

\section{Dimensión: Certificación y registro}

\subsection{Categoría: Validez de la certificación}

\subsubsection{Sin subcategoría}

6.1.0.1. Indicador: Existe un órgano habilitado para emitir y registrar certificaciones tras la validación.

\section{- ESPAÑA}

\section{- LEGISLACIÓN}

Legislación nacional: el artículo 17 del RD 1224/2009 establece la entrega, a los candidatos que superen el proceso de evaluación, de una acreditación de las unidades de competencia en las que hayan demostrado su competencia profesional. En el caso de que el candidato haya logrado, a través del procedimiento de evaluación y acreditación de competencias, los requisitos para la obtención de un certificado de profesionalidad o un título de formación profesional, se le indicarán los trámites para su obtención, es decir, para la certificación.

El artículo 18 de este real decreto, sobre la expedición y registro de las acreditaciones, establece que la administración correspondiente (la Administración General del Estado, el Ministerio de Trabajo e Inmigración ${ }^{104}$ y el

\footnotetext{
104 Actualmente denominado Ministerio de Empleo y Seguridad Social.
} 
Ministerio de Educación ${ }^{105}$, según el artículo 21.1 del RD 1224), deberá expedir la acreditación de unidades de competencia y transferirá los resultados a un registro estatal. El responsable de dicho fichero será el Servicio Público de Empleo Estatal.

Legislación autonómica: el artículo 2 de la ORDEN/HAC 1605/2011, siguiendo el RD 1224/2009, establece la expedición de una acreditación por cada una de las unidades de competencia en las que el candidato haya demostrado su capacitación personal. El artículo también indica que se informará al candidato, en su caso, sobre los trámites necesarios para lograr un certificado de profesionalidad o título de formación profesional, estando este certificado y este título reconocidos a nivel nacional. Por último, se añade que los datos se incorporarán al registro que se creerá para este efecto en la Comunidad de Castilla y León.

El artículo 17, de la misma orden, habla de la expedición de las acreditaciones. El artículo indica que una vez terminada la fase de evaluación, la comisión de evaluación remitirá las actas, el expediente y la propuesta de certificación para acreditación de competencias al Servicio Público de Empleo de Castilla y León. La acreditación de las UC demostradas será expedida por la Consejería con competencias en materia de empleo. Asimismo, el órgano encargado de la gestión transferirá los resultados al registro estatal del Servicio Público de Empleo Estatal, con copia a la Consejería de Educación.

\section{- ENTREVISTAS}

El gestor/organizador entrevistado ha declarado que las Consejerías de Educación y Trabajo han emitido un documento de acreditación de competencias que han enviado al centro de Servicio Público de Empleo de Castilla y León, para poder seguir con el procedimiento legal. Sin embargo, ha comentado que hubo ciertos problemas con el registro de Castilla y León, que hoy, según ha afirmado, están solucionados.

Entrevistador: "¿Qué institución se encarga de la acreditación oficial de las competencias?"

"Nosotros, la Consejería de Educación...emitimos un documento de acreditación de competencias que va firmado por nuestro director general y el gerente del Servicio Público de Empleo de Castilla y León. También ese documento de acreditación es conjunto,

105 Actualmente denominado Ministerio de Educación, Cultura y Deporte. 
para las dos administraciones. Pero lo bicimos nosotros, lo enviamos a los centros para que lo recibiesen los interesados y luego comunicamos al Servicio de Empleo de Castilla y León (el ECYL), para que ellos hiciesen el registro. Pero en ese momento ellos no tenian creado el registro de certificados, y quedó en el limbo, en espera, hace unos días, supe que eso se solucionó. Ahora pueden registrar las acreditaciones." (J.I.N. Gestor/organizador).

\section{- ITALIA}

\section{- LEGISLACIÓN}

Legislación nacional: no se han encontrado referencias al respecto.

Legislación regional: la DGR 530 establece, en el Anexo A, en el punto 1.2.4 (p. 27), que el sistema Regional de Formalización y Certificación de competencias de Emilia-Romagna otorgará según corresponda: un certificado de cualificación profesional, un certificado de competencias o una ficha de capacidades y conocimientos.

Además, en el punto 2.1 de la DGR 1434/2005, se señala que la Regione asegura el registro, archivo y reproducción de información relevante con el fin de dar validez oficial a las fichas (schede) y certificados.

\section{- ENTREVISTAS}

Uno de los gestores/organizadores del procedimiento ha afirmado que la entidad encargada de otorgar la certificación, es la Regione. Regione?”

Entrevistador: " ¿El organismo/entidad que otorga la titulación es la

"Si, es la Regione la que da la cualificación." (P.A. en P.V y P.A. Gestores/organizadores).

6.1.0.2. Indicador: la certificación tiene una validez nacional/regional

\section{- ESPAÑA}

\section{- LEGISLACIÓN}

Legislación nacional: el artículo 1 del RD 1224/2009 determina la validez en todo el territorio español del procedimiento de evaluación y acreditación de competencias profesionales.

Legislación autónoma: la ORDEN/HAC 1536/2011, sobre la convocatoria del procedimiento, establece, en el decimoquinto apartado, que las acreditaciones concedidas tendrán carácter oficial con validez en todo el 
La validación de competencias profesionales en España e Italia

territorio nacional, y añade que tendrán los efectos académicos y profesionales previstos en la legislación vigente en lo referente a exenciones, correspondencias y convalidaciones.

\section{- ENTREVISTAS}

No existen referencias al respecto.

\section{- ITALIA}

\section{- LEGISLACIÓN}

Legislación nacional: el artículo 5 del Decreto Legislativo 13/2013 expone que la "attestazione" es la fase dirigida a la entrega de documentos de validación o certificados, estandarizados, que documentan las competencias identificadas y validadas o certificadas relacionadas con una o más cualificaciones.

Legislación regional: el punto 2.1 de la DGR 1434/2005 establece la entrega de documentos formales al candidato que haya superado el proceso de formalizzazione e certificazione de competencias. Se debe entregar, por tanto, un documento válido para asegurar la certificación de las competencias que posee el candidato. El punto 3.1 de la misma deliberación habla también de la entrega de documentos en los que están formalizadas y certificadas las competencias poseídas, se entrega a la persona una cualificación o un certificado o una ficha (scheda) de formalización de conocimientos y capacidades (Qualifica o un Certificato di UC o una Scheda di formalizzazione di conoscenze e capacita).

Además este punto señala que la Regione asegura el registro, archivo y reproducción de información relevante con el fin de dar validez oficial a las fichas (schede) y certificados.

\section{- ENTREVISTAS}

Dos de los gestores entrevistados han declarado que la Regione entrega al candidato la cualificación, en el caso de logar demostrarla. Como se ha comentado con anterioridad, la cualificación que se entrega pertenece al Catálogo Regional de Cualificaciones, por lo que tiene una validez regional y en la mayoría de los casos tiene su equivalente nacional.

Entrevistador: "¿El organismo/entidad que otorga la titulación es la Regione?

Si, es la Regione la que da la cualificación" (P.A. en P.V y P.A. Gestores/organizadores). 
6.1.0.3. Indicador: Los certificados de validación deben tener el mismo estatus que los certificados formales o diplomas.

\section{- ESPAÑa}

\section{- LEGISLACIÓN}

Legislación nacional: el RD 1224/2009 establece, en su artículo 19 sobre el efecto de las acreditaciones obtenidas, que:

- la Administración educativa reconocerá las unidades de competencia acreditadas y realizará la convalidación correspondiente en los módulos profesionales que corresponda;

- la Administración laboral reconocerá las unidades de competencia acreditadas que tendrán efecto de exención de los módulos formativos ligados a las UC de los certificados de profesionalidad.

Este tema es abordado también por el artículo 17 del RD 1224/2009, el cual establece que la administración competente indicará al candidato, cunado cumpla los requisitos, los trámites necesarios para obtener un certificado de profesionalidad o un título de formación profesional. En el punto 3 del mismo artículo se añade que el candidato debe cumplir los requisitos de acceso previos a las enseñanzas correspondientes, como lo prevé la Ley Orgánica 2/2006 de Educación.

Legislación autonómica: la ORDEN HAC 1605/2011, sobre la gestión del procedimiento en Castilla y León, repite el artículo 17 del RD 1224/2009 que acabamos de mencionar.

También la ORDEN/HAC 1536/2011 sobre la convocatoria del procedimiento establece en punto 2 del apartado decimoquinto que, siguiendo con el artículo 19 del RD 1224/2009, la acreditación de las UC tendrá efectos de acreditación parcial acumulable y de convalidación en los certificados de profesionalidad y en los títulos de formación profesional.

\section{- ENTREVISTAS}

No existen referencias al respecto.

\section{- ITALIA}

- LEGISLACIÓN

Legislación nacional: el artículo 5 del Decreto Legislativo 13/2013 expone que la "attestazione" es la fase dirigida a la entrega de documentos de 
La validación de competencias profesionales en España e Italia

validación o certificados estandarizados, que documentan las competencias identificadas y validadas o certificadas relacionadas con una o más cualificaciones.

Legislación regional: el punto 2.1 de la DGR 1434/2005 establece la entrega de documentos formales al candidato que haya superado el proceso de formalización y certificación de competencias. Por tanto, se debe entregar un documento válido para asegurar la certificación de las competencias que posee el candidato. El punto 3.1 de la misma deliberación habla también de la entrega de documentos en los que están formalizadas y certificadas las competencias poseídas, se entrega a la persona una cualificación o un certificado de competencias o una ficha (scheda) de formalización de conocimientos y capacidades (Qualifica o un Certificato di UC o una Scheda di formalizzazione di conoscenze e capacita). Las cualificaciones pertenecen al Catálogo Regional de Cualificaciones y la mayoría tienen correspondencia con cualificaciones nacionales.

\section{- ENTREVISTAS}

No existen referencias al respecto.

\section{Dimensión: Examen/control del procedimiento}

\subsection{Categoría: Control interno del procedimiento}

\subsubsection{Sin subcategoría}

*Con el fin de facilitar el análisis legislativo y de entrevistas, se ha procedido a la agrupación de dos de los indicadores pertenecientes a la categoría de "control interno del procedimiento".

Los indicadores 7.1.0.1 y 7.1.0.2, listados a continuación, se agrupan para analizar si se hace un control/evaluación interno/a del procedimiento por parte de un organismo interno.

7.1.0.1. Indicador: Se hace un examen/control interno del procedimiento.

7.1.0.2. Indicador: Existe un organismo interno (cuerpo competente), a la organización del procedimiento, encargado del examen/control del mismo.

A continuación analizamos esta agrupación.

Indicador. 7.1.0.1. y 7.1.0.2: Se hace un control/evaluación interno/a del procedimiento, por parte de un organismo interno (cuerpo competente) encargado del procedimiento. 
Análisis y resultados

\section{- ESPAÑA}

\section{- LEGISLACIÓN}

Legislación nacional: el artículo 6 del RD 1224/2009 menciona que el procedimiento se regirá por el principio de calidad, indicando que un mecanismo de verificación interno y externo asegurará la calidad, el rigor técnico y la validez del mismo.

Asimismo, en la disposición adicional primera sobre la gestión de la calidad se indica que el proceso de evaluación y acreditación de la competencia será verificado a través de evaluaciones internas y auditorías externas que contribuyan a una mejora continua.

Legislación autonómica: La ORDEN HAC 1605/2011 sobre la gestión del procedimiento en Castilla y León establece en su artículo 20.1 y 20.4, sobre seguimiento y evaluación del procedimiento, los siguientes aspectos respectivamente:

- el órgano o la unidad responsable de la gestión del procedimiento facilitará a la Administración General del Estado los datos necesarios para el seguimiento y evaluación del procedimiento, en los términos establecidos en los artículos 10.6 y 17 de la Ley Orgánica 5/2002, de 19 de junio, de las Cualificaciones y de la Formación Profesional;

- el Consejo de la Formación Profesional de Castilla y León y el Consejo General de Empleo participarán en el seguimiento y evaluación del procedimiento a través de sus órganos colegiados o de las Comisiones de Trabajo que establezca al efecto.

\section{- ENTREVISTAS}

Los profesionales entrevistados han declarado que no existe un proceso de control o examen del procedimiento como tal, pero el dirigente/organizador del procedimiento ha hablado de una cierta coordinación que ha realizado con las comisiones de evaluación. Sin embargo, no tenía poder ni para corregir, ni para rectificar. Uno de los asesores ha hablado de las recomendaciones a tener en cuenta en el procedimiento que ha hecho el dirigente del procedimiento. Asimismo, uno de los evaluadores entrevistados también ha comentado que ha realizado, por iniciativa propia, una revisión entre los evaluadores de sus trabajos, para intentar evitar erro- 
La validación de competencias profesionales en España e Italia

res. Por último, el otro evaluador entrevistado ha negado la existencia de un control del procedimiento.

Entrevistador: "¿Existe algún tipo de control interno o externo del procedimiento?"

"Yo bablaba con los presidentes de las comisiones de evaluación, por correo electrónico. Me comunicaba con ellos para saber cómo iba cada comisión, y de alguna forma entre los comentarios, yo veia que el riesgo era que utilizaran criterios de evaluación... erróneos para este procedimiento. También es verdad que algunos interpretaron como que la Consejería de Educación les forzaba a que acreditasen a todo el mundo, alguno entendió que mi mensaje era que nosotros queríamos que acreditásemos a todo el mundo, y no es verdad, no era la intención,... pero si que era la intención el situar la forma de evaluar en el objetivo de este procedimiento. Bueno fueron situaciones que abora en la segunda fase no se están dando, porque la gente entendió que esto no es hacer el examen de prueba libre de un certificado de profesionalidad o prueba libre de un título"

Entrevistador: "Entonces podemos decir que sí que ha habido un control interno por parte vuestra, suya..."

"Si, pero no corregíamos, no rectificábamos a nadie, a ninguna comisión, [...]". (J.I.N. Gestor/organizador).

"No se ha dado el caso, es verdad que al final, José Ignacio nos remite a una serie de propuestas de mejora que podemos hacer, [...]” (J.L. As).

Entrevistador: “¿Existe algún tipo de control interno o externo del procedimiento de validación?”

"No, pero a mi se me ha ocurrido, ha sido cosa mia, que entre nosotros leamos los informes finales de los compañeros, por si vemos si hay algún error, si nos hemos confundido... La organización me gusta mucho, no es que vayas a controlar a tu compañero, es solo una manera de controlar que las cosas vayan bien, para comprobar que no hay errores, como medida de seguridad, pero esto no está estipulado, sólo lo hacemos asi nosotros por iniciativa mía como presidenta de la comisión de evaluación"(A.D. Ev).

Entrevistador: ¿Existe algún tipo de control interno y/o externo?

"No ba babido, no." (TM. Ev).

\section{- ITALIA}

- LEGISLACIÓN

Legislación nacional: no se han encontrado referencias al respecto. 
Legislación regional: la DGR 1434/2005, en su punto 3.1, indica que la aplicación del SRFC será experimental en su primera fase. Para poder realizar un seguimiento/evaluación del funcionamiento del sistema y posteriormente realizar las modificaciones e integraciones necesarias que garanticen una mejora del procedimiento. El punto 3.2 de la misma deliberación encarga a la Regione la tarea del seguimiento/evaluación de la validación. La deliberación especifica que deberá efectuar estadísticas sobre el funcionamiento del sistema, someter a exámenes y controles, de forma periódica, a los procedimientos de validación puestos en marcha.

\section{- ENTREVISTAS}

Uno de los gestores/organizadores, ha indicado que él es el encargado de hacer el control del procedimiento, apuntando también, que se han incorporados cambios de mejora a través de la DGR 739/2013, tras hacer estos controles sobre el procedimiento. El responsable de la formalización y certificación entrevistado (RFC) ha afirmado que la Regione realiza controles del procedimiento, pudiendo hacerlos sin previo aviso y en todo momento.

"Yo aqui dentro soy la referente del Sistema di formalizzazione e certificazione y tengo la responsabilidad del control, superviso el sistema, en base a la normativa que lo ba definido, y de cómo afecta operativamente en los sujetos que tienen que ponerlo en marcha en el territorio.

Por lo tanto, la referente sobre el funcionamiento de la máquina y sobre los documentos relacionados con ella soy yo [...] Normalmente controlo el procedimiento en las sedes de los entes cuando ellos llevan a cabo el sistema, y por lo tanto, controlar el procedimiento, los documentos, ver si los han hecho correctamente, ver si han seguido correctamente los procedimientos [...] La nueva normativa contiene aspectos que nosotros hemos visto en la práctica que no funcionaban muy bien [...] Esta nueva normativa es el fruto de lo que hemos comprendido que funciona y no funciona de la primera versión de la formalización y certificación de competencias. [...]Y Yo he ido a ver por lo menos 200 comisiones (in situ) y luego hago un informe a mi dirigente diciendo lo que creo que funciona y lo que no, luego bacemos una confrontación con los expertos...con un grupo de expertos... les preguntamos la impresión que han tenido, con algunos entes, con expertos de área profesional y cualificación, les preguntamos que creen que va y que no va” (V.F. Gestor/organizador).

"Si, absolutamente,... la Regione puede venir a ver las pruebas, a controlar la parte del servicio antes del examen, cuando se controlan las evidencias, cuando se hace el dossier, pueden venir a ver las entrevistas con las personas, estamos supeditados a todos los 
La validación de competencias profesionales en España e Italia

controles que nos quieran hacery cada vez que activamos un curso SRFC lo tenemos que inserir dentro del SIFER.” (M.M. RFC).

7.1.0.3. Indicador: Existe un plan de seguimiento interno (control del procedimiento)

\section{LEGISLACIÓN}

Legislación nacional: no se han encontrado referencias al respecto.

Legislación autonómica, cabe decir que la ORDEN HAC 1605/20011 hace referencia a este aspecto en su artículo $5 \mathrm{k}$ ), sobre competencias de la comisión directora y en su artículo 20, sobre seguimiento y evaluación del procedimiento. Estos artículos indican que la comisión directora deberá elaborar el plan de seguimiento y evaluación, que formará parte del plan de calidad, con el objetivo de comprobar la calidad, la eficacia y el impacto del procedimiento de evaluación y acreditación en Castilla y León.

- ENTREVISTAS

No existen referencias al respecto.

\section{- ITALIA}

- LEGISLACIÓN

Legislación nacional y legislación regional: No se han encontrado alusiones al respecto.

\section{- ENTREVISTAS}

No existen referencias al respecto.

\subsection{Categoría: Control externo del procedimiento}

\subsubsection{Sin subcategoría}

*Con el fin de facilitar el análisis legislativo y de entrevistas, se ha procedido a la agrupación de dos de los indicadores pertenecientes a la categoría de "control interno del procedimiento".

Los indicadores 7.2.0.1 y 7.2.0.2, listados a continuación, se agrupan para analizar si se hace un control/evaluación interno/a del procedimiento por parte de un organismo interno.

7.2.0.1. Indicador: Se hace un examen/control externo del procedimiento. 
7.2.0.2. Indicador: Existe un organismo externo (cuerpo competente), a la organización del procedimiento, encargado del examen/control del mismo.

A continuación analizamos esta agrupación.

Indicador. 7.2.0.1. y 7.2.0.2: Se hace un control/evaluación externo/a del procedimiento, por parte de un organismo externo (cuerpo competente) encargado del procedimiento.

\section{- ESPAÑA}

Legislación nacional: coincide con la legislación nacional que hace referencia al control/evaluación interno del procedimiento por parte de un organismo interno de los indicadores 7.1.0.1 y 7.1.0.2.

El artículo 6 del RD 1224/2009 menciona que el procedimiento se regirá por el principio de calidad, indicando que un mecanismo de verificación interno y externo asegurará la calidad, el rigor técnico y la validez del mismo.

Asimismo, en la disposición adicional primera sobre la gestión de la calidad, punto 3 , se indica que el proceso de evaluación y acreditación de la competencia será verificado a través de evaluaciones internas y auditorías externas que contribuyan a una mejora continua.

Legislación autonómica: coincide con la legislación autonómica que hace referencia al control/evaluación interno del procedimiento por parte de un organismo interno de los indicadores 7.1.0.1 y 7.1.0.2.

La ORDEN HAC 1605/2011 sobre la gestión del procedimiento en Castilla y León, establece en su artículo 20.1 y 20.4, sobre seguimiento y evaluación del procedimiento, los siguientes aspectos respectivamente:

- el órgano o la unidad responsable de la gestión del procedimiento facilitará a la Administración General del Estado los datos necesarios para el seguimiento y evaluación del procedimiento, en los términos establecidos en los artículos 10.6 y 17 de la Ley Orgánica 5/2002, de 19 de junio, de las Cualificaciones y de la Formación Profesional.

- el Consejo de la Formación Profesional de Castilla y León y el Consejo General de Empleo participarán en el seguimiento y evaluación del procedimiento a través de sus órganos colegiados o de las Comisiones de Trabajo que establezca al efecto. 
La validación de competencias profesionales en España e Italia

- ENTREVISTAS

No existen referencias al respecto.

\section{- ITALIA}

\section{- LEGISLACIÓN}

Legislación nacional: el artículo 7 del Decreto Ministerial 174/2001 prevé que las comisiones (definidas en el anexo B del Acuerdo Stato-Regioni de 18 de febrero del año 2000) se encarguen del seguimiento y evaluación de los procedimientos de validación, con la asistencia técnica del ISFOL. Dichas comisiones estarían compuestas por representantes del Ministerio de Trabajo y Seguridad Social ${ }^{106}$, del Ministerio de Educación, de la Universidad y de la Investigación y de las regiones.

Asimismo, el artículo 9 del DL 13/2013, repite y completa lo expuesto en el DM 174/2001, decretando que el sistema nacional de certificación de competencias debe ser objeto de seguimiento y evaluación, dirigido a una mejora constante por parte del Ministerio de Trabajo y de Políticas Sociales; del Ministerio de Educación, de la Universidad y de la Investigación y de las administraciones públicas centrales y regionales. El artículo también indica que podrán colaborar: el ISFOL; el INVALSI (Instituto nacional para evaluación del sistema educativo y formativo); el INDIRE (Instituto nacional de investigación educativa); el ANVUR (Agencia nacional de evaluación del sistema universitario y de investigación de documentación, innovación) y la Unión nacional de las cámaras de comercio, industria, artesanía y agricultura.

Asimismo, el artículo indica que los resultados del seguimiento y de la evaluación deberán comunicarse, cada 3 años, al Parlamento.

Legislación regional: no se han encontrado alusiones al respecto.

\section{- ENTREVISTAS}

No existen referencias al respecto.

7.2.0.3. Indicador: Existe un plan de seguimiento externo (control del procedimiento)

\section{- ESPAÑA}

106 Actualmente denominado Ministerio de Trabajo y Políticas Sociales. 


\section{- LEGISLACIÓN}

Legislación nacional: el RD 1224/2009 expone, en el artículo 30 sobre seguimiento y evaluación, que la Administración General del Estado, en colaboración con las comunidades autónomas y previa consulta al Consejo General de la Formación Profesional, elaborará un Plan de Seguimiento y Evaluación que permita comprobar la calidad, la eficacia y el impacto del procedimiento. Para ello, las comunidades autónomas proporcionarán a la Administración General del Estado la información y los datos necesarios. La Administración General del Estado elaborará anualmente un informe que presentará al Consejo General de la Formación Profesional y que incluirá, en su caso, propuestas de mejora para los distintos aspectos del procedimiento.

Legislación autonómica: no se han encontrado referencias al respecto.

\section{- ENTREVISTAS}

No existen referencias al respecto.

\section{- ITALIA}

\section{- LEGISLACIÓN}

Legislación nacional y legislación regional: no se han encontrado referencias al respecto.

- ENTREVISTAS

No se han hecho alusiones sobe este argumento.

\section{Dimensión: Coordinación en el procedimiento}

\subsection{Sin categoría}

\subsubsection{Sin subcategoría}

8.0.0.1. Indicador: Existe una figura encargada de la coordinación del procedimiento.

\section{- ESPAÑA}

\section{- LEGISLACIÓN}

Legislación nacional: el artículo 6 del RD 1224/2009 habla sobre el principio de coordinación, garantizando una adecuada coordinación y complementariedad en las actuaciones de todas las partes responsables de su 
La validación de competencias profesionales en España e Italia

desarrollo, con el objetivo de lograr la máxima eficacia y eficiencia en su implementación.

Legislación autonómica: no se han encontrado referencias al respecto.

\section{- ENTREVISTAS}

El gestor/organizador entrevistado ha atribuido a la figura del coordinador provincial de las direcciones provinciales de educación la función de transmisor de información entre las consejerías y los profesionales del procedimiento, así como la función de unificar los criterios de evaluación en las diferentes comisiones de evaluación. Uno de los asesores entrevistados del procedimiento de Castilla y León también ha hecho mención a esta figura, señalando, sin embargo, que este coordinador simplemente asistía a las reuniones iniciales de las convocatorias y firmaba el acta al finalizar las mismas.

"Si, hemos coordinado, a través de los coordinadores provinciales de las direcciones provinciales de educación y a través de instrucciones y plataformas de formación de grupos colaborativos, es decir, los coordinadores provinciales actuaban como vía de transmisión de las informaciones que se daban desde aquí y unificaban los criterios de evaluación entre las comisiones de evaluación. También habia una plataforma de un grupo colaborativo para que asesores y evaluadores se pusieran en contacto entre ellos y con nosotros. Asi, todos los archivos que se van a utilizar, las comunicaciones, los correos, que se quieren dar a todos, se hace a través de esa vía, a través de un grupo colaborativo. La mayor parte de los archivos los he colgado yo, pero el primer año babia muchas cosas que no babiamos previsto $y$ los asesores y evaluadores lo crearon y pusieron en común para todos a través de esa plataforma." (J.I.N. Gestor/organizador).

"[...] creo que el papel de... en este caso era Sonia, que era la coordinadora, asistía a las reuniones grupales. La coordinadora es una funcionaria de la Consejería de Educación, venia a las reuniones grupales, en ambas convocatorias. En la primera convocatoria tuve veinticinco personas, en la segunda catorce, al principio se presentaron siete, los otros que no vinieron fueron excluidos automáticamente y llamaron a los que estaban detrás. En la primera sesión estuvo Sonia, en la segunda con los nuevos candidatos estuvo Sonia, y luego falló otra y convocaron a una nueva y estuvo también Sonia, luego todos firmamos el acta, las candidatas el impreso de que habian asistido, nosotros como asesores y ella también firmaba, y no volvia a aparecer en el procedimiento." (J.L. As).

\section{- ITALIA}

- LEGISLACIÓN 
Legislación nacional: no se han encontrado alusiones sobre este tema.

Legislación regional: el punto 3.2. de la DGR 1434/05 sobre el responsable de la formalización y certificación de competencias (RFC), otorga a dicha figura el papel de referente procedimental y organizativo, en cuanto a la puesta en marcha de todo el procedimiento.

Establece que el RFC es el responsable de asegurar el respeto de los procesos previstos y de las necesidades y características de las personas, atribuyéndole las siguientes funciones:

- transmitir correctamente la información relativa a modalidades de formalización y certificación, documentos entregados al finalizar el procedimiento y firmar los contratos formativos;

- garantizar la homogeneidad de los procesos de formalización y certificación de competencias realizadas en diferentes convocatorias o sedes;

- nombrar a los expertos de la evaluación a través de evidencias;

- instituir la comisión para el desarrollo del examen y comunicar dicha constitución a la administración responsable; asegurar a los componentes de la comisión de examen, la información resultante de la evaluación a través de evidencias, así como cualquier otro tipo de información que pueda resultar útil para la realización del examen;

- firmar los documentos resultantes (las fichas de conocimientos y capacidades, junto con el expertos certificados, junto con el presidente de la comisión de examen).

El RFC posee competencias técnico-profesionales relativas a la gestión del proceso, a la relación con el candidato, a las normas y a los procedimientos administrativos pertinentes. Sus competencias están definidas según los estándares del SRQ y coherentemente certificadas.

Asimismo, esta deliberación establece que los entes formativos son los encargados de nombrar su propio responsable y lo comunican a la Regio$n e$, que lo introduce en una específica "lista regional". Además, la presencia de este responsable constituye un requisito para que la Regione autorice el desarrollo de las actividades previstas por el proceso de formalización y certificación de competencias.

\section{- ENTREVISTAS}


La validación de competencias profesionales en España e Italia

El RFC entrevistado ha explicado que su función es la de coordinar el procedimiento, para asegurar el buen funcionamiento y la calidad del mismo. Asimismo, indica que cada provincia tiene como mínimo un RFC encargado de controlar que todo vaya bien.

Dos de los EPV entrevistados hablan también de esta figura definiéndola como un vigilante, un supervisor que garantiza el buen funcionamiento del procedimiento, aunque uno de ellos ha indicado que no ha notado mucho seguimiento por parte de esta figura.

"Yo soy Responsable de Formalización y Certificación y he hecho una formación especifica para esto, y estoy inscrita en la lista de la Regione. Y soy también EPV, he hecho otra formación para esto. La formación siempre impartida por la Regione. [...] Mi figura es la de uno que asegura la calidad del procedimiento, como en las empresas está el que te asegura que todo el proceso ha sido controlado y funciona, que todos los expertos están preparados. Es el que te asegura que todo el procedimiento funciona [...] Al menos hay un RFC por cada provincia, al menos somos diez: Llevo el control del procedimiento, dentro de una empresa o del centro de formación privado que hace la formalizzazione e certificazione de las competencias, y mi función consiste en organizar y controlar que todo vaya bien. Cada provincia tiene al menos un RFC y al menos un EPV. Puede tener más. El responsable controla, que todo vaya bien, firma, organiza, si hay problemas te los resuelve, por ejemplo si un miembro de la comisión no está muy de acuerdo por cómo se ha hecho el examen, interviene el responsable, para las pruebas de examen está el responsable, para explicar a los alumnos cuando llegan qué es el servicio, está el responsable, pero toda la impartición del servicio la hace el EPV, en realidad, porque él es el experto." (M.M. RFC).

"[...] el RFC...es un elemento que entra en contacto con todos los otros roles pero de forma muy superficial, porque siendo solo una garantía de todo el proceso...es como un vigilante, tiene que garantizar que toda el procedimiento se haga siguiendo la normativa, la ley. Hace un control de los documentos que tiene que haber (se tienen que hacer como dice la normativa) tiene que conocer la normativa como la Biblia." (N.B. EPV).

"[...] mi experiencia el RFC ba sido el que controla, supervisa. No sé, yo siempre he trabajado mucho con autonomía desde este punto de vista. No lo sé, quizás el RFC da por descontadas muchas cosas, pero... yo este seguimiento no lo be notado mucho." (S.C. EPV).

8.0.0.2. Indicador: Se realizan encuentros/reuniones de puesta en común entre los profesionales, dirigidos a mejorar el procedimiento. 
Análisis y resultados

\section{- ESPAÑA}

\section{- LEGISLACIÓN}

Legislación nacional y legislación autonómica: no se han encontrado referencias al respecto.

\section{- ENTREVISTAS}

Uno de los asesores entrevistados ha indicado que se reúne con otros asesores y evaluadores cuando tiene alguna duda sobre algún candidato. El otro asesor entrevistado ha señalado que no se hacen reuniones para hablar de los problemas que surgen y como resolverlos en el procedimiento, aunque menciona el uso de una plataforma que posibilita a los profesionales del procedimiento comunicarse entre ellos. Sin embargo, ha señalado que en la segunda fase de la convocatoria la plataforma no ha estado muy activa.

Uno de los evaluadores entrevistados ha declarado haber tenido contacto con otros evaluadores, pero no con los asesores. Asimismo ha comentado que tampoco se han reunido, entre los profesionales, para comentar problemas o mejoras en el procedimiento.

"Sí claro, tenemos reuniones, por ejemplo, para los casos que son más complicados, que tenemos más dudas, porque no siempre es todo tan fácil, hay casos que te dan mucha duda. Yo con evaluadores me he reunido una very con asesores otra" (C.T. As).

Entrevistador: "¿Se hacen reuniones?, ¿se comunicaban los asesores sobre cómo llevar a cabo el asesoramiento, dudas o problemas que van surgiendo? [...]"

"no, no, no".

Entrevistador: "¿Usan el grupo colaborativo para poner en común dudas problemas, etc...?”

"Hay una plataforma que gestiona José Ignacio, que cada vez que se inicia un procedimiento se abre, se nos da la clave, se cuelga toda la información y documentación. Toda la documentación que necesitamos, correos electrónicos entre nosotros, foros de debate entre nosotros para dudas, en la primera convocatoria estuvo muy activa pero en esta segunda la verdad es que no la be visto muy activa". (J.L. As).

"Con los evaluadores sí hemos tenido relación, con los asesores no, reunión como tal no, les hemos visto, pero no, no, no, no ha babido ninguna relación, ha babido algún asesor que no he visto. Ellos tenian sus instrucciones, cada semana tenian que presentar un número determinado de expedientes que nos dejaban en un lugar determinado. Y 
La validación de competencias profesionales en España e Italia

nosotros íbamos cogiendo los expedientes de los candidatos con dossier y ya está, no bemos tenido ninguna relación con ellos".

Entrevistador: "¿Tampoco al finalizar la evaluación os habéis reunido con los asesores o evaluadores para comentar fallos o mejoras?”

"No, no, no, para nada". (T.M. Ev).

\section{- ITALIA}

\section{- LEGISLACIÓN}

Legislación nacional y legislación regional: no se han encontrado referencias al respecto.

\section{- ENTREVISTAS}

Dos de los EPV entrevistados han declarado haberse reunido con los EAPQ para planificar el examen, pero no mencionan otro tipo de reuniones dirigidas a mejorar el procedimiento. El otro de los EPV entrevistados ha señalado que no se han hecho reuniones con objeto de mejorar el procedimiento, pero lo considera de mucha utilidad. En cuanto al RFC entrevistado también ha indicado que no se han realizado estas reuniones pero las considera muy útiles, aunque ha señalado que resultarían bastante costosas y que por ahora lo que hacen los RFC es intentar solucionar los problemas que van detectando durante el procedimiento. Por último, uno de los gestores/organizadores del procedimiento ha declarado haberse reunido con los profesionales de los entes que están llevando a cabo el procedimiento, para "romper el hielo", darles seguridad e indicarles que pueden llamar ante cualquier problema. Sin embargo, también ha indicado que son muchos los centros que ponen en práctica el procedimiento y que necesita de la colaboración de los profesionales del mismo para conocer las dificultades que surgen.

"Sí... la relación con los EAPQ... el EPV tiene una relación estrecha porque es con los que trabaja más cuando planifica el examen y cuando lo bace a los participantes, yo tengo dos grandes amigos EAPQ. Con el RFC...es un elemento que entra en contacto con todos los otros roles pero de forma muy superficial, [...]” (N. B. EPV).

"A algunos EAPQ les he conocido la mañana del examen, a otros les conozco más porque he hecho muchos exámenes y ya les conozco, pero el sistema SIFER extrae las personas y quien encuentras encuentras y te encuentras con persones nuevas en sede de examen, planificas y haces tres o cuatro días de examen con ellos." (S.C. EPV). 
Entrevistador: "Una vez que el procedimiento termina, chacen reuniones para hablar de problemas, comunicaros, ver si se puede mejorar algo con el responsable para luego reunirse otra vez con la Regione?”

"Si no recuerdo mal, en la nueva Deliberación 739, se dice que se prevén momentos...en mi opinión seria utilísimo, no está previsto por la normativa." ha ido?’

Entrevistador: “ ¿No viene alguien de la región para preguntar cómo

"No, pero sería muy útil." (G.G. EPV).

Entrevistador: “¿Hacen reuniones entre ustedes?”

"No, porque cada uno sabe lo que tiene que hacer, si que nos consultamos y nos preguntamos entre nosotros, pero es consultación, nos llamamos, "mira, tengo este problema, ¿tú como lo solucionas?" no es una actualización, a través de reuniones."

Entrevistador: "Cuando termina el proceso, ¿se hace una reunión entre ustedes, los expertos, al menos ustedes?"

"No, esto es lo que te decía que hace falta. Nosotros nos reunimos para decidir si el candidato pasa o no, sobre todo si no está muy claro. No está escrito, pero en la práctica... nosotros nos reunimos y decimos éste y éste, no lo tenemos muy claro... Reunirnos como dices tú, sería muy costoso, se tendría que pagar a parte, los EAPQ es gente que trabaja, vienen a hacer los exámenes cogiendo días de vacaciones o en el tiempo libre, es gente que trabaja, vienen aqui por dinero."

Entrevistador: "Ellos no pero... ¿Ustedes se reúnen para decidir que no va bien y que se puede cambiar?"

"Nosotros lo que hemos hecho es, cuando nos hemos encontrado un EAPQ que está suspendiendo a todos nos dirigimos a la Regione y le decimos: "mira éste lo que está baciendo, baz algo" (M.M. RFC).

"[...] Verse ayuda. Esto es un sistema de personas, la relación con las personas es muy importante. Nos cuesta mucho pero tenemos que recuperarlo, es una debilidad que hemos visto en la primera fase, pero ahora está mejorando muchísimo, desde que yo voy a los entes todos los dias, se sienten más seguros, reforzados, comparto con ellos, también lo que te estoy diciendo a ti, si tienen dificultades te llaman, porque se rompen las barreras y es más fácil, si tienen alguna duda o alguna dificultad en la aplicación del sistema te llaman. Esto es un sistema de personas, pero es dificil hacer esto así.

Luego, todos los expertos de área profesional y cualifica... con ellos tengo encuentros pero son personas no típicas de nuestro sistema, por lo que las reglas que se usan 
La validación de competencias profesionales en España e Italia

dentro de la formación profesional... Por ejemplo, se les da la plataforma on-line, pero también dos o tres encuentros de un día, se han hecho, el primero lo be hecho siempre yo, con todos, en un aula, be becho encuentros con toda la lista. A todos les he contado lo que se encontrarán en la plataforma, a todos les he dicho llamadme si lo necesitáis, quizás no me encuentren siempre, pero asi se rompe el bielo que existe con la institución, pero si ellos no colaboran que están en la práctica, para mi es difícil estar detrás de ellos tenemos 160 los centros acreditados que activan comisiones, asi que o son ellos los que me ayudan a comprender o yo sola no puedo." (V.F. Gestor/organizador).

\section{Dimensión: Trazabilidad}

\subsection{Sin categoría}

\subsubsection{Sin subcategoría}

9.0.0.1. Indicador: Cada paso en el proceso de evaluación se documen$\mathrm{ta} /$ registra

\section{- ESPAÑA}

\section{- LEGISLACIÓN}

Legislación nacional: el artículo 16.5 del RD 1224/2009, sobre el proceso de evaluación, indica que las actividades de evaluación se desarrollarán siguiendo una planificación previa, en la que constarán, al menos, las actividades y métodos de evaluación y los lugares y fechas previstos. Asimismo, indica que por cada actividad deberá quedar un registro firmado por el candidato y el evaluador.

El punto 8, del mismo artículo, expone que el expediente resultante del proceso, en el que se recogerán todos los registros y resultados producidos a lo largo del procedimiento, será custodiado por la administración competente.

Legislación autonómica: sigue lo establecido por el RD 1224/2009 con la Orden Hac 1536/2011 sobre el procedimiento, indicando en los puntos:

- Decimotercero, punto 9, sobre la fase de evaluación, que de cada actividad de evaluación realizada quedará un registro firmado por el candidato y el evaluador;

- Decimocuarto, punto 1 , sobre los resultados de la evaluación, que una vez finalizada la etapa de evaluación, se completará el expediente de evidencias, que recogerá los resultados y los registros 
producidos a lo largo del procedimiento y que estará custodiado durante el período reglamentario para atender los posibles procesos de reclamación en las sedes donde se desarrolle el citado procedimiento.

\section{- ENTREVISTAS}

Uno de los asesores y los dos evaluadores entrevistados han declarado haber dejado constancia, a través de un registro, de las actividades que se han ido realizando durante el procedimiento. Asimismo, el gestor/organizador del procedimiento ha indicado que efectivamente al finalizar el procedimiento recibe toda la documentación producida durante el procedimiento, sobre los pasos que se han ido dando.

Entrevistador: "¿Existe un registro de lo que se va haciendo durante el procedimiento?”

"Sí, registramos lo que vamos haciendo." (C.T. As).

Entrevistador: "¿Existe un registro de los pasos que se van dando durante el proceso de evaluación?"

"El propio procedimiento te lleva a eso porque tienes que ir cumplimentando una serie de documentos, por ejemplo, esta persona... se le ha pasado una entrevista profesional, el acta individual es que esta persona lo ha pasado, aqui en el propio informe, lo va registrando, todos los pasos, la propia documentación te obliga." (A.D. Ev). incidencias..."

Entrevistador: “¿Existe un registro del procedimiento? Los pasos,

"Teniamos que presentar un acta diaria, eso ha quedado en el centro integrado, era la secretaria la que se encargaba o la que debería de haberse encargado de hacer las actas, pero como comisión, no como evaluadores, eran actas de la comisión de evaluación, pero yo realmente cuando he estado evaluando no he llevado un registro, sino que mi registro ha sido el informe de evaluación y nada más, y los registros que yo he tenido que presentar para la candidata. [...] Me parece fundamental que quedara constancia, que nosotros hemos hecho la evaluación siguiendo esa ficha que viene en el guía, este año no la bemos hecho pero me parece fundamental que esa ficha fuera un documento exigible para los evaluadores. También de cara a una reclamación" (T.M. Ev).

Entrevistador: "¿Existe un registro de todo lo que se va haciendo durante el procedimiento, documentando todo lo que hace?" 
La validación de competencias profesionales en España e Italia

"Si, el asesor controla todo lo que va haciendo, los pasos... La comisión de evaluación también, pero desde aqui no tenemos ese control, excepto que al final del procedimiento recibimos y recabamos toda la documentación de asesores y evaluadores y está aqui archivada, pero durante el procedimiento no. Abora mismo yo no sé lo que está baciendo cada asesor o comisión de evaluación, lo sabré al final cuando reciba toda la documentación" (J.I.N. gestor/organizador).

\section{- ITALIA}

\section{- LEGISLACIÓN}

Legislación nacional y legislación regional: no se han encontrado referencias al respecto.

\section{- ENTREVISTAS}

El EAPQ, los tres EPV y el RFC entrevistados han declarado que el procedimiento queda registrado en documentos dispuestos por la Regione. Asimismo han señalado que el registro es una buena idea de cara a posibles reclamaciones. Uno de los gestores/organizadores habla del sistema informático en el que queda registrado el procedimiento, desde la evaluación de evidencias. Dicho sistema es capaz de ordenar cronológicamente los documentos producidos, posibilita a la Regione hacer un seguimiento del procedimiento, da autonomía a los profesionales y ha aligerado el trabajo a los gestores/organizadores.

Entrevistador: “¿Existe un registro del procedimiento? ¿De lo que sucede durante la evaluación?

"Si, en los anexos de la Deliberación, está el dossier de los alumnos." (C.C. EAPQ).

"Desde este año nos piden un informe detallado, justamente, en mi opinión. Es una novedad. Por si hay reclamaciones. Está bien registrar los problemas que surgen y está bien que esté todo registrado [...]” (G.G. EPV).

Entrevistador: “¿Existe un registro de todo el procedimiento?”

"Tenemos documentos que se usan que son estándar que los da la Regione (creo que los tiene la normativa al final) hay toda una seria de documentos desde el dossier de las evidencias...por ejemplo el documento de evaluación de las evidencias lo firma el RFC junto con el EPV." (N.B. EPV).

"[...] Informamos en esta plataforma, también, tenemos que decir, quienes son los candidatos, tenemos que meter dentro el dossier de las evidencias, decir cuándo se hará el 
examen, quienes serán los miembros de la comisión, todo aqui dentro, que es la gestión, aqui decimos: estamos haciendo esto". (M.M. RFC).

Entrevistador: "¿Registran lo que hacen con el candidato durante todo el procedimiento?"

"Sí, los instrumentos son el verbal y la prueba de examen, al menos en las que preparo yo hay una parte para las notas pero se trata de cosas relativas a la evaluación, de la cualificación y certificación. Uno como EPV podría mandarlo al RFC y decir hoy he encontrado gente con poco nivel o no se ban encontrado bien con la prueba práctica, pero no hay documentos oficiales para registrar. Lo único que se registra es cuando los exámenes no van bien, porque luego pueden reclamar. Porque quizás uno dice tenemos una comisión mala y hemos aprendido a registrar todo." (S.C. EPV).

[...] nosotros tenemos un sistema informático, es decir, la parte inicial del proceso no se sigue, empezamos a seguir el sistema desde el documento de evaluación de las evidencias, es el documento que va después del dossier, desde abi seguimos todo el sistema, y lo bacemos en un modo que yo... el análisis que yo be hecho... he pedido que las informaciones inseridas tengan un orden cronológico, porque hemos visto que hasta ahora estaban metiendo los datos según pillaban y el problema de hacer esto es que si se bace un control sobre nuestro sistema informático que es una base de datos oficial que tiene la Regione sobre todos los sistemas de formación, servicios de formación que aprueba con financiación o sin financiación, [...] Ahora, hemos revisado el sistema informático para que los datos entren en el orden que queremos nosotros aunque no lo metan de forma ordenada. Lo que sí tienen que hacer es poner bien la fecha y asi el sistema lo ordena.

Este es un buen sistema, porque en el momento en el que se da la autorización a un ente autónomo para llevar a cabo el servicio, yo no puedo saber qué está haciendo, si lo está haciendo bien, porque él en realidad lo puede empezar a hacer cuando quiera. Hasta la emisión del certificado yo no sé de ellos. También es una ventaja porque tienen una autonomía total y a nosotros nos ha descargado de toda una serie de actividades. Por ejemplo, inicialmente nosotros firmábamos todos los certificados, lo firmaba nuestro responsable de repertorio, abora lo firman ellos a nombre nuestro, llevan nuestro logo, nuestras reglas y actos, es un certificado que tiene un valor público y debemos garantizar que lo bagan bien (V.F. gestor/organizador). 


\subsection{Análisis comparativo por indicadores}

Tras haber presentado con detalle los datos derivados del análisis documental de la legislación y del análisis de entrevistas semiestructuradas, en este apartado presentamos el resultado del análisis comparativo por indicadores, y según la fuente de la que hemos obtenido la información. En esta exposición de resultados están también integrados los datos obtenidos del análisis cuantitativo y cualitativo de los cuestionarios, representados principalmente por gráficos que expresan porcentajes de las respuestas a los cuestionarios.

Para ello, hemos extraído las dimensiones, categorías, subcategorías (en su caso) e indicadores de la matriz. Cada indicador contiene una breve comparación de los resultados obtenidos del análisis de datos, en cuanto a legislación, entrevistas y cuestionarios (ver Figura 6). Asimismo, hemos incluido, debajo de las categorías o subcategorías (según corresponda) un cuadro sobre la "presencia" (representada con un "SI') o "no presencia" (representada con un "NO") de datos, derivados del análisis legislativo, de entrevistas y de cuestionarios, respecto al indicador:

Figura 6: Esquema seguido en el análisis compararado por indicadores

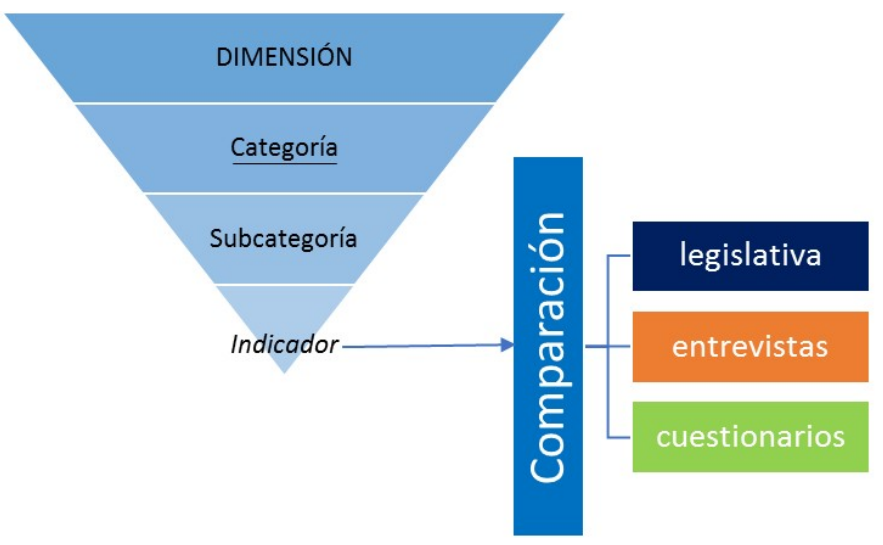


1. DIMENSIÓN EVENTO: INFORMACIÓN PREVIA AL PROCEDIMIENTO

1.1. CATEGORÍA: INFORMACIÓN PREVIA SOBRE EL PROCEDIMIENTO DE VALIDACIÓN A LAS PARTES INTERESADAS

\subsubsection{Sin subcategoría}

\begin{tabular}{|c|c|c|c|c|c|c|c|c|}
\hline \multirow[b]{3}{*}{ IND. } & \multicolumn{4}{|c|}{ ESPAÑA } & \multicolumn{4}{|c|}{ ITALIA } \\
\hline & \multicolumn{2}{|c|}{ Legislación } & \multirow{2}{*}{$\begin{array}{l}\text { Entrevis- } \\
\text { tas }\end{array}$} & \multirow{2}{*}{$\begin{array}{c}\text { Cues- } \\
\text { tio- } \\
\text { narios }\end{array}$} & \multicolumn{2}{|c|}{ Legislación } & \multirow{2}{*}{$\begin{array}{l}\text { Entre- } \\
\text { vistas }\end{array}$} & \multirow{2}{*}{$\begin{array}{c}\text { Cues- } \\
\text { tio- } \\
\text { narios }\end{array}$} \\
\hline & $\begin{array}{c}\text { Nacio- } \\
\text { nal }\end{array}$ & $\begin{array}{c}\text { Auto- } \\
\text { nómica }\end{array}$ & & & $\begin{array}{c}\text { Nacio- } \\
\text { nal }\end{array}$ & $\begin{array}{c}\text { Regio- } \\
\text { nal }\end{array}$ & & \\
\hline 1.1.0.1 & sí & sí & sí & sí & sí & sí & sí & sí \\
\hline
\end{tabular}

\subsubsection{INDICADOR: Se da una información previa a las partes interesadas (empresas, sindicatos, centros formativos) sobre el procedimiento de valida- ción.}

\section{Comparación:}

\section{Legislación}

Tanto la legislación nacional española e italiana como la autonómica de Castilla y León/regional de Emilia-Romagna, contemplan este aspecto. La española se refiere a esta fase de formación de manera algo vaga e inconcreta. Sin embargo, la legislación autonómica de Castilla y León es un poco más explícita, estableciendo una página web informativa e indicando quiénes deben proporcionar la información. Por otro lado, tanto la legislación nacional italiana como la regional de Emilia-Romagna, hablan de adoptar medidas para informar sobre el sistema. Sin embargo, ambas lo hacen de forma bastante general y la legislación nacional no especifica que dicha información se proporcionará a las partes interesadas.

\section{Entrevistas}

El gestor/organizador entrevistado, del procedimiento de Castilla y León, ha afirmado que se ha dado este tipo de información a algunas de las partes interesadas, sin embargo, dos de los profesionales implicados en el procedimiento (un asesor y un evaluador), han comentado que el proceso 
La validación de competencias profesionales en España e Italia

de información no se hizo correctamente, al menos para las empresas, ya que muchas tenían un desconocimiento total del procedimiento. En cuanto al procedimiento de Emilia-Romagna, uno de los gestores/organizadores, reconoce que no se ha hecho una buena publicidad del procedimiento a las empresas como partes interesadas. Podemos decir por tanto, que la opinión general, de los profesionales entrevistados, en ambos territorios, es que la información a las partes interesadas no ha sido suficiente.

\section{Cuestionarios}

Al preguntar a los encuestados sobre los aspectos a mejorar del procedimiento, un alto porcentaje, tanto de asesores como los evaluadores de ambos procedimientos, ha indicado que la información previa que se proporciona a las empresas debería mejorar.

\subsection{CATEGORÍA: INFORMACIÓN PREVIA SOBRE EL PROCEDIMIENTO DE VALIDACIÓN A LOS CANDIDATOS}

\begin{tabular}{|c|c|c|c|c|c|c|c|c|}
\hline & \multicolumn{4}{|c|}{ ESPAÑA } & \multicolumn{4}{|c|}{ ITALIA } \\
\hline & \multicolumn{2}{|c|}{ Legislación } & \multirow{2}{*}{$\begin{array}{c}\text { Entrevis- } \\
\text { tas }\end{array}$} & \multirow{2}{*}{$\begin{array}{c}\text { Cues- } \\
\text { tio- } \\
\text { narios }\end{array}$} & \multicolumn{2}{|c|}{ Legislación } & \multirow{2}{*}{$\begin{array}{l}\text { Entre- } \\
\text { vistas }\end{array}$} & \multirow{2}{*}{$\begin{array}{c}\text { Cues- } \\
\text { tio- } \\
\text { narios }\end{array}$} \\
\hline IND. & $\begin{array}{l}\mathrm{Na-} \\
\text { cional }\end{array}$ & $\begin{array}{c}\text { Autonó- } \\
\text { mica }\end{array}$ & & & $\begin{array}{c}\text { Nacio- } \\
\text { nal }\end{array}$ & $\begin{array}{c}\text { Regio- } \\
\text { nal }\end{array}$ & & \\
\hline 1.2.0.1 & sí & sí & sí & sí & sí & NO & sí & NO \\
\hline
\end{tabular}

1.2.0. Sin subcategoría.

\subsubsection{INDICADOR: Existe una fase de información previa, al candidato, so- bre el procedimiento}

\section{Comparación:}

\section{Legislación:}

La legislación nacional española y autonómica de Castilla y León, garantizan dispositivos de información y orientación permanente. La primera también establece que en las convocatorias de validación deberá aparecer información relativa al procedimiento, con el objetivo de que las personas conozcan el procedimiento de validación y así valoren su participación en el mismo. Por otro lado, la legislación nacional italiana establece medidas per- 
sonalizadas de información y orientación por parte del mismo procedimiento, pero sin especificar que se haga antes de que comience el mismo. Respecto a la legislación regional de Emilia-Romagna, no se han encontrado referencias al respecto.

\section{Entrevistas:}

El gestor/organizador entrevistado ha afirmado que ha habido una fase informativa previa. Sin embargo, tanto los dos asesores como los dos evaluadores entrevistados han declarado que esta fase o no se ha llevado a cabo o se ha hecho deficientemente, porque, según han indicado, los candidatos no estaban bien informados sobre el procedimiento. Respecto al procedimiento de Emilia-Romagna, podemos indicar que, a pesar de la poca relevancia que se da a este aspecto en la legislación, sí se ve reflejado en la práctica, dos gestores/organizadores y tres EPV han incidido en la importancia de esta fase y han indicado que existe una fase de información previa, proporcionada por los centros de empleo y por los centros formativos acreditados por la Regione.

\section{Cuestionarios}

Al preguntar a los encuestados sobre los aspectos a mejorar del procedimiento, un porcentaje elevado de asesores y evaluadores del procedimiento de Castilla y León ha expresado su disconformidad con la falta de información previa, sobre el procedimiento, proporcionada a los candidatos.

\subsection{CATEGORÍA: ACCESIBILIDAD DE LA INFORMACIÓN}

1.3.0. Sin subcategoría.

\begin{tabular}{|c|c|c|c|c|c|c|c|c|}
\hline \multirow[b]{3}{*}{ IND. } & \multicolumn{4}{|c|}{ ESPAÑA } & \multicolumn{4}{|c|}{ ITALIA } \\
\hline & \multicolumn{2}{|c|}{ Legislación } & \multirow{2}{*}{$\begin{array}{l}\text { Entrevis- } \\
\text { tas }\end{array}$} & \multirow{2}{*}{$\begin{array}{c}\text { Cues- } \\
\text { tio- } \\
\text { narios }\end{array}$} & \multicolumn{2}{|c|}{ Legislación } & \multirow{2}{*}{$\begin{array}{c}\text { Entrevis- } \\
\text { tas }\end{array}$} & \multirow{2}{*}{$\begin{array}{c}\text { Cues- } \\
\text { tio- } \\
\text { narios }\end{array}$} \\
\hline & $\begin{array}{c}\mathrm{Na-} \\
\text { cional } \\
\end{array}$ & $\begin{array}{c}\text { Autonó- } \\
\text { mica }\end{array}$ & & & $\begin{array}{c}\text { Nacio- } \\
\text { nal }\end{array}$ & $\begin{array}{c}\text { Regio- } \\
\text { nal }\end{array}$ & & \\
\hline 1.3.0.1 & NO & Sí & NO & $\mathrm{NO}$ & $\mathrm{NO}$ & NO & NO & NO \\
\hline
\end{tabular}

1.3.0.1. INDICADOR: La información es accesible a través de internet y otras vías.

\section{Comparación:}

\section{Legislación}


La validación de competencias profesionales en España e Italia

Solamente contamos con datos provenientes de la legislación autonómica de Castilla y León, siendo esta la única que contempla este aspecto, indicando que se podrá acceder a la información sobre el procedimiento a través de internet.

\section{Entrevistas}

No existen referencias al respecto, ni por parte de los entrevistados del procedimiento de Castilla y León, ni por los entrevistados del procedimiento de Emilia-Romagna.

2. ACCESO AL PROCEDIMIENTO

2.1. FACILIDAD DE ACCESO AL PROCEDIMIENTO

2.1.0. Sin subcategoría

\begin{tabular}{|c|c|c|c|c|c|c|c|c|}
\hline \multirow[b]{3}{*}{ IND. } & \multicolumn{4}{|c|}{ ESPAÑA } & \multicolumn{4}{|c|}{ ITALIA } \\
\hline & \multicolumn{2}{|c|}{ Legislación } & \multirow{2}{*}{$\begin{array}{l}\text { Entre- } \\
\text { vistas }\end{array}$} & \multirow{2}{*}{$\begin{array}{c}\text { Cues- } \\
\text { tio- } \\
\text { narios }\end{array}$} & \multicolumn{2}{|c|}{ Legislación } & \multirow{2}{*}{$\begin{array}{c}\text { Entrevis- } \\
\text { tas }\end{array}$} & \multirow{2}{*}{$\begin{array}{c}\text { Cues- } \\
\text { tio- } \\
\text { narios }\end{array}$} \\
\hline & $\begin{array}{c}\mathrm{Na}- \\
\text { cional } \\
\end{array}$ & $\begin{array}{c}\text { Auto- } \\
\text { nómica }\end{array}$ & & & $\begin{array}{c}\text { Nacio- } \\
\text { nal }\end{array}$ & $\begin{array}{c}\text { Regio- } \\
\text { nal }\end{array}$ & & \\
\hline 2.1.0.1 & sí & Sí & Sí & NO & NO & NO & Sí & NO \\
\hline 2.1.0.2 & Sí & Sí & Sí & Sí & NO & NO & sí & NO \\
\hline 2.1.0.3 & Sí & Sí & Sí & Sí & NO & NO & Sí & Sí \\
\hline 2.1.0.4 & Sí & Sí & NO & NO & NO & NO & sí & NO \\
\hline
\end{tabular}

Comparación

Legislación

Solamente la legislación nacional española y la autonómica de Castilla y León, hacen referencia a este punto, indicando la aplicación de tasas (sin embargo, a día de hoy estas tasas suponen un interrogante porque todavía no han sido fijadas). En la legislación nacional italiana y regional de EmiliaRomagna no se han encontrado referencias al respecto.

\section{Entrevistas}


El gestor/organizador entrevistado del procedimiento de Castilla y León ha señalado que al no haberse fijado unas tasas para el procedimiento, no se aplicaron en ninguna de las dos partes de la convocatoria que se ha llevado a cabo en Castilla y León, por lo que el procedimiento ha resultado gratuito para los candidatos y muy caro para la administración. No obstante, está prevista la creación de una tasa para futuras convocatorias. Respecto al procedimiento de Emilia-Romagna, el RFC y un gestor/organizador entrevistados han declarado que este sistema resulta costoso, ya que son las empresas o los candidatos los que asumen el coste del procedimiento, sobre todo si estos últimos quisieran activar el procedimiento de evaluación por su cuenta.

2.1.0.2. INDICADOR: Resulta fácil para los candidatos acceder al sistema en relación a la inscripción y admisión al procedimiento

\section{Comparación}

Legislación

Como en el caso del indicador anterior, solo se trata este aspecto en la legislación nacional española y en la autonómica de Castilla y León. Por el contrario, en la legislación nacional italiana y en la regional de EmiliaRomagna no se han encontrado referencia al respecto. La legislación nacional española menciona la inscripción y admisión al procedimiento, sin embargo no se ocupa directamente de ellas, ya que delega en las administraciones competentes la decisión de lugares y medios para dicha inscripción y admisión. En lo relativo a la legislación autonómica, esta especifica minuciosamente los criterios de prioridad para acceder al procedimiento.

\section{Entrevistas}

Uno de los asesores entrevistados del procedimiento de Castilla y León, ha manifestado su desacuerdo con la forma de realizar la fase de admisión en la segunda convocatoria del procedimiento, ya que muchos de los aspirantes a entrar en este, se quedaron fuera al no haberse enterado de que habían sido convocados, ya que se hizo a través de publicación en el boletín oficial y no estaban avisados. Por su parte, dos de los gestores/organizadores entrevistados, del procedimiento de Emilia-Romagna, han reflejado que todo el que quiere acceder al procedimiento puede hacerlo sin problema, porque se trata de un procedimiento abierto y no suele haber problemas para entrar. Sin embargo, en casos de masificación no se han tomado medidas para el acceso. Dos de los gestores/organizadores entre- 
La validación de competencias profesionales en España e Italia

vistados han comentado que solo han tenido un caso de acceso "difícil" por masificación, en el que la Regione se encargó de decidir quién entraba, aunque sin tener en cuenta unos criterios específicos prefijados.

\section{Cuestionarios}

Coincidiendo con el asesor entrevistado, en torno al 15\% de los asesores y al 10\% de los evaluadores encuestados del procedimiento de Castilla y León considera que el acceso al procedimiento debe mejorarse. Afirman, al igual que el entrevistado, que muchos de los candidatos pierden la posibilidad de participar en el procedimiento por la forma de convocatoria y por no informar bien sobre ella.

\subsubsection{INDICADOR: Resulta fácil para los candidatos acceder al sistema en relación a la documentación a presentar con la inscripción}

\section{Comparación}

\section{Legislación}

Como en los dos casos anteriores, solo la legislación nacional española y la autonómica de Castilla y León, se ocupan de este aspecto, detallando la documentación que debe presentar el candidato.

\section{Entrevistas}

Uno de los asesores del procedimiento de Castilla y León ha comentado que a los candidatos les ha resultado difícil completar algunos de los documentos necesarios para la inscripción. Respecto a los entrevistados del procedimiento de Emilia-Romagna, uno de los gestores/organizadores ha declarado que no existen requisitos de entrada al procedimiento, únicamente se pide justificar, al candidato, las competencias que quiera justificar.

\section{Cuestionarios}

En torno al 10\% de los asesores y de los evaluadores de Castilla y León y al 5\% de los profesionales de Emilia-Romagna, encuestados, han coincidido en que la documentación a presentar por los candidatos para acceder al procedimiento resulta excesiva y complicada.

\subsubsection{INDICADOR: Resulta fácil para los candidatos acceder al sistema en relación a los requisitos de formación y experiencia profesional}


Análisis y resultados

\section{Comparación}

\section{Legislación}

Como en los tres casos anteriores, solamente la legislación nacional española y la autonómica de Castilla y León se ocupan de este aspecto, ambas contemplan con detalle los requisitos de formación y la experiencia, requeridos por parte del candidato.

\section{Entrevistas}

Los entrevistados del procedimiento de Castilla y León, no han hecho referencias a este aspecto. Mientras que uno de los gestores entrevistados del procedimiento de Emilia-Romagna, ha declarado que el único requisito de entrada al procedimiento, para el candidato, consiste en justificar las competencias que quiera certificar.

2.2. CARACTER VOLUNTARIO DEL ACCESO AL PROCEDIMIENTO

2.2.0. Sin subcategoría

\begin{tabular}{|c|c|c|c|c|c|c|c|c|}
\hline \multirow[b]{3}{*}{ IND. } & \multicolumn{4}{|c|}{ ESPAÑA } & \multicolumn{4}{|c|}{ ITALIA } \\
\hline & \multicolumn{2}{|c|}{ Legislación } & \multirow{2}{*}{$\begin{array}{l}\text { Entrevis- } \\
\text { tas }\end{array}$} & \multirow{2}{*}{$\begin{array}{c}\text { Cues- } \\
\text { tio- } \\
\text { narios }\end{array}$} & \multicolumn{2}{|c|}{ Legislación } & \multirow{2}{*}{$\begin{array}{l}\text { Entre- } \\
\text { vistas }\end{array}$} & \multirow{2}{*}{$\begin{array}{c}\text { Cues- } \\
\text { tio- } \\
\text { narios }\end{array}$} \\
\hline & $\begin{array}{l}\mathrm{Na-} \\
\text { cional }\end{array}$ & $\begin{array}{c}\text { Autonó- } \\
\text { mica }\end{array}$ & & & $\begin{array}{l}\text { Nacio- } \\
\text { nal }\end{array}$ & $\begin{array}{c}\text { Regio- } \\
\text { nal }\end{array}$ & & \\
\hline 2.2.0.1 & Sí & NO & NO & sí & NO & NO & NO & sí \\
\hline
\end{tabular}

2.2.0.1. INDICADOR: Se hace saber al candidato la voluntariedad respecto al acceso al procedimiento.

\section{Comparación}

\section{Legislación}

Solamente la legislación nacional española hace referencia a este punto, reflejando el principio de respeto a los derechos individuales.

\section{Entrevistas}

En cuanto a las entrevistas no hay referencias sobre el tema, ni en el procedimiento de Castilla y León, ni en el de Emilia-Romagna 
La validación de competencias profesionales en España e Italia

\section{Cuestionarios}

Para obtener información de los cuestionarios sobre este indicador, hemos tomado estas dos graficas de la Figura 12 k) en relación a las respuestas de los asesores y de la Figura 30 l) en cuanto a las respuestas de los evaluadores, sobre la información proporcionada al candidato en relación al carácter voluntario del procedimiento:

Figura 7: Información de asesores sobre el carácter voluntario del procedimiento Información sobre: [El carácter voluntario del procedimiento]

asesores (ES) $\quad$ EPV (IT)

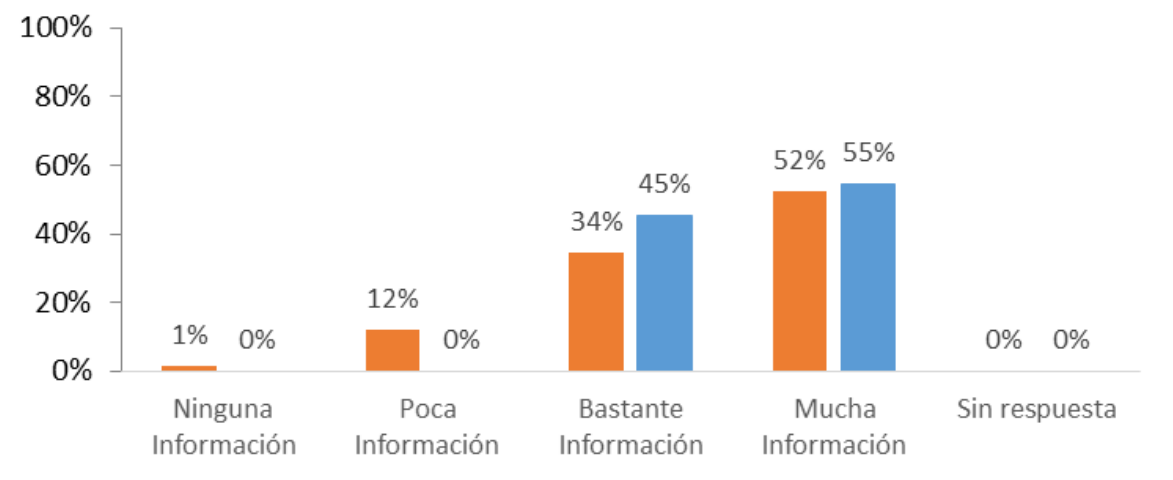


Figura 8: Información de evaluadores sobre el carácter voluntario del procedimien-

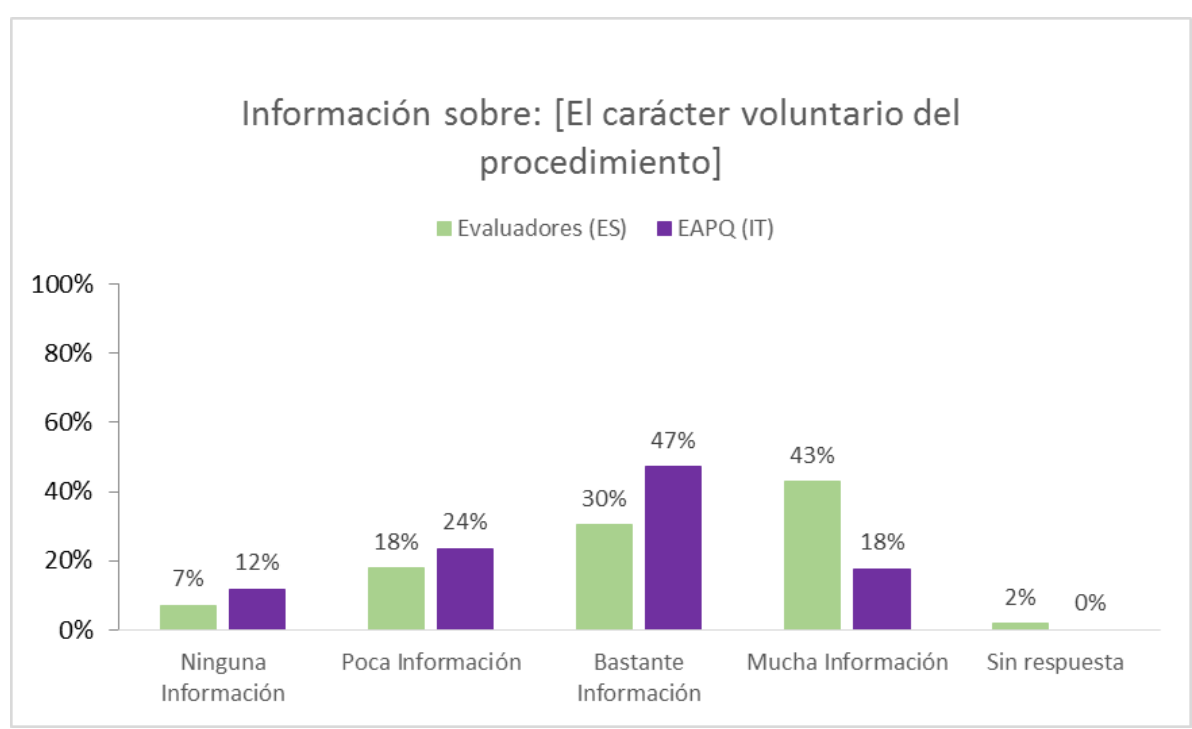

Podemos observar que en general se ha facilitado bastante información sobre este aspecto en los dos procedimientos (ver Figura 7 y Figura 8). Especificando un poco más, afirmamos que en ambos procedimientos los encargados del asesoramiento han proporcionado más información sobre este punto respecto a los evaluadores. Asimismo, en el procedimiento de Castilla y León, el porcentaje de profesionales que ha proporcionado información sobre este aspecto es más alto que en el de Emilia-Romagna, sin ser esta una diferencia significativa.

\section{ORIENTACIÓN}

\subsection{ORIENTACIÓN DURANTE EL PROCEDIMIENTO}

\subsubsection{Sin subcategoría}

\begin{tabular}{|c|c|c|c|c|c|c|c|c|}
\hline \multirow[b]{3}{*}{ IND. } & \multicolumn{4}{|c|}{ ESPAÑA } & \multicolumn{4}{|c|}{ ITALIA } \\
\hline & \multicolumn{2}{|c|}{ Legislación } & \multirow{2}{*}{$\begin{array}{l}\text { Entrevis- } \\
\text { tas }\end{array}$} & \multirow{2}{*}{$\begin{array}{c}\text { Cues- } \\
\text { tio- } \\
\text { narios }\end{array}$} & \multicolumn{2}{|c|}{ Legislación } & \multirow{2}{*}{$\begin{array}{l}\text { Entre- } \\
\text { vistas }\end{array}$} & \multirow{2}{*}{$\begin{array}{c}\text { Cues- } \\
\text { tio- } \\
\text { narios }\end{array}$} \\
\hline & $\begin{array}{l}\text { Nacio- } \\
\text { nal }\end{array}$ & $\begin{array}{c}\text { Auto- } \\
\text { nómica }\end{array}$ & & & $\begin{array}{l}\text { Nacio- } \\
\text { nal }\end{array}$ & $\begin{array}{c}\text { Regio- } \\
\text { nal }\end{array}$ & & \\
\hline 3.1.0.1 & Sí & sí & sí & NO & sí & sí & sí & NO \\
\hline
\end{tabular}


La validación de competencias profesionales en España e Italia

\section{Comparación}

\section{Legislación}

Tanto la legislación nacional española como la autonómica de Castilla y León, garantizan un servicio abierto y permanente de información y orientación sobre el procedimiento. En cuanto a la legislación nacional italiana, esta asegura la adopción de medidas personalizadas de información y orientación en favor de los destinatarios de los servicios de identificación, validación y certificación de competencias, sin embargo, no menciona que deba proporcionarse durante todo el procedimiento. La legislación regional hace referencia a la orientación, por parte del EPV, pero tampoco indica en qué momento ni sobre qué aspectos se proporcionará dicha orientación.

\section{Entrevistas}

Uno de los evaluadores entrevistados del procedimiento de Castilla y León, ha puesto en duda la existencia de esta fase y en su caso, su efectividad. En cuanto al procedimiento de Emilia-Romagna, uno de los gestores/dirigentes ha explicado que la orientación sería un paso previo al procedimiento, en manos de los servicios de empleo, en el que todavía se está trabajando. Por tanto, no se trataría de una fase transversal, aunque se pretende que lo sea.

3.2. ORIENTACIÓN AL FIN ALIZAR EL PROCEDIMIENTO

\subsubsection{Sin subcategoría}

\begin{tabular}{|c|c|c|c|c|c|c|c|c|}
\hline \multirow[b]{3}{*}{ IND. } & \multicolumn{4}{|c|}{ ESPAÑA } & \multicolumn{4}{|c|}{ ITALIA } \\
\hline & \multicolumn{2}{|c|}{ Legislación } & \multirow{2}{*}{$\begin{array}{c}\text { Entrevis- } \\
\text { tas }\end{array}$} & \multirow{2}{*}{$\begin{array}{c}\text { Cues- } \\
\text { tio- } \\
\text { narios }\end{array}$} & \multicolumn{2}{|c|}{ Legislación } & \multirow{2}{*}{$\begin{array}{l}\text { Entre- } \\
\text { vistas }\end{array}$} & \multirow{2}{*}{$\begin{array}{c}\text { Cues- } \\
\text { tio- } \\
\text { narios }\end{array}$} \\
\hline & $\begin{array}{l}\mathrm{Na-} \\
\text { cional }\end{array}$ & $\begin{array}{l}\text { Autonó- } \\
\text { mica }\end{array}$ & & & $\begin{array}{c}\text { Nacio- } \\
\text { nal }\end{array}$ & $\begin{array}{c}\text { Regio- } \\
\text { nal }\end{array}$ & & \\
\hline 3.2.0.1 & sí & sí & sí & sí & sí & sí & sí & sí \\
\hline
\end{tabular}

3.2.0.1. INDICADOR: Se proporciona al candidato una orientación suplementaria, al finalizar el procedimiento, sobre las posibilidades de formación $y / 0$ de salidas profesionales.

\section{Comparación}

\section{Legislación}


La legislación nacional española y la legislación autonómica de Castilla y León distinguen dos tipos de orientación al finalizar el procedimiento: la dirigida a las personas que no hayan logrado acreditar sus competencias, a las que se les debe proporcionar orientación sobre cómo lograr la acreditación en posteriores convocatorias y la dirigida a las personas que superen la evaluación, a las cuales se les debe orientar sobre cómo lograr el certificado de profesionalidad o título correspondiente. Por su parte, la legislación nacional italiana y la autonómica de Emilia-Romagna, como hemos comentado en el anterior indicador 3.1.0.1, hablan de proporcionar información y orientación, pero no especifican ni los aspectos ni el momento.

\section{Entrevistas}

Los dos evaluadores entrevistados del procedimiento de Castilla y León, han declarado haber proporcionado este tipo de información y orientación. Uno de ellos ha señalado que la orientación para ayudar al candidato a solicitar el título está en la web de la Junta, lo cual no resulta fácil a muchos candidatos de escasos conocimientos informáticos. Respecto a los entrevistados del procedimiento de Emilia-Romagna, el EAPQ y uno de los EPV entrevistados han declarado que esta fase no está prevista en el procedimiento, a pesar de ello, el EAPQ entrevistado ha afirmado haber proporcionado orientación a los candidatos, al término del procedimiento, si estos la han demandado.

\section{Cuestionarios}

Exponemos las repuestas obtenidas en las siguientes gráficas (ver Figura 9) sobre las preguntas realizadas a los asesores y evaluadores, de ambos procedimientos, relacionadas con la orientación/información proporcionada al candidato, al finalizar el asesoramiento o el procedimiento. Para profundizar más en este aspecto hemos preguntado por la información que se ha dado al candidato sobre: oportunidades en el campo formativo, a partir de sus competencias; los puntos fuertes y débiles del candidato; las posibles dificultades en el campo formativo y las posibles salidas profesionales. 
La validación de competencias profesionales en España e Italia

Figura 9: Información de asesores al finalizar el procedimiento

a)

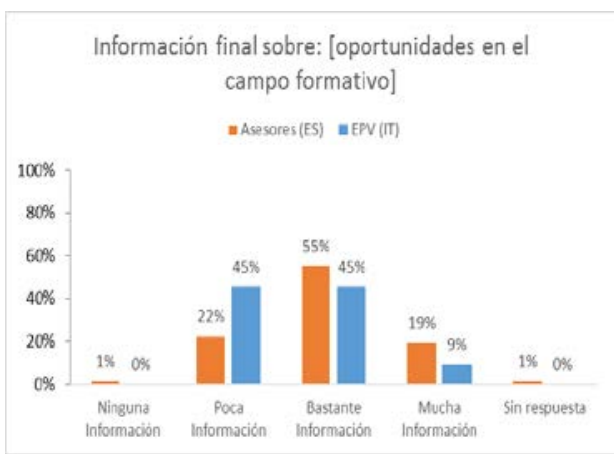

c)

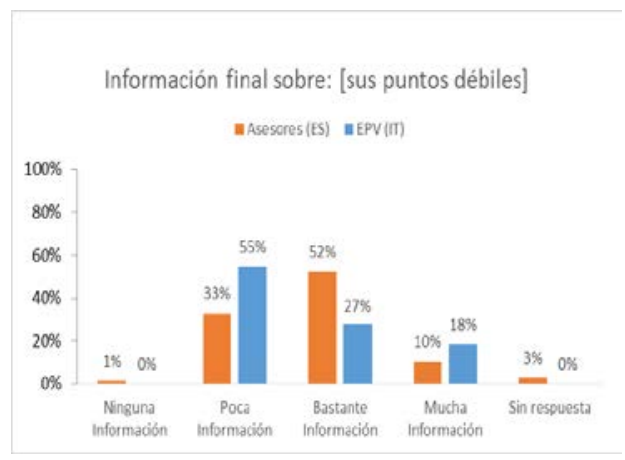

b)

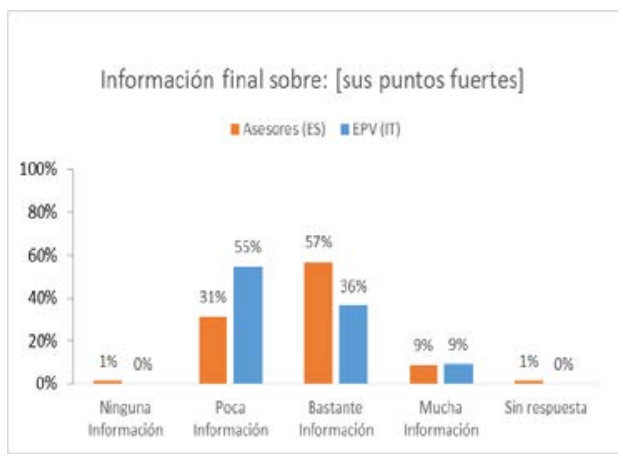

d)

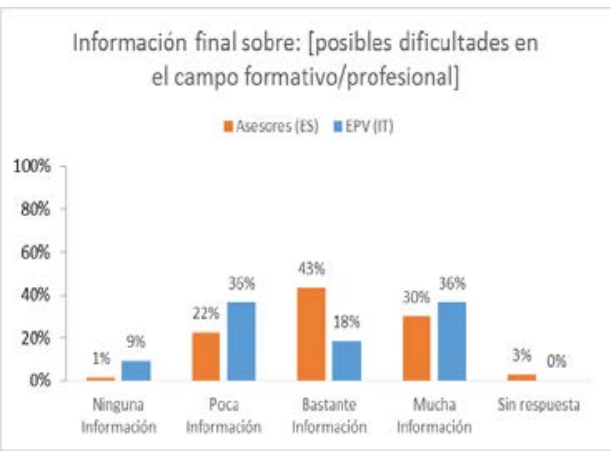

e)

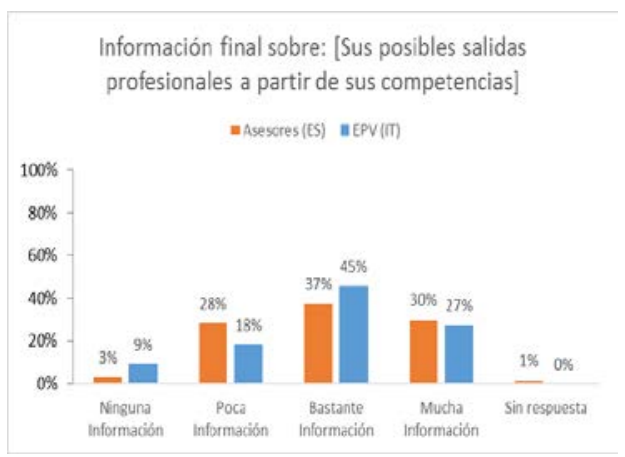

Como se observa en estas gráficas, en general, los asesores del procedimiento de Castilla y León han proporcionado mayor cantidad de información, sobre los aspectos por los que se ha preguntado, que los EPV 
(asesores) del procedimiento de Emilia-Romagna (ver Figura 9 a), b), c) y d). En concreto, los asesores de Castilla y León han proporcionado más información, respecto a los demás puntos, sobre las posibilidades del candidato en el campo formativo, con un 55\% y un 19\% que han señalado haber proporcionado bastante y mucha información respectivamente (ver Figura 9 a). También han facilitado gran cantidad de información, al candidato, sobre sus posibles dificultades en el campo formativo/profesional con un $43 \%$ y $30 \%$ que han indicado haber proporcionado bastante y mucha información respectivamente, sobre este punto (ver Figura 9 d). En el procedimiento de Emilia-Romagna, comprobamos que el mayor porcentaje sobre información proporcionada al candidato recae en las salidas profesionales a partir de sus competencias profesionales, con un $45 \%$ y un $27 \%$ que han afirmado haber proporcionado bastante y mucha información respectivamente, referida a este tema ( ver Figura 9 e). Según estos porcentajes, los asesores del procedimiento castellanoleonés han dado más peso a la información relacionada con la formación, mientras que los EAPQ (evaluadores) del procedimiento de Emilia-Romagna han dado más relevancia a informar sobre las salidas profesionales.

Dado que en el procedimiento de Emilia-Romagna no está previsto que el EAPQ (evaluador) proporcione información al candidato sobre formación o trabajo (ver subapartado 4.3.8.3 en el que se tratan las funciones de los profesionales), hemos preguntado a estos profesionales encuestados, quiénes de ellos habían proporcionado este tipo de información.

Figura 10: Porcentaje de EAPQ que ha proporcionado información al candidato al finalizar el procedimiento

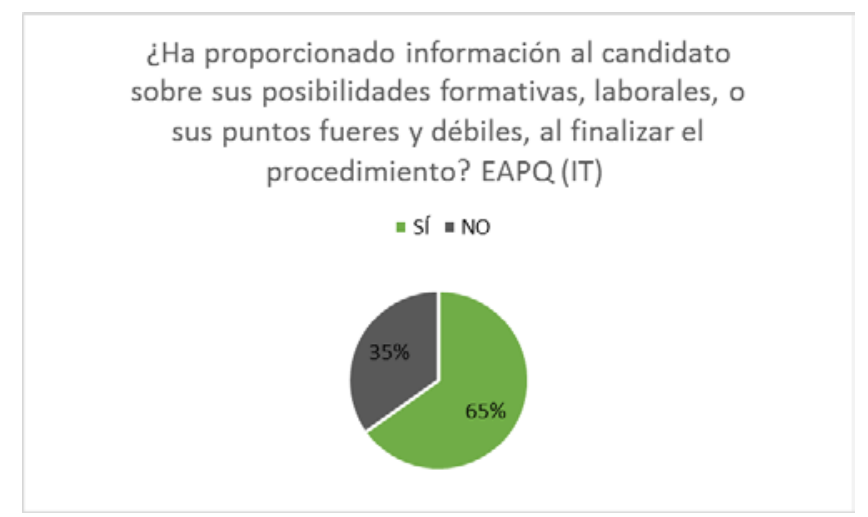


La validación de competencias profesionales en España e Italia

Como puede observarse, un $65 \%$ de los EAPQ (evaluadores) ha manifestado haber proporcionado al candidato información de este tipo, a pesar de no estar previsto por el procedimiento (ver Figura 10).

A continuación, se valora el grado de información que han proporcionado los evaluadores del procedimiento de Castilla y León y aquellos EAPQ (evaluadores) del procedimiento de Emilia-Romagna, que sí han proporcionado información, sobre los mismos aspectos por los que se ha preguntado a los asesores:

Figura 11: Información final por parte de los evaluadores sobre el procedimiento

a)

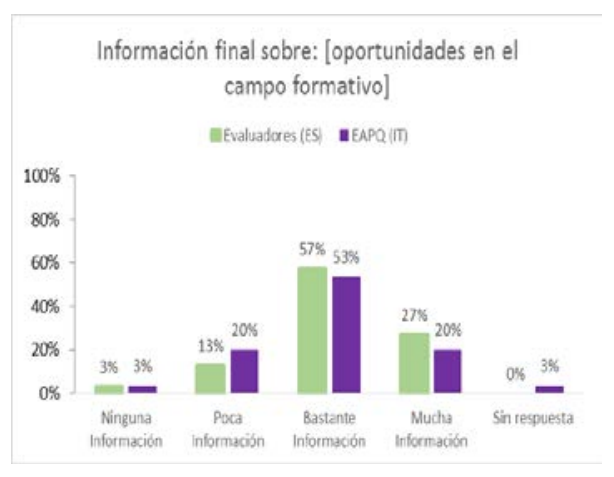

c)

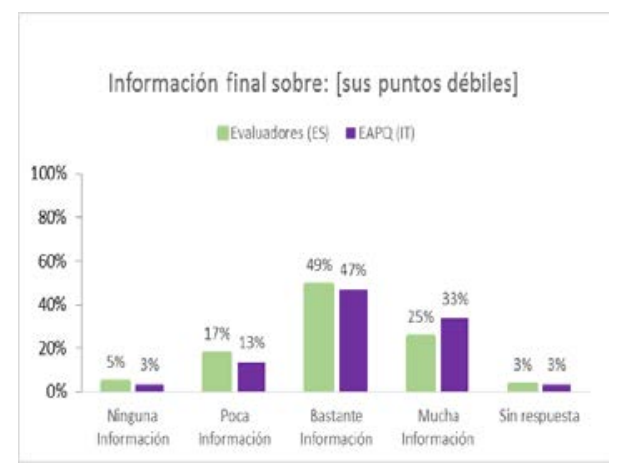

b)

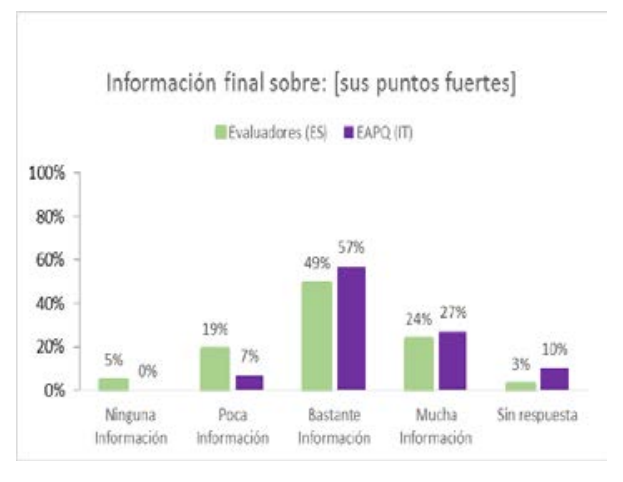

d)

Información final sobre: [posibles dificultades en el campo formativo/profesional]

$$
\text { mEvaluadores (ES) - IEAPQ (iT) }
$$

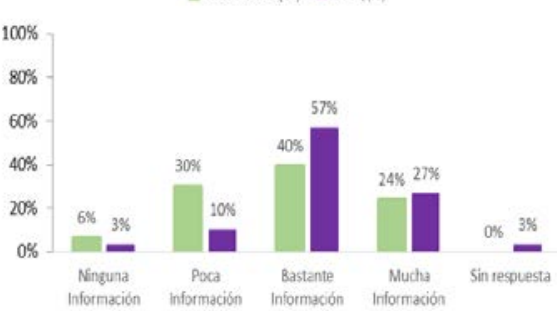


e)

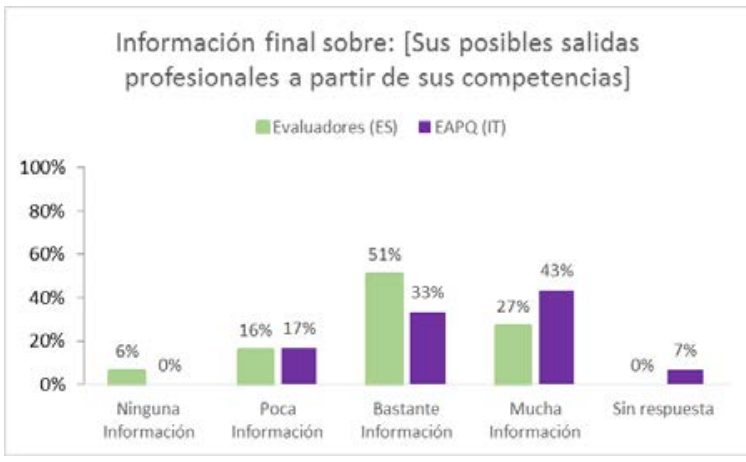

Como podemos observar en estas gráficas, los evaluadores de los dos procedimientos han proporcionado bastante información relacionada con todos los puntos por los que les hemos preguntado ver Figura 11 a), b), c), d) y e). El aspecto sobre el que más información han proporcionado los evaluadores en el procedimiento de Castilla y León, ha sido el referido a las oportunidades formativas del candidato (ver Figura 11 a). Por el contrario, en Emilia-Romagna, aunque también han informado sobre este aspecto, pero en mucha menor medida, respecto a las demás cuestiones y al procedimiento castellanoleonés. Por su parte, los EAPQ han proporcionado mayor información sobre los puntos fuertes del candidato y sobre las dificultades que puede encontrar en el campo formativo/profesional (ver Figura 11 a) y b) que en contraposición, han sido los argumentos menos mencionados por los evaluadores del procedimiento castellanoleonés. Para concluir, cabe señalar que los EPV, que sí han proporcionado este tipo de información, han señalado haberlo hecho en mayor medida que los asesores del procedimiento castellanoleonés. 
La validación de competencias profesionales en España e Italia

4. ASESORAMIENTO

4.1. INFORMACIÓN EN EL PROCESO DE ASESORAMIENTO

4.1.0. Sin subcategoría

\begin{tabular}{|c|c|c|c|c|c|c|c|c|}
\hline \multirow[b]{3}{*}{ IND. } & \multicolumn{4}{|c|}{ ESPAÑA } & \multicolumn{4}{|c|}{ ITALIA } \\
\hline & \multicolumn{2}{|c|}{ Legislación } & \multirow{2}{*}{$\begin{array}{l}\text { Entrevis- } \\
\text { tas }\end{array}$} & \multirow{2}{*}{$\begin{array}{c}\text { Cues- } \\
\text { tio- } \\
\text { narios }\end{array}$} & \multicolumn{2}{|c|}{ Legislación } & \multirow{2}{*}{$\begin{array}{l}\text { Entre- } \\
\text { vistas }\end{array}$} & \multirow{2}{*}{$\begin{array}{c}\text { Cues- } \\
\text { tio- } \\
\text { narios }\end{array}$} \\
\hline & $\begin{array}{l}\mathrm{Na}- \\
\text { cional }\end{array}$ & $\begin{array}{c}\text { Autonó- } \\
\text { mica }\end{array}$ & & & $\begin{array}{c}\text { Nacio- } \\
\text { nal }\end{array}$ & $\begin{array}{c}\text { Regio- } \\
\text { nal }\end{array}$ & & \\
\hline 4.1.0.1 & sí & sí & sí & sí & sí & sí & NO & sí \\
\hline
\end{tabular}

\section{Comparación}

\section{Legislación}

Este aspecto no se toca directamente en el ámbito legislativo. La legislación española aborda este argumento de forma indirecta, hablando de asesorar al candidato en la preparación y puesta a punto del proceso de evaluación, lo que implica proporcionar información sobre el procedimiento. La legislación autonómica de Castilla y León dispone que la información sobre el procedimiento (asesor asignado, fecha, provincia y lugar de la primera reunión) se publique online, lo cual tampoco supone una referencia directa al respecto, porque no indica que sea el asesor quien deba proporcionar dicha información. En cuanto a la legislación nacional italiana, hace referencia a la adopción de medidas personalizadas de información pero no especifica quién debe hacerlo, en qué momento y sobre qué aspectos. La legislación regional, aunque no indica quién debe hacerlo, establece que debe darse información al candidato sobre aspectos del procedimiento (articulación, valor, salidas, condiciones de asesoramiento).

\section{Entrevistas}

Uno de los asesor entrevistados del procedimiento de Castilla y León, ha declarado que se ha proporcionado información general sobre el procedimiento al candidato (fases, qué deben hacer, gestión del procedimiento, papel del asesor y del evaluador, los certificados de profesionalidad y los certificados de profesionalidad y las Unidades de Competencia). También 
indicó que en la primera parte de la convocatoria, los candidatos llegaban más desinformados y con bastante miedo al procedimiento. Por otro lado, no existen referencias al respecto por parte de los EPV (asesores) entrevistados del procedimiento de Emilia-Romagna.

\section{Cuestionarios}

A través de los cuestionarios hemos valorado este aspecto, preguntando a los asesores de ambos procedimientos acerca de la cantidad de información proporcionada por ellos mismos a los candidatos, sobre diferentes aspectos relacionados con el procedimiento:

Figura 12: Información por parte asesores al candidato sobre el procedimiento

a)

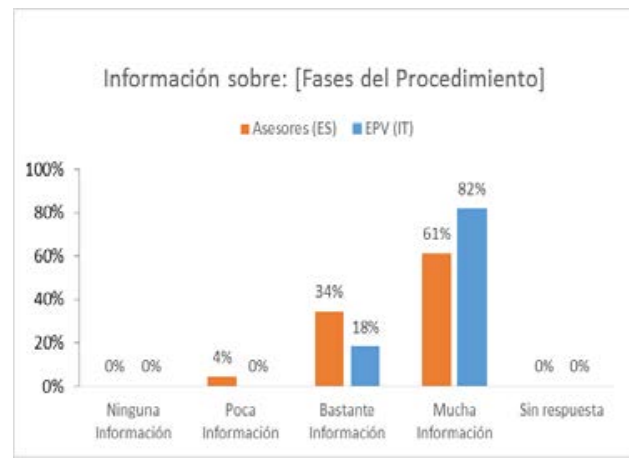

c)

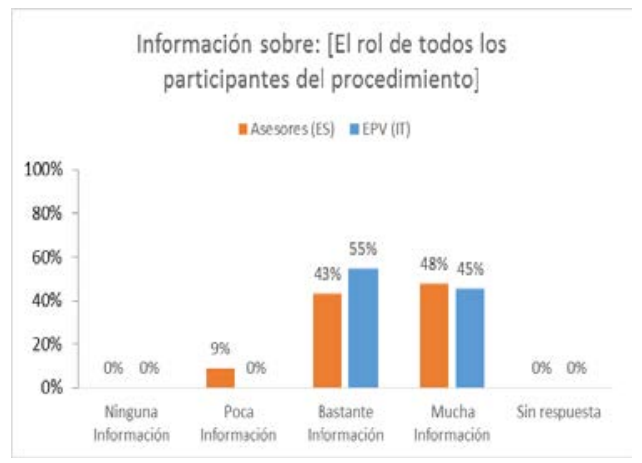

b)

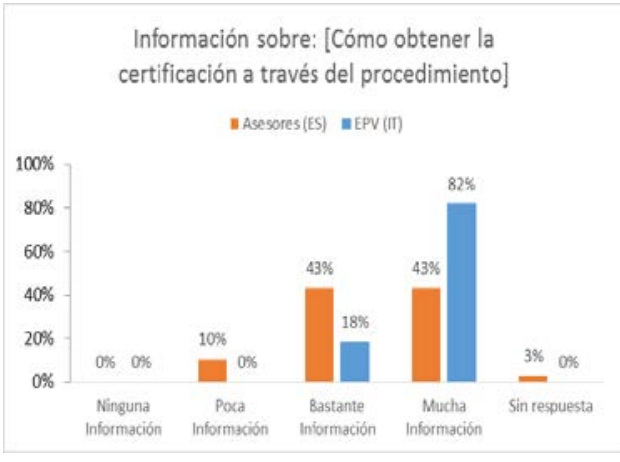

d)

Información sobre: [La metodología a seguir en el proceso de evaluación] nAsesores (ES) $\mid$ EPV (II)

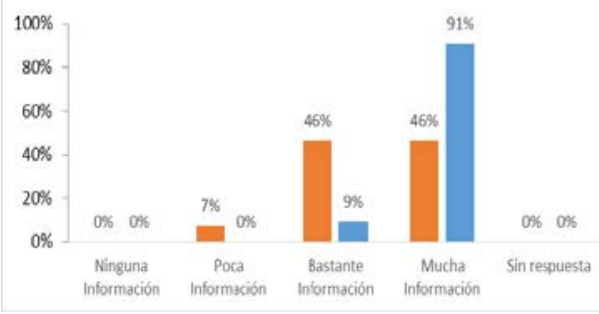


La validación de competencias profesionales en España e Italia

e)

Información sobre: [Los instrumentos que se utilizarian en el procedimiento]

\#Asesores (ES) =EPV (IT)

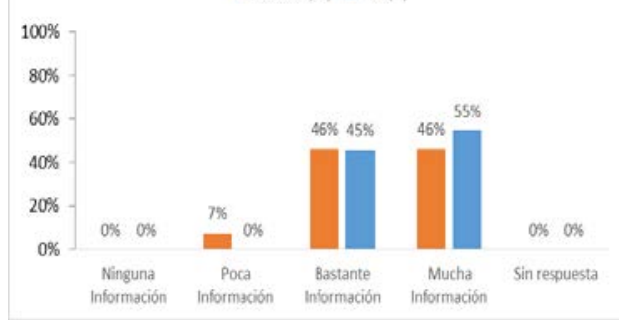

g)

Información sobre: [Las tareas a realizar por el candidato durante todo el procedimiento]

- Asesores (ES) IEPV (II)

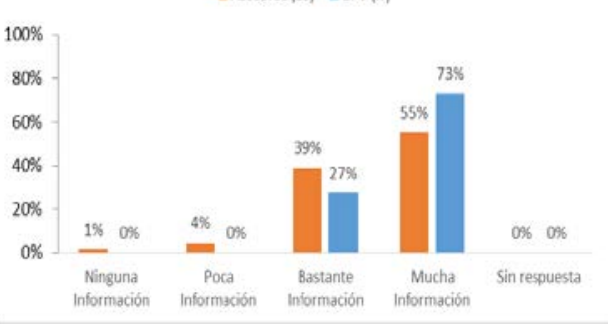

i)

Información sobre: [Dónde se llevaría a cabo el proceso de evaluación]

$\because$ Asesores (ES) $\amalg E P V($ II)

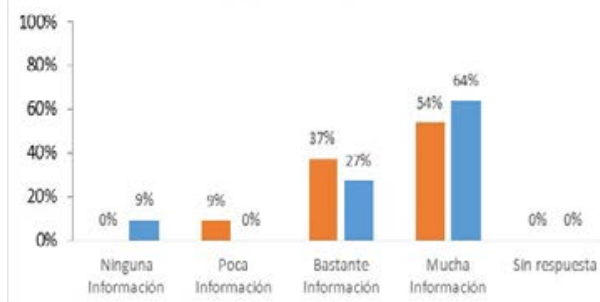

f)

Información sobre: [El funcionamiento de los instrumentos que se utilizarian]

- Asesores (ES) a EPV (IT)

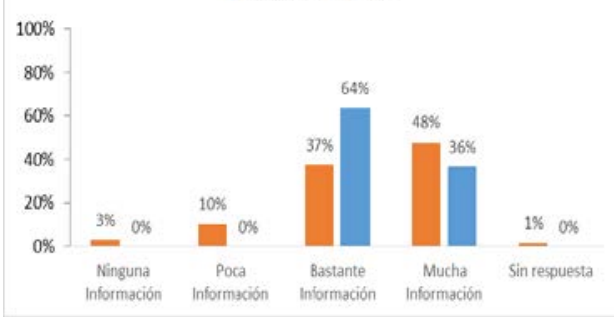

h)

Información sobre: [La cantidad de tiempo que invertiría el candidato durante todo el procedimiento]

-Asesores (ES) IEPV (IT)

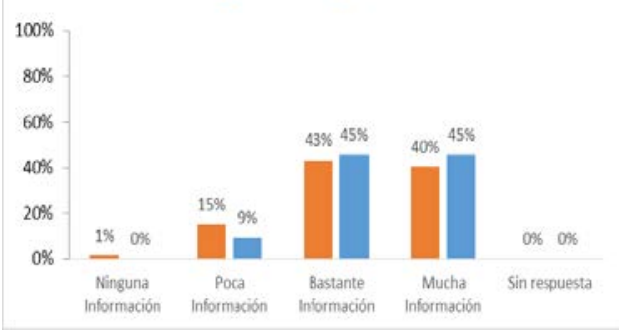

j)

Información sobre: [Cuándo se llevaría a cabo el proceso de evaluación]

uAsesores (ES) $=$ EPV (in)

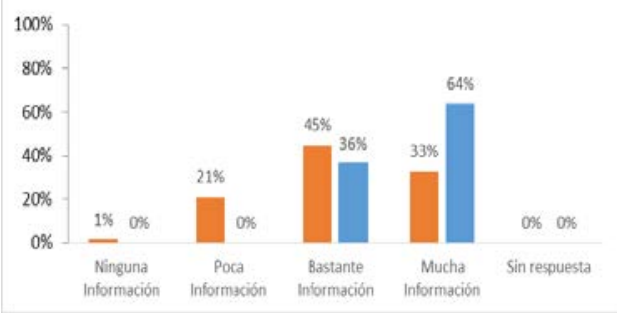


$\mathrm{k})$

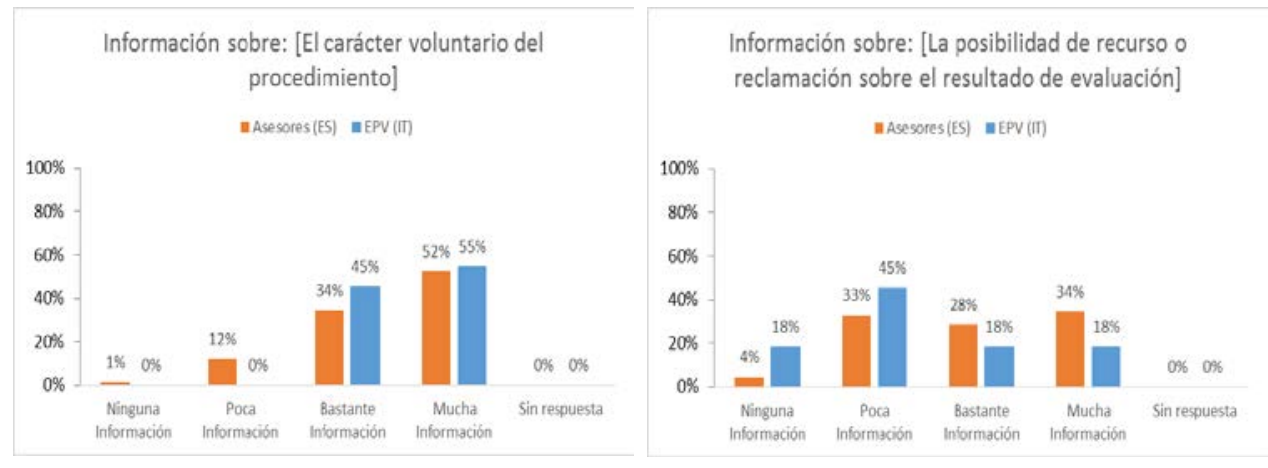

Según estas gráficas, los asesores de ambos procedimientos han proporcionado bastante información sobre todos los aspectos por los que se ha preguntado (ver Figura 12). Sin embargo, debemos exceptuar el punto sobre la información acerca de la posibilidad de recurso o reclamación, aspecto sobre el que menos han informado los asesores en los dos procedimientos, (un 4\% y 33\% ninguna y poca información respectivamente, en Castilla y León y un $18 \%$ y $45 \%$ ninguna y poca información respectivamente, en Emilia-Romagna, (ver Figura 12 j). Exceptuando este aspecto, los EPV (asesores) han proporcionado más información que los asesores de Castilla y León, el punto al que han dado mayor importancia, en cuanto a información, ha sido la metodología a seguir en el proceso de evaluación. Por su parte, los asesores del procedimiento de Castilla y León han indicado haber dado más información, respecto a los otros aspectos, sobre las fases del procedimiento y las tareas que debe realizar el candidato durante el procedimiento.

Con objeto de evitar dejar fuera cualquier aspecto informativo que se haya proporcionado a los candidatos en ambos procedimientos, hemos preguntado a los encuestados si habían proporcionado algún otro tipo de información relacionada con el procedimiento, a parte de los puntos expuestos con anterioridad.

Varios de los asesores del procedimiento en Castilla y León, han manifestado haber proporcionado explicaciones y aclaraciones, al candidato, sobre cómo presentar las evidencias de las competencias profesionales objeto de acreditación. Algunos han indicado haber informado sobre la importancia de la acreditación, en cuanto a la estabilidad profesional. Otro grupo de asesores ha explicado el hecho de que a través de este procedi- 
miento el candidato obtenía una acreditación, pero no un título oficial, el cual debería ser solicitado tras la superación de la evaluación. Por último, en menor medida, han señalado haber proporcionado información sobre la acreditación parcial de las UC, sobre el material del que dispone el candidato para el procedimiento (guía del candidato del manual de procedimiento) y sobre la normativa relacionada con el procedimiento.

En Italia, los EPV (asesores) han reflejado haber proporcionado otra información al candidato sobre los posibles resultados que podría obtener con el procedimiento y, como en los asesores del procedimiento castellanoleonés, sobre la validez de los certificados que otorga el procedimiento.

También hemos querido indagar sobre las vías utilizadas para proporcionar toda esta información sobre el procedimiento a los candidatos:

Figura 13: Vías de información utilizadas por los asesores

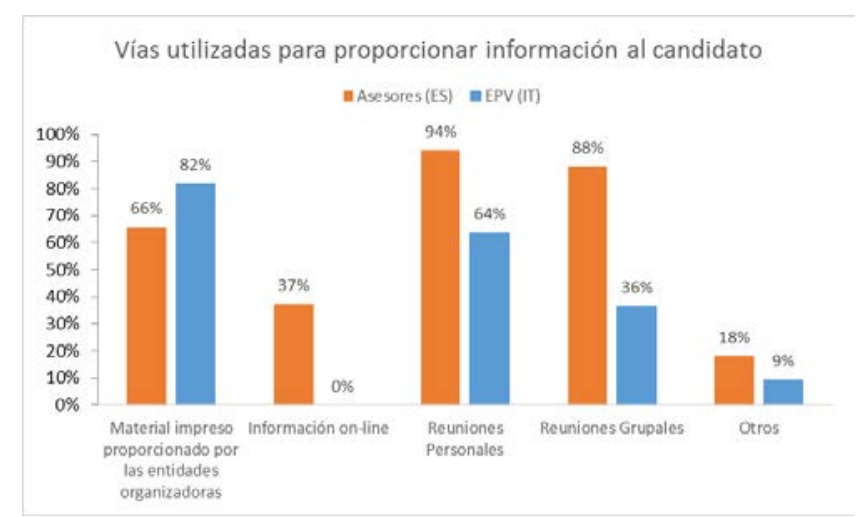

La vía más utilizada en el procedimiento de Castilla y León, por los asesores, ha sido la reunión personal mientras que en Italia se ha utilizado más el material impreso (ver Figura 13).

Además, los asesores del procedimiento de Castilla y León han señalado otras vías, como el teléfono (explicando que se ha utilizado con el fin de adaptarse a la disponibilidad de tiempo del candidato); las presentaciones informáticas elaboradas por el asesor; los mensajes de móvil y la carta certificada. Los EPV (asesores) del procedimiento de no han especificado otras vías de información. 
4.2. CATEGORÍA: PROCESO DE RECOGIDA DE EVIDENCLAS

\subsubsection{SUBCATEGORÍA: Adecuación del proceso de recogida de evidencias}

\begin{tabular}{|c|c|c|c|c|c|c|c|c|}
\hline \multirow[b]{3}{*}{ IND. } & \multicolumn{4}{|c|}{ ESPAÑA } & \multicolumn{4}{|c|}{ ITALIA } \\
\hline & \multicolumn{2}{|c|}{ Legislación } & \multirow{2}{*}{$\begin{array}{l}\text { Entrevis- } \\
\text { tas }\end{array}$} & \multirow{2}{*}{$\begin{array}{c}\text { Cues- } \\
\text { tio- } \\
\text { narios }\end{array}$} & \multicolumn{2}{|c|}{ Legislación } & \multirow{2}{*}{$\begin{array}{l}\text { Entre- } \\
\text { vistas }\end{array}$} & \multirow{2}{*}{$\begin{array}{c}\text { Cues- } \\
\text { tio- } \\
\text { narios }\end{array}$} \\
\hline & $\begin{array}{c}\mathrm{Na}- \\
\text { cional }\end{array}$ & $\begin{array}{c}\text { Autonó- } \\
\text { mica }\end{array}$ & & & $\begin{array}{c}\text { Nacio- } \\
\text { nal }\end{array}$ & $\begin{array}{c}\text { Regio- } \\
\text { nal }\end{array}$ & & \\
\hline 4.2.1.1 & Sí & Sí & sí & NO & NO & sí & sí & $\mathrm{NO}$ \\
\hline 4.2.1.2 & Sí & NO & Sí & $\mathrm{NO}$ & NO & sí & sí & NO \\
\hline 4.2.1.3 & SÍ & Sí & SÍ & NO & NO & Sí & sí & NO \\
\hline
\end{tabular}

\section{Comparación}

\section{Legislación}

La legislación nacional española y la legislación autonómica de Castilla y León establecen con precisión con qué documentos se justificará la experiencia laboral, con objeto de que los candidatos apoyen las evidencias presentadas para el reconocimiento de sus competencias. Respecto a la legislación nacional italiana, no hace referencia a este aspecto, aunque si lo hace la regional, estableciendo unas pautas sobre el tipo de evidencias que deben presentarse y cómo deben ser.

\section{Entrevistas}

En cuanto a las entrevistas, uno de los asesores entrevistados, del procedimiento de Castilla y León, ha asegurado que este aspecto está muy definido en el procedimiento. Respecto a las entrevistas realizadas a los profesionales del procedimiento de Emilia-Romagna, un gestor/organizador y un EPV han expuesto en sus declaraciones, que existen pautas para la recogida de evidencias en la normativa regional (Deliberación 530). 
La validación de competencias profesionales en España e Italia

4.2.1.2. INDICADOR: Las evidencias documentadas por un individuo están directamente relacionadas con los estándares utilizados para la validación.

\section{Comparación}

\section{Legislación}

En la legislación autonómica de Castilla y León no se han encontrado referencias. No obstante no existan alusiones directas en la legislación nacional, en ella se menciona la Guía del Asesor, la cual hace referencia a este tema indicando los referentes que deben utilizarse para la validación. En cuanto a la legislación nacional italiana, no se han encontrado referencias a este aspecto, sin embargo, en la regional de Emilia-Romagna, se indica que las evidencias que presente el candidato deben estar relacionadas con los estándares utilizados para la validación.

\section{Entrevistas}

Los profesionales del asesoramiento, de ambos procedimientos, han asegurado la relación entre las evidencias y los estándares de validación. En el procedimiento de Castilla y León, dos asesores entrevistados, han comentado que las evidencias que han recogido estaban relacionadas con los estándares de validación. Respecto al procedimiento de Emilia-Romagna, uno de los gestores/dirigentes entrevistado ha asegurado que para la recogida de evidencias se tienen en cuenta los estándares de validación, a través de una ficha descriptiva de las competencias que debe demostrar el candidato.

\subsubsection{INDICADOR: El proceso de documentación está dirigido}

\section{Comparación}

\section{Legislación}

Tanto la legislación nacional española, como la autonómica de Castilla y León, contemplan este aspecto, indicando cómo deberá dirigir el asesor esta fase. En cuanto a la legislación nacional italiana, no se han encontrado referencias sobre este aspecto, sin embargo la legislación regional sí refleja este tema, señalando que debe ser el EPV (asesor) quien debe guiar al candidato en este proceso.

\section{Entrevistas}


En cuanto a las entrevistas, cabe señalar que tanto los dos asesores entrevistados del procedimiento de Castilla y León, como los dos EPV (asesores) entrevistados del procedimiento de Emilia-Romagna, han declarado haber dirigido al candidato en el proceso de asesoramiento.

\subsubsection{SUBCATEGORÍA: Adecuación de los instrumentos para la recogida de} evidencias

\begin{tabular}{|c|c|c|c|c|c|c|c|c|}
\hline \multirow[b]{3}{*}{ IND. } & \multicolumn{4}{|c|}{ ESPAÑA } & \multicolumn{4}{|c|}{ ITALIA } \\
\hline & \multicolumn{2}{|c|}{ Legislación } & \multirow{2}{*}{$\begin{array}{l}\text { Entrevis- } \\
\text { tas }\end{array}$} & \multirow{2}{*}{$\begin{array}{c}\text { Cues- } \\
\text { tio- } \\
\text { narios }\end{array}$} & \multicolumn{2}{|c|}{ Legislación } & \multirow{2}{*}{$\begin{array}{l}\text { Entre- } \\
\text { vistas }\end{array}$} & \multirow{2}{*}{$\begin{array}{c}\text { Cues- } \\
\text { tio- } \\
\text { narios }\end{array}$} \\
\hline & $\begin{array}{l}\mathrm{Na-} \\
\text { cional }\end{array}$ & $\begin{array}{c}\text { Autonó- } \\
\text { mica }\end{array}$ & & & $\begin{array}{c}\text { Nacio- } \\
\text { nal }\end{array}$ & $\begin{array}{c}\text { Regio- } \\
\text { nal }\end{array}$ & & \\
\hline 4.2.2.1 & sí & Sí & Sí & Sí & $\mathrm{NO}$ & sí & sí & Sí \\
\hline 4.2 .2 .2 & NO & NO & sí & sí & NO & NO & sí & sí \\
\hline
\end{tabular}

\section{Comparación}

\section{Legislación}

En la legislación nacional española no existen referencias directas sobre este aspecto, aunque la Guía del Asesor (indicada en el RD 1224/2009) habla de diferentes instrumentos para la recogida de evidencias. Asimismo, la legislación autonómica de Castilla y León, indica el uso de varios instrumentos para este fin. Respecto a la legislación nacional italiana, no se han encontrado referencias sobre este aspecto, sin embargo, en la regional de Emilia-Romagna, sí se hace alusión a diferentes tipos de instrumentos para la recogida de evidencias.

\section{Entrevistas}

Los dos asesores entrevistados, del procedimiento de Castilla y León, han afirmado haber utilizado diferentes instrumentos para la recogida de evidencias. Respecto a los entrevistados del procedimiento de EmiliaRomagna, uno de los gestores/organizadores del procedimiento, ha comentado que se han tenido en cuenta diversos tipos de justificación de evidencias. 
La validación de competencias profesionales en España e Italia

\section{Cuestionarios}

A través de las respuestas a los cuestionarios (expuestas en el indicador 4.2.2.2, ver Figura 14 y Figura 17) podemos comprobar que efectivamente se utilizó una amplia variedad de instrumentos, en el procedimiento de Castilla y León (ver Figura 14) se ha utilizado: el historial formativo/profesional; cuestionarios de autoevaluación; fichas sobre funciones desempeñadas en el puesto de trabajo y la entrevista de asesoramiento. Por otro lado, en el procedimiento de Emilia-Romagna, se ha hecho uso de: declaraciones; contratos de colaboración; autodeclaraciones; diplomas certificados; muestras del producto de trabajo; documentos realizados por el candidato; testimonios; grabaciones de audio/video y diarios del candidato.

\subsubsection{INDICADOR: Los instrumentos para la documentación de eviden-} cias reflejan las competencias del solicitante.

\section{Comparación}

\section{Legislación}

No se han encontrado referencias al respecto en la legislación, ni en la nacional española/italiana, ni en la autonómica de Castilla y León/regional de Emilia-Romagna.

\section{Entrevistas}

Respecto a las entrevistas, los dos asesores entrevistados del procedimiento de Castilla y León han coincidido en la utilidad de los instrumentos para determinar las competencias del candidato, aunque también han señalado, como aspecto negativo, la dificultad del lenguaje utilizado en los mismos. En cuanto a los entrevistados del procedimiento de EmiliaRomagna, uno de los EAPQ entrevistados también ha considerado de utilidad de estos instrumentos para determinar las competencias del sujeto.

\section{Cuestionarios}

En lo referido a los cuestionarios, se ha pedido a los profesionales encargados del asesoramiento, de ambos procedimientos, valorar la utilidad de los instrumentos en esta fase, indicándoles que por instrumento útil entendíamos, que este lograse reflejar las competencias del candidato, favoreciendo el asesoramiento. Dada la diferencia de los instrumentos entre 
un procedimiento y otro, hemos decidido indagar de forma separada sobre la utilidad de estos instrumentos (por un lado los instrumentos utilizados en el procedimiento de Castilla y León y por el otro, los utilizados en el procedimiento de Emilia.Romagna).

En primer lugar presentamos, a través de gráficas, los resultados de las respuestas dadas por asesores de Castilla y León. Para empezar, exponemos su opinión sobre los instrumentos utilizados en el proceso de asesoramiento, a continuación presentamos el uso, por parte de los asesores encuestados, de otros instrumentos no mencionados en el cuestionario y por último, indicamos las respuestas a la pregunta de si han echado en falta otros instrumentos.

Para el procedimiento de Castilla y León, teniendo en cuenta los instrumentos previstos por la guía del asesor, (ver subapartado 4.2.6.2) hemos pedido a los asesores su opinión respecto al historial formativo/profesional; los cuestionarios de autoevaluación; los documentos/fichas sobre las actividades llevados a cabo por el candidato en el trabajo y la entrevista con fines de asesoramiento:

Figura 14: Utilidad de instrumentos de asesoramiento en el procedimiento de Castilla y León

a)

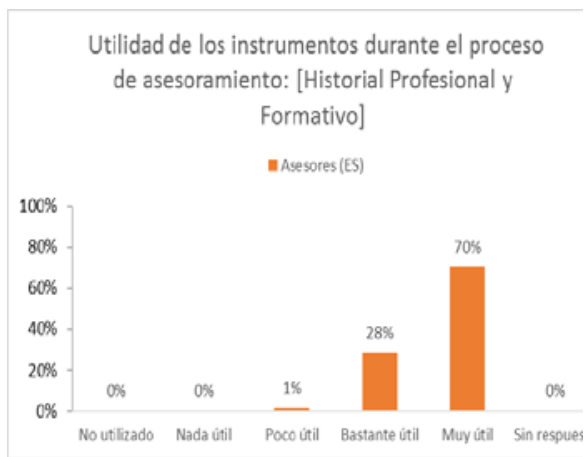

b)

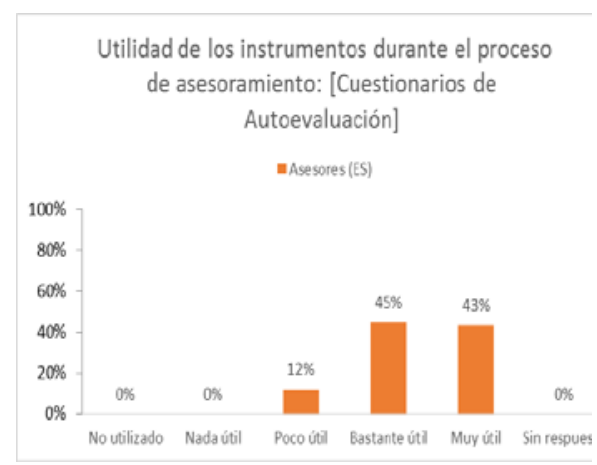


c)

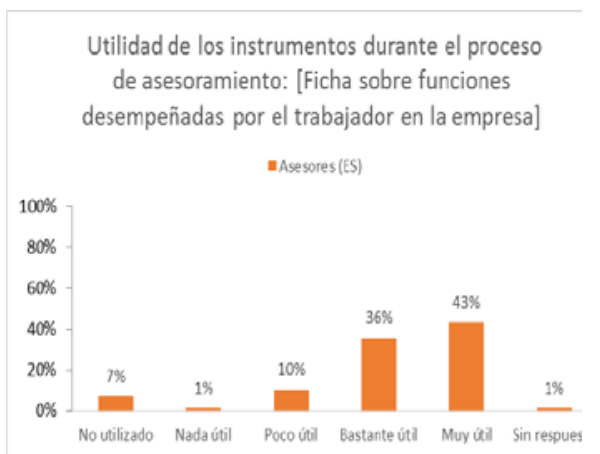

d)

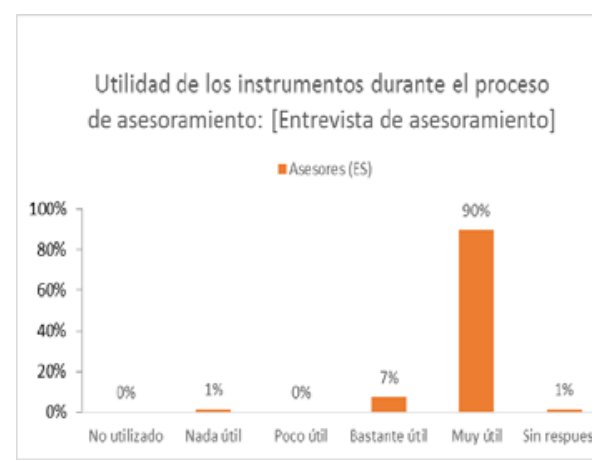

Como podemos ver en la Figura 14 d), el instrumento valorado como el más útil es la entrevista de asesoramiento, valorado como muy útil por el $90 \%$ de los asesores encuestados. Asimismo, el historial formativo/profesional es otro instrumento especialmente valorado, considerado muy útil por un $70 \%$ de los asesores encuestados (ver Figura 14 a). Cabe destacar que más de un $79 \%$ de los encuestados considera bastante o muy útil los 4 instrumentos presentados.

Asimismo, cuando hemos indagado sobre otros instrumentos utilizados por los asesores encuestados, hemos comprobado que estos también han considerado muy útil el $\mathrm{CV}$ Europass que, según han declarado, ha ayudado a valorar las competencias de los candidatos y ha facilitado el inicio de la entrevista con fines de asesoramiento.

Cuando se ha preguntado a los asesores del procedimiento castellanoleonés si habían echado en falta algún instrumento en el proceso de asesoramiento, sólo el 17\% de los asesores contestaron que sí (ver Figura 15): 
Figura 15: Porcentaje de asesores del procedimiento de Castilla y León que han echado en falta algún instrumento

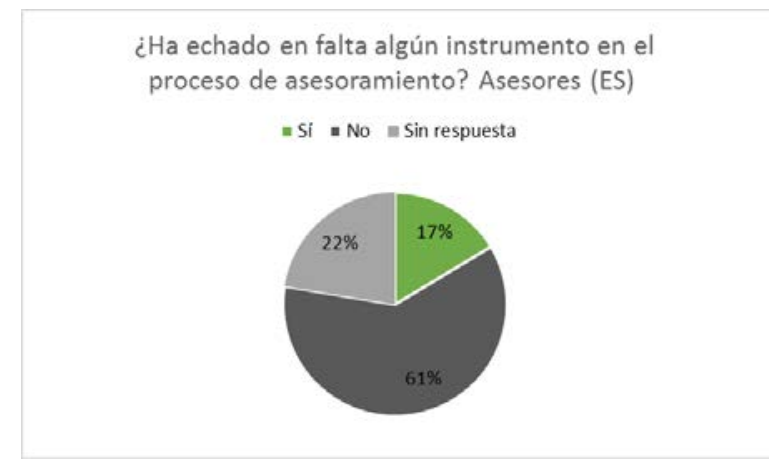

En particular, varios asesores han indicado que les hubiese gustado encontrar un mejor modelo de entrevista y de redacción del informe, que facilitasen su elaboración con algunas variantes según el candidato. También han manifestado la necesidad de mejorar los certificados de empresa, realizados por los empleadores del candidato, con objeto de que las tareas estén bien definidas. Asimismo, se ha revindicado la creación de un sistema informático que recoja todo el $\mathrm{CV}$ del candidato, en lugar de los documentos impresos y un cuestionario más elaborado para medir el grado de competencia que tiene y debe de tener el candidato. Han añadido también, que estos cuestionarios resultan de difícil realización, ya que en numerosas ocasiones los candidatos no entienden las palabras, expresiones o sentido de la pregunta, por lo que opinan que deberían mejorar en ese aspecto. En definitiva, los asesores del procedimiento castellanoleonés, piden algunas mejoras en algunos de los instrumentos de asesoramiento que ofrece el procedimiento.

Respecto al estudio sobre los instrumentos en el procedimiento de Emilia-Romagna, seguimos la misma estructura que con los instrumentos de Castilla y León. Primero presentamos los resultados obtenidos de las respuestas de los EPV (asesores) y de los EAPQ (evaluadores), a estos últimos, a pesar de ser evaluadores, se les ha preguntado también sobre este aspecto, porque el procedimiento prevé que ellos también participen en la fase de asesoramiento, cuando el EPV así lo requiera (ver subapartado 4.3.8.3). Después exponemos el uso de otros instrumentos no mencionados en el cuestionario y por último, indicamos las respuestas, de los profesionales del procedimiento, a la pregunta de si han echado en falta otros instrumentos. 
La validación de competencias profesionales en España e Italia

Antes de preguntar por los instrumentos, hemos querido distinguir a los EAPQ que han participado en la fase de asesoramiento, de aquellos que no lo han hecho.

Figura 16: Porcentaje de asesores del procedimiento de Emilia-Romagna que han participado en el asesoramiento

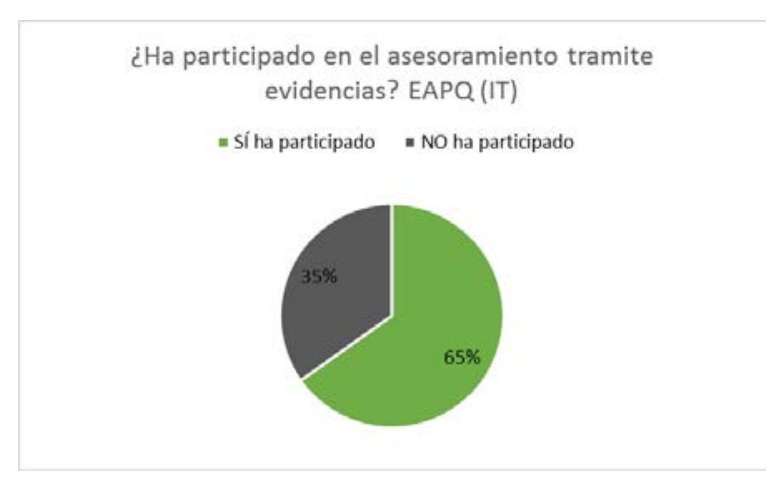

Como podemos observar, el 65\% de EAPQ encuestados ha afirmado haber participado en la evaluación a través de evidencias (asesoramiento). Por tanto, teniendo en cuenta los instrumentos descritos en la Delibera 530/2006 y en la Delibera 739/2013 (ver subapartado 4.3.8.3), hemos preguntado a este porcentaje de EAPQ y a todos los EPV, por los siguientes instrumentos organizados en 3 categorías:

- los documentos formales (declaraciones; contratos de colaboración; autodeclaraciones; diplomas, certificados);

- las evidencias de resultado (muestras del producto del trabajo; documentos realizados);

- las evidencias de acción (testimonios de personas; grabaciones de audio/video; "diarios de a bordo" del candidato). 
Análisis y resultados

Figura 17: Utilidad de instrumentos de asesoramiento en el procedimiento de Emilia-Romagna

a)

Utilidad de los instrumentos durante el proceso de asesoramiento: [Documentos formales:

Declaraciones]

$\pm E P V(I T)$ mEAPQ (IT)

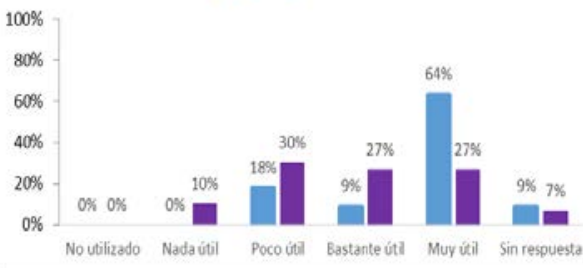

c)

Utilidad de los instrumentos durante el proceso de asesoramiento: [Documentos formales: Autodeclaraciones]

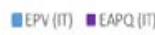

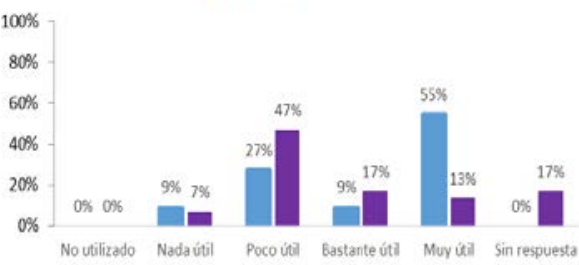

e)

Utilidad de los instrumentos durante el proceso de asesoramiento: [Evidencias de resultado: Muestras del producto del trabajo]

IEPV (IT) $=$ EAPQ (IT)

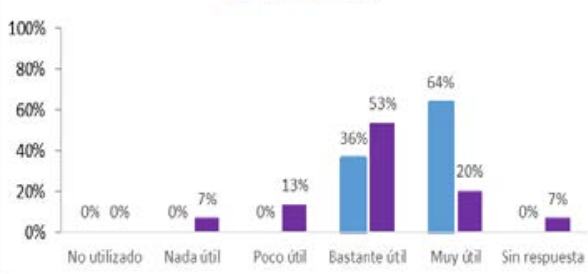

b)

Utilidad de los instrumentos durante el proceso de asesoramiento: [Documentos formales: Contratos de colaboración]

IEPV (II) $\mathbf{E}$ EAPQ(IT)

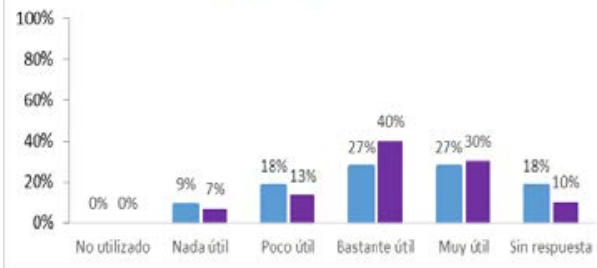

d)

Utilidad de los instrumentos durante el proceso de asesoramiento: [Documentos formales: Diplomas, certificados]

IEPV (II) - EAPQ (IT)

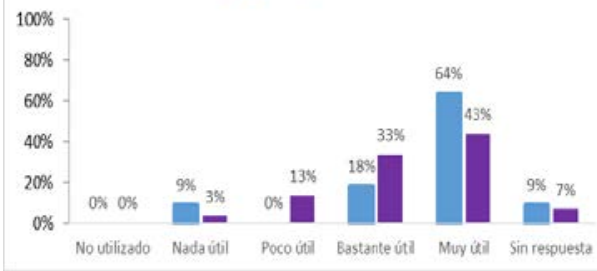

f)

Utilidad de los instrumentos durante el proceso de asesoramiento: [Evidencias de resultado: Documentos realizados]

IEPV (IT) - EAPQ (TT)

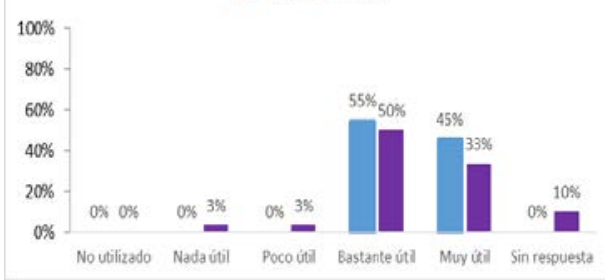


g)

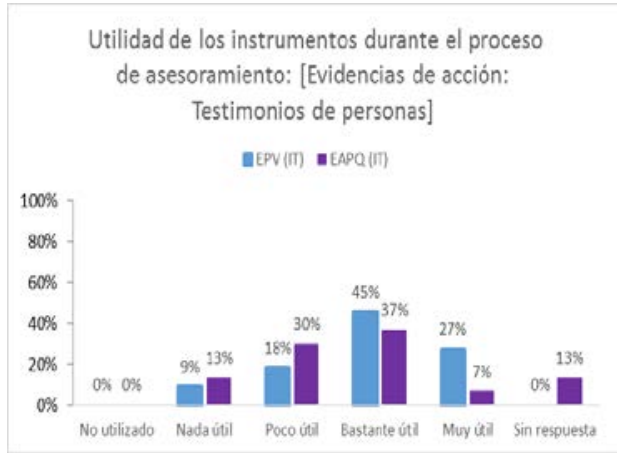

h)

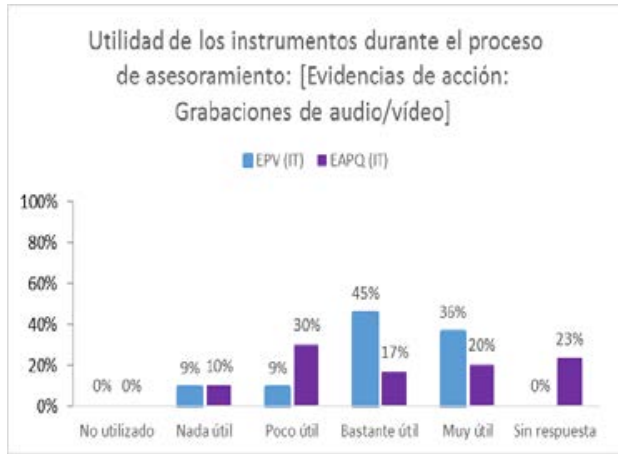

i)

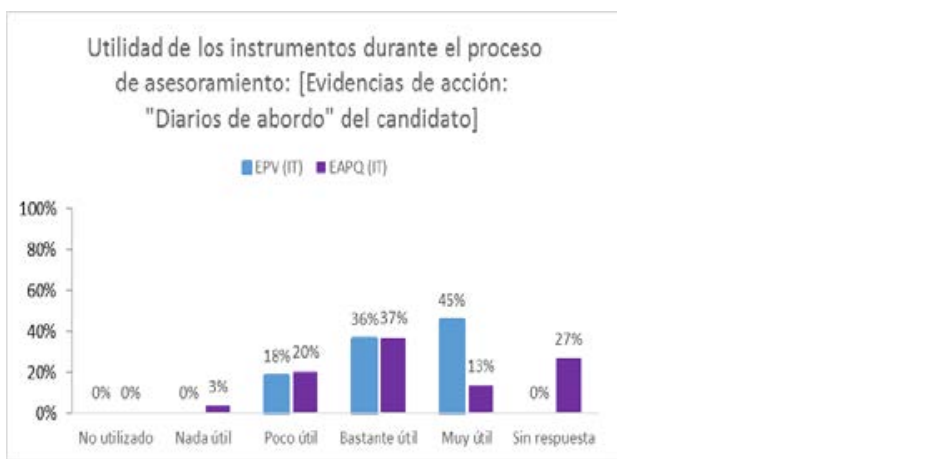

Según estas gráficas, los instrumentos para reflejar las evidencias, sobre las competencias de los candidatos, considerados más útiles por los EPV (asesores) han sido las muestras del producto del trabajo (36\% bastante y $64 \%$ muy útil, ver Figura 17 e) y los documentos realizados por el candidato (55\% bastante y $45 \%$ muy útil, ver Figura 17 f) ambas pertenecientes a la categoría de evidencias de resultado.

Por su parte, los EAPQ (evaluadores), coinciden en la buena valoración a las evidencias de resultado, considerando los documentos realizados por los candidatos como los instrumentos más útiles del asesoramiento (50\% bastante y 33\% muy útil, ver Figura 17 f). Asimismo, valoran positivamente las muestras del producto del trabajo (53\% bastante y $20 \%$ muy útil, ver Figura 17 f), pertenecientes a la misma categoría. También considera de utilidad notable, los diplomas y certificados, pertenecientes a la categoría de documentos formales (33\% bastante y $43 \%$ muy útil, ver Figura $17 \mathrm{~d}$ ). 
En general, los EAPQ han sido más críticos con los instrumentos respecto a los EPV. Los primeros han identificado como el instrumento menos útil las autodeclaraciones (poco 47\% y nada útil 7\%, ver Figura 17 c); testimonios de personas (poco 30\% y 13\% nada útil, ver Figura $17 \mathrm{~g}$ ) y grabaciones (30\% poco, el 10\% nada útil y 23\% sin respuesta, ver Figura $17 \mathrm{~h}$ ). Los EPV han coincidido con los EAPQ en la baja valoración del instrumento de autodeclaraciones ( $27 \%$ poco y $9 \%$ nada útil, ver Figura 17 c). Sin embargo, en el instrumento de grabaciones, observamos una discrepancia entre EAPQ y EPV, mientras que los EAPQ, como acabamos de comentar, no le han situado en una buena posición, los EPV le han otorgado una valoración positiva (45\% bastante y 36\% muy útil, ver Figura 17 h).

Cuando se ha preguntado a estos profesionales por otros instrumentos utilizados durante el asesoramiento, los EAPQ (evaluadores) han declarado haber utilizado también: entrevistas; declaraciones de parientes (en caso de candidatos que asistían a familiares); fotos del candidato trabajando en su puesto y la propia experiencia profesional de los EAPQ para valorar las evidencias del candidato. Por su parte los EPV (asesores) no han indicado ningún instrumento.

En cuanto a la pregunta sobre instrumentos echados en falta, ninguno de los encuestados ha indicado haber echado en falta algún instrumento.

Comparando los resultados de Emilia-Romagna y Castilla y León, comprobamos que el procedimiento de Emilia-Romagna ha sido más preciso que el de Castilla y León definiendo los instrumentos para la recogida de evidencias, distinguiendo entre documentos formales, evidencias de acción y evidencias de resultado. Si comparamos los instrumentos de EmiliaRomagna con los de Castilla y León, podemos encontrar ciertas similitudes en algunos de ellos, por ejemplo, el historial formativo/profesional podría corresponderse con la mayor parte de los documentos formales para la recogida de evidencias de Emilia-Romagna. En los dos casos nos encontramos evidencias documentales sobre formación y contratos de trabajo. Asimismo, consideramos que las evidencias de acción del procedimiento de Emilia-Romagna, también encuentran similitudes con las fichas de los empleadores, sobre las funciones realizadas por el candidato y con la entrevista de asesoramiento, en la que el candidato expresa sus conocimientos profesionales, en el caso del procedimiento castellanoleonés. Sin embargo, Emilia-Romagna, incluye el aspecto de las evidencias de resultado, 
algo que el procedimiento de Castilla y León, no contempla, a la hora de recoger las evidencias del candidato.

En general, los instrumentos de ambos procedimientos han recibido una buena valoración por parte de los encuestados, un poco más alta por parte de los asesores de Castilla y León. Según los profesionales de EmiliaRomagna (EPV y EAPQ) encuestados, los instrumentos más útiles han sido los relacionados con las evidencias de resultado (ver Figura 17 e) y f). Por su parte, para los asesores del procedimiento castellanoleonés el instrumento mejor valorado ha sido la entrevista de asesoramiento (ver Figura $14 \mathrm{~d}$ ).

En cuanto a los instrumentos echados en falta en esta fase, solo un pequeño porcentaje de los asesores del procedimiento castellanoleonés encuestados ha indicado que le gustaría que se realizasen mejoras en los instrumentos ya existentes. Sobre todo les gustaría que existiese una aplicación informática para el CV; los certificados de empresa mejor definidos; guías de evidencias y criterios de evaluación más concretos; mayor concreción en el guion de la entrevista y en el modelo de informe de asesoramiento.

\subsection{CATEGORÍA: PREPARACIÓN DE LOS ASESORES}

\subsubsection{Sin subcategoría}

\begin{tabular}{|c|c|c|c|c|c|c|c|c|}
\hline \multirow[b]{3}{*}{ IND. } & \multicolumn{4}{|c|}{ ESPAÑA } & \multicolumn{4}{|c|}{ ITALIA } \\
\hline & \multicolumn{2}{|c|}{ Legislación } & \multirow{2}{*}{$\begin{array}{l}\text { Entrevis- } \\
\text { tas }\end{array}$} & \multirow{2}{*}{$\begin{array}{c}\text { Cues- } \\
\text { tio- } \\
\text { narios }\end{array}$} & \multicolumn{2}{|c|}{ Legislación } & \multirow{2}{*}{$\begin{array}{l}\text { Entre- } \\
\text { vistas }\end{array}$} & \multirow{2}{*}{$\begin{array}{c}\text { Cues- } \\
\text { tio- } \\
\text { narios }\end{array}$} \\
\hline & $\begin{array}{c}\mathrm{Na}- \\
\text { cional }\end{array}$ & $\begin{array}{c}\text { Autonó- } \\
\text { mica }\end{array}$ & & & $\begin{array}{c}\text { Nacio- } \\
\text { nal }\end{array}$ & $\begin{array}{c}\text { Regio- } \\
\text { nal }\end{array}$ & & \\
\hline 4.3.0.1 & SÍ & sí & sí & NO & NO & Sí & SÍ & NO \\
\hline 4.3.0.2 & sí & sí & NO & sí & NO & NO & sí & NO \\
\hline 4.3.0.3 & Sí & NO & sí & Sí & NO & Sí & Sí & sí \\
\hline 4.3.0.4 & sí & NO & NO & sí & NO & NO & NO & sí \\
\hline
\end{tabular}

4.3.0.1. INDICADOR: Existen unos requisitos especificos para ser asesor.

\section{Comparación}

\section{Legislación}

La legislación nacional española y la autonómica de Castilla y León, establecen unos criterios específicos para los profesionales del procedimien- 
to, como la experiencia laboral y la formación como figuras del procedimiento. Por su parte, la legislación nacional italiana no hace referencia al respecto, sin embargo, la legislación regional define los criterios para ser EPV (asesor), relativos a la experiencia profesional, a la relación profesional con el centro que proporciona el servicio y al título académico, que debe tener el aspirante a EPV (asesor).

\section{Entrevistas}

Los asesores entrevistados del procedimiento de Castilla y León, han comentado el aspecto relativo a la formación de asesores, indicando que cada uno de ellos se ha formado por una vía distinta, (Uned y Observal), y que ambos están satisfechos con la formación recibida. Asimismo, los entrevistados, del procedimiento de Emilia-Romagna (dos EPV y un gestor/organizador), han hablado de la realización de un curso formativo, que en un principio fue presencial y on-line y ahora solamente on-line, que no se menciona en la legislación.

\subsubsection{INDICADOR: Existe una formación continua para el desarrollo de competencias, dirigido a asesores}

\section{Comparación}

\section{Legislación}

La legislación nacional española como la autonómica de Castilla y León, hacen referencia a la formación continua de asesores y evaluadores, aunque de forma general, sin entrar en detalle. Por su parte la legislación nacional italiana y la regional de Emilia-Romagna, no hacen alusiones al respecto.

\section{Entrevistas}

Sobre las entrevistas, los entrevistados del procedimiento de Castilla y León, no han hecho comentarios sobre este aspecto. Por su parte, uno de los EPV entrevistados del procedimiento de Emilia-Romagna, ha indicado que no se hace formación continua para los profesionales del procedimiento. Sin embargo, uno de los gestores/organizadores entrevistados, ha afirmado que está previsto proporcionar esta formación, con la nueva normativa, a través de una plataforma informática.

\section{Cuestionarios}


La validación de competencias profesionales en España e Italia

En torno al 5\% de los evaluadores encuestados del procedimiento de Castilla y León ha considerado que debería mejorar la formación de asesores y evaluadores, para valorar aspectos técnicos.

\subsubsection{INDICADOR: Los asesores tienen acceso a material de apoyo para llevar a cabo el proceso de asesoramiento}

\section{Comparación}

\section{Legislación}

La legislación nacional española decreta la elaboración de instrumentos para optimizar el procedimiento y garantizar la homogeneidad y fiabilidad, facilitando un manual de procedimiento, compuesto entre otras cosas, por una guía para el asesor. La legislación autonómica de Castilla y León no hace referencia a este aspecto.

Contrariamente a lo que ocurre en el caso español, la legislación nacional italiana no hace referencia al respecto, sin embargo, la regional de Emilia-Romagna, da directrices y material de apoyo para ayudar a los profesionales a desarrollar adecuadamente el procedimiento.

\section{Entrevistas}

Los profesionales entrevistados, de ambos procedimientos hablan de este tipo de material de apoyo. Los dos asesores entrevistados, del procedimiento de Castilla y León, hablan de la guía del asesor y de una plataforma, con información y documentos que les apoyan en el asesoramiento. Por otra parte, dos de los EPV (asesores) entrevistados, del procedimiento de Emilia-Romagna, han mencionado el SIFER como red de apoyo. Uno de los gestores/organizadores ha señalado que dicha red está en proceso de mejora. También dos EPV mencionan la DGR 350/2006 como documento de apoyo.

\section{Cuestionarios}

Se ha pedido a los profesionales de ambos procedimientos (asesores de Castilla y León y EPV de Emilia-Romagna), valorar la utilidad de los instrumentos de apoyo (ver subapartados 4.2.6.2y 4.3.8.3 respectivamente) establecidos para ayudar a llevar a la práctica el procedimiento.

En el procedimiento de Castilla y León se ha preguntado a los asesores por la utilidad de la guía del Asesor: 
Figura 18: Utilidad de la guía según asesores del procedimiento de Castilla y León

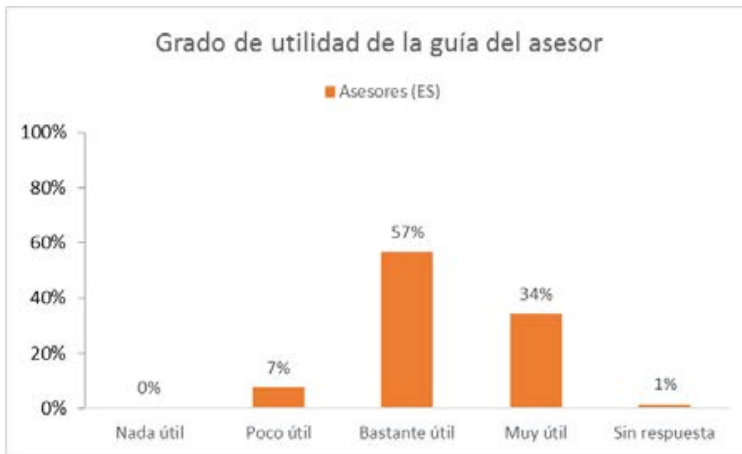

Como podemos ver en la Figura 18, casi la totalidad de los asesores han considerado la guía bastante o muy útil, y solo un $7 \%$ la ha considerado poco útil.

En el caso de Italia, como se ha venido mencionando, se han usado dos tipos de deliberaciones (con motivo del cambio que se está produciendo de una a otra) como instrumentos de apoyo a los profesionales del procedimiento. Recordamos que se trata de la DGR 530/2006 y de la DGR 739/2013. El siguiente gráfico muestra qué porcentaje de los encuestados usó cada una de ellas, o ambas, durante el proceso de asesoramiento.

Figura 19: Instrumento utilizado por los evaluadores en el procedimiento de EmiliaRomagna

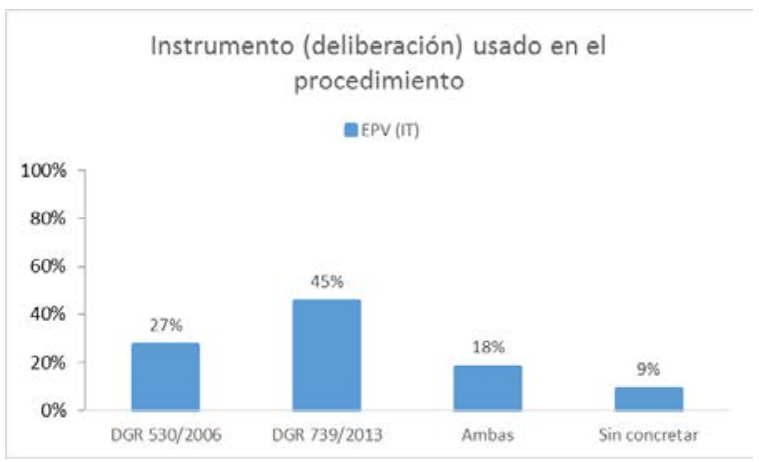

Como vemos en la Figura 19, el instrumento de apoyo más utilizado, por los EPV (asesores) encuestados, ha sido la nueva DGR 739/2013, con un $45 \%$, más un $18 \%$ que ha usado ambas deliberaciones.

A continuación mostramos el grado de satisfacción de las personas que han usado cada una de ellas. 
La validación de competencias profesionales en España e Italia

Figura 20: Satisfacción de los evaluadores del procedimiento de Emilia-Romagna con la DGR 530/2006

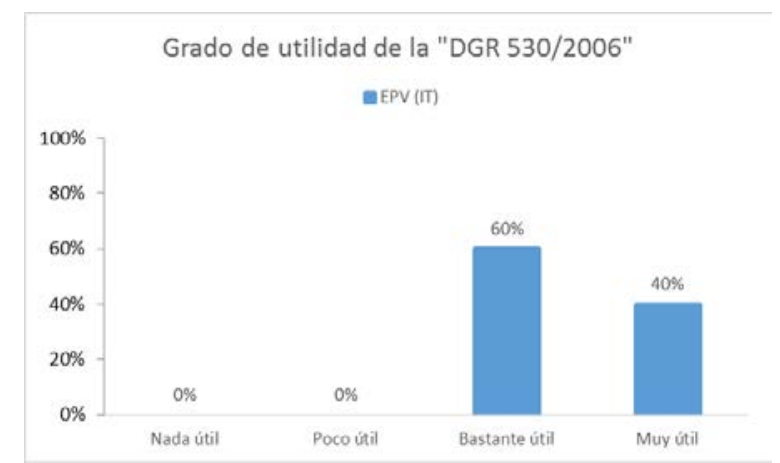

Figura 21: Satisfacción de los evaluadores del procedimiento de Emilia-Romagna con la DGR 739/2013

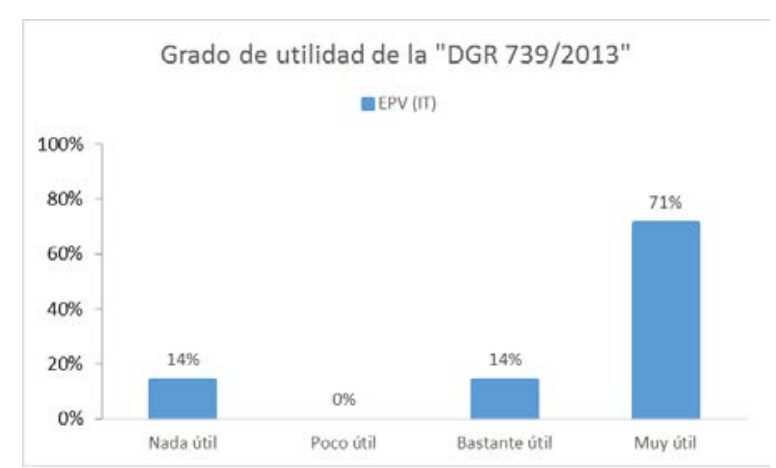

Aunque ambas han obtenido una valoración bastante buena, en cuanto a su utilidad para ayudar a llevar a cabo el procedimiento, los EPV (asesores) se decantan por la nueva deliberación (DGR 739/2013).

\subsubsection{INDICADOR: Los asesores conocen el sistema de validación y certifi- cación de competencias y otros aspectos relacionados con el mismo}

\section{Comparación}

\section{Legislación}

Solo la legislación nacional española hace alusión al respecto, decretando que los asesores deben realizar un curso formativo para tener una serie de conocimientos y proponiendo los contenidos.

Entrevistas 
No existen comentarios al respecto por parte de los entrevistados de ambos procedimientos.

\section{Cuestionarios}

Respecto a los cuestionarios, se ha indagado sobre el grado de conocimiento, de los asesores de ambos procedimientos, en referencia a diferentes aspectos relacionados con los correspondientes procedimientos de validación. En primer lugar, el cuestionario pregunta sobre conocimientos generales, para indagar a continuación sobre aspectos específicos del sistema en Castilla y León (para los asesores del procedimiento castellanoleonés) y en Emilia Romagna (para los EPV del procedimiento emilianoromagnolo) de validación de competencias.

En algunos casos las gráficas resultantes de las respuestas de los profesionales del procedimiento de Castilla y León están separadas de las respuestas de los profesionales del procedimiento de Emilia-Romagna, con objeto de no crear confusión al lector en cuanto a lo que se pregunta.

Figura 22: Conocimiento de los asesores sobre aspectos generales de los sistemas, en Castilla y León y en Emilia-Romagna

a)

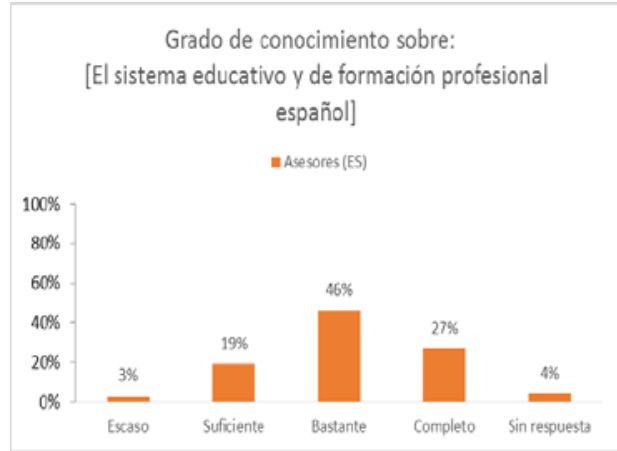

b)

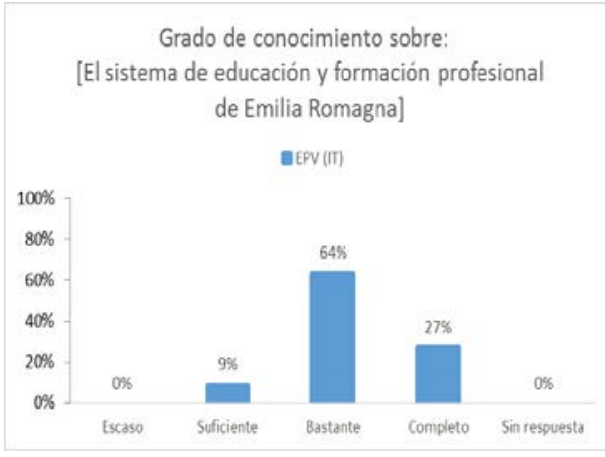


La validación de competencias profesionales en España e Italia

c)

Grado de conocimiento sobre:

[Las cualificaciones del catálogo nacional de

competencias profesionales correspondientes a

la familia profesional a la que pertenece la

Unidad o Unidades de Competencia que han sido objeto de evaluación

asesores (ES)

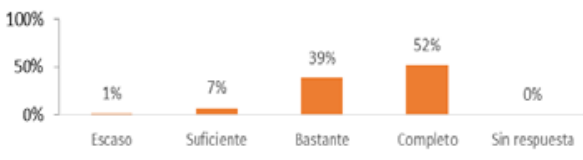

e)

Grado de conocimiento sobre:

[Los requisitos necesarios para poder solicitar la

cualificación correspondiente a la unidad o unidades de competencia que se han evaluado]

"Asesores (ES) $=$ EPV (II)

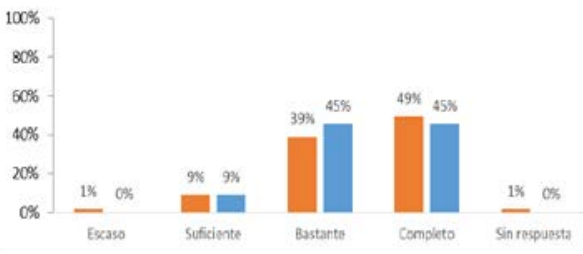

g)

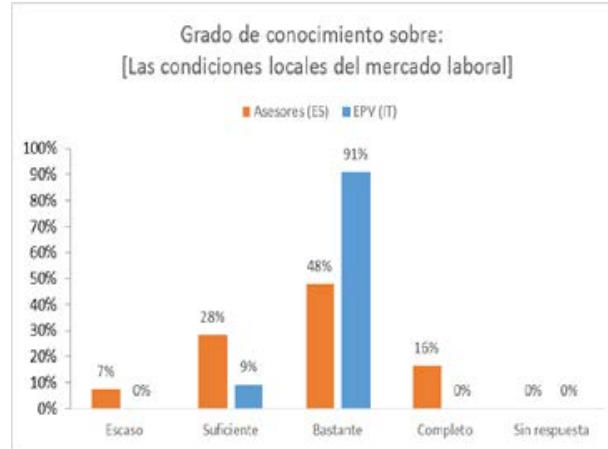

d)

Grado de conocimiento sobre:

[Las cualificaciones del repertorio de Emilia

Romagna correspondientes a la familia

profesional a la que pertenece la Unidad o

Unidades de Competencia que han sido objeto de evaluación]

$$
\text { EEPV (TiT) }
$$

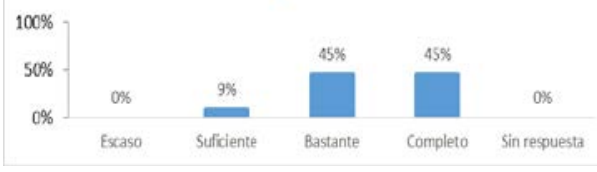

f)

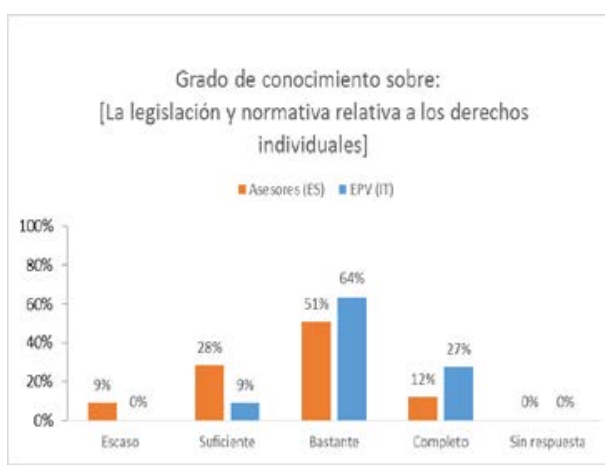

h)

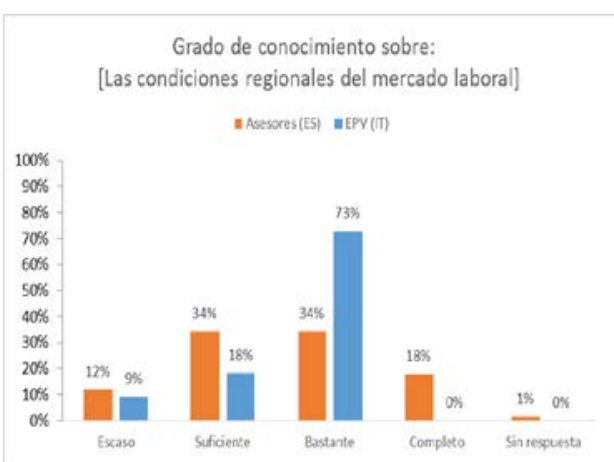


j)

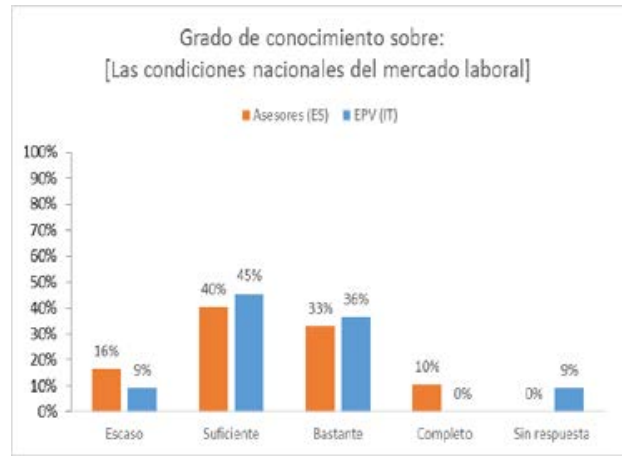

En cuanto a los aspectos generales relacionados con los sistemas de validación, podemos decir que los EPV (asesores) de Emilia-Romagna han indicado tener mayor grado de conocimiento sobre estos aspectos, en general, que los asesores de Castilla y León. Solo en las condiciones de mercado nacional, los profesionales españoles han indicado tener un conocimiento un poco más elevado que los italianos (ver Figura 22). El punto sobre el que los EPV (asesores) han señalado tener un mayor conocimiento ha sido el de las cualificaciones del repertorio regional, relacionadas con la familia profesional de las UC objeto de certificación (ver Figura 22 d), seguido por el conocimiento del sistema educativo formativo regional (ver Figura 22 b) y después por las condiciones locales del mercado laboral (ver Figura $22 \mathrm{~g}$ ). Por su parte, los asesores del procedimiento castellanoleonés, también han indicado tener mayor conocimiento sobre las cualificaciones del repertorio nacional (ver Figura 22 c), seguido de los requisitos para solicitar la cualificación (ver Figura 22 e).

Cabe destacar que el aspecto relacionado con las condiciones nacionales del mercado laboral, es el punto sobre el que los asesores, de ambos procedimientos, han indicado tener menos conocimiento (ver Figura 22 i). 
La validación de competencias profesionales en España e Italia

Figura 23: Conocimiento de los asesores sobre aspectos específicos de los sistemas en Castilla y León y en Emilia-Romagna
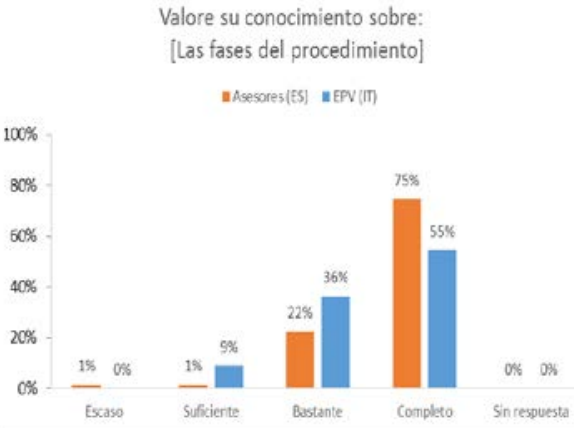

c)

Valore su conocimiento sobre:

[El rol de los participantes en el procedimiento]

- Asesores (ES) a EPV (T)

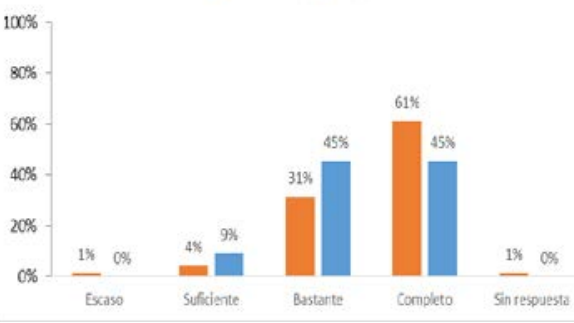

e)

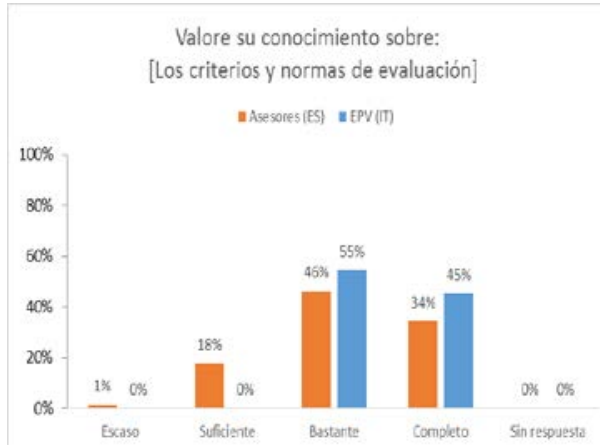

b)

Valore su conocimiento sobre:

[El funcionamiento del procedimiento]

$$
\text { ansesores[(ES) a EPV (II) }
$$

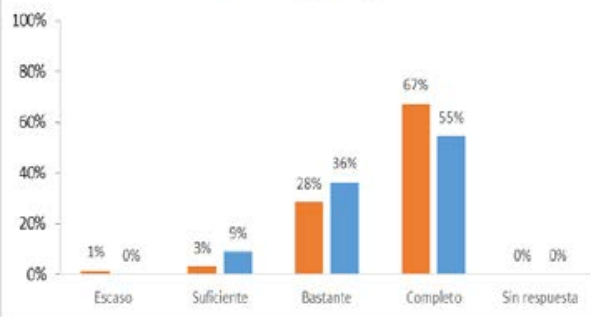

d)

$$
\text { Valore su conocimiento sobre: [La legislación y }
$$
normativa relativa al proceso de validación]

$$
\text { - Asesores (ES) a EPV (T) }
$$

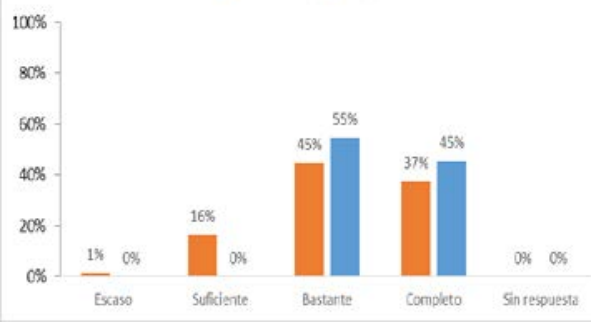

f)

Valore su conocimiento sobre: [Los instrumentos de evaluación]

$$
\text { a Asesones (ES) a EPV(T) }
$$

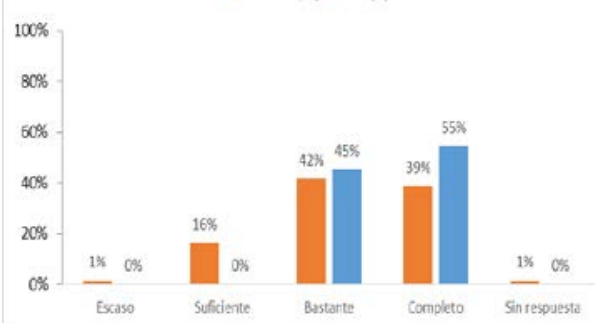

Respecto a los aspectos específicos, relacionados con los sistemas de validación, los profesionales de ambos procedimientos han indicado tener 
un conocimiento bastante alto en todos los puntos sobre los que hemos preguntado (ver Figura 23) y con poca diferencia entre los asesores de Castilla y León y los de Emilia-Romagna. Concretando más, los asesores del procedimiento en Castilla y León han indicado tener más conocimiento que los EPV (asesores) respecto a las fases, el funcionamiento y el rol de los profesionales, del procedimiento de validación, aunque como podemos ver en las Figura 23 a), b) y c) la diferencia no es muy sustancial. Por otro lado, como vemos en la Figura 23 d), e) y f), los profesionales del procedimiento de Emilia-Romagna, han indicado, en mayor medida que los asesores del procedimiento castellanoleonés, poseer conocimientos respecto a la legislación, los criterios y normas de evaluación y los instrumentos.

También hemos preguntado a los profesionales del asesoramiento de ambos procedimientos, sobre su conocimiento acerca de otros sistemas de validación:

Figura 24: Conocimiento por parte de los asesores de otros sistemas de validación

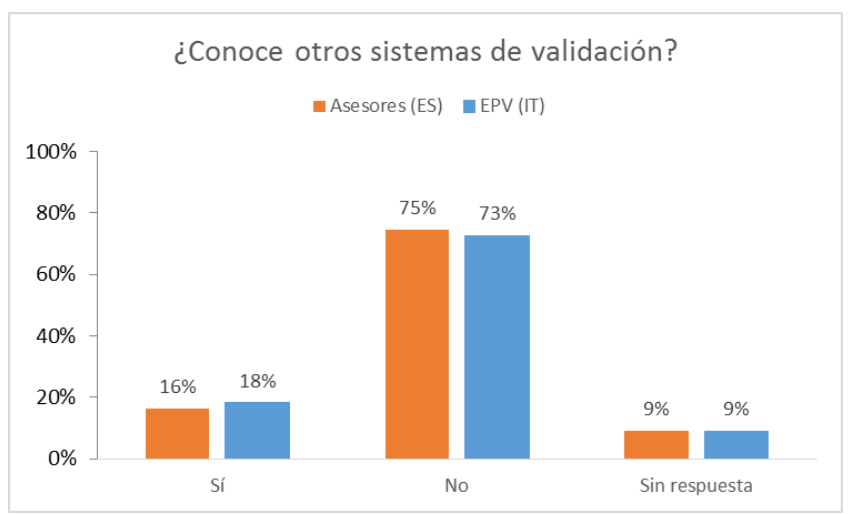

Como vemos en la Figura 24, la mayor parte de los asesores encuestados, en Castilla y León y en Emilia-Romagna, no conocen otros sistemas relacionados con la validación (75\% y 73\% respectivamente). Solo un 16\% en Castilla y León un 18\% en Emilia-Romagna, han contestado afirmativamente a la pregunta. Tras preguntar específicamente que sistemas conocían, los primeros han declarado conocer exámenes de acreditación; acreditaciones por tiempo trabajado y formación; otras convocatorias; planes regionales de formación (en formación para el empleo); cursos a través de sindicatos; la vía de formación profesional reglada y procedimientos en otras comunidades autónomas. Los segundos han indicado conocer los sistemas francés e inglés de validación. 
La validación de competencias profesionales en España e Italia

4.4. CATEGORÍA: COMPORTAMIENTO ÉTICO

4.4.0. Sin subcategoría

\begin{tabular}{|c|c|c|c|c|c|c|c|c|}
\hline \multirow[b]{3}{*}{ IND. } & \multicolumn{4}{|c|}{ ESPAÑA } & \multicolumn{4}{|c|}{ ITALIA } \\
\hline & \multicolumn{2}{|c|}{ Legislación } & \multirow{2}{*}{$\begin{array}{l}\text { Entrevis- } \\
\text { tas }\end{array}$} & \multirow{2}{*}{$\begin{array}{c}\text { Cues- } \\
\text { tio- } \\
\text { narios }\end{array}$} & \multicolumn{2}{|c|}{ Legislación } & \multirow{2}{*}{$\begin{array}{l}\text { Entre- } \\
\text { vistas }\end{array}$} & \multirow{2}{*}{$\begin{array}{c}\text { Cues- } \\
\text { tio- } \\
\text { narios }\end{array}$} \\
\hline & $\begin{array}{l}\mathrm{Na-} \\
\text { cional }\end{array}$ & $\begin{array}{c}\text { Autonó- } \\
\text { mica }\end{array}$ & & & $\begin{array}{c}\text { Nacio- } \\
\text { nal }\end{array}$ & $\begin{array}{c}\text { Regio- } \\
\text { nal }\end{array}$ & & \\
\hline 4.4.0.1 & sí & NO & $\mathrm{NO}$ & $\mathrm{NO}$ & sí & NO & NO & NO \\
\hline
\end{tabular}

4.4.0.1. INDICADOR: El asesor proporciona un trato igualitario a todos los candidatos

\section{Comparación}

\section{Legislación}

La legislación nacional española e italiana contemplan este aspecto. La primera con el principio sobre el respeto de los derechos individuales, el cual pretende que se dé un trato igualitario a los candidatos en el procedimiento. En cuanto a la legislación nacional italiana, se hace referencia al principio de objetividad, encaminado a dar un trato igualitario a los candidatos.

Respecto a la legislación autonómica de Castilla y León y regional de Emilia-Romagna, no se han encontrado alusiones sobre este aspecto.

\section{Entrevistas}

No existen alusiones a este aspecto. 
Análisis y resultados

\subsection{CATEGORIAA: PRIV ACIDAD Y CONFIDENCIALIDAD DEL PROCESO DE ASESORAMIENTO}

\subsubsection{Sin subcategoría}

\begin{tabular}{|c|c|c|c|c|c|c|c|c|}
\hline \multirow[b]{3}{*}{ IND. } & \multicolumn{4}{|c|}{ ESPAÑA } & \multicolumn{4}{|c|}{ ITALIA } \\
\hline & \multicolumn{2}{|c|}{ Legislación } & \multirow{2}{*}{$\begin{array}{l}\text { Entrevis- } \\
\text { tas }\end{array}$} & \multirow{2}{*}{$\begin{array}{c}\text { Cues- } \\
\text { tio- } \\
\text { narios }\end{array}$} & \multicolumn{2}{|c|}{ Legislación } & \multirow{2}{*}{$\begin{array}{l}\text { Entre- } \\
\text { vistas }\end{array}$} & \multirow{2}{*}{$\begin{array}{c}\text { Cues- } \\
\text { tio- } \\
\text { narios }\end{array}$} \\
\hline & $\begin{array}{l}\mathrm{Na}- \\
\text { cional }\end{array}$ & $\begin{array}{c}\text { Autonó- } \\
\text { mica }\end{array}$ & & & $\begin{array}{l}\text { Nacio- } \\
\text { nal }\end{array}$ & $\begin{array}{c}\text { Regio- } \\
\text { nal }\end{array}$ & & \\
\hline 4.5.0.1 & NO & NO & Sí & sí & NO & NO & sí & sí \\
\hline
\end{tabular}

4.5.0.1. INDICADOR: El asesor comunica los resultados del asesoramiento unicamente al candidato

\section{Comparación}

\section{Legislación}

La privacidad y confidencialidad en el proceso de asesoramiento no se trata en la legislación ni nacional española/italiana, ni autonómica de Castilla y León/regional de Emilia-Romagna.

\section{Entrevistas}

Los profesionales entrevistados de ambos procedimientos han asegurado, sin embargo, haber respetado esta privacidad a la hora de comunicar los resultados del asesoramiento a los candidatos, haciéndolo en persona o por vía telefónica. Los dos asesores entrevistados, del procedimiento de Castilla y León, han afirmado haber entregado los resultados verbalmente, por vía telefónica, con la intención de no obligar al candidato a desplazarse para firmar un documento y respetando igualmente la privacidad. Respecto a los profesionales entrevistados del procedimiento de Emilia-Romagna, uno de los expertos en procesos de evaluación ha afirmado que los resultados del asesoramiento no son públicos, y que se llama al candidato para informarle de ellos personalmente o telefónicamente, de forma individual.

\section{Cuestionarios}

Hemos preguntado a los asesores de ambos procedimientos la vía para comunicar el resultado, para saber si se ha hecho de forma privada. 
La validación de competencias profesionales en España e Italia

Figura 25: Vías de comunicación de resultados utilizadas por los asesores de ambos procedimientos

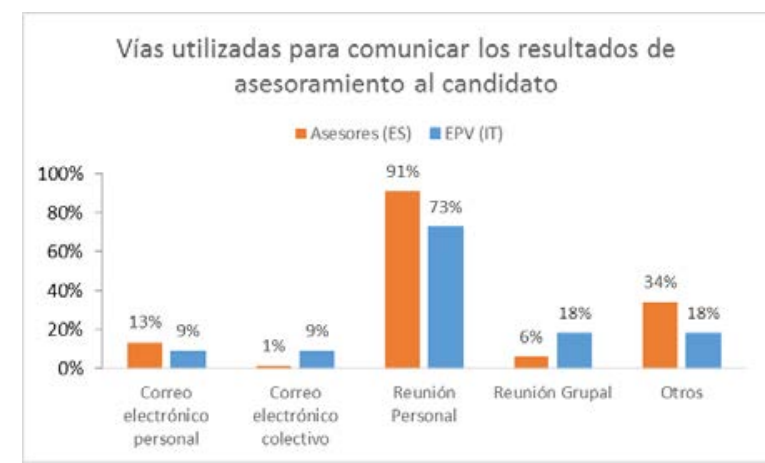

Observando la Figura 25, comprobamos que la mayor parte de los encuestados, de ambos procedimientos, aunque en mayor medida en el procedimiento de Castilla y León, ha utilizado vías de comunicación que garantizan la confidencialidad, como encuentros personales con el candidato, (el $91 \%$ en Castilla y León y el $73 \%$ en Emilia-Romagna) o el uso, en menor medida, del correo electrónico personal (el 13\% en Castilla y León y el 9\% en Emilia-Romagna). Asimismo, como otras vías utilizadas, los asesores del procedimiento de Castilla y León, han indicado el teléfono.

Los porcentajes de las vías de comunicación que no garantizan del todo la privacidad de los resultados, como el correo colectivo o la reunión grupal, han sido menores (del 1\% y el 6\% en Castilla y León y del $9 \%$ y el $18 \%$ en Emilia-Romagna respectivamente). Como otras vías utilizadas, los EAPQ han indicado el tablón de anuncios.

\subsection{CATEGORIA A: CARACTER PERSONALIZADO DEL ASESORAMIENTO}

4.6.1. SUBCATEGORÍA: Conocimiento del candidato por parte del asesor

\begin{tabular}{|c|c|c|c|c|c|c|c|c|}
\hline \multirow[b]{3}{*}{ IND. } & \multicolumn{4}{|c|}{ ESPAÑA } & \multicolumn{4}{|c|}{ ITALIA } \\
\hline & \multicolumn{2}{|c|}{ Legislación } & \multirow{2}{*}{$\begin{array}{l}\text { Entrevis- } \\
\text { tas }\end{array}$} & \multirow{2}{*}{$\begin{array}{c}\text { Cues- } \\
\text { tio- } \\
\text { narios }\end{array}$} & \multicolumn{2}{|c|}{ Legislación } & \multirow{2}{*}{$\begin{array}{l}\text { Entre- } \\
\text { vistas }\end{array}$} & \multirow{2}{*}{$\begin{array}{l}\text { Cues- } \\
\text { tio- } \\
\text { narios }\end{array}$} \\
\hline & $\begin{array}{l}\mathrm{Na}- \\
\text { cional }\end{array}$ & $\begin{array}{c}\text { Auto- } \\
\text { nómica }\end{array}$ & & & $\begin{array}{c}\text { Nacio- } \\
\text { nal }\end{array}$ & $\begin{array}{c}\text { Regio- } \\
\text { nal }\end{array}$ & & \\
\hline 4.6.1.1 & NO & NO & Sí & Sí & NO & NO & Sí & sí \\
\hline 4.6.1.2 & NO & NO & Sí & Sí & NO & NO & sí & sí \\
\hline
\end{tabular}




\begin{tabular}{|c|c|c|c|c|c|c|c|c|}
\hline \multirow[b]{3}{*}{ IND. } & \multicolumn{4}{|c|}{ ESPAÑA } & \multicolumn{4}{|c|}{ ITALIA } \\
\hline & \multicolumn{2}{|c|}{ Legislación } & \multirow{2}{*}{$\begin{array}{l}\text { Entrevis- } \\
\text { tas }\end{array}$} & \multirow{2}{*}{$\begin{array}{c}\text { Cues- } \\
\text { tio- } \\
\text { narios }\end{array}$} & \multicolumn{2}{|c|}{ Legislación } & \multirow{2}{*}{$\begin{array}{l}\text { Entre- } \\
\text { vistas }\end{array}$} & \multirow{2}{*}{$\begin{array}{c}\text { Cues- } \\
\text { tio- } \\
\text { narios }\end{array}$} \\
\hline & $\begin{array}{l}\mathrm{Na}- \\
\text { cional }\end{array}$ & $\begin{array}{c}\text { Auto- } \\
\text { nómica }\end{array}$ & & & $\begin{array}{c}\text { Nacio- } \\
\text { nal }\end{array}$ & $\begin{array}{c}\text { Regio- } \\
\text { nal }\end{array}$ & & \\
\hline 4.6.1.3 & NO & NO & Sí & Sí & NO & NO & NO & Sí \\
\hline 4.6.1.4 & $\mathrm{NO}$ & $\mathrm{NO}$ & Sí & Sí & NO & sí & NO & sí \\
\hline
\end{tabular}

* Recordamos que para facilitar el análisis de datos se agruparon algunos indicadores de esta categoría, en este caso, se agrupan dos indicadores de la subcategoría de: "conocimiento del candidato por parte del asesor" (ver apartado 6.1).

\subsubsection{INDICADOR: El asesor conoce las motivaciones del candidato para someterse al procedimiento de validación.}

4.6.1.2. INDICADOR: El asesor conoce los objetivos del candidato para someterse al procedimiento de validación

\section{Comparación}

\section{Legislación}

No se han encontrado referencias legislativas. Ni en el plano legislativo nacional español/italiano, ni en el plano legislativo autonómico de Castilla y León/regional de Emilia-Romagna.

\section{Entrevistas}

Los dos asesores entrevistados, del procedimiento de Castilla y León, han manifestado que la experiencia del asesoramiento ha sido muy buena, han empatizado mucho con los candidatos y señalan que la mayor motivación de estos para someterse al procedimiento ha sido el miedo a quedarse sin trabajo. Respecto a las respuestas dadas por los entrevistados del procedimiento de Emilia-Romagna, existe disparidad sobre este aspecto, ya que uno de los EPV asegura haber tenido mucho contacto con los candidatos y haber conocido en profundidad la dimensión laboral de los candidatos, mientras que otro EPV entrevistado dice no haber tenido mucha relación con estos. Esto es debido a que el segundo EPV, era externo al centro en el 
que se realizaba el procedimiento (ver subapartado 4.3.8.3), por lo que el candidato ha estado más apoyado por otros profesionales del centro.

\section{Cuestionarios}

Para indagar sobre los aspectos concernientes a estos dos indicadores, hemos realizado las siguientes preguntas, a los asesores de ambos procedimientos, sobre el conocimiento de la motivación y de los objetivos del candidato para someterse al procedimiento de validación.

Figura 26: Conocimiento de los asesores de ambos procedimientos sobre el candidato

a)

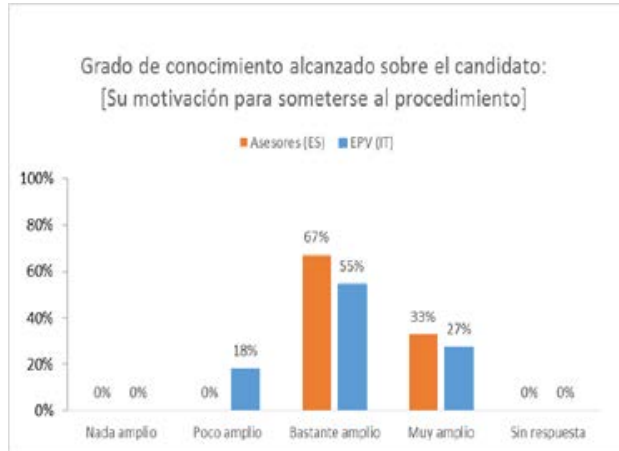

b)

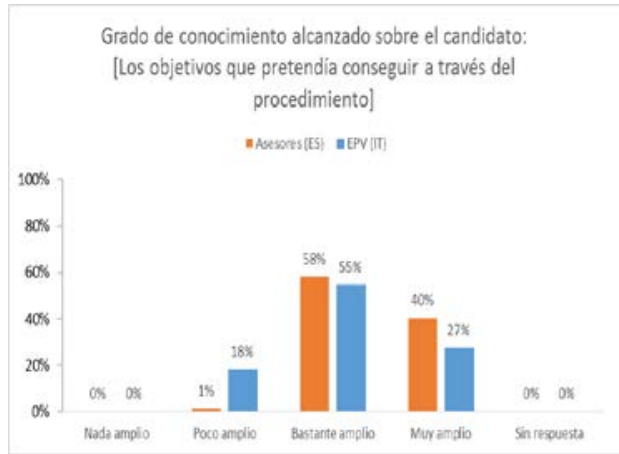

Como vemos en la Figura 26 el grado de conocimiento, sobre estos aspectos, expresado por los asesores de ambos procedimientos, es bastante alto en los dos procedimientos. No obstante, el porcentaje es más elevado en el de Castilla y León que en Emilia-Romagna, tanto en el conocimiento de las motivaciones como en el conocimiento de los objetivos.

*Como hemos hecho anteriormente en esta categoría, presentamos los resultados de la agrupación de los siguientes indicadores, pertenecientes a la subcategoría: "Conocimiento del candidato por parte del asesor y de la flexibilidad en el proceso de asesoramiento" (ver apartado 6.2):

4.6.1.3. INDICADOR: El asesor conoce las condiciones personales del candidato (nivel, cultural; problemas laborales, personales, familiares, etc.). Analizado conjuntamente con el indicador 4.6.1.4. de su misma subcategoría y con los indicadores: 4.6.2.1 y 4.6.2.2, de la subcategoría de: flexibilidad en el proceso de asesoramiento. 
4.6.1.4. INDICADOR: El asesor conoce la disponibilidad del candidato para el procedimiento (tiempo, horarios a disposición del procedimiento, colaboración con el mismo, etc.). Analizado conjuntamente con el indicador 4.6.1.3, de su misma subcategoría y con los indicadores: 4.6.2.1 y 4.6.2.2, de la subcategoría de: flexibilidad en el proceso de asesoramiento.

4.6.2. SUBCATEGORÍA: Flexibilidad en el proceso de asesoramiento

\begin{tabular}{|c|c|c|c|c|c|c|c|c|}
\hline \multirow[b]{3}{*}{ IND. } & \multicolumn{4}{|c|}{ ESPAÑA } & \multicolumn{4}{|c|}{ ITALIA } \\
\hline & \multicolumn{2}{|c|}{ Legislación } & \multirow{2}{*}{$\begin{array}{l}\text { Entrevis- } \\
\text { tas }\end{array}$} & \multirow{2}{*}{$\begin{array}{c}\text { Cues- } \\
\text { tio- } \\
\text { narios }\end{array}$} & \multicolumn{2}{|c|}{ Legislación } & \multirow{2}{*}{$\begin{array}{l}\text { Entre- } \\
\text { vistas }\end{array}$} & \multirow{2}{*}{$\begin{array}{c}\text { Cues- } \\
\text { tio- } \\
\text { narios }\end{array}$} \\
\hline & $\begin{array}{l}\mathrm{Na-} \\
\text { cional } \\
\end{array}$ & $\begin{array}{c}\text { Autonó- } \\
\text { mica }\end{array}$ & & & $\begin{array}{c}\text { Nacio- } \\
\text { nal }\end{array}$ & $\begin{array}{c}\text { Regio- } \\
\text { nal }\end{array}$ & & \\
\hline 4.6.2.1 & NO & NO & Sí & Sí & NO & NO & NO & Sí \\
\hline 4.6.2.2 & NO & NO & Sí & Sí & NO & Sí & NO & Sí \\
\hline
\end{tabular}

4.6.2.1. INDICADOR: El asesor tiene en cuenta las condiciones personales del candidato (nivel, cultural; problemas laborales, personales, familiares, etc.), a la hora de llevar a cabo el asesoramiento. Analizado conjuntamente con el indicador 4.6.1.3, 4.6.1.4 de la subcategoría: conocimiento del candidato por parte del asesory con el indicador 4.6.2.2, de su misma subcategoría (flexibilidad en el proceso de asesoramiento).

4.6.2.2. INDICADOR: El asesor tiene en cuenta la disponibilidad del candidato (tiempo, horarios a disposición del procedimiento, colaboración con el mismo, etc.), a la hora de llevar a cabo el asesoramiento. Analizado conjuntamente con el indicador 4.6.1.3 y 4.6.1.4 de la subcategoría de: conocimiento del candidato por parte del asesor y con el indicador 4.6.2.1, de su misma subcategoría (flexibilidad en el proceso de asesoramiento).

\section{Comparación}

\section{Legislación}


La validación de competencias profesionales en España e Italia

Respecto al conocimiento y consideración de condiciones personales y disponibilidad del candidato, solamente se ha encontrado una pequeña referencia en la legislación regional de Emilia-Romagna, que insta al asesor a tener en cuenta la disponibilidad del candidato en la recogida de evidencias.

\section{Entrevistas}

Los dos asesores entrevistados, del procedimiento de Castilla y León, han asegurado conocer y tratar de tener en cuenta las condiciones personales y la disponibilidad de los candidatos en el procedimiento. Por el contrario, los entrevistados del procedimiento de Emilia-Romagna no han hecho alusiones al respecto.

\section{Cuestionarios}

Mostramos a continuación, las gráficas relacionadas con los 4 últimos indicadores que hemos visto y agrupado para su análisis: 4.6.1.3; 4.6.1.4; 4.6.2.1 y 4.6.2.2.

c) Figura relativa al indicador 4.6.1.3

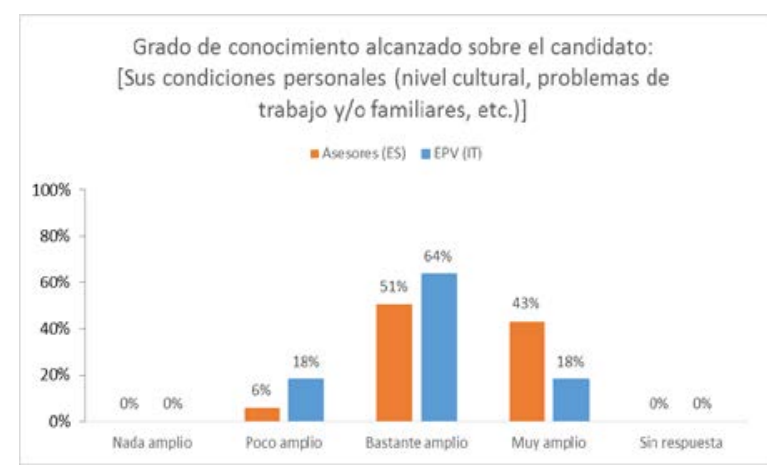


d) Figura relativa al indicador 4.6.1.4

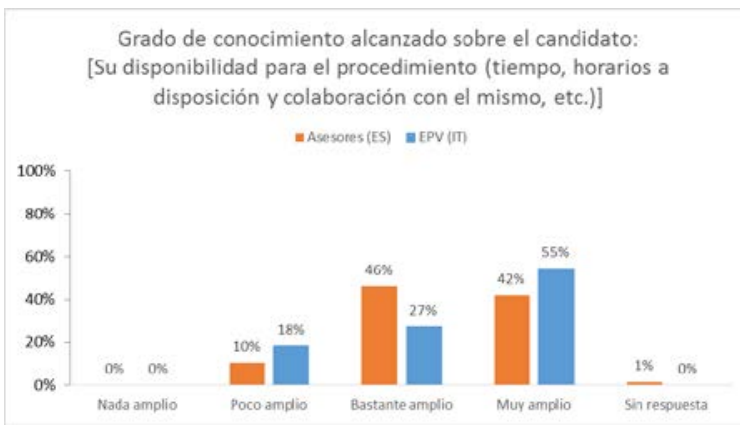

Figura 27: Flexibilidad por parte de los asesores de ambos procedimientos hacia el candidato

a) Figura relativa al indicador 4.6.2.1

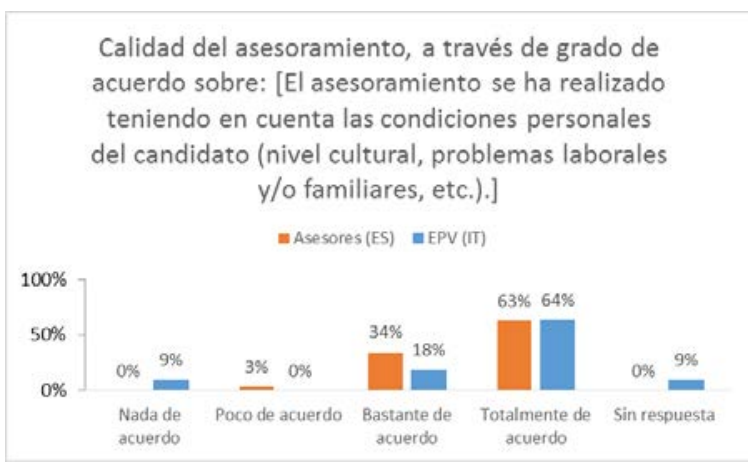

b) Figura relativa al indicador: 4.6.2.2.

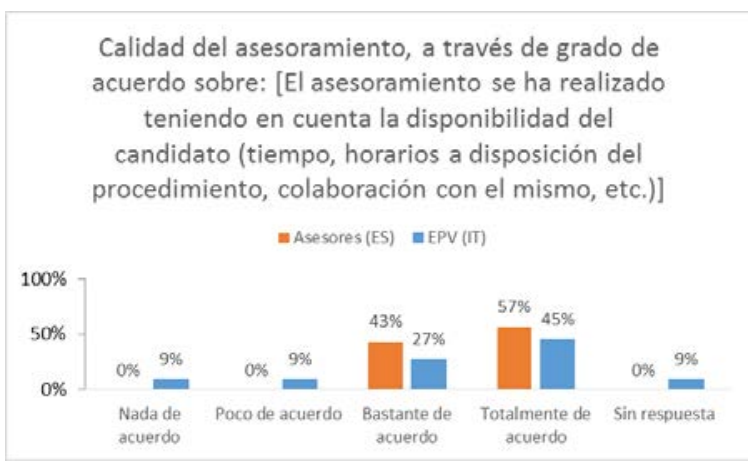

Según los resultados, observables en las anteriores gráficas (ver Figura 26 y Figura 27), los asesores de ambos procedimientos han indicado cono- 
cer y tener en cuenta las condiciones personales y la disponibilidad de los candidatos, expresando porcentajes bastante elevados en las opciones de respuesta: "bastante de acuerdo" y "muy de acuerdo". Sin embargo, los asesores del procedimiento en Castilla-León, han indicado conocer y tener en cuenta, en mayor medida, respecto a los EPV (asesores) del procedimiento de Emilia-Romagna, las condiciones personales y la disponibilidad de los candidatos.

\subsubsection{SUBCATEGORÍA: Lenguaje adaptado}

\begin{tabular}{|c|c|c|c|c|c|c|c|c|}
\hline \multirow[b]{3}{*}{ IND. } & \multicolumn{4}{|c|}{ ESPAÑA } & \multicolumn{4}{|c|}{ ITALIA } \\
\hline & \multicolumn{2}{|c|}{ Legislación } & \multirow{2}{*}{$\begin{array}{l}\text { Entrevis- } \\
\text { tas }\end{array}$} & \multirow{2}{*}{$\begin{array}{l}\text { Cues- } \\
\text { tio- } \\
\text { narios }\end{array}$} & \multicolumn{2}{|c|}{ Legislación } & \multirow{2}{*}{$\begin{array}{l}\text { Entre- } \\
\text { vistas }\end{array}$} & \multirow{2}{*}{$\begin{array}{c}\text { Cues- } \\
\text { tio- } \\
\text { narios }\end{array}$} \\
\hline & $\begin{array}{c}\text { Na- } \\
\text { cional }\end{array}$ & $\begin{array}{c}\text { Autonó- } \\
\text { mica }\end{array}$ & & & $\begin{array}{c}\text { Nacio- } \\
\text { nal }\end{array}$ & $\begin{array}{c}\text { Regio- } \\
\text { nal }\end{array}$ & & \\
\hline 4.6.3.1 & NO & NO & Sí & Sí & NO & NO & NO & sí \\
\hline
\end{tabular}

\section{Comparación}

\section{Legislación}

La legislación no contempla este aspecto, ni en el plano nacional español/italiano, ni en el autonómico de Castilla y león/regional de EmiliaRomagna.

\section{Entrevistas}

Los asesores entrevistados del procedimiento castellanoleonés, han indicado haber adaptado el vocabulario utilizado en algunos instrumentos de recogida de evidencias, ya que resultaba de difícil comprensión para el candidato. Por el contrario, los EPV (asesores) del procedimiento de Emilia-Romagna, no han hecho declaraciones al respecto.

\section{Cuestionarios}

Se ha preguntado a los asesores de ambos procedimientos sobre el tipo de lenguaje que han utilizado con el candidato. 
Figura 28: Lenguaje utilizado con el candidato por los asesores de ambos procedimientos

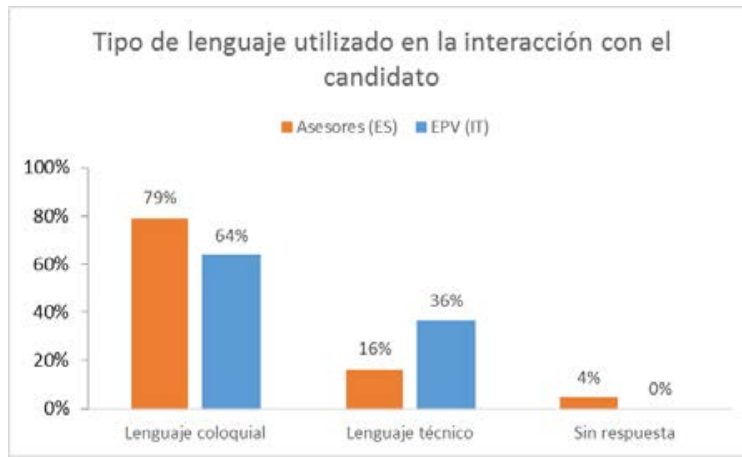

Como puede observarse en la Figura 28, los asesores de ambos procedimientos, han utilizado en su gran mayoría, sobre todo el caso del procedimiento castellanoleonés, un lenguaje coloquial con el candidato, con el fin de facilitar el proceso.

\subsection{CATEGORÍA: RECURSO O RECLAMACIÓN DEL} RESULTADO DEL ASESORAMIENTO

4.7.0. Sin subcategoría

\begin{tabular}{|c|c|c|c|c|c|c|c|c|}
\hline \multirow[b]{3}{*}{ IND. } & \multicolumn{4}{|c|}{ ESPAÑA } & \multicolumn{4}{|c|}{ ITALIA } \\
\hline & \multicolumn{2}{|c|}{ Legislación } & \multirow{2}{*}{$\begin{array}{l}\text { Entrevis- } \\
\text { tas }\end{array}$} & \multirow{2}{*}{$\begin{array}{c}\text { Cues- } \\
\text { tio- } \\
\text { narios }\end{array}$} & \multicolumn{2}{|c|}{ Legislación } & \multirow{2}{*}{$\begin{array}{l}\text { Entre- } \\
\text { vistas }\end{array}$} & \multirow{2}{*}{$\begin{array}{c}\text { Cues- } \\
\text { tio- } \\
\text { narios }\end{array}$} \\
\hline & $\begin{array}{c}\mathrm{Na-} \\
\text { cional } \\
\end{array}$ & $\begin{array}{c}\text { Autonó- } \\
\text { mica }\end{array}$ & & & $\begin{array}{c}\text { Nacio- } \\
\text { nal }\end{array}$ & $\begin{array}{c}\text { Regio- } \\
\text { nal }\end{array}$ & & \\
\hline 4.7.0.1 & NO & NO & sí & NO & $\mathrm{NO}$ & NO & sí & $\mathrm{NO}$ \\
\hline
\end{tabular}

4.7.0.1. INDICADOR: Existe un procedimiento de recurso o reclamación del resultado del asesoramiento, disponible para el candidato.

\section{Comparación}

\section{Legislación}

No se han encontrado referencias legislativas, ni en el plano nacional español/italiano, ni en el autonómico de Castilla y León/regional de EmiliaRomagna. 
La validación de competencias profesionales en España e Italia

\section{Entrevistas}

Los dos asesores entrevistados del procedimiento de Castilla y León, han declarado que el recurso o reclamación no sería necesario, porque el resultado del asesoramiento es orientativo para el candidato, él es quien decide pasar o no a la fase de evaluación, a pesar de que el resultado del asesoramiento haya resultado negativo. Por el contrario, uno de los EPV (asesores) entrevistados del procedimiento de Emilia-Romagna, ha afirmado la existencia de recurso durante todo el procedimiento, y por tanto en este caso.

\section{EVALUACIÓN}

5.1. CATEGORÍA: INFORMACIÓN EN EL PROCESO DE EVALUACIÓN

\subsubsection{Sin subcategoría}

\begin{tabular}{|c|c|c|c|c|c|c|c|c|}
\hline \multirow{3}{*}{$\begin{array}{l}\text { IND. } \\
5.1 .0 .1\end{array}$} & \multicolumn{4}{|c|}{ ESPAÑA } & \multicolumn{4}{|c|}{ ITALIA } \\
\hline & $\begin{array}{l}\text { Legisl } \\
\mathrm{Na-} \\
\text { cional }\end{array}$ & $\begin{array}{l}\text { ión } \\
\text { Auto- } \\
\text { nómica }\end{array}$ & $\begin{array}{l}\text { Entrevis- } \\
\text { tas }\end{array}$ & $\begin{array}{l}\text { Cues- } \\
\text { tio- } \\
\text { narios }\end{array}$ & $\begin{array}{l}\text { Legisla } \\
\text { Nacio- } \\
\text { nal }\end{array}$ & $\begin{array}{l}\text { Regio- } \\
\text { nal }\end{array}$ & $\begin{array}{l}\text { Entre- } \\
\text { vistas }\end{array}$ & $\begin{array}{l}\text { Cues- } \\
\text { tio- } \\
\text { narios }\end{array}$ \\
\hline & NO & أ & sí & sí & sí & NO & NO & sí \\
\hline
\end{tabular}

\section{Comparación}

\section{Legislación}

La legislación nacional española no indica que el evaluador deba proporcionar información al candidato sobre el procedimiento. Sin embargo, la legislación autonómica, aunque no especifica que deba hacerlo el evaluador, establece que debe informarse al candidato sobre la fecha, la provincia y el lugar en el que tendrá lugar la fase de evaluación. Por su parte, la legislación nacional italiana, hace referencia a la proporción de información personalizada sobre el procedimiento, pero no especifica que deba ser facilitada en la fase de evaluación. En cuanto a la legislación regional, de Emilia-Romagna, no se han encontrado referencias al respecto. 


\section{Entrevistas}

Solo los profesionales entrevistados del procedimiento de Castilla y León, se han referido a este aspecto. Los dos evaluadores han manifestado que se ha explicado al candidato, antes de empezar la evaluación, en qué consistía el proceso, sobre todo, con la intención de tranquilizarles respecto al mismo, porque, según han señalado, estaban bastante desinformados.

\section{Cuestionarios}

Hemos preguntado a los evaluadores de ambos procedimientos si han proporcionado información al candidato sobre el procedimiento, ya que en ambos casos la función de dar información al candidato recae más sobre el asesor que sobre el evaluador (ver subapartados 4.2.6.1 y 4.3.8.3):

Figura 29: Porcentaje de evaluadores de ambos procedimientos que han proporcionado información al candidato

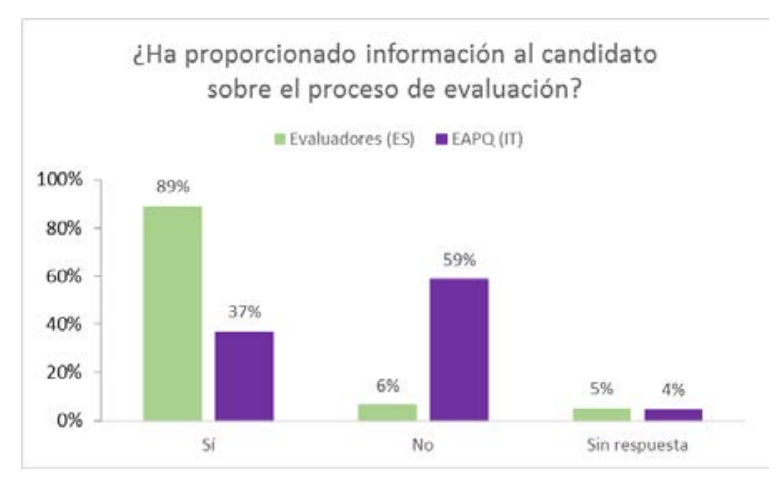

Como podemos observar en la Figura 29, un alto porcentaje de evaluadores del procedimiento en Castilla y León $(89 \%)$ ha indicado haber proporcionado información al candidato sobre el procedimiento. Por el contrario, el porcentaje de EAPQ (evaluadores) encuestados, del procedimiento de Emilia-Romagna, que ha señalado haber proporcionado esta información, es mucho menor $(37 \%)$.

A las personas que sí han proporcionado información, se les ha pedido valorar la cantidad de información que han proporcionado al candidato, sobre diferentes aspectos del procedimiento: 
La validación de competencias profesionales en España e Italia

Figura 30: Cantidad de información proporcionada por evaluadores al candidato sobre el procedimiento

a)

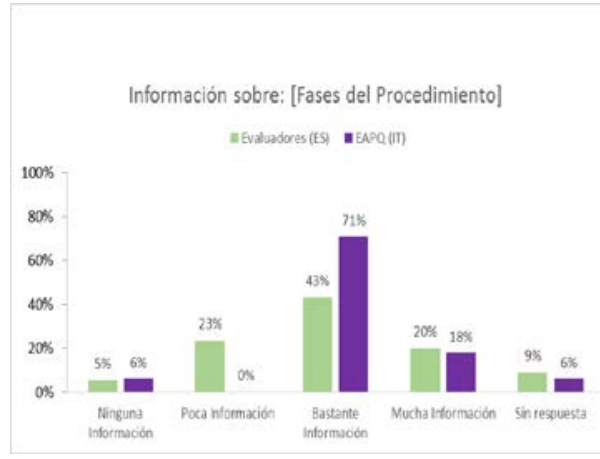

c)

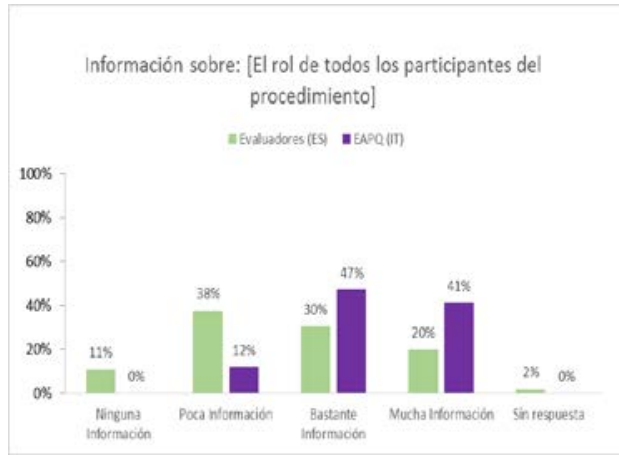

e)

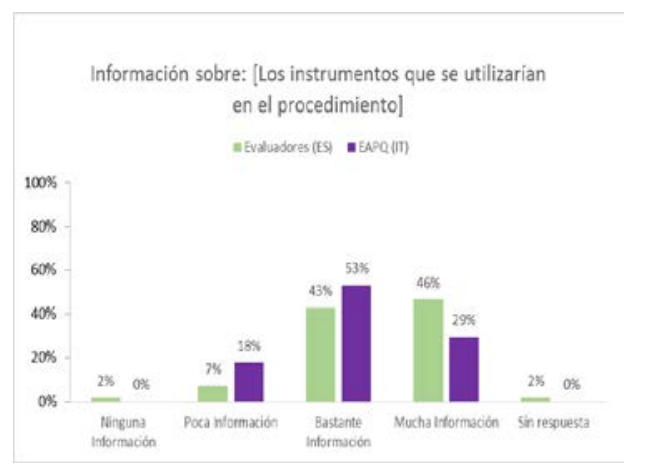

b)

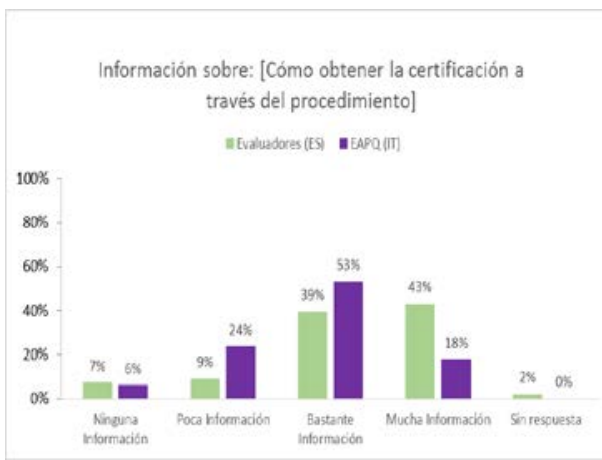

d)

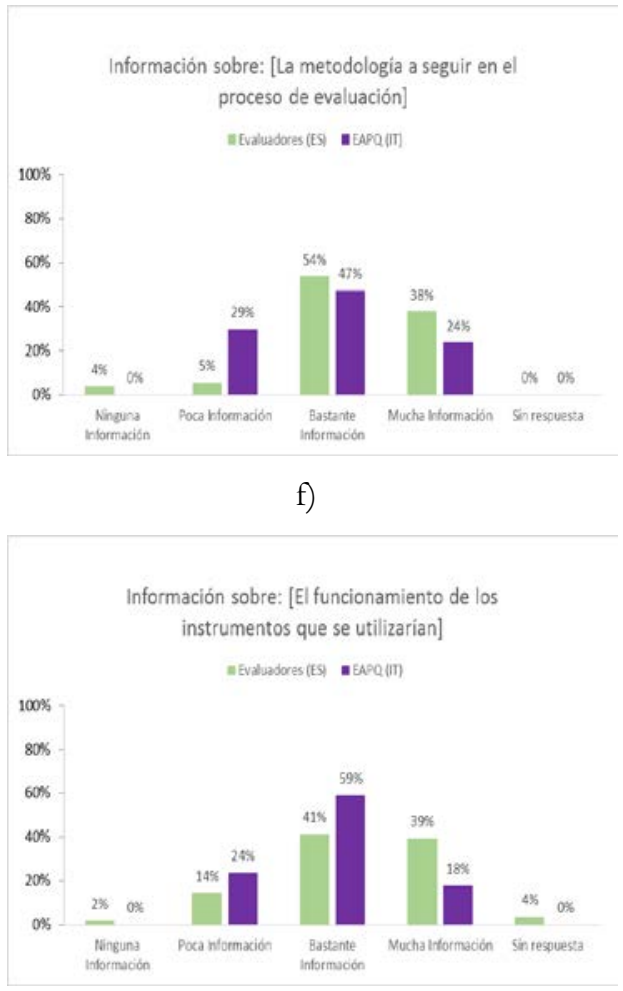


g)

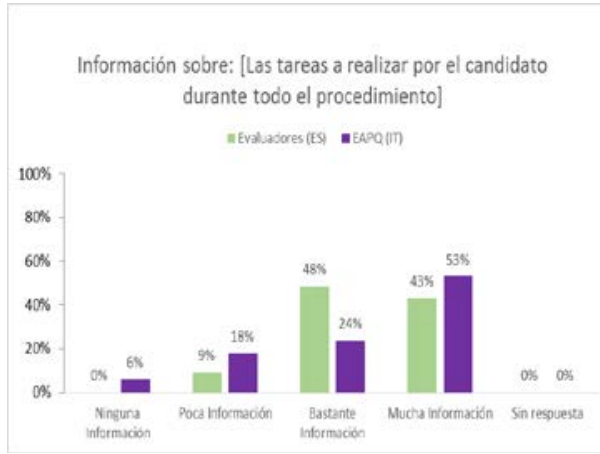

i)

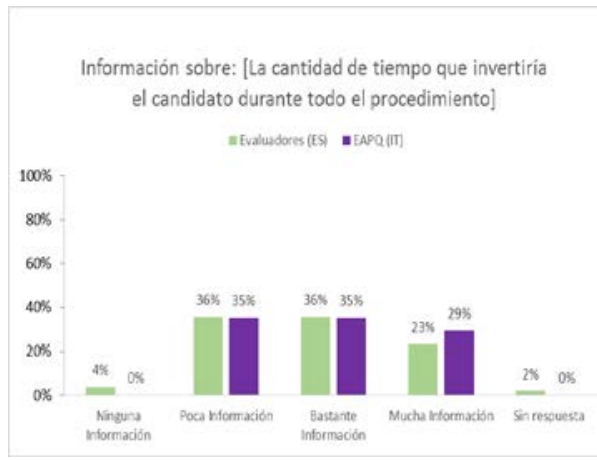

k)

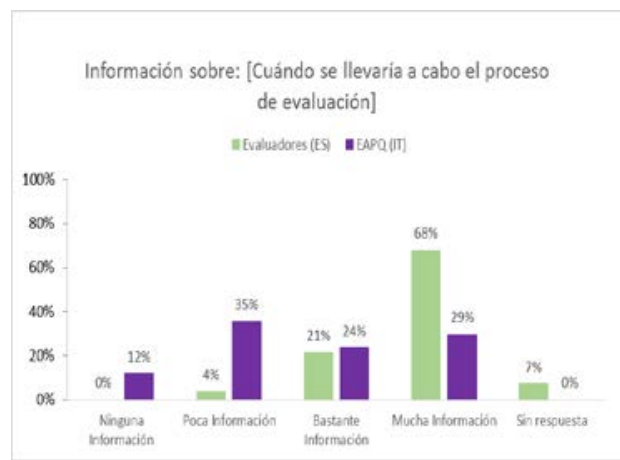

h) 107

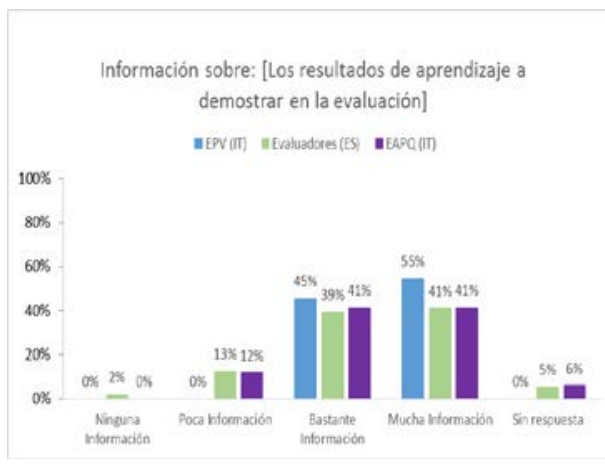

j)

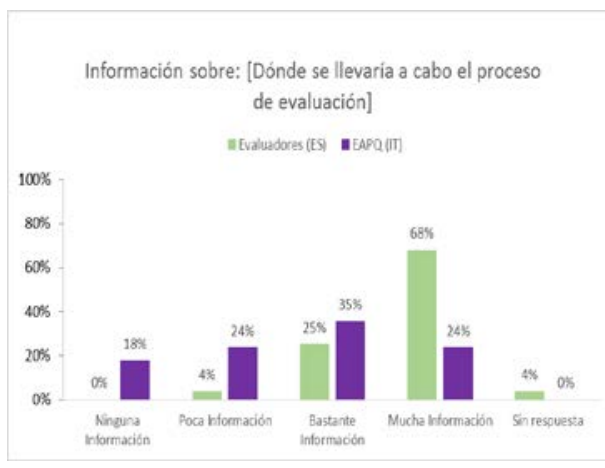

1)

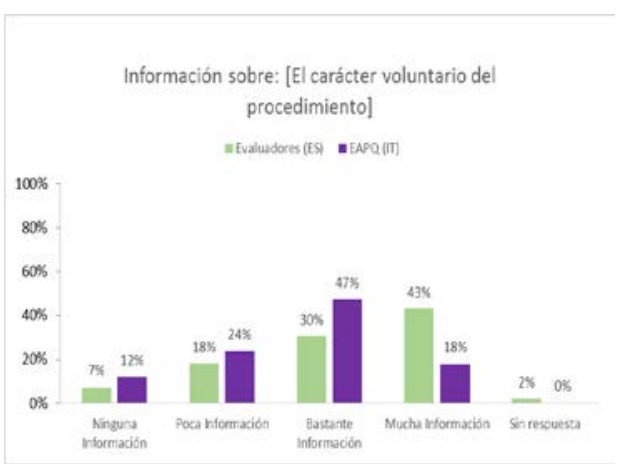

107 En esta gráfica incluye también los resultados de los asesores del procedimiento de Emilia-Romagna (EPV), ya que estos participan también en el proceso de evaluación y deberían, por tanto, informar sobre este aspecto (ver subapartado 4.3.8.3). 
$\mathrm{m})$

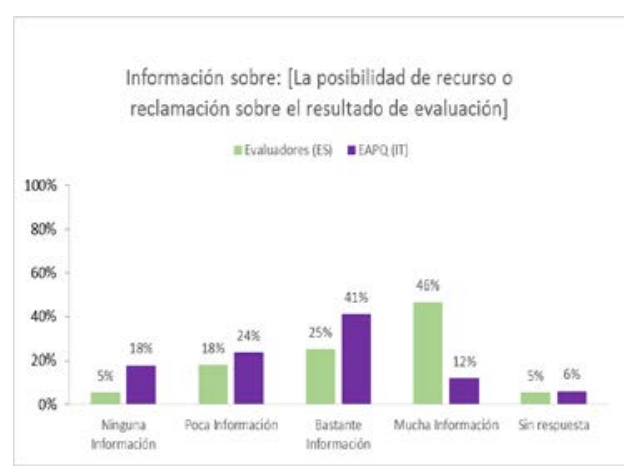

Observando estas gráficas, podemos decir que, en general, los evaluadores del procedimiento castellanoleonés señalan haber proporcionado más información que los EAPQ del procedimiento de Emilia-Romagna. Siendo más concretos, observamos que los puntos sobre los que los evaluadores de Castilla y León han proporcionado más información, han sido el dónde se lleva a cabo la evaluación (25\% bastante y $68 \%$ mucha, ver Figura 30 j); la metodología a seguir en el proceso de la misma (54\% bastante y $38 \%$ mucha, ver Figura 30 d) y las tareas que debe realizar el candidato en el proceso (48\% bastante y 43\%, ver Figura 30 g. Por su parte los EAPQ (evaluadores) han proporcionado más información sobre las fases del procedimiento ( $71 \%$ bastante y $18 \%$ mucha, ver Figura 30 a) y sobre los instrumentos de la evaluación (53\% bastante y 29\% mucha, ver Figura 30 e). Sobre lo que menos información han proporcionado los evaluadores de Castilla y León, ha sido sobre el rol de los participantes (11\% ninguna y 38\% poca información mucha, ver Figura 30 c) y los EAPQ (evaluadores) de Emilia-Romagna, sobre cuándo se lleva a cabo la evaluación (12\% ninguna y 35\% poca información, ver Figura $30 \mathrm{k}$ ). Por tanto, los evaluadores del procedimiento de Castilla y León, han dado más importancia al dónde se realizará la evaluación, a la metodología y a las tareas que debe realizar el candidato durante el proceso. Por el contrario, los del procedimiento de EmiliaRomagna han informado más sobre las fases y los instrumentos de evaluación. Asimismo, los EPV entrevistados ha informado en gran medida sobre los resultados de aprendizaje (indicando haber proporcionado en un $45 \%$ bastante información y en un 55\% mucha información sobre dicho aspecto). 
Adicionalmente, se ha preguntado a los evaluadores de ambos procedimientos, si habían facilitado información, al candidato, sobre otros aspectos. Varios evaluadores del procedimiento castellanoleonés han señalado haber proporcionado bastante información relativa a opciones formativas a las que podían optar los candidatos tras el procedimiento. Algunos también han indicado haber proporcionado bastante información sobre la importancia de acreditarse y la validez de la certificación. Otros han declarado haber facilitado información sobre los términos "saber ser", "saber hacer" y "saber estar". Este último aspecto nos resulta particularmente interesante, ya que como dijimos en el apartado 2.1, estos términos dan nombre a las tres dimensiones de las competencias que la persona debe demostrar para acreditarse. Por su parte, los EAPQ (evaluadores) del procedimiento de Emilia-Romagna, coincidiendo con algunos asesores de Castilla y León, han indicado haber proporcionado información sobre la importancia de certificar las competencias y sobre el valor de la certificación.

Asimismo, hemos preguntado a los evaluadores de ambos procedimientos por la vía utilizada para proporcionar la información sobre el procedimiento:

Figura 31: Vías de información utilizadas por los evaluadores de ambos procedimientos

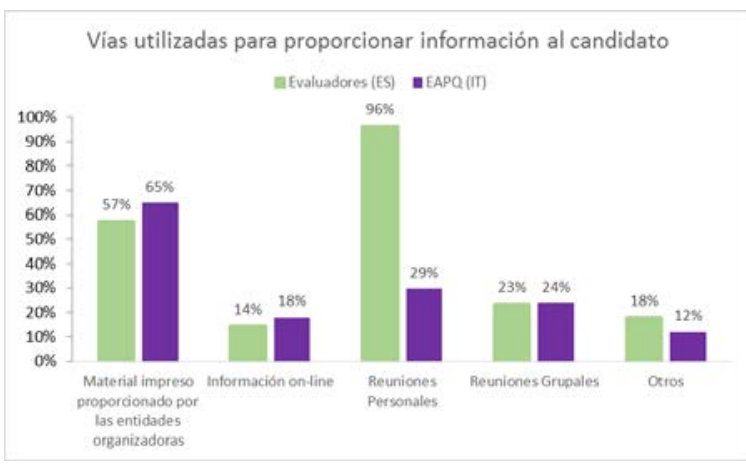

Observando la Figura 31, comprobamos que los evaluadores de Castilla y León han utilizado la reunión personal como principal vía ( $96 \%$ de los encuestados) para proporcionar información sobre el procedimiento, coincidiendo por tanto con los asesores (ver Figura 13). Por el contrario, los EAPQ, coincidiendo también con la respuesta dada por los EPV (ver Figu- 
ra 13), han señalado en su mayoría el material impreso proporcionado por las entidades organizadoras.

Algunos evaluadores del procedimiento de Castilla y León, han indicado como otras vías utilizadas, el teléfono y material impreso elaborado por ellos mismos. Por su parte, los evaluadores del procedimiento de Emilia-Romagna (EAPQ) han indicado haber utilizado, también para proporcionar la información, las directivas regionales que describen el procedimiento.

\subsection{CATEGORÍA: ADECUACIÓN EN LA INVESTIGACIÓN $Y$ ANALISIS DE EVIDENCIAS CON LAS NORMAS ESTANDARES.}

\subsubsection{SUBCATEGORÍA: Existencia de estándares/referentes de evaluación}

\begin{tabular}{|c|c|c|c|c|c|c|c|c|}
\hline \multirow[b]{3}{*}{ IND. } & \multicolumn{4}{|c|}{ ESPAÑA } & \multicolumn{4}{|c|}{ ITALIA } \\
\hline & \multicolumn{2}{|c|}{ Legislación } & \multirow{2}{*}{$\begin{array}{l}\text { Entrevis- } \\
\text { tas }\end{array}$} & \multirow{2}{*}{$\begin{array}{l}\text { Cues- } \\
\text { tio- } \\
\text { narios }\end{array}$} & \multicolumn{2}{|c|}{ Legislación } & \multirow{2}{*}{$\begin{array}{l}\text { Entre- } \\
\text { vistas }\end{array}$} & \multirow{2}{*}{$\begin{array}{c}\text { Cues- } \\
\text { tio- } \\
\text { narios }\end{array}$} \\
\hline & $\begin{array}{c}\text { Nacio- } \\
\text { nal }\end{array}$ & $\begin{array}{c}\text { Autonómi- } \\
\text { ca }\end{array}$ & & & $\begin{array}{c}\text { Nacio- } \\
\text { nal }\end{array}$ & $\begin{array}{c}\text { Regio- } \\
\text { nal }\end{array}$ & & \\
\hline 5.2 .1 .1 & Sí & Sí & Sí & NO & sí & Sí & Sí & NO \\
\hline 5.2 .1 .2 & Sí & NO & Sí & NO & sí & Sí & Sí & NO \\
\hline 5.2 .1 .3 & Sí & NO & sí & NO & NO & NO & sí & NO \\
\hline
\end{tabular}

5.2.1.1. INDICADOR: Las evaluaciones se basan en estándares/referentes/normas especificos/as y claros/as

\section{Comparación}

\section{Legislación}

Tanto la legislación española como la italiana (en el plano nacional y en el autonómico/regional) hacen alusión a la importancia de una evaluación basada en estándares/referentes/normas, estableciendo las UC de las cualificaciones como estándar/referente, en ambos casos. En el caso de España, la legislación nacional y la autonómica, establecen como referentes de evaluación las unidades de competencia del Catálogo Nacional de Cualificaciones Profesionales, concretamente, las realizaciones profesionales, los criterios de realización y el contexto profesional de cada una de ellas. En Italia, la legislación nacional insta a las regiones a establecer estos estándares y la regional establece como referencia el Sistema Regional de Cualificacio- 
nes, que contiene las cualificaciones y las unidades de competencia correspondientes.

\section{Entrevistas}

Los entrevistados de ambos procedimientos han afirmado que en la práctica se ha cumplido lo establecido en la legislación. Una de las evaluadoras del procedimiento de Castilla y León, habla de las actividades profesionales secundarias y primarias (de las UC), que se toman como referente de evaluación. Por su parte, dos de los EPV entrevistados, el EAPQ, y los tres gestores/organizadores entrevistados del procedimiento de EmiliaRomagna, han afirmado que las evaluaciones se basan en estándares/referentes de evaluación y que serían las unidades de competencia que componen las cualificaciones.

\subsubsection{INDICADOR: Los estándares están ligados/relacionados con el Marco Nacional de Cualificaciones.}

\section{Comparación}

\section{Legislación}

La legislación nacional española e italiana y la regional de EmiliaRomagna, establecen dicha relación de una forma u otra. La legislación nacional española indica que la evaluación y la acreditación tendrán como referentes las unidades de competencias del Catálogo Nacional de Cualificaciones Profesionales, el cual define una parte del marco nacional de cualificaciones que en España se encuentra en proceso de construcción (ver subapartado 4.2.2.1). En Italia, la legislación nacional establece que todos los estándares de las cualificaciones y competencias certificables deben recogerse en repertorios codificados en ámbito nacional o regional, reconocidos oficialmente y accesibles en un repertorio de títulos de educación y formación profesional. Respecto a la legislación regional, esta señala que la formalización y certificación de competencias se hace tomando como referencia los estándares profesionales. Es decir, las competencias, objeto de este proceso, se miden y evalúan respecto a las presentes en el repertorio del Sistema Regional de las Cualificaciones, el cual está relacionado con el marco nacional y el europeo de cualificaciones. Por el contrario, en la legislación autonómica de Castilla y León, no se han encontrado alusiones al respecto.

\section{Entrevistas}


La validación de competencias profesionales en España e Italia

Tanto en el procedimiento de Castilla y León como en el de EmiliaRomagna, uno de los gestores/organizadores entrevistados ha confirmado la relación entre su respectivo catálogo de cualificaciones (el nacional en el caso de Castilla y León y el regional en el de Emilia-Romagna) y el proceso de evaluación. En el procedimiento de Castilla y León, el gestor/dirigente entrevistado ha afirmado que se ha hecho la evaluación y acreditación haciendo uso del Catálogo Nacional de Cualificaciones. En cuanto al procedimiento de Emilia-Romagna, uno de los gestores/organizadores, ha afirmado que las UC de las cualificaciones, de las que salen los indicadores para la validación, están dentro del catálogo regional de cualificaciones.

\subsubsection{INDICADOR: Los resultados de aprendizaje que debe demostrar el candidato están debidamente indicados}

\section{Comparación}

\section{Legislación}

La legislación nacional española es la única que hace mención al aspecto relacionado con la claridad sobre los resultados de aprendizaje, indicando las realizaciones profesionales como resultados de aprendizaje.

A pesar de que este aspecto apenas aparece en la legislación, relativa a ambos procedimientos, los profesionales entrevistados, de los dos procedimientos, indican que los resultados de aprendizaje están perfectamente definidos. En el caso de Castilla y León, un evaluador entrevistado ha afirmado que estos resultados se definen en las guías de evidencia correspondientes. En cuanto al procedimiento de Emila-Romagna, el EAPQ entrevistado, ha indicado que los resultados de aprendizaje están definidos por la Regione, por cada unidad de competencia.

5.2.2. SUBCATEGORIA: Adecuación de los instrumentos de evaluación

\begin{tabular}{|c|c|c|c|c|c|c|c|c|}
\hline \multirow[b]{3}{*}{ IND. } & \multicolumn{4}{|c|}{ ESPAÑA } & \multicolumn{4}{|c|}{ ITALIA } \\
\hline & \multicolumn{2}{|c|}{ Legislación } & \multirow{2}{*}{$\begin{array}{c}\text { Entrevis- } \\
\text { tas }\end{array}$} & \multirow{2}{*}{$\begin{array}{c}\text { Cues- } \\
\text { tio- } \\
\text { narios }\end{array}$} & \multicolumn{2}{|c|}{ Legislación } & \multirow{2}{*}{$\begin{array}{l}\text { Entre- } \\
\text { vistas }\end{array}$} & \multirow{2}{*}{$\begin{array}{c}\text { Cues- } \\
\text { tio- } \\
\text { narios }\end{array}$} \\
\hline & $\begin{array}{c}\mathrm{Na}- \\
\text { cional }\end{array}$ & $\begin{array}{c}\text { Autonó- } \\
\text { mica }\end{array}$ & & & $\begin{array}{c}\text { Nacio- } \\
\text { nal }\end{array}$ & $\begin{array}{c}\text { Regio- } \\
\text { nal }\end{array}$ & & \\
\hline 5.2.2.1 & Sí & NO & Sí & Sí & NO & NO & Sí & sí \\
\hline 5.2.2.2 & Sí & NO & sí & sí & NO & NO & sí & sí \\
\hline
\end{tabular}


Análisis y resultados

\begin{tabular}{lcc|c|c|cc|c|c}
\hline 5.2 .2 .3 & SÍ & NO & SÍ & SÍ & NO & NO & sí & sí \\
\cline { 2 - 9 } 5.2 .2 .4 & NO & NO & NO & sí & NO & NO & NO & sí \\
\cline { 2 - 8 } 5.2 .2 .5 & Sí & NO & sí & sí & NO & sí & sí & sí \\
\hline
\end{tabular}

*Recordamos que para facilitar el análisis de datos se agruparon los dos indicadores siguientes, pertenecientes a la misma subcategoría de: adecuación de los instrumentos de evaluación (ver apartado 6.1):

\subsubsection{INDICADOR: Los instrumentos miden las competencias que preten- den medirse y no otras. \\ 5.2.2.2. INDICADOR: Los instrumentos permiten al candidato demostrar los aprendizajes que posee.}

\section{Comparación}

\section{Legislación}

La legislación nacional española hace referencia a estos aspectos, señalando que debe cumplirse el principio de validez. En cuanto a la autonómica de Castilla y León, no se han encontrado referencias al respecto. En Italia no se han encontrado referencias, ni en ámbito nacional ni regional de Emilia-Romagna.

\section{Entrevistas}

Uno de los evaluadores entrevistados del procedimiento de Castilla y León, cree que los instrumentos son adecuados, aunque no siempre se usan los más completos, como la observación en el puesto de trabajo, que nunca ha utilizado en la evaluación. En cuanto a las entrevistas, el EAPQ entrevistado ha mostrado alguna duda sobre la validez, ya que ha comentado que en algunas ocasiones las pruebas eran adecuadas y en otras no.

\section{Cuestionarios}

Por medio del cuestionario hemos pedido la opinión, sobre los aspectos relacionados con estos dos indicadores, a los profesionales de ambos procedimientos, implicados en la validación. Es decir, en Castilla y León a los evaluadores y en Emilia-Romagna a los evaluadores (EAPQ) y a los asesores (EPV), ya que estos últimos también se encuentran presentes durante el proceso de evaluación. 
La validación de competencias profesionales en España e Italia

Figura 32: Opinión de los profesionales de la evaluación, de ambos procedimientos, sobre la calidad de esta

Calidad de la evaluación, a través de grado de acuerdo sobre: [Los intrumentos de evaluación han sido capaces de medir las competencias del candidato que se pretendian evaluar]

MEPV (IT) EEvaluadores (ES) aEAPQ (TT)

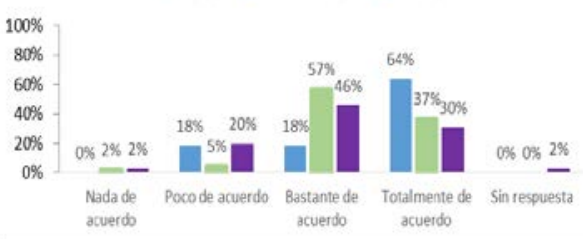

c)

Calidad de la evaluación, a través de grado de acuerdo

sobre: [El intrumento de evaluación, en caso de

simulación, ha sido capaz de recrear el contexto de

trabajo en el que el candidato ha adquirido el

aprendizaje que pretendia demostrar]

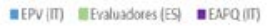

$100 \%$

$80 \%$

$60 \%$

$40 \%$

O\%

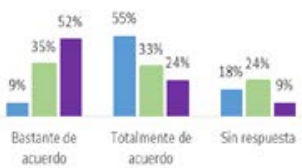

b)

Calidad de la evaluación, a través de grado de acuerdo sobre: [Los intrumentos de evaluación

han permitido al candidato demostrar el aprendizaje que poseía]

IEPV (TiT) $=$ Evaluadores (ES) $\quad$ a EAPQ (T)

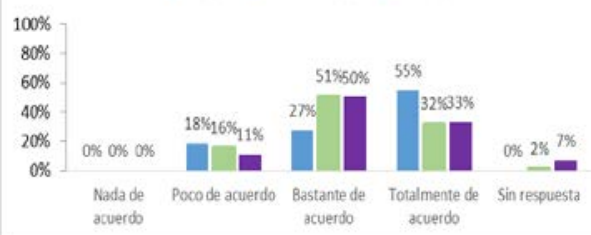

Observando estas gráficas (ver Figura 32) podemos afirmar que todos los profesionales entrevistados, de ambos procedimientos, se han mostrado bastante o totalmente de acuerdo en que los instrumentos son válidos. Cabe destacar una pequeña diferencia, el referente a la capacidad del instrumento para medir las competencias (ver Figura 32 a). En este sentido, los profesionales italianos se han mostrado ligeramente más disconformes que los españoles (el 20\% de los EAPQ el 18\% de los EPV se han mostrado poco de acuerdo en Emilia-Romagna, frente al 5\% de evaluadores poco de acuerdo en Castilla y León).

Cabe señalar que la pregunta sobre la capacidad de recrear el contexto de trabajo por parte de los instrumentos, tiene el mayor porcentaje sin respuesta, sobre todo en los EPV (asesores) de Emilia-Romagna (18\% sin 
respuesta) y en los evaluadores de Castilla y león (24\% sin respuesta), (ver Figura $32 \mathrm{c}$ ).

\subsubsection{INDICADOR: Los instrumentos permiten medir: el "saber"; el" sa-} ber hacer"; el "saber estar".

\section{Comparación}

\section{Legislación}

En la legislación nacional española no se han encontrado referencias directas al respecto, sin embargo, en ella se mencionan las guías de evidencia, que hablan de medir las tres dimensiones de la competencia profesional: el "saber", el "saber hacer" y el "saber estar". En referencia a la legislación autonómica, no se han encontrado alusiones al respecto. Respecto a Italia, no se han encontrado referencias este tema, ni en la legislación nacional, ni en la regional de Emilia-Romagna.

\section{Entrevistas}

El gestor/organizador entrevistado del procedimiento de Castilla y León, ha incidido en la importancia de la evaluación de los "saberes" del "saber hacer" y del "saber estar". Por su parte, los gestores/organizadores entrevistados del procedimiento de Emilia-Romagna, han explicado que en el sistema de Emilia-Romagna no hay competencias transversales, solo profesionales. Con ello pretenden ser lo más objetivos posibles, por lo que el "saber estar", según esto, quedaría fuera, aunque también han añadido que ciertas figuras profesionales contienen algunas competencias transversales.

\section{Cuestionarios}

Hemos preguntado sobre la calidad de los instrumentos respecto a su capacidad para medir los tres saberes, a todos los profesionales, en ambos procedimientos, que han participado en el proceso de evaluación. 
d)

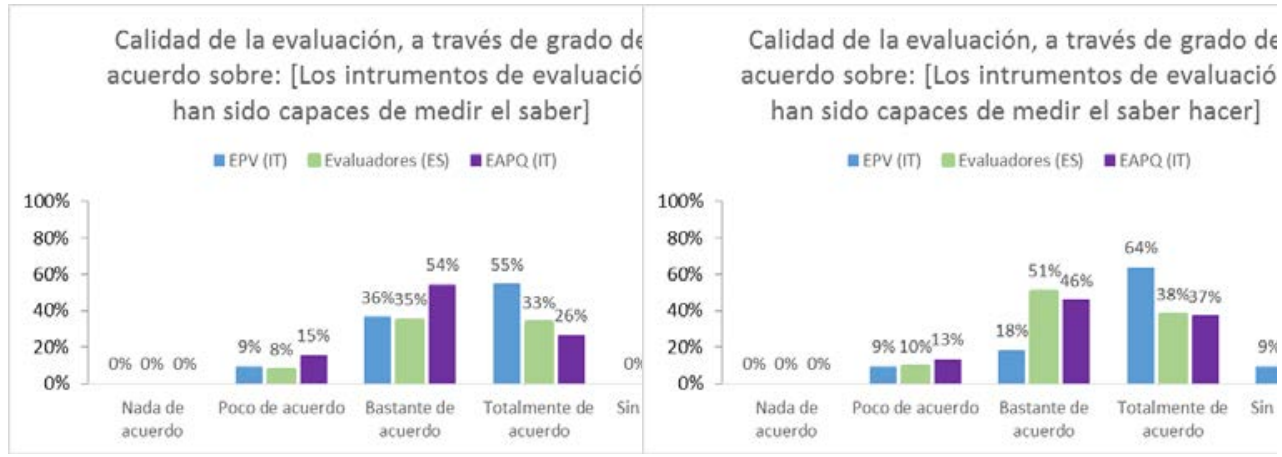

Calidad de la evaluación, a través de grado de acuerdo sobre: [Los intrumentos de evaluació han sido capaces de medir el saber estar] mEPV (IT) EEvaluadores (ES) —EAPQ(IT)

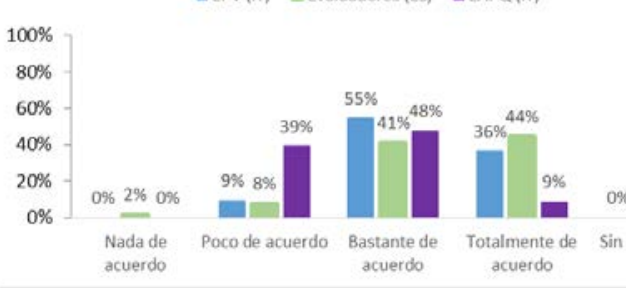

El saber (que logra medir mejor los instrumentos de evaluación) más señalado por los profesionales de la evaluación, de ambos procedimientos, ha sido el "saber hacer" (ver Figura 32 e). En cuanto al "saber", ha sido más señalado por los profesionales del procedimiento de Emilia-Romagna que por los del castellanoleonés (EAPQ: 54\% bastante y 26\% totalmente de acuerdo y EPV: $36 \%$ bastante y 55\% totalmente de acuerdo, frente a un $35 \%$ bastante y un 33\% totalmente de acuerdo de los evaluadores del procedimiento de Castilla y León, (ver Figura 32 d).

Por último, cabe destacar las respuestas obtenidas en cuanto al "saber estar". En Castilla y León, el porcentaje de asesores que está bastante (41\%) y totalmente $(44 \%)$ de acuerdo con que este saber se mide a través de los instrumentos de evaluación, es bastante elevado. Sin embargo, en Italia hay un hecho que nos llama la atención, los EPV, al igual que los evaluadores españoles, han considerado que los instrumentos, han logrado en un gran porcentaje (55\% bastante y 36\% totalmente de acuerdo) medir el "saber 
estar". Sin embargo, los EAPQ no lo han considerado así (otorgando un $39 \%$ a poco de acuerdo y un $48 \%$ a bastante y solo un $9 \%$ a totalmente de acuerdo), (ver Figura 32 f).

\subsubsection{INDICADOR: El individuo conoce sus competencias a través del proceso de evaluación (autoevaluación).}

\section{Comparación}

\section{Legislación}

No se han encontrado referencias legislativas sobre este aspecto, ni en el ámbito legislativo nacional español/italiano, ni en el plano autonómico de Castilla y León/regional de Emilia-Romagna.

\section{Entrevistas}

Tampoco existen alusiones al respecto en las entrevistas sobre ambos procedimientos.

\section{Cuestionarios}

Hemos pedido a los profesionales, de ambos procedimientos, presentes en la evaluación, su opinión sobre el aspecto de la autoevaluación del candidato a través de los instrumentos de evaluación:

g)

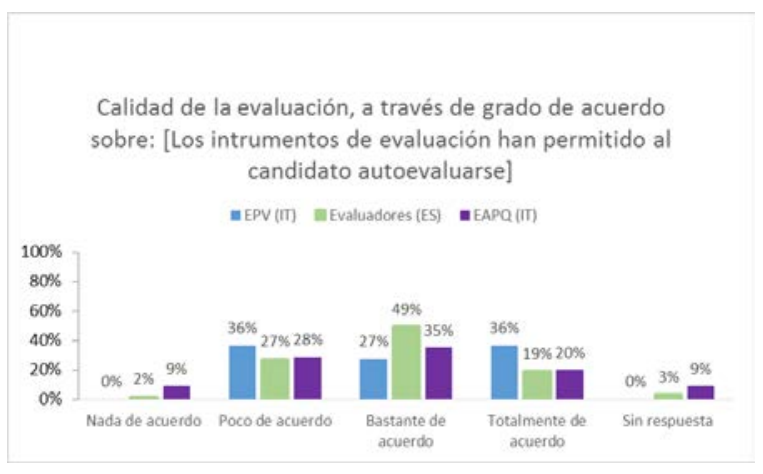

Según esta gráfica (ver Figura $32 \mathrm{~g}$ ), en ambos procedimientos la mayoría de los profesionales está bastante y totalmente de acuerdo con que los instrumentos han permitido la autoevaluación al candidato, aunque un por- 
La validación de competencias profesionales en España e Italia

cetaje de profesionales se ha mostrado poco o nada de acuerdo (la suma de estas respuestas sobrepasa el $30 \%$ en todos los casos).

\subsubsection{INDICADOR: Al realizar una evaluación a dos o más candidatos de características similares los resultados son los mismos o muy simila- res}

\section{Comparación}

\section{Legislación}

La legislación autonómica no hace alusión a este aspecto, pero la legislación nacional española sí lo hace, a través del principio de fiabilidad. Asimismo, la legislación nacional insta al Ministerio de Educación y de Trabajo e Inmigración, en colaboración con las comunidades autónomas a la elaboración de instrumentos que garanticen la fiabilidad del procedimiento. Dichos instrumentos fueron creados, en concreto, las guías de evidencia de las unidades de competencia contienen pautas para evaluar con precisión las competencias contenidas en las mismas. Todas las unidades de competencia evaluables cuentan con explicaciones y pautas de evaluación (ver subapartado 4.2.6.2). Aunque en la legislación nacional italiana no menciona este aspecto, la regional de Emilia-Romagna propone algunos ejemplos de evaluación en algunas cualificaciones (ver subapartado 4.3.8.3).

\section{Entrevistas}

Los evaluadores entrevistados del procedimiento de Castilla y León han afirmado haber utilizado la guía del evaluador y las guías de evidencias para realizar la evaluación. Guías creadas con el fin de ayudar a garantizar la fiabilidad de la evaluación. En cuanto a los entrevistados en EmiliaRomagna, un EAPQ (evaluador) y un EPV (asesor) entrevistados han asegurado que se intenta mantener una homogeneidad en la evaluación de los candidatos, favoreciendo la fiabilidad de proceso de evaluación.

\section{Cuestionarios}

Para indagar sobre este aspecto con los cuestionarios, hemos tenido en cuenta la definición que dan las Líneas Directrices de 2009: Un instrumento es fiable en la medida en la cual se obtienen resultados idénticos cada vez que se evalúa a un candidato bajo las mismas condiciones. Por ello hemos realizado la pregunta que exponemos a continuación, con las 
correspondientes respuestas, a los profesionales de ambos procedimientos que han participado en el proceso de evaluación:

Figura 33: Fiabilidad de la evaluación en ambos procedimientos

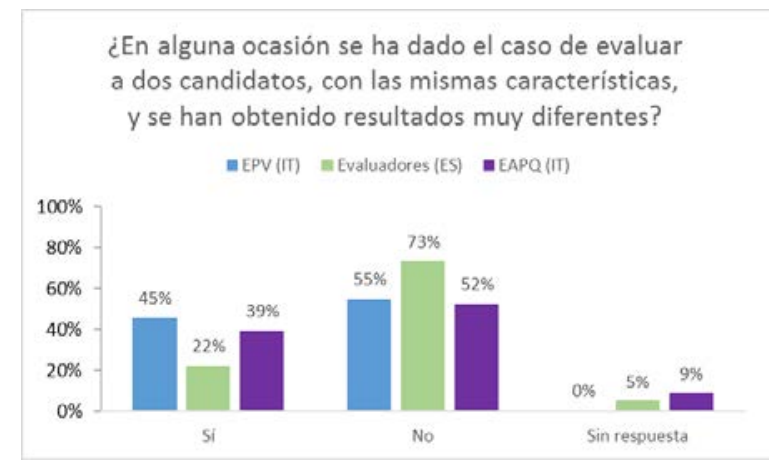

La mayor parte de los profesionales a los que se les ha preguntado por este aspecto, han contestado que "no" (ver Figura 33), lo cual indica fiabilidad en ambos procedimientos. Sin embargo, en Castilla y León el porcentaje de la respuesta "no" ha sido mayor (73\%) respecto a los EPV $(55 \%)$ y a los EAPQ (52\%). En Italia los porcentajes son similares, lo cual resulta lógico, teniendo en cuenta que tanto los EPV como los EAPQ evalúan al candidato de forma conjunta.

Asimismo, se ha preguntado a los profesionales que han contestado afirmativamente a la pregunta, por los factores a los que atribuían esas diferencias.

Muchos de los evaluadores del procedimiento de Castilla y León, y de los profesionales que han participado en el proceso de evaluación en el procedimiento de Emilia-Romagna (EAPQ y EPV), coinciden en los factores a los que atribuyen las diferencias en los resultados de evaluación de candidatos con las mismas características. En su mayoría, son factores relacionados con la motivación del candidato para someterse a la evaluación, con el nerviosismo y el estrés en el momento de la evaluación y con el saber estar del candidato (forma de comportarse, escuchar), lo cual se ha atribuido a la experiencia personal.

Algunos profesionales de Emilia-Romagna, también han relacionado este hecho con el dominio de la lengua y a aspectos culturales. Uno de los evaluadores de Castilla y León, ha indicado que algunos candidatos con mucha experiencia laboral no sabían realizar ciertas funciones que exigía su 
contrato, porque en su trabajo se le asignaban otras tareas diferentes a las que debería realizar. Asimismo, un EAPQ ha señalado que a pesar de tener características similares, los candidatos no siempre tienen los mismos conocimientos.

Según estas respuestas, el hecho de que los resultados de candidatos con las mismas características sean muy diferentes se debe a aspectos personales del candidato. Tan solo una persona encuestada, un EPV, lo ha atribuido a la subjetividad del evaluador.

Ninguno de los encuestados ha relacionado este hecho con una deficiencia en los instrumentos.

Para cerrar el análisis de esta subcategoría con la intención de indagar más sobre los instrumentos utilizados en la evaluación con los candidatos y obtener más información relacionada con los indicadores de esta subcategoría, hemos pedido a los profesionales encuestados valorar la utilidad de todos los instrumentos. Hemos preguntado por la utilidad de cada uno de los instrumentos, entendiendo como útil la capacidad de lograr medir las competencias del candidato y su nivel de adquisición:

Figura 34: Utilidad de los instrumentos de evaluación según los evaluadores del procedimiento de Castilla y León

a)

Utilidad de los instrumentos durante el proceso de evaluación: [Observación de la práctica por parte de expertos en el puesto de trabajo] entraluadores (ES)

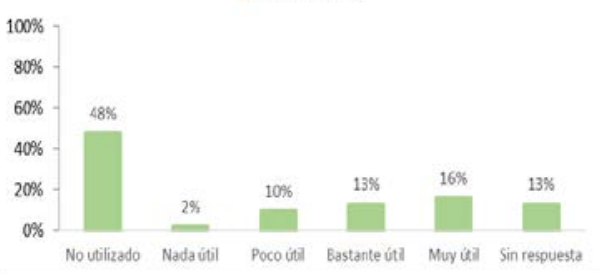

b)

Utilidad de los instrumentos durante el proceso de evaluación: [Observación de la práctica por parte de expertos en una simulación] envaluadares (ES)

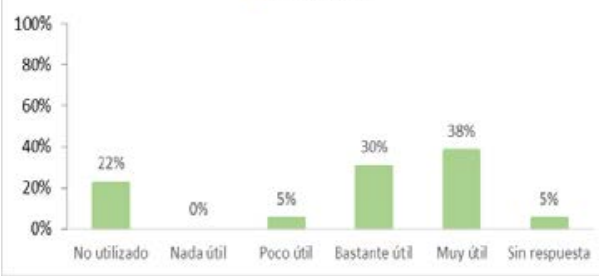


c)

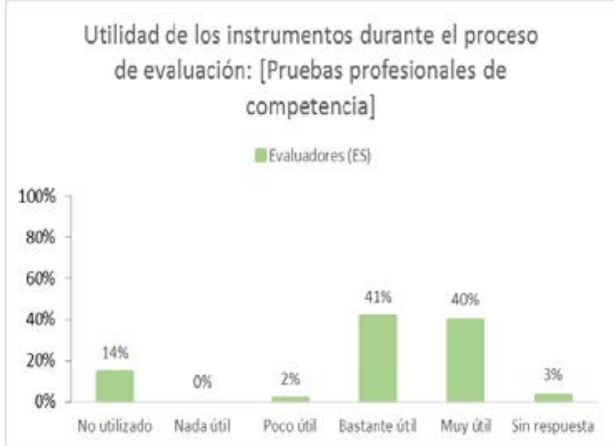

e)

Utilidad de los instrumentos durante el proceso de evaluación: [Entrevista profesional estructurada con fines de evaluación]

Evvaluadores (ES)

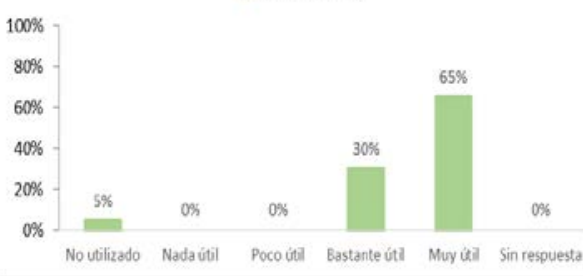

g)

Utilidad de los instrumentos durante el proceso

de evaluación: [Justificantes, títulos, certificados]

avaluadores(ES)

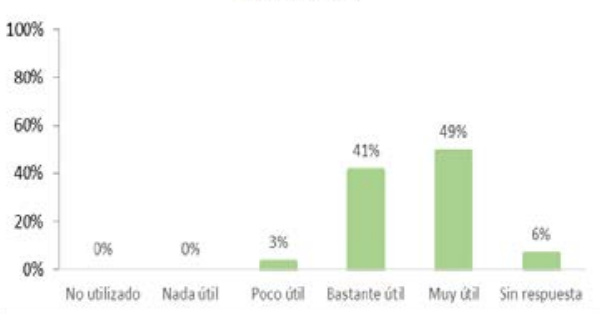

d)

Utilidad de los instrumentos durante el proceso

de evaluación: [Historial profesional y formativo]

vinvaluadores (ES)

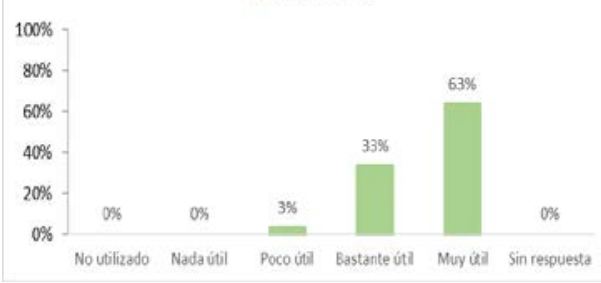

f)

Utilidad de los instrumentos durante el proceso de evaluación: [Declaración de aprendizajes en forma de autoevaluación]

nevaluadores (ES)

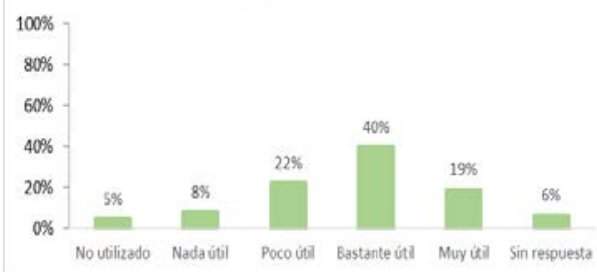

Comprobamos, según estas gráficas, que algunos de los instrumentos previstos para esta fase no han sido utilizados por varios de los evaluadores encuestados (ver Figura 34 a), b), c), e) y f), contrariamente a lo que ocurre con los instrumentos del asesoramiento, donde el único instrumento no 
utilizado ha sido la ficha de la empresa, con un porcentaje del 7\% de asesores encuestados que han contestado "no utilizado", ver Figura 14). En el caso de los evaluadores, el instrumento menos utilizado ha sido la observación en el puesto de trabajo ( $48 \%$ no utilizado). El instrumento mejor valorado ha sido la entrevista profesional con fines de evaluación, considerada por el $30 \%$ como bastante útil y por el $63 \%$ como muy útil (ver Figura 34 e), seguido del historial profesional y formativo (33\% bastante y $63 \%$ muy útil). Los justificantes, títulos y certificados también han obtenido una buena valoración (ver Figura $34 \mathrm{~g}$ ). Asimismo, las pruebas de competencia también han tenido una valoración bastante buena ver Figura 34 c) entre los profesionales que las han utilizado.

A continuación mostramos los resultados de los EPV (asesores) y de los EAPQ (evaluadores) del procedimiento de Emilia-Romagna, en relación a la valoración de la utilidad de los instrumentos utilizados con el candidato durante el proceso de evaluación.

Figura 35: Utilidad de los instrumentos de evaluación según los evaluadores del procedimiento de Emilia-Romagna

a)

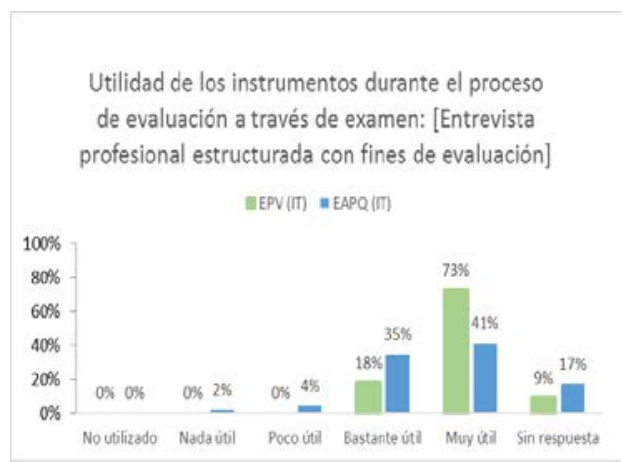

b)

Utilidad de los instrumentos durante el proceso de evaluación a través de examen: [Observación de la práctica por parte de expertos en el puesto de trabajo] mEPV (IT) =EAPQ(IT)

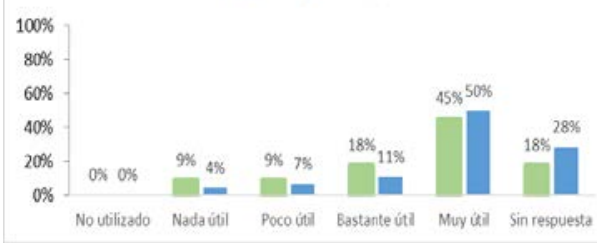


c)

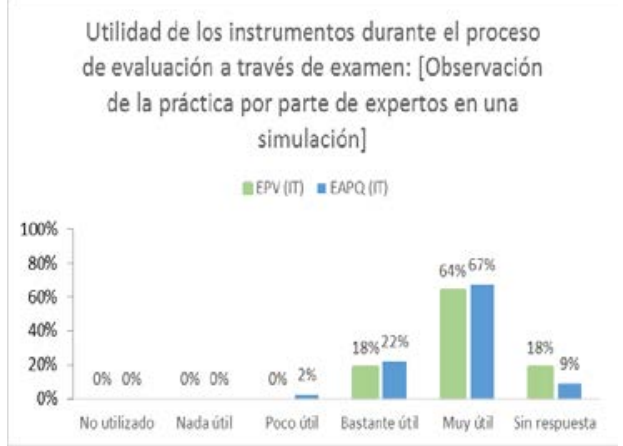

e)

Utilidad de los instrumentos durante el proceso de evaluación a través de examen: [Test y exảmenes (prueba escrita)]

$\triangle E P V(\pi)=E A P Q(\pi)$

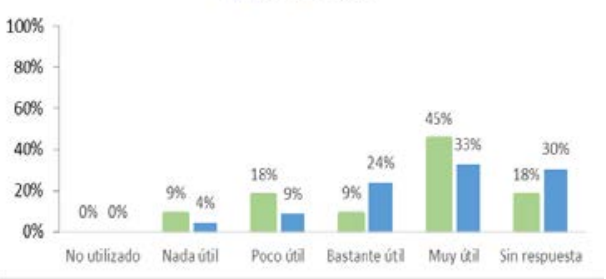

Como podemos observar en estas gráficas, los profesionales italianos encuestados no han indicado en ningún instrumento, sobre el que se les pregunta, la respuesta: "no utilizado". Sin embargo, en algunos instrumentos observamos un elevado número de profesionales que no ha contestado a la pregunta (una media del 17\%, ver Figura 35 e). El instrumento mejor valorado por los EPV (asesores) ha sido la entrevista profesional estructurada y por los EAPQ (evaluadores) la entrevista para completar/compensar la prueba práctica. Los porcentajes de las respuestas de estos dos profesionales son bastante homogéneos. Podemos observar una mayor diferencia en la entrevista profesional estructurada (ver Figura 35 a), mejor valorada por los EPV (18\% bastante y 73\% muy útil) que por los EAPQ (35\% bastante y $41 \%$ muy útil).

También, hemos pedido a los profesionales participantes en la evaluación, de ambos procedimientos, indicar el uso de otros instrumentos. La mayor parte de los evaluadores, del procedimiento de Castilla y León, que 
ha indicado otros instrumentos utilizados, ha señalado las pruebas escritas tipo test, considerándolas muy útiles. Otros, han señalado haber obtenido información del centro de trabajo, preguntando a superiores y compañeros de equipo de trabajo. Considerándolo, bastante útil.

Los EPV (asesores) no han declarado haber utilizado otros instrumentos. Por su parte, los EAPQ (evaluadores) han indicado el uso de tablas/fichas que indican los resultados esperados; la propia experiencia; la entrevista precedente a la prueba práctica sobre la experiencia profesional del candidato, con la idea de favorecer y hacer más distendido el clima de examen. Uno de los EAPQ (evaluadores) ha señalado haber dado al candidato la oportunidad de corregir los errores cometidos en la prueba escrita, a través de una entrevista posterior a esta.

$\mathrm{Al}$ contrario de lo que ocurre con los instrumentos del proceso de asesoramiento (ver Figura 17), el procedimiento de Castilla y León prevé más instrumentos para la evaluación, que el procedimiento de EmiliaRomagna. Observando los instrumentos utilizados en uno y otro procedimiento, podemos decir que ambos coinciden en la entrevista profesional estructurada; la observación en el puesto de trabajo y en un contexto de trabajo simulado; así como en los test y en las pruebas escritas tipo test (que los evaluadores de Castilla y León han señalado como otros instrumentos utilizados). Hemos observado que existen similitudes en las valoraciones otorgadas a estos instrumentos por los profesionales de ambos procedimientos: La entrevista estructurada con fines de evaluación ha sido muy bien valorada por todos los profesionales encuestados, tanto por los evaluadores de Castilla y León como por los EPV y los EAPQ (ver Figura 34 e) y Figura 35 a) respectivamente). La observación de la práctica a través de una simulación también ha obtenido una buena valoración por parte de todos los profesionales encuestados que han hecho uso de ella, a pesar de que en Castilla y León muchos no la han utilizado (ver Figura 34 b) y Figura 35 c). Por último, en cuanto al instrumento de la observación en el puesto de trabajo, este ha obtenido una valoración más baja por parte de todos los profesionales encuestados sobre este aspecto (ver Figura 34 a) y Figura 35 b). Asimismo, queremos señalar que mientras los evaluadores de Castilla y León que han utilizado los test, los consideran de mucha utilidad, los EPV y EAPQ de Emilia-Romagna se muestran menos satisfechos al respecto. 
También hemos preguntado a los profesionales, de ambos procedimientos, participantes en la evaluación, si habían echado en falta algún instrumento en el proceso de evaluación.

Figura 36: Porcentaje de evaluadores de ambos procedimientos que han echado en falta algún instrumento

\section{a) Evaluadores de Castilla y León}

¿Ha echado en falta algún instrumento en el proceso de evaluación? Evaluadores (ES)

\# Sí $=$ No $=$ Sin respuesta

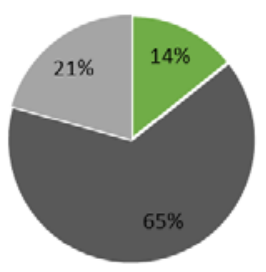

b) EAPQ (evaluadores) de Emilia-Romagna

¿Ha echado en falta algún instrumento en el proceso de evaluación? EAPQ (IT)

" Sí = No

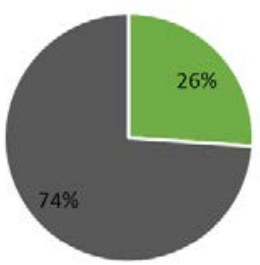

Solo el 14\% de los evaluadores del procedimiento de Castilla y León ha echado en falta algún instrumento (ver Figura 36 a). A este porcentaje de profesionales les hubiese gustado disponer de mayores facilidades para la observación en simulaciones y en el puesto de trabajo. Asimismo, algunos han manifestado que hubiesen querido contar con más instrumentos estandarizados a nivel estatal o autonómico; con algún instrumento que permitiese medir la actitud del candidato en su puesto de trabajo y con 
pruebas más elaboradas, en general. También han comentado la posibilidad de que las personas en activo, pudiesen ser evaluadas por las personas a las que ofrecen sus servicios.

Ninguno de los EPV (asesores) encuestados, de Emilia-Romagna, ha echado en falta otros instrumentos. En cuanto a los EAPQ (evaluadores), el porcentaje de profesionales que ha echado en falta algún instrumento ha sido más elevado (26\%, ver Figura 36 b) respecto a los evaluadores del procedimiento Castellanoleonés. Los EAPQ han señalado como posibles instrumentos o recursos, el uso de test de conocimientos específicos; un balance de competencias, incluyendo competencias profesionales y transversales; realizar una entrevista de preparación al examen, para crear un clima distendido. Uno de ellos, ha creído oportuno realizar siempre una prueba escrita que sea capaz de profundizar en los saberes relacionados con la competencia que se quiere certificar; el uso de instrumentos multimedia. También, coincidiendo con los evaluadores de Castilla y León, algunos EAPQ han señalado la necesidad de instrumentos más elaborados y definidos.

\subsubsection{SUBCATEGORÍA: Adecuación de la metodología}

\begin{tabular}{|c|c|c|c|c|c|c|c|c|}
\hline \multirow[b]{3}{*}{ IND. } & \multicolumn{4}{|c|}{ ESPAÑA } & \multicolumn{4}{|c|}{ ITALIA } \\
\hline & \multicolumn{2}{|c|}{ Legislación } & \multirow{2}{*}{$\begin{array}{l}\text { Entrevis- } \\
\text { tas }\end{array}$} & \multirow{2}{*}{$\begin{array}{c}\text { Cues- } \\
\text { tio- } \\
\text { narios }\end{array}$} & \multicolumn{2}{|c|}{ Legislación } & \multirow{2}{*}{$\begin{array}{l}\text { Entre- } \\
\text { vistas }\end{array}$} & \multirow{2}{*}{$\begin{array}{c}\text { Cues- } \\
\text { tio- } \\
\text { narios }\end{array}$} \\
\hline & $\begin{array}{c}\mathrm{Na}- \\
\text { cional }\end{array}$ & $\begin{array}{c}\text { Autonó- } \\
\text { mica }\end{array}$ & & & $\begin{array}{c}\text { Nacio- } \\
\text { nal }\end{array}$ & $\begin{array}{c}\text { Regio- } \\
\text { nal }\end{array}$ & & \\
\hline 5.2.3.1 & sí & Sí & sí & NO & NO & NO & sí & NO \\
\hline 5.2 .3 .2 & NO & NO & Sí & NO & NO & NO & sí & NO \\
\hline 5.2.3.3 & sí & Sí & sí & NO & NO & NO & sí & NO \\
\hline 5.2 .3 .4 & sí & sí & Sí & NO & NO & NO & sí & NO \\
\hline 5.2.3.5 & NO & NO & Sí & Sí & NO & NO & Sí & sí \\
\hline
\end{tabular}




\subsubsection{INDICADOR: Está claro quién es el responsable de la elaboración de metodologias pertinentes para la validación.}

\section{Comparación}

\section{Legislación}

La legislación nacional española y autonómica de Castilla y León, establecen que las comisiones de evaluación serán las encargadas de la metodología e instrumentos de evaluación. Respecto a la legislación nacional italiana y a la regional de Emilia-Romagna, no se han encontrado referencias al respecto.

\section{Entrevistas}

Los evaluadores y el gestor/organizador entrevistados del procedimiento de Castilla y León, han declarado que efectivamente, siguiendo las pautas dadas por la legislación, las comisiones de evaluación se han encargado de este aspecto, dando peso a la decisión de los evaluadores que se encargaban de cada caso concreto, ya que eran los que conocían bien al candidato. En cuanto a los entrevistados del procedimiento de EmiliaRomagna, un EAPQ, un EPV y un gestor/organizador entrevistados, han declarado que la comisión evaluadora es la encargada de planificar las pruebas que se pasan a los candidatos, siguiendo la normativa. Por lo tanto, en ambos procedimientos la comisión evaluadora es la encargada de la metodología de evaluación.

\subsubsection{INDICADOR: Se siguen unas pautas claras para la elaboración de la metodología a seguir en la evaluación}

\section{Comparación}

\section{Legislación}

No se han encontrado referencias legislativas, ni en plano nacional español/italiano, ni en el autonómico de Castilla y León/regional de EmiliaRomagna.

\section{Entrevistas}

El gestor/organizador entrevistado del procedimiento de Castilla y León, ha declarado que los evaluadores no tenían muy clara la metodología a seguir en la evaluación, por ello, ha añadido que han intentado atajar el problema, advirtiendo que no se podían utilizar criterios de evaluación de la 
La validación de competencias profesionales en España y en Italia

educación formal, como estaban haciendo. Asimismo, un EPV y un EAPQ del procedimiento de Emilia-Romagna han manifestado que las pautas que se daban para la metodología resultaban un tanto complicadas y restrictivas. Por ello, podemos decir que los entrevistados de ambos procedimientos, no se muestran muy satisfechos con este aspecto.

\subsubsection{INDICADOR: Existe variación en la elección del método, depen- diendo de la persona y de las UC en las que esta se quiera acreditar.}

\section{Comparación}

\section{Legislación}

Solo existen referencias en la legislación nacional española y en la autonómica de Castilla y León. Ambas hacen referencia a este aspecto, indicando que la selección de los métodos y de las actividades de evaluación debe hacerse según la naturaleza de la unidad de competencia, las características del candidato y los criterios para la evaluación recogidos en las guías de evidencia. En Italia no se han encontrado referencias, ni en la legislación nacional, ni en la regional de Emilia-Romagna.

\section{Entrevistas}

Los profesionales entrevistados de ambos procedimientos han indicado que se cumple este aspecto. Uno de los evaluadores entrevistados del procedimiento de Castilla y León, ha afirmado que existe variación en la elección del método de evaluación según la persona y las unidades de competencia que quiera acreditar. Por su parte, uno de los EPV entrevistados del procedimiento de Emilia-Romagna, ha comentado que las pruebas se planifican según las unidades de competencia que se pretendan evaluar.

\subsubsection{INDICADOR: Existe una combinación de métodos usados}

\section{Comparación}

\section{Legislación}

Solo en la legislación española se han encontrado referencias sobre la existencia de una combinación de métodos usados: Tanto la legislación nacional como la autonómica de Castilla y León, hablan del uso de todos los métodos necesarios para la evaluación del candidato. Respecto a la legislación italiana analizada (nacional y regional de Emilia-Romagna), no se han encontrado referencias, sobre este aspecto. 
Análisis y resultados

\section{Entrevistas}

Los entrevistados de ambos procedimientos han indicado que sí ha existido una combinación de métodos utilizados en la evaluación. Uno de los evaluadores de Castilla y León, ha comentado que se han usado todos los métodos, del listado que se les proporciona, que se han considerado convenientes para la evaluación de candidatos. En cuanto al procedimiento de Emilia-Romagna, dos EPV y un RFC entrevistados han afirmado haber utilizado varios métodos para la evaluación.

\subsubsection{INDICADOR: Existen espacios físicos a disposición de la evaluación}

\section{Comparación}

\section{Legislación}

No existen referencias legislativas sobre este indicador, ni en el plano nacional español/italiano, ni en el autonómico de Castilla y León/regionales de Emilia-Romagna.

\section{Entrevistas}

Los evaluadores entrevistados del procedimiento castellanoleonés no han hecho referencias sobre este tema durante las entrevistas. Sin embargo, uno de ellos, al finalizar la entrevista, nos mostró algunas dependencias en las que se habían realizado las evaluaciones, lo que deja constancia de su existencia. En cuanto a los entrevistados del procedimiento de EmiliaRomagna, un EPV ha afirmado disponer de espacios físicos para la evaluación de competencias y nos los ha mostrado al finalizar la entrevista (ver Anexo 38).

\section{Cuestionarios}

$\mathrm{Al}$ menos 5\% de los asesores y evaluadores encuestados, tanto del procedimiento español como del italiano, han mencionado la necesidad de mejorar los espacios y los recursos materiales a la hora de realizar simulaciones en las evaluaciones.

\subsection{CATEGORÍA: PREPARACIÓN DE LOS EVALUADORES}

\subsubsection{Sin subcategoría}


La validación de competencias profesionales en España y en Italia

\begin{tabular}{|c|c|c|c|c|c|c|c|c|}
\hline \multirow[b]{3}{*}{ IND. } & \multicolumn{4}{|c|}{ ESPAÑA } & \multicolumn{4}{|c|}{ ITALIA } \\
\hline & \multicolumn{2}{|c|}{ Legislación } & \multirow{2}{*}{$\begin{array}{l}\text { Entrevis- } \\
\text { tas }\end{array}$} & \multirow{2}{*}{$\begin{array}{c}\text { Cues- } \\
\text { tio- } \\
\text { narios }\end{array}$} & \multicolumn{2}{|c|}{ Legislación } & \multirow{2}{*}{$\begin{array}{l}\text { Entre- } \\
\text { vistas }\end{array}$} & \multirow{2}{*}{$\begin{array}{c}\text { Cues- } \\
\text { tio- } \\
\text { narios }\end{array}$} \\
\hline & $\begin{array}{c}\mathrm{Na}- \\
\text { cional } \\
\end{array}$ & $\begin{array}{c}\text { Autonómi- } \\
\text { ca }\end{array}$ & & & $\begin{array}{c}\text { Nacio- } \\
\text { nal }\end{array}$ & $\begin{array}{c}\text { Regio- } \\
\text { nal }\end{array}$ & & \\
\hline 5.3.0.1 & Sí & Sí & Sí & $\mathrm{NO}$ & $\mathrm{NO}$ & sí & sí & $\mathrm{NO}$ \\
\hline 5.3.0.2 & sí & Sí & NO & sí & NO & NO & sí & sí \\
\hline 5.3 .0 .3 & sí & $\mathrm{NO}$ & sí & sí & $\mathrm{NO}$ & sí & sí & sí \\
\hline 5.3.0.4 & NO & NO & NO & sí & NO & NO & NO & sí \\
\hline
\end{tabular}

5.3.0.1. INDICADOR: Existen unos requisitos especificos para ser evaluador.

\section{Comparación}

\section{Legislación}

La legislación nacional española y la autonómica de Castilla y León establecen unos requisitos que los evaluadores deben cumplir. Estos requisitos se centran en la experiencia laboral y la formación como figuras del procedimiento. Por otro lado, la legislación nacional italiana no hace referencias al respecto, sin embargo, la regional de Emilia-Romagna especifica requisitos de edad, experiencia laboral y titulación.

\section{Entrevistas}

Los profesionales entrevistados de ambos procedimientos han hablado sobre la formación que han realizado para ser evaluadores, por parte de la Uned y Observal en el caso de Castilla y León y por parte de la Regione en el caso de Emilia-Romagna. Cabe destacar, que la formación señalada por los profesionales del caso italiano, no se menciona en la legislación, ni nacional, ni regional de Emilia-Romagna.

\subsubsection{INDICADOR: Existe una formación continua para el desarrollo de competencias, dirigida a evaluadores}

\section{Comparación}

\section{Legislación}

Solo la legislación nacional española y la autonómica de Castilla y León aluden a la formación continua de asesores y evaluadores, pero lo 
hacen de forma general, sin entrar en detalle. En la legislación nacional italiana y en la regional de Emilia-Romagna no se han encontrado referencias al respecto.

\section{Entrevistas}

Los asesores del procedimiento de Castilla y León no mencionan ningún tipo de formación continua. Respecto al procedimiento de EmiliaRomagna, uno de los EPV de evaluación ha declarado que no se hace formación continua para los profesionales del procedimiento. No obstante, uno de los gestores del procedimiento entrevistados ha hecho alusión a una futura información (escrita y on-line) sobre la nueva normativa.

\section{Cuestionarios}

En torno al 5\% de los evaluadores encuestados del procedimiento de Castilla y León ha considerado que debería mejorar la formación de asesores y evaluadores, para valorar aspectos técnicos. Por otro lado, sobre el 10\% de los EAPQ (evaluadores) del procedimiento de Emilia-Romagna, también creen oportuno mejorar la objetividad de los EAPQ a la hora de evaluar.

\subsubsection{INDICADOR: Los evaluadores tienen acceso a material de apoyo para llevar a cabo el proceso de evaluación}

\section{Comparación}

\section{Legislación}

La legislación nacional española decreta la elaboración de instrumentos para optimizar el procedimiento y garantizar la homogeneidad y fiabilidad, facilitando un manual de procedimiento, compuesto entre otras cosas, por una guía para el evaluador. Sin embargo, la legislación autonómica de Castilla y León no hace referencia sobre este aspecto. En el caso italiano, la legislación nacional tampoco hace alusión a este punto, pero desde la legislación regional se dan directrices y material de apoyo para ayudar a los profesionales a desarrollar adecuadamente el procedimiento.

\section{Entrevistas}

Los profesionales entrevistados de ambos procedimientos confirman la existencia de material de apoyo para llevar a cabo el proceso de evaluación. Dos evaluadores del procedimiento de Castilla y León han hablado de 
la guía del evaluador y de las guías de evidencia, como instrumentos facilitadores de información y documentos para favorecer la evaluación. En el caso de Emilia-Romagna, uno de los gestores/dirigentes ha afirmado la existencia de una plataforma de apoyo para los profesionales del sistema, sobre información relacionada con el procedimiento. Asimismo, ha comentado que actualmente la plataforma está en proceso de mejora. El EAPQ entrevistado, también menciona la DGR 350/2006 y la nueva DGR 739 como documentos de apoyo, aunque indica que los cuadros de evaluación que presentan, resultan restrictivos.

\section{Cuestionarios}

Hemos querido indagar sobre la utilidad de los principales materiales de apoyo para la evaluación en los procedimientos de los dos territorios, la guía del evaluador y la guía de evidencia en el procedimiento de Castilla y León y las Deliberaciones 530/2006 y 739/2013 en el de Emilia-Romagna. En el último caso preguntamos por estas dos deliberaciones porque, como se ha venido mencionando, el procedimiento se encuentra en un periodo de cambio de una a otra y por el momento conviven las dos.

Las dos gráficas siguientes muestran el grado de utilidad otorgado, por los evaluadores del procedimiento de Castilla y León, a la guía del evaluador y a la guía de evidencia:

Figura 37: Utilidad de instrumentos de apoyo para evaluadores en el procedimiento de Castilla y León

a)

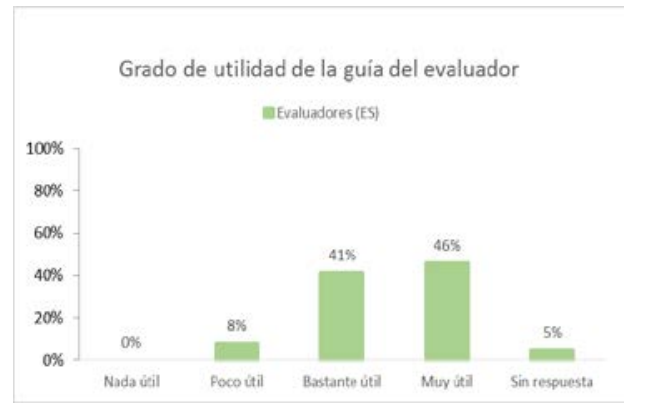

b)

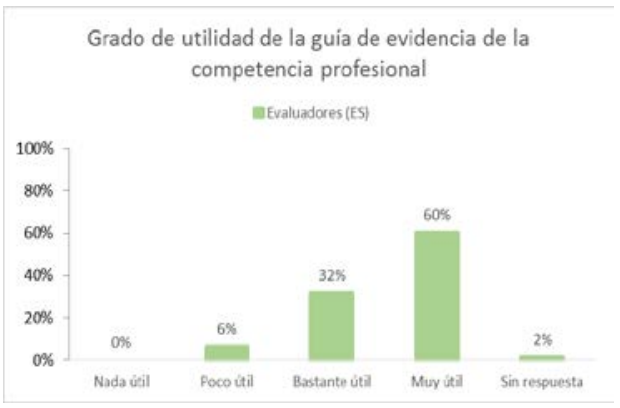

Como podemos observar, los dos instrumentos han obtenido una valoración bastante positiva. Sin embargo, debemos señalar que la guía de evidencia ha obtenido un porcentaje mayor en cuanto al grado de utilidad 
(el 32\% bastante útil y el 60\% muy útil, frente al 41\% bastante útil y al 46\% muy útil de la guía del evaluador, ver

Figura 37 a) y b).

La siguiente gráfica muestra qué porcentaje de los evaluadores encuestados, del procedimiento de Emilia-Romagna (EAPQ), usaron la DGR 350/2006, la DGR 739/2013 o ambas, durante el proceso de evaluación:

Figura 38: Instrumento de apoyo utilizado por los profesionales de la evaluación en el procedimiento de Emilia-Romagna

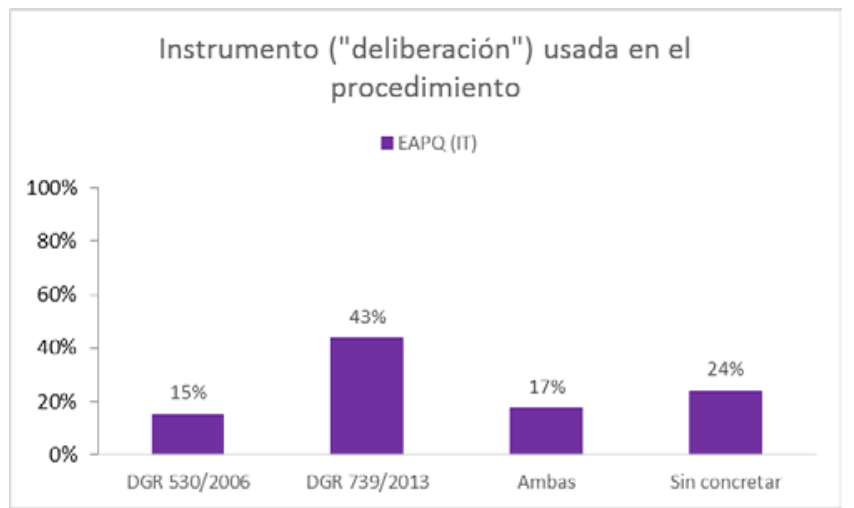

Como puede observarse, la deliberación más utilizada ha sido la DGR 739/2013 (ver Figura 38).

A continuación mostramos el grado de satisfacción de las personas que han usado cada una de ellas.

Figura 39: Utilidad de las DGR 530/2006 y 739/2013 según los evaluadores del procedimiento de Emilia-Romagna

a)

Grado de utilidad de la "DGR 530/2006"

- EAPQ (TI)

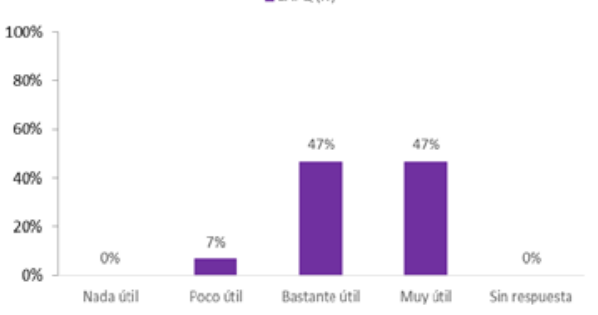

b)

Grado de utilidad de la "DGR 739/2013"

- EAPQ (IT)

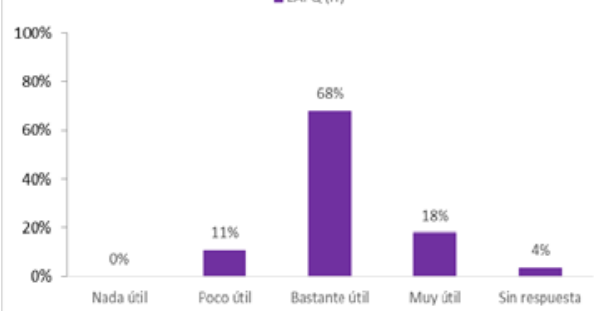


La validación de competencias profesionales en España y en Italia

Como se puede apreciar, el grado de satisfacción con la nueva deliberación (DGR 739/2013) ha bajado notablemente en el caso de los EAPQ (evaluadores).

El instrumento de apoyo mejor valorado en cuanto a utilidad, por los profesionales de la evaluación, teniendo en cuenta los dos procedimientos (Castilla y León y Emilia-Romagna), ha sido la DGR 530. No obstante, hemos comprobado que, en general, todos los instrumentos han obtenido una buena valoración (ver Figura 37 y Figura 39).

5.3.0.4. INDICADOR: El evaluador conoce el sistema de validación y certificación de competencias y otros aspectos relacionados con el mismo

\section{Comparación}

\section{Legislación}

No se han encontrado referencias al respecto, ni en la legislación nacional española/italiana, ni en la autonómica de Castilla y León/regional de Emilia-Romagna.

\section{Entrevistas}

Ninguno de los entrevistados, de ambos procedimientos, ha hecho alusión a este tema.

\section{Cuestionarios}

Hemos indagado, en relación a este aspecto, sobre el grado de conocimiento, de los evaluadores de ambos procedimientos, en referencia a diferentes aspectos relacionados con los correspondientes procedimientos de validación. En primer lugar (como hicimos con los asesores, (ver indicador 4.3.0.4), indagamos sobre el conocimiento de aspectos generales y posteriormente sobre aspectos específicos del sistema en Castilla y León (para los evaluadores del procedimiento castellanoleonés) y en Emilia Romagna (para los EPV del procedimiento de Emilia-Romagna) de validación de competencias.

En algunos casos las gráficas resultantes de las respuestas de unos y otros profesionales, de ambos sistemas, están separadas para no crear confusión al lector en cuanto a lo que se pregunta. 
Figura 40: Conocimiento de los evaluadores sobre aspectos generales de los sistemas en Castilla y León y en Emilia-Romagna

a)

Grado de conocimiento sobre:

[El sistema educativo y de formación profesional español]

nEvaluadores (ES)

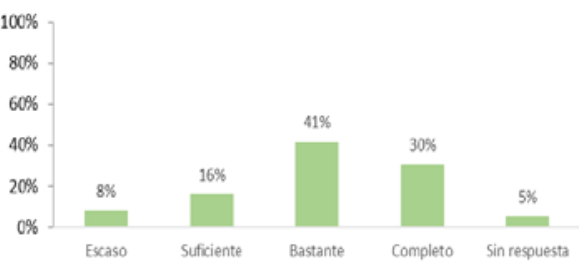

c)

Grado de conocimiento sobre: [Las

cualificaciones del catálogo nacional de competencias profesionales correspondientes a

la familia profesional a la que pertenece la

Unidad o Unidades de Competencia que han sido objeto de evaluación

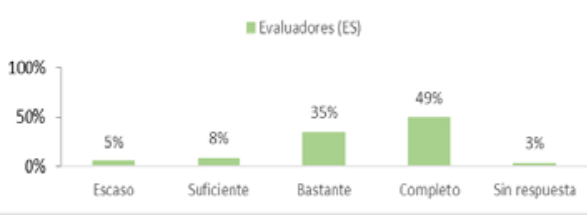

e)

Grado de conocimiento sobre:

[Los requisitos necesarios para poder solicitar la cualificación correspondiente a la unidad o unidades de competencia que se han evaluado]

$$
\text { wEvaluadores (ES) aEAPQ (IT) }
$$

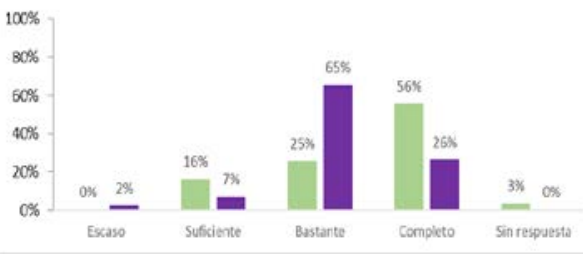

g) b)

Grado de conocimiento sobre:

[El sistema de educación y formación profesional de Emilia Romagna]

- EAPQ(m)

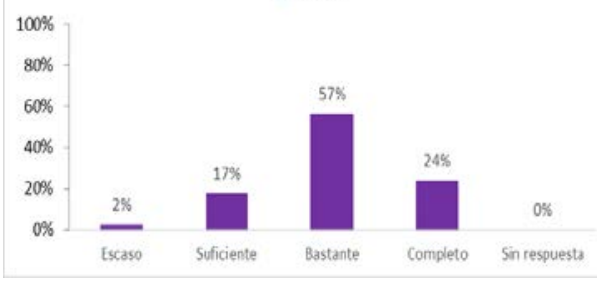

d)

Grado de conocimiento sobre: [Las cualificaciones del repertorio de Emilia Romagna correspondientes a la familia profesional a la que pertenece la Unidad o Unidades de Competencia que han sido objeto de evaluación]

- EAPQ (IT)

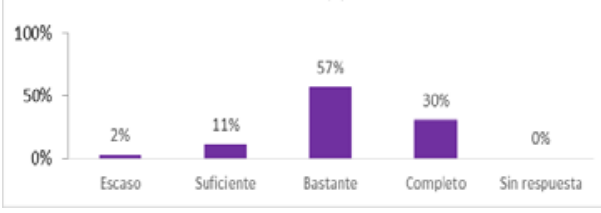

f)

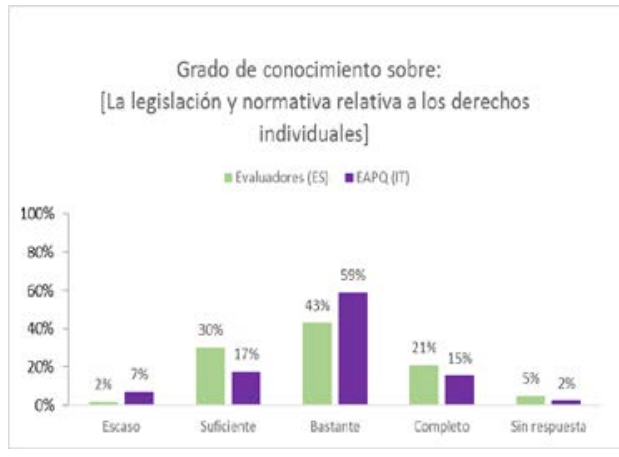

h) 
La validación de competencias profesionales en España y en Italia

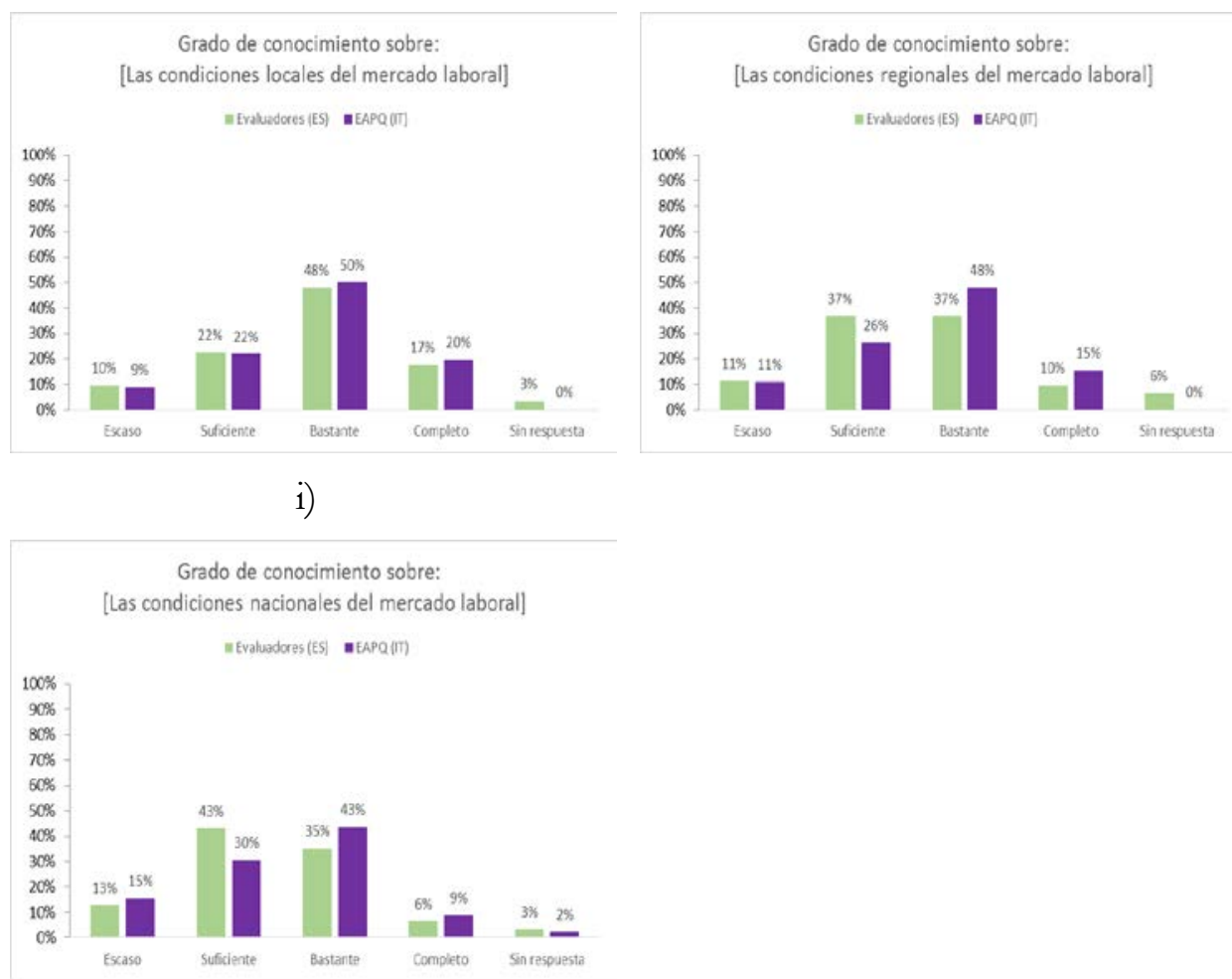

Como vemos en estas gráficas, los EAPQ (evaluadores) del procedimiento de Emilia-Romagna han indicado tener más conocimiento sobre todos los aspectos relacionados con el conocimiento de aspectos generales relativos al sistema de validación, por los que hemos preguntado, que los evaluadores del procedimiento de Castilla y León (ver Figura 40). Aunque bien es cierto que las diferencias entre las respuestas de estos profesionales (de ambos procedimientos) no han sido muy sustanciales. Según estos resultados, el aspecto mejor conocido por los EAPQ (evaluadores) de EmiliaRomagna ha sido el relacionado con los requisitos para solicitar la cualificación ( $65 \%$ bastante conocimiento y $26 \%$ completo, ver Figura 40 e). Por su parte, en el procedimiento de Castilla y León el aspecto más conocido ha sido el de las cualificaciones del catálogo, pertenecientes a la familia profesional de la UC objeto de evaluación (35\% bastante conocimiento y $49 \%$ completo, ver Figura 40 c). En cuanto al aspecto menos conocido, los profesionales de ambos procedimientos coinciden en las condiciones nacionales del mercado laboral (con menos de un 10\%, en ambos procedi- 
mientos, de profesionales entrevistados que indican tener un conocimiento completo, ver Figura 40 i).

Específicamente sobre el sistema en Castilla y León/Emilia Romagna, se pidió a los encuestados valorar su conocimiento sobre los siguientes aspectos:

Figura 41: Conocimiento de los evaluadores sobre aspectos específicos de los sistemas, en Castilla y León y en Emilia-Romagna

a)

$$
\begin{aligned}
& \text { Valore su conocimiento sobre: } \\
& \text { [Las fases del procedimiento] } \\
& \text { "Evaluadores (ES) } \quad \text { UAPQ (IT) }
\end{aligned}
$$

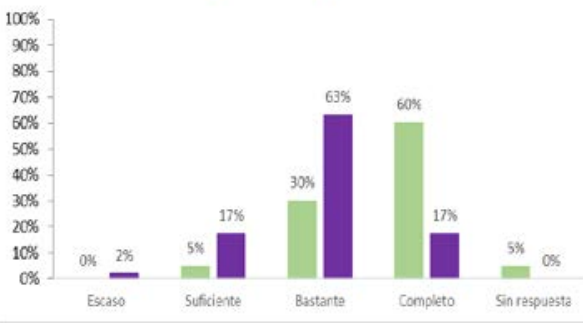

c)

Valore su conocimiento sobre:

[El rol de los participantes en el procedimiento]

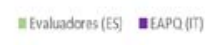

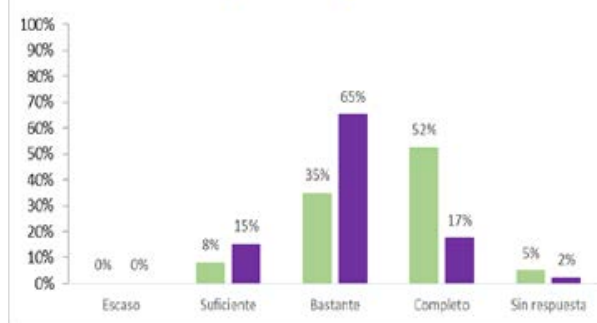

b)

Valore su conocimiento sobre: [El funcionamiento del procedimiento]

$$
\text { "Evaluadores (ES) aEAPQ(T) }
$$

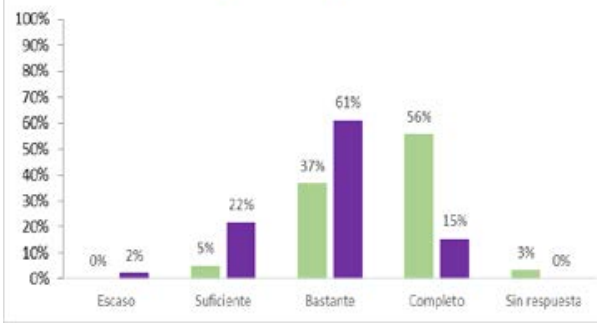

d)

Valore su conocimiento sobre: [la legislación y normativa relativa al procedimiento de validación]

$$
\text { "Evaluaderes (ES) - }
$$

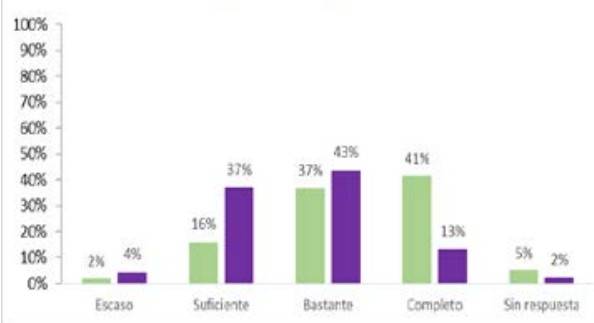


e)

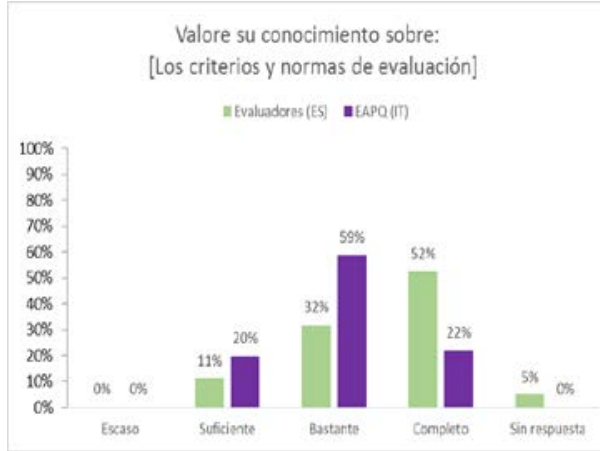

f)

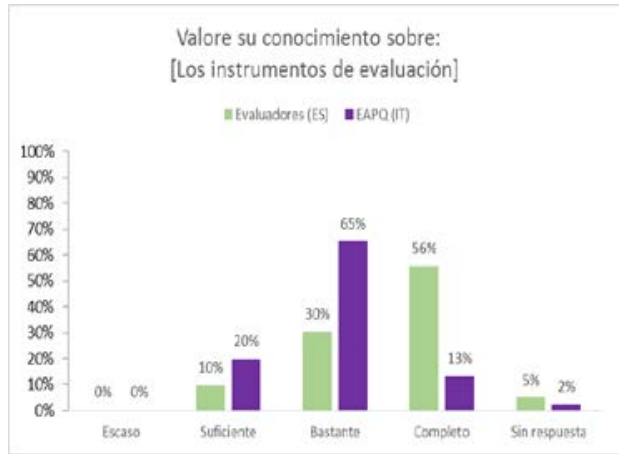

Contrariamente a lo que ocurre en el caso de conocimientos generales relacionados con el procedimiento de validación (ver Figura 40), en este caso, las respuestas obtenidas reflejan un mayor conocimiento específico sobre el procedimiento de validación, por parte de los evaluadores del procedimiento de Castilla y León, respecto a los EAPQ (evaluadores) del procedimiento de Emilia-Romagna (ver Figura 41).

El aspecto indicado como el más conocido por los evaluadores del procedimiento de Castilla y León ha sido el funcionamiento del procedimiento (37\% bastante y 56\% completo, ver Figura 41 b), mientras que los EAPQ (evaluadores) de Emilia-Romagna han señalado como tal el rol de los participantes en el procedimiento (65\% bastante y $17 \%$ completo, ver Figura $41 \mathrm{c}$ ). En cuanto al aspecto menos conocido, vuelve a coincidir para los evaluadores de ambos procedimientos, siendo en este caso la legislación y la normativa relativa a la validación, aunque los evaluadores de Castilla y León han indicado conocerlo mejor que los de Emilia-Romagna (ver Figura $41 \mathrm{~d})$.

En general, observando los resultados de los aspectos generales y de los específicos, podemos afirmar que todos los puntos por los que hemos preguntado han obtenido porcentajes bastante altos, salvo alguna excepción, en cuanto al conocimiento de los mismos, por parte de los evaluadores de ambos procedimientos. El aspecto al que nos referimos como excepción es el relacionado con el conocimiento sobre las condiciones regionales y nacionales del mercado laboral, que registra porcentajes bastante bajos de conocimiento por parte de los evaluadores de ambos procedimientos (ver Figura 40 h) e i). 
Asimismo, hemos preguntado a los evaluadores de ambos procedimientos, sobre su conocimiento acerca de otros sistemas de validación.

Figura 42: Porcentaje de evaluadores de ambos procedimientos que conoce otros sistemas de validación

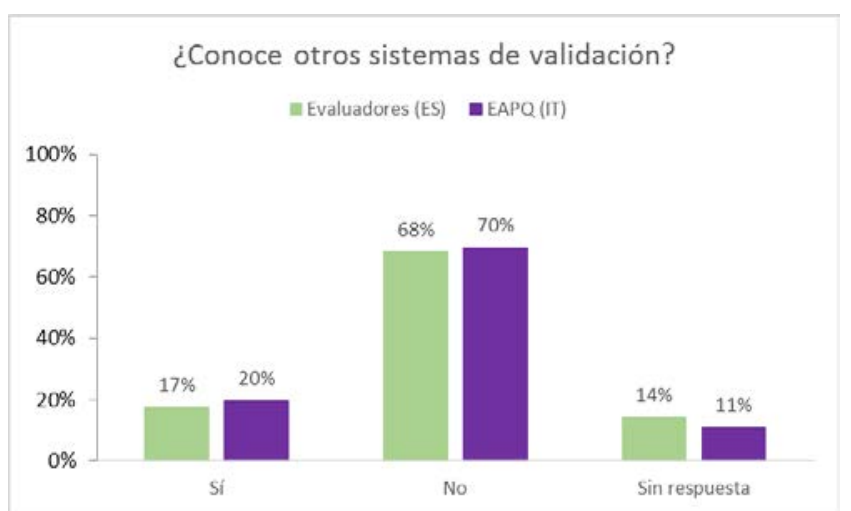

Como vemos en la Figura 42, la mayor parte de los evaluadores encuestados, de ambos procedimientos, no conocen otros sistemas relacionados con la validación (el 68\% en Castilla y León y el 73\% en Emilia-Romagna). Solo un 17\% en Castilla y León un 20\% en Emilia-Romagna, han contestado afirmativamente a la pregunta. Los primeros han hecho referencia a procedimientos de otras comunidades autónomas, como la Rioja, al sistema alemán de validación y a la validación a través de la formación no formal, relacionados con certificados de profesionalidad. Los segundos han indicado conocer los sistemas de certificación de competencias del sistema formal de educación de Emilia-Romagna y los sistemas de certificación de otras regiones italianas como Sardegna o Piemonte. Asimismo, han señalado conocer el sistema de validación universitario.

5.4. CATEGORÍA: COMPORTAMIENTO ÉTICO EN EL PROCESO DE EVALUACIÓN

5.4.0. Sin subcategoría

\begin{tabular}{|c|c|c|c|c|c|c|c|c|}
\hline \multirow[b]{3}{*}{ IND. } & \multicolumn{4}{|c|}{ ESPAÑA } & \multicolumn{4}{|c|}{ ITALIA } \\
\hline & \multicolumn{2}{|c|}{ Legislación } & \multirow{2}{*}{$\begin{array}{l}\text { Entrevis- } \\
\text { tas }\end{array}$} & \multirow{2}{*}{$\begin{array}{c}\text { Cues- } \\
\text { tio- } \\
\text { narios }\end{array}$} & \multicolumn{2}{|c|}{ Legislación } & \multirow{2}{*}{$\begin{array}{l}\text { Entre- } \\
\text { vistas }\end{array}$} & \multirow{2}{*}{$\begin{array}{c}\text { Cues- } \\
\text { tio- } \\
\text { narios }\end{array}$} \\
\hline & $\begin{array}{c}\mathrm{Na}- \\
\text { cional } \\
\end{array}$ & $\begin{array}{c}\text { Autonómi- } \\
\text { ca }\end{array}$ & & & $\begin{array}{c}\text { Nacio- } \\
\text { nal }\end{array}$ & $\begin{array}{c}\text { Regio- } \\
\text { nal }\end{array}$ & & \\
\hline 5.4.0.1 & Sí & NO & NO & NO & sí & NO & NO & NO \\
\hline
\end{tabular}


La validación de competencias profesionales en España y en Italia

\subsubsection{INDICADOR: El evaluador proporciona un trato igualitario a todos los candidatos.}

\section{Comparación}

\section{Legislación}

La legislación nacional española y la italiana abordan el trato igualitario al candidato, aunque no lo hacen la legislación autonómica de Castilla y León, ni la regional de Emilia-Romagna. La legislación nacional española contempla este aspecto con los principios del respeto de los derechos individuales y de objetividad. Por su parte, la legislación nacional italiana se refiere a este punto con el principio de objetividad en las fases del procedimiento.

\section{Entrevista}

En lo que respecta a las entrevistas, no existen alusiones al respecto por parte de los evaluadores de ambos procedimientos.

\subsection{CATEGORIA: PRIVACIDAD Y CONFIDENCIALIDAD DEL PROCESO DE EVALUACIÓN}

\subsubsection{Sin subcategoría}

\begin{tabular}{|c|c|c|c|c|c|c|c|c|}
\hline \multirow[b]{3}{*}{ IND. } & \multicolumn{4}{|c|}{ ESPAÑA } & \multicolumn{4}{|c|}{ ITALIA } \\
\hline & \multicolumn{2}{|c|}{ Legislación } & \multirow{2}{*}{$\begin{array}{l}\text { Entrevis- } \\
\text { tas }\end{array}$} & \multirow{2}{*}{$\begin{array}{c}\text { Cues- } \\
\text { tio- } \\
\text { narios }\end{array}$} & \multicolumn{2}{|c|}{ Legislación } & \multirow{2}{*}{$\begin{array}{l}\text { Entre- } \\
\text { vistas }\end{array}$} & \multirow{2}{*}{$\begin{array}{c}\text { Cues- } \\
\text { tio- } \\
\text { narios }\end{array}$} \\
\hline & $\begin{array}{c}\mathrm{Na}- \\
\text { cional }\end{array}$ & $\begin{array}{c}\text { Autonómi- } \\
\text { ca }\end{array}$ & & & $\begin{array}{c}\text { Nacio- } \\
\text { nal }\end{array}$ & $\begin{array}{c}\text { Regio- } \\
\text { nal }\end{array}$ & & \\
\hline 5.5.0.1 & Sí & Sí & sí & sí & NO & NO & sí & sí \\
\hline
\end{tabular}

\section{Comparación}

\section{Legislación}

Solo la legislación nacional española y la autonómica de Castilla y León contemplan el aspecto de la confidencialidad. La legislación nacional establece el cumplimiento del principio sobre el respeto de los derechos individuales, que incluye la confidencialidad del resultado de la evaluación del candidato y la protección de datos del mismo. A través de la legislación autonómica se designa al presidente de la comisión de evaluación como 
responsable para comunicar, por escrito, al candidato el resultado de la evaluación.

Respecto a Italia, no se han encontrado alusiones legislativas a este tema, ni en ámbito nacional, ni regional de Emilia-Romagna.

\section{Entrevistas}

Los profesionales entrevistados, de ambos procedimientos, han asegurado haber mantenido la privacidad, entregando únicamente al candidato los resultados de su evaluación. En el caso de Emilia-Romagna, hemos preguntado sobre este aspecto a los EPV (asesores) ya que son estos, los encargados de comunicar dicho resultado.

\section{Cuestionarios}

Hemos indagado sobre este aspecto preguntando cómo se habían comunicado al candidato los resultados de la evaluación, a los profesionales encargados de ello. Es decir, a los evaluadores en el procedimiento de Castilla y León y a los EPV (asesores) en Emilia-Romagna:

Figura 43: Vías utilizadas por los evaluadores para comunicar los resultados de evaluación

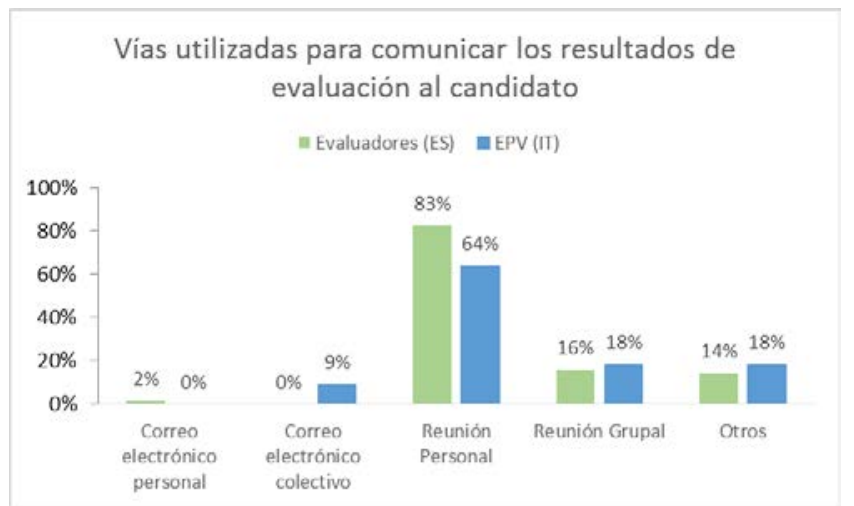

Según los resultados que muestra esta gráfica el medio más utilizado, en los dos procedimientos, ha sido la reunión personal ( $83 \%$ en Castilla y León y 64\% en Emilia-Romagna, ver Figura 43).

Cuando se les ha preguntado por los otros medios utilizados, los evaluadores de Castilla y León, han señalado sobre todo el teléfono y también la carta. Por su parte, uno de los EPV (asesores) del procedimiento de Emi- 
lia-Romagna, ha indicado haber utilizado un tablón de anuncios para colgar los resultados.

En general, según estos resultados, podemos decir que la privacidad se respeta en un porcentaje bastante alto en los dos procedimientos, aunque en mayor medida en el procedimiento de Castilla y León, respecto al de Emilia-Romagna.

\subsection{CATEGORIA: CARACTER PERSONALIZADO DE LA EVALUACIÓN}

* Recordamos que para facilitar el análisis de datos se agruparon algunos indicadores, en este caso, agrupamos dos indicadores de la categoría: "conocimiento del candidato por parte del evaluador":

\subsubsection{SUBCATEGORÍA: Conocimiento del candidato por parte del evaluador}

\begin{tabular}{|c|c|c|c|c|c|c|c|c|}
\hline \multirow[b]{2}{*}{ IND. } & \multicolumn{4}{|c|}{ ESPAÑA } & \multicolumn{4}{|c|}{ ITALIA } \\
\hline & $\begin{array}{l}\text { Le } \\
\mathrm{Na}- \\
\text { cion } \\
\mathrm{al}\end{array}$ & $\begin{array}{l}\text { gislación } \\
\text { Autonómi- } \\
\text { ca }\end{array}$ & $\begin{array}{c}\text { Entrevis- } \\
\text { tas }\end{array}$ & $\begin{array}{c}\text { Cues- } \\
\text { tio- } \\
\text { narios }\end{array}$ & $\begin{array}{l}\text { Legis } \\
\text { Nacio- } \\
\text { nal }\end{array}$ & $\begin{array}{l}\text { ación } \\
\text { Regio- } \\
\text { nal }\end{array}$ & $\begin{array}{l}\text { Entre- } \\
\text { vistas }\end{array}$ & $\begin{array}{c}\text { Cues- } \\
\text { tio- } \\
\text { narios }\end{array}$ \\
\hline 5.6.1.1 & NO & NO & sí & Sí & NO & NO & Sí & Sí \\
\hline 5.6.1.2 & NO & NO & sí & sí & NO & NO & Sí & sí \\
\hline 5.6.1.3 & NO & NO & sí & sí & NO & NO & sí & sí \\
\hline 5.6.1.4 & NO & NO & sí & sí & NO & NO & Sí & sí \\
\hline
\end{tabular}

5.6.1.2. INDICADOR: El evaluador conoce los objetivos del candidato para someterse al procedimiento de validación.

\section{Comparación}

\section{Legislación}

No se han encontrado referencias legislativas sobre el conocimiento de la motivación y los objetivos del candidato a la hora de someterse al pro- 
cedimiento de validación, por parte del evaluador, ni en el plano legislativo nacional español/italiano, ni en el plano autonómico de Castilla y León/regional de Emilia-Romagna.

\section{Entrevistas}

Los dos evaluadores entrevistados, del procedimiento de Castilla y León, han afirmado conocer las motivaciones de los candidatos para someterse al procedimiento, indicando que la mayoría lo ha hecho por miedo a perder su trabajo. Por su parte, uno de los EAPQ (evaluadores) entrevistados, del procedimiento de Emilia-Romagna, ha declarado haber tenido muy poco contacto con el candidato, únicamente en el momento de la evaluación, por lo que se deduce que no puede tener conocimiento, o no muy amplio, sobre los objetivos y/o motivaciones del candidato.

\section{Cuestionarios}

Hemos preguntado a los evaluadores, de los dos procedimientos, sobre el conocimiento del candidato, respecto a su motivación y a sus objetivos para someterse a la validación de competencias:

Figura 44: Conocimiento de los evaluadores de ambos procedimientos sobre el candidato

a)

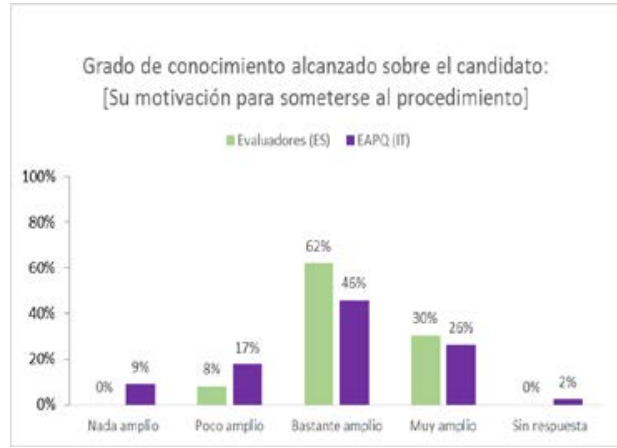

b)

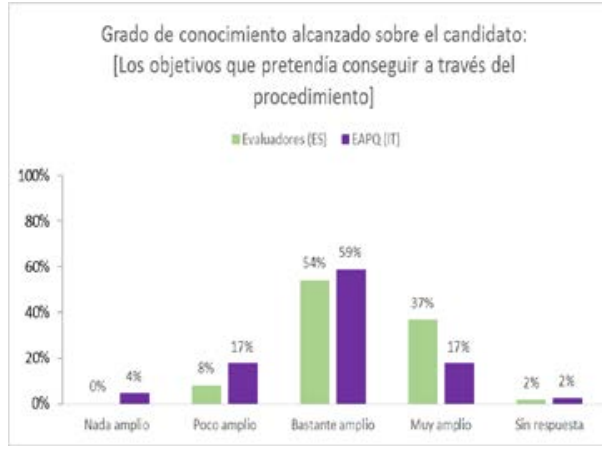

Observando estas gráficas podemos decir que los evaluadores, de ambos procedimientos, han indicado tener un conocimiento bastante alto sobre la motivación y los objetivos del candidato a la hora de someterse al procedimiento. El conocimiento de estos dos aspectos es sustancialmente más alto en los evaluadores de Castilla y León (62\% bastante y 30\% muy 
amplio respecto al conocimientos de la motivación y 54\% bastante y 37\% muy amplio en cuanto al conocimiento de los objetivos, ver Figura 44), que en los de Emilia-Romagna (46\% bastante y $26 \%$ muy amplio sobre la motivación y el $59 \%$ bastante y $17 \%$ muy amplio en cuanto a los objetivos, ver Figura 44).

A continuación presentamos los resultados de la agrupación de los siguientes indicadores, pertenecientes a las subcategorías: "conocimiento del candidato por parte del evaluador" y "flexibilidad en el proceso de evaluación":

5.6.1.3. INDICADOR: El evaluador conoce las condiciones personales del candidato (nivel, cultural; problemas laborales, personales, familiares, etc.).Analizado conjuntamente con el indicador 5.6.1.4., 5.6.2.1 y 5.6.2.2.

5.6.1.4. INDICADOR: El evaluador conoce la disponibilidad del candidato para el procedimiento (tiempo, horarios a disposición del procedimiento, colaboración con el mismo, etc.). Analizado conjuntamente con el indicador 5.6.1.3., 5.6.2.1. y 5.6.2.2.

5.6.2. SUBCATEGORÍA: Flexibilidad en el proceso de evaluación

\begin{tabular}{|c|c|c|c|c|c|c|c|c|}
\hline \multirow[b]{3}{*}{ IND. } & \multicolumn{4}{|c|}{ ESPAÑA } & \multicolumn{4}{|c|}{ ITALIA } \\
\hline & \multicolumn{2}{|c|}{ Legislación } & \multirow{2}{*}{$\begin{array}{l}\text { Entrevis- } \\
\text { tas }\end{array}$} & \multirow{2}{*}{$\begin{array}{c}\text { Cues- } \\
\text { tio- } \\
\text { narios }\end{array}$} & \multicolumn{2}{|c|}{ Legislación } & \multirow{2}{*}{$\begin{array}{l}\text { Entre- } \\
\text { vistas }\end{array}$} & \multirow{2}{*}{$\begin{array}{c}\text { Cues- } \\
\text { tio- } \\
\text { narios }\end{array}$} \\
\hline & $\begin{array}{l}\mathrm{Na}- \\
\text { cional }\end{array}$ & $\begin{array}{c}\text { Autonó- } \\
\text { mica }\end{array}$ & & & $\begin{array}{c}\text { Nacio- } \\
\text { nal }\end{array}$ & $\begin{array}{c}\text { Regio- } \\
\text { nal }\end{array}$ & & \\
\hline 5.6.2.1 & NO & NO & Sí & Sí & NO & NO & Sí & Sí \\
\hline 5.6.2.2 & NO & NO & Sí & Sí & NO & NO & sí & sí \\
\hline
\end{tabular}

5.6.2.1. INDICADOR: El evaluador tiene en cuenta las condiciones personales del candidato (nivel, cultural; problemas laborales, personales, familiares, etc.), a la hora de llevar a cabo la evaluación. Analizado conjuntamente con el indicador 5.6.1.3, 5.6.1.4 y 5.6.2.2.

5.6.2.2. INDICADOR: El evaluador tiene en cuenta la disponibilidad del candidato para el procedimiento (tiempo, horarios a disposición del procedimiento, colaboración con el mismo, etc.), a la hora de llevar a cabo la evaluación. Analizado conjuntamente con el indicador 5.6.1.3, 5.6.1.4 y 5.6.2.2. 
Análisis y resultados

\section{Comparación}

\section{Legislación}

No se han encontrado referencias legislativas sobre conocer y tener en cuenta las condiciones personales y la disponibilidad del candidato, por parte del evaluador, ni en el plano legislativo nacional español/italiano, ni en el plano autonómico de Castilla y León/regional de Emilia-Romagna.

\section{Entrevistas}

Uno de los evaluadores entrevistados, del procedimiento de Castilla y León, ha afirmado que los evaluadores conocen y han intentado tener en cuenta, en la medida de lo posible, las condiciones personales y la disponibilidad del candidato. En cuanto al procedimiento de Emilia-Romagna, el EAPQ entrevistado ha declarado que se tienen en cuenta las características personales del candidato, aunque su conocimiento sobre el mismo no es directo.

\section{Cuestionarios}

Mostramos a continuación, las gráficas relacionadas con los 4 últimos indicadores que hemos visto y agrupado para su análisis: 5.6.1.3; 5.6.1.4; 5.6.2.1 y 5.6.2.2.

c) Figura relativa al indicador 5.6.1.3.

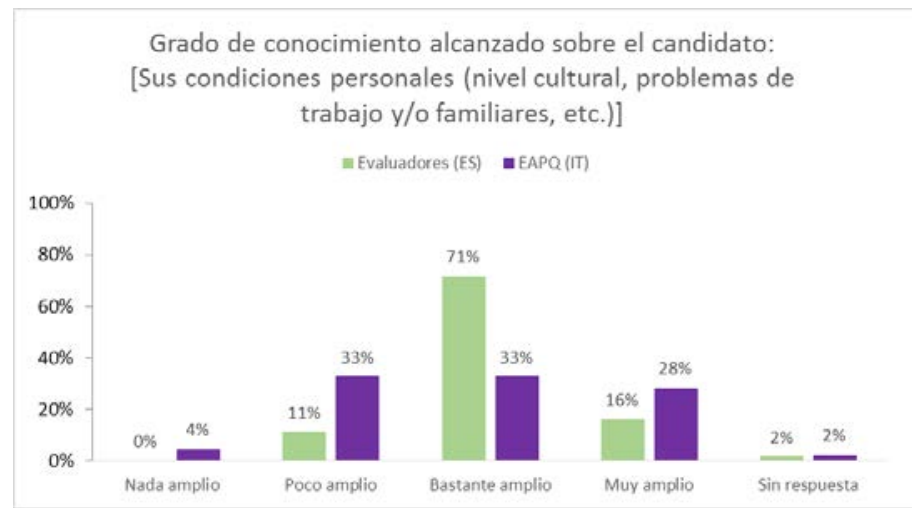


La validación de competencias profesionales en España y en Italia

d) Figura relativa al indicador 5.6.1.4.

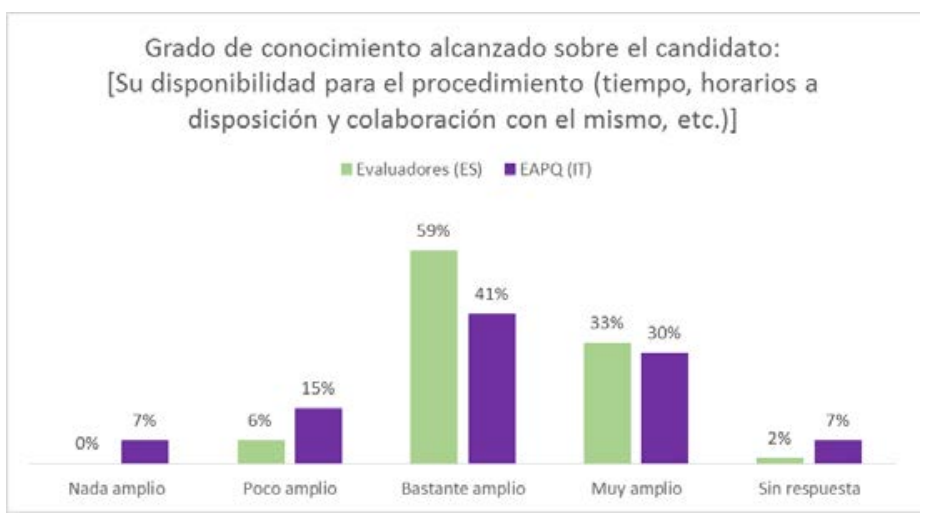

Figura 45: Flexibilidad por parte de los evaluadores de ambos procedimientos hacia el candidato

a) Figura relativa al indicador 5.6.2.1.

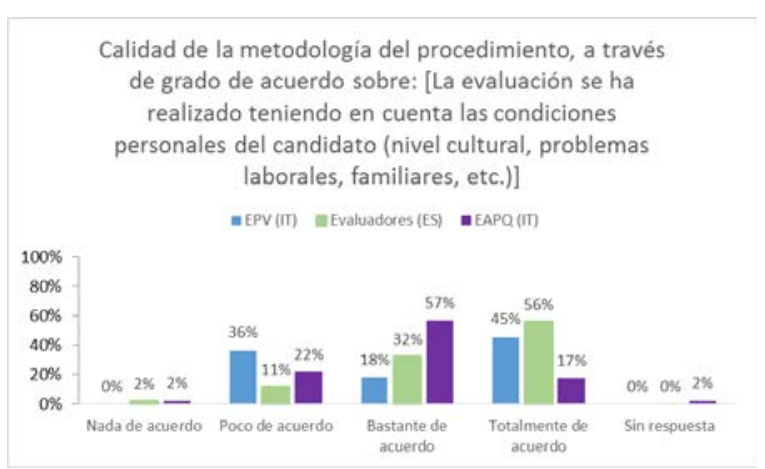

b) Figura relativa al indicador 5.6.2.2.

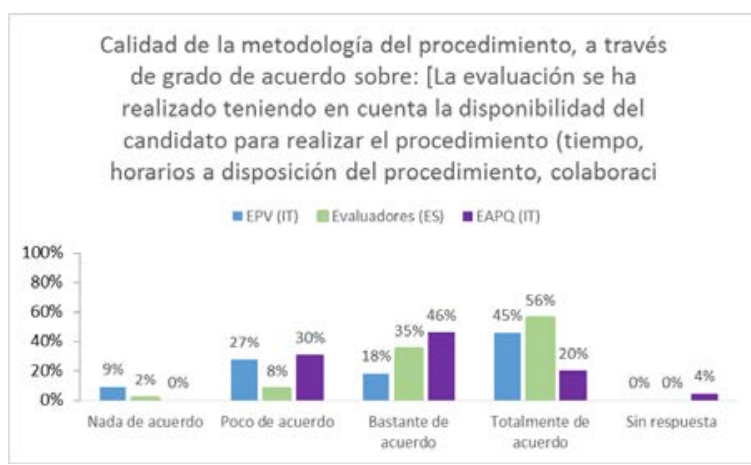

Como podemos observar, en la Figura 45 a) y b) se han añadido las respuestas de los EPV (asesores) de Emilia Romagna, ya que estos también 
participan en el proceso de evaluación. Respecto a las respuestas de los EPV sobre si conocían las condiciones personales y la disponibilidad del candidato, ver análisis sobre indicadores 4.6.1.3 y 4.6.1.4.

Según los resultados, observables en estas gráficas (ver Figura 44 c) y d) y Figura 45 a) y b), los evaluadores del procedimiento de Castilla y León, han manifestado haber tenido un alto conocimiento de las condiciones personales y de la disponibilidad de los candidatos, asimismo, han señalado haberlas tenido muy en cuenta en la evaluación. En las respuestas sobre conocimiento, de condiciones y disponibilidad, bastante y muy amplio, se han registrado niveles en torno al 90\%. También en las respuestas sobre tener en cuenta las condiciones y la disponibilidad, el número de encuestados que ha respondido muy o totalmente de acuerdo supera el $90 \%$. Por otro lado, los EAPQ (evaluadores) del procedimiento de Emilia-Romagna, también han indicado conocer y tener bastante en cuenta las condiciones y la disponibilidad de candidato, aunque en un porcentaje menor respecto a los españoles (entre el 60\% y el 70\%). En cuanto a los EPV (asesores) del procedimiento de Emilia-Romagna, llama la atención que hayan otorgado altos niveles de conocimiento del candidato (en torno al $80 \%$ bastante y completo, ver Figura 26 c) y d) y luego el porcentaje de EPV que han tenido en cuenta las condiciones y disponibilidad sea sustancialmente más bajo (en torno al 60\% bastante y totalmente de acuerdo, ver Figura 45 a) y b).

\subsubsection{SUBCATEGORÍA: Lenguaje adaptado del evaluador}

\begin{tabular}{|c|c|c|c|c|c|c|c|c|}
\hline \multirow[b]{3}{*}{ IND. } & \multicolumn{4}{|c|}{ ESPAÑA } & \multicolumn{4}{|c|}{ ITALIA } \\
\hline & \multicolumn{2}{|c|}{ Legislación } & \multirow{2}{*}{$\begin{array}{l}\text { Entrevis- } \\
\text { tas }\end{array}$} & \multirow{2}{*}{$\begin{array}{c}\text { Cues- } \\
\text { tio- } \\
\text { narios }\end{array}$} & \multicolumn{2}{|c|}{ Legislación } & \multirow{2}{*}{$\begin{array}{l}\text { Entre- } \\
\text { vistas }\end{array}$} & \multirow{2}{*}{$\begin{array}{c}\text { Cues- } \\
\text { tio- } \\
\text { narios }\end{array}$} \\
\hline & $\begin{array}{c}\text { Nacio- } \\
\text { nal }\end{array}$ & $\begin{array}{c}\text { Autonómi- } \\
\text { ca }\end{array}$ & & & $\begin{array}{c}\text { Nacio- } \\
\text { nal }\end{array}$ & $\begin{array}{c}\text { Regio- } \\
\text { nal }\end{array}$ & & \\
\hline $\begin{array}{c}5.6 .3 \\
1\end{array}$ & NO & NO & sí & sí & NO & NO & NO & sí \\
\hline
\end{tabular}

\section{Comparación}

\section{Legislación}


La validación de competencias profesionales en España y en Italia

No se han encontrado referencias legislativas al respecto, ni en el plano nacional español/italiano, ni en el autonómico de Castilla y León/regional de Emilia-Romagna.

\section{Entrevistas}

Los evaluadores entrevistados del procedimiento de Castilla y León han asegurado que se han adaptado al lenguaje de los candidatos. Por totra parte, los profesionales del procedimiento de Emilia-Romagna no han hecho alusiones sobre este aspecto.

\section{Cuestionarios}

Se ha preguntado a los evaluadores de ambos procedimientos sobre el tipo de lenguaje que han utilizado con el candidato.

Figura 46: Lenguaje utilizado con el candidato por los evaluadores de ambos procedimientos

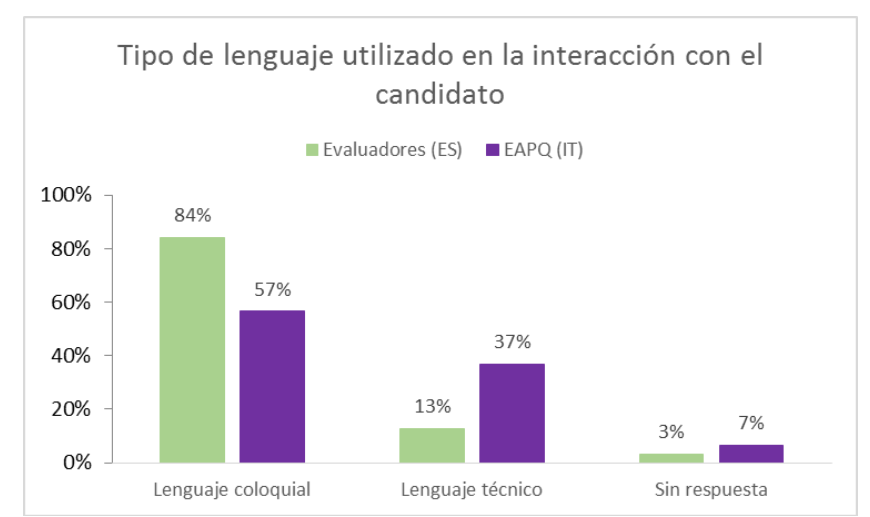

Como puede observarse en esta gráfica, la mayor parte de los evaluadores de ambos procedimientos ha utilizado un lenguaje coloquial con el candidato, lo que ayuda a la fácil comprensión, de este último, sobre lo que se le pide y sobre el procedimiento en general.

Sin embargo, como vemos, el porcentaje de evaluadores, del procedimiento de Castilla y León, que ha utilizado un lenguaje coloquial es más elevado (84\%) que el de los evaluadores de Emilia-Romagna (EAPQ) (57\%), (ver Figura 46).

\subsection{CATEGORÍA: CARÁCTER FORMATIVO DE LA EVALUACIÓN}


5.7.0. Sin subcategoría

\begin{tabular}{|c|c|c|c|c|c|c|c|c|}
\hline \multirow[b]{3}{*}{ IND. } & \multicolumn{4}{|c|}{ ESPAÑA } & \multicolumn{4}{|c|}{ ITALIA } \\
\hline & \multicolumn{2}{|c|}{ Legislación } & \multirow{2}{*}{$\begin{array}{l}\text { Entrevis- } \\
\text { tas }\end{array}$} & \multirow{2}{*}{$\begin{array}{c}\text { Cues- } \\
\text { tio- } \\
\text { narios }\end{array}$} & \multicolumn{2}{|c|}{ Legislación } & \multirow{2}{*}{$\begin{array}{l}\text { Entre- } \\
\text { vistas }\end{array}$} & \multirow{2}{*}{$\begin{array}{c}\text { Cues- } \\
\text { tio- } \\
\text { narios }\end{array}$} \\
\hline & $\begin{array}{l}\mathrm{Na-} \\
\text { cional } \\
\end{array}$ & $\begin{array}{c}\text { Autonómi- } \\
\text { ca }\end{array}$ & & & $\begin{array}{c}\text { Nacio- } \\
\text { nal }\end{array}$ & $\begin{array}{c}\text { Regio- } \\
\text { nal }\end{array}$ & & \\
\hline 5.7.0.1 & sí & sí & Sí & NO & NO & NO & NO & NO \\
\hline
\end{tabular}

5.7.0.1. INDICADOR: El procedimiento ayuda a la reinserción, de los candidatos que lo requieran, en el mundo formativo, tras el procedimiento.

\section{Comparación}

Legislación

En España, la legislación nacional contempla este punto, mencionando que uno de los fines del procedimiento es que el candidato pueda adquirir una acreditación parcial acumulable que le lleve a completar su formación para obtener un título de formación profesional o un certificado de profesionalidad. Asimismo, se menciona la realización y entrega de un plan de formación para el candidato, al finalizar todo el procedimiento de evaluación y acreditación. En cuanto a la legislación autonómica de Castilla y León, prevé la entrega de un informe por candidato con una propuesta formativa. Respecto a la legislación nacional italiana y regional de EmiliaRomagna, no se han encontrado referencias sobre este tema.

\section{Entrevistas}

El gestor/organizador entrevistado del procedimiento de Castilla y León cree que el procedimiento facilita, a los candidatos, una formación complementaria. Dos evaluadores y un asesor opinan que el procedimiento todavía no ha logrado que los candidatos sigan formándose tras el mismo.

En cuanto a los entrevistados del procedimiento de Emilia-Romagna no han hecho alusiones sobre este aspecto.

\subsection{CATEGORÍA: RECURSO O RECLAMACIÓN DEL RESULTADO DE LA EVALUACIÓN}

\subsubsection{Sin subcategoría}

\begin{tabular}{cc|c|c|c|c|c}
\hline & \multicolumn{3}{c|}{ ESPAÑA } & \multicolumn{3}{c}{ ITALIA } \\
\cline { 2 - 6 } IND. & Legislación & Entrevis- & Cues- & Legislación & Entre- & Cues- \\
\hline
\end{tabular}


La validación de competencias profesionales en España y en Italia

\begin{tabular}{|c|c|c|c|c|c|c|c|c|}
\hline & $\begin{array}{l}\mathrm{Na-} \\
\text { cional }\end{array}$ & $\begin{array}{c}\text { Autonó- } \\
\text { mica }\end{array}$ & tas & $\begin{array}{l}\text { tio- } \\
\text { narios }\end{array}$ & $\begin{array}{c}\text { Nacio- } \\
\text { nal }\end{array}$ & $\begin{array}{c}\text { Regio- } \\
\text { nal }\end{array}$ & vistas & $\begin{array}{c}\text { tio- } \\
\text { narios }\end{array}$ \\
\hline 5.8 .0 .1 & sí & sí & Sí & sí & NO & NO & sí & Sí \\
\hline
\end{tabular}

\section{Comparación}

Legislación

La legislación nacional española hace referencia a este argumento con el principio de objetividad, que permite, entre otras cosas, la revisión del resultado de las evaluaciones y también alude, específicamente, al derecho del evaluado a reclamar el resultado de evaluación. La legislación autonómica de Castilla y León, hace referencia al argumento sobre la reclamación, de forma menos explícita, señalando que deben recogerse todos los resultados y registros producidos en el procedimiento, de cara a posibles reclamaciones por parte de los candidatos. En cuanto a la legislación nacional italiana y regional de Emilia-Romagna, no se han encontrado referencias al respecto.

\section{Entrevistas}

Los dos evaluadores entrevistados del procedimiento de Castilla y León han manifestado que efectivamente se ha llevado a cabo el proceso de reclamación con los candidatos que lo han solicitado. Respecto a las entrevistas, el EAPQ y uno de los EPV entrevistados, han comentado que es posible que el candidato pueda reclamar durante todo el procedimiento.

\section{Cuestionarios:}

Para obtener información de los cuestionarios sobre este indicador, hemos recuperado estas dos graficas de la Figura 12 l) en relación a las respuestas de los asesores y de la Figura $30 \mathrm{~m}$ ) en cuanto a las respuestas de los evaluadores, sobre la información proporcionada al candidato en relación a la posibilidad de recurrir el resultado de la evaluación.

Figura 47: Información de los profesionales de ambos procedimientos, a los candidatos, sobre la posibilidad de recurrir el resultado de la evaluación

a) Respuestas de los asesores de ambos procedimientos 


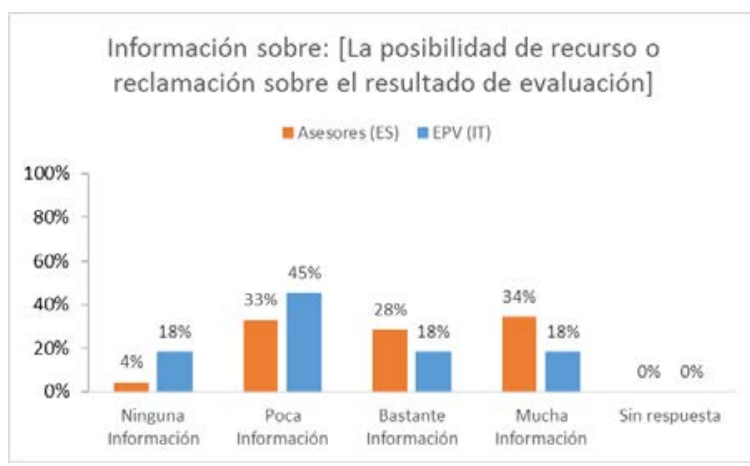

b) Respuestas de los evaluadores de ambos procedimientos

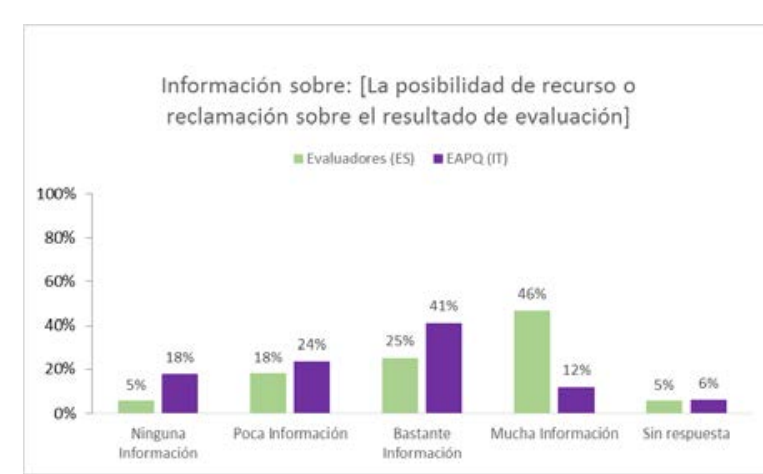

En general han informado más sobre este aspecto los evaluadores que los asesores y más los profesionales del procedimiento de Castilla y León que los del procedimiento de Emilia-Romagna. Concretamente, la suma de asesores españoles que ha indicado bastante y mucha información es del $62 \%$ y de evaluadores del $71 \%$. Por el contrario, la suma de los EPV que ha indicado las respuestas de bastante y mucha información es de solo el 36\% y del 53\% de los EAPQ (evaluadores).

\section{DIMENSIÓN: CERTIFICACIÓN Y REGISTRO}

6.1. CATEGORÍA: VALIDEZ DE LA CERTIFICACIÓN

6.1.0. Sin subcategoría

\begin{tabular}{|c|c|c|c|c|c|c|c|c|}
\hline \multirow[b]{3}{*}{ IND. } & \multicolumn{4}{|c|}{ ESPAÑA } & \multicolumn{4}{|c|}{ ITALIA } \\
\hline & \multicolumn{2}{|c|}{ Legislación } & \multirow{2}{*}{$\begin{array}{c}\text { Entrevis- } \\
\text { tas }\end{array}$} & \multirow{2}{*}{$\begin{array}{c}\text { Cues- } \\
\text { tio- } \\
\text { narios }\end{array}$} & \multicolumn{2}{|c|}{ Legislación } & \multirow{2}{*}{$\begin{array}{l}\text { Entre- } \\
\text { vistas }\end{array}$} & \multirow{2}{*}{$\begin{array}{c}\text { Cues- } \\
\text { tio- } \\
\text { narios }\end{array}$} \\
\hline & $\begin{array}{l}\mathrm{Na}- \\
\text { cional }\end{array}$ & $\begin{array}{c}\text { Autonó- } \\
\text { mica }\end{array}$ & & & $\begin{array}{c}\text { Nacio- } \\
\text { nal }\end{array}$ & $\begin{array}{l}\text { Regio- } \\
\text { nal }\end{array}$ & & \\
\hline
\end{tabular}


La validación de competencias profesionales en España y en Italia

\begin{tabular}{|c|c|c|c|c|c|c|c|c|}
\hline 6.1.0.1 & Sí & sí & sí & $\mathrm{NO}$ & NO & sí & Sí & $\mathrm{NO}$ \\
\hline 6.1.0.2 & sí & sí & NO & $\mathrm{NO}$ & sí & sí & sí & $\mathrm{NO}$ \\
\hline 6.1 .0 .3 & sí & sí & NO & NO & Sí & sí & NO & NO \\
\hline
\end{tabular}

\section{Legislación}

Tanto la legislación nacional española como la autonómica de Castilla y León establecen que la administración correspondiente (la Administración General del Estado, el Ministerio de Trabajo e Inmigración ${ }^{108}$ y el Ministerio de Educación ${ }^{109}$ ) expedirá la acreditación de unidades de competencia correspondiente y transferirá los resultados a un registro estatal: Asimismo, indican que cuando se cumplan las condiciones establecidas, el candidato será informado para solicitar el título o certificado correspondiente. Por otro lado, aunque la legislación nacional italiana no toca este aspecto, la regional establece que el Sistema Regional de Formalización y Certificación de competencias de Emilia-Romagna otorgará las certificaciones pertinentes. Este sistema pertenece a la Regione. Por lo tanto, la Regione sería el órgano habilitado por esta deliberación para emitir las certificaciones. Además, la Regione asegura el registro para dar validez oficial a las fichas (schede) y certificados.

\section{Entrevistas}

Los gestores/organizadores entrevistados de ambos procedimientos han confirmado lo expuesto en la legislación. En el caso de Castilla y León uno de los gestores/ organizadores ha declarado que la Consejería de Educación y la de empleo emiten la acreditación (de forma conjunta) y se manda al registro del Servicio de Empleo de Castilla y León. En Emilia-Romagna, otro de los gestores/organizadores del procedimiento ha afirmado que la entidad encargada de otorgar la certificación, es la Regione.

\subsubsection{INDICADOR: la certificación tiene una validez nacional/ regional}

\section{Legislación}

\footnotetext{
108 Actualmente denominado Ministerio de Empleo y Seguridad Social.

109 Actualmente denominado Ministerio de Educación, Cultura y Deporte.
} 
La legislación nacional española y la autonómica de Castilla y León determinan la validez en todo el territorio español del procedimiento de evaluación y acreditación de competencias profesionales. También se ocupan de este aspecto la legislación nacional italiana y la regional de EmiliaRomagna. En ellas se expone que deben entregarse documentos de validación o certificados, estandarizados, que documentan las competencias identificadas y validadas o certificadas relacionadas con una o más cualificaciones regionales, la mayoría de las cuales tiene correspondencia con las cualificaciones nacionales.

\section{Entrevistas}

Los profesionales del procedimiento de Castilla y León no han hecho referencia al respecto. Por el contrario, los profesionales entrevistados del procedimiento de Emilia-Romagna, dos gestores/dirigentes entrevistados han confirmado en la práctica lo expuesto en la legislación, declarando que, en caso de demostrarla, la Regione entrega al candidato una cualificación del Catálogo Regional de Cualificaciones. Esta cualificación tiene una validez regional y en la mayoría de los casos tiene su equivalente nacional.

\subsubsection{INDICADOR: Los certificados de validación deben tener el mismo estatus que los certificados formales o diplomas.}

\section{Legislación}

Tanto la legislación nacional española como la autonómica de Castilla y León establecen que se reconocerán, por las administraciones competentes, las unidades de competencia acreditadas correspondientes a títulos profesionales y a certificados de profesionalidad, y cuando corresponda se les indicarán los trámites para obtener los títulos y certificados que corresponda. Por lo tanto las acreditaciones tienen el mismo estatus porque se trata del mismo título (o parte de él) que el de la formación formal. Lo mismo ocurre en la legislación nacional italiana y la regional de EmiliaRomagna, indicando que las certificaciones, cualificaciones y fichas que se entregan con la validación al candidato, tienen el mismo estatus que los títulos formales, ya que es el mismo título (o parte de él), como ocurre en el caso de Castilla y León.

\section{Entrevistas}

Sobre las entrevistas no existen referencias al respecto. 
La validación de competencias profesionales en España y en Italia

7. DIMENSIÓN: EXAMEN/CONTROL DEL PROCEDIMIENTO

7.1. CATEGORÍA: CONTROL INTERNO DEL PROCEDIMIENTO

7.1.0. Sin subcategoría

\begin{tabular}{|c|c|c|c|c|c|c|c|c|}
\hline \multirow[b]{3}{*}{ IND. } & \multicolumn{4}{|c|}{ ESPAÑA } & \multicolumn{4}{|l|}{ ITALIA } \\
\hline & \multicolumn{2}{|c|}{ Legislación } & \multirow{2}{*}{$\begin{array}{l}\text { Entrevis- } \\
\text { tas }\end{array}$} & \multirow{2}{*}{$\begin{array}{l}\text { Cues- } \\
\text { tio- } \\
\text { narios }\end{array}$} & \multicolumn{2}{|c|}{ Legislación } & \multirow{2}{*}{$\begin{array}{l}\text { Entre- } \\
\text { vistas }\end{array}$} & \multirow{2}{*}{$\begin{array}{l}\text { Cues- } \\
\text { tio- } \\
\text { narios }\end{array}$} \\
\hline & $\begin{array}{l}\mathrm{Na-} \\
\text { cional }\end{array}$ & $\begin{array}{l}\text { Autonómi- } \\
\text { ca }\end{array}$ & & & $\begin{array}{l}\text { Nacio- } \\
\text { nal }\end{array}$ & $\begin{array}{l}\text { Regio- } \\
\text { nal }\end{array}$ & & \\
\hline 7.1.0.1 & sí & sí & sí & NO & NO & sí & Sí & NO \\
\hline 7.1.0.2 & NO & sí & sí & NO & NO & sí & sí & NO \\
\hline 7.1.0.3 & NO & SÍ & NO & NO & NO & NO & NO & NO \\
\hline
\end{tabular}

* Recordamos que para facilitar el análisis de datos se agruparon algunos indicadores, en este caso agrupamos dos indicadores de la misma categoría: "control interno del procedimiento":

7.1.0.1. INDICADOR: Se hace un examen/control interno del procedimiento.

7.1.0.2. INDICADOR: Existe un organismo interno (cuerpo competente), a la organización del procedimiento, encargado del examen/control del mismo.

\section{Legislación}

La legislación nacional establece que el proceso de evaluación y acreditación de la competencia se verificará a través de evaluaciones internas y auditorías externas para su mejora continua, pero no especifica un organismo encargado de esto. La legislación autonómica de Castilla y León, establece que el órgano gestor facilite datos de seguimiento y evaluación del procedimiento a la Administración General del Estado. Así como que el Consejo de la Formación Profesional de Castilla y León y el Consejo General de Empleo participen en el seguimiento y evaluación del procedimiento. Lo que implica que dos órganos internos del procedimiento, (la gestión de este y el Consejo de Formación Profesional de Castilla y León) deben realizar un control/examen del procedimiento. 
Por su parte, aunque en la legislación nacional italiana no se han encontrado referencias al respecto, la legislación regional de Emilia-Romagna indica que la primera fase del procedimiento será experimental, con el objetivo de realizar un seguimiento/evaluación sobre el mismo y poder corregir posibles defectos e incluir mejoras en el mismo, por parte de la Regione.

\section{Entrevistas}

Los profesionales entrevistados del procedimiento de Castilla y León han declarado que no existe un proceso de control o examen del procedimiento como tal. No obstante, el dirigente/organizador y un evaluador, han declarado haber llevado a cabo una especie de coordinación con las comisiones de evaluación, para su mejor funcionamiento. Por el contrario, los profesionales entrevistados del procedimiento de Emilia-Romagna, (un gestor/organizador y un responsable de la formalización y certificación) han afirmado que se realiza un control interno del procedimiento por parte de la Regione.

\subsubsection{INDICADOR: Existe un plan de seguimiento interno}

\section{Legislación}

Sobre este aspecto solo se han encontrado referencias en la legislación autonómica de Castilla y León, en la que se menciona que la comisión directora será quién elabore el plan de seguimiento y evaluación, que formará parte de un plan de calidad, con el objetivo de comprobar la eficacia y el impacto del procedimiento en Castilla y León

\section{Entrevistas}

No existen alusiones al respecto en las entrevistas.

\subsection{CATEGORIA: CONTROL EXTERNO DEL PROCEDIMIENTO}

\subsubsection{Sin Subcategoría}

\begin{tabular}{|c|c|c|c|c|c|c|c|c|}
\hline \multirow[b]{3}{*}{ IND. } & \multicolumn{4}{|c|}{ ESPAÑA } & \multicolumn{4}{|c|}{ ITALIA } \\
\hline & \multicolumn{2}{|c|}{ Legislación } & \multirow{2}{*}{$\begin{array}{l}\text { Entrevis- } \\
\text { tas }\end{array}$} & \multirow{2}{*}{$\begin{array}{l}\text { Cues- } \\
\text { tio- } \\
\text { narios }\end{array}$} & \multicolumn{2}{|c|}{ Legislación } & \multirow{2}{*}{$\begin{array}{l}\text { Entre- } \\
\text { vistas }\end{array}$} & \multirow{2}{*}{$\begin{array}{l}\text { Cues- } \\
\text { tio- } \\
\text { narios }\end{array}$} \\
\hline & $\begin{array}{l}\mathrm{Na-} \\
\text { cional }\end{array}$ & $\begin{array}{l}\text { Autonó- } \\
\text { mica }\end{array}$ & & & $\begin{array}{l}\text { Nacio- } \\
\text { nal }\end{array}$ & $\begin{array}{l}\text { Regio- } \\
\text { nal }\end{array}$ & & \\
\hline 7.2.0.1 & sí & sí & NO & NO & sí & NO & NO & NO \\
\hline
\end{tabular}


La validación de competencias profesionales en España y en Italia

\begin{tabular}{lll|l|l|ll|l|l}
\hline 7.2 .0 .2 & NO & Sí & NO & NO & Sí & NO & NO & NO \\
\cline { 2 - 8 } 7.2 .0 .3 & SÍ & NO & NO & NO & NO & NO & NO & NO \\
\hline
\end{tabular}

* Recordamos que para facilitar el análisis de datos se agruparon algunos indicadores, en este caso agrupamos dos indicadores de la misma categoría: "control externo del procedimiento":

7.2.0.1. INDICADOR: Se hace un examen/control externo del procedimiento.

7.2.0.2. INDICADOR: Existe un organismo externo (cuerpo competente), a la organización del procedimiento, encargado del examen/control del mismo.

\section{Legislación}

La legislación nacional española establece que el proceso de evaluación y acreditación de la competencia se verificará a través de evaluaciones internas y auditorías externas para su mejora continua, pero no especifica un organismo encargado de esto. Asimismo, la legislación autonómica de Castilla y León establece que la Administración General del Estado, el Consejo de la Formación Profesional de Castilla y León y el Consejo General de Empleo (órganos externos al procedimiento) participarán en el seguimiento y evaluación del procedimiento.

Respecto al caso italiano, solo la legislación nacional italiana se refiere a este aspecto. Esta prevé unas comisiones, compuestas por representantes del Ministerio de Trabajo y Seguridad Social, del Ministerio de Educación, de la Universidad y de la Investigación y de las regiones, que se encarguen del seguimiento y evaluación de los procedimientos de validación, con la asistencia técnica del ISFOL; el INVALSI (Instituto nacional para evaluación del sistema educativo y formativo), el INDIRE (Instituto nacional de investigación educativa); el ANVUR (Agencia nacional de evaluación del sistema universitario y de investigación de documentación, innovación) y la Unión nacional de las cámaras de comercio, industria, artesanía y agricultura. Además, la legislación prevé que los resultados del seguimiento y de la evaluación deberán comunicarse, cada 3 años, al Parlamento.

\section{Entrevistas}

No existen alusiones a este aspecto en las entrevistas. 


\subsubsection{INDICADOR: Existe un plan de seguimiento externo}

\section{Legislación}

Únicamente la legislación nacional española hace referencia a este aspecto. Se contempla que la Administración General del Estado (órgano externo) elabore un plan de seguimiento y evaluación anual a partir de la información proporcionada por las comunidades autónomas. Asimismo, incluirá, en caso necesario, propuestas de mejora.

\section{Entrevistas}

No existen comentarios sobre este tema.

\section{DIMENSIÓN: COORDINACIÓN EN EL PROCEDIMIENTO}

\subsection{SIN CATEGORÍA}

8.1.0. Sin subcategoría

\begin{tabular}{|c|c|c|c|c|c|c|c|c|}
\hline \multirow[b]{3}{*}{ IND. } & \multicolumn{4}{|c|}{ ESPAÑA } & \multicolumn{4}{|c|}{ ITALIA } \\
\hline & \multicolumn{2}{|c|}{ Legislación } & \multirow{2}{*}{$\begin{array}{l}\text { Entrevis- } \\
\text { tas }\end{array}$} & \multirow{2}{*}{$\begin{array}{c}\text { Cues- } \\
\text { tio- } \\
\text { narios }\end{array}$} & \multicolumn{2}{|c|}{ Legislación } & \multirow{2}{*}{$\begin{array}{l}\text { Entre- } \\
\text { vistas }\end{array}$} & \multirow{2}{*}{$\begin{array}{c}\text { Cues- } \\
\text { tio- } \\
\text { narios }\end{array}$} \\
\hline & $\begin{array}{l}\text { Na- } \\
\text { cional }\end{array}$ & $\begin{array}{c}\text { Autonó- } \\
\text { mica }\end{array}$ & & & $\begin{array}{l}\text { Nacio- } \\
\text { nal }\end{array}$ & $\begin{array}{c}\text { Regio- } \\
\text { nal }\end{array}$ & & \\
\hline 8.0 .0 .1 & sí & NO & Sí & NO & NO & Sí & sí & NO \\
\hline 8.0.0.2 & NO & NO & Sí & Sí & NO & NO & sí & Sí \\
\hline 8.0.0.3 & Sí & Sí & Sí & NO & NO & NO & sí & NO \\
\hline
\end{tabular}

\section{Legislación}

En el caso español, solo la legislación nacional española contempla este aspecto, intentando garantizar, con el principio de coordinación, la coordinación y complementariedad en las actuaciones de todas las partes responsables del desarrollo del procedimiento, con el objetivo de lograr la máxima eficacia y eficiencia en su implementación. Por el contrario, en el caso italiano es la legislación regional de Emilia-Romagna la que hace mención a este aspecto. Esta otorga el papel de coordinador del procedimiento al responsable de la formalización y certificación de competencias (RFC), 
La validación de competencias profesionales en España y en Italia

estableciendo que dicho profesional será nombrado por el centro organizador del procedimiento e informará a la Regione sobre su nombramiento.

\section{Entrevistas}

El gestor/organizador entrevistado ha hablado de la figura del coordinar provincial de las direcciones provinciales de educación. Atribuyéndole, la función de transmisor de información, entre las consejerías y los profesionales del procedimiento, y la función de unificar los criterios de evaluación en las diferentes comisiones de evaluación. Uno de los asesores entrevistados, del procedimiento de Castilla y León, también ha mencionado esta figura, señalando, sin embargo, que este coordinador simplemente asistía a las reuniones iniciales de las convocatorias y firmaba el acta al finalizar las mismas.

En cuanto a los entrevistados del procedimiento de Emilia-Romagna, estos han indicado contar con una figura de coordinador más definida respecto a los profesionales entrevistados en Castilla y León. El RFC entrevistado ha explicado que todas las provincias de la región tienen como mínimo un RFC encargado de coordinar el procedimiento, para asegurar el buen funcionamiento y la calidad del mismo. Por su parte, dos de los EPV entrevistados, han comentado que esta figura (el RFC) es para ellos un supervisor que garantiza el buen funcionamiento del procedimiento, aunque uno de ellos, ha indicado que no ha notado mucho seguimiento por parte de este profesional.

\subsubsection{INDICADOR: Se realizan encuentros/reuniones de puesta en común entre los profesionales, dirigidos a mejorar el procedimiento.}

\section{Legislación}

Sobre este tema no se han encontrado referencias legislativas, ni en el plano nacional español/italiano, ni en el autonómico de Castilla y León/regional de Emilia-Romagna.

\section{Entrevistas}

La mayoría de los profesionales entrevistados de ambos procedimientos afirma haberse reunido con otros profesionales, para consultar dudas que surgen durante el procedimiento. No obstante, todos han negado la existencia de reuniones para mejorar el procedimiento. 
Respecto a los entrevistados en Castilla y León, uno de los asesores entrevistados ha indicado que se reúne con otros asesores y evaluadores cuando tiene alguna duda sobre algún candidato. El otro asesor entrevistado ha señalado que no se hacen reuniones para hablar de los problemas que surgen y como resolverlos en el procedimiento, aunque menciona el uso de una plataforma, que da la posibilidad, a los profesionales del procedimiento, de comunicarse entre ellos, a pesar de haber señalado que en la segunda fase de la convocatoria, no ha estado muy activa. Asimismo, uno de los evaluadores entrevistados ha afirmado haber tenido contacto con otros evaluadores, aunque no con los asesores, también ha comentado que tampoco se han hecho reuniones para comentar problemas o mejoras en el procedimiento.

Por su parte, dos de los EPV entrevistados del procedimiento de Emilia-Romagna han declarado haberse reunido con los EAPQ para planificar el examen, pero no mencionan otro tipo de reuniones dirigidas a mejorar el procedimiento. El otro de los EPV entrevistados ha señalado que no se han hecho reuniones con objeto de mejorar el procedimiento pero lo considera de mucha utilidad. En cuanto al RFC entrevistado, también ha indicado que no se han realizado estas reuniones pero las considera muy útiles, aunque ha señalado que resultarían bastante costosas y que por ahora lo que hacen los RFC es intentar solucionar los problemas que van detectando durante el procedimiento. Por último uno de los gestores/organizadores del procedimiento, ha declarado haberse reunido con los profesionales del procedimiento de los entes que están llevando a cabo el procedimiento, para "romper el hielo", darles seguridad e indicarles que pueden llamar ante cualquier problema.

\section{Cuestionarios}

Hemos preguntado a todos los profesionales de ambos procedimientos que intervienen en la evaluación, por la realización de reuniones para poner en común experiencias con el objetivo de mejorar el procedimiento. 
La validación de competencias profesionales en España y en Italia

Figura 48: Porcentaje de profesionales de la evaluación de ambos procedimientos que han hecho reuniones para mejorar el procedimiento

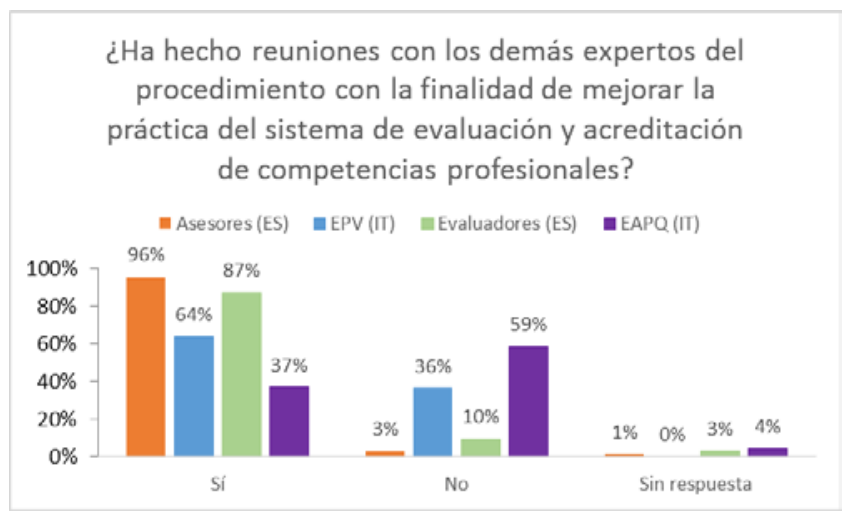

Figura 49: Porcentaje de profesionales de la evaluación de ambos procedimientos que consideran útiles las reuniones para mejorar el procedimiento

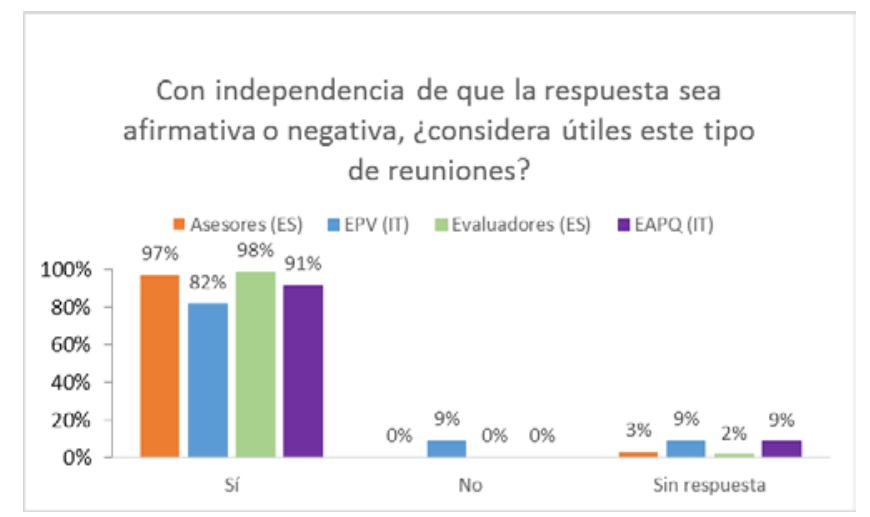

Los asesores de ambos procedimientos han indicado en mayor medida que los evaluadores haber hecho este tipo de reuniones $(96 \%$ de los asesores del procedimiento de Castilla y León y $87 \%$ los asesores del procedimiento de Emilia-Romagna, ver Figura 48). Sin embargo, todos los profesionales consideran que sería muy útil realizar este tipo de encuentros (ver Figura 49), aunque no están previstos por la legislación en ninguno de los dos procedimientos.

Cuando hemos preguntado a los encuestados sobre los aspectos a mejorar del procedimiento, el punto al que han hecho mayor alusión los profesionales encuestados de ambos procedimientos ha sido el de la coordinación (en torno a un 20\%-30\%, tanto en el procedimiento español como en el italiano y casi la totalidad de encuestados que ha contestado a esa pre- 
gunta). Estos piensan que este aspecto ha fallado, tanto en Castilla y León como en Emilia-Romagna, y que sería necesario realizar encuentros entre profesionales, que propiciasen la unificación de criterios de evaluación y el intercambio de opiniones y experiencias para optimizar el procedimiento.

9. DIMENSIÓN: TRAZABILIDAD

9.0. SIN CATEGORIA

9.0.0. Sin subcategoría

\begin{tabular}{|c|c|c|c|c|c|c|c|c|}
\hline \multirow[b]{3}{*}{ IND. } & \multicolumn{4}{|c|}{ ESPAÑA } & \multicolumn{4}{|c|}{ ITALIA } \\
\hline & \multicolumn{2}{|c|}{ Legislación } & \multirow{2}{*}{$\begin{array}{c}\text { Entrevis- } \\
\text { tas }\end{array}$} & \multirow{2}{*}{$\begin{array}{c}\text { Cues- } \\
\text { tio- } \\
\text { narios }\end{array}$} & \multicolumn{2}{|c|}{ Legislación } & \multirow{2}{*}{$\begin{array}{l}\text { Entre- } \\
\text { vistas }\end{array}$} & \multirow{2}{*}{$\begin{array}{c}\text { Cues- } \\
\text { tio- } \\
\text { narios }\end{array}$} \\
\hline & $\begin{array}{l}\mathrm{Na}- \\
\text { cional }\end{array}$ & $\begin{array}{c}\text { Autonó- } \\
\text { mica }\end{array}$ & & & $\begin{array}{c}\text { Nacio- } \\
\text { nal }\end{array}$ & $\begin{array}{c}\text { Regio- } \\
\text { nal }\end{array}$ & & \\
\hline 9.0 .0 .1 & sí & Sí & sí & sí & NO & NO & sí & NO \\
\hline
\end{tabular}

\section{Legislación}

Tanto la legislación nacional española como la autonómica de Castilla y León, indican que por cada actividad de evaluación deberá quedar un registro firmado por el candidato y el evaluador y que se generará un expediente del proceso, que recogerá todos los registros y resultados producidos a lo largo del procedimiento. Por el contrario, en la legislación nacional italiana y en la regional de Emilia-Romagna no se han encontrado referencias sobre este aspecto.

\section{Entrevistas}

Casi todos los profesionales entrevistados de ambos procedimientos han confirmado que el procedimiento queda registrado. En el caso de Castilla y León (un asesor, dos evaluadores y el gestor organizador), han afirmado la existencia y el funcionamiento del registro de actividades del procedimiento. Por otra parte, los profesionales de Emilia-Romagna, (tres EPV; un RFC y un gestor organizador), han declarado que el procedimiento queda registrado en documentos dispuestos por la Regione, a través de un sistema informático, capaz de ordenar cronológicamente los documentos producidos. 
La validación de competencias profesionales en España y en Italia

\section{Cuestionarios}

Uno de los aspectos que los asesores y evaluadores (5\%) encuestados del procedimiento de Castilla y León han considerado que puede mejorar la forma de documentar el procedimiento, ya que en esta los documentos se solapan y resultan excesivos. 


\section{Conclusiones}

En este último capítulo presentamos las conclusiones de la tesis, derivadas del análisis de datos. Para finalizar el trabajo incluimos un apartado en el que exponemos algunas aportaciones y la prospectiva que supone este estudio en ámbito científico. 
La validación de competencias profesionales en España y en Italia

\subsection{Conclusiones generales}

La validación de competencias profesionales se perfila actualmente como una de las respuestas ante los cambios que hoy en día se imponen con fuerza, motivados por una nueva forma de entender el mercado, más competitiva, de más calidad y muy versátil. Por este motivo, la Unión Europea anima a los Estados miembros a llevar a cabo estas prácticas de validación, al tiempo que propone homogeneizarlas para dotarlas de mayor validez y fiabilidad, y facilitar la movilidad de los trabajadores.

Para lograr estos objetivos, el Cedefop (Centro Europeo para el Desarrollo de la Formación Profesional) publicó las Directrices Europeas 2009. Guiándonos por las pautas proporcionadas en este documento, hemos estudiado los procedimientos de validación de competencias profesionales en Castilla y León y en Emilia-Romagna. Este estudio lo hemos hecho, fundamentalmente, a través de un doble análisis, legislativo y de las opiniones de profesionales, con el que hemos querido comprobar, en los dos procedimientos, el cumplimiento de los principios que estas directrices proponen (ver capítulo 5 sobre metodología).

Con la intención de alcanzar tal propósito y tras el análisis de datos, damos respuesta a cada uno de los cuatro objetivos que definimos al principio de nuestra investigación, y cuyas conclusiones detallaremos en este capítulo.

De forma general podemos decir que a través de este trabajo hemos constatado que el discurso teórico sobe la terminología relacionada con la validación de competencias profesionales, en España y en Italia, ha seguido caminos parecidos. Asimismo, hemos confirmado las muchas similitudes y escasas disimilitudes entre los sistemas educativos y de formación profesional. También hemos comprobado que a diferencia de España, Italia todavía no ha logrado instaurar un procedimiento nacional de validación debido a la heterogeneidad en los sistemas de formación profesional regionales.

En cuanto a los procedimientos de validación en Castilla y León y en Emilia-Romagna, y como ha ido mostrando el análisis de datos del capítulo anterior, ambos procedimientos muestran puntos fuertes y débiles, tanto en la legislación como en la práctica (desde la opinión de los profesionales entrevistados y encuestados). En las siguientes páginas, ofrecemos una panorámica general sobre estos aspectos, para después explicarlo en detalle. 
La Figura 50 y la Figura 51 ilustran el grado de presencia de los principios propuestos por las líneas directrices en cada fase del procedimiento, según la legislación (Figura 50) y las opiniones de los profesionales (Figura 51). Las flechas de color verde oscuro indican mucha presencia; las verde claro bastante presencia; las naranjas poca presencia y las rojas ninguna presencia de los principios en la fase correspondiente. Cada fase está dividida en procedimiento de Castilla y León (CL), y de Emilia-Romagna (ER).

Figura 50: Presencia de principios en cada fase del procedimiento (legislación).

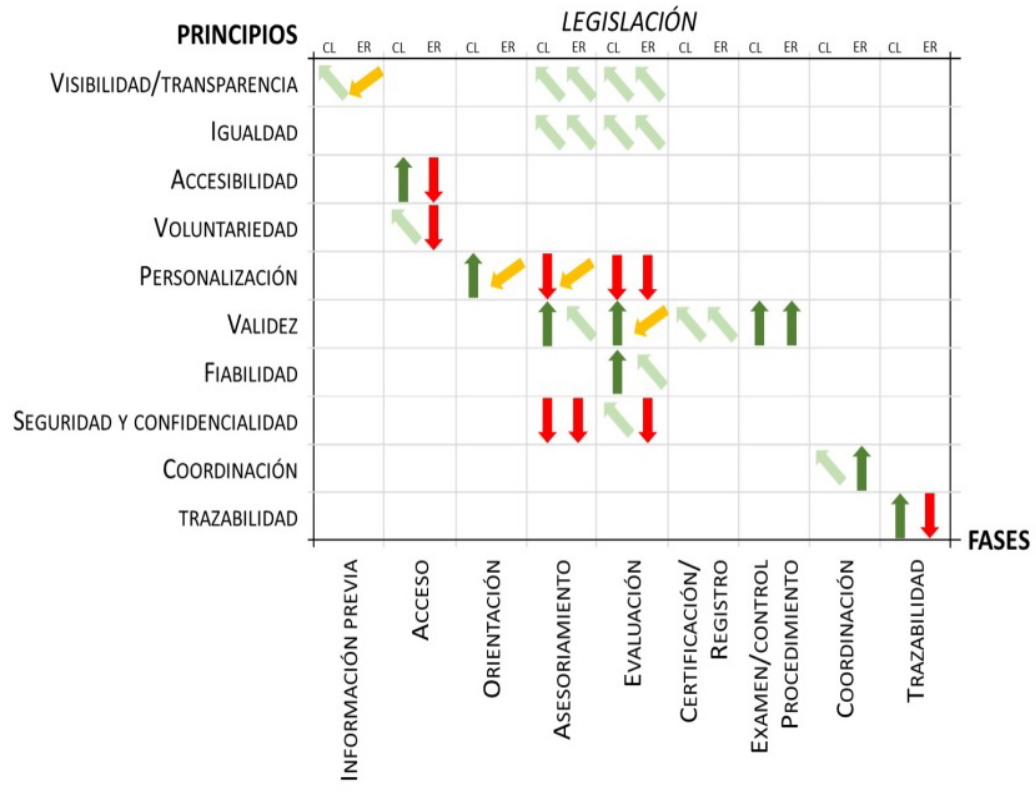


La validación de competencias profesionales en España y en Italia

Figura 51: Presencia de principios en cada fase del procedimiento (opiniones profesionales).

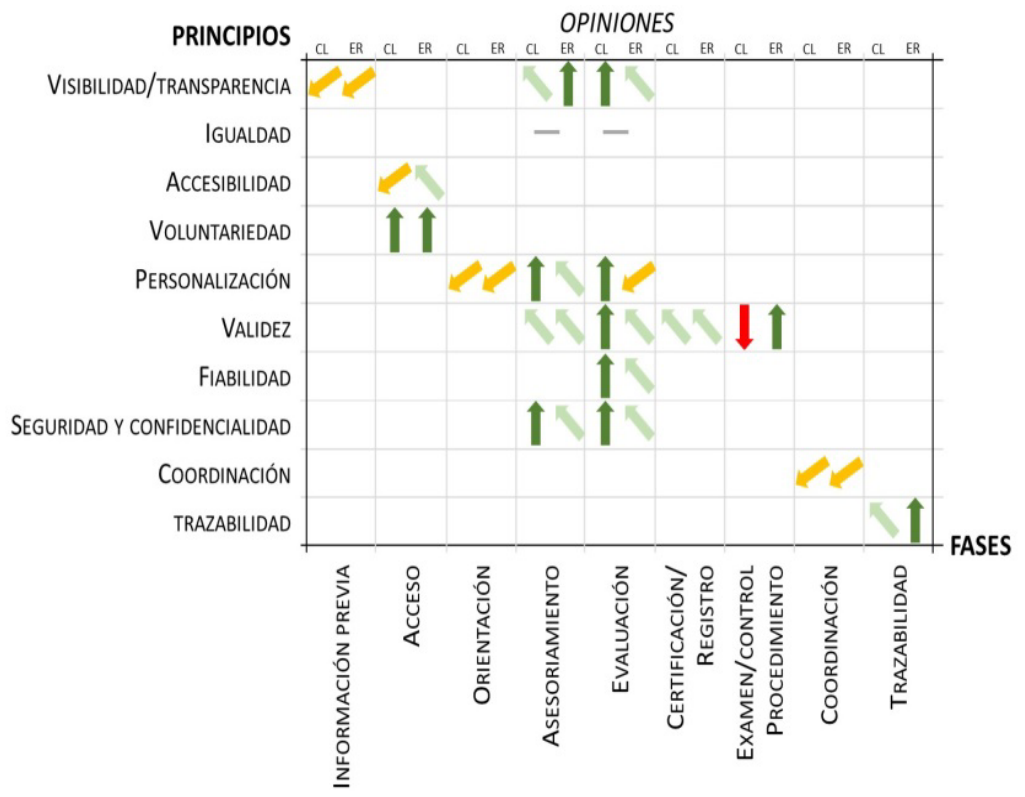

En la Figura 52 y Figura 53, indicamos, a través de un polígono, en qué medida aparecen los principios, sin especificar por fases, en ambos procedimientos, según la legislación y las opiniones respectivamente. Esta medida se representa en una escala de 0 a 3 , donde 0 significa nula presencia, y 3 significa mucha presencia. Cuanto más cerca del centro del polígono (0) se sitúe un principio menor será su presencia en el procedimiento, siendo mayor cuanto más lejos se sitúe de este (3). Este tipo de representación también se emplea en la Figura 54 y Figura 55, en las que comparamos los resultados de legislación y opiniones de cada procedimiento. Cabe destacar que en la Figura 53, Figura 54 y Figura 55, el principio de igualdad, en cuanto a las opiniones, aparece represando con el valor de " 0 ". En este caso particular, esto no significa que los profesionales le hayan otorgado una baja valoración, sino que no existen referencias sobre el mismo, ya que los profesionales no lo han mencionado en las entrevistas y en los cuestionarios no se ha indagado sobre ello para evitar deseabilidad social en la respuesta. 
Figura 52: Presencia de principios en los procedimientos (legislación).

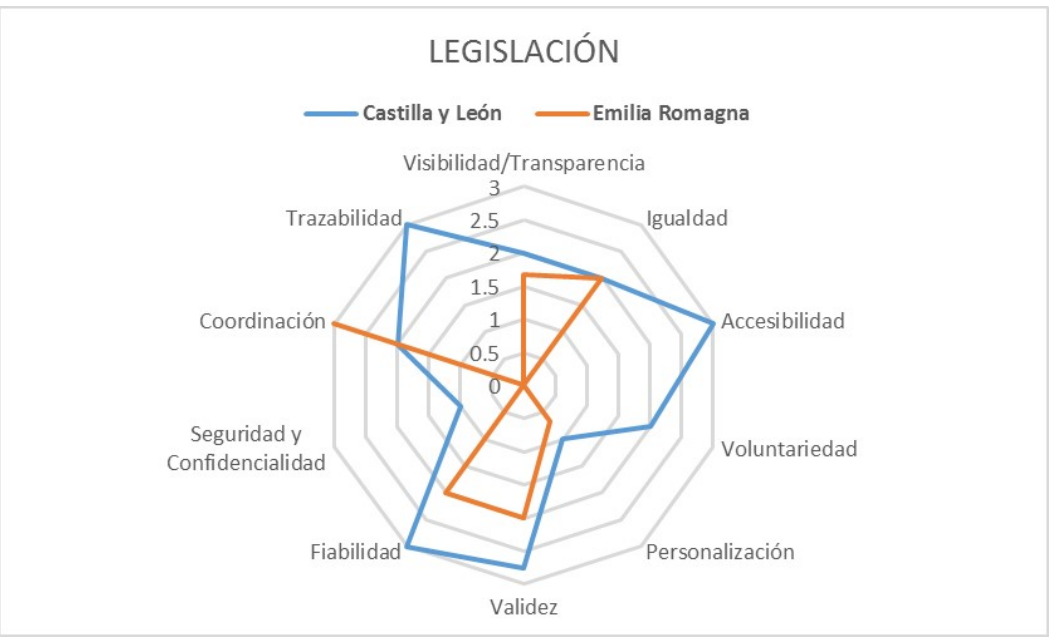

Figura 53: Presencia de principios en los procedimientos (opinión profesionales)

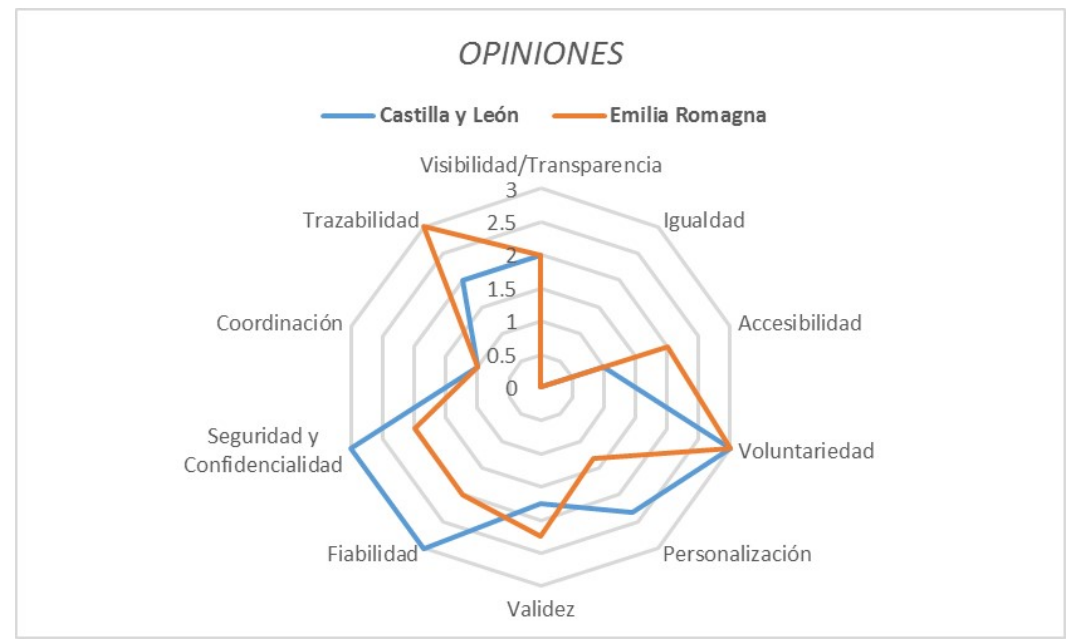

Como vemos en la Figura 50 y en la Figura 52, en el procedimiento de Castilla y León, la legislación referida a este se perfila como un punto fuerte de este procedimiento y respecto al de Emilia-Romagna, que cuenta con una legislación sobre el procedimietno menos definida.

Por otra parte, como ilustran la Figura 51 y la Figura 53, las opiniones de los profesionales indican algunos puntos más fuertes en un procedimien- 
to y otros en el otro. En concreto, en el procedimiento de Castilla y León, la personalización hacia el candidato (sobre todo en cuanto a flexibilidad durante toda la validación) y la validez, fiabilidad y seguridad en el asesoramiento y en la evaluación se sitúan como los aspectos más adecuados, respecto al resto y al procedimiento de Emilia-Romagna. Por otro lado, en Emilia-Romagna, la forma de convocatoria, los controles y las mejoras realizadas en la práctica se alzan como los puntos fuertes de su procedimiento, y destacan respecto al procedimiento español. En cuanto a las debilidades detectadas, ambos procedimientos comparten la necesidad de mejorar la información inicial sobre la validación, a entes y sujetos susceptibles de implementar el procedimiento y a posibles candidatos. Asimismo, la formación de los profesionales, en especial la continua; la coordinación de profesionales durante la práctica y la orientación al candidato, sobre todo la transversal, son los puntos más débiles que ambos procedimientos comparten, según la opinión de sus profesionales. Concretamente, el procedimiento de Castilla y León también debería simplificar la forma de acceso y realizar un control del procedimiento. Por su parte, el de Emilia-Romagna tendría también que reforzar la flexibilidad hacia el candidato durante la evaluación.

En la Figura 50 y Figura 52 vemos que en el procedimiento de Castilla y León la legislación de referencia es bastante completa. Sin embargo, según las opiniones de los profesionales hemos comprobado que esto no garantiza forzosamente una práctica correcta en los aspectos definidos por la ley y viceversa, el hecho de que algunos puntos no se traten en la legislación no indica que la práctica haya sido inadecuada (ver Figura 51 y Figura 53). Como vemos en la Figura 50, el principio de personalización en la fase de asesoramiento y evaluación no está presente, sin embargo en las opiniones este aspecto se valora con una elevada presencia (ver Figura 51). El principio de seguridad y confidencialidad en asesoramiento tampoco aparece mencionado por la legislación (ver Figura 50), y los profesionales han indicado que sí se ha respetado dicho principio (ver Figura 51). Por otro lado, la legislación define muy bien el acceso al procedimiento, la personalización en la orientación y el control del procedimiento (ver Figura 50), aspectos que no han tenido una buena valoración por parte de los encuestados y entrevistados (ver Figura 51). La imagen de la Figura 54 ilustra las diferencias en la presencia de principios en el procedimiento, según tengamos en cuenta la legislación o las opiniones de los profesionales. 
Figura 54: Presencia de principios en procedimiento de Castilla y León, comparación entre legislación y opiniones

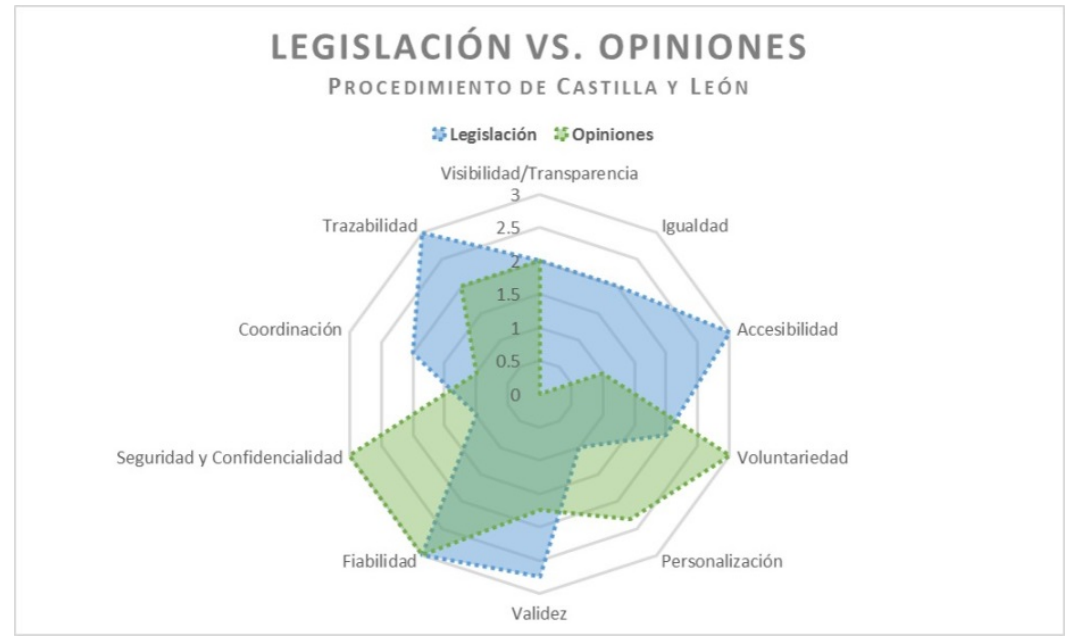

En el caso de Emilia-Romagna comprobamos, al observar la Figura 50 , que la voluntariedad y la accesibilidad en el acceso y la trazabilidad son aspectos que la legislación omite, pero que obtienen una buena valoración en la práctica por parte de los profesionales entrevistados y encuestados (ver Figura 51). Asimismo, la seguridad y confidencialidad en el asesoramiento y en la evaluación tampoco se tratan en la legislación (ver Figura 50), y en la práctica no obtiene una valoración negativa (Figura 51). También existen disimilitudes en caso contrario, la legislación referente al procedimiento hace bastante mención a la coordinación en el mismo (ver Figura 50), sin embargo, las opiniones de los profesionales no le han otorgado un valor elevado (Figura 51). La imagen de estas diferencias en cuanto a legislación y opiniones queda patente en la Figura 55. 
La validación de competencias profesionales en España y en Italia

Figura 55: Presencia de principios en procedimiento de Emilia-Romagna, comparación entre legislación y opiniones

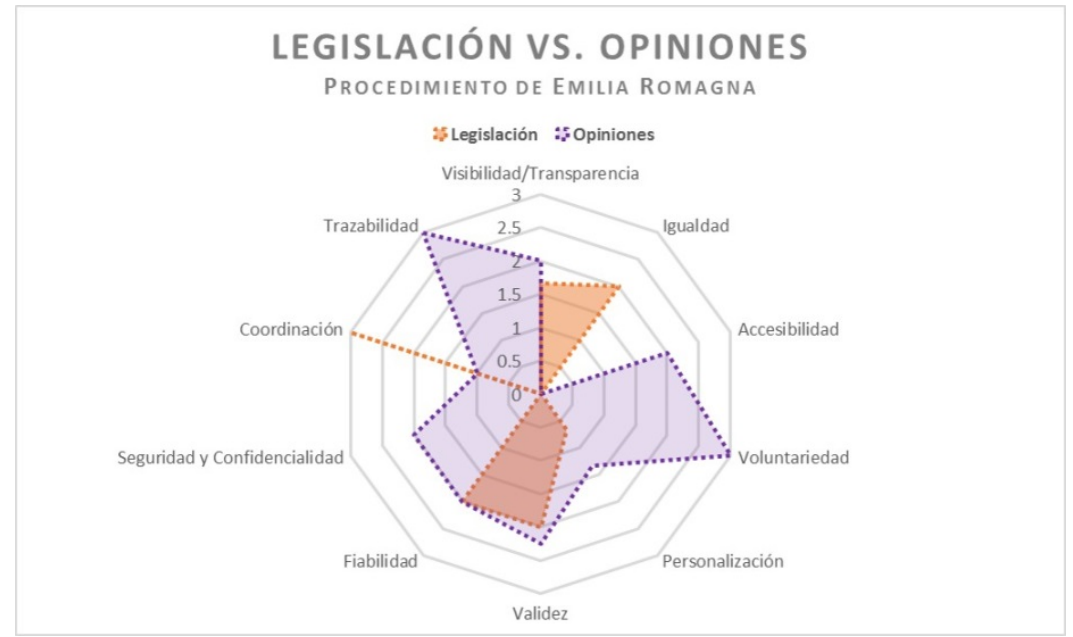

A continuación, de forma detallada presentamos cada objetivo con las conclusiones obtenidas sobre este durante nuestro trabajo:

- Identificar la estructura de los sistemas educativos y de formación profesional en España, en Castilla y León, en Italia y en EmiliaRomagna, para conocer su organización y funcionamiento y así entender mejor el sistema de evaluación y validación de competencias profesionales de ambos territorios.

A través del análisis documental para la construcción del marco teórico hemos podido comprobar la similitud de la estructura entre los sistemas educativo y formativo de España e Italia.

Los dos países estructuran sus sistemas educativos en niveles: no obligatorio; primario; secundario y superior. En ambos territorios los alumnos deben decidir con 14 años continuar sus estudios por una vía más académica dirigida al ámbito universitario, o por el contrario seguir una vía más profesional. La educación universitaria adopta también formas parecidas en ambos países, rigiéndose en los dos casos, aunque con modalidades distintas, por el Plan Bologna.

En cuanto a los sistemas de formación profesional, tanto en Italia como en España, estos se organizan en dos tipos de enseñanzas, una formación inicial y otra formación dirigida a la población activa (trabajadores ocupados y en situación de empleo). A su vez, la formación inicial cuenta 
con tres niveles en ambos casos (básica, media y superior). A pesar de las similitudes en cuanto a la estructura, hemos observado que en Italia la formación profesional ofrece más vías de realización y de mayor duración respecto a España.

También hemos observado que los dos sistemas cuentan con contratos de formación, esta modalidad recibe el nombre de formación dual en España (de reciente incorporación) y de apprendistato en Italia, abarcando este último un mayor número de enseñanzas respecto a España, llegando a incluir también los estudios de doctorado (Decreto Legislativo 167, 2011). Sin embargo, en España se contempla la formación dual para los trabajadores, mientras que en Italia solo se desarrolla en el ámbito de lo que entenderíamos por formación inicial.

Como gran diferencia a mencionar entre estos dos sistemas, es que la totalidad del sistema educativo-formativo profesional español es de competencia estatal, mientras que en Italia, la formación profesional (IeFP) está en manos de las regiones. No obstante, estas deben respetar unos estándares formativos mínimos establecidos por el Estado (duración de los cursos, validez nacional de las certificaciones, respeto de criterios nacionales de acreditación para los sujetos que proporcionen la formación).

Hemos podido constatar esta autonomía de las regiones italianas, sobre todo, en cuanto a la IeFP está suponiendo grandes consecuencias para la validación de competencias no formales e informales, debido a que cada región describe su propio sistema de cualificaciones y por tanto tiene también su particular sistema de validación. Esto obstaculiza la homogeneización de las prácticas en el territorio italiano y aleja la posibilidad de tener un sistema nacional de validación de competencias profesionales italiano.

De igual modo, queremos señalar que hoy en día estos sistemas educativo-formativos son más homogéneos que hace unos años. Con el objetivo de adecuarse a las recomendaciones europeas, los sistemas educativo-formativos de ambos países han sufrido cambios recientemente y en la actualidad existen todavía modificaciones en curso, como por ejemplo la educación secundaria en Italia o la modificación de itinerarios en ESO y la nueva formación profesional de base en España.

En cuanto a la comunidad autónoma de Castilla y León y a la región de Emilia-Romagna, podemos decir que ofrecen la formación profesional que se establece en los sistemas nacionales, en el ámbito de sus competen- 
cias y según su capacidad de decisión respecto a las enseñanzas que procuran. En Emilia-Romagna el poder de decisión es mucho mayor que en Castilla y León, en lo que a IeFP y formación profesional continua se refiere, porque como hemos comentado, las regiones italianas tienen competencia exclusiva en estos ámbitos.

Encontramos una diferencia destacable en el sistema de EmiliaRomagna respecto al nacional italiano. Se trata de la oferta de IeFP, ya que esta región ofrece solo una formación de tres años de duración y no de cuatro, como se indica en la IeFP definida en ámbito nacional. No obstante, la formación profesional en este nivel sigue ofreciendo más vías y sigue siendo de mayor duración que la ofrecida por Castilla y León. En lo referente al resto de aspectos, ambos sistemas se desarrollan como indican los sistemas nacionales y no presentan desemejanzas importantes.

Según estos datos, podemos afirmar por tanto, que al menos en el aspecto relacionado con la variedad de vías formativas y duración de las mismas, Italia, en general y Emilia-Romagna, en concreto, son más fuertes que España y Castilla y León.

- Comparar la terminología relacionada con la validación de competencias profesionales, según se entiende en España y en Italia, para comprender la importancia y el enfoque que ambos países conceden al procedimiento de validación.

Tras analizar el estudio del estado del arte en relación al concepto de competencia, hemos comprobado que Italia ha mantenido un discurso más amplio que España sobre este aspecto. Sin embargo, en ambos países se ha llegado a entender el término de forma dinámica y se ha abandonado la idea estática que se tenía sobre él en el pasado. Esto ha permitido que en ambos territorios se considerasen las tres dimensiones contempladas en las directrices europeas relativas a la competencia profesional, el "saber" (teoría), "saber hacer" (práctica), "saber ser/estar" (competencias transversales relacionadas con aptitudes y actitudes), así como la dimensión del "poder hacer" (contexto). También, en el discurso italiano se habla de las dimensiones del "saber y querer actuar" como activadora de las competencias necesarias para realizar una actividad con éxito, la primera, y como el aspecto motivacional para querer hacerlo, la segunda. Sin embargo, nosotros, apoyándonos en los escritos de Benito Echeverría, hemos considerado que estas dos últimas dimensiones pueden incluirse en el ser/estar como competencias transversales. 
Siguiendo la idea de autores como Rodríguez Moreno, Le Boterf o Alberici, en esta tesis hemos entendido el concepto de competencia como la interacción del "saber", "saber hacer" y "saber ser/estar", adquiridos a lo largo y ancho de su vida, en un contexto determinado en el que el sujeto utiliza su experiencia (aprender a aprender) para llevar a cabo una actividad.

En cuanto al concepto del aprendizaje permanente, hemos comprobado que tanto en España como en Italia es un término en constante evolución, que se refleja en la continua y reciente transformación que están experimentando la formación profesional y continua en estos países, para adecuarse a las exigencias europeas.

En sintonía con la línea europea, ambos países conciben el aprendizaje permanente como un aprendizaje a lo largo (durante) y a lo ancho (en todos los contextos) de la vida, comprendiendo por tanto los aprendizajes formales (estudios estructurados y organizados, tras los que se otorga un título oficial) no formales (actividades de aprendizaje planificadas con un fin pero sin título oficial) e informales (actividades cotidianas en el trabajo, la familia o el ocio).

España e Italia son dos países que aún deben aumentar la cualificación de la población, las cualificaciones intermedias en España y las superiores en Italia, para adecuarse a las exigencias europeas. El aprendizaje permanente en general y la validación de competencias profesionales en particular, suponen, en nuestra opinión, una buena herramienta para ello, a través de la formación y recualificación de los ciudadanos.

- Caracterizar la implantación de los sistemas de España, de Castilla y León, de Italia y de Emilia-Romagna de validación y certificación de competencias profesionales, para tener una visión sobre las medidas legislativas y las experiencias realizadas al respecto.

Hemos observado una gran diferencia entre España e Italia en cuanto a la producción de legislación y políticas en lo que a validación y certificación se refiere. En Italia empezó en el año 2000 con el Accordo Stato-Regioni y en España en 2002 con la LO 5/2002. No obstante, las normativas más relevantes en estos territorios son el RD 1224/2009 en España y el DL 13/2013 en Italia. El real decreto español define y establece para todo el territorio español un procedimiento de evaluación y acreditación de competencias profesionales. El decreto legislativo italiano define la organización y 
La validación de competencias profesionales en España y en Italia

estructura generales de los procedimientos de identificación, validación y certificación de aprendizajes no formales e informales.

En cuanto a la creación de un Marco Nacional de Cualificaciones, Italia ha relacionado las cualificaciones italianas con los niveles del Marco Europeo de Cualificaciones (EQF), mientras que España está en proceso de definición del mismo.

A pesar de los avances en Italia en cuanto a la creación de perfiles profesionales nacionales y a la unificación de cualificaciones regionales para poder homogeneizar las prácticas de validación en las diferentes regiones, no se ha logrado todavía establecer un sistema nacional de validación como se ha hecho en España. La existencia de las comentadas diferencias entre la formación profesional de las diferentes regiones italianas implica que cada una defina sus propias cualificaciones siguiendo sus propios criterios. Esto a su vez dificulta la tarea de unificación de los repertorios regionales de cualificaciones en uno nacional y provoca grandes diferencias en cuanto al nivel de implantación de los dispositivos dependiendo de la región.

Por el contrario, en España, el procedimiento se desarrolla en un marco nacional y aunque con variaciones en el número de convocatorias, todas las comunidades autónomas han puesto en marcha este procedimiento de validación.

En cuanto a la producción legislativa autonómica de Castilla y León y la regional de Emilia-Romagna, debemos mencionar que la primera, acogiéndose al RD 1224/2009, se limita a dos órdenes, una para convocar el procedimiento (Orden HAC 1536/2011) y la otra para desarrollar la gestión del procedimiento y crear las Comisiones Directora y Asesora (Orden HAC 1605/2011).

Emilia-Romagna, por el contrario, ha desarrollado su propio marco normativo para poder poner en marcha sus prácticas de validación, creando un sistema regional de cualificaciones con la D.G.R. 936/2004; un sistema de formalización y certificación de competencias regional a través de la DGR 1434/2005 y definiendo el procedimiento en detalle con las DGR $1434 / 2005$ y 739/2013. Cabe señalar que estas deliberaciones han creado un sistema único integrado para la validación, en el ámbito formal y en el no formal e informal. Es decir, que en el caso de Emilia-Romagna, la validación de competencias profesionales está integrada en el sistema formativo formal y no es un sistema separado de este, como ocurre en Castilla y León, donde el procedimiento de validación no se integra en el sistema formal. 
En Castilla y León, las encargadas de convocar el procedimiento de validación son las administraciones educativa y laboral, aunque también puede hacerlo la misma Administración General del Estado y las principales organizaciones sindicales. Cada convocatoria debe ser publicada en el boletín o diario oficial de la comunidad autónoma. Por el contrario en EmiliaRomagna, son las empresas, los centros formativos y los centros de empleo, previamente acreditados por la Regione, los que pueden poner en marcha directamente esta práctica. Esto supone una mayor rapidez respecto a Castilla y León en cuanto a la publicación de convocatorias. Esto podría explicar, en parte, el hecho de que, hasta el año 2016, en Castilla y León solo se hayan realizado dos convocatorias y en Emilia-Romagna más de 100.

En cuanto a las fases del procedimiento, podemos afirmar que ambos cuentan con una fase de admisión y de asesoramiento, esta última denominada "evaluación a través de evidencias" en Emilia-Romagna. Una particularidad en el procedimiento de Emilia-Romagna es que la fase de evaluación se desdobla en dos posibilidades, dependiendo de si los candidatos pretenden lograr la totalidad de la cualificación (examen de evaluación) o parte de ella (entrevista de evaluación), mientras que en Castilla y León todos los candidatos siguen la misma fase de evaluación.

Otra de las diferencias la encontramos al finalizar el procedimiento. En Castilla y León se entrega la certificación a través de la acreditación de las UC demostradas. Si con ellas puede obtenerse un certificado de profesionalidad o un título de formación profesional, el candidato podrá solicitarlo a la administración educativa/laboral correspondiente, aunque esto ocurre fuera del procedimiento de validación propiamente dicho. En cambio, en Emilia-Romagna, la Regione entrega directamente a los candidatos, sin tener que pasar por más trámites como ocurre en Castilla y León, la certificación en forma de un certificado de competencias o de cualificación, según se logre demostrar una o más UC o la totalidad de las UC de una cualificación respectivamente. Como vemos, en Emilia-Romagna, se entregan directamente los títulos que otorga la formación formal, ya que, como hemos comentado, el procedimiento de validación de competencias profesionales está integrado en el sistema formativo formal. Además, el procedimiento de Emilia-Rommagna, concede una ficha de capacidades y conocimientos a los candidatos que no logran evidenciar, en la fase de asesoramiento, la totalidad de una UC. 
La validación de competencias profesionales en España y en Italia

En cuanto a las figuras del procedimiento, en Castilla y León la legislación define dos figuras profesionales para llevar a cabo el procedimiento: el asesor, que se ocupa del asesoramiento, y el evaluador, que se encarga de la fase evaluación. Por otra parte, la legislación relativa al procedimiento de Emilia-Romagna define tres figuras profesionales: el experto de los procesos de evaluación (EPV) que por las funciones que desarrolla se puede equiparar al asesor del procedimiento castellanoleonés; el experto de área profesional y la cualificación (EAPQ) que podemos equiparar al evaluador de Castilla y León; el responsable de la formalización y certificación de competencias (RFC), encargado de asegurar el buen funcionamiento del procedimiento. La legislación en relación al procedimiento de Castilla y León no hace mención a esta última figura. Sin embargo, en el análisis de las entrevistas hemos comprobados que algunos entrevistados mencionan la figura de un coordinador que aparece en el momento de iniciar el procedimiento.

Además, otra disimilitud concerniente a los profesionales del procedimiento, tiene que ver con las funciones atribuidas a estos. En el procedimiento de Castilla y León, solo los asesores participan en la fase de asesoramiento y únicamente los evaluadores se encargan de la fase de evaluación. Por el contrario, en el procedimiento de Emilia-Romagna los EAPQ (evaluadores) pueden participar en la fase de asesoramiento si son requeridos por el EPV (asesor) y la presencia de este último es obligada en la fase de evaluación. Concretamente, un $65 \%$ de los EAPQ (evaluadores) encuestados, ha participado en la fase de asesoramiento.

- Valorar la implantación de los dispositivos de validación y certificación de competencias profesionales de Castilla y León y EmiliaRomagna, desde una perspectiva europea, a través de una matriz comparativa, resultante del estudio de las Directrices Europeas de 2009 , sobre validación de aprendizajes no formales e informales, para establecer semejanzas y diferencias entre ambos dispositivos.

Para dar respuesta a este objetivo nos ayudamos de los principios propuestos por las directrices europeas, definidos en el capítulo de metodología de este estudio. Recordamos que a cada categoría de la matriz comparativa le corresponden unos principios determinados (ver Figura 4 y Tabla 5).

\section{Visibilidad/transparencia}


Según las directrices europeas la transparencia en el procedimiento es fundamental para generar confianza en el mismo.

Por eso la información previa que se ha proporciona sobre el procedimiento es un punto importante dentro de este aspecto. El hecho de que únicamente la legislación española contemple este tema de forma general, demuestra que no se ha tenido muy en cuenta en ninguno de los dos procedimientos. Al analizar las entrevistas y las encuestas de ambos procedimientos comprobamos que los asesores de Castilla y León y los evaluadores de las dos prácticas de validación, consideran insuficiente la información proporcionada a las partes interesadas (centros formativos, empresas) y a los candidatos. Ya que creen que debería ser más completa, amplia y personalizada. Asimismo, los dirigentes de Emilia-Romagna han añadido que la falta de información genera desconfianza y rechazo hacia el procedimiento.

En cuanto a la facilidad de acceso a la información sobre el procedimiento, solo es mencionado por la legislación autonómica de Castilla y León. La falta de mención en el resto de la legislación (nacional italiana y autonómica de Castilla y León/regional de Emilia-Romagna), es significativa, ya que nos hace ver que este aspecto no ha sido considerado como un aspecto importante en la legislación de los dos casos estudiados.

Según las directrices europeas los asesores y evaluadores del procedimiento deben proporcionar al candidato información sobre el mismo. La legislación analizada relacionada con ambos procedimientos contempla la proporción de información sobre el procedimiento a los candidatos, pero no especifica que sea la figura del asesor o del evaluador quién deba hacerlo. No obstante, según las respuestas de las entrevistas y de los cuestionarios de ambos procedimientos, estos sí han proporcionado dicha información. Concretamente en el procedimiento de Castilla y León, los entrevistados han indicado que en la primera parte de la convocatoria, los candidatos llegaban muy desinformados y con bastante miedo al procedimiento, lo cual manifiesta las carencias o ausencia de la fase de información previa al procedimiento.

A través de los cuestionarios hemos podido conocer la cantidad de información proporcionada a los candidatos sobre los puntos del procedimiento que proponen las directrices europeas: las fases del procedimiento; cómo obtener el certificado; el rol de los participantes en el procedimiento; la metodología a seguir en la evaluación; los instrumentos 
utilizados en el procedimiento y su funcionamiento; las tareas a realizar por el candidatos; el tiempo que lleva el procedimiento; dónde y cuándo se lleva a cabo; el carácter voluntario de la validación; los resultados de aprendizaje a demostrar (preguntado sólo a los profesionales participantes en la evaluación) y la posibilidad de recurrir el resultado de la validación.

Los asesores de ambos procedimientos reflejan haber proporcionado bastante información sobre los puntos mencionados, a excepción del aspecto referente a la reclamación o recurso de la evaluación, sobre el que ambos han informado notablemente menos. En general, los EPV (asesores) de Emilia-Romagna han señalado haber dado más cantidad de información que los de Castilla y León.

No obstante los evaluadores, de ambos procedimientos, no tengan definidas funciones de información, debemos indicar que casi todos los encuestados de Castilla y León $(89 \%$ ) han indicado haber dado información sobre el procedimiento a los candidatos, frente a un bajo porcentaje de EAPQ (evaluadores) de Emilia-Romagna que lo ha hecho (37\%). Este bajo porcentaje en Emilia-Romagna puede deberse al hecho de que el EPV es quién tiene la función de informar y además se encuentra presente en la fase de evaluación.

Al contrario de lo que ocurre con los asesores, hemos observado que los evaluadores del procedimiento de Castilla y León han señalado haber proporcionado más información, en general, que los del procedimiento de Emilia-Romagna. Cabe señalar también que no han coincidido en los puntos sobre los que más han informado. Los evaluadores de Castilla y León han dado prioridad a informar sobre dónde se realizará la evaluación, la metodología y las tareas que debe realizar el candidato durante el proceso. Por el contrario, los EAPQ (evaluadores) de Emilia-Romagna, han informado más sobre las fases y los instrumentos de evaluación.

El análisis de encuestas también demuestra que los profesionales de ambos procedimientos, han coincidido en la importancia de informar también, a los candidatos, y así lo han hecho, sobre el significado de la validación y lo que supone (en cuanto a la estabilidad profesional). Los evaluadores del procedimiento castellanoleonés han proporcionado también información sobre las tres dimensiones de la competencia el "saber ser", el "saber hacer" y el "saber estar".

Sobre las vías utilizadas para proporcionar la información, consideramos más acertada, a la hora de dotar de transparencia el procedimiento, la 
más empleada por los profesionales encuestados del procedimiento de Castilla y León $(96 \%)$, la reunión personal. Por su parte, la mayoría de los profesionales encuestados del procedimiento italiano (65\%) se ha decantado por el marial impreso proporcionado por las entidades organizadoras.

Para dotar de transparencia al procedimiento, también es importante que se pueda recurrir el resultado del mismo. En este punto existe una disimilitud entre los procedimientos. La legislación relacionada con el procedimiento en Castilla y León, solamente prevé el procedimiento de reclamación de la evaluación, no del asesoramiento, aunque el resultado de este no sea vinculante y sea el propio candidato el que decide si pasar o no a la fase de evaluación. Por el contrario, aunque no se menciona en la legislación, en el procedimiento de Emilia-Romagna, es posible reclamar en cualquier momento del procedimiento. A pesar de ello, a través del análisis de los cuestionarios, los profesionales españoles han informado en mayor medida sobre la posibilidad de recurrir el resultado de evaluación que los italianos.

Tras el análisis de datos podemos concluir que la transparencia del procedimiento es un aspecto mejorable, tanto en la práctica de Castilla y León como en la de Emilia-Romagna. Sobre todo en cuanto a la información inicial del procedimiento, tanto a empresas y centros susceptibles de implementar el procedimiento como a posibles candidatos. Ya que una buena información inicial fomenta la confianza en el procedimiento.

\section{Igualdad}

Sobre el principio de igualdad de trato a todos los candidatos, marcado por las directrices europeas, cabe decir que se contempla en la legislación nacional de ambos procedimientos, aunque no se menciona en la legislación autonómica de Castilla y León y regional de Emilia-Romagna. La legislación nacional española aborda el tema con el trato de igualdad a los candidatos, a través de la propuesta del principio sobre el respeto de los derechos individuales y del principio de objetividad en el caso de la nacional italiana.

\section{Accesibilidad}

Según las directrices, el acceso al procedimiento de validación debe facilitarse todo lo posible para que pueda acceder al mismo el mayor número de personas. El acceso está más regulado, a través de la legislación, en el procedimiento de Castilla y León que en el de Emilia-Romagna. La legislación nacional española y sobre todo la autonómica de Castilla y León, detallan 
los documentos que deben entregar los candidatos para la inscripción en el procedimiento y los requisitos formativo-laborales que deben poseer para poder participar en el mismo. Sin embargo, esto no garantiza que el acceso al procedimiento de Castilla y León sea fácil, ya que a través de las declaraciones de los entrevistados y encuestados hemos detectado algunas complicaciones. Por ejemplo, los profesionales han mencionado en varias ocasiones las dificultades que han tenido los candidatos por la burocracia y para rellenar los documentos de acceso al procedimiento, en especial el CV europeo.

Por el contrario, el acceso al procedimiento de Emilia-Romagna no está regulado en la legislación, lo cual permite que los candidatos accedan al procedimiento presentando simplemente evidencias de las competencias que pretenden certificar. Esto facilita el acceso, sin embargo, la falta de unos criterios de entrada ha provocado problemas en un caso de masificación que hubo, como ha señalado uno de los entrevistados. Por otro lado, la accesibilidad en Emilia-Romagna es complicada en cuanto al costo que debe afrontar el candidato por la validación, sobre todo si se presenta de forma individual, ya que es este quién debe hacerse cargo del coste, debido, según la opinión de los entrevistados a la crisis económica que atraviesa el país. En el caso de España, el procedimiento ha sido gratis para el candidato, pero costoso para la administración, dado que en el momento del acceso todavía no se habían fijado las tasas, aunque sí están previstas en un futuro.

Otro aspecto importante concerniente al acceso, es el tipo de convocatoria que se realiza para llevar a cabo el procedimiento, como ya hemos mencionado, en Emilia-Romagna son los propios centros acreditados los encargados de poner en funcionamiento el procedimiento de validación. Sin embargo, en Castilla y León el procedimiento resulta más farragoso, ya que se convoca a través del BOCYL por orden ministerial, lo cual retrasa y dificulta las convocatorias. Esto genera enormes diferencias en cuanto al número de convocatorias entre Castilla y León y Emilia-Romagna. El problema de Castilla y León no ha pasado desapercibido por el gestor/organizador entrevistado, quién revindica un sistema como el que se está llevando a cabo en Emilia-Romagna.

Por tanto, el acceso sería mejorable en ambos procedimientos, en Castilla y León debería ser menos burocrático y más conciso. Por otro lado, en Emilia-Romagna tendría que estar más definido en cuanto a criterios de 
entrada. Asimismo, debería encontrar una vía de financiación para que acceder al procedimiento no suponga una barrera económica a los candidatos.

\section{Voluntariedad}

Las directrices europeas consideran importante que la participación en el procedimiento sea completamente voluntaria. Este es un aspecto que en el plano legislativo únicamente se refleja en la legislación nacional española, con el principio del respeto de los derechos humanos.

A través del análisis de los cuestionarios hemos comprobado que en general han informado más sobre el carácter voluntario los profesionales del procedimiento de Castilla y León que los del procedimiento de EmiliaRomagna. Cabe destacar que los asesores de ambos procedimientos han informado más sobre la voluntariedad que los evaluadores, lo cual sería lógico, teniendo en cuenta que es más usual proporcionar este tipo de información, sobre el procedimiento, en las fases iniciales.

\section{Personalización}

Las directrices europeas indican que el procedimiento debe enfocarse al individuo y organizarse en la medida de lo posible en torno a él. Según este principio, la orientación al candidato debe encontrarse presente durante todo el procedimiento, de forma transversal, y específicamente al finalizar el mismo para orientarle de manera personalizada hacia un futuro formativoprofesional.

La legislación relacionada con el procedimiento en Emilia-Romagna no es muy concreta en lo que a este aspecto se refiere, ya que hace una referencia general sobre la orientación, sin especificar si debe estar presente o no durante todo el procedimiento o de qué tipo debe ser. Por otro lado, la legislación relacionada con el procedimiento de Castilla y León garantiza un servicio abierto y permanente de información y orientación sobre el procedimiento, y también hace referencia a la orientación formativa, aunque no laboral.

Observando los resultados del análisis de encuestas, los asesores del procedimiento de Castilla y León han proporcionado más asesoramiento final que los EPV (asesores) del procedimiento de Emilia-Romagna. Además, los primeros se han centrado más en dar información relacionada con el ámbito formativo (las oportunidades y dificultades formativas), mientras que los segundos han dado más énfasis a la información sobre el ámbito laboral (salidas profesionales). 
La validación de competencias profesionales en España y en Italia

Como aspecto destacable cabe mencionar que, según datos obtenidos del análisis de cuestionarios, el 65\% de los EAPQ (evaluadores) del procedimiento de Emilia-Romagna ha proporcionado orientación/información al candidato al finalizar el procedimiento, a pesar de no estar contemplado entre sus competencias. Además, estos lo han hecho en mayor medida que los evaluadores del procedimiento de Castilla y León, en concreto, sobre los puntos fuertes del candidato y las dificultades formativas con las que podría encontrarse. Por su parte, los evaluadores de Castilla y León han dado más importancia a las oportunidades formativas, al igual que los asesores de su mismo procedimiento.

Sin embargo, los entrevistados de ambos procedimientos creen que la fase de orientación sería mejorable. Los profesionales del procedimiento de Emilia-Romagna consideran una debilidad del procedimiento la fase de orientación final, que han dado solo en caso de que los candidatos la hayan solicitado y no a todos. Los profesionales de Castilla y León creen que el aspecto de la orientación transversal no ha funcionado y que la orientación final debería mejorar en cuanto a explicitud y sencillez.

Por tanto, en el procedimiento de Emilia-Romagna la orientación final debería darse a todos los candidatos y hacer más hincapié en las posibilidades formativas, por otro lado, en el procedimiento de Castilla y León, la orientación transversal debe estar más presente y la final debería ser más concreta y también más dirigida a las posibilidades profesionales, además de a las formativas.

Otro de los aspectos relacionados con la personalización del procedimiento que piden las directrices europeas es la flexibilidad en el procedimiento.

Este argumento apenas tratado por la legislación analizada (a excepción de la legislación de Emilia-Romagna que habla de tener en cuenta la disponibilidad del candidato para el asesoramiento), parece indicar que este punto es pasado por alto. Sin embargo, a través del análisis de las encuestas comprobamos que en la práctica sí se ha tenido en cuenta. Los profesionales del procedimiento de Castilla y León, tanto asesores como evaluadores, han indicado haber sido más flexibles que los profesionales del procedimiento italiano. Los profesionales españoles han indicado conocer más la motivación y los objetivos del candidato para someterse a la validación. Según han comentado los profesionales entrevistados la principal motivación de estos era el miedo a perder el puesto de trabajo. Asimismo, han 
indicado conocer en mayor medida, que los profesionales de EmiliaRomagna, la situación personal y disponibilidad del candidato.

Tal vez el hecho de que algunos de los profesionales del procedimiento de Emilia-Romagna, sobre todo EAPQ (evaluadores), tengan menos conocimiento del candidato y por tanto mayor dificultad para ser flexibles con él, tenga relación con el hecho comentado en el marco teórico de esta tesis y por los entrevistados, sobre que los EAPQ suelen ser externos al centro formativo en el que se realiza el procedimiento y en estos casos, el contacto con el candidato no es muy prolongado (ver subapartado 4.3.8.3).

Otro aspecto a destacar es que, entre los EPV (asesores) del procedimiento de Emilia-Romagna que hemos encuestado, una amplia mayoría (en torno al 80\%) afirmó conocer al candidato ampliamente, mientras que tan sólo algo más de la mitad $(60 \%)$ reconoció tener en cuenta las condiciones y disponibilidad de los candidatos.

Asimismo, según el análisis de los cuestionarios, los asesores y evaluadores de Castilla y León han adaptado en mayor medida su lenguaje al candidato (en torno al 80\%) respecto a los profesionales del procedimiento de Emilia-Romagna, aunque estos también han indicado haberlo hecho (en torno al 65\%).

Por tanto, la flexibilidad ha sido un aspecto más presente en el procedimiento castellanoleonés que en el de Emilia-Romagna, en el que debería mejorar el contacto con el candidato, sobre todo con los profesionales externos al centro en el que se lleva a cabo el procedimiento de validación.

\section{Validez}

Según las directrices europeas, la validez es un principio fundamental para el éxito del procedimiento, ya que garantiza que la puesta en práctica del mismo sea adecuada.

Para asegurar la validez es necesario que la recogida y valoración de evidencias y la evaluación final se realicen adecuadamente. Del mismo modo, debe cuidarse la preparación de los profesionales que llevan a cabo estas actividades. Así como el cumplimiento de la función formativa de este procedimiento y que el procedimiento tenga una validez oficial en el territorio en el que se lleva a cabo.

La recogida y evaluación de evidencias debe hacerse a través de los instrumentos más apropiados para tal fin. 
La validación de competencias profesionales en España y en Italia

En cuanto a la legislación relativa a la validez, podemos decir que en el procedimiento de Castilla y León, la referida al asesoramiento y a la evaluación, es bastante completa. Por el contrario, en el procedimiento de Emilia-Romagna la legislación relativa a la validez en el asesoramiento es más extensa que la referida a la evaluación.

Respecto a las opiniones, por medio del análisis de cuestionarios comprobamos que, en general, los instrumentos de recogida y evaluación de evidencias definidos por ambos procedimientos han recibido una buena valoración por parte de los asesores encuestados, aunque ligeramente más alta por parte de los profesionales de Castilla y León.

Asimismo, hemos comprobado que existen algunas similitudes entre los instrumentos de recogida de evidencias de Emilia-Romagna con los de Castilla y León. El historial formativo/profesional de Castilla y León y los documentos formales de recogida de evidencias de Emilia-Romagna son muy parecidos, ya que en ambos casos se recoge información sobre las actividades desarrolladas en el puesto de trabajo. También en los dos casos se hacen entrevistas de asesoramiento. A pesar de estas semejanzas, el procedimiento de Emilia-Romagna ha definido un mayor número de instrumentos para la recogida de evidencias, respecto al procedimiento de Castilla y León, incluyendo también la recogida de evidencias de resultado (muestras del producto del trabajo).

No obstante la buena valoración de los instrumentos, algunos encuestados del procedimiento castellanoleonés $(17 \%)$ han indicado que deberían mejorarse los instrumentos, en cuanto al vocabulario utilizado en los mismos, y en los certificados de empresa, detallando más y mejor las funciones desarrolladas.

Asimismo, a través de las opiniones de los profesionales entrevistados de ambos procedimientos, hemos verificado que estos han seguido las pautas marcadas por la legislación correspondiente. Sin embargo, en el análisis de cuestionarios se ha detectado falta de unificación de criterios para la evaluación de evidencias en el procedimiento de Castilla y León. También los EPV (asesores) del procedimiento de Emilia-Romagna han encontrado dificultades en la evaluación de evidencias.

En cuanto a los instrumentos de la fase de evaluación, podemos decir que los profesionales encuestados de ambos procedimientos se han mostrado bastante o totalmente de acuerdo en la validez de estos (teniendo en cuenta si medían las competencias del candidato correctamente, permitían la 
autoevaluación, medían las tres dimensiones del saber de la competencia y recreaban correctamente el contexto de trabajo en caso de simulación).

El alto porcentaje sin contestar sobre la capacidad de recrear el contexto de trabajo por parte de los instrumentos, en todos los profesionales encuestados, nos hace intuir que muchos de ellos no han utilizado la simulación. Uno de los evaluadores entrevistados del procedimiento de Castilla y León lamenta este hecho, ya que considera que es un buen instrumento y el más completo. Sin embargo el procedimiento no prevé que sea obligatorio y ante buenas evidencias no realizan la evaluación, para aligerar y ahorrar tiempo y costes.

Sobre las dimensiones del saber (el "saber", el "saber hacer" y el "saber estar") que deben ser capaces del medir los instrumentos, para ser adecuados, en la competencia del candidato, el procedimiento de Castilla y León prevé medir las tres dimensiones, a las que otorga una gran importancia, indicándolo también en la legislación. En Emilia-Romagna, el tercer aspecto no se contempla directamente ("saber estar"). Según explica un gestor organizador de Emilia-Romagna no se miden competencias transversales relacionadas con el "saber estar" sino competencias más profesionales en relación al "saber" y "saber hacer", aunque reconoce que algunas figuras si tienen incluidas competencias transversales.

Prueba de que la dimensión del "saber estar" también se encuentra presente en la evaluación del procedimiento de Emilia-Romagna, es que los encuestados participantes en esta evaluación han indicado, en un alto porcentaje, que efectivamente los instrumentos han medido esta dimensión. No obstante, hay que señalar la discrepancia existente entre las respuestas de los EPV (asesores) y de los EAPQ (evaluadores), ya que en torno al $90 \%$ de los primeros se muestran de acuerdo con que los instrumentos logran medir bastante o mucho esta dimensión. Por el contrario, menos del 60\% de los EAPQ (evaluadores) lo considera de este modo. Dado que ambos profesionales se encuentran presentes en la evaluación, esta diferencia nos resulta llamativa. Esto podría explicarse con que estos tienen una visión diferente sobre el saber estar, ya que son dos tipos diferentes de profesionales. Asimismo, los evaluadores del procedimiento de Castilla y León afirman en gran porcentaje (85\%) la medición de este "saber estar" por parte de los instrumentos. Sin embargo, el saber que mejor logran medir los instrumentos según todos los participantes en la evaluación de ambos procedimientos ha sido el "saber hacer". También cabe mencionar que en el procedimiento 
La validación de competencias profesionales en España y en Italia

de Emilia-Romagna se ha valorado mejor la medición del "saber", por lo que otorgarían más importancia a evaluar el saber teórico que en Castilla y León.

Resulta paradójico que el procedimiento de Emilia-Romagna no contemple de manera explícita la evaluación del saber estar, teniendo en cuenta que Italia ha mantenido una discusión más amplia que España sobre la definición de dimensiones de la competencia, aunque como hemos podido comprobar si lo hace de forma implícita.

Otra dimensión que consideramos importante, es la del "poder hacer", es decir, el contexto (ver apartado 2.1). Para poder llebar a cabo una acción profesional es imprescindible contar con un espacio y unos materiales. Así pues, sobre este aspecto debemos mencionar que el análisis de entrevistas y de cuestionarios ha desvelado varias propuestas de mejora en cuanto a los espacios físicos en los que se realiza la evaluación. Tanto evaluadores de Castilla y León como de Emilia-Romagna han indicado que no todos los centros en los que se lleva a cabo la evaluación ofrecen buenos espacios y materiales para ello.

Sobre la autoevaluación, en ambos procedimientos la mayoría de los profesionales está bastante y totalmente de acuerdo con que los instrumentos han permitido la autoevaluación al candidato, aunque llama la atención el porcentaje de profesionales poco o nada de acuerdo (la suma de estas respuestas sobrepasa el $30 \%$ en todos los casos). Quizás esto tenga que ver, al menos en el caso español, con que algunos encuestados han comentado entre las posibles mejoras, utilizar un lenguaje más coloquial en los cuestionarios.

Siendo más específicos en relación a los instrumentos de evaluación, hemos comprobado con el análisis de cuestionarios que, al contrario de lo que ocurre con los instrumentos del proceso de asesoramiento, esta vez es el procedimiento de Castilla y León el que prevé más instrumentos para la evaluación que el de Emilia-Romagna. En esta ocasión también encontramos similitudes con algunos instrumentos utilizados en ambos territorios. En los dos casos se utiliza la entrevista profesional estructurada; la observación en el puesto de trabajo y en un contexto de trabajo simulado; así como las pruebas escritas tipo test.

Del análisis de cuestionarios emergen valoraciones bastante positivas y similares, otorgadas a estos instrumentos por los profesionales de ambos procedimientos. 
La entrevista estructurada con fines de evaluación ha sido muy bien valorada por todos los profesionales encuestados de ambos procedimientos. Así como la observación de la práctica a través de una simulación, que también ha obtenido una buena valoración por parte de todos los profesionales encuestados que han hecho uso de ella. Por el contrario, la observación en el puesto de trabajo ha obtenido una valoración más baja por parte de todos los profesionales encuestados. Como disimilitud entre los profesionales de uno y otro procedimiento, señalamos que mientras los evaluadores de Castilla y León han considerado de gran utilidad los test, los EPV (asesores) y EAPQ (evaluadores) de Emilia-Romagna se muestran menos satisfechos al respecto.

Asimismo, hemos detectado posibles mejoras en los instrumentos de evaluación, según los evaluadores de Castilla y León, sería interesante utilizar un lenguaje más coloquial en algunos instrumentos. Por su parte los EAPQ (evaluadores) de Emilia-Romagna, hacen mayor hincapié en evaluar las competencias del "saber estar", para ello, uno de ellos propone el uso del balance de competencias (ver subapartado 4.3.6.2). Los evaluadores de los dos procedimientos coinciden en que son necesarios criterios de evaluación e instrumentos mejor definidos y detallados y también plantean la informatización de algunos de ellos, como en el caso del historial formativo/profesional, en el procedimiento español, con la intención de facilitar su compilación al candidato.

Respecto a la metodología de evaluación, hemos comprobado a través del análisis legislativo y de entrevistas, que son las comisiones de evaluación las encargadas de elaborar la metodología para la evaluación en los dos casos. Asímismo, hemos confirmado que en ambos procedimientos se ha usado variación y combinación de métodos según el candiadato y las UC a evaluar. No obstante, se han detectado también algunos fallos en cuanto a este aspecto. Respecto al procedimiento Castellanoleonés, el gestor/organizador ha indicado que fue necesario reconducir la metodología de evaluación en algunos casos, porque se estaban centrando en evaluar como en el campo formal, es decir, contenidos teóricos. Uno de los problemas que nos señala es que desde la Administración simplemete pueden aconsejar pero no modificar lo que decidan las comisiones de evaluación. Asimismo, algunos profesionales entrevistados de EmiliaRomagna, han indiado que las pautas metodológicas resultaban restrictivas y complicadas. 
La validación de competencias profesionales en España y en Italia

Ambos procedimientos basan el análisis de evidencias y la evaluación en estándares/referentes, que en los dos casos son la unidad de competencia. Asimismo, definen los resultados de aprendizaje que debe realizar el candidato, en realizaciones profesionales en Castilla y León y en actividades que deben realizar en Emilia-Romagna

En el caso español, dichas UC se encuentran dentro del CNCP mientras que en el caso italiano, las UC pertenecen al SRQ, es decir a un catálogo nacional y no regional. Sin embargo ambos catálogos están relacionados con sus correspondientes Marcos Nacionales de Cualificaciones.

Cabe decir también que en el procedimiento de Emilia-Romagna hemos encontrado, a través del análisis de entrevistas y de encuestas, una falta de coherencia entre las UC descritas en el catálogo con las actividades profesionales que efectivamente se realizan en el mundo laboral. Asimismo, hemos comprobado la preocupación de los dirigentes del procedimiento en cuanto a la unificación de estándares profesionales en todo el territorio italiano, debido a la heterogeneidad que existe en las cualificaciones de las diferentes regiones. Del mismo modo hemos detectado, en el procedimiento de Castilla y León, malestar por parte de los encuestados en cuanto a la estructura del procedimiento, ya que consideran el asesoramiento demasiado complejo para el poco tiempo en el que tienen que llevarlo a cabo. Además, varios evaluadores se quejan del solapamiento que suele ocurrir entre la fase de asesoramiento y evaluación, lo que dificulta el buen funcionamiento del procedimiento.

Otro argumento que consideramos importante para ofrecer validez en el procedimiento es el de la adecuada formación de los profesionales que participan en este. Hemos constatado que en ambos casos se piden unos requisitos descritos en la correspondiente legislación, sobre experiencia laboral y formación. Sin embargo, la formación continua se contempla poco en el ámbito legislativo del procedimiento de Castilla y León y nada en el de Emilia-Romgana.

Según el análisis de las entrevistas, todos los asesores y evaluadores de ambos procedimientos son preparados a través de un curso de formación, pero de momento no se está realizando formación continua. En el caso de Emilia-Romagna el curso de formación que se lleva a cabo no es mencionado por la legislación y también se encarga de formar a los referentes del procedimiento de validación (RFC). 
A través del análisis de los cuestionarios hemos comprobado la percepción que tienen los profesionales en los dos casos estudiados, sobre su conocimiento en cuanto a aspectos relacionados con el procedimiento de validación, de forma general (sistema educativo-formativo; catálogo de cualificaciones; requisitos para solicitar una cualificación; legislación y normativa; condiciones del mercado local, regional, nacional) y de forma específica sobre el procedimiento (fases; funcionamiento; rol de los participantes; legislación; criterios, normas e instrumentos de evaluación).

Constatamos que todos los encuestados afirman poseer un conocimiento bastante amplio sobre todos los aspectos por los que hemos indagado, a excepción, en ambos casos, de las condiciones nacionales del mercado laboral, en las que se registran porcentajes más bajos por parte de todos los profesionales, y de las condiciones regionales, solo por parte de los evaluadores de ambos procedimientos.

Otro aspecto sobre el que los asesores y evaluadores han indicado tener un bajo conocimiento ha sido el relacionado con otros sistemas de validacion.

Tanto los evaluadores del procedimiento de Castilla y León, como los del procedimiento de Emilia-Romagna hacen hincapié en mejorar la formación de los profesionales del procedimiento. En torno al 5\% de los encuestados en Castilla y León quieren mejorar la formación de asesores y evaluadores para evaluar mejor aspectos técnicos de las competencias del candidato. Por su parte, el 10\% de los EAPQ (evaluadores) de EmiliaRomagna, han criticado que en muchas ocasiones esta figura (EAPQ) no es del todo objetiva realizando las evaluaciones. Puede que este hecho influya en el aspecto comentado con anterioridad, relacionado con la forma de los EAPQ de entender de forma diferente a los EPV (asesores) el "saber estar" También los gestores/dirigentes y el referente del proceso (RFC) han hecho incidido en la necesidad de mejorar la formación de los expertos (EPV y EAPQ) ya que son la base del buen funcionamiento de la formalización y certificación.

La formación de los profesionales podría mejorarse en los dos procedimientos, sobre todo la relativa a la formación continua, enfocada a mejorar la forma y objetividad a la hora de evaluar al candidato.

Que el procedimiento sea válido también depende de que se logre el objetivo de ayudar al candidato a reinsertarse en el mundo formativo. 
La validación de competencias profesionales en España y en Italia

La legislación relativa al procedimiento castellanoleonés contempla este aspecto, tanto en la legislación nacional como en la autonómica, hablando de un plan formativo para los candidatos. Asimismo, el gestor organizador entrevistado en Castilla y León opina que el procedimiento tiene un gran valor en cuanto al carácter formativo. Sin embargo, los evaluadores y uno de los asesores discrepan de dicha función formativa, indicando que el espíritu de la formación permanente en los candidatos no ha cuajado y que se debe mejorar este aspecto. En cuanto al caso italiano, tras el análisis documental y de entrevistas, hemos comprobado que este aspecto ha sido obviado. Podemos decir que en opinión de los profesionales, este importante aspecto ha sido descuidado por parte de los dos procedimientos. Ambos deberían centrarse en recuperar el objetivo formativo del procedimiento e impulsar el aprendizaje permanente, ya que este podría contribuir en gran medida a mejorar las cualificaciones de los ciudadanos de Castilla y León y de Emilia-Romagna.

Por último, para terminar con este principio sobre validez, mencionamos que la certificación que se entregue al candidato al finalizar el procedimiento debe tener una validez oficial para que esta tenga un valor real. Ambos procedimientos cuentan con órganos habilitados para emitir y registrar las certificaciones tras la evaluación, la Administración General del Estado, el Ministerio de Trabajo e Inmigración ${ }^{110}$ y el Ministerio de Educación $^{111}$ en el caso de Castilla y León y la Regione de Emilia-Romagna, en el procedimiento de Emilia-Romagna. Además, toda la legislación analizada dota la certificación de validez nacional en el caso de Castilla y León y de validez regional en el caso de Emilia-Romagna (que además tiene correspondencias con los títulos definidos en ámbito nacional). La validación supone, en ambos procedimientos, la entrega de títulos formales o parte de ellos, por lo que tienen el mismo estatus y validez que estos. Sin embargo, como podemos comprobar, en este aspecto existen dos disimilitudes importantes, en Castilla y León se otorga una certificación válida en todo el territorio nacional y en Emilia-Romagna por el contrario, la certificación es válida en ámbito regional. Por otro lado, el procedimiento de Castilla y León en caso de que el candidato haya obtenido un título o certificado de profesionalidad formal, deben solicitarlo, fuera del procedimiento, a la administración correspondiente. Por el contrario, en Emilia-Romagna, es el

110 Actualmente denominado Ministerio de Empleo y Seguridad Social.

111 Actualmente denominado Ministerio de Educación, Cultura y Deporte. 
propio procedimiento el que entrega directamente el título formal en caso de haberlo logrado.

Concluimos diciendo que el procedimiento de Castilla y León debería facilitar la entrega de títulos/certificados de profesionalidad formales. El aspecto a mejorar por Emilia-Romagna sería más complicado, ya que no podrán dotar de validez nacional las certificaciones hasta que Italia logre crear un sistema nacional de validación o por lo menos hasta que consiga homogeneizar y unir las cualificaciones regionales en un catálogo nacional de cualificaciones.

\section{Fiabilidad}

Siguiendo las directrices europeas, consideramos fiable el procedimiento de evaluación si el método y los instrumentos logran que dos candidatos de características similares obtengan resultados parecidos. A partir del análisis de los cuestionarios, comprobamos que la mayoría de los profesionales de ambos procedimientos, participantes en la evaluación, opinan que los candidatos de características similares no han obtenido resultados muy diferentes, por lo que lo que existiría fiabilidad en los procedimientos. Sin embargo existe una diferencia sustancial entre los porcentajes de los profesionales de los dos procedimientos. En Castilla y León el 73\% opina que la evaluación es fiable, por otra parte, en torno al 51\% de los profesionales encuestados en Emilia-Romagna ha indicado fiabilidad en la evaluación, aunque este porcentaje alcanza el 50\% debería mejorar.

En caso de que estos candidatos hayan obtenido resultados muy diferentes, los profesionales de ambos procedimientos, atribuyen este hecho, en su mayoría, a aspectos personales del candidato (motivación para someterse a la evaluación, nerviosismo, estrés por el momento de la evaluación o saber estar del candidato). Algunos profesionales de Emilia-Romagna han atribuido dichas diferencias a aspectos relacionados con la cultura o el dominio de la lengua, por lo que debería mejorarse la comunicación con los candidatos de diferente cultura y/o lengua. Solo un encuestado ha atribuido la diferencia de resultados a la subjetividad del evaluador.

Asimismo, los profesionales de los dos procedimientos cuentan con material de apoyo para dotar de fiabilidad la validación de competencias. Se trata de las guías de asesor, evaluador y de evidencia, en el caso de Castilla y León, y de las directrices y pautas que se dan para recoger y evaluar con precisión competencias, en el caso de Emilia-Romagna (las DGR 530/2006 y 739/2013). 
La validación de competencias profesionales en España y en Italia

A través del análisis de los cuestionarios comprobamos que los profesionales de los dos procedimientos valoran muy bien, en cuanto a utilidad, estos instrumentos. En torno al 90\% de los asesores de Castilla y León considera que la guía del asesor es bastante o muy útil. EL $87 \%$ de los evaluadores, de este procedimiento, también valoran bastante positivamente la guía del evaluador, aunque la guía de evidencias ha obtenido una mejor valoración ( $92 \%$ bastante o muy útil). Por su parte, los profesionales de Emilia-Romagna, tanto los EPV (asesores) como los EAPQ (evaluadores) encuestados, han utilizado dos deliberaciones, por el cambio que se está produciendo de una a otra, la más usada por ambos ha sido la nueva DGR 739/2013. Las dos deliberaciones han obtenido una valoración bastante buena pero los profesionales discrepan a la hora de decantarse por una u otra. Los EPV (asesores) prefieren la nueva (DGR 739/2013), considerada por el $71 \%$ como muy útil, mientras que los EAPQ (evaluadores) consideran más útil la antigua (DGR 530/206), valorada por el 47\% como bastante y por otro $47 \%$ como muy útl. Esto podría ser así, porque según han manifestado algunos EAPQ entrevistados y encuestados, los cuadros de evaluación que ofrece la DGR 739/2013 son bastante restrictivos.

Cabe señalar también, respecto a este material de apoyo para los profesionales, una disimilitud encontrada en el análisis documental. Las guías de evidencia del procedimiento castellanoleonés definen en detalle la evaluación de cada cualificación existente en el catálogo de cualificaciones, mientras que el material de Emilia-Romagna solo ilustra algunos ejemplos de evaluación de algunas cualificaciones. Por lo que en Castilla y León los instrumentos de apoyo están más definidos que en Emilia-Romagna.

Para que el procedimiento sea fiable necesita pasar un control de calidad que se asegure de que las prácticas se realizan correctamente.

Sobre este aspecto encontramos diferencias entre ambos procedimientos. En Castilla y León la legislación relacionada habla de llevar a cabo este control. Sin embargo, todos los entrevistados han dicho que no ha tenido lugar o han hecho referencia a otros aspectos como la trazabilidad o la coordinación cuando se les ha preguntado por el control. Por el contrario, la legislación regional de Emilia-Romagna habla de realizar la práctica del procedimiento de forma experiencial para estudiar el funcionamiento y proponer mejoras, lo cual se ha materializado con la creación de la DGR $739 / 2013$. 
Por tanto, en cuanto al control, el procedimiento de Castilla y León debería mejorar, poniendo en práctica algún tipo de evaluación del procedimiento que ayude a detectar fallos en la práctica y a garantizar el buen funcionamiento del mismo

\section{Seguridad y confidencialidad}

La privacidad y confidencialidad en el procedimiento es un aspecto que apenas se trata en la legislación relativa a ambos procedimientos. Solo la legislación relacionada con el procedimiento de Castilla y León indica que el resultado de la evaluación debe ser confidencial y comunicado por el evaluador.

Tras el análisis de los cuestionarios y de las entrevistas, podemos decir que la privacidad se respeta en un porcentaje bastante alto en los dos procedimientos. Los entrevistados y la mayor parte de los encuestados (asesores y evaluadores), de los dos procedimientos, ha utilizado vías de comunicación del resultado que garantizan la confidencialidad (reunión personal, correo personal, llamada personal). No obstante, también se han detectado en un pequeño porcentaje, en el procedimiento de Emilia-Romagna, vías que no garantizan del todo la privacidad de los resultados (reunión grupal, correo colectivo, o tablón de anuncios).

En la comunicación de resultados encontramos otra de las diferencias entre ambos procedimientos, ya que en Castilla y León el encargado de transmitir el resultado de la evaluación es el evaluador y por el contrario en Emilia-Romagna lo hace el EPV (asesor).

Respecto a la seguridad y confidencialidad podemos decir que el procedimiento de Emilia-Romagna debería eliminar las vías de comunicación que no garantizan la confidencialidad del resultado y utilizar más reuniones, llamadas o cartas personalizadas.

\section{Coordinación}

Las directrices consideran importante la coordinación de los profesionales que trabajan en el procedimiento, para que exista coherencia y corrección en las prácticas de validación.

En el caso español, la legislación nacional española contempla este aspecto con el principio de coordinación, el cual asegura la máxima eficacia y eficiencia en la implementación del procedimiento. Por el contrario, en el caso italiano, la legislación regional de Emilia-Romagna es más específica 
que la española, otorgando el papel de coordinador del procedimiento al responsable de la formalización y certificación de competencias (RFC), profesional nombrado por el centro organizador del procedimiento.

Sin embargo, a través del análisis de entrevistas, comprobamos que en el procedimiento de Castilla y León, existe la figura del coordinador provincial, encargado de transmitir información entre consejerías y unificar criterios de evaluación, aunque uno de los asesores ha comentado la poca presencia de este (solo en las reuniones iniciales de las convocatorias). Por otro lado en Emilia-Romagna, el análisis de entrevistas muestra que, el RFC es considerado como un supervisor del procedimiento y también uno de los entrevistados indica no haber notado mucho seguimiento por su parte.

A pesar de que ni la legislación, ni la práctica de los procedimientos analizados prevén encuentros entre profesionales para mejorar el desarrollo del procedimiento, los asesores y evaluadores de Castilla y León y de Emilia-Romagna entrevistados consideran muy útiles este tipo de encuentros. La mayoría de estos profesionales afirma haberse reunido con otros participantes en el procedimiento, para consultar dudas que surgen durante el procedimiento, aunque todos han negado que estén previstas reuniones para mejorar el procedimiento.

No obstante, el análisis de los cuestionarios demuestra que han sido bastantes los profesionales encuestados que han realizado reuniones para mejorar el procedimiento, a pesar de no estar previstas. Los encuestados del procedimiento de Castilla y León han indicado en mayor medida que los del procedimiento de Emilia-Romagna haber hecho este tipo de encuentros ( $96 \%$ de los asesores y el $87 \%$ de los evaluadores españoles). Por el contrario, el porcentaje de EPV (asesores) de Emilia-Romagna que han llevado a cabo estas reuniones es del 64\% y el de los EAPQ (evaluadores) desciende al 37\% (ver Figura 48). Sin embargo, coincidiendo con los profesionales entrevistados, casi todos los profesionales consideran que sería muy útil realizar este tipo de reuniones (en tonto al 90\%, ver Figura 49).

Del análisis de cuestionarios también emerge el descontento en relación a la coordinación en ambos procedimientos. Un alto porcentaje de las figuras entrevistadas (asesores y evaluadores) consideran que debería mejorarse la coordinación del procedimiento, de hecho, este aspecto ha sido el más mencionado cuando se les ha preguntado acerca de posibles mejoras para optimizar la práctica del procedimiento. Los profesionales proponen más encuentros y trabajo en equipo entre todos los profesionales, para con- 
tribuir a unificar criterios de valoración y a facilitar y agilizar todo el procedimiento.

Por tanto podemos concluir, que el aspecto de la coordinación es un aspecto que debería mejorar en ambos procedimientos, organizando encuentros entre profesionales, dirigidos a compartir experiencias y problemas surgidos en la práctica, así como criterios para valorar evidencias o evaluaciones finales, con el objetivo de optimizar las prácticas de validación.

\section{Trazabilidad}

Es importante que quede constancia del procedimiento a través de la documentación de las actividades realizadas para facilitar un control del procedimiento y un posible recurso o reclamación por parte del candidato.

Este aspecto se contempla en la legislación referida al procedimiento de Castilla y León, indicando que por cada actividad de evaluación deberá quedar un registro firmado por el candidato y el evaluador. Asimismo menciona que se generará un expediente que recoja todos los registros y resultados producidos a lo largo del procedimiento. Por el contrario, la legislación referente al procedimiento de Emilia-Romagna no hace referencia a este tema.

Sin embargo a través de las entrevistas, comprobamos que ambos procedimientos realizan este paso. Dejando registro de las actividades realizadas en el procedimiento, en Emilia-Romagna también, de hecho en Emilia-Romagna queda registrado a través de un sistema informático que ordena cronológicamente los documentos.

Algunos de los asesores encuestados en Castilla y León han manifestado un cierto descontento en cuanto a este proceso, ya que consideran excesiva la documentación a presentar, para optimizar el registro proponen digitalizar el proceso con aplicaciones informáticas que faciliten el trabajo. Asimismo el gestor dirigente menciona que no le llega toda la documentación hasta que el procedimiento termina, por lo que podría ser una buena idea digitalizar este proceso, como ocurre en Emilia-Romagna. 
La validación de competencias profesionales en España y en Italia

\subsection{Aportaciones y prospectiva}

En los últimos años, la creciente importancia de los procedimientos de validación en ámbito europeo, sobre todo desde la Cumbre de Lisboa en el año 2000, ha motivado la implementación de estas prácticas en numerosos países europeos.

Sin embargo, la heterogeneidad de los sistemas educativo-formativos y la forma de entender el aprendizaje permanente en los diferentes países europeos deriva en el desarrollo de sistemas de validación diferentes entre sí. Es por ello que se hace necesario conocer y comparar experiencias de validación de los países europeos, con la intención de ofrecer diferentes perspectivas y referencias del procedimiento (Cedefop, 2009).

Por este motivo, en esta investigación presentamos un estudio comparado sobre dos procedimientos europeos de validación de aprendizajes no formales e informales. En particular, esta investigación desgrana y detalla la práctica de validación en Castilla y León (España) y en Emilia-Romagna (Italia), dentro de sus correspondientes marcos educativo-formativos.

Con el fin de realizar la comparación de ambos procedimientos, hemos elaborado una matriz comparativa siguiendo las pautas de las directrices europeas, y adaptándola según las características de estos dos procedimientos de validación, ofrecemos la base para realizar un control/seguimiento para prácticas europeas de naturaleza similar.

De igual modo, con la creación de cuestionarios dirigidos a los principales profesionales del procedimiento, asesores y evaluadores, proporcionamos la base de una herramienta para indagar en el funcionamiento de otros procedimientos de validación similares.

Este trabajo, que se proyecta principalmente a personas implicadas en la investigación relacionada con la validación de competencias profesionales, permite abrir nuevas e interesantes líneas de investigación. En primer lugar, consideramos que nuestra metodología se puede extrapolar para llevar a cabo estudios comparados entre las prácticas de validación de otros países europeos o no europeos, con la idea de conocer otras experiencias que ayuden a unos y a otros a mejorar en su forma de llevar a la práctica el procedimiento. 
En segundo lugar, la investigación ha podido revelar que existe una creciente necesidad de elaborar estrategias que ayuden a mejorar la difusión de información sobre este tipo de procedimientos, dependiendo del ente, sujeto, o persona que los recibe, con el objetivo de proporcionar confiabilidad en este tipo de prácticas.

Por último, los resultados el estudio, y en particular las entrevistas y cuestionarios, muestran que es posible, y necesario, elaborar estrategias de coordinación y de control de calidad para los procedimientos de evaluación, con la intención de optimizar la validación de aprendizajes no formales e informales. 



\section{Resumen en italiano}


La validación de competencias profesionales en España e Italia

\subsection{Introduzione}

La globalizazione e il continuo cambio che prevale nelle nostre vite stanno causando cambiamenti nei processi tecnologici e di produzione, così come l'avanzamento continuo della società dell'informazione.

Come conseguenza di tutto ciò, l'Unione Europea (da adesso in poi UE), ha cominciato a orientare il suo lavoro verso lo svillupo di cittadini attivi e qualificati. Per ciò, nel Consiglio di Lisbona, dell'anno 2000, la UE ha riconosciuto l'importanza della educazione nelle politiche economiche e sociali per aumentare la competitività del suo mercato del lavoro. Alla luce di tutto ciò la UE ha proposto, agli Stati membri, la sfida di basare l'economia sulla conoscenza e farla diventare la più competitiva e dinamica al mondo. Una delle strategie per raggiungere questo obbiettivo è quella del lifelong e lifewide learning, che riconosce e concede un grande valore al apprendimento lungo tutto l'arco della vita: apprendimento che si svolge e si sviluppa, cioè, durante tutta la vita della persona (lifelong) e in tutti gli ambiti in cui essa si muove (lifewide).

In base a questa idea, siamo nella condizione di esperire apprendimenti acquisti in ambiti al di là della formazione formale, tra cui quello professionale.

L'UE ha proposto la validazione e certificazione di competenze acquisite attraverso l'esperieza lavorativa o i percorsi non formali e informali, con l'obbiettivo di favorire ai cittadini l'accesso al mondo del lavoro, l'apprendimento lungo tutto l'arco della vita, la mobilità e la coesione sociale. Nello stesso modo, ha fatto la richiesta, ai paesi menbri dell'UE, di mettere in pratica, al massimo nel 2018, le risorse necessarie per realizzare questo tipo di pratiche (Recomendación del Consejo, 2012).

Così, i paesi della UE hanno incominciato a lavorare alla messa in pratica dei dispositivi di validazione di competenze professionali. L'UE ha pubblicato le linee guida da seguire per cercare di concedere omogeneità $\mathrm{e}$ validità a queste procedure, inoltre, incoraggia costantemente i paesi della Unione a fare degli studi comparati sulle diverse procedure, con l'intenzione di offrire diverse perspective e riferimenti della procedura (Cedefop, 2009). 


\subsection{Quadro teorico di riferimento}

Il nostro studio si colloca all'interno del quadro dell'apprendimento lungo tutto l'arco della vita, in cui interagiscono due dimensioni, tra cui una è riferita all'apprendimento nelle diverse tappe della vita, non solo nell'infanzia e nella giovaneza. Da un'altra parte, troviamo la dimensione trasversale, essa è in rapporto con gli apprendimenti che hanno luogo in tutti i contesti della vita (formali, non formali e informali) in cui si includono, tra gli altri, il tempo libero e il 1 lavoro.

Grazie alla spinta dell'UE, attraverso la valorizzazione di questo tipo di apprendimenti, dall'anno 2000, la creazione di sistemi di validazione delle competenze acquisite in ambiti non formali e informali è in aumento. Alcune aree europee hanno raggiunto progressi significativi, soprattutto riguardo alla strategia, ai quadri normativi, all'incorporazione della validazione nei sistemi di qualificazione, al collegamento con i quadri nazionali di qualifiche e alla creazione di sinergie con dei sistemi di crediti, nei paesi dove i dispositivi di validazione sono in corso, e al coinvolgimento delle parti interessate in questi sistemi di validazione.

Anche se in generale ci sono stati dei grandi progressi rispetto alle politiche di validazione, nella pratica l'evoluzione è stata più lenta, poichè nella magior parte dei paesi ci sono delle barriere socioeconomiche, che rendono difficile un'importante crescita in questo campo (European Commission et al., 2014).

Spagna e Italia sono due nazioni che hanno quadri educativoformativi simili e hanno sviluppato un discorso teorico sulle competenze non formali e informali che si assomiglia. Per questo, tra altri motivi, sono oggetto di analisi nella nostra ricerca, riguardo all'implementazione dei loro rispettivi dispositivi di validazione delle competenze professionali.

\subsubsection{Bibliografía COLLEGATA ALLO STUdio}

Ci sono alcuni studi riguardanti al nostro tema di ricerca, tra cui:

- Making learning visible: identification, assessment and recognition of non-formal learning in Europe, pubblicato da Björnavåld nel anno 2000: questa pubblicazione verte sul come fare più visibile l'apprendimento che 
La validación de competencias profesionales en España e Italia

ha luogo al di là dell'educazione e della formazione formale (Jens Bjørnavold, 2000);

- L'Inventario Europeo sulla convalida dell'apprendimento non formale e informale: viene effettuato con periodicità (per ora sono stati presentati 5 rapporti, nel 2004, nel 2005, nel 2008, nel 2010 e nel 2014). La sua funzione è fornire delle informazioni sulle pratiche europee di individuazione, evidenziazione, valutazione $\mathrm{e}$ certificazione delle competenze provenienti dagli apprendimenti non formali e informali (European Commission et al., 2014, pp. 3 4);

- The unfinished story of VPL. Valuation \& Validation of Prior Learning in Europes learning cultures, nel 2005: questo libro vuole mostrare l'esistenza di una base solida per offrire un approccio più rivolto alla persona, nell'apprendimento e nel lavoro. Cioè, creare una strategia personale per l'apprendimento permanente (Duvekot et al., 2005).

- Recognising Non-Formal and Informal Learning: Outcomes, Policies and Practices, realizzato da Werquin nel 2010: questo libro è l'esito dello studio della OECD, sul riconoscimento degli apprendimenti non formali e informali. Il documento cerca di mostrare una prospettiva interna dei 22 paesi oggetto di studio. Descrive le caratteristiche nazionali, secondo i rapporti degli stessi paesi, e allo stesso tempo fornisce delle informazioni sulle loro pratiche (Werquin, 2010).

- Quality in validation in the nordic countries. Final report for "Quality in the Nordic Countries - A Mapping Project": si tratta di un progetto sviluppato nel 2012 dai paesi nordici: Islanda, Norvegia; Svezia; Finlandia e Danimarca. Questo progetto vuole migliorare la trasparenza e la garanzia di qualità nelle procedure di validazione delle competenze non formali e informali nelle pratiche locali e nazionali. Per ciò mostra le pratiche specifiche di validazione e come conducono alla qualità nella validazione (Dahler \& Grunnet, 2012).

- Linee guida Europee del 2009 per la convalida degli apprendimenti non formali e informali, pubblicate dal Cedefop: questo documento include delle linee guida per garantire la qualita nella validazione e mette a fuoco il bisogno di conoscere altre pratiche di valutazione in altri paesi (Cedefop, 2009). 


\subsection{Obbiettivi della ricerca}

\subsubsection{OBIETTIVO GENERALE}

- Paragonare l'impianto del dispositivo di validazione e certificazione delle comeptenze professionai nella comunità autonoma di Castilla y León (Spagna) e nella Regione di Emilia-Romagna (Italia), per individuare somiglianze e differenze fra di loro, secondo le Linee guida Europee sulla convalida degli apprendimenti non formali e informali.

\subsubsection{OBJETTIVI SPECIFICI}

- Individuare la struttura dei sistemi educativi e di formazione professionale in Spagna, in Castilla y León e in Italia, nell'EmiliaRomagna, per conoscere la loro organizzazione e il loro funzionamento, al fine di capire meglio il sistema di validazione di competenze in embrambi i territori.

- Confrontare il modo di intendere la terminologia riferita alla validazione delle competenze professionali, in Spagna e in Italia, per capire l'importanza e l'approccio che questi due paesi attribuiscono alla procedura di validazione.

- Caratterizzare l'impianto dei sistemi di validazione e certificazione delle competenze professionali in Spagna, in Castilla y León, in Italia, in Emilia-Romagna, per conoscere le misure legislative e le esperienze realizzate al riguardo.

- Valutare l'impianto dei dispositivi della validazione e certificazione delle competenze professionali, in Castilla y León ed EmiliaRomagna, da una prospettiva europea, attraverso una matrice comparativa, creata dallo studio delle Linee guida Europee del 2009, sulla validazione degli apprendimenti non formali e informali, per stabilire somiglianze e differenze fra i due dispositivi. 
La validación de competencias profesionales en España e Italia

\subsection{Metodologia}

Nella nostra ricerca, la natura dei dati determina che alcuni di questi siano trattati qualitativamente ed altri quantitativamente, per ciò abbiamo deciso di utilizzare entrambi gli approcci, in maniera complementare, seguendo il paradigma olistico. Secondo questo paradigma, la ricerca è composta da otto fasi: descrittiva, comparativa, analitica, esplicativa, progettuale, interattiva, confirmatoria e valutativa, che fanno riferimento alle diverse procedure da seguire e alle loro corrispondenti attività per l'elaborazione della tesi. Il ricercatore deve passare sempre da queste fasi, a prescindere del livello a cui apartiene la sua ricerca, come se fosse una spirale (Carro Sancristóbal, 2010).

\subsubsection{L'EVENTO DI STUDIO}

L'evento comparativo dello studio è la procedura di validazione e certificacione delle competence in Castilla y León e in Emilia-Romagna, secondo le Linee guida Europee.

A sua volta, questo evento comparativo ha delle sinergie e coinvolge altri eventi: il concetto di lifelong learning e di competenza, in entrambi i paesi $\mathrm{e}$ in rapporto con la definizione della UE; i sistemi di istruzione e formazione professionale nei due paesi e nella comunità autónoma spagnola di Castilla y León e nella regione italiana dell'Emilia-Romagna; lo sviluppo e la procedura dei sistemi di validazione e certificazione delle competenze non formali e informali in Spagna, Italia, Castilla y León ed Emilia-Romagna.

\subsubsection{L'UNITÀ DI STUDIO}

Dopo di aver definito l'evento di studio, individuamo in cosa o in chi studiamo il sopra-citato evento. In altre parole, in quale soggetto o soggetti viene manifestata l'azione oggetto di studio (Hurtado de Barrera, 2002), che nella nostra ricerca è costituita da:

- La procedura di valutazione e acreditamento delle competenze non formali e informali in Castillay León.

- La procedura di formalizzazione e certificazione delle competenza da esperienza in Emilia-Romagna. 
In questo caso non è possibile avere le informazioni direttamente dall'unità di studio, per ciò, ci siamo rivolti alle fonti capaci di facilitarci le informazioni necessarie per la ricerca.

Abbiamo utilizzato fonti documentali: documenti legislativi e fonti viventi: professionisti di embrambe le procedure.

\subsubsection{CRITERI DELL'ANALISI}

Abbiamo definito i criteri dell'analisi dalle Linee guida Europee del 2009. Dopo lo studio e l'analisi di questo documento, abbiamo tirato fuori dei criteri, definiti come principi e fasi che deve avere una procedura di validazione delle competenze non formali e informali (Cedefop, 2009):

- Principi: Visibilità/trasparenza; uguaglianza; accessibilità; volontarietà; personalizzazione; validità; affidabilità; sicurezza e riservatezza; coordinamento; tracciabilità.

- Fasi: informazione; accesso; orientamento; consulenza; valutazione; certificazione e registro; controllo; coordinamento e tracciabilità. 
La validación de competencias profesionales en España e Italia

\subsection{Le fasi della ricerca}

\subsubsection{RACCOLTA D'INFORMAZIONE ED ELABORAZIONE DEL QUADRO TEORICO}

Dopo di avere individuato l'argomento oggetto di studio, abbiamo cominciato a leggere e a raccogliere qualsiasi informazione utile alla nostra ricerca, contando anche sull'aiuto di diversi professionisti esperti nella validazione delle compentenze professionali, provenenti da centri di ricerca, sia spagnoli che italiani.

Ci siamo anche aiutati con alcuni strumenti per poter sviluppare il quadro teorico:

- WorldCat e Dialnet: piataforme di risorse e servizi documentali, il cui scopo è migliorare la visibilità e l'accesso alla letteratura scientifica attraverso Internet;

- Eurydice: rete europea d'informazione sull'educazione nei paesi europei;

- il Diario Oficial de la Unión Europea (DOUE): fonte ufficiale del diritto comunitario europeo;

- il Boletín Oficial del Estado (BOE): organo ufficiale di pubblicazione di leggi, disposizioni e atti di inserzione obbligatoria, dello Stato spagnolo;

- il Boletín Oficial de Castilla y León, (BOCYL): giornale ufficiale della Comunità di Castilla y León, attraverso cui vengono pubblicati dei documenti ufficali, d'accordo all'ordinamento giuridico;

- la Gazzetta Ufficiale: fonte ufficiale di conoscenza delle norme in vigore in Italia. È uno strumento di diffusione e informazione, che ha l'incarico di ufficializzare dei testi legislativi, atti pubblici e privati;

- il Bollettino Ufficiale della Regione Emilia-Romagna: organo ufficiale di pubblicazione di leggi, regolamenti, disposizioni regionali in Emilia-Romagna. 


\subsubsection{COSTRUZIONE E UTILIZZO DI STRUMENTI PER LA RACCOLTA DEI DATI E LORO SUCCESSIVA ANALISI}

\subsubsection{La matrice di analisi}

Allo scopo di favorire un confronto approfondito e analitico tra le procedure di validazione, abbiamo deciso di individuare, ordinare e mettere in evidenza le parti descrittibili e misurabili di esse (Todeschini \& Ziglio, 1992, p. 16). Per ciò, abbiamo costruito una matrice di analisi, elaborata seguendo le indicazioni delle Linee guida Europee del 2009 sulla convalida degli apprendimenti non formali e informali, e a partire dello studio delle procedure di validazione delle competenze professionali in Castilla y León ed Emilia-Romagna. Concretamente, ci siamo serviti della matrice per raccogliere dei dati, e il loro successiva analisi, provenenti dai documenti legislativi, interviste e questionari.

La matrice raccoglie l'evento dello studio con le sue sinergie, espresse in categorie e in subcategorie, (definizione teorica) e con i suoi indicatori (definizione operativa).

Nella costruzione della nostra matrice, abbiamo messo sotto studio e continuo adattamento il disegno della ricerca, i problemi posti per lo studio, la specificazione delle categorie, i rapporti fra i dati, ecc., in accordo con le scoperte sorte nel corso della ricerca (Woods, 1998, p. 55). Per questo motivo la matrice comincia a costruirsi dal quadro teorico fino, quasi, alla conclusione dell'analisi documentale e di interviste, allo scopo di fare un'analisi più approfondita (Todeschini \& Ziglio, 1992, p. 16).

\subsubsection{L'intervista semistrutturata}

Abbiamo utilizzato l'intervista semistrutturata composta da una serie di domande "obbligatorie" che si situano nel quadro dell'intervista aperta (Pellicciari, 1993, p. 197). Queste domande hanno lo scopo di indagare su alcuni aspetti concreti e possono guidarci ad altri che risultino interessanti per la nostra ricerca.

L'intenzione di queste interviste è conoscere in maniera approfondita emtrambi le procedure, per poter ottenere delle informazioni relevanti su di loro; aiutare a dare forma alla matrice di analisi e facilitare la costruzione dei questionari. 
La validación de competencias profesionales en España e Italia

Abbiamo cominciato a costruire questo strumento dopo uno studio previo degli aspetti che volevamo conoscere, in rapporto alle procedure di validazione delle competenze professionali in Castilla y León e in EmiliaRomagna. Alla luce di tutto ciò, abbiamo deciso fare quattro tipi di interviste, una per ogni tipo di esperto da intervistare come testimone significativo.

\subsubsection{Il questionario}

Abbiamo ottenuto dell'informazione anche attraverso l'intervista strutturata. Questa tecnica utilizza il questionario per la sua realizzazione, attraverso il quale si fa una raccolta sistematica delle informazioni, atteggiamenti; opinioni, ecc., attraverso delle persone, sulla ricerca (Pellicciari, 1993, pp. 201-202).

C'è da dire che attraverso i questionari abbiamo cercato di ottenere delle informazioni in rapporto ad alcuni indicatori, quelli che abbiamo ritenuto più suscettibili di fornire più informazioni attraverso questo strumento.

Come abbiamo fatto con le interviste, abbiamo sviluppato quattro tipi di questionario, uno per ogni tipo di figura professionale che ha risposto al questionario.

\subsubsection{ANALISI DEI DATI}

Allo scopo di rendere più facile la comprensione dell'analisi, spieghiamo separatamente l'analisi qualitativa dell'analisi quantitativa.

\subsubsection{Analisi qualitativo documentale e delle interviste}

L'anali qualitativa che abbiamo fatto dei documenti legislativi e delle interviste è stato un'analisi interattiva, con essa sono venuti fuoiri dei temi e concetti che sono sorti tra i dati raccolti (Rubin \& Rubin, 1995).

I passi che abbiamo seguito sono stati i seguenti: (Álvarez-Gayou, 2005; Miles \& Huberman, 1994; Rubin \& Rubin, 1995):

Raccogliere le informazioni attraverso i documenti in rapporto alla legislazione legata all'oggetto di studio e attraverso la realizzazione di interviste semistrutturate. 
Ottenere, trascrivere e ordinare le informazioni ottenute. Nel caso dei documenti, abbiamo ottenuto le informazioni attraverso la raccolta di materiale on-line dal: BOE, BOCYL, Gazzetta Uficciale; Bollettino Ufficiale della Regione Emilia-Romagna, sito web: todofp.es ed E-R Il portale della Regione Emilia-Romagna; attraverso fotocopie e scansioni di documenti originali facilitati dagli esperti nel tema.

Riguardo le interviste, la cattura delle informazioni è stata fatta attraverso una registrazione elettronica che poi è stata trasformata in formato digitale e posteriormente trascritta.

Codificare l'informazione, grazie e questa procedura abbiamo ragruppato le informazioni ottenute in categorie, concetti o temi scoperti nella ricerca (Rubin \& Rubin, 1995).

Abbiamo codificato utilizando la matrice sopra-citata. Abbiamo preso come elenco di codici gli indicatori definiti nella matrice. Allo stesso tempo, ci siamo serviti di tecniche di codificazione induttive. Cioè, abbiamo fatto una codificazione dei dati, con quelli che sono rimasti fuori della codificazione iniziale (fuori degli indicatori della matrice di analisi), allo scopo di non dimenticare e lasciare fuori alcun argomento importante. Cosí, la nostra matrice è andata modificandosi e prendendo forma.

Comparare, dopo queste fasi cercammo analogía e differenze fra le due procedure di validazione, riguardo alle risposte delle interviste e la documentazione riguardante alla legislazione.

\subsubsection{Analisi quantitativa dei questionari}

Riguardo all'analisi quantitativa dei questionarii, essa è stata fatta attraverso il programma Lime Survey, lo stesso che abbiamo utilizzato per costruire e far compilare i questionari. Attraverso questo programa abbiamo ottenuto i dati per fare la comparazione, cioè, il percentuale di respuesta scelto, dai diversi tipi di professionisti che hanno partecipato nel questionario, per ogni domanda fatta.

Di seguito, attraverso il programa Excel, abbiamo organizzato e creato le grafiche neccessarie per presentare i risultati della forma più chiara e semplice per confrontare gli esiti dei professionisti di emtrambi le procedure e individuare somiglianze e differenze per ogni indicatore studiato. 
La validación de competencias profesionales en España e Italia

\subsubsection{Integrazione dell'informazione analizata e realizzazione delle conclusioni}

L'ultima fase nell'analisi di dati è integrare l'informazione (Álvarez-Gayou, 2005; Miles \& Huberman, 1994; Rubin \& Rubin, 1995). A questo punto abbiamo collegato gli esiti ottenuti con i fondamenti teorici della ricerca, e abbiamo scritto le conclusioni dello studio, collegando gli indicatori della matrice fra di loro nel quadro dei principi proposti per le Linee guida europee. 


\subsection{Conclusioni della ricerca}

Rispondendo agli obietivi posti in questa ricerca, possiamo dire che attraverso il nostro studio abbiamo riscontrato che il discorso teorico sui termini collegati alla validazione delle competenze professionali, in Spagna e in Italia, ha percorso due strade simili. Inoltre, abbiamo confermato il fatto che ci sono molte somiglianze e poche differenze fra i sistema di istruzione e formazione professionale. Abbiamo anche constatato che, diversamente da quello che capita in Spagna, L'Italia non è riuscita a instaurare una procedura nazionale di validazione delle competenze, questo è dovuto alla eterogeneità fra i sistemi di formazione professionale regionali.

Riguardo alle procedure di validazione in Castilla y León e in EmiliaRomagna, entrambe le procedure mostrano degli aspetti forti e deboli, sia nella legislazione (secondo i documenti legislativi) che nella pratica (secondo l'opinione degli esperti che hanno partecipato all'indagine). Nelle prossime pagine offriamo una panoramica generale su questi aspetti.

La Figura 56 e la Figura 57 illustrano il grado di presenza dei principi posti nelle Linee guida Europee in ogni fase della procedura, secondo la legislazione (Figura 56) e le opinioni dei professionisti (Figura 57). Le frecce verde scuro indicano molta presenza; quelle verde chiaro parecchia presenza; quelle arancioni poca presenza e quelle rosse nessuna presenza, dei principi nella fase corrispondente. Ogni fase è divisa nella procedura di Castilla y León (CL) e nella procedura dell'Emilia-Romagna (ER).

Figura 56: Presenza dei principi in ogni fase della procedura (legislazione). 
La validación de competencias profesionales en España e Italia

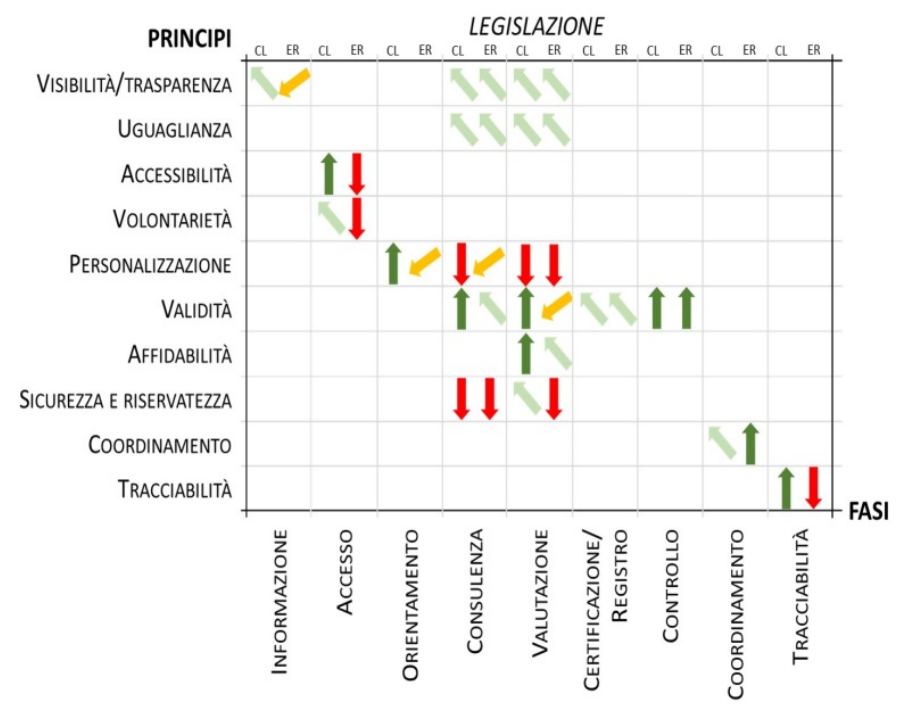

Figura 57: Presenza dei principi in ogni fase della procedura (opinioni professionisti).

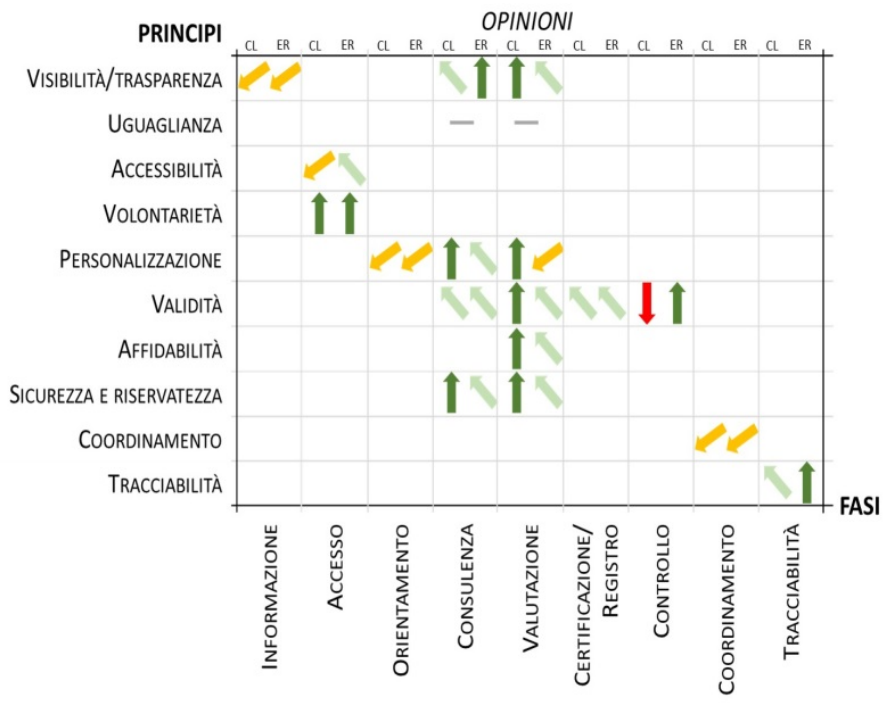


La Figura 58 e Figura 4, indicano, nella rappresentazione di un poligono, in quale misura appaiono i principi in ogni procedura (senza specificare le fasi), secondo la legislazione e le opinioni rispetivamente. Questa misura si rappresenta in una scala da 0 a 3, dove 0 vuol dire assenza totale, e 3 molta presenza. Quanto maggiore è la vicinanza di un principio al centro del poligono $(0)$ tanto minore sarà la sua presenza nella proceduta, e viceversa. Quanto minore è la vicinanza dal centro, tanto maggiore sarà la sua presenza nella procedura. Abbiamo usato anche questo tipo di rappresentazione per la Figura 60 e la Figura 61, queste mettono a confronto gli esiti dell'analisi legislativa e le opinioni dei professionisti su ogni procedura. C'è da dire che nella Figura 59, Figura 60 e Figura 61, il principio di uguaglianza, riguardo le opinioni, appare rappresentato col valore " 0 ". In questo caso, questo non vuol dire che i professionisti gli abbiamo assegnato una bassa valutazione, ma che non esistono riferimenti su questo aspetto da parte dei professionisti.

Figura 58: Presenza dei principi nelle procedure (legislazione).

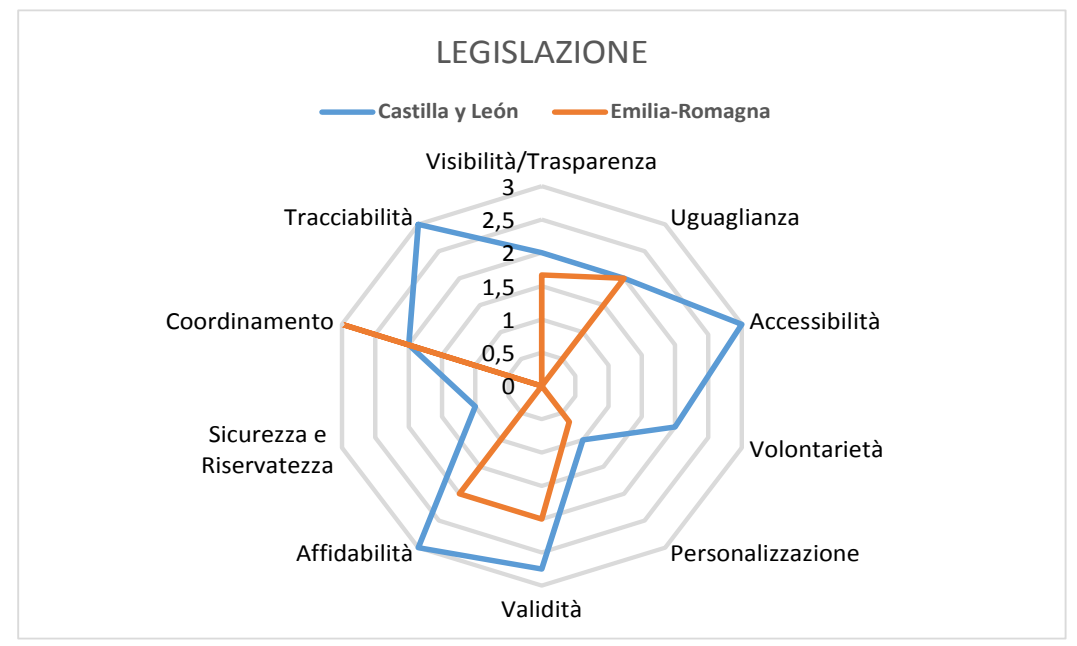


La validación de competencias profesionales en España e Italia

Figura 59: Presenza dei principi nelle procedure (opinioni professionisti)

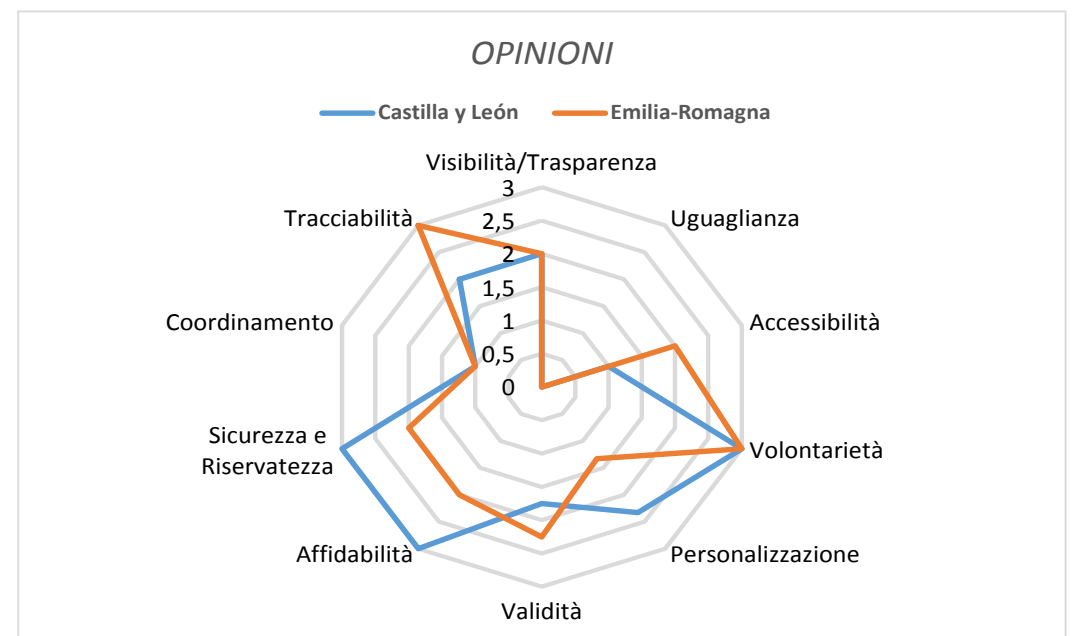

Come possiamo osservare nella Figura 56 e nella Figura 58, nella procedura di Castilla y León, la legislazione riferita emerge come un aspetto forte in questa pratica.

D’altro lato, come ilustrano la Figura 57 e la Figura 59, le opinioni dei professionisti indicano alcuni aspetti più forti in una procedura e altri nell'altra. Di preciso, nella procedura di Castilla y León, la personalizazione con il candidato (soprattutto rispetto alla flessibilità nel corso della validazione) e la validità, affidabilità e sicurezza nella fase di consulenza, si profilano come gli aspetti più adeguati rispeto agli altri. Dall'altra parte, in Emilia-Romagna, i bandi per l'accesso, i controlli e i miglioramenti nella pratica, emergono come gli aspetti forti della sua procedura. Rispetto alle debolezze individuate, emtrambi le procedure condividono il bisogno di migliorare l'erogazione delle informazioni iniziali sulla validazione, ai soggetti o enti sucettibili di mettere in pratica la proceduta e ai potenziali candidati. Inoltre, la formazione dei professionisti, specialmente quella continua; il coordinamento fra i professionisti durante la pratica e l'orientamento al candidato, soprattutto quello trasversale, sono gli aspetti più deboli di emtrambe procedure, secondo l'opinione dei loro professionisti. Concretamente, la procedura di Castilla y León dovrebbe semplificare il modo di accesso e fare un controllo della proceduta. Dall'altro canto, Emilia-Romagna dovrebbe rinforzare la felssibilità verso il candidato durante la valutazione. 
Nella Figura 56 e Figura 58 possiamo vedere che nella procedura di Castilla y León la legislazione di riferimento è molto completa. Tuttavia, secondo le opinioni dei professionisti abbiamo riscontrato che questo fatto non garantisce per forza una adeguata pratica negli aspetti definiti per legge e, viceversa, il fatto che alcuni aspetti non appaiano nella legislazione non vuol dire che la pratica sia stata inadeguata (si vedano la Figura 57 e la Figura 59). Come possiamo osservare nella Figura 56, il principio di personalizzazione nella fase di consulenza e valutazione non è presente, ma nelle opinioni questo aspetto è stato considerato con un alta presenza (si veda la Figura 57). Il principio di sicurezza e riservatezza nella consulenza non appare, neanche, nella legislazione (rivolgersi alla Figura 56), e i professionisti hanno indicato che detto principio è stato rispettato (si veda la Figura 57). Da un'altra parte, la legislazione definisce in dettaglio l'accesso alla procedura, la personalizzazione nell'orientamento e il controllo della procedura (si veda la Figura 56), aspetti che non sono stati considerati molto bene da parte dei professsionisti (Figura 57). L'imagine della Figura 60 illustra le differenze nella presenza dei principi nella procedura, a seconda che si prenda in considerazione la legislazione o, per contro, le opinioni dei professionisti.

Figura 60: Presenza dei principi nella procedura di Castilla y León, comparazione fra legislazione e opinioni

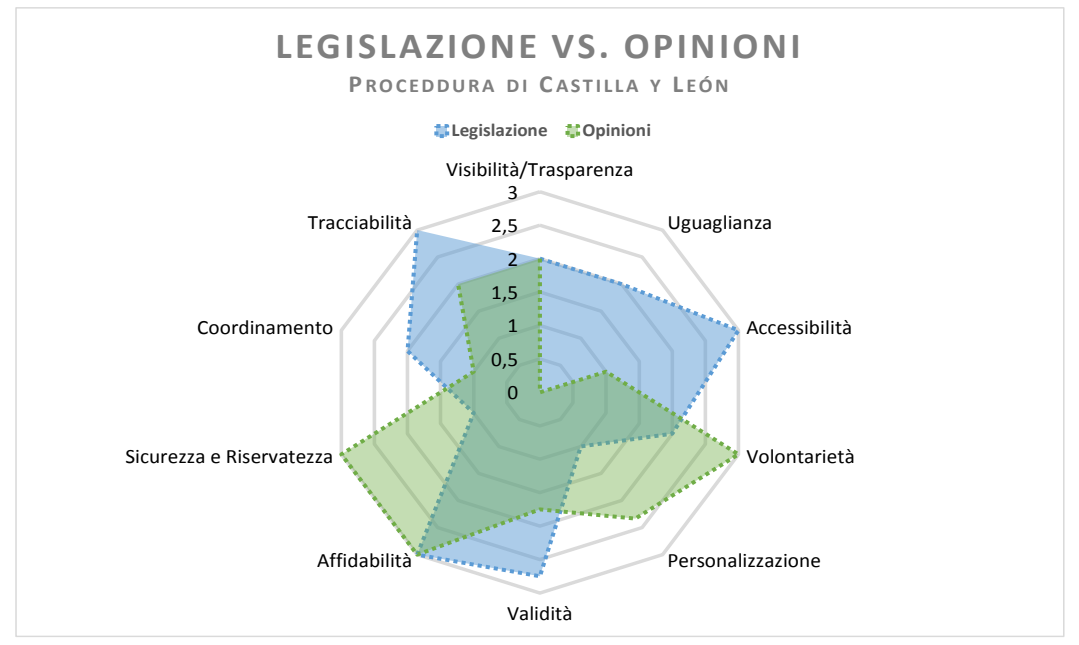

Riguardo la pratica in Emilia-Romagna, osservando la Figura 56, riscontriamo che la volontarietà e l'accessibilità nella fase di accesso e la 
La validación de competencias profesionales en España e Italia

tracciabilità sono degli aspetti che la legislazione omette, ma che hanno una una buona valutazione nella pratica da parte dei professionisti (si veda la Figura 57). Nello stesso modo, la sicurezza e riservatezza nell'orientamento e nella valutazione non vengono prese in considerazione dalla legislazione (si veda la Figura 56), ma i professionisti non le assegnano un valore positivo (si veda la Figura 57). Esistono anche delle diferenze in caso contrario, cioè, la legislazione in rapporto alla procedura si riferisce assai al coordinamento di essa (si veda la Figura 56), tuttavia, le opinioni dai professionisti non gli assegnano un valore elevato (si veda la Figura 57). L'immagine di queste diferenze, fra legislazione e opinioni, è rispecchiata nella Figura 61.

Figura 61: Presenza dei principi nelle procedure di Emilia-Romagna, comparazione fra legislazione e opinioni

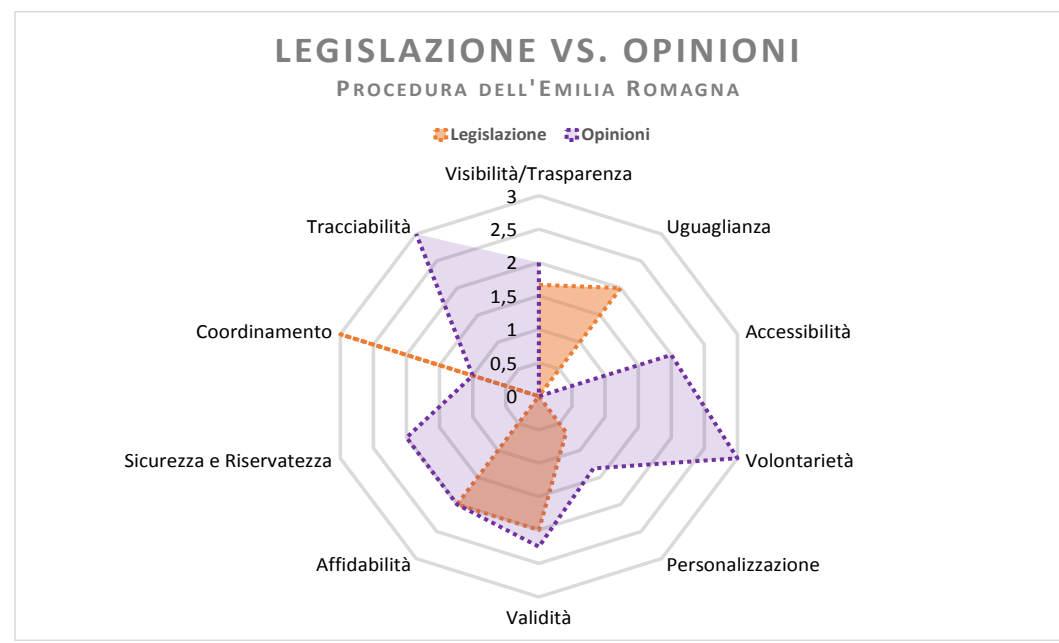




\section{Referencias bibliográficas}

Accordo Governo-Sindacati. (1993). Protocollo sulla politica dei redditi e dell'occupazione, sugli assetti contrattuali, sulle politiche del lavoro e sul sostegno al sistema produttivo (3 luglio 1993). Presidenza del Consiglio dei Ministri. Retrieved from http://www.ecn.org/coord.rsu/doc/norme93/930723.htm

Accordo per il Lavoro. (1996). Patto per il lavoro, 24 settembre 1996. Presidenza del consiglio dei Ministri. Retrieved from http://www.indire.it/ifts/normanew/allegati/31.pdf

Accordo Stato-Regioni. (2000). Accordo in sede di Conferenza StatoRegioni de 18 di febbraio 2000 tra il Ministro del lavoro e della previdenza sociale, le Regioni e le province autonome di Trento e Bolzano per l'individuazione degli standards minimi delle qualifiche professionali e dei criteri formativi e per l'accreditamento delle strutture della formazione professionale. Presidenza del Consiglio dei Ministri. Retrieved from http://www.lavoro.gov.it/NR/rdonlyres/DB95028B-A040-4DE7AA72-19B72EA58A52/0/accordo2000.pdf 
La validación de competencias profesionales en España e Italia

Accordo Stato-Regioni. (2003). Accordo quadro in sede di Conferenza Unificata del 19 giugno 2003, tra il Ministro dell'istruzione, dell'università e della ricerca, del Ministro del lavoro e delle politiche sociali, le Regioni, le Province autonome di Trento e Bolzano, le Province, i Comuni e le Comunità montane per la realizzazione dell'anno scolastico 2003-2004 di un'offerta formativa sperimentale di istruzione e formazione professionale nelle more dell'emanazione dei decreti legislativi di cui alla legge 28 marzo 2003, n. 53. Presidenza del Consiglio dei Ministri.

Accordo Stato-Regioni. (2004). Accordo in sede di Conferenza StatoRegioni del 15 gennaio 2004, tra il Ministro dell'istruzione, dell'università e della ricerca, il Ministro del lavoro e delle politiche sociali, le Regioni e le Province autonome di Trento e Bolzano, per la definizione degli standard formativi minimi in attuazione dell'accordo quadro sancito in Conferenza Unificata il 19 giugno 2003. Presidenza del Consiglio dei Ministri.

Accordo Stato-Regioni. (2006). Accordo in sede di Conferenza StatoRegioni del 5 ottobre 2006, ai sensi dell'articolo 4 del decreto legislativo 28 agosto 1997, n.281 tra Ministro della Pubblica Istruzione, il Ministro del Lavoro e della previdenza Sociale, le Regioni e la Provincie Autonome di Trento e di Bolzano, per la definizione degli standard formativi minimi relativi alle competenze tecnico-professionali, in attuazione di cui all'Accordo Quadro sancito in Conferenza Unificata il 19 giugno 2003. Presidenza del Consiglio dei Ministri.

Accordo Stato-Regioni. (2010). Accordo in sede di Conferenza StatoRegioni del 29 aprile 2010, tra il Ministro dell'istruzione, dell'università e della ricerca, il Ministro del lavoro e delle politiche sociali, le regioni e le Province autonome di Trento e Bolzano riguardante il primo anno di attuazione 2010-2011 dei percorsi di istruzione e formazione professionale a norma dell'articolo 27, comma 2, del decreto legislativo 17 ottobre 2005, n . 226. Accordo ai sensi dell'articolo 4, comma 1, del decreto legislativo 28 agosto 1997, n. 281. Presidenza del Consiglio dei Ministri.

Alberici, A. (1999). Imparare sempre nella società conoscitiva. Torino: Paravia Scriptorium. 
Alberici, A. (2000). La dimensione lifelong learning nella teoria pedagogica. In C. Montedoro (Ed.), Dalla pratica alla teoria per la formazione: un percorso di ricerca epistemologica (1st ed.). Milano: FrancoAngeli.

Alberici, A. (2001). La dimensione lifelong learning nella teoria pedagogica. In C. Montedoro (Ed.), Dalla pratica alla teoria per la formazione: un percorso di ricerca epistemologica (2nd ed.). Milano: FrancoAngeli.

Alberici, A. (2002). L'educazione degli adulti. Roma: Carocci.

Alberici, A. (2008). La possibilità di cambiare. Apprendere ad apprendere come risorsa strategica per la vita. Milano: Franco Angeli.

Alberici, A., \& Serreri, P. (2005). Competencias y formación en la edad adulta. El balance de competencias. Barcelona: Laertes.

Álvarez Bermúdez, N. (2014). European inventory on validation of nonformal and informal learning 2014: country report Spain. Retrieved from http://libserver.cedefop.europa.eu/vetelib/2014/87056_ES. pdf.

Álvarez-Gayou, J. . (2005). Cómo hacer investigación cualitativa. Fundamentos y metodología. México: Paidós.

Aree Politiche per l'Orientamento. (2007). Le parole dell'orientamento: un puzzle da comporre. Roma: Isfol.

Balboni, C. (2011). I Quaderni. ER Educazione Ricerca. Il Sistema di Istruzione e Formazione Professionale in Emilia-Romagna. EmiliaRomagna.

Bandura, A. (1997). Self-efficacy: The exercise of control. New York: Freeman.

Battistelli, A. (1996). La percezione della propria competenza professionale. Risorsa Uomo, (2).

Bertolini, P. (1996). Dizionario di pedagogia e scienze dell'educazione. Bologna: Zanichelli.

Bishop, G. ., Tuchfarber, A. ., \& Oldendick, R. . (1986). Opinions on fictitious issues: the pressure to answer survey questions. Public Opinion Quarterly, (50), 240-250. 
La validación de competencias profesionales en España e Italia

Bjørnavold, Jean. (2009). Validation of non-formal and informal learning in Europe: key developments and challenges. The Quality of Higher Education, (6), 36-71.

Biørnavold, Jens. (2000). Making learning visible: Identification, Assessment and Recognition of Non-formal Learning in Europe (p. 223). Cedefop.

Blas Aritio, F. de A. (2007). La formación profesional basada en la competencia. Avances En Supervisión Educativa: Revista de La Asociación de Inspectores de Educación de España, 7. Retrieved from http://www.adide.org/revista/index.php?option=com_content\&task $=$ view $\&$ id $=223 \&$ Itemid $=49$

Bosco, A. (2003). Come si costruisce un questionario. Roma: Carocci.

Bresciani, P. G. (1997). Le comeptenze: approcci e modelli di intervento. Professionalità, 38 .

Bulgarelli, A. (2011). Scenari del lifelong learning in Italia. In A. Viteritti (Ed.), Scuola Democratica. Milano: Guerini e Associati.

Bulgarelli, A., Zucchermaglio, C., \& Provenzano, F. (2011). Il lifelong Learning in Italia. A partire dal quaderno TreeLLe. In A. Viteritti (Ed.), Scuola Democratica. Milano: Guerini e Associati.

Carretta, A., Dalziel, M. ., \& Mitrani, A. (1992). Dalle risorse umane alle competenze: metodi, strumenti e casi in Europa per una gestione e sviluppo delle risorse umane basata su un modello comune di competenza. Milano: Franco Angeli.

Carro Sancristóbal, L. (2010). Fases del proyecto de investigación. Métodos de Investigación Social. Universid de Valladolid. Retrieved from http:// educa.feyts.uva.es/feyts/cursos/course/view.php?id=5

Castelli, C., \& Ancona, C. (1998). Il Bilancio di Competenze nell'orientamento e nella formazione continua. Milano: I.S.U. Università Cattolica.

Cedefop. (2002). Ágora-V. Detección, evaluación y reconocimiento de competencias no formalizadas. Salónica 15 y 16 de marzo de 1999. Luxemburgo: Oficina de Publicaciones Oficiales de las Comunidades Europeas. 
Cedefop. (2008). Terminology of European education and training policy. Luxenbourg: Cedefop.

Cedefop. (2009). Lignes directrices européennes pour la validation des acquis non formels et informels. Luxembourg: Office des publications de l'Union européenne.

Cedefop. (2014). Terminology of European education and training policy. Luxembourg: Publications office of the european union.

Cedefop. (2016). Directrices europeas para la validación del aprendizaje no formal e informal. Luxenbourg: Oficina de publicaciónes de la Unión Europea.

Chomsky, N. (1965). Aspects of syntax. Cambridge: MIT Press.

Colardyn, D., \& Bjørnavold, J. (2004). Validation of formal, non-formal and informal learning: policy and practices in EU Member States. European Journal of Education, 39(1), 77-88.

Comisión de las Comunidades Europeas. (1995). Libro Blanco sobre la educación y la formación. Enseñar a aprender. Hacia la sociedad cognitiva. Bruselas. Retrieved from http://eurlex.europa.eu/LexUriServ/LexUriServ.do?uri=COM:1995:0590:FIN: ES:PDF

Comisión Europea. (2004). Sistema Europeo de transferencia y acumulación de créditos (ETCS). Características esenciales. Bruselas: Comunidades Europeas.

Comisión Europea. (2010). Comunicación de la Comisión Europa 2020. Una estrategia para un crecimiento inteligente, sostenible e integrador. Bruselas, Comisión de las Comunidades Europeas, de 3 de marzo de $2010 \operatorname{COM}(2010) 2020$ final.

Comisión Europea. (2013). ¿Qué es el FSE? Retrieved from http://ec.europa.eu/esf/main.jsp?catId=35\&langId=es

Commissione delle Comunità Europee. (2000). Memorandum sull'istruzione e la formazione permanente. Bruxelles.

Comunicación de la Comisión. (2001). Comunicación de la comisión. Hacer realidad un espacio europeo del aprendizaje permanente. Bruselas, Comisión de las Comunidades Europeas, de 21 de noviembre de 2001 COM (2001) 678 final. 
La validación de competencias profesionales en España e Italia

Comunidades Europeas. (2009). El Marco Europeo de Cualificaciones para el aprendizaje permanente (EQF-MEC). Luxemburgo: Autor.

Conferencia Europea de Ministros de Educación Superior. (1998). Declaración de La Sorbona. Declaración conjunta para la armonización del diseño del sistema de Educación Superior Europeo, a cargo de los cuatro ministros representantes de Francia, Alemania, Italia y el Reino Unido, reunidos en La Sorbona, París, el 25 de mayo de 1998. París. Retrieved from https://ujiapps.uji.es/estudis/eees/titols/documents/docs/sorbona. pdf

Consejo Europeo de Barcelona. (2002). Conclusiones de la Presidencia. Consejo europeo de Barcelona 15 y 16 de marzo de 2002. Retrieved from

http://www.consilium.europa.eu/uedocs/cms_data/docs/pressdata/ es/ec/70829.pdf

Coombs, P. (1980). La crisis mundial de la educación. Un análisis de sistemas. Barcelona: Ediciones 62.

D.G.R. 1434. (2005). Deliberación de Junta Regional 1434/2005 del 12 de septiembre de 2005, Orientamenti, metodologia e struttura per la definizione del sistema regionale di formalizzazione e certificazione delle competenze. Giunta della Regione Emilia-Romagna.

D.G.R. 530. (2006). Deliberación de Junta Regional 530 de 19 de abril de 2006, de Il Sistema Regionale di Formalizzazione e Certificazione delle competenze. (Bollettino Ufficiale dell'Emilia-Romagna, núm. 63 del 05 de mayo de 2006).

D.G.R. 739. (2013). Deliberación de Junta Regional 739 de 10 de junio de 2013, de Modifiche e integrazioni al Sistema Regionale di Formalizzazione e Certificazione delle competenze di cui alla DGR. núm. 530/2006. (Bollettino Ufficiale Regionale dell'Emilia-Romagna núm. 168 de 20 de junio de 2013).

D.G.R. 841. (2006). Deliberación de Junta Regional 841/2006 de Adozione di procedure di evidenza publica e approvazione di modalità e requisiti per il reclutamento dei ruoli prodessionali di cui al allegato B della Delibera de G.R. 530/06. (Bollettino Ufficiale dell'EmiliaRomagna, núm. 93 del 28 de junio de 2006). 
D.G.R. 936. (2004). Deliberación de Junta Regional 936 de 17 de mayo de 2004, de Orientamenti, metodología e struttura per la definizione del Sistema Regionale delle Qualifiche. (Seduta di Giunta Regionale dell'Emilia-Romagna, núm. 20, de 17 de mayo de 2004, Deliberación núm 936). Retrieved from http://formazionelavoro.regione.emiliaromagna.it/qualifiche/approfondimenti/allegati_qualifiche/deliberadi-gr-n-936-del-17-maggio-2004/view

D.M. 174. (2001). Decreto Ministerial 174/2001, de 31 de mayo sul sistema di certificazione delle competenze nella formazione professionale. (Gazzetta Ufficiale, núm. 139 de 18 de junio de 2001).

D.P.C.M. (2008). Decreto Presidencial Del Consejo De Ministros de 25 de enero de 2008, Recante linee guida per la riorganizzazione del sistema di istruzione e formazione tecnica superiore e la costituzione degli istituti tecnici superiori. (Gazzetta Ufficiale núm. 86 de 11 de abril de 2008).

D.P.R. 87. (2010). Decreto del Presidente de la Repubblica 15 marzo 2010, n. 87 Regolamento recante norme per il riordino degli istituti professionali, a norma dell'articolo 64, comma 4, del decreto-legge 25 giugno 2008, n. 112, convertito, con modificazioni, dalla legge 6 agosto 2008, n. 133. (10G0109). (Gazzeta Ufficiale núm.137 del 15-62010 - Suppl. Ordinario núm. 128 ).

Dahler, A. M., \& Grunnet, H. (2012). Quality in validation in the nordic countries. Final report for "Quality in the Nordic Countries - A Mapping Project" Anne Marie Dahler and Håkon Grunnet. Denmark: National Knowledge Centre for Validation of Prior Learning.

Daniele, L. (2010). Il quadro europeo per il riconoscimento e la convalida degli apperndimenti informali e non formali. In P. Di Rienzo (Ed.), Il riconoscimento e la validazione degli apprendimenti non formali e informali nell'Università. Primo rapporto di ricerca: politiche $\mathrm{e}$ modelli in Europa. Roma: Anicia.

Decisión de la Comisión. (2007). Decisión de la Comisión 172/CE de 19 de marzo de 2007 por la que se crea el Grupo de Coordinadores para el Reconocimiento de las Cualificaciones Profesionales. (DOUE, L 79/38, de 20 de marzo de 2007).

Decisión del Consejo. (1985). Decisión 85/368/CEE del Consejo, de 16 de julio de 1985, relativa a la correspondencia de las calificaciones de 
La validación de competencias profesionales en España e Italia

formación profesional entre los Estados miembros de las Comunidades Europeas. (DOUE, L 199 de 31 de julio de 1985).

Decisión del Parlamento y del Consejo. (2004). Decisión 2241/2004/CE del Parlamento Europeo y del Consejo de 15 de diciembre de 2004 relativa a un marco comunitario único para la transparencia de las cualificaciones y competencias (Europass). (DOUE, L 390/6, de 31 de diciembre de 2004).

Decisión del Parlamento y del Consejo. (2008). Decisión 1065/2008/CE del Parlamento europeo y del Consejo de 22 de octubre de 2008 por la que se deroga la Desición 85/368/CEE del Consejo, relativa a la correspondencia de las calificaciones de formación profesional entre los Estados miembros de las Comunidades Europeas. (DOUE, L 288/4, de 30 de octubre de 2008).

Decreto Interministerial. (2005). Approvazione del modello di libretto formativo del cittadino. (Gazzetta Ufficiale del 3 de noviembre de 2005, núm. 256).

Decreto Legislativo 13. (2013). Decreto Legislativo 13/2013 de 16 de enero de 2013, de definizione delle norme generali e dei livelli essenziali delle prestazioni per l'individuazione e validazione degli apprendimenti non formali e informali e degli standard minimi di servizio del sistema nazionale di certificazione delle competenze, a norma dell'articolo 4, commi 58 e 68, della legge 28 giugno 2012, n. 92. (Gazzetta Ufficiale del 15 de febrero de 2013, núm. 39).

Decreto Legislativo 167. (2011). Decreto Legislativo 167 de 14 de septiembre de 2011, sobre Testo unico dell'apprendistato, a norma dell'articolo 1, comma 30, della legge 24 dicembre 2007, n. 247. (11G0209). (Gazzetta Ufficiale, núm. 236 del 10-10-2011).

Decreto Legislativo 276. (2003). Decreto Legislativo 276/2003, del 10 de septiembre de Attuazione delle deleghe in materia di occupazione e mercato del lavoro, di cui alla legge 14 febbraio 2003, n. 30. (Gazzetta Ufficiale del 9 de octubre de 2003, núm. 235, Suplemento Ordinario núm. 159).

Delamare Le Deist, F., \& Winterton, J. (2005). What is competence? Human Resource Development International, 8(1), 27-46.

Delors, J. (1996). L'Éducation. Un trésor est caché dedans. París: Unesco. 
Dewey, J. (1916). Democracy and Education: An Introduction to the Philosophy of Education. New York: Macmilian.

Di Francesco, G., \& Perulli, E. (2011). European Inventory on Validation of Non Formal and Informal Learning 2010. Cedefop. Grecia.

Di Rienzo, P. (2015). Dar la palabra a la experiencia. Barcelona: Laertes.

Directiva del Consejo. (1989). Directiva 89/48/CEE del Consejo de 21 de diciembre de 1988 relativa a un sistema general de reconocimiento de los títulos de enseñanza superior que sancionan formaciones profesionales de una duración mínima de tres años. (DOUE, L 019, de 24 de enero de 1989).

Directiva del Parlamento y del Consejo. (2005, 36/CE). Directiva 2005/36/CE del Parlamento Europeo y del Consejo de 7 de septiembre de 2005 relativa al reconocimiento de cualificaciones profesionales. (DOUE, L 255/22, de 30 de septiembre de 2005).

Documento de trabajo ECVET. (2006). Documento de trabajo de los servicios de la Comisión. Los créditos de aprendizaje europeos para la educación y la formación profesionales (ECVET). Un dispositivo para la transferencia, la acumulación y el reconocimiento de los resultados de los aprendizajes en Europa. Bruselas, Comisión Europea, SEC (2006) 1431, 31.10.2006. Retrieved from http:/ / ec.europa.eu/education/lifelong-learningpolicy/doc/ecvet/work_es.pdf

Duvekot, R., Schuur, K., \& Paulusse, J. (2005). The unfinished story of VPL. Valuation \& Validation of Prior Learning in Europe's learning cultures Ruud Duvekot Kees Schuur Jos Paulusse. Utrecht: Foundation EC-VPL \& Kenniscentrum EVC. Retrieved from http://www.educacion.gob.es/educa/incual/pdf/rec/06_VPL_the_u nfished_story_in_Europe.pdf

Echeverría, B. (2002). Gestión de la competencia de acción profesional. Revista de Investigación Educativa, 20(1), 7-43.

Educación y Formación 2010. (2004). Educación y Formación 2010. Urgen las reformas para coronar con éxito la estrategia de Lisboa. Informe intermedio conjunto del Consejo y la Comisión sobre la ejecución del programa de trabajo detallado relativo al seguimiento de los objetivos 
La validación de competencias profesionales en España e Italia

de los sistemas de educación y formación en Europa. (DOUE, C 104/01, de 30 de abril de 2004).

Elisabetta Perulli. (2014). European inventory on validation of non-formal and informal learning 2014. Country report Italy. European Commission. Retrieved from https://cumulus.cedefop.europa.eu/files/vetelib/2014/87064_IT.pdf

Emilia-Romagna. (2007). Il Sistema Regionale delle Qualifiche in EmiliaRomagna. Tracce.com.

EUR-Lex. (2015). Cedefop. Retrieved from http://eur-lex.europa.eu/legalcontent/ES/TXT/?uri=URISERV:c11008a

European Commission, Cedefop, \& ICF International. (2014). European inventory on validation of non-formal and informal learning 2014. Final synthesis report. European Commission. Retrieved from https://cumulus.cedefop.europa.eu/files/vetelib/2014/87244.pdf

Eurydice. (2009). Estructuras de los sistemas educativos y de formación en Europa. España. Madrid: Comisión Europea.

Fabri, D. (1990). La memoria della regina. Milano: Guerini e Associati.

Flick, U. (2007). Introducción a la Investigación cualitativa. Madrid: Morata.

Florenzano, F. (2011). Retorica del lifelong learning: molte parole, zero fatti. In A. Viteritti (Ed.), Scuola Democratica. Milano: Guerini e Associati.

Foulquié, P. (1997). La memoria della regina. Milano: Guerini e Associati.

Fundación Tripartita. (2011). Presentación. Fundación Tripartita para la Formación en el Empleo. Retrieved December 8, 2011, from http://www.fundaciontripartita.org/index.asp?MP=12\&MS $=29 \& M$ $\mathrm{N}=1 \& \mathrm{r}=1024 * 600$

Geertz, C. (1989). El antropológo como autor. Barcelona: Paidós.

Gonczi, A. (1994). Developing a competent workforce. Adelaide: National Centre for Vocational Education Research.

Grimaldi, A. (2010). Il documento Isfol sul bilancio di competenze/1. Da "Bi.dicomp" al documento: un apremessa explicativa dell'esperienza Isfol. Professionalità, (108), 17-27.

Hager, P. (1998). Recognition of informal learning: challenges and issues. Journal of Vocational Education and Training, 50(4), 521-535. 
Homs, O. (2008). La formación profesional en España. Hacia la sociedad del conocimiento. Barcelona: Fundación "la Caixa."

Hurtado de Barrera, J. (2000). Metodología de la investigación holística. Caracas: Fundación Sypal.

Hurtado de Barrera, J. (2002). El proyecto de investigación holística. Bogotá: Magisterio.

ICE. (2001, March 26). Consejo Europeo de Estocolmo: conclusiones de la presidencia. Boletín Económico de ICE, 2686, 39-56.

INCUAL. (2010a). Manual de procedimiento para el reconocimiento de las competencias profesionales adquiridas por la experiencia laboral; Guía del asesor. Madrid: Ministerio de Educación.

INCUAL. (2010b). Manual de procedimiento para el reconocimiento de las competencias profesionales adquiridas por la experiencia laboral; Guía del evaluador. Madrid: Ministerio de Educación.

INCUAL. (2010c). Procedimiento de evaluación y acreditación de las competencias profesionales. Cualificación profesional: educación infantil, establecida por RD 368/2007, de 25 de octubre. Guías de evidencias de la competencia profesional. Ministerio de Educación. Retrieved from

http://www.educacion.gob.es/educa/incual/pdf/Acreditacion/Guia s/GEC_EDUCACION\%20INFANTIL.pdf

INCUAL. (2014). Catalogo Nacional de Cualificaciones Profesionales. Retrieved from http://www.educacion.gob.es/educa/incual/ice_catalogoWeb.html

INCUAL. (2015a). Catálogo Nacional de Cualificaicones Profesionales (CNCP). Retrieved from http://www.mecd.gob.es/educa/incual/ice_ncfp.html

INCUAL. (2015b). Sistema Nacional de Cualificaicones y Formación Profesional (SNCFP). Retrieved from http://www.mecd.gob.es/educa/incual/ice_ncfp.html

Informe Consejo Educación. (2001). Informe del Consejo Educación al Consejo Europeo. Futuros objetivos precisos de los sistemas de educación y formación. Bruselas, Consejo de la Unión Europea (16.02) (OR. en) 5980/01, 14.02.2001. 
La validación de competencias profesionales en España e Italia

Isfol. (2015a). Formazione degli adulti. Retrieved from http://www.isfol.it/temi/Formazione_apprendimento/formazionedegli-adulti

Isfol. (2015b). Isfol. Chi siamo. Retrieved from http://www.isfol.it/Istituto/chi-siamo

Isfol, Dipartimento per le politiche europee, Ministero del Lavoro e delle Politiche Sociali, \& MIUR. (2012). Primo rapporto italiano di referenziazione delle qualificazioni al quadro europeo EQF (No. 331.1142 - Economia del lavoro. Qualificazioni). Italia. Retrieved from

http://bw5.cilea.it/bw5ne2/opac.aspx?web=ISFL\&opac=Default\&i $\mathrm{ds}=18746$

Italia 2020. (2009). Piano di azione per l'occupabilità dei giovani attraverso l'integrazione tra apprendimento e lavoro. ITALIA 2020. Ministero del Lavoro, della Salute e delle Politiche Sociali.

Jarvis, P. (1992). Paradoxes of Learning. San Francisco: Jossey-Bass.

Jolis, N. (1997). Piloter les Competénces. De la logique de poste à l'atoutCompetences. Paris: Les Editions d'Organisation.

Joras, M. (1995). Le Bilan de Compétences. Paris: PUF.

Junta de Castilla y León. (2015a). Empleo en Castilla y León. Retrieved from

http://www.empleo.jcyl.es/web/jcyl/Empleo/es/Plantilla100/12843 67350368/_/_/_

Junta de Castilla y León. (2015b). Oferta Educativa de Formación Profesional. Retrieved from http://www.educa.jcyl.es/alumnado/es/formacion-profesionalcastilla-leon/formacion-profesional-inicial/oferta-educativaformacion-profesional

Kytola, L., \& Hawley, J. (2007). European inventory on validation of informal and non-formal learning. Italy. ECOTEC.

L.O. 2. (2006). LEY ORGÁNICA 2/2006, de 3 de mayo, de Educación. (Boletín Oficial del Estado núm. 106, de 4 de mayo de 2006).

L.R. 12. (2003). Ley Regional 12/2003, de 30 de junio de 2003, de Norme per l'uguaglianza delle opportunità di accesso al sapere, per ognuno e 
per tutto l'arco della vita, attraverso il rafforzamento dell'istruzione e della formazione professionale, anche in integrazione tra loro. (Bollettino Ufficiale della Regione Emilia-Romagna, núm 12, de 30 de junio de 2003).

Le Boterf, G. (2000). Costruire les compétences individuelles et collectives (Organisation). Paris.

Le Boterf, G. (2001). Ingégnierie et évaluation des compétences. Paris: Les Éditions d'Organisation.

Levati, W. (1993). Assessment Center: analisi di un metodo di valutazione delle Risorse Umane. Milano: Franco Angeli.

Levy-Leboyer, C. (1996). La gestion des compétences. Paris: Les Editions d'Organisation.

Ley 196. (1997). Ley 196/1997 de Norme in materia di promozione dell'occupazione. (Gazzetta Ufficiale del 4 de julio de 1997, núm. 154, Suplemento Ordinario núm. 136).

Ley 236. (1993). Conversione in legge, con modificazioni, del decreto-legge 20 maggio 1993, n. 148, recante interventi urgenti a sostegno dell'occupazione. (Gazzetta Ufficiale del 19 de julio de 1993, núm. 167).

Ley 30. (2003). Ley 30/2003, del 14 de febrero de 2003 de Delega al Governo in materia di occupazione e mercato del lavoro. (Gazzetta Ufficiale del 26 Febbraio de 2003, núm. 47).

Ley 53. (2003). Ley 53/2003, del 28 de marzo, de Delega al Goberno per la definizione delle norme generali sull'istruzione e dei livelli essenziali delle prestazioni in materia di istruzione e formazione professionale. (Gazzetta Ufficiale, núm. 77, de 2 de abril de 2003).

Ley 56. (2003). Ley 56/2003, de 16 de diciembre, de Empleo. (Boletín Oficial del Estado núm. 301, de 17 de diciembre de 2003).

Ley 845. (1978). Ley 845/1978 de 21 de diciembre de 1978 Legge-quadro in materia di formazione professionale. (Gazzetta Ufficiale núm. 362, de 30 de diciembre de 1978).

Ley 92. (2012). Ley 92/2012, de 28 de junio de 2012, de Disposizioni in materia di riforma del mercato del lavoro in una prospettiva di 
La validación de competencias profesionales en España e Italia

crescita. (Gazzetta Ufficiale de 3 de julio de 2012, núm. 153, Suplemento Ordinario núm. 136).

Ley Orgánica 1. (1990). Ley Orgánica 1/1990, de 3 de octubre, de Ordenación General del Sistema Educativo. (Boletín Oficial del Estado, núm. 238, de 4 de octubre de 1990).

Ley Orgánica 5. (2002). LEY ORGÁNICA 5/2002, de 19 de junio, de las Cualificaciones y de la Formación Profesional. (Boletín Oficial del Estado, núm.147, de 20 de junio de 2002).

Ley Orgánica 8. (2013). Ley Orgánica 8/2013, de 9 de diciembre, para la mejora de la calidad educativa. (Boletín Oficial del Estado, núm. 295, de 10 de diciembre de 2013).

Linee guida. (2010). Intesa tra Governo, Regioni, Province Autonome e Parti Sociali. Linee guida per la formazione nel 2010. Roma. Retrieved from

http://www.governo.it/GovernoInforma/Dossier/formazione_2010 /linee_guida_def.pdf

Lipari, D. (2009). Progettazione e valutazione nei processi formativi. Roma: Edizioni Lavoro.

LO. (2002, May). Ley Orgánica 5/2002, de 19 de junio, de las Cualificaciones y de la Formación Profesional.

Löwen, C. L. (2009). La cuestión socioambiental en comunidades tradicionales de Faxinais en Paraná, Brasil: reflexiones sobre una pedagogía holística e integrativa. Revista de Didácticas Específicas, 130-147.

Malglaive, G. (1992). L'alternance dans la formation des ingenieurs. L'orientation Scolaire et Professionnelle, (3).

Martínez, F. M., \& Carmona, G. (2009). Aproximación al conceto de competencias emprendedoras: Valor social e implicaciones educativas. REICE. Revista Iberoamericana Sbre Calidad, Eficacia y Cambio En Educación, 7(3), 82-98.

McClelland, D. (1995). Introducción. In L. Spencer \& S. Spencer, Competenza nel lavoro. Modelli per una performance superiore. Milano: Franco Angeli.

Meghnagi, S. (1992). Conoscenza e competenza. Torino: Loescher. 
Mialaret, G. (1979). Compétence. In Compétence, in: Vocabulaire de l'éducation, 1979. Paris: PUF.

Michel, S. (1993). Sens et contresens des Bilans de Compétences. Paris: LIAISONS.

Miles, M. B., \& Huberman, A. M. (1994). Qualitative data analysis: An expanded sourcebook (2nd ed.). Thousand Oaks, California: Sage.

Ministerio de Educación. (2011). El aprendizaje permanente en España. Madrid: Secretaría General Técnica.

Ministerio de Educación Cultura y Deporte. (2004). Memoria final del proyecto ERA. Proyecto experimental para la evaluación, el reconocimiento y acreditación de competencias profesionales. Ministerio de Educación, Cultura y Deporte. Retrieved from http://www.educacion.gob.es/educa/incual/pdf/rec/09_memoria $\%$ 20final\%20ERA-03.pdf

Ministero del Lavoro e delle Politiche Sociali. (2011). Europa Lavoro Libretto formativo. Retrieved August 10, 2011, from http://www.lavoro.gov.it/lavoro/europalavoro/sezionecittadini/for marsi/formazionepermanente/libretform.htm

Ministero del Lavoro e delle Politiche Sociali. (2015). Educazione degli adulti. Retrieved from http://europalavoro.lavoro.gov.it/EuropaLavoro/Glossario/Educazi one-degli-adulti

Ministero del Lavoro, della Salute e delle Politiche Sociali. (2009). Libro Bianco sul futuro del modello sociale. La vita buona nella società attiva. Roma.

MIUR. (2008). DG Istruzione e Formazione Tecnica Superiore. Retrieved from

http://archivio.pubblica.istruzione.it/dg_post_secondaria/figure_naz ionali.shtml

MIUR. (2009). Area ITS.

Mulder, M., Weigel, T., \& Collings, K. (2008). El concepto de competencia en el desarrollo de la educación y formación profesional en algunos Estados miembros de la UE: un análisis crítico. Profesorado: Revista de Curriculum y Formación Del Profesorado, 12(3). 
La validación de competencias profesionales en España e Italia

Norris, N. (1991). The trouble with competence. Cambridge Journal of Education, 21(3), 331-341.

OCDE. (2015). ¿Qué es la OCDE? Retrieved from http://www.oecd.org/centrodemexico/laocde/

OECD. (2007). Terms, concepts and models for analysing the value of recognition programmes. Vienna. Retrieved from http:/ /www.oecd.org/edu/skills-beyond-school/41834711.pdf

Orden EDU/915. (2014). Orden EDU/915/2014, de 23 de octubre, por la que se convocan subvenciones destinadas al desarrollo de proyectos del programa Aula Empresa Castilla y León, financiados por el Ministerio de Educación, Cultura y Deporte y cofinanciados por el Fondo Social Europeo, en centros docentes de la Comunidad de Castilla y León que impartan ciclos formativos de Formación Profesional en régimen de concierto, durante el curso 2014/2015. (Boletín Oficial de Castilla y León, núm. 211, de 3 de noviemnre de 2014).

Orden EYE/952. (2012). Orden EYE/952/2012, de 9 de noviembre, por la que se establecen las bases reguladoras de las subvenciones, cofinanciadas por el Fondo Social Europeo, destinadas a la financiación del Programa Dual de Formación y Empleo, y la convocatoria de las subvenciones para el ejercicio 2012. (Boletín Oficial de Castilla y León, núm. 217, de 12 de noviemnre de 2012).

Orden HAC/1605. (2011). Orden HAC/1605/2011, de 29 de diciembre, por la que se desarrolla la gestión del procedimiento de evaluación y acreditación de competencias profesionales adquiridas por experiencia laboral en Castilla y León, así como la estructura organizativa responsable. (Boletín Oficial de Castilla y León, núm. 250, de 30 de diciembre de 2011).

Parlamento Europeo. (2000). Consejo Europeo Lisboa 23 y 24 de marzo 2000: Conclusiones de la Presidencia. Retrieved May 9, 2011, from http://www.europarl.europa.eu/summits/lis1_es.htm

Patton, M. . (1990). Qualitative evaluation and research methods (2nd ed.). Newbury Park, California: Sage.

Pellerey, M. (1983). La progettazione formativa. Teoría e metodologia. Roma: Quadreni di formazione Isfol. 
Pellicciari, G. (1993). Il questionario e l'intervista. In P. Guidicini (Ed.), Nuovo manuale della ricerca sociologica (pp. 193-249). Milano: FrancoAngeli.

Perulli, E. (2011). Validazione delle competenze da esperienza: approcci e pratiche in Italia e in Europa. Roma: Isfol.

Perulli, E. (2013). Validazione delle competenze da esperienza: approcci e pratiche in Italia e in Europa Edizione aggiornata 2013. Roma: Isfol.

Pineda, P., \& Sarramona i López, J. (2006). El nuevo modelo de formación continua en España: balance de un año de cambios. Revista de Educación, 341, 705-736.

Principios europeos. (2004). Proyecto de Conclusiones del Consejo y de los Representantes de los Gobiernos de los Estados miembros reunidos en el seno del Consejo sobre los Principios europeos comunes para la determinación y convalidación de la educación no formal e informal. Bruselas, Cosejo de la Unión Europea, EDUC 118, SOC 253, 18 de mayo de 2004.

Programa de trabajo. (2002). Programa de trabajo detallado para el seguimiento de los objetivos concretos de los sistemas de educación y formación en Europa. (DOUE, C 142/01, de 14 de junio de 2002).

Propuesta de Directiva del Parlamento y del Consejo. (2002). Propuesta de Directiva del Parlamento Europeo y del Consejo relativa al reconocimiento de cualificaciones profesionales. Bruselas, Comisión de las Comunidades Europeas, COM (2002) 119 final 2002/0061 (COD), 07.03.2002.

Propuesta del Parlamento y del Consejo. (2006). Propuesta de Recomendación del Parlamento y del Consejo relativa a la creación del Marco Europeo de Cualificaciones para el aprendizaje permanente. Bruselas, Comisión de las Comunidades Europeas, COM (2006) 479 final, 5.9.2006.

R.D. 1147. (2011). Real Decreto 1147/2011, de 29 de julio, por el que se establece la ordenación general de la formación profesional del sistema educativo. (Boletín Oficial del Estado, núm. 182, de 30 de julio de 2011). 
La validación de competencias profesionales en España e Italia

R.D. 1224. (2009). Real Decreto 12224/2009, de julio, de reconocimiento de las competencias profesionales adquiridas por experiencia laboral. (Boletín Oficial del Estado, núm. 205, de 25 de agosto de 2009).

Real Decreto 1027. (2011). Real Decreto 1027/2011, de 15 de julio, por el que se establece el Marco Español de Cualificaciones para la Educación Superior. (Boletín Oficial del Estado núm. 185, de 3 de agosto de 2011).

Real Decreto 1529. (2012). Real Decreto 1529/2012, de 8 de noviembre, por el que se desarrolla el contrato para la formación y el aprendizaje y se establecen las bases de la formación profesional dual. (Boletín Oficial del Estado, núm. 270, de 9 de noviembre de 2012).

Real Decreto 1538. (2006). Real Decreto 1538/2006, de 15 de diciembre, por el que se establece la ordenación general de la formación profesional del sistema educativo,. (Boletín Oficial del Estado, núm. 3, de 3 de enero de 2007).

Real Decreto 282. (1999). Real Decreto 282/1999, de 22 de febrero, por el que se establece el programa de talleres de empleo. (Boletín Oficial del Estado, núm. 46, de 23 de febrero de 1999).

Real Decreto 395. (2007). Real Decreto 395/2007, de 23 de marzo, por el que se regula el subsistema de formación profesional para el empleo. (Boletín Oficial del Estado, núm. 87, de 11 de abril de 2007).

Real Decreto-ley 4. (2015). Real Decreto-ley 4/2015, de 22 de marzo, para la reforma urgente del Sistema de Formación Profesional para el Empleo en el ámbito laboral. (Boletín Oficial del Estado, núm.70, de 23 de marzo de 2015).

Recomendación del Consejo. (2012). Recomendación del Consejo, de 20 de diciembre de 2012, sobre la validación del aprendizaje no formal e informal (2012/C 398/01). (DOUE, C 398/01, de 22 de diciembre de 2012).

Recomendación del Parlamento Europeo y el Consejo. (2009). Recomendación del Parlamento Europeo y del Consejo de 18 de junio de 2009 relativa a la creación del Sistema Europeo de Créditos para la Educación y Formación Profesionales (ECVET). (DOUE, C 155/11, de 8 de julio de 2009). 
Recomendación del Parlamento y el Consejo. (2008). Recomendación del Parlamento Europeo y del Consejo de 23 de abril de 2008 relativa a la creación del Marco Europeo de Cualificaciones para el aprendizaje permanente. (DOUE, C 111/01, de 6 de mayo de 2008).

Regione Emilia-Romagna. (2015). Qualifiche Triennali. Retrieved from http://formazionelavoro.regione.emiliaromagna.it/iefp/approfondimenti/qualifiche-triennali

Resolución del Consejo. (1974). Resolución del Consejo, de 6 de junio de 1974, relativa al reconocimiento recíproco de diplomas, certificados y otros títulos. (DOUE, C 098, de 20 de agosto de 1974).

Rodríguez Moreno, M. ., Serreri, P., \& Del Cimmuto, A. (2010). Desarrollo de competencias: Teoría y Práctica. Balance, proyecto profesional y aprendizaje basado en el trabajo. Barcelona: Laertes.

Rubin, H. ., \& Rubin, I. . (1995). Qualitative interviewing. The art of hearing data. Thousand Oaks, California: Sage.

Rubio Herráez, E. (2007). Aprendizaje a lo largo de la vida. Vivir y trabajar en una Europa del conocimiento. CEE Participación Educativa, (6), 14-29.

Ryan, G. ., \& Bernard, H. . (2003). Data management and analysis methods. In N. . Denzin \& Y. . Lincoln (Eds.), Collecting and interpreting qualitative materials (2nd ed., pp. 259-309). Thousand Oaks, California: Sage.

Sabán Vera, C. (2009). Educación permanente y aprendizaje: dos modelos teórico-aplicativos diferentes. Revista Iberoamericana de Educación, 52.

Sandberg, J. (1994). Human competence at work: An interpretative approach. Sweden: Bas.

Sandberg, J. (2000). Understanding human competenze at work: An interpretative approach. Academi of Management Journal, 43(6).

Schön, D. A. (1983). The reflexive Practitioner. New York: Basic Books.

Spencer, L., \& Spencer, S. (1993). Competence at work: a model for superior performance. New York: Wiley. 
La validación de competencias profesionales en España e Italia

Spencer, L., \& Spencer, S. (1995). Competenza nel lavoro. Modelli per una performance superiore. Milano: Franco Angeli.

Todeschini, M., \& Ziglio, C. (1992). Comparazione Educativa. Studiare l'educazione attraverso la comparazione. Comparare per imparare. Firenze: La Nuova Italia.

Ugolini, F. C. (2013). Introduzione. Apprendimento informale: inquadramento storico, politico e concettuale. In F. C. Ugolini (Ed.), Apprendimento informale. Aspetti multidisciplinari e prospettive di ricerca. Lecce: Pensa MultiMedia.

UNESCO. (2015). Sobre la UNESCO. Retrieved from http://www.unesco.org/new/es/unesco/about-us/who-weare/introducing-unesco/

Varchetta. (1993). Il metodo delle competenze. Sviluppo e Organizzazione, (140).

Varchetta, G. (2003). "Prefazione" a AAVV Apprendimento di competenze strategiche. Milano: Isfol, Franco Angeli.

Veres, J., Locklear, T. S., \& Sims, R. R. (1990). Job analysis in practice: A brief review of the role of job analysis in human resources management. In G. R. Ferris, K. M. Rowland, \& R. M. Buckley (Eds.), Human resource management: perspectives and issues (pp. 79-103). Boston: Allyn \& Bacon.

Weinert, F. E. (2001). Concept of competence: a conceptual clarification. In D. S. Rychen \& L. H. Salganik (Eds.), Defining and selecting key competencies. Göttingen: Hogrefe.

Werquin, P. (2010). Recognising Non-Formal and Informal Learning: Outcomes, Policies and Practices. OECD. Retrieved from http://www.oecd.org/edu/skills-beyond-school/44600408.pdf

Woods, P. (1998). Investigar el arte de la enseñanza. El uso de la etnografía en la educación. Barcelona: Paidós.

Youthpass.eu. (2015). ¿Qué es youthpass? Retrieved from https://www.youthpass.eu/es/youthpass/about/

Yus Ramos, R. (2001). Educación integral: una educación holística para el siglo XXI (Vol. 1). Bilbao: Desclée de Brouwer. 
Referencias Bibliográficas

Zammuner, V. L. (1998). Tecniche dell'intervista e del questionario. Bologna: Il Mulino. 



\section{Lista de anexos}

A continuación mostramos el listado de anexos que acompañan el trabajo en formato digital.

- Anexo 1: Repertorio de cualificaciones de Emilia-Romagna

- Anexo 2: Correlación entre figuras nacionales italianas y cualificaciones regionales de Emilia-Romagna

- Anexo 3: Solicitud de inscripción al procedimiento de validación de Castilla y León

- Anexo 4: Curriculum Vitae europeo a presentar en el procedimiento de validación de Castilla y León

- Anexo 5: Guía del asesor del procedimiento de validación de Castilla y León

- Anexo 6: Cuestionario de autoevaluación a realizar por los candidatos del procedimiento de validación de Castilla y León 
La validación de competencias profesionales en España e Italia

- Anexo 7: Historial formativo profesional a rellenar por los candidatos del procedimiento de validación de Castilla y León

- Anexo 8: Modelo ficha de recogida de información sobre funciones desempeñadas por el trabajador en la empresa del procedimiento de validación de Castilla y León

- Anexo 9: Ejemplo de entrevista profesional con fines de asesoramiento del procedimiento de validación de Castilla y León

- Anexo 10: Modelo de ficha de sistematización de evidencias de competencia del procedimiento de validación de Castilla y León.

- Anexo 11: Modelo de informe del asesor para la comisión de evaluación del procedimiento de validación de Castilla y León.

- Anexo 12: Documento para el dictamen de valoración de evidencias de competencia indirectas del procedimiento de validación de Castilla y León.

- Anexo 13: Modelo de ficha del plan individualizado de evaluación.

- Anexo 14: Ficha de seguimiento de actividades realizadas por el evaluador/a en el proceso de evaluación por cada persona candidata, del procedimiento de validación de Castilla y León.

- Anexo 15: Guía del evaluador del procedimiento de validación de Castilla y León.

- Anexo 16: Guía de evidencia de las unidades de competencia de la cualificación profesional de educación infantil, del procedimiento de validación de Castilla y León.

- Anexo 17: Modelo de informe de evaluación del procedimiento de validación de Castilla y León.

- Anexo 18: Acta final de la comisión de evaluación del procedimiento de validación de Castilla y León.

- Anexo 19: Modelo de acta de valoración individual de la competencia profesional, través de un acta de valoración individual de la competencia profesional, del procedimiento de validación de Castilla y León.

- Anexo 20: Modelo de solicitud de revisión individualizada, del procedimiento de validación de Castilla y León.

- Anexo 21: Modelo de documento de acreditación de unidades de competencia incluidas en títulos de formación profesional y certificados de profesionalidad, del procedimiento de validación de Castilla y León.

- Anexo 22: Clasificación por áreas profesionales de la oferta del sistema de IeFp en Emilia-Romagna. 
- Anexo 23: Ficha descriptiva de la cualificación del "Operador de la producción química) del procedimiento de validación de Emilia-Romagna.

- Anexo 24: Plan de Evaluación de la experiencia del procedimiento de validación de Emilia-Romagna.

- Anexo 25: Dossier de evidencias del procedimiento de validación de Emilia-Romagna.

- Anexo 26a: Documento de evaluación de las evidencias, integrado en la DGR 530/2006, del procedimiento de validación de Emilia-Romagna.

- Anexo 26b: Documento de evaluación de las evidencias, integrado en la DGR 739/2013, del procedimiento de validación de Emilia-Romagna.

- Anexo 27: Documento de evaluación de competencias del procedimiento de validación de Emilia-Romagna.

- Anexo 28: Ejemplos, propuestos por la DGR 530/2006, para seguir los criterios de completitud y de medio grado de complejidad en la prueba práctica del procedimiento de validación de Emilia-Romagna.

- Anexo 29: Ejemplos, propuestos por la DGR 530/2006, para indicar los materiales o el tiempo a disposición en la prueba práctica del procedimiento de validación de Emilia-Romagna.

- Anexo 30: Ejemplos, propuestos por la DGR 530/2006, para evaluar el proceso y el producto en la prueba práctica del procedimiento de validación de Emilia-Romagna.

- Anexo 31: Ejemplos sobre materiales, uso de lenguaje, adecuación de respuesta, propuestos por la DGR 530/2006, para realizar la entrevista del procedimiento de validación de Emilia-Romagna.

- Anexo 32a: Documento de evaluación de las actividades, propuesto por el DGR 530/2006, del procedimiento de validación de EmiliaRomagna.

- Anexo 32b: Documento de evaluación de las actividades, propuesto por el DGR 739/2013, del procedimiento de validación de EmiliaRomagna.

- Anexo 33: Entrevistas realizadas a los profesionales del procedimiento de validación de Castilla y León y a los profesionales del procedimiento de validación de Emilia-Romagna.

- Anexo 34: Guiones de las entrevistas semiestructuradas realizadas a los profesionales del procedimiento de validación de Castilla y León y a los profesionales del procedimiento de validación de Emilia-Romagna. 
La validación de competencias profesionales en España e Italia

- Anexo 35: Cuestionarios realizados a los profesionales del procedimiento de validación de Castilla y León y a los profesionales del procedimiento de validación de Emilia-Romagna.

- Anexo 36: Documento para la validación de expertos del cuestionario de asesores del procedimiento de validación de Castilla y León.

- Anexo 37: Correspondencias de indicadores con las preguntas realizadas en los cuestionarios dirigidos a los profesionales de ambos procedimientos.

- Anexo 38: Fotos de las instalaciones, del centro de formación ECIPAR de Módena, en las que se llevan a cabo pruebas de validación relacionadas con peluquería y estética, en el contexto del procedimiento de validación en Emilia-Romagna. 